ALEXANDRE COUTINHO DA SILVEIRA

\title{
GOVERNANÇA PÚBLICA DE ROYALTIES: FEDERALISMO FISCAL E FUTURAS GERAÇÕES
}

\author{
DISSERTAÇÃO DE MESTRADO \\ ORIENTADOR: PROFESSOR ASSOCIADO FERNANDO FACURY SCAFF
}

FACULDADE DE DIREITO DA UNIVERSIDADE DE SÃO PAULO

SÃo PAULO 


\author{
Dissertação de mestrado apresentada ao \\ Departamento de Direito Econômico, \\ Financeiro e Tributário da Faculdade de \\ Direito da Universidade de São Paulo, como \\ requisito parcial para obtenção do título de \\ Mestre em Direito, sob orientação do \\ Professor Associado Fernando Facury Scaff.
}

FACULDADE DE DIREITO DA UNIVERSIDADE DE SÃO PAULO SÃO PAULO 


\title{
ALEXANDRE COUTINHO DA SILVEIRA
}

\section{GOVERNANÇA PÚBLICA DE ROYALTIES: FEDERALISMO FISCAL E FUTURAS GERAÇÕES}

\author{
Dissertação de mestrado apresentada ao \\ Departamento de Direito Econômico, \\ Financeiro e Tributário da Faculdade de \\ Direito da Universidade de São Paulo, como \\ requisito parcial para obtenção do título de \\ Mestre em Direito, sob orientação do \\ Professor Associado Fernando Facury Scaff.
}

Aprovado em:

BANCA EXAMINADORA:

Professor Associado FERNANDO FACURY SCAFF (Orientador)

Instituição: Faculdade de Direito da Universidade de São Paulo

Assinatura:

Professor(a):

Instituição: Faculdade de Direito da Universidade de São Paulo Assinatura:

Professor(a):

Instituição:

Assinatura: 
A ela, BRUnA, em cujos olhos encontro paz. A quem tenho satisfação de chamar de esposa, namorada, companheira, cúmplice. Que comigo compartilha o extraordinário e $\mathrm{o}$ trivial. Que espero esteja comigo sempre. Que me faz tão bem. A quem quero, um dia, ter a oportunidade de retribuir. 


\section{AGRADECIMENTOS}

Agradeço à BRUNA, pela ajuda incessante, e por dividir comigo a rotina quotidiana - sempre agradável a seu lado.

Muito agradeço a meus queridos e amados pais, REYNALDO e CLÁUDIA, por terem me proporcionado, das mais diversas formas, a caminhada até aqui. Pelos maiores e menores gestos, devo-lhes tudo, especialmente gratidão e admiração.

Aos meus irmãos, DANIEL, FILIPE e MARCELO, pelo constante apoio. Ao DANIEL, especialmente, pelo interesse sobre o tema e pelas sugestões e empréstimos bibliográficos.

Ao meu orientador, Prof. FERNANDO FACURY SCAFF, pela paciência inesgotável; pelas lições proveitosas; pelas leituras e sugestões; pelas conversas. Por estar presente na vida acadêmica. Aos amigos FERNANDO e DENISE SCAFF, pela acolhida fraternal.

Aos grandes amigos de todas as horas, SÉRGIO, TÔNIA e JULIANA.

Aos amigos e colegas de trabalho ISABELA e DANIEL, sempre dispostos a ajudar.

Ao Escritório Silveira, Athias, Soriano DE MELlo, Guimarães, PinHEIRO \& SCAFF, por todo o apoio desde o início da jornada acadêmica, e pela liberdade na visitação e utilização da biblioteca.

Aos professores e colegas da FDUSP, na pessoa do Prof. JOSÉ MAURÍcIO CONTI, que tanto contribuíram nos últimos anos.

Os agradecimentos são sinceros e merecidos. As falhas, impropriedades e incoerências do trabalho são, contudo, única e exclusivamente do autor. 
"O trem vai vendo o Brasil. O Brasil é uma República Federativa cheia de árvores e de gente dizendo adeus. Depois todos morrem" (OSWALD DE ANDRADE).

“O leite amamentado nunca voltará à teta. A manteiga nunca se dissolverá de novo em leite. O som do mar nunca voltará à concha quebrada, nem a vida ao corpo quebrado. A flor aberta e o fruto que tombou não reaparecerão na árvore. E os mortos nunca, nunca, nunca renascerão" (CIVAVAKKIYAR). 


\section{RESUMO}

Esta dissertação tem por objetivo analisar criticamente a governança das receitas públicas de recursos naturais não renováveis no Brasil. Considerando a característica essencial de finitude dos recursos naturais explorados, que importa também em negar às gerações pósteras o acesso aos bens minerais e petrolíferos, impõe-se reconhecer nos diversos aspectos dessa governança a necessidade de tratar essa receita de forma singular. Para compreender quais são estas especificidades, foram eleitos dois eixos de análise: o primeiro, com a revisão da literatura sobre a "maldição" dos recursos naturais, a doença holandesa, e fenômenos (especialmente econômicos) relacionados à exploração mineral; e o segundo, com consulta à doutrina de diversos ramos (no Direito e fora dele) sobre a noção de justiça, solidariedade ou equidade entre gerações, bem como com a busca de especificação do conteúdo desta perspectiva, que se aplica a diversas áreas do Direito, inclusive e especialmente ao Direito Financeiro. Com essas bases, elegem-se aspectos da governança brasileira de royalties a serem analisados: o federalismo fiscal dessas receitas públicas patrimoniais; a forma de tratamento financeiro-orçamentário dos royalties, especialmente sua classificação consoante a Lei n 4.320/1964; a utilização de Fundos para gestão dessas receitas (o Fundo Social); a relação entre a arrecadação de royalties e a arrecadação tributária, especialmente nos entes subnacionais beneficiados em grande monta com essas receitas patrimoniais; os modos de direcionamento e coação que a lei impõe ao gestor no gasto dos royalties; a transparência fiscal brasileira; e, de forma ampla, as recentes alterações (efetivadas e propostas) nas leis que regem as explorações de minérios e de petróleo no país. Conclui-se que, apesar de o ordenamento jurídico brasileiro ter avançado significativamente em alguns desses aspectos recentemente (especialmente com a criação do Fundo Social no âmbito da União, e no que diz respeito à transparência fiscal relacionada à atividade exploratória), ele não está, sob as perspectivas de análise escolhidas, adequadamente aparelhado para a governança das receitas públicas de recursos naturais não renováveis.

Palavras-chave: Direito Financeiro; royalties; recursos naturais não renováveis; governança; maldição; volatilidade; finitude; equidade intergeracional; princípio da poupança justa; federalismo fiscal; fundos; receitas correntes; receitas de capital; esforço fiscal; sustentabilidade financeira; diversificação produtiva. 


\begin{abstract}
This dissertation aims to critically analyze the Brazilian governance of public revenues from nonrenewable natural resources. Considering that finiteness is an essential characteristic of natural resources that are exploited, which implies in denying future generations the access to mineral and oil assets, one must acknowledge, in various aspects of governance, the necessity to treat these revenues singularly. To understand what these specificities are, two axes of analysis were elected: the first envolves revisiting the "curse" of natural resources, the Dutch disease, and phenomena (especially those of economic nature) related to the mineral exploitation; and the second involves consulting doctrine of different areas of study (in and out of Law) about notions of justice, solidarity or equity between generations, as well as searching for specification of this content, which applies to various areas of Law, including and especially Public Finance Law. Building on these foundations, some aspects of Brazilian governance of royalties were elected to be analyzed: fiscal federalism applied to these public revenues; the financial-budgetary treatment of royalties, especially its classification under Law $n^{\circ} 4.320 / 1964$; the utilization of Funds to manage these revenues (the Social Fund); the relationship between the collection of royalties and the collection of taxes, especially in subnational governmental entities largely benefited by these revenues; the ways the law directs and coerces the expenditure of royalties; Brazilian fiscal transparency; and, broadly, the recent modifications (finished and proposed) in the laws that conduct the exploitation of minerals and oil in the country. It is concluded that, although the Brazilian legal system has advanced significantly in some aspects as of late (especially the creation of the Social Fund by the central government, and in respects to fiscal transparency related to the exploratory activities), it is not, under the elected perspectives of analysis, adequately prepared to regulate the governance of public revenues originating from exploration of nonrenewable natural resources.
\end{abstract}

Palavras-chave: Public Finance Law; royalties; nonrenewable natural resources; governance; curse; volatility; finiteness; intergenerational equity; Just Savings principle; fiscal federalism; funds; current revenues; capital revenues; fiscal effort; financial sustainability; productive diversification. 


\section{SUMÁRIO}

INTRODUÇÃO 12

1. A EXPLORAÇÃO DE RECURSOS NATURAIS NÃO RENOVÁVEIS E SUAS ARMADILHAS .... 21

1. A exploração de recursos naturais não renováveis e suas armadilhas ..... 21

1.a. Notas sobre a relevância da receita de exploração de recursos naturais não renováveis. 22

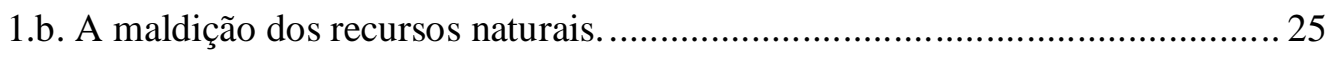

1.b.i. Há mesmo uma maldição?........................................................ 25

1.b.ii. Características da receita pública oriunda de recursos naturais não renováveis. 32

1.b.iii. A chamada maldição: o que ela causa? ........................................... 34

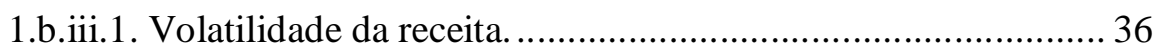

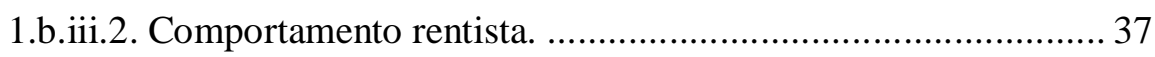

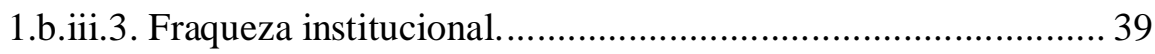

1.b.iii.4. Corrupção. ..................................................................... 43

1.b.iii.5. Ausência de Transparência. ................................................. 47

1.b.iii.6. Outros efeitos. Conduta antidemocrática, Desigualdade, Guerras Civis, Liberdades das Mulheres............................... 57

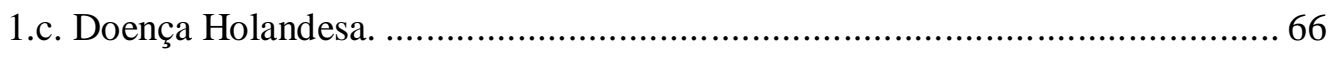

1.d. Redução da carga tributária............................................................. 71

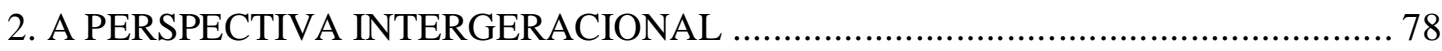

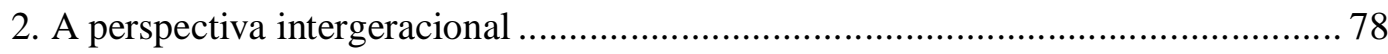

2.a. Recursos naturais não renováveis e as gerações futuras um elo necessário. A finitude como elemento intrínseco e inafastável da exploração e que se reflete na receita pública decorrente.

2.b. Por quê vincular royalties de recursos naturais não renováveis à ideia de

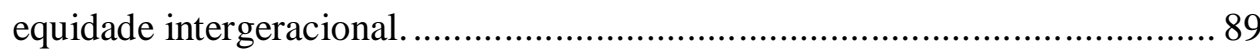

2.b.i. Explorar para quê? Uma breve menção ao pensamento furtadiano........ 90

2.b.ii. Economia dos Recursos Naturais: Hotelling, Solow, Hartwick. ........... 99

2.b.iii. A Filosofia política de John Rawls e o problema da justiça entre gerações.

2.b.iii.1. Aspectos fundamentais da justiça como equidade. 
2.c. O que é equidade intergeracional: o que devemos às gerações futuras?

2.d. Equidade intergeracional, estrutura constitucional e representação.

2.e. Equidade intergeracional, finanças públicas e direito financeiro.

3. ROYALTIES NO BRASIL. FEDERALISMO FISCAL E ASPECTOS DO ORDENAMENTO PARA A GOVERNANÇA DOS ROYALTIES, SOB ANÁLISE DA EQUIDADE ENTRE GERAÇÕES E DOS EFEITOS DELETÉRIOS DA EXPLORAÇÃO.

3. Como o Brasil se comporta perante a receita pública de recursos naturais não renováveis. Federalismo Fiscal e outras instituições, instrumentos e aspectos do ordenamento jurídico para a governança dos royalties. Superando os efeitos deletérios da exploração e observando as futuras gerações

3.a. A equidade intergeracional nos ordenamentos internacional e brasileiro. As disposições do direito financeiro brasileiro.

3.b. Sobre o domínio dos recursos naturais não renováveis no Brasil. 184

3.c. Sobre a justificação e identidade dos royalties no direito brasileiro. 188

3.d. Royalties e federalismo fiscal. Notas sobre a partilha espacial e sobre uma orientação temporal à partilha espacial. 205

3.d.i. Sobre a teoria do federalismo fiscal.

3.d.ii. A partilha espacial dos royalties de recursos naturais não renováveis no

Brasil. A recente batalha legislativa e a corrente batalha judicial. 219

3.d.ii.1. São procedentes as reivindicações dos Estados do Rio de Janeiro, do Espírito Santo e de São Paulo?

3.d.iii. Crítica à atual partilha espacial dos royalties. E: uma orientação de natureza temporal.

3.d.iv. Crítica ao regime de vinculações a órgãos da União. 248

3.e. Racionalidade no trato dos royalties e classificação financeiroorçamentária. 253

3.e.i. Receita originária, patrimonial. 253

3.e.ii. Receita de capital. 257

3.f. Fundos. 270

3.f.i. Os Fundos brasileiros. O Fundo Social da União................................ 289

3.f.ii. Críticas ao Fundo Social da União. 296

3.g. Exploração de recursos naturais não renováveis e tributação. A relação entre a receita proveniente da exploração do patrimônio público e o financiamento das despesas estatais. Notas sobre a realidade brasileira. 
3.h. Constrangimentos na perspectiva do gasto e suas burlas. Nota sobre a qualidade do gasto. Necessidade de regras de vinculação/afetação do gasto público da receita de royalties.

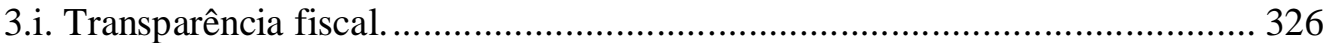

3.j. Uma crítica aos novos marcos regulatórios das explorações mineral e petrolífera. Oportunidades desperdiçadas. Ausência de regras que tragam as futuras gerações ao debate.

CONCLUSÃO 346

REFERÊNCIAS BIBLIOGRÁFICAS 350 


\section{INTRODUÇÃO}

A exploração de recursos naturais não renováveis tem recebido crescente atenção nos debates políticos, econômicos, ambientais e sociais.

Isso se deve, em grande parte, à importância cada vez maior que o setor extrativo possui no Estado brasileiro: de um lado, a extração dos recursos naturais é parte importante, embora ainda modesta, do Produto Interno Bruto do Brasil; ${ }^{1}$ a participação do setor extrativo - especialmente de recursos minerais, destacando-se o minério de ferro - é responsável por grande monta das exportações anuais, ${ }^{2}$ contribuindo significativamente com a manutenção da balança comercial favorável e alcance de superávits primários. Vale observar que, por estudos do Fundo Monetário Internacional datados de 2007 e 2012, o Brasil, não foi considerado como "rico em hidrocarbonetos ou recursos minerais". 3 Contudo, a tendência é que estes números sigam trajetória crescente. Afinal, como observa estudo do Instituto Brasileiro de Mineração (IBRAM), a produção mineral brasileira

1 Estudo do Conselho Internacional de Mineração e Metais, de 2013, afirma que a participação da indústria extrativa (minérios e petróleo) no PIB do Brasil é de cerca de 3\%. ICMM. O setor de mineração no Brasil: fortalecimento institucional para o desenvolvimento sustentável. Mineração: parcerias para o desenvolvimento. 2013. p. 6. Considerando, contudo, o forte incremento de produção dos últimos 10 anos, espera-se que esses números sejam revistos com dados mais acurados sobre os PIBs dos últimos três anos. Fique-se com a lição de George Anderson, que referindo-se especificamente ao setor petrolífero, afirma tratar-se de uma significante, embora ainda pequena, parte da economia nacional. ANDERSON, George. Reflections on oil and gas in federal systems. In: ANDERSON, George (Ed.). Oil \& gas in federal systems. Ontario: Oxford University Press, 2012. p. 373.

2 Os itens "Minérios" e "Petróleo e Combustíveis" são, respectivamente, 1. e e 2. lugar na relação de principais produtos exportados em 2011. Juntos, representaram $29,4 \%$ das exportações brasileiras neste ano. O percentual chega a 36,2\% se acrescidos os "produtos metalúrgicos". Conforme relatório de dados consolidados da balança comercial brasileira em 2011, produzido pelo Ministério do Desenvolvimento, Indústria e Comércio Exterior. Disponível em: <http://www.desenvolvimento.gov.br/ arquivos/dwnl_1331125742.pdf>. Acesso em: 23 jun. 2012. O setor mineral participou com 20\% do total de exportações do país em 2010, como divulgado pelo DNPM (Disponível em: <investimentos.mdic.gov.br/public/arquivo/arq1314392332.pdf>. Acesso em: 3 jan. 2014, p. 19); com 25,3\% em 2011 (BRASIL. Departamento Nacional de Produção Mineral. Sumário mineral. Brasília: DNPM, 2012. p. 9) e 23,5\% em 2012 (Disponível em: <http://www.mme.gov.br/mme/noticias/ lista_destaque/destaque_879.html>. Acesso em: 3 jan. 2014).

3 Para o estudo de 2007, um país é considerado "rico" quando, nos 05 (cinco) anos anteriores à análise, ou (i) a receita pública oriunda da exploração desses bens naturais tenha sido superior a $25 \%$ da receita total; ou (ii) o valor das exportações desses bens naturais tenha sidos superior a $25 \%$ do total das exportações nacionais. INTERNATIONAL MONETARY FUND. Guide on resource revenue transparency. Washington D.C.: IMF Media Service Division, 2007. p. 4, nota de rodapé n. 08. Já no estudo de 2012, estes percentuais foram reduzidos para 20\%, ainda sem a participação do Brasil. Em: INTERNATIONAL MONETARY FUND. Macroeconomic policy frameworks for resource-rich developing countries. Washington D.C., 2012. p. 6, nota de rodapé n. 1. Considerando os números da Nota acima, em breve o Brasil pode passar a ser considerado como "resorce-rich". 
cresceu superlativos $550 \%$ entre 2001 e $2011 .^{4}$ No mais, o início das operações nos poços de petróleo da camada do Pré-Sal e os projetos de exploração de nova mina de ferro no Pará (S11D), tido como o maior projeto de exploração de ferro do mundo, igualmente tendem a suportar um crescimento do setor nos próximos anos.

Especialmente com o boom dos preços das commodities nos primeiros anos do Século XXI, ocorreu a escalada dos valores de receita pública diretamente decorrente da exploração desses recursos (que ainda se mantém, apesar de períodos de variação). Isto é: da participação que cabe ao Estado pela exploração desses bens - que não se confunde com a tributação sobre a operação. São os chamados royalties.

A arrecadação destes tem sido crescente na última década, assim como sua relevância para os entes federativos receptores. É o que consta dos gráficos:

Gráfico 1 - Arrecadação de CFEM 2004-2012

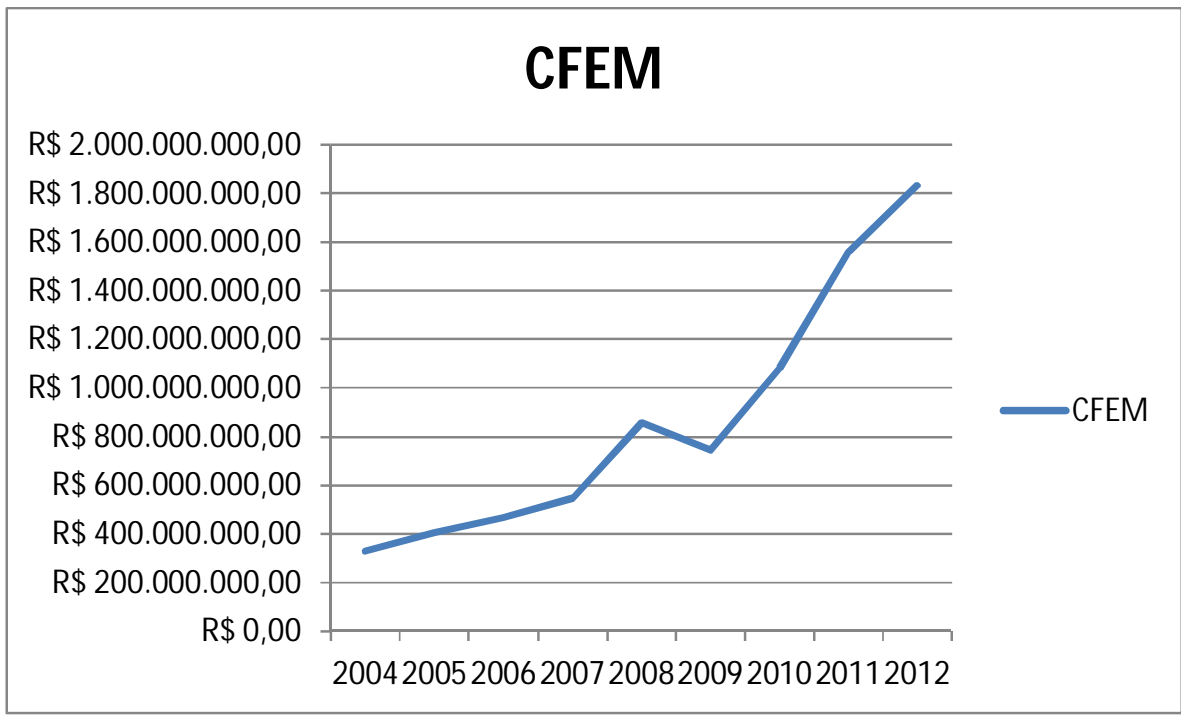

Elaboração própria

Dados: DNPM

Instituto Brasileiro de Mineração - IBRAM. Informações e análises da economia mineral brasileira. 6. ed. Brasília: IBRAM, 2011. 


\section{Gráfico 2 - Arrecadação de Participações Governamentais na exploração petrolífera 2004-2011 (inclui os valores de Royalties, Participação Especial, Taxa de Ocupação ou Retenção de Área, e Bônus de Assinatura)}

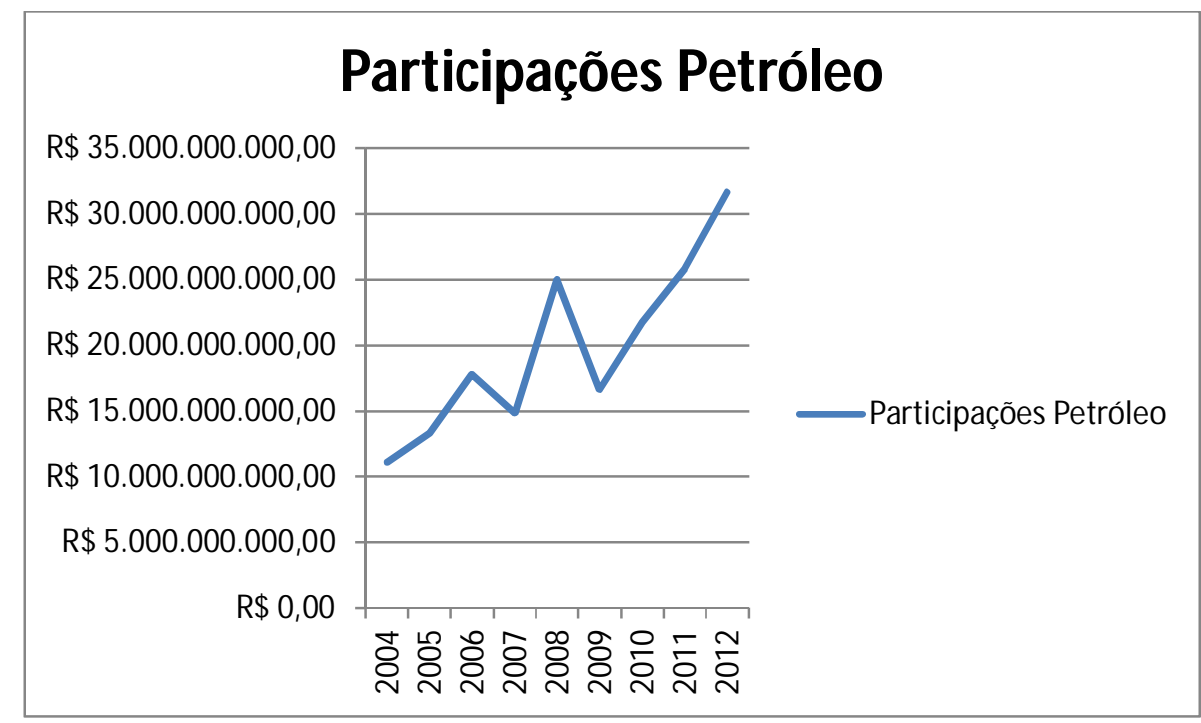

Elaboração própria

Dados: ANP

É notável a semelhança entre os gráficos acima colacionados, ambos crescentes na década, mas contando com significativo decréscimo no período 2008-2009 imediatamente posterior à crise econômica que impactou sensivelmente a demanda mundial. É conveniente recordar que as receitas públicas decorrentes da exploração dos recursos naturais não renováveis estão umbilicalmente relacionadas aos preços praticados no mercado internacional desses bens. Análises da variação desses preços revelam padrões também muito semelhantes aos dos gráficos acima. ${ }^{5-6}$

Estando fixado que a quantidade de arrecadação da receita pública de royalties está diretamente relacionada aos preços dos bens no mercado internacional, deve-se ressaltar que minério e petróleo têm como característica a volatilidade dos preços - o que torna mais perigoso para qualquer ente público depender desse tipo de arrecadação para financiamento de suas atividades básicas. Nada obstante, vê-se no cenário internacional que as receitas de recursos naturais não renováveis moldam instituições e políticas. Países vários - com destaque para os do Oriente Médio e da África - sustentam suas economias

5 Evolução dos preços do barril de petróleo. Disponível em: <http://www.eia.gov/ finance/markets/reports_presentations/eia_what_drives_crude_oil_prices.pdf>. Acesso em: 13 jul. 2012. 6 Idem, ibidem, p. 21. 
com grande dependência dessas receitas. ${ }^{7}$ As variadas formas de trato desse fluxo de valores são, quotidianamente, objeto de exposição e crítica na imprensa internacional. ${ }^{8}$

O impacto dessas receitas causa transformações nos Entes Públicos receptores.

Mas a história e a experiência internacional ensinam que nem sempre essa mudança ocorre para melhor. Termos como "maldição" (“curse") e "doença" (“disease") passaram, especialmente a partir do final dos anos 1980 e correr dos anos 1990, a ser vinculados com os países ricos em recursos naturais. Questões díspares como os reflexos cambiais da exportação massiva desses recursos; a transparência no trato da exploração e dos valores decorrentes dessa atividade; a distribuição dos valores entre os Entes Federativos do país; e, especialmente, a destinação que é dada a essa receita já no âmbito do gasto público; todas passaram a ser objeto de análise, buscando compreender de que forma aquilo que antes foi tido por bênção ou dádiva (a propriedade de bens naturais que significaria bilhete de saída do subdesenvolvimento) transformou-se em fardo ou dificuldade. E que instrumentos e políticas seriam recomendados a afastar esta condição viciosa, permitindo que a premissa básica da exploração - ter mais recursos é melhor que ter menos recursos possa se desenvolver.

De outro lado, o intrínseco caráter de finitude ${ }^{9}$ desses recursos minerais e petrolíferos também tem sido um dos aspectos da exploração a chamar atenção. Fundados

7 O economista Joseph Stiglitz, em entrevista, critica o Reino Unido, que nos anos 1980, à época do Governo de Margareth Thatcher, cresceu baseado apenas em tão somente nas rendas minerais. Afirma que este crescimento não é sustentável, por basear-se na riqueza do Estado. Afirma, mais, que as ações então desenvolvidas foram equivocadamente entendidas como baseadas em boas políticas econômicas, quando na realidade o sucesso esteve baseado apenas em "viver de sua riqueza e deixar as futuras gerações empobrecidas". Disponível em: <http://www.newsnetscotland.com/index.php? option=com_content\&view=article\&id=517:nobel-prize-winner-oil-wealth-was-qsquanderedq-by-uk>. Acesso em: 24 jun. 2012.

8 Para ficar em poucos exemplos, vejam-se reportagens sobre Mongólia: <http://www.economist. com/node/21543113>; Azerbaijão: <http://www.economist.com/blogs/ easternapproaches/2012/05/ eurovision-2012-diary>; Moçambique: <http://www.reuters.com/article/ 2012/06/19/us-mozambiquewealth-idUSBRE85IOLB20120619>; Uganda: <http://af.reuters.com/article/ investingNews/idAFJOE85I07F20120619?pageNumber=2\&virtualBrandChannel=0>; Iraque: <http:// www.economist.com/node/21556977?fsrc=scn/tw_ec/lots_of_black_stuff > e <http://www.nytimes. com/2012/07/01/world/middleeast/fueled-by-oil-wealth-malls-rise-in-baghdad.html?_r=1\&smid=twnytimes\&seid=auto>; Nigéria: <http://af.reuters.com/article/topNews/idAFJOE86100O20120702?feed Type=RSS\&feedName=topNews > África: <http://www.unmultimedia.org/radio/english/2012/06/ african-counties-need-to-diversity-their-economies/>; Leste Africano: <http://www. economist.com/node/21552265? fsrc=scn/tw/te/ar/easterneldorado>; Golfo Pérsico: <http://www. economist.com/node/21551484? fsrc=scn/tw/te/ar/keepingittothemselves $>$.

9 Por definição, os bens minerais e petrolíferos de que se tratarão são finitos: existem em determinada quantidade e não serão renovados. Podem ser válidas as críticas a uma postura excessivamente cautelosa de exploração, baseadas na inovação tecnológica (que pode substituir os bens não renováveis por outros renováveis ou mesmo encontrar outros não renováveis de mesma função, como é o caso do gás de xisto) ou na frequente descoberta de novas minas e jazidas - como fazem, por exemplo: DIAMANDIS, Peter H.; KOTLER, Steven. Abundance: the future is better than you think. New York: Free Press, 2012; The 
em pressupostos morais, religiosos, ou simplesmente intuitivos, doutrinadores de diversas áreas têm postulado pela aplicação da ideia de equidade intergeracional.

Afinal, a exploração hodierna desses bens, considerado seu caráter de recursos naturais não renováveis, implica, necessariamente, que as gerações vindouras não terão as mesmas possibilidades de ação.

Essa perspectiva de análise levanta diversas questões. Dentre elas: há fundamento para sustentar que as gerações futuras devem ter seus interesses observados atualmente? Caso aceito o fundamento-base, mas sendo os recursos naturais finitos e o número de gerações infinito, isto implicaria a impossibilidade de rateio dos recursos entre as gerações atual e vindouras? Isto demandaria que os recursos fossem, pura e simplesmente, não explorados (entesourados)? No que consiste - se é que há - a equidade intergeracional? Como promovê-la?

A perspectiva intergeracional ainda carece de avanços para sua melhor compreensão e aplicação, especialmente no âmbito do Direito Financeiro e das finanças públicas. John Hartwick, ${ }^{10}$ já nos anos 1970, propôs que as receitas decorrentes dessa exploração, tendo em vista especialmente seu caráter finito, sejam reinvestidas em máquinas e capital reprodutível, de forma que o consumo dessa riqueza não se dê de imediato, mas seja prolongado no tempo, permitindo que as gerações futuras gozem da riqueza e dos benefícios oriundos da extração, esta que tem como consequência necessária a diminuição do patrimônio do Estado.

Mas o que se vê no Brasil? Há estudos que parecem indicar no sentido inverso: no período de 2003 a 2008, quando mais se arrecadou royalties de recursos naturais não renováveis, os gastos correntes do Governo Federal saltaram de 11,4\% do PIB para 15,7\% do PIB; os investimentos foram reduzidos de $1,6 \%$ para $0,9 \%{ }^{11}$ - embora caiba apontar que o estudo se refere apenas à União, não aos entes subnacionais, que recebem grande parte das receitas públicas decorrentes da exploração. No sentido oposto, uma análise tomando

economist. yesterday's fuel: the world's thirst for oil could be nearing a peak. That is bad news for producers, excellent for everyone else. 03 de agosto de 2013; MAUGERI, Leonardo. Oil: the next revolution: the unprecedented upsurge of oil production capacity and what it means for the world. Belfer Center for Science and International Affairs Discussion Paper, n. 2012-10, Cambridge: Harvard University, 2012. Mas tais críticas não retiram desses bens minerais sua característica intrínseca e inafastável, que é sua finitude.

10 HARTWICK, John M. Intergenerational equity and the investing of rents from exhaustible resources. American Economic Review, v. 67, n. 5, 1977.

11 Os dados são do documento "A indústria e o Brasil: uma agenda para crescer mais e melhor", elaborado pela Confederação Nacional da Indústria (CONFEDERAÇÃO NACIONAL DA INDÚSTRIA. A indústria e o Brasil: uma agenda para crescer mais e melhor. Brasília, 2010. p. 87). 
como referência um período mais largo indica o inverso: que o Brasil, entre 1970 e 2000, investiu até mais do que seria demandado pela regra de Hartwick ${ }^{12}$ - o estudo também não considerou diferenças entre os investimentos da União, dos Estados e dos Municípios

Tendo em vista estes dois eixos principais - os possíveis efeitos deletérios da exploração e a equidade intergeracional, que serão melhor detalhados -, o que se pretende levar a cabo não são estudos empíricos tampouco econômicos. Mas, utilizando ambos de suporte sempre que possível, quer-se analisar as instituições, os instrumentos e os aspectos do ordenamento jurídico brasileiro, que dizem com o tema da exploração dos recursos naturais não renováveis, buscando entender se estão ou não aptos a promover os efeitos positivos que se esperam dessa atividade, bem como se estão ou não observando os interesses das gerações futuras.

A dissertação pretende atuar sobre o ordenamento jurídico posto, criticando-o e por vezes buscando identificar quais seriam os desenhos jurídico-normativos recomendados para atender aos pressupostos teóricos levantados.

Vale, nessa oportunidade introdutória, expor alguns pressupostos para clareza metodológica e melhor compreensão dos temas adiante debatidos.

A dissertação será limitada à análise da exploração de recursos naturais não renováveis e à governança sua receita.

São recursos naturais não renováveis os que estão "disponíveis em quantidade limitada, com inerente tendência à exaustão e geralmente com reservas de tamanho apenas estimado (com potencial exato desconhecido)", sendo sua finitude "uma realidade inafastável, na medida em que, invariavelmente, quanto maior a exploração de determinada reserva de recurso exaurível no presente, menor será a potencial exaustão desta mesma reserva no futuro". ${ }^{13}$ Os recursos hídricos para fins de geração de energia elétrica não se consomem com o uso, não tendem de forma inerente à exaustão. Logo, não são imediatamente não renováveis (embora a circunstância concreta possa indicar que sejam assim classificados), pelo que, apesar de as receitas públicas de sua exploração (CFURH) receberem tratamento constitucional similar àquelas receitas que decorrem da exploração de minérios e de petróleo (Constituição Federal, art. 20, § 1.º), delas não se tratará.

12 HAMILTON, Kirk; RUTA, Giovanni; TAJIBAEVA, Liaila. Capital accumulation and resource depletion: a hartwick rule counterfactual. World Bank Policy Research Working Paper, n. 3480, 2005, p. 5-6.

13 RUBINSTEIN, Flávio. Receitas públicas de recursos naturais no direito financeiro brasileiro. 2012. Tese (Doutorado) - Faculdade de Direito da Universidade de São Paulo. p. 16 e 18-19. 
Embora seja frequente na doutrina a dissociação, para fins analíticos, dos modelos jurídicos do petróleo e dos minérios, busca-se unir as análises sob a rubrica de "recursos naturais não renováveis", excepcionando, sempre que necessário, seus regimes jurídicos específicos. Da mesma forma, muitos desses estudos direcionados especificamente à exploração mineral ou à exploração petrolífera, quando cabíveis, serão utilizados como fundamentação para considerações que dizem respeito aos "recursos naturais não renováveis" em geral.

Tendo sido tomado por objeto de análise a governança das receitas de royalties, entende-se esta como

o exercício de autoridade econômica, política e administrativa para gerir os assuntos de um país em todos os níveis. Compreende os mecanismos, processos e instituições pelos quais cidadãos e grupos articulam seus interesses, exercem seus direitos, cumprem suas obrigações e mediam suas diferenças. ${ }^{14}$

Ou: “é o processo - pelo qual autoridade é conferida aos governantes, pelo qual eles fazem as regras, e pelo qual essas regras são aplicadas e modificadas"; ${ }^{15}$ ou ainda, governança representa "as tradições e instituições que determinam como a autoridade é exercida em um determinado país". ${ }^{16}$ Como se vê, trata-se de conceito amplo, que busca extrapolar a simples ideia de funcionamento e gestão da máquina administrativa para englobar não só o Estado, mas também a sociedade; para alcançar todos os níveis de governo; para observar não apenas o direito posto, mas sua construção desde o nível de reconhecimento da autoridade estatal.

14 UNDP. Governance for sustainable human development: a UNDP policy document. United Nations Development Programme, 1997. Disponível em: <http://mirror.undp.org/magnet/policy/ chapter1.htm\#b>. Acesso em: 15 fev. 2013. Tradução livre.

15 WORLD BANK. What is governance?. Disponível em: <http://go.worldbank.org/G2CHLXX0Q0>. Acesso em: 15 fev. 2013. Tradução livre. Ou ainda, governança é: "The rules and process governing the exercise of authority in the name of a constituency, including the selection and replacement of those who exercise that authority. In public governance, this process takes place between two actors, broadly characterized as the people (citizens) and the government" (WORLD BANK. Better governance for development in the Middle East and North Africa: enhancing inclusiveness and accountability. MENA development report. Washington, DC: World Bank, 2003).

16 KAUFMANN, Daniel; KRAAY, Aart; ZOIDO-LOBATÓN, Pablo. Governance matters: from measurement to action. Finance and development, v. 37, n. 2. 2000. Disponível em: <http://www.imf.org/external/pubs/ft/fandd/2000/06/pdf/kauf.pdf>. Acesso em: 15 fev. 2013. Tradução livre. Prosseguem na explicação: "This includes (1) the process by which governments are selected, held accountable, monitored, and replaced; (2) the capacity of governments to manage resources efficiently and formulate, implement, and enforce sound policies and regulations; and (3) the respect of citizens and the state for the institutions that govern economic and social interactions among them". 
As receitas públicas oriundas dos recursos naturais não renováveis, que serão analisadas, são doravante referidas como royalties, estes que são "preço público pago ao proprietário do recurso natural não renovável que for extraído, inserido ou consumido por processo produtivo", ${ }^{17}$ representados, no Brasil, pela CFEM, pelos royalties do petróleo, e pelas participações especiais da indústria petrolífera - não estão incluídos nesse conceito, por terem natureza jurídica distinta, os bônus de assinatura e o pagamento pela ocupação ou retenção da área, ambos previstos pela legislação de regência da exploração petrolífera, ${ }^{18}$ e a Taxa Anual por Hectare, contida na legislação da exploração mineral.

A lente de exame prioritária, nessa empreitada, é a do Direito Financeiro (em um foco "pós-arrecadatório") na governança que dá à receita pública de royalties, embora se imponha em ocasiões que outros setores do direito, e mesmo outras áreas de conhecimento, sejam chamadas a emprestar seus conceitos. Notando, contudo, com Ataliba, que "tôda a atividade do estado é regida pelo direito. $\mathrm{O}$ estado age na forma do direito e segundo o direito. Portanto, também a atividade financeira do estado se rege pelo direito". 19

Então, as análises concentram-se no Estado, este que, argumentar-se-á, é quem deve tomar a dianteira para que a exploração dos recursos naturais não renováveis obtenha efeitos positivos; que intervém no domínio econômico visando promover o desenvolvimento sustentável; ${ }^{20}$ que está apto a zelar pelos interesses das gerações pósteras, ${ }^{21}$ já que se trata de entidade contínua, representando gerações passadas, atuais e futuras, ${ }^{22}$ gozando de perenidade, ${ }^{23}$ tendo objetivos variáveis no tempo, ${ }^{24}$ formando uma realidade atemporal. ${ }^{25}$

17 SCAFF, Fernando Facury. Royalties decorrentes da exploração de recursos naturais não renováveis: incidência e rateio federativo. 2013. Tese (Livre-Docência) Faculdade de Direito da Universidade de São Paulo. p. 137.

18 Idem, ibidem, p. 338 e 340.

19 ATALIBA, Geraldo. Apontamentos de ciência das finanças, direito financeiro e tributário. São Paulo: RT, 1969. p. 33.

20 NUSDEO, Ana Maria. Desenvolvimento sustentável do Brasil e o protocolo de Quioto. Revista de Direito Ambiental, v. 37, 2005.

21 COMPARATO, Fábio Konder. A afirmação histórica dos direitos humanos. 7. ed. rev. e atual. São Paulo: Saraiva, 2010. p. 438-440.

22 WEISS, Edith Brown. In fairness to future generations: international law, common patrimony, and intergenerational equity. Tokyo: The United Nations University, 1989. p. 48.

23 BALEEIRO, Aliomar. Uma introdução à ciência das finanças. 16. ed. rev. e atual. Dejalma de Campos. Rio de Janeiro: Forense, 2004. p. 460.

24 BORGES, José Souto Maior. Introdução ao direito financeiro. São Paulo: Max Limonad, 1998. p. 14.

25 ADI 3273, rel. Min. Carlos Britto, rel. p/ Ac Min. Eros Grau, Tribunal Pleno, j. 16.03.2005, DJ 02.03.2007, p. 141 . 
Para além desta Introdução e de breve Conclusão ao final, a dissertação conta com 03 (três) capítulos:

O primeiro, em que se busca, através de revisão da literatura, compreender os diversos efeitos deletérios a que estão sujeitos os países que promovem intensamente a atividade de exploração de recursos naturais não renováveis. Quer-se identificar especialmente quais são esses efeitos e por que razões ocorrem.

$\mathrm{O}$ segundo capítulo diz respeito à perspectiva intergeracional. Iniciando por fixar os motivos pelos quais se entende que a característica de finitude dos bens explorados é de ser ressaltada, e que ela se reflete na forma de governança das receitas públicas que derivam dessa exploração, busca-se observar, por diferentes fontes (o desafio furtadiano, a economia de Hotelling, Solow e Hartwick, e a filosofia política de Rawls), porquê os royalties devem ser atrelados aos interesses das futuras gerações. Prossegue visando identificar caracteres mais concretos do quê se pode entender por equidade intergeracional. Finalmente, são apresentadas algumas aplicações dessa noção intergeracional, destacandose sua relação com o Direito Financeiro e as Finanças Públicas.

No terceiro e último capítulo, buscam-se identificar instituições, instrumentos e aspectos do ordenamento jurídico brasileiro, que dizem sobre a governança pública dos royalties decorrentes da exploração dos recursos naturais não renováveis, criticando-os a partir dos instrumentos teóricos dos capítulos antecedentes.

Após algumas considerações iniciais sobre o tema - que tratam da equidade intergeracional nos ordenamentos internacional e brasileiro, do domínio dos bens minerais e petrolíferos na Constituição Federal de 1988, e da justificação dos royalties no Brasil são selecionados instituições, instrumentos e aspectos para análise. São eles: (i) o Federalismo Fiscal dos royalties - sua partilha federativa; (ii) a criação, manutenção e administração de Fundos destinados à gestão dessa receita; (iii) a relação entre royalties e tributação; (iv) a classificação financeiro-orçamentária dos royalties; (v) as formas como a legislação brasileira constrange o gasto dessa receita pública, na forma de direcionamentos e vedações; (vi) a transparência dessa receita e de seu gasto. Ao final, são analisadas de forma ampla, também, a recente modificação da lei que rege a exploração de petróleo, e a proposta de modificação da lei que rege a exploração de minérios. 


\section{A EXPLORAÇÃO DE RECURSOS NATURAIS NÃO RENOVÁVEIS E SUAS ARMADILHAS}

1. A exploração de recursos naturais não renováveis e suas armadilhas

a. Notas sobre a relevância da receita de exploração de recursos naturais não renováveis

b. A maldição dos recursos naturais

i. Há mesmo uma maldição?

ii. Características da receita pública oriunda de recursos naturais não renováveis

iii. A chamada maldição: o que ela causa?

1. Volatilidade da receita;

2. Comportamento rentista;

3. Fraqueza institucional;

4. Corrupção;

5. Ausência de Transparência;

6. Outros efeitos. Conduta antidemocrática, Desigualdade, Guerras Civis, Liberdades das Mulheres.

c. Doença Holandesa

d. Redução da carga tributária

\section{A exploração de recursos naturais não renováveis e suas armadilhas}

Convém iniciar expondo que as receitas públicas diretamente decorrentes da exploração dos recursos naturais não renováveis por vezes apresentam efeitos indesejados nos Estados que as percebem.

Embora estes malefícios - comumente chamados de maldição, paradoxo, ou de armadilhas - tenham raízes mais identificadas e estudadas pela Economia e pela Ciência Política $^{26}$ (não pela literatura jurídica tradicional, embora esta se aplique em diversas oportunidades), reputa-se necessário conhecer dessas questões previamente.

Isso porque as instituições jurídicas a serem analisadas deverão

necessariamente observar as recomendações trazidas pelos demais campos de conhecimento, possibilitando ofertar modelos normativos que façam frente às vicissitudes

26 Terry Lynn Karl afirma peremptoriamente que a maldição dos recursos naturais é primariamente um fenômeno político/institucional, e não econômico. KARL, Terry Lynn. Ensuring fairness: the case for a transparent fiscal social contract. In: HUMPHREYS, Macartan; SACHS, Jeffrey D.; STIGLITZ, Joseph E. (Org.). Escaping the resource curse. New York: Columbia University Press, 2007. p. 256. 
da receita oriunda de recursos naturais não renováveis. Seria de todo inconsequente criticar instituições e propor modificações cerrando os olhos às evidências extrajurídicas.

É dizer: as considerações sobre as armadilhas que se escondem por detrás do aparente "bilhete premiado" da riqueza de recursos naturais não renováveis são inerentes à matéria e servem para lhe ofertar conformação, também assim importando no desenho jurídico-institucional que se analisa e critica.

\section{1.a. Notas sobre a relevância da receita de exploração de recursos naturais não renováveis.}

Já se referiu, na Introdução, que as receitas públicas derivadas de recursos naturais não renováveis têm relevância no Brasil atual. Embora os números da arrecadação de royalties não se revelem de tamanho tal que rivalizem com a arrecadação tributária, ${ }^{27}$ é imperativo notar que as exportações minerais são relevantíssimas na manutenção do saldo favorável da balança comercial. Da mesma forma, impõe-se também observar que a participação relativa do setor de petróleo e gás no Produto Interno Bruto brasileiro alcançou em 2010 a marca de 12\%, segundo estudo da Confederação Nacional da Indústria em conjunto com o Instituto Brasileiro de Petróleo, Gás e Biocombustíveis, apresentado na Conferência Rio+20. ${ }^{28}$

O que se pretende ressaltar, por ora, e abrindo caminho às intempéries que acompanham os Estados ricos em recursos naturais não renováveis, é que as experiências internacionais - e também nacionais, embora em menor escala e número - apontam com segurança para a tendência que tal setor da economia tenha impacto marcante nas contas públicas dos países abundantes nesses recursos. ${ }^{29}$

27 Em 2012, as receitas tributárias (encampando as Receitas Tributárias propriamente ditas e as Receitas de Contribuições) da União alcançaram mais de R \$ 930 bilhões; as receitas de royalties de recursos naturais não renováveis foram pouco superiores a R\$ 33 bilhões. Os dados tributários são da Prestação de Contas da Presidenta da República de 2012, Parte II (Orçamento Fiscal e da Seguridade Social), item 2.2.1 (Análise da Execução Orçamentária da Receita). Os dados dos royalties são dos sítios da Agência Nacional do Petróleo - ANP e do Departamento Nacional de Produção Mineral - DNPM.

28 CNI. A contribuição do setor brasileiro de petróleo, gás e biocombustíveis para o desenvolvimento sustentável no país. Confederação Nacional da Indústria, Instituto Brasileiro de Petróleo, Gás e Biocombustíveis. Cadernos Setoriais Rio +20 , Brasília, 2012. Disponível em: <arquivos.portaldaindustria.com.br/app/conteudo_18/2013/09/23/4970/20131003104228715851e.pdf>. Acesso em: 22 dez. 2013, p. 25.

29 A relevância dos recursos naturais não renováveis para a arrecadação foi uma vez mais ressaltada por estudo recente da OECD: "Los recursos naturales no renovables han desempeñado uma significativa función económica em América Latina, donde las principales economías han sido tradicionalmente exportadoras netas de productos básicos. La importancia estratégica que revisten los recursos no 
Os exemplos, nesse sentido, são variados.

A Venezuela, durante o boom dos preços do petróleo dos anos 1970, arrecadou, em 05 (cinco) anos, quase $150 \%$ (cento e cinquenta por cento) do arrecadado nos 57 (cinquenta e sete) anos anteriores. ${ }^{30} \mathrm{Na}$ Nigéria, as receitas públicas aumentaram de \$4.9 para \$21.5 bilhões de dólares entre 1969 e 1977, ${ }^{31}$ já excluídos os efeitos da inflação, com o aumento da produção do petróleo associado ao aumento do preço deste no mercado internacional. Em Gana, as receitas públicas quadruplicaram em um ano (entre 2010 e 2011), sendo a exploração petrolífera a explicação para tamanho incremento. ${ }^{32}$

No Golfo da Guiné, que tem se destacado na produção e exportação de petróleo, a dependência dessas receitas se revela evidente quando analisados o percentual de receitas decorrentes do petróleo em relação às receitas públicas totais. Numa verificação do conjunto de nações formado por Angola, Congo, Guiné Equatorial, Nigéria, Gabão e Camarões, apenas este último apresenta essa relação em nível inferior a 50\% (as receitas oriundas do petróleo são $20 \%$ das receitas totais). Todos os demais têm sua receita pública formada, em mais da metade, por rendas decorrentes de recurso natural não renovável, destacando-se Angola e Nigéria (90 e 83\%, respectivamente). ${ }^{33}$

As iniciativas não governamentais Revenue Watch e EITI têm compilado tais dados (percentual da receita oriunda da indústria extrativa como percentual da receita pública total) em países que ofertaram dados suficientes, encontrando outros exemplos notáveis, como são os casos de Iêmen (74\%), Azerbaijão (78\%), e Timor Leste (91\%). ${ }^{34}$

Também o Banco Mundial oferta dados que dizem da relevância da economia desses recursos naturais, sugerindo sua altíssima participação nas contas de determinados

renovables para esas economías há implicado que dichos recursos centraran la política tributaria, lo que, al reciente auge de los precios de los productos básicos, há impulsado los ingresos tributarios proicedentes de esta fuente". p. 45. O documento mostra o Brasil em primeiro lugar, dentre os países da América Latina selecionados, em ingressos de recursos naturais não renováveis em relação ao PIB em 2008 (p. 48). OECD/ECLAC/CLAT. Estadísticas tributarias em América Latina. OECD Publishing, 2011. Disponível em: 〈http://dx.doi.org/10.1787/9789264110540-en-fr〉.

30 KARL, Terry Lynn. The paradox of plenty: oil booms and petro-states. Berkeley: University of California Press, 1997. p. 116.

31 ROSS, Michael L. The oil curse: how petroleum wealth shapes the development of nations. Princeton: Princeton University Press, 2012. p. 27.

32 BLEISCHWITZ, Raimund. Forget "the resource curse". Resource hope is on the ascent. United Nations News \& Commentary Global News: Forum, 2013. Disponível em: $<$ http://www.undispatch.com/forget-the-resource-curse-resource-hope-is-on-the-ascent>. Acesso em: 23 dez. 2013.

33 OLIVEIRA, Ricardo Soares de. Oil and politics in the gulf of guinea. New York: Columbia University Press, 2007. p. 56.

34 Disponível em: <http://data.revenuewatch.org/eiti/all.php〉. Acesso em: 15 ago. 2013. 
países, como o combalido Iraque, que em 2011 teve 77\% de seu PIB formado a partir de rendas petrolíferas, ${ }^{35}$ a Arábia Saudita (55\%) e os Emirados Árabes Unidos (22\%).

A Rússia tem economia altamente dependente do petróleo e do gás natural, tanto que o setor responde por entre 20 e $25 \%$ do Produto Interno Bruto e cerca de $50 \%$ da receita pública total. ${ }^{36}$

No México, a estatal petrolífera PEMEX “tem sido fonte de aproximadamente um terço do total de recursos federais nos últimos 20 anos, frequentemente bancando o estado durante as últimas três décadas. Além de apoiar a economia nacional, a PEMEX recentemente também proveu recursos adicionais aos governos estadual e local". ${ }^{37}$

No Canadá, por volta de 2008, o PIB per capita da província de Alberta - rica em hidrocarbonetos - excedia em $130 \%$ a média nacional. ${ }^{38}$

Os países produtores de petróleo cresceram aproximadamente $40 \%$ mais rapidamente do que o resto do mundo entre 1990 e 2006. Excluídos os países da Europa e América do Norte, esse percentual sobe para $55 \%{ }^{39}$

Todos esses números dão cores mais vivas ao tema sobre o qual se pretende dissertar. A opulência dos números sustenta a relevância dos recursos naturais não renováveis para as economias dos países que exploram essa riqueza natural.

E, com muita frequência, a grandiosidade dos números toma conta dos discursos político-econômicos, trazendo os recursos naturais à condição de protagonistas do cenário nacional - quando não heróis da modernidade e tesouros que farão o povo mudar de vida do dia para a noite.

Mas, como de costume, deve-se agir com prudência.

Ao passo em que a exploração de petróleo ou de minérios pode representar uma mudança efetiva nas liberdades de um povo, pode também causar intempéries. Ou, no mínimo, o desperdício de uma grande oportunidade de superar deficiências históricas (especialmente nos países em desenvolvimento).

Disponível em: 〈http://data.worldbank.org/indicator/NY.GDP.PETR.RT.ZS〉. Acesso em: 15 ago. 2013. KURLYANDSKAYA, Galina; POKATOVICH, Gleb; SUBBOTIN, Mikhail. Russia. In: ANDERSON, George (Ed.). Oil \& gas in federal systems cit., p. 284.

CARREON-RODERIGUEZ, Victor G.; ROSSELLÓN, Juan. Mexico. In: ANDERSON, George (Ed.). Oil \& gas in federal systems cit., p. 193. Tradução livre.

PLOURDE, André. Canada. In: ANDERSON, George (Ed.). Oil \& gas in federal systems cit., p. 114.

ROSS, Michael L. The oil curse cit., p. 196. 
É sobre esse tema que o capítulo se debruça: as formas, identificadas pela literatura especializada, pelas quais vê-se a riqueza causando (ao fim e ao cabo) prejuízos econômicos e sociais ou, simplesmente, sendo desperdiçada irremediavelmente (e em prejuízo às gerações posteriores de cidadãos que, pelo simples posicionamento temporal, não terão sequer a oportunidade de fazer diferente).

\section{1.b. A maldição dos recursos naturais.}

Convencionou-se chamar de Maldição dos Recursos Naturais os efeitos econômicos deletérios causados pela exploração desses recursos, especialmente de minérios e petróleo. É este o tema que ora se quer apresentar, na forma de revisão da literatura posta - repita-se: especialmente econômica -, identificando quais são esses males e por quê eles ocorrem.

\section{1.b.i. Há mesmo uma maldição?}

É relevante tomar nota, ainda que brevemente, sobre a terminologia trazida pela literatura - especialmente econômica -, e ora utilizada: a que chama de maldição o fenômeno acima revisado.

A nota faz-se necessária porque maldição traz conotação de inevitabilidade. $\mathrm{O}$ amaldiçoado sofrerá por forças externas, superiores, não importa o que fizer para evitar.

Não é o que ocorre na exploração dos recursos naturais não renováveis.

Que se registre, de início, que não se trata de nomenclatura totalmente despropositada. Ela serviu (e serve) para destacar a presença dos mencionados efeitos deletérios, chamando a atenção da comunidade internacional para eles. Basta lembrar que essas colocações são contraintuitivas: o raciocínio primeiro será o de que a descoberta desses recursos naturais importa em uma dádiva, um maná do céu, que surge para beneficiar determinado país, gerando emprego, renda, divisas, desenvolvimento, etc. Por essa primeira impressão, a população do país que descobre grandes reservas minerais está sentada sobre um bilhete premiado, que em breve será descontado trazendo riqueza, material ou não, a todos. 
Então, a "frase de efeito" se prestou a despertar a curiosidade sobre esses fenômenos, sendo inegável que a quantidade e qualidade de estudos sobre o tema cresceu substancialmente da segunda metade da década de 1990 até o presente. ${ }^{40}$

Mas retome-se: há uma maldição, no sentido de inevitabilidade? Não.

Em verdade, é difícil até mesmo encontrar quem - embora apoie a utilização da nomenclatura - o defenda. Como já se referiu, são paradigmáticos os estudos de Richard Auty, e de Jeffrey Sachs e Andrew Warner. Eis, contudo, que embora defendam suas conclusões básicas com vigor, reafirmando que suas análises indicam claramente que a exploração dos recursos naturais não renováveis implica efeitos deletérios no crescimento econômico, não sustentam sua inevitabilidade.

Auty, por exemplo, é explícito ao afirmar que não se trata de um resultado inevitável - não há determinismo -, sendo relevantes as políticas públicas ${ }^{41}$ adotadas. Cita como exemplos Botsuana, Chile, Indonesia e Malásia, abundantes em minerais, que são fartamente reconhecidos como exceções à literatura da maldição. ${ }^{42}$ Sachs e Warner, por sua vez, embora não descartem expressamente o determinismo, consignam que os efeitos podem ser minorados também a partir de políticas públicas focadas nas trocas internas, então evitando ao que identificam como a causa principal do problema (migração de setores transacionáveis para não transacionáveis). ${ }^{43}$ Negam que seja adequada a proteção governamental aos setores não extrativos, preferindo políticas "mais simples e mais

40 Mister lembrar que Celso Furtado já havia descrito vários dos sintomas ora abordados quando da análise feita sobre a Venezuela em 1957, acrescida em 1974. Ver: FURTADO, Celso. Ensaios sobre a Venezuela: subdesenvolvimento com abundância de divisas. Rio de Janeiro: Contraponto, 2008 (arquivos Celso Furtado, v. 1). Já em 1957 apontava, abordando o caso da Venezuela (FURTADO, Celso. O desenvolvimento recente da economia venezuelana, 1957. In: FURTADO, Celso. Ensaios sobre a Venezuela: subdesenvolvimento com abundância de divisas. Rio de Janeiro: Contraponto, 2008, arquivos Celso Furtado, v. 1, p. 45): "O elemento dinâmico primário da grande expansão econômica venezuelana é, sabidamente, o setor petroleiro exportador. Essa atividade, ocupando uma fração muito pequena da força de trabalho do país - e uma porcentagem decrescente do total - cresceu intensamente e com relativa regularidade, no último decênio. Ademais - e este é o fator realmente importante - a renda gerada pela atividade petroleira e que retorna ao país também cresceu com intensidade". A análise de Furtado é apontada como pioneira e premonitória por Carlos Aguiar de Medeiros, "já que será na década de 1970, com os dois choques do petróleo, que os problemas examinados por Furtado como 'peculiaridades' da Venezuela, depois conhecidos na literatura do desenvolvimento como 'doença holandesa', atingirão expressão máxima. Em 1974, em 'Notas sobre a economia venezuelana', o autor retoma a análise daquele país num momento em que a alta extraordinária do petróleo radicalizava e confirmava, no essencial, os traços básicos daquele modelo" (MEDEIROS, Carlos Aguiar de. Celso Furtado na Venezuela. In: FURTADO, Celso. Ensaios sobre a Venezuela... cit., p. 139).

41 Para conceituação de "políticas públicas", v.: DOMINGUES, José Marcos. Tributação, orçamento e políticas públicas. Revista Tributária e de Finanças Públicas, v. 99, 2011.

42 AUTY, Richard M. Natural resources, capital accumulation and the resource curse. Ecological Economics, 2007, n. 61, p. 630.

43 SACHS, Jeffrey D.; WARNER, Andrew M. NBER Working Paper 5398, natural resource abundance and economic growth, 1995, p. 21-22. 
básicas" de livre comércio - embora isto diga respeito mais à sua posição econômicoideológica do que às suas convicções quanto aos impactos da exploração mineral.

E se há dúvida, ainda assim, sobre seu posicionamento, convém observar que Jeffrey Sachs (em artigo escrito sem a assinatura de Andrew Warner) consigna que "a ideia de que petróleo é uma 'maldição' é apenas parcialmente verdadeira". ${ }^{44} \mathrm{E}$ afirma que a parte real dessa maldição está na observação de que os países que têm o recurso natural em abundância apenas raramente atingem as "expectativas plausíveis" de desenvolvimento econômico de longo prazo. ${ }^{45}$ Mas ressalta: os efeitos deletérios não são um destino ${ }^{46}$ e as receitas do petróleo não precisam, em qualquer caso, representar uma maldição. ${ }^{47}$

Essa perspectiva não determinista é recorrente. Também Van der Ploeg a verbaliza, afirmando não se tratar de males inevitáveis, e da possibilidade de escapar da maldição, prescrevendo para tanto especialmente a melhora das instituições e do sistema legal, além da ênfase em transparência e accountability. ${ }^{48}$ Michael Ross vai na mesma toada, consignando que "nada há de inevitável na maldição dos recursos naturais". ${ }^{49}$ Paul Collier é enfático ao sustentar que ainda hoje a "opção padrão" é a de pilhagem dos recursos naturais e das receitas deles oriundas. A boa governança é difícil. Mas há formas de encontrá-la (e há exemplos de quem o fez), aproveitando ao máximo a exploração. ${ }^{50}$

Terry Lynn Karl evita o termo maldição. Afirma que é equivocado questionar se se trata de uma benção ou de maldição, devendo o foco ser na identificação dos tipos políticos e de trajetórias de desenvolvimento econômico são encorajados pela atividade extrativa. ${ }^{51}$ Portanto, prefere falar em um paradoxo da abundância, que "não é inevitável. Paradoxos podem ser resolvidos e trajetórias de desenvolvimento econômico podem ser alteradas, mesmo se tomem décadas ou às vezes séculos. Não há nada inescapável sobre as futuras repercussões do petróleo ou de qualquer outra commodity".52_53

44 SACHS, Jeffrey D. How to handle the macroeconomics of oil wealth?. In: HUMPHREYS, Macartan; SACHS, Jeffrey D.; STIGLITZ, Joseph E. (Org.). Escaping the resource curse cit., p. 173.

45 Idem, ibidem, p. 174.

46 Idem.

47 Idem, p. 192.

48 VAN DER PLOEG, Frederick. Challenges and opportunities for resource rich economies. OxCarre Research Paper, n. 2008-05, Oxford University, 2007, p. 50-51.

49 ROSS, Michael L. Does oil hinder democracy?. World Politics, 2001, n. 53, p. 357.

50 COLLIER, Paul. Small countries and big resources: harnessing natural resources for development in the g7+ countries. Paper prepared for the g7+ high level ministerial retreat. 2012. Disponível em: <http://www.g7plus.org/news-feed/2013/1/10/small-countries-and-big-resources.html>. Acesso em: 27 ago. 2013.

$51 \quad$ KARL, Terry Lynn. The paradox of plenty... cit., p. 235.

52 Idem, ibidem, p. 242. 
Cabe lembrar que o Índice de Governança dos Recursos Naturais (Resource Governance Index) também parece caminhar nesse sentido: há vários países ricos nesses recursos que estão dentre os identificados como de melhor governança. Então, como o próprio estudo aponta, "a dependência dos recursos naturais não impede transparência e accountability", sendo possível adotar as medidas, identificadas pelo estudo como demonstradoras de boa governança, "quando o setor extrativo é da máxima importância política e econômica". ${ }^{54}$

Em uma abordagem um pouco distinta, Dunning afirma que há uma maldição - pelo menos no que se refere ao efeito antidemocrático da atividade -, mas que ela é "condicional". ${ }^{55}$ Essa perspectiva é diversa porque não está ligada a um mal que pode ser ultrapassado; mas a um mal que só se faz presente em determinadas circunstâncias, mas não em outras, que o autor identifica em seus escritos. Para ele, a mesma exploração dos recursos naturais não renováveis pode (dependendo das referidas circunstâncias) promover regimes autocráticos ou promover regimes democráticos.

E há também os que negam totalmente a existência de uma maldição - o que fazem não só denunciando a conotação de inevitabilidade, mas apresentando suas análises para concluir que as não há correlação entre a exploração dos recursos naturais não renováveis e os efeitos deletérios acima apresentados. Sustentam, em síntese, que esses efeitos são causados por circunstâncias outras, especialmente históricas e culturais, e que apenas cálculos enviesados é que demonstram o inverso. Nesse grupo de "céticos"

53 É vasto o anedotário de termos utilizados para se referir aos recursos naturais não renováveis (especialmente petróleo) quando da análise de seus efeitos deletérios. Citem-se como exemplos: Juan Pablo Pérez Alfonso, ex-Ministro venezuelano chamou o petróleo de "excremento do demônio" (ROSS, Michael L. The oil curse... cit., p. 1); Nancy Birdsall e Arvind Subramanian (BIRDSALL, Nancy; SUBRAMANIAN, Arvind. Saving Iraq from its oil. Foreign Affairs, n. 83[4]) apresentam como os recursos minerais podem se transformar, de um "maná" para o "caldo da bruxa". Terry Lynn Karl (KARL, Terry Lynn. Ensuring fairness: the case for a transparent fiscal social contract. In: HUMPHREYS, Macartan; SACHS, Jeffrey D.; STIGLITZ, Joseph E. (Org.). Escaping the resource curse cit., p. 257) se refere à dependência dos recursos minerais transformando os Estados em "potes de mel" a serem tomados de assalto por todo tipo de atores.

54 RESOURCE GOVERNANCE INDEX 2013. A measure of transparency and accountability in the oil, gas and mining sector. Revenue Waych Institute, 2013, p. 11.

55 DUNNING, Thad. Natural resources and democracy in latin america. Background paper prepared for latin america and caribbean regional flagship report on commodities (Office of the Regional Chief Economist, IBRD). 2009. Disponível em: <http://siteresources.worldbank.org/ EXTLACOFFICEOFCE/Resources/870892-1253047679843/6438618-1254513204494/Dunning2009. pdf>. Acesso em: 29 ago. 2013. 
destacam-se Christa Brunnschweiler, ${ }^{56}$ Daniel Lederman e William Maloney, ${ }^{57}$ e Stephen Haber e Victor Menaldo. ${ }^{58}$

\author{
Como é natural, as posições "céticas" não passaram sem críticas - e fortes \\ críticas. Van der Ploeg e Poelhekke responderam a Brunnschweiler e Bulte afirmando
}

terem encontrado diversos itens passíveis de reforma na montagem de seus cálculos, que

56 BRUNNSCHWEILER, Christa N. Cursing the blessings? Natural resource abundance, institutions, and economic growth. World Development, v. 36, 3, Elsevier, 2008. Afirma: "estimations contradict most of the resource curse literature so far, showing that natural resources, and in particular mineral resources, have a positive direct association with real GDP growth over the period 1970-2000, even when controlling for the quality of institutions. In addition, there is no evidence that resource abundance negatively affects institutional quality, contradicting the hypothesis of an indirect natural resource curse, for example through rent-seeking behavior. Interestingly however, the beneficial growth effects seem to diminish as institutional quality improves, although they remain strongly positive overall [...] In sum, an abundance of natural resources may in fact generally be much less of a curse and more of a boon for economic performance than often believed" - p. 412-413; ainda: BRUNNSCHWEILER, Christa N.; BULTE, Erwin H. The resource curse revisited and revised: A tale of paradoxes and red herrings. Journal of Environmental Economics and Management, v. 55, 3, Elsevier, 2008. Sustentam: "Treating resource dependence as endogenous, we find it to be insignificant in growth regressions, with no effect on institutional quality. While we find resource abundance to be significantly associated with both growth and institutional quality, the association runs contrary to the resource curse hypothesis: greater abundance leads to better institutions and more rapid growth [...] The empirically significant relationship between institutional quality and resource dependence reflects that countries with poor institutions are unlikely to develop non-primary production sectors to reduce their dependence on resource exports. If so, the causality would be from institutions to dependence, and not the other way around. It would be inappropriate to talk about the 'curse of resources' then. Instead, growth regressions in the resource curse literature may be viewed as a reminder of the important direct and indirect impacts of institutions on economic outcomes" - p. 261.

57 LEDERMAN, Daniel; MALONEY, William F. Trade structure and growth. In: LEDERMAN, Daniel; MALONEY, William F. (Ed.). Natural resources, neither curse nor destiny. Washington: Stanford University Press e The World Bank, 2007. p. 32-33. "In the case of natural resources, Sachs and Warner's assertion that resource abundance adversely affects growth is found not to be robust to a variety of measures of resource abundance or estimation technique [...] At very least we should abandon the stylized fact that natural resource abundance is somehow bad for growth and even perhaps consider a research agenda on the channels through which it may have a positive effect, possibly through inducing higher productivity growth [...] To summarize the last two paragraphs, we can find no evidence of a negative impact of natural resource abundance on growth. There is no resource curse". E ainda: LEDERMAN, Daniel; MALONEY, William F. In search of the missing resource curse. Policy research working paper, n. 4766, World Bank, 2008, p. 19. "The review of the literature on the resource curse indicated that the evidence in support of the curse is weak at best. There are important issues of measurement of relative endowments, of potential heterogeneity in the effects of such endowments on development and growth, and some of the international econometric evidence that appears to support the curse hypothesis has been based on the use of weak proxies, and even on nonstandard manipulations of influential data points. This mixed evidence in favor of the resource curse also needs to face up to some obvious historical facts, ranging from the successful development of now rich countries, to the success of numerous developing economies, ranging from Rwanda to Chile. Moreover, the idea that natural resources inevitably worsen political or other institutions that might be important for development also seems to have ignored historical facts related to the evolution of such institutions, and there are examples where "good" institutional characteristics had emerged prior to the discovery of natural resources, for example, in the case of Venezuela, which may explain the strong economic growth of this economy for almost 50 years".

58 HABER, Stephen H.; MENALDO, Victor A. Do natural resources fuel authoritarianism? A reappraisal of the resource curse. American Political Science Review, v. 105, n. 1, 2010. "Our results indicate that oil and mineral reliance does not promote dictatorship over the long run. If anything, the opposite is true". p. 25 . 
levariam a resultados enviesados e sustentados em dados incompatíveis com a finalidade da pesquisa. E sustentando que, corrigidas essas falhas, os resultados reafirmam o "amparo a um efeito indireto dos recursos naturais no crescimento através do canal da volatilidade" 59

Igualmente, Ivar Kolstad e Arne Wiig rebatem essas teses, especialmente sob a verificação de que seus cálculos consideram medidas de quantidade de recursos naturais quando, em verdade, a literatura da maldição diz respeito aos efeitos deletérios ocasionados pelas rendas decorrentes da exploração. É nessa distinção (quantidade x renda) que, afirmam, está a ponto fulcral que conduz às conclusões "céticas" - conclusões que seriam diversas tivessem os autores considerado as rendas, como deve ser. Pelo que consignam que "os estudos empíricos que usam medidas de abundância dos recursos não refutam a maldição dos recursos naturais, já que eles não captam as principais implicações dos modelos teóricos principais". 60

É de se ressaltar, pois, revisitadas todas essas diversas posições doutrinárias, que se há - e parece claro que há, ao menos em alguns dos casos listados - uma relação de causa e efeito entre a exploração dos recursos naturais não renováveis e os efeitos deletérios acima mencionados, então ela deve ser endereçada com seriedade.

$\mathrm{E}$ as ações a serem tomadas passam necessariamente pelo papel e pela postura do Estado na governança dessas receitas e no enfrentamento dos "desafios políticos únicos" ${ }^{61}$ trazidos pela exploração desses recursos naturais.

Afinal, quando se fala dos males da volatilidade, o tema está diretamente relacionado à receita pública e ao gasto público, assim como ao equilíbrio e à sustentabilidade financeira do Estado. Quando se trata do comportamento rentista, o tema não pode ser abordado sem referir as pressões sofridas pelos administradores públicos, e os mecanismos de representatividade da população na gestão pública; a tributação - e seu exercício a nível ótimo em comparação à ausência deste em prol do financiamento público

59 VAN DER PLOEG, Frederick; POELHEKKE, Steven. The pungent smell of "red herrings": subsoil assets, rents, volatility and the resource curse. Journal of Environmental Economics and Management, $\mathrm{n}$. 60, Elsevier, 2010, p. 50-52.

60 KOLSTAD, Ivar; WIIG, Arne. It's the rents, stupid! The political economy of the resource curse. Energy Policy, n. 37, Elsevier, 2009. Interessante notar que os autores debitam parte dessa confusão aos próprios Sachs e Warner, autores de texto paradigmático sobre a maldição, especialmente porque mencionam no título desse texto a abundância dos recursos naturais, quando não é ela (abundância) que é relevante, mas as rendas decorrentes dela.

61 BOADWAY, Robin; SHAH, Anwar. Fiscal federalism: principles and practice of multiorder governance. Nova York: Cambridge University Press, 2009. p. 212. 
mediante transferências - deve ser destacada; mesmo em tratando do rentismo referente ao particular (que busca lucros marginas à atividade extrativista, abandonando outros setores de produção), não se deve esquecer que é dever do Estado fomentar um "desenvolvimento nacional equilibrado", ${ }^{62}$ o que inclui a diversificação produtiva. Efeitos como a piora das instituições, o alto nível de corrupção e a fragilização dos mecanismos de transparência referem-se diretamente ao Estado - que poderá ser responsável por parte dos efeitos deletérios e, proporcionalmente, responsável por ultrapassá-los, governando a exploração dos recursos minerais em prol do bem-estar da sociedade.

Então, "o país precisa planejar como utilizar as novas fontes de renda [...] Isto não ocorrerá como resultado automático das forças de mercado, mas apenas com planejamento e atuação deliberada do Estado". ${ }^{63}$ É como Terry Lynn Karl se posiciona, sustentando que a demanda por encolhimento do Estado "ignora a necessidade gritante de fortalecimento de sua autoridade". ${ }^{64}$ Logo, com Humphreys, Sachs e Stiglitz, vê-se que "o foco nos governos é natural: essas ações [necessárias para escapar aos efeitos adversos da exploração] funcionarão apenas se os governos liderarem o caminho". ${ }^{65}$ É também como leciona Celso Furtado, para quem "cabe ao setor fiscal, portanto, o papel do mecanismo de transmissão do impulso gerado no setor petroleiro ao conjunto da economia do país". ${ }^{66-67}$

62 Art. 174, I, da Constituição Federal.

63 BERCOVICI, Gilberto. Direito econômico do petróleo e dos recursos minerais. São Paulo: Quartier Latin, 2011. p. 42.

64 KARL, Terry Lynn. The paradox of plenty... cit., p. 240.

65 HUMPHREYS, Macartan; SACHS, Jeffrey D.; STIGLITZ, Joseph E. Future Directions for the Management os Natural Resources. In: HUMPHREYS, Macartan; SACHS, Jeffrey D.; STIGLITZ, Joseph E. (Org.). Escaping the resource curse cit., p. 324.

66 FURTADO, Celso. O desenvolvimento recente da economia venezuelana. 1957. In: FURTADO, Celso. Ensaios sobre a Venezuela... cit., p. 46. E ainda, em outro texto (Idem, ibidem): "Pelo menos sobre um ponto básico existe hoje consenso: a inação ou a omissão do Estado não constitui uma opção. Dado que o excedente petroleiro passa pelo Tesouro Público, a responsabilidade do Estado é inescapável". p. 125.

67 À mesma conclusão chega grupo de economistas em trabalho que avalia o consumo excessivo feito pelos Estados a partir da exploração de recursos naturais (ARROW, Kenneth; DASGUPTA, Partha; GOULDER, Lawrence; DAILY, Gretchen; EHRLICH, Paul; HEAL, Geoffrey; LEVIN, Simon; MÄLER, Karl-Göran; SCHNEIDER, Stephen; STARRETT, David; WALKER, Brian. Are we consuming too much?. Journal of Economic Perspectives, 118, n. 3, 2004). Apontam que "the need for vigorous public policies to support more efficient consumption and investment choices is unambiguous". p. 168. No mais, Boadway e Shah afirmam: "The decision about the disposition of natural resource revenues is of relevance for how the national economy is affected by the resource boom, as we have seen. The potentially adverse consequences for other industries will be dampened if the revenues are saved. This will especially be the case if they are saved in foreign assets so that real exchange rate effects are minimized" (BOADWAY, Robin; SHAH, Anwar. Fiscal federalism... cit., p. 217). Flávio Rubinstein, por sua vez, sustenta: "A disponibilidade limitada dos recursos naturais não renováveis, aliada ao seu alto valor econômico e estratégico, tornam o papel dos governos fundamental no âmbito da exploração de tais recursos. Essa função do Estado é exercida de forma abrangente, por meio da regulação deste setor, da estruturação e aplicação de sistemas fiscais e, em muitos casos, da intensa participação governamental direta na própria atividade de exploração, especialmente no caso do petróleo" (RUBINSTEIN, Flávio. Receitas públicas de recursos naturais no direito financeiro brasileiro 
O Estado pode e deve tomar a frente na luta contra os efeitos deletérios da exploração dos recursos naturais não renováveis. E a sociedade pode e deve fiscalizar e cobrar do Estado que atue da melhor forma ${ }^{68}$ nesse mister (respeitadas, é claro, as preferências e particularidades nacionais), nas diversas formas de atuação demandadas, incluindo (ou especialmente) na governança da receita pública oriunda desses recursos.

\section{1.b.ii. Características da receita pública oriunda de recursos naturais não renováveis.}

Cabe de início identificar no que as receitas oriundas desses recursos naturais são diversas de quaisquer outras receitas públicas. No afã de sistematizar as sensíveis diferenças entre a receita pública oriunda de recursos naturais e as demais (especialmente as tributárias), Michael L. Ross ${ }^{69}$ distingue umas e outras quanto ao seu volume, sua fonte, sua estabilidade e sua transparência. Isto é: de acordo com o mencionado autor, "receitas de petróleo são marcadas por seu tamanho excepcionalmente grande, sua fonte incomum, falta de estabilidade, e sigilo", ${ }^{70}$ e daí decorrem os efeitos deletérios comumente lembrados e que serão referidos adiante.

Quanto ao volume, Ross observa que a exploração petrolífera gera receitas públicas superiores a outros tipos de atividade, daí incentivando o Governo a também gastar mais do que o de outros Estados.

Igualmente, a dimensão maiúscula dessas receitas traz reflexos na fonte da receita pública. Isto é: enquanto os demais Estados devem recorrer à tributação regular para custear suas atividades, os países ricos em minérios podem substituir sua fonte primária de receita. Assim, é comum que nesses lugares a arrecadação tributária seja

cit., p. 19-20). E ainda vale colacionar: "Despite the solid consensus that resource wealth + governance deficit $=$ the resource curse, the reality is that the recent boom in natural resource exploitation is happening in countries that have very weak governance systems" (FERREIRA, Patrícia Galvão. Breaking the weak governance curse: global regulation and governance reform in resource-rich developing countries. 2012. Tese (Doutorado) - Faculdade de Direito da Universidade de Toronto. p. 53).

68 "Leaders have free will. Oil exporters need not be prisoners of a curse that has befallen others. Countries can choose to use their resource bonanzas for the long-term economic advancement of their people, not just that of their leaders" (FRANKEL, Jeffrey. Escaping the oil curse. Project syndicate, 09 de dezembro de 2011. Disponível em: <http://www.project-syndicate.org/commentary/escaping-the-oil-curse>. Acesso em: 23 dez. 2013). 
inferior à capacidade, ${ }^{71}$ escorando-se o Estado nas receitas decorrentes da exploração da mineração - receitas que são "burocraticamente mais fáceis e politicamente mais populares". ${ }^{72}$ Ross afirma mesmo que se dá uma dependência desproporcional, bem como uma desproporcional liberação da arrecadação tributária. ${ }^{73}$ Essa desproporcionalidade se funda na observação de que as receitas públicas ligadas ao petróleo são maiores do que a participação da indústria petrolífera na economia nacional (em comparação com a relação receita pública $x$ PIB de outras atividades econômicas).

As receitas oriundas da exploração mineral são marcadas ainda pela falta de estabilidade, sofrendo bruscas mudanças em curto espaço de tempo. Isso se deve à volatilidade dos preços ${ }^{74}$ - que Ross debita principalmente à inelasticidade tanto da oferta quanto da demanda ${ }^{75}$ à cambiante produção, especialmente naquelas reservas de minerais que se aproximam da exaustão; e a contratos (entre Estados soberanos e empresas que se propõem a explorar) e regras de recolhimento de royalties desprovidos de cláusulas estabilizantes, e muitas vezes até mesmo mais propensos à volatilidade.

A falta de transparência é tido como outro elemento distintivo: as receitas públicas decorrentes da exploração são mais frequentemente escondidas, seja no Orçamento, seja na contabilidade das empresas públicas responsáveis pela exploração. Mundo afora, são vários os casos - alguns mais outros menos bem trabalhados - em que Estados estabelecem limitações à informação que vai a público sobre a quantidade e destinação dessas receitas. O Brasil, note-se, foi eleito o país mais transparente no ranking, organizado conjuntamente pelas instituições Revenue Watch Institute e Transparência Internacional, que mediu a transparência das receitas oriundas da exploração de recursos naturais não renováveis. ${ }^{76}$ Nada obstante essa láurea, que deve ser louvada, ela não importa em dizer que toda a institucionalidade brasileira relacionada ao tema está livre de críticas o que será desenvolvido em outra oportunidade, neste trabalho.

Ressalta, finalmente, Michael Ross, que na exploração do petróleo não se veem algumas externalidades positivas presentes em outros setores da economia. Principalmente: demanda elevadas somas de capital, mas relativamente pequena mão de obra, assim

71 Adiante, referindo o critério de esforço fiscal que pode integrar um quadro de rateio federativo, serão referidos alguns métodos propostos de medição da capacidade de arrecadação própria.

ROSS, Michael L. The oil curse... cit., p. 31.

Idem, ibidem, p. 31.

BERCOVICI, Gilberto. Direito econômico do petróleo e dos recursos minerais cit., p. 52.

ROSS, Michael L. The oil curse... cit., p. 50.

REVENUE WATCH INDEX 2010. Transparency: Governments and the oil, gas and mining industries.

Revenue Waych Institute, 2010. 
deixando de causar impacto no consumo; e compram poucos insumos no âmbito local, dada a especificidade do maquinário utilizado. ${ }^{77}$ Há ainda a questão da doença holandesa, que será melhor referida adiante.

Outras características da indústria extrativa podem ser destacadas. ${ }^{78}$ É comum, por exemplo, também, que se aponte como predicado deste tipo de atividade o fato de que os minérios e o petróleo não precisam ser produzidos, mas simplesmente extraídos. Daí que a riqueza mineral se dá independentemente de outros processos econômicos dentro de um país. ${ }^{79}$

E, finalmente, deve-se referir a questão da não renovabilidade desses recursos naturais. Essa condição, que entendemos da maior relevância, confere contornos especiais à atividade e, especialmente, à receita pública dela decorrente. Isto é: em razão dessa especificidade, mostra-se equivocado o tratamento - tão disseminado - desses bens como fonte de receita equiparável à arrecadação de impostos. Em se tratando de recursos naturais exauríveis, fazem parte do patrimônio ${ }^{80}$ da nação, ${ }^{81}$ e sua extração atual, por melhor que sejam os termos econômicos da exploração, deve enfrentar a difícil constatação de que importa necessariamente em redução do patrimônio da presente e das futuras gerações. Essas considerações serão melhor exploradas nos capítulos adiante.

\section{1.b.iii. A chamada maldição: o que ela causa?}

Já se tendo referido à Maldição dos Recursos Naturais, cumpre questionar: quais são os tais efeitos deletérios por ela causados?

$\mathrm{O}$ assunto tem sido tema de diversos estudos, centrados nas perspectivas econômica e da ciência política. É claro que alguns dos suscitados efeitos da exploração de recursos naturais não renováveis, embora propostos, não têm sido confirmados. Nessa matéria, como em qualquer outra, não há unanimidades. Mas é possível descrever algumas

ROSS, Michael L. The oil curse... cit., p. 45-47.

Explorando as características da exploração em si - e não das receitas delas oriundas - e sob uma perspectiva de desenho da tributação ótima incidente, v. BOADWAY, Robin; KEEN, Michael. Theoretical perspectives on resource tax design. In: DANIEL, Philip; KEEN, Michael; McPHERSON, Charles (Ed.). The taxation of petroleum and minerals: principles, problems and practice. New York: Routledge, 2010. p. 14 e ss.

79 HUMPHREYS, Macartan; SACHS, Jeffrey D.; STIGLITZ, Joseph E. Introduction: What is the problem with natural resource wealth?. In: HUMPHREYS, Macartan; SACHS, Jeffrey D.; STIGLITZ, Joseph E. (Org.). Escaping the resource curse cit., p. 4. Idem, ibidem, p. 4.

81 São bens da União, lembre-se, consoante dispõe o art. 20, IX, da CF/1988. 
implicações que restam assentadas na literatura especializada. Não se pretende criticar os dados e cálculos dos trabalhos adiante referidos, nem suas interpretações sobre as causas explicativas de cada um dos efeitos. Pretende-se apresentar com brevidade alguns desses efeitos, sempre que possível referindo as contraproposições doutrinárias. Os debates sobre as divergências acadêmicas relativas às razões específicas que explicam a maldição podem ser consultados na bibliografia contida no rodapé e ao final da dissertação.

O tema surgiu com impacto dada especialmente sua natureza contraintuitiva. É dizer: a descoberta de grandes reservas minerais é (e deve ser) vista com otimismo para o país onde se localizam tais reservas. De fato, a exploração desses recursos põe no horizonte a possibilidade de tradução desse patrimônio natural em riqueza e desenvolvimento.

Por isso mesmo é que Richard Auty observa que "evidências sugerem que não apenas os países ricos em recursos naturais falham em se beneficiar desse dote favorável, eles podem na verdade obter resultados piores que países com menos dotes. Esse resultado contraintuitivo é a base da tese da maldição dos recursos". ${ }^{22}$ A partir de uma série de comparações, o autor apontou que o desempenho dos países ricos em minerais se revela inferior ao desempenho de outros países que não contam com tal riqueza.

Portanto, a maldição nada mais é do que a constatação de que os países ricos em recursos naturais não renováveis costumam - embora isso não seja necessário e absoluto, como já se viu - ter pior desempenho econômico do que os países cuja economia está ancorada em outras atividades.

Essa constatação foi reforçada por Jeffrey Sachs e Andrew Warner, que, em trabalho publicado em 1995, voltaram a demonstrar a relação de inversa proporcionalidade entre as economias minerais e o desenvolvimento econômico. ${ }^{83} \mathrm{O}$ estudo se pretendeu não apenas comparativo dos desempenhos econômicos, mas fazê-lo eliminando uma série de variáveis que poderiam afetar seu desempenho. E as conclusões são de uma "associação estatisticamente significante, inversa e robusta, entre a intensidade dos recursos naturais e o crescimento". ${ }^{84}$ Interpretando esses resultados, os autores sugerem que os números encontrados são consistentes "com a visão de que a principal divisão, no que importa aos efeitos do crescimento endógeno, é do setor manufaturado transacionável contra os setores

82 AUTY, Richard M. Sustaining development in mineral economies: the resource curse thesis. New York: Routledge, 1993. p. 1. Tradução livre.

83 SACHS, Jeffrey D.; WARNER, Andrew M. NBER Working Paper 5398 cit.

84 Idem, ibidem, p. 21. 
de recursos naturais", ${ }^{85}$ a significar que uma maior dependência das atividades de extração mineral importa em um menor desenvolvimento do setor interno de manufaturas e que essa redução causa prejuízos ao crescimento nacional.

A partir desses estudos paradigmáticos, outras diversas correlações, econômicas e políticas, entre a exploração de recursos naturais não renováveis e efeitos deletérios aos países que os hospedam e exploram, foram sendo construídas.

1.b.iii.1. Volatilidade da receita.

A enorme volatilidade, já referida acima, intrínseca às receitas minerais, é frequentemente abordada, inclusive como responsável pelos principais efeitos adversos da exploração de recursos naturais na taxa de crescimento dos países, ${ }^{86}$ tendo sido referida, mesmo, como "quintessência da maldição dos recursos naturais" ${ }^{87}$ Seu efeito negativo é claro, conduzindo ao que alguns chamam de "boom-bust cycles", ${ }^{88}$ que pode ser traduzido como ciclo de expansão e recessão. Nesses casos, o sucesso econômico de um primeiro momento (por exemplo, com a alta de preços) é sucedido por queda acentuada em alguns meses ou anos (por exemplo, com a queda de preços ou dificuldades exploratórias supervenientes ou mesmo pela exaustão das jazidas). Van der Ploeg afirma estar bem estabelecido que a volatilidade é perniciosa para “o crescimento, investimento, distribuição de renda, pobreza e obtenção de educação". ${ }^{89-90}$

O referido ciclo prejudica o planejamento de longo prazo - afinal, os momentos de alta e queda são incertos. ${ }^{91}$ Mais: causa prejuízos severos quando as receitas

SACHS, Jeffrey D.; WARNER, Andrew M. NBER Working Paper 5398 cit., p. 22.

VAN DER PLOEG, Frederick. Challenges and opportunities for resource rich economies cit., p. 23.

VAN DER PLOEG, Frederick; POELHEKKE, Steven. The pungent smell of "red herrings": subsoil assets, rents, volatility and the resource curse cit., p. 52.

88 HUMPHREYS, Macartan; SACHS, Jeffrey D.; STIGLITZ, Joseph E. Introduction: What is the problem with natural resource wealth?. In: HUMPHREYS, Macartan; SACHS, Jeffrey D.; STIGLITZ, Joseph E. (Org.). Escaping the resource curse cit., p. 8.

89 VAN DER PLOEG, Frederick. Challenges and opportunities for resource rich economies cit., p. 24.

90 A mesma afirmativa exata, estranhamente sem nenhuma referência cruzada, pode ser encontrada em HAUSMANN, Ricardo; RIGOBON, Roberto. An alternative interpretation of the "resource curse". In: DAVIS, J.; OSSOWSKI, R.; FEDELINO, A. (Org.). Fiscal policy formulation and implementation in oil-producing countries. Washington, D.C.: International Monetary Fund. p. 19. Os autores postulam, contra a doutrina tradicional, contudo, que o impacto da volatilidade, salvo em caso de dependência extrema, não é tão relevante, representando mais um "incômodo" do que uma "maldição".

91 BAUNSGAARD, Thomas; VILLAFUERTE, Mauricio; POPLAWSKI-RIBEIRO, Marcos; RICHMOND, Christine. Fiscal frameworks for resource rich developing countries. IMF Staff Discussion Note SDN/12/04. 2012, p. 21. "The volatility and uncertainty of resource revenue is critical for the design of fiscal frameworks, and having sufficient precautionary fiscal buffers is critical. 
são adiantadas e comprometidas, mediante empréstimos públicos ou mesmo através da criação de novas despesas, o que se faz sentir tão mais quanto menor for o ente público receptor da receita, maior for sua dependência, e menos diversificada for sua base produtiva, inclusive com respeito aos recursos naturais não renováveis: os monodependentes serão mais afetados que os que exploram simultaneamente vários bens minerais. Se hospitais são planejados com os olhos nos indicadores da fase de expansão, o dinheiro pode faltar à obra quando chegada a fase de recessão. Ou pior: ainda que encerradas e concluídas as despesas de capital previstas, a fase de recessão, se não planejada adequadamente, pode drenar os recursos das despesas correntes associadas: faltará verba para o pagamento de médicos nos hospitais; de professores nas escolas.

O que se vê com frequência, entretanto, é que "os benefícios dos anos bons são transitórios, enquanto os problemas gerados nos anos ruins são duradouros". ${ }^{92}$

\section{1.b.iii.2. Comportamento rentista.}

A exploração dos recursos naturais não renováveis, diz-se, costuma provocar, na Administração Pública do Estado produtor, assim como no setor privado, o chamado comportamento rentista ("rent-seeking behavior"), que dá "margem a desvios e oportunismos, em detrimento de visões com perspectiva coerente e de longo prazo".93

Esse tipo de comportamento é recorrente e compreensível. As notícias que chegam aos políticos e ao público sobre o desenvolvimento da economia mineral, assim como o crescimento das receitas, geram pressões por gastos públicos maiores, imediatos, e muitas vezes divorciados das melhores práticas fiscais. A população pressiona por "melhoras rápidas e visíveis em seu bem-estar"; 94 eleitores "pressionam por favores em troca de apoio político". ${ }^{95}$ Todos desejam arrecadar para si uma parte daquela riqueza.

Technically, a strong revenue forecasting framework needs to be developed and spending plans framed in a medium-term perspective".

92 HUMPHREYS, Macartan; SACHS, Jeffrey D.; STIGLITZ, Joseph E. Introduction: What is the problem with natural resource wealth?. In: HUMPHREYS, Macartan; SACHS, Jeffrey D.; STIGLITZ, Joseph E. (Org.). Escaping the resource curse cit., p. 8. Tradução livre.

93 BERCOVICI, Gilberto. Direito econômico do petróleo e dos recursos minerais cit., p. 29.

94 HUMPHREYS, Macartan; SACHS, Jeffrey D.; STIGLITZ, Joseph E. Introduction: What is the problem with natural resource wealth?. In: HUMPHREYS, Macartan; SACHS, Jeffrey D.; STIGLITZ, Joseph E. (Org.). Escaping the resource curse cit., p. 9.

95 Idem, ibidem. 
Afinal, como acima já mencionado, a riqueza não é produzida, mas extraída. Daí que em alguns aspectos, é uma riqueza mais "fácil" que outras. ${ }^{96}$

O empresariado não é diferente. Diante da perspectiva de maior retorno nesse setor específico, tende a migrar para a atividade extrativa, ${ }^{97}$ ou para outras atividades que a cercam - especialmente prestação de serviços relacionados. Essa conduta prejudica a economia nacional, que perde fôlego nos setores com maior agregação de valor, prejudicando o desempenho de exportação de outros produtos, ${ }^{98}$ virando-se em direção à exploração dos recursos naturais, que é sabidamente capital intensiva. Fique-se com o ensinamento de Jeffrey Frankel que, embora apresente dúvidas de que a industrialização é o sine qua non do desenvolvimento econômico, ${ }^{99}$ conclui afirmando que há "no mínimo alguma verdade" nas proposições que sustentam que a "especialização em recursos naturais pode ser prejudicial ao crescimento se ela esvaziar o setor manufatureiro e que este é o locus de externalidades positivas", ${ }^{100}$ especialmente vinculadas aos níveis de criação de empregos e à assimilação de qualidades técnicas destes empregados.

O comportamento rentista, que pode também ser interfederativo - situação na qual o Ente Público é financiado por transferências internas, deixando de desenvolver sua capacidade arrecadatória, o que é comum no Brasil, infelizmente -, caracteriza-se por apresentar quadro em que "apenas uma pequena parcela da sociedade está envolvida na geração de renda/riqueza. A maior parte se envolve na distribuição ou utilização da riqueza". ${ }^{101}$ Esse tipo particular de riqueza debilita o empreendedorismo, e torna outros negócios simplesmente menos atrativos, ${ }^{102}$ levando os interesses das elites empresariais a se limitar às atividades relacionadas à exploração de recursos naturais. ${ }^{103}$ Van der Ploeg argumenta que esse movimento "diminui a renda [do país] em mais do que [se aumenta] a renda extra oriunda das receitas de recursos naturais, assim rebaixando os níveis de bemestar". 104

96 BERCOVICI, Gilberto. Direito econômico do petróleo e dos recursos minerais cit., p. 27, citando Oysten Noreng.

97 BOADWAY, Robin; SHAH, Anwar. Fiscal federalism cit., p. 216.

98 SACHS, Jeffrey D.; WARNER, Andrew M. The curse of natural resources. European Economic Review, n. 45, Elsevier, 2001.

99 FRANKEL, Jeffrey. The natural resource curse: a survey. Discussion paper 2010-21. Cambridge, Mass.: Harvard Environmental Economics Program, 2010. p. 14.

100 Idem, ibidem, p. 37.

101 BERCOVICI, Gilberto. Direito econômico do petróleo e dos recursos minerais cit., p. 30.

102 SUROWIECKI, James. The real price of oil. In: the new yorker. 03 de dezembro de 2001.

103 OLIVEIRA, Ricardo Soares de. Oil and politics in the gulf of guinea cit., p. 141.

104 VAN DER PLOEG, Frederick. Challenges and opportunities for resource rich economies cit., p. 29. Tradução livre. 
Enfim, o rentismo importa em comportamento parasitário dos agentes públicos ${ }^{105}$ e privados, que se vinculam fortemente à riqueza gerada pela exploração dos recursos naturais não renováveis, dela dependendo. E deixam em segundo plano a criação de riqueza através das fontes tradicionais: especialmente o trabalho, a inovação, a empresa, a criação de riqueza (para os particulares); e a tributação (para os Entes Públicos). Então, como adverte Terry Lynn Karl, "a influência econômica e o poder político são especialmente concentrados, os limites entre o público e o privado muito confusos, e o comportamento oportunista como estratégia para a criação de riquezas é desmedido". ${ }^{106}$

Fenômeno semelhante foi identificado como "efeito voracidade" por Aaron Tornell e Philip Lane, ${ }^{107}$ que indicam que nos períodos de expansão, com o boom das rendas minerais, cresce o lucro dos investimentos no setor formal; o "efeito voracidade" se manifesta nos grupos de poder (sejam públicos ou privados), que são levados a tentar agarrar maior parte da riqueza nacional demandando maiores transferências a si. Essas transferências podem ser federativas (no caso de entes subnacionais) como podem ser através de contratos com o Poder Público ou mesmo com facilidades setoriais. Isso conduz a uma maior tributação do setor formal (já que o Estado precisa suportar essas transferências), o que induz a realocação do capital ao setor informal, onde está protegido dessa maior tributação. Essa mudança de direção dos investimentos reduz o crescimento da economia, contrabalanceando os efeitos positivos iniciais. Os cálculos levados a efeito pelos autores apontam para um aumento dessas transferências de forma mais que proporcional à bonança trazida pela exploração mineral. Os resultados, contudo, são mais significativos nos países dominados por um ou poucos grupos de poder, e que contam com poucas barreiras legais/institucionais às transferências discricionárias.

\section{1.b.iii.3. Fraqueza institucional.}

105 Contestando a doutrina tradicional que trata dos malefícios do comportamento rentista dos governantes, Francesco Caselli e Tom Cunningham contestam que esse fenômeno seja sempre prejudicial. Supondo que as rendas de recursos naturais sejam altas o suficiente para aumentar seu interesse em permanecer na gestão pública, suscitam que o seu comportamento egoísta, inicialmente vicioso, pode facilmente se tornar socialmente virtuoso, como por exemplo, na tentativa de permanecer no poder, buscar agradar os cidadãos promovendo oportunidades no setor privado. Construindo cenários dessa natureza, concluem que "é possível descrever cenários igualmente plausíveis onde a expansão de recursos é benéfica assim como é prejudicial" (CASELLI, Francesco; CUNNINGHAM, Tom. Leader behaviour and the natural resource curse. Oxford Economic Papers, n. 61, 2009).

106 KARL, Terry Lynn. Entendendo a maldição dos recursos naturais. In: TSALIK, Svetlana; SCHIFFRIN, Anya (Org.). Reportando o petróleo: um guia jornalístico sobre energia e desenvolvimento. Open Society Institute: Nova York, 2005. p. 25.

107 TORNELL, Aaron; LANE, Philip. Voracity and growth. NBER Working Paper, n. 6498, 1998. 
Outras pesquisas indicam que a exploração dos recursos naturais não renováveis também provoca a piora das instituições ${ }^{108}$ de governo do Estado explorador. Sala-i-Martin e Subramanian assim defendem, apontando que suas pesquisas levam à conclusão de que essa correlação negativa (entre fraqueza institucional e exploração de recursos naturais ${ }^{109}$ ) é forte e robusta. Concluem que esse efeito é o "canal pelo qual a maldição opera", ${ }^{110}$ e que o impacto é não linear, de forma que se faz tão mais forte quanto maior o nível de exploração. ${ }^{111}$ Essa ênfase do papel das instituições internas é compartilhada por Van der Ploeg, que sustenta que "a qualidade institucional parece ser a ligação crucial entre a dotação de recursos em uma mão e os resultados econômicos em outra. E também a ligação crucial entre abundância de recursos e indicadores sociais". ${ }^{112}$

Esse enfraquecimento institucional ${ }^{113}$ pode se dar de várias formas e por várias razões. O vasto influxo de dinheiro oriundo dessa atividade permite aos governos "pacificar dissensos, evitar responsabilidades e resistir à modernidade". ${ }^{114}$ Permite comprar o consenso de adversários políticos. Permite calar eleitores ofertando empregos bem pagos, mas improdutivos; ofertar subsídios e incentivos fiscais desnecessários. ${ }^{115}$

Alega-se que esse tipo particular de renda torna mais difícil a sustentação de um eleitorado em favor de uma gestão econômica saudável e de longo prazo "porque enfraquece os incentivos aos agentes para apoiar os freios e contrapesos que colidem com seus planos individuais de apropriar essas rendas". ${ }^{116}$

108 Para definição do que são instituições, ver: "Institutions are rules of the game of a society, or, more formally, are the humanly devised constraints that structure human interactions". NORTH, Douglas C. The New Institutional Economics and Development. Disponível em: <http:// www.deu.edu.tr/userweb/sedef.akgungor/Current\%20topics\%20in\%20Turkish\%20Economy/north.pdf $>$. Acesso em: 2 jul. 2013. Ainda: PRZEWORSKI, Adam. Institutions Matter? Disponível em: <http://as.nyu.edu/docs/IO/2800/go_2004.pdf>. Acesso em: 2 jul. 2013. E também: PRADO, Mariana Mota; TREBILCOCK, Michael J. Path dependence, development, and the dynamics of institutional reform. University of Toronto Law Journal - U Toronto, Legal Studies Research Paper, n. 09-04, 2009, p. 10 .

109 Apontam que se trata de fenômeno especificamente relacionado a petróleo e minérios, descartando a mesma relação com outros recursos naturais.

110 Negam, por consequência, um visível impacto da Doença Holandesa.

111 SALA-I-MARTIN, Xavier; SUBRAMANIAN, Arvind. Addressing the natural resource curse: an illustration from Nigeria. NBER Working Paper, n. 9804, 2003, p. 12.

112 VAN DER PLOEG, Frederick. Challenges and opportunities for resource rich economies cit., p. 14.

113 Erwin Bulte, Richard Damania e Robert Deacon referem o fenômeno como "instituições sociais menos produtivas", e concordam com sua existência, a partir de suas análises. V. BULTE, Erwin; DAMANIA, Richard; DEACON, Robert. Resource intensity, institutions, and development. World Development, v. 33(7), Elsevier, 2005, p. 1038.

114 VAN DER PLOEG, Frederick. Challenges and opportunities for resource rich economies cit., p. 29.

115 Idem, ibidem, p. 29.

116 EIFERT, Benn; GELB, Alan; TALLROTH, Nils Borje. The political economy of fiscal policy and economic management in oil-exporting countries. In: DAVIS, J.; OSSOWSKI, R.; FEDELINO, A. 
Também a independência dos governos quanto à receita tributária (já que podem obter suas receitas diretamente da atividade exploratória, sendo desnecessário impor tributos ${ }^{117}$ ) é fator relevante nessa equação: depender menos dos cidadãos pode conduzir a elos mais fracos entre governo e jurisdicionados, a menos informação, a menos poder de pressão dos cidadãos, e a menor necessidade de estabelecimento de instituições operantes e confiáveis. $^{118}$

Frankel suscita a explicação de que nos países com grande renda de exploração de recursos naturais, incentiva-se a disputa política pelo domínio dessas rendas - que controlarão o poder. Enquanto que, na ausência dessas rendas, o governo deve motivar a criação de riqueza pelos particulares, inclusive através da promoção de igualdade e de uma sociedade civil forte. ${ }^{119}$ Fator este que estaria presente mesmo na diversidade da cultura institucional que se vê entre o nordeste e o sul estadunidenses. Conclui afirmando que é ao menos minimamente verdadeira a proposição de que os dotes naturais "podem levar a instituições pobres, como corrupção, desigualdade, estrutura de classes, crônicos conflitos pelo poder, e ausência do estado de direito e de direitos de propriedade". ${ }^{20}$

Isham, Woolcock, Pritchett e Busby corroboram esses resultados. Suas investigações apontam no sentido de que os países dependentes da exploração de recursos minerais cuja fonte é pontual (isto é: vinculada a uma estreita base geográfica ou econômica, como minérios e alguns bens da agricultura, embora não outros) estão "predispostos a aumentadas divisões sociais e a capacidade institucional enfraquecida, o que por sua vez afeta sua habilidade de responder com eficiência a choques". ${ }^{121}$ Os autores preferem explicar esse fenômeno a partir de três efeitos: ${ }^{122}$ o efeito rentista, já acima referido; o efeito da modernização atrasada - que se dá porque as elites evitam a industrialização, porque ela importa em criação de fontes alternativas de poder, assim como também se dá pela falta de pressão da sociedade organizada, uma vez que a fonte de receitas públicas é o próprio setor extrativo (este que não demanda modernização

(Org.). Fiscal policy formulation and implementation in oil-producing countries cit., p. 116. Tradução livre.

117 Assunto que será novamente abordado adiante.

118 HUMPHREYS, Macartan; SACHS, Jeffrey D.; STIGLITZ, Joseph E. Introduction: What is the problem with natural resource wealth?. In: HUMPHREYS, Macartan; SACHS, Jeffrey D.; STIGLITZ, Joseph E. (Org.). Escaping the resource curse cit., p. 11-12.

119 FRANKEL, Jeffrey. The natural resource curse cit., p. 17.

120 Idem, ibidem, p. 37.

121 ISHAM, Jonatham; WOOLCOCK, Michael; PRITCHETT, Lant; BUSBY, Gwen. The varieties of resource experience: how natural resource export structures affect the political economy of economic growth. Middlebury College Economics Discussion Paper, n. 03-08, 2003, p. 11.

122 Idem, ibidem, p. 6. 
principalmente porque sua alta tecnologia aplicada na atividade é principalmente importada $\left.{ }^{123}\right)$; e finalmente o efeito da desigualdade entricheirada - que ocorre em algumas áreas geográficas em que são conduzidas produções de larga escala, o que induz que os relacionamentos intrassociais se deem pela ligação de cada trabalhador a um "superior social", como um nobre ou fazendeiro, conduzindo então a uma estrutura social estratificada, clientelista, e marcada pela ausência de voz dos trabalhadores. ${ }^{124}$

É veemente a voz de Ricardo Soares de Oliveira, em trabalho dedicado ao estudo do impacto da exploração de petróleo no golfo africano da Guiné. Afirma:

De um ponto de vista institucional, o petróleo garante que o Estado não desapareça totalmente. Mas ele não alimenta a genuína construção de um Estado, ao inverso promovendo a criação de Estados enclave baseados em commodities, da mesma forma que o comércio de longa distância levou à criação de Estados costeiros até o fim do século XIX. São estruturas decrépitas e provisórias, ainda que internacionalmente reconhecidas, organizadas em torno da exportação de uma substância premiada: eles não são a semente de um futuro Estado convencional e eles não são viáveis sem petróleo". ${ }^{125}$

Merece registro o protesto de alguns pelo que entendem ser uma inversão da ordem dos fatores. Afirmam que a relação de pertinência é inversa: não é a atividade petrolífera que enfraquece as instituições, conduzindo a um pior desempenho. Mas que as más instituições preexistentes é que, incapazes de pensar e efetivar políticas públicas seguras de tratamento dessa renda mineral, conduzem ao mau desempenho. O trabalho de Christa Brunnschweiler é paradigmático nesse sentido, ponderando, por seus cálculos, que não há evidências de que a abundância de recursos afeta a qualidade institucional. ${ }^{126}$ Também Paul Collier e Benedikt Goderis concluem que o enfraquecimento das instituições de governo não causa a Maldição, mas sim que esta é prevenida por instituições sólidas. ${ }^{127}$ E Michael Ross segue a mesma linha, indicando que essas rendas não causam piores níveis de governo, mas que apenas os mantém nos mesmos padrões, enquanto a exploração dos recursos aumenta rapidamente o patamar de receitas e despesas, daí parecendo que esses países, em comparação com outros mais estabelecidos que já estão nestes mesmos níveis,

123 ISHAM, Jonatham; WOOLCOCK, Michael; PRITCHETT, Lant; BUSBY, Gwen. The varieties of resource experience... cit., p. 8-9.

${ }^{124}$ Idem, ibidem, p. 10.

125 OLIVEIRA, Ricardo Soares de. Oil and politics in the gulf of guinea cit., p. 56-57. Tradução livre.

126 BRUNNSCHWEILER, Christa N. Cursing the blessings? natural resource abundance, institutions, and economic growth cit., p. 412.

127 COLLIER, Paul; GODERIS, Benedikt. Commodity prices, growth, and the natural resource curse: reconciling a conundrum. Centre for the studies of African economies Working Paper Series, 2007-15, University of Oxford, 2007, p. 17-18 e 25. 
tiveram uma piora quando, em verdade, apenas mantiveram suas instituições públicas estáveis, sem melhoras significativas - melhoras essas que são demandadas pela mudança na configuração das rendas do país, em especial diante das características essenciais desse tipo de atividade, especialmente a volatilidade. ${ }^{128}$

Outros sustentam, ainda, que esse efeito não é adstrito à exploração de recursos naturais não renováveis, valendo para quaisquer fontes de rendas, incluindo ajuda externa, monopólios como de telecomunicações, restrições comerciais, entre outros. ${ }^{129}$

\section{1.b.iii.4. Corrupção.}

De forma intimamente associada ao impacto sentido pelas instituições do país explorador - e muitas vezes até analisando como se de um tema só se tratasse (afinal, a ausência de corrupção é pedra de toque da boa governança ${ }^{130}$ ) -, pesquisas indicam também que a exploração de recursos naturais não renováveis induz corrupção. Os Estados dependentes dessas rendas tendem a ser mais corruptos que os demais. ${ }^{131}$

Essa é a afirmação de Carlos Leite e Jens Weidmann, em estudo que se tornou marco do tema: os recursos naturais capital-intensivos são um grande determinante de corrupção estatal. ${ }^{132-133}$ Para indicar a causa que leva a essa constatação, destacam questões de abertura de mercado, interpretando que os países mais abertos aos mercados externos

128 ROSS, Michael L. The oil curse... cit., p. 208-215. O autor argumenta de maneira condescendente (na pior acepção), parecendo partir da pressuposição de que os recursos naturais não renováveis trazem problemas apenas aos países em desenvolvimento, a quem faltaria sofisticação institucional ou mesmo seriedade governamental. A analogia do tema com o seriado de televisão "A Família Buscapé” ("Beverly Hillbillies") é particularmente ofensiva. Não subscrevemos essa sorte de posicionamento, embora essas constatações também não prejudiquem outras análises do mesmo autor. Observação semelhante já foi feita por Fernando Facury Scaff (SCAFF, Fernando Facury. Royalties decorrentes da exploração de recursos naturais não renováveis cit., p. 526, nota de rodapé n. 897).

129 LEDERMAN, Daniel; MALONEY, William F. In search of the missing resource curse cit., p. 4.

130 McPHERSON, Charles; MacSEARRAIGH, Stephen. Corruption in the petroleum sector. In: CAMPOS, J. Edgardo; PRADHAN, Sanjay (Ed.). The many faces of corruption: tracking vulnerabilities at the sector level. Washington: The World Bank, 2007. p. 194.

131 Joseph Stiglitz (STIGLITZ, Joseph E. What is the role of tha state? In: HUMPHREYS, Macartan; SACHS, Jeffrey D.; STIGLITZ, Joseph E. (Org.). Escaping the resource curse cit., p. 24), apreciando o papel do Estado na gerência dos recursos naturais não renováveis, e especialmente o relacionamento entre os agentes públicos e a iniciativa privada, ressalta essa característica, apontando: "It is all too easy for politicians to connive with those in the private sector to take from you what is yours".

132 LEITE, Carlos; WEIDMANN, Jens. Does mother nature corrupt? Natural resources, corruption, and economic growth. IMF Working Paper, n. 99/85, 1999, p. 30.

133 CASELLI, Francesco; MICHAELS, Guy. Do oil windfalls improve living standards? Evidence from Brazil. NBER Working Paper, n. 15550, 2009, p. 30. "Among the many theoretical models that have been put forward to link socio-economic outcomes to oil abundance and fiscal windfalls the one that seems most consistent with the data is the old political-science view that oil royalties are somehow more 'stealable' than other types of revenues". 
tendem a ter menos corrupção. ${ }^{134} \mathrm{E}$ apontam, mais, que o rápido crescimento econômico, em determinados períodos curtos de tempo (como os booms minerais), igualmente conduzem a maior corrupção, ${ }^{135}$ especialmente porque trazem alterações nos métodos de produção e nas relações sociais, sem que, dada a rapidez, as instituições governamentais (responsáveis por regular ou normatizar essas relações) evoluam no mesmo passo. E isso se vê com ainda maior força na exploração de minérios ou petróleo, em que as rendas são mais líquidas (mais apropriáveis, diferente das rendas oriundas de atividades trabalhointensivas) e percebidas diretamente pelo Estado, então aumentando o comportamento rentista dos líderes governamentais e dos agentes privados mais próximos. ${ }^{136}$

Não se pode deixar de registrar, contudo, que embora as conclusões acima pareçam sólidas e fundadas em dados confiáveis, as explicações para esse fenômeno seguem agenda que se conecta com ideias liberais de menos Estado e mais liberdade ao mercado. Posições político-econômicas, contudo, que não definem o estudo nem são condição necessária para alcançar o resultado básico, que é a relação de pertinência direta entre a exploração de recursos naturais não renováveis e os índices de corrupção.

Giorgio Brosio, por exemplo, ignora a relação entre corrupção e abertura de mercado, explicando que os Estados receptores de renda de recursos naturais se tornam mais corruptos conforme "o nível de informação, o sistema político, as tradições administrativas, a homogeneidade das jurisdições locais e a composição setorial do gasto nos níveis local e nacional". ${ }^{137}$ Destaca, ademais, que o nível de governo responsável pela arrecadação/gestão desses valores também importa: a sua concentração em entes federativos menores fragiliza as barreiras contra a corrupção.

Ricardo Soares de Oliveira põe a questão em termos mais políticos, identificando o Estado dependente de petróleo como uma cleptocracia onde corrupção é organizada nos altos níveis de governo por grupos que se veem diante de um grande número de potenciais pagadores de propina desorganizados. ${ }^{138}$ Van der Ploeg, na mesma linha, relaciona a corrupção nessas sociedades com o comportamento rentista extremo, ${ }^{139}$

134 LEITE, Carlos; WEIDMANN, Jens. Does mother nature corrupt? Natural resources, corruption, and economic growth cit., p. 23.

135 Idem, ibidem.

136 Idem, p. 19.

137 BROSIO, Giorgio. Oil revenue and fiscal federalism. In: DAVIS, J.; OSSOWSKI, R.; FEDELINO, A. (Org.). Fiscal policy formulation and implementation in oil-producing countries cit., p. 254.

138 OLIVEIRA, Ricardo Soares de. Oil and politics in the gulf of guinea cit., p. 139.

139 É também a visão de Susan Rose-Ackerman: "The countries least likely to reform would seem to be those with more natural resources than others in the region. Then corruption and patronage can extract 
praticado pelas (e em prol das) elites nacionais, que incorrem nestas práticas com o objetivo de obter proteção e licenças exclusivas para exploração e exportação dos recursos, visando ao final capturar as receitas e o poder político ${ }^{140}$ que esse tipo de atividade é geralmente percebido como podendo proporcionar. Sala-i-Martin e Subramanian resumem sua abordagem afirmando que o petróleo corrompe, mas “o petróleo em excesso corrompe mais que excessivamente". ${ }^{141-142}$

O Banco Mundial, em obra especialmente dedicada ${ }^{143}$ ao estudo da corrupção suas causas, consequências, atores, sintomas, possíveis formas de combate -, dedica um de seus capítulos ${ }^{144}$ à relação com o setor petrolífero. Nele, são identificadas as nuances especiais dessa atividade, que, entendem os Autores, proporcionam a relação entre exploração de recursos naturais não renováveis e maior corrupção. São elas: (i) o altíssimo volume de dinheiro envolvido, sem precedentes em outros tipos de atividade, de forma que comumente um enorme volume de dinheiro representa apenas pequeníssima fração do montante total, daí nascendo suas relativas insignificância e imperceptibilidade, então aumentando ao potencial corrupto não apenas maiores ganhos como também menores chances de ser flagrado; ${ }^{145}$ (ii) magnitude dos lucros, onde os preços são tipicamente muito superiores ao custo; (iii) o fato de que os recolhedores das rendas públicas são poucos e geralmente estrangeiros, o que reduz a confiabilidade dos governos na prestação de contas à população sobre esses dinheiros; (iv) complexidade da indústria extrativa e das normas que as regem, o que aumenta a possibilidade de esconder valores nesses meandros; (v)

huge economic costs without a country's citizens feeling disadvantaged compared with their more impoverished neighbours" (ROSE-ACKERMAN, Susan. Corruption and government: causes, consequences and reform. New York: Cambridge University Press, 1999. p. 213).

140 VAN DER PLOEG, Frederick. Challenges and opportunities for resource rich economies cit., p. 13.

141 SALA-I-MARTIN, Xavier; SUBRAMANIAN, Arvind. Addressing the natural resource curse: an illustration from Nigeria cit., p. 10.

142 Interessante a abordagem que Sala-i-Martin e Subramanian utilizam para explicar o aumento da corrupção, o que fazem a partir de noções mais comportamentais do que políticas. Dizem: "the main problem affecting the Nigerian economy is the fact that the oil revenues that the government gets are regarded as manna from heaven which tends to corrupt institutions and lower the long-term growth prospects. Starting from this premise, the logical conclusion is that the best way to deal with the problem is to transform Nigeria into a 'non-oil' economy [...] If this 'easy revenue' (and the incentives for corruption that it generates) is eliminated, much of the problem would disappear. One of the direct benefits of this would be that Nigerians would have an initial endowment superior to that of other nations" (idem, ibidem, p. 17).

143 CAMPOS, J. Edgardo; PRADHAN, Sanjay (Ed.). The many faces of corruption. Washington D.C.: World Bank, 2007.

144 McPHERSON, Charles; MacSEARRAIGH, Stephen. Corruption in the petroleum sector. In: CAMPOS, J. Edgardo; PRADHAN, Sanjay (Ed.). The many faces of corruption... cit.

145 Cabendo lembrar que Gary Becker põe nessas duas variáveis - pena imposta e probabilidade de ela ser efetivamente aplicada - sua análise das probabilidades de cometimento de crimes. V. BECKER, Gary. S. 1968. Crime and punishment: an economic approach. Journal of Political Economy, 76 (2): 169-217. 
monopólios naturais, especialmente no setor de infraestrutura relacionado, que cria oportunidades para o abuso mediante condições discricionárias de acesso, especialmente na fixação da respectiva contraprestação; (vi) significância estratégica, a significar que nessa atividade, o Estado participa de variadas fases de regulação, incluindo formulação e implementação da política de aproveitamento, o estabelecimento de legislação específica, o controle de acesso à infraestrutura, a regulação das operações (inclusive do ponto de vista ambiental, cabe acrescer) e o estabelecimento de companhias petrolíferas estatais - de forma que a pluralidade da atuação estatal nessa seara implica numerosas autoridades atuantes e, então, numerosas oportunidades de se estabelecerem práticas corruptas; ${ }^{146}$ (vii) efeito "transbordamento", a significar que a corrupção possivelmente existente na indústria de exploração de recursos naturais não renováveis pode ter efeitos negativos (transbordo) a outras práticas da Administração. ${ }^{147}$

Segue o texto não apenas apontando uma "tipologia" da corrupção e os atores em geral envolvidos, mas também examinando as vulnerabilidades em cada segmento da produção: ${ }^{148}$ fases de exploração, ${ }^{149}$ desenvolvimento, ${ }^{150}$ produção, ${ }^{151}$ comércio, ${ }^{152}$ transporte, ${ }^{153}$ refinamento e comércio, ${ }^{154}$ e contabilidade corporativa, administração e finanças. $^{155}$

146 McPHERSON, Charles; MacSEARRAIGH, Stephen. Corruption in the petroleum sector. In: CAMPOS, J. Edgardo; PRADHAN, Sanjay (Ed.). The many faces of corruption... cit., p. 199. "The more heavily regulated the system, the higher the degree of government control, and the greater the scope for administrative corruption".

147 Idem, ibidem, p. 196-198.

148 Idem, p. 203 e ss.

149 Idem, p. 204. "Corruption has been especially associated with the awards process itself and the subsequent negotiation of contract terms, the most important of which relate to the work to be performed, the recovery of costs, sharing of profits, and the rate and extent of obligatory relinquishments to the state".

150 Idem, p. 205. "Capital and operating costs, along with the potential for abuse of the procurement process, begin to skyrocket. The full range of industry actors and procurement tricks comes into play. Kickbacks to officials-a form of success fee dependent on contract award- appear to be the most common form of corrupt payment in procurement. Payments can be made equally to government or private contractorsthe same principles apply [...] Government agencies, NOCs among them, are often able to use their influence to direct procurement toward government-favored or government-affiliated suppliers".

151 Idem, p. 206. "This phase is particularly vulnerable to grand corruption-theft on a major scale, involving serious criminal elements. This may occur through underreporting and diversion of production volumes or through more direct means, such as tapping into producing wells or pipelines and carrying off the oil".

152 Idem, p. 207-208. "Theft under this heading often involves the underinvoicing of the value of the oil sold, allowing its purchaser to resell the oil at an inflated margin. The parties involved in corrupt transactions of this type are typically a government agency or NOC as the first seller and an oil trader as the first purchaser and onward seller".

153 Idem, p. 208. "Transport infrastructure, including pipelines, storage or transfer terminals, and port jetties, are often correctly characterized as natural monopolies. Owners of infrastructure, which may be the state itself, are in a position to extract monopoly rents and commonly do so. Corruption enters when rents are extracted not as official, published tariffs payable to the state but as clandestine payments to officials in control of access". 
Portanto, apesar dos protestos de alguns, a maior parte da doutrina parece concordar que o aumento da corrupção é um dos efeitos deletérios da exploração de recursos naturais não renováveis. ${ }^{156}$

\section{1.b.iii.5. Ausência de Transparência.}

De forma intimamente ligada às verificações de corrupção, má-gestão, e fragilidade institucional, está a preocupação quanto à transparência das receitas oriundas da exploração de recursos naturais não renováveis. Trata-se de um item que vem sendo extensamente abordado, especialmente por organizações não governamentais que se dedicam a promover a transparência e a responsabilidade desses valores - notadamente, as iniciativas internacionais EITI (Extractive Industries Transparency Initiative), Revenue Watch Institute, e PWYP (Publish What You Pay), além da Transparência Internacional, que não tem como foco os recursos naturais, mas que frequentemente os aborda. ${ }^{157}$

A ênfase é muito similar à apresentada acima. Por suas características, a receita decorrente da atividade de exploração dos recursos exauríveis é comumente governada de forma afastada das melhores práticas administrativas. Os meios pelos quais transitam esses valores; as rubricas nas quais são contabilizados; a destinação que lhes é dada - são todas informações de amplo interesse da sociedade civil mas que vêm sendo negligenciadas, de

154 McPHERSON, Charles; MacSEARRAIGH, Stephen. Corruption in the petroleum sector. In: CAMPOS, J. Edgardo; PRADHAN, Sanjay (Ed.). The many faces of corruption... cit., p. 208-209. "Opportunities for illegal profits are often created by official policies. Price controls on refined petroleum products represent perhaps the most important, common, and invidious driver of corruption in this segment of the oil value chain [...] Populist pressure and corruption at the policy level create the opportunity, while corruption at the administrative level allows it to thrive [...] In addition to these difficulties, differential price controls among petroleum products can create opportunities for illegal activities and will be encouraged by those who stand to profit".

155 Idem, ibidem, p. 210. "Suffice it to say once again that the petroleum sector is a favored target because the money it generates offers huge returns to accounting fraud, tax evasion, and illegal financial manipulation and because the complexity of the sector reduces the risk of detection. The widely publicized case of the American energy trader Enron is a prime example of the scale of fraud that can occur, but there is no shortage of other examples. Accounting practices of most NOCs should be a cause for concern. Often, the books are unavailable or, if available, they are nontransparent and confusing. In general, lack of transparency, weak or nonexistent audits, and unnecessarily convoluted accounting, tax, or financial structures should be taken as signals of possible problems".

156 "While it is hard to generalize about federalism and corruption, it is clear that petroleum wealth increases the risks of corruption, especially in poor societies" (ANDERSON, George. Reflections on oil and gas in federal systems. In: ANDERSON, George (Ed.). Oil \& gas in federal systems cit., p. 398).

157 Para uma abordagem sobre como essas instituições podem melhorar a qualidade da gestão pública dos recursos decorrentes da exploração, buscando identificar especialmente lacunas de avaliação da efetividade dessas medidas, v. ACOSTA, Andrés Mejía. The impact and effectiveness of accountability and transparency initiatives: the governance of natural resources. Disponível em: $<$ http://eiti.org/files/the\%20impact\%20and\%20effectiveness\%20f\%20accountability\%20and\%20transp arency\%20initiatives.pdf $>$. Acesso em: 2 set. 2013. 
forma explícita (com a afirmação expressa de que se tratam de informações confidenciais ${ }^{158}$ ) ou mediante subterfúgios diversos, que vão desde a mentira pura e simples à maquiagem fiscal coberta por linguajar técnico de difícil acesso.

Bom exemplo dessas más práticas é encontrado em Camarões, onde, apesar de os contratos de exploração firmados serem favoráveis ao Estado, garantindo que boa parte da riqueza mineral volte aos seus cofres, entre 1977 e 2006 apenas 46\% desses valores chegaram ao Orçamento, tendo os demais 54\% desaparecido em meandros contábeis ininteligíveis, possivelmente sido desviados. ${ }^{159}$

Esse é um dos pontos sucessivas vezes realçado por Michael Ross. Como já se viu acima, aquele autor afirma que a facilidade de ser escondida deve ser indicada como uma característica básica da receita do petróleo. ${ }^{160}$ Embora reconhecendo que o sigilo é

158 O tema "despesas sigilosas" é objeto da análise de Fernando Facury Scaff, que põe tal classificação em perspectiva com o direito humano fundamental à "liberdade de informação" para analisar as possíveis limitações a esse direito, buscando definir o que pode ser mantido à reserva do conhecimento da sociedade. Observou o autor, com base em Resolução do Conselho de Ministros da Europa: "Para conferir se estas limitações se encontram adequadas a cada ordenamento jurídico criou-se um teste tripartite, por meio do qual se constatará se tais limitações encontram-se adequadas. Tal análise deverá observar se: a) as informações sigilosas são relativas a um objetivo legítimo registrado na lei; b) sua divulgação ameaça causar danos substanciais a esse objetivo; e c) se o dano ao objetivo é maior do que o interesse público de ter as informações" (p. 219). Prossegue, analisando a Constituição Federal brasileira, a Lei federal específica a regrar o tema (8.159/1991), verificando o significativo aumento da quantidade de despesas sigilosas da União nos últimos anos, e constata que "o Congresso Nacional autoriza a realização destes gastos sigilosos sem discriminação dos projetos, programas ou elementos de despesa em que devem ser realizados, indicando apenas o órgão destinatário da verba" (p. 225), observando também os debates que vêm sendo travados no âmbito do Tribunal de Contas da União. Conclui, invectivando também contra o prazo de manutenção desse sigilo, que a "exceção ao direito à verdade constitucionalmente permitida não pode ser usada de forma indiscriminada, mas apenas nas estritas hipóteses estabelecidas que, como exceção, devem ser utilizadas e interpretadas restritivamente. Esta exceção permite também a realização de despesas sigilosas por parte do Estado; 3. Estas despesas sigilosas devem ser objeto de aprovação orçamentária pelo Parlamento - quanto mais discriminadas puderem ser, tanto melhor - e sua realização deve ser objeto de análise e julgamento por parte do Tribunal de Contas e pelo próprio Parlamento, por meio de mecanismos que permitam a manutenção do sigilo; 4. Quando for constatada a realização de despesas sigilosas que não possuem este caráter, tanto o Tribunal de Contas quanto o Parlamento possuem o dever de reclassificá-las, tornando-as públicas de imediato" (p. 231). SCAFF, Fernando Facury. Direitos fundamentais e orçamento: despesas sigilosas e o direito à verdade. In: CONTI, José Maurício; SCAFF, Fernando Facury (Org.). Orçamentos públicos e direito financeiro. São Paulo: RT, 2011.

159 GAUTHIER, Bernard; ZEUFACK, Albert. Governance and oil revenues in Cameroon. OxCarre Research Paper 38, Oxford University, 2009. Afirmam os autores: "Secrecy has been the norm in the oil sector in Cameroon since the beginning of oil production. While the Government of Cameroon has agreed to gradually provide more transparency over the period, mainly in response to donor pressure, the situation, as we will see, is still very far from full transparency and accountability" - p. 30. Há registros de que as receitas oriundas da exploração petrolífera eram guardadas em "contas secretas", no início da exploração, controladas diretamente pelo Presidente da República. Os cidadãos tinham "virtualmente nenhuma informação" sobre essas receitas (p. 30-31). No presente, após pressão internacional, muitas mudanças nos quesitos de transparência foram levadas a efeito; nada obstante, os autores apontam que várias das instituições criadas para responder à falta de transparência são "ocas", sem efetividade (p. 42), de forma que o impacto no nível estimado de corrupção foi apenas "leve" (p. 46).

160 ROSS, Michael L. The oil curse... cit., p. 6. 
algo difícil de mensurar, ${ }^{161}$ insiste que as análises das finanças públicas dos países ricos em recursos naturais são incomumente opacas, ${ }^{162}$ muitas vezes com o auxílio das empresas públicas destinadas à exploração. ${ }^{163}$ Essa afirmação tem base em relatório de organização internacional (International Budget Partnership) sobre os orçamentos de vários países mudo afora. Ross, com base nesses dados, sustenta que quanto maior a riqueza oriunda do petróleo, mais secreto será o orçamento nacional. ${ }^{164} \mathrm{E}$ isso prejudica a governança pública, ajudando autocratas a permanecer no poder, impedindo a resolução de guerras que tenham como o petróleo como elemento central, tornando mais difícil impedir a corrupção, levando a menores níveis de desenvolvimento humano, e menor disciplina fiscal. ${ }^{165}$ Esses males, embora não sejam resolvidos, poderão ser endereçados de forma mais eficaz através da transparência - que Ross apresenta como não apenas a divulgação de informações, mas sua divulgação de maneira completa e precisa, sujeita a auditorias independentes, disponíveis a pouco ou nenhum custo, e apresentada de forma a poder ser lida por todos e não apenas em linguagem técnica. ${ }^{166}$

Vale recordar também que um dos efeitos da dependência das receitas de recursos naturais não renováveis, comumente apontados, é o da diminuição da arrecadação tributária, a valores inferiores ao da capacidade arrecadatória do Ente Público. A relação dessa constatação - que será melhor explorada adiante - com o quesito transparência está no enfraquecimento do vínculo entre Estado e cidadão: o Estado passa a depender menos do dinheiro dos tributos para consecução de suas atividades essenciais, assim ficando menos suscetível à pressão da sociedade civil, que, por outro lado, também se torna mais desinteressada em fiscalizar as contas públicas, uma vez que o dinheiro que lá transita não saiu de seus bolsos. ${ }^{167}$

Estudo do Banco Mundial, liderado por James Otto, e que se destina a averiguar o impacto dos royalties da mineração em investidores, governo e sociedade civil,

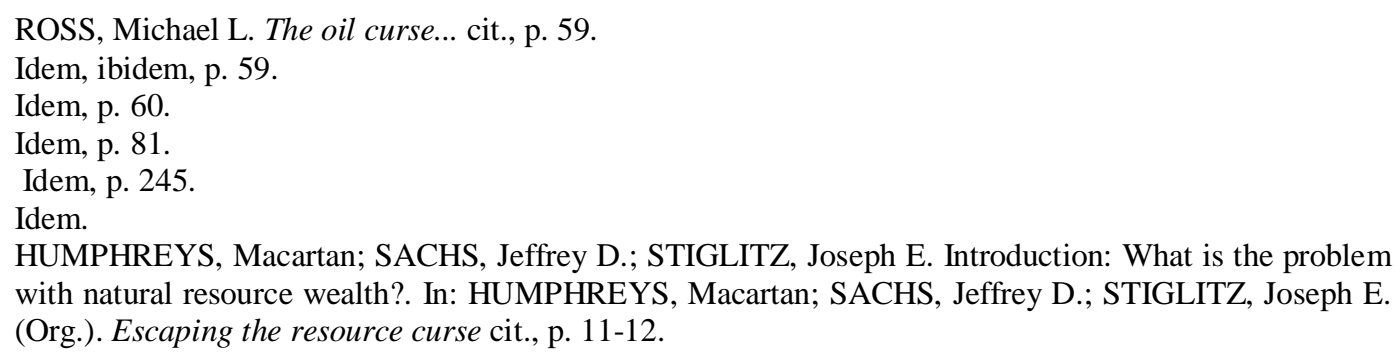
with natural resource wealth? In: HUMPHREYS, Macartan; SACHS, Jeffrey D.; STIGLITZ, Joseph E. (Org.). Escaping the resource curse cit., p. 11-12. 
igualmente destaca a transparência, dedicando-lhe um capítulo inteiro. ${ }^{168}$ Destacando que a atenção internacional está voltada ao tema, apresentam linhas mestras para o debate. Estabelecem "Princípios gerais de divulgação e relato", ${ }^{169}$ quais sejam: relevância (os dados ou informações devem responder às questões que estão sendo postas, pondo-os em contexto), materialidade (os métodos devem ser apresentados e as discrepâncias entre dados - por exemplo, diferença entre a divulgação do valor pago pelas empresas e do valor recebido pelo Estado - devem ser identificadas, explicadas, e corrigidas, ainda que revelem não um equívoco, mas uma distinta forma de cálculo), níveis de relato (em respeito à livre concorrência, os relatos devem ser feitos em níveis: dados que importam em fragilização de uma empresa perante seus pares devem ser apresentados por esta ao Governo, em um nível, mas esses dados, e apenas esses vitais à concorrência, devem ser filtrados e eventualmente suprimidos da divulgação pelo Governo à sociedade, em outro nível), confidencialidade (deve ser previamente estabelecido quais informações relativas a acordos de confidencialidade empresas-Estado ou empresas-fornecedores podem ou não ser divulgados, presumindo-se sempre pela divulgação total e, em qualquer caso, suprimindo a informação apenas de maneira explicada e justificada), compreensibilidade (dados e informações devem ser compreendidos por todos e não apenas pelos iniciados nos setores relacionados, reconhecendo para tanto as diferenças quanto à linguagem, cultura e níveis de educação de todos os atingidos, e habilitando fácil e efetivo acesso), confiabilidade (relatos devem ser completos, devem referir os documentos que lhes dão suporte, admitindo seu refazimento a partir deles, devem apresentar metodologia fixa, clara e adequada, definições dos conceitos utilizados precisam ser pré-estabelecidas e respeitadas, dúvidas devem ser suprimidas), oportunidade (dados e informações devem ser apresentados logo após findo o período-referência, enquanto são mais relevantes, nem que para isso promovam divulgações preliminares para apenas semanas ou meses depois apresentem os documentos completos), auditabilidade (dados e informações devem ser mantidos e apresentados de forma a permitir auditorias internas ou externas), e comparabilidade e consistência (procedimentos e definições devem ser estabelecidos previamente de forma a permitir comparar dados e informações entre diferentes áreas ou diferentes empresas sem significativas distinções conceituais, e devem permitir também

168 OTTO, James; ANDREWS, Craig; CAWOOD, Fred; DOGGETT, Michael; GUJ, Pietro; STERMOLE, Frank; STERMOLE, John; TILTON, John. Mining royalties: a global study of their impact on investors, government, and civil society. Washington: The World Bank, 2006. Capítulo 6.

169 Idem, ibidem, p. 241 e ss. 
que se promova de forma adequada à evolução desses dados e informações ano a ano, sempre possibilitando pôr esses subsídios em perspectiva).

A publicação apresenta ainda os principais desafios na divulgação de informações, ${ }^{170}$ trazendo questões que devem ser dirigidas e respondidas, dentre elas se os dados das empresas devem ser divulgados individualmente ou por setor, quais os padrões metodológicos a serem utilizados, se as informações das empresas devem constar, além de informações de tributação e royalties, outros desembolsos (como doações, contribuições sociais, culturais, em resposta a condicionantes ambientais, folha de pagamentos, número de empregados, valor investido em infraestrutura, etc.). Destacam, sobre esse último ponto, que é relevante mesmo conhecer menos os valores envolvidos e mais os resultados dos programas incentivados, exemplificando pela construção de um hospital, com recursos da empresa mineradora: nesse caso, é importante analisar não apenas quanto foi gasto, mas se houveram benefícios efetivos à população afetada, medidos pelos indicadores utilizados nessa seara específica, como o aumento da longevidade. ${ }^{171}$

O Fundo Monetário Internacional, ponderando que "muitos analistas enfatizam o papel essencial desempenhado pela transparência fiscal em melhorar a gestão das receitas de recursos naturais, que irá nutrir o uso eficiente de fundos públicos, reduzindo o risco de políticas macroeconômicas instáveis e melhorar a confiança no processo orçamentário", ${ }^{172}$ também editou um guia de transparência de receita de recursos naturais, ${ }^{173} \mathrm{em}$ que apresenta como pilares da transparência fiscal (i) clareza de funções e responsabilidades, (ii) abertura do processo orçamentário, (iii) disponibilidade pública de informações e (iv) garantias de integridade.

Ricardo Soares de Oliveira lembra que os países produtores de petróleo vêm sofrendo pressões da comunidade internacional pelo aumento de transparência nas transações comerciais. Mas não apenas eles: essa pressão passou a ser dirigida também às multinacionais que atuam no ramo para que divulguem com exatidão os valores pagos aos governos dos países extrativistas. Argumenta-se que a sociedade civil desses países pode

170 OTTO, James; ANDREWS, Craig; CAWOOD, Fred; DOGGETT, Michael; GUJ, Pietro; STERMOLE, Frank; STERMOLE, John; TILTON, John. Mining royalties cit., p. 247 e ss.

171 Idem, ibidem, p. 254.

172 INTERNATIONAL MONETARY FUND. Guide on resource revenue transparency cit., p. 4. Tradução livre.

173 Idem, ibidem. 
apenas chamar seus governantes à responsabilidade sabendo com precisão sobre os valores acrescidos ao Erário. ${ }^{174}$

Por isso mesmo, a organização PWYP (Publish What You Pay) parte de igual premissa. Considera que a falta de transparência dá espaço à corrupção e à má-gestão dos dinheiros públicos. $\mathrm{E}$, especialmente, que o conhecimento do quanto é pago torna muito mais fácil o monitoramento de como esses valores serão gastos. ${ }^{175}$ Contudo, concentra-se em pressionar as partes privadas (multinacionais exploradoras de recursos naturais) para que disponibilizem informações sobre os pagamentos a governos. O fazem por questões estratégicas, embora também tenham por objetivo reunir informações prestadas diretamente pelos Estados exploradores, função essa que ainda pretendem desempenhar de forma mais aguda. ${ }^{176}$ Nesse quesito, portanto, difere diametralmente da EITI (Extractive Industries Transparency Initiative), que dá mais ênfase à participação dos Governos, que são "principal força motriz de implementação" do programa nos países, ${ }^{177}$ embora se trate de projeto que conta com envolvimento múltiplo de interessados, incluindo as empresas envolvidas e a sociedade civil. Em verdade, trata de estabelecer padrões globais de boas práticas, e funciona a partir da inscrição dos próprios Estados para participar, comprometendo-se a obedecer aos princípios estabelecidos mas também obtendo os benefícios oriundos desse comprometimento, especialmente aqueles derivados da pressão exercida por organismos internacionais como o Banco Mundial.

O Revenue Watch Index, por sua vez, embora também pressione por maior transparência institucionalmente, muitas vezes juntando-se aos grupos já citados, tem atuação mais ligada à análise dos dados existentes, comparando-os e pondo-os em perspectiva para divulgação geral, visando a formação de políticas públicas assim como a capacitação de pessoal para participar da governança dessas receitas. Assim é que publicou inicialmente um índice de 41 (quarenta e um) países relevantes no contexto de exploração de recursos naturais não renováveis, analisando apenas a transparência relacionada ao relato de informações dessa atividade. ${ }^{178}$ Já em 2013, contudo, veio a lançar índice

174 OLIVEIRA, Ricardo Soares de. Oil and politics in the gulf of guinea cit., p. 275-276.

175 Disponível em: <Publishing what we learned. http://eiti.org/files/Publishing\%20What\% 20We\%20Learned.pdf $>$. p. 15 e 21.

176 Ibidem, p. 29-30.

177 Implementing eiti for impact - A handbook for policy makers and stakeholders. Disponível em: $<$ http://eiti.org/files/Implementing\%20EITI\%20for\%20Impact_Handbook\%20for\%20Policy\%20Makers $\% 20$ and\%20Stakeholders.pdf>. p. 121.

178 REVENUE WATCH INDEX 2010. Transparency: Governments and the oil, gas and mining industries cit. Analisou-se a disponibilidade de informações sobre (i) acesso aos recursos naturais; (ii) geração de receita; (iii) definições institucionais; (iv) empresas públicas; (v) fundos de recursos naturais; (vi) 
substancialmente mais refinado, dessa vez incluindo 58 (cinquenta e oito) países em sua base, e indo além da transparência para lançar uma medida geral de qualidade de governança, a partir de 04 (quatro) amplos componentes: (i) definições legais e institucionais; (ii) práticas de relato de dados e informações; (iii) salvaguardas e controles de qualidade; e (iv) ambiente capacitador (que utiliza medidas de accountability, efetividade da governança, estado de direito, corrupção e democracia). ${ }^{179}$

Interessante notar, deste estudo, que ele aponta uma significativa relação entre a dependência dos recursos naturais com a má qualidade (segundo as referidas medidas) da gestão pública: 9 (nove) dos 15 (quinze) piores classificados estão dentre os mais dependentes. ${ }^{180}$

Todas as organizações internacionais ${ }^{181}$ acima referidas atuaram fortemente no lobby em defesa da Seção 1504 da Lei estadunidense que ficou conhecida como DoddFrank (Lei da Reforma de Wall Street e da Proteção ao Consumidor - H.R. 4173, Lei n. 203 do $111 .^{\circ}$ Congresso Estadunidense), norma de regulação do mercado financeiro gestada após a crise econômica de 2008. O dispositivo obriga que as empresas sob jurisdição dos EUA divulguem todos os valores pagos àquele país e (especialmente) a governos estrangeiros, com o propósito de desenvolvimento comercial de petróleo, gás natural ou minerais. A norma, embora resistida pelas empresas atuantes no setor, foi mantida no Parlamento, e está hoje sendo desafiada judicialmente em ação movida pelo Instituto Americano do Petróleo ${ }^{182}$ em ação que tramita perante o Distrito de Columbia.

Também a União Europeia divulgou em junho/2013 novas diretivas sobre transparência e contabilidade públicas, dirigidas às indústrias extrativas. ${ }^{183}$

transferências subnacionais; (vii) participação e cumprimento dos padrões estabelecidos pela EITI. Explicitamente, o índice não analisou medidas de corrupção ou de abertura orçamentária.

179 RESOURCE GOVERNANCE INDEX 2013. A measure of transparency and accountability in the oil, gas and mining sector. Revenue Waych Institute, 2013. Disponível em: <http://www. revenuewatch.org/sites/default/files/rgi_2013_Eng.pdf>.

180 RESOURCE GOVERNANCE INDEX 2013. A measure of transparency and accountability in the oil, gas and mining sector. Revenue Waych Institute, 2013, p. 10-11.

181 Some-se a elas a Transparência Internacional, outra que acredita na transparência como modo de melhora da governança pública, e trabalha na elaboração de estudos que a promovam. Cabe ver seu Relatório Anual de 2008 (Promoting Revenue Transparency - 2008 Report on Revenue Transparency of Oil and Gas Companies) referente especialmente às economias dependentes de recursos naturais. Disponível em: <http://pwypdev.gn.apc.org/sites/pwypdev.gn.apc.org/files/prt_companies_ report_280408.pdf>. Acesso em: 2 set. 2013.

182 Disponível em: <http://www.revenuewatch.org/news/press_releases/oil-companies\%E2\%80\%99lawsuit-seeks-undermine-global-transparency>.

183 Disponível em: <http://europa.eu/rapid/press-release_MEMO-13-541_en.htm>. Acesso em: 8 set. 2013. 
Cabe, finalmente, ponderar pela relevância da transparência: quão importante é para a boa governança? Há uma relação direta entre bons indicadores sociais e econômicos e a maior ou menor transparência do Estado?

É necessário desde já registrar que o direito à informação oriunda dos órgãos públicos é um direito humano - portanto relevante em si, independente de quaisquer colocações sobre seu respeito como escada para atingir o que seja. Há expressa previsão desse direito na Declaração Universal dos Direitos Humanos, artigo XIV. ${ }^{184}$ Trata-se também de pressuposto básico para efetiva participação do cidadão na administração pública, reconhecida no art. XXI da mesma Declaração, ${ }^{185}$ este que tem por fundamento a ideia de liberdade humana, não apenas em sua dimensão individual, mas especialmente em sua dimensão política. ${ }^{186}$ Assim é que Toby Mendel ressalta que as autoridades governamentais precisam se atentar ao fato de que a transparência "não é apenas uma obrigação (indesejada), mas também um direito humano fundamental e essencial para a governança efetiva e apropriada". ${ }^{187}$

Portanto, a fragilização da transparência pública é, sim, de pronto e intrinsecamente, algo deletério e indesejado. Afinal, como adverte a organização Human Rights Watch, "é difícil imaginar que programas de governo ou instituições essenciais à proteção dos direitos humanos sejam capazes de funcionar propriamente até que as receitas do Estado e seus gastos sejam total e corretamente divulgados". 188

Mas ainda: é relevante ao bom desempenho social e econômico nos países exploradores de recursos minerais? A resposta também é positiva.

184 “Toda pessoa tem direito à liberdade de opinião e expressão; este direito inclui a liberdade de, sem interferência, ter opiniões e de procurar, receber e transmitir informações e ideias por quaisquer meios e independentemente de fronteiras".

185 "1. Toda pessoa tem o direito de tomar parte no governo de seu país, diretamente ou por intermédio de representantes livremente escolhidos. 2. Toda pessoa tem igual direito de acesso ao serviço público do seu país. 3. A vontade do povo será a base da autoridade do governo; esta vontade será expressa em eleições periódicas e legítimas, por sufrágio universal, por voto secreto ou processo equivalente que assegure a liberdade de voto."

186 COMPARATO, Fábio Konder. A afirmação histórica dos direitos humanos cit., p. 242. Prossegue o jurista: "Reconhece-se, com isto, que ambas as dimensões da liberdade são complementares e interdependentes. A liberdade política, sem as liberdades individuais,não passa de engodo demagógico de Estados autoritários ou totalitários e o reconhecimento das liberdades individuais, sem efetiva participação política do povo no governo, mal esconde a dominação oligárquica dos mais ricos".

187 MENDEL, Toby. Liberdade de informação: um estudo de direito comparado 2. ed. Brasilia: Unesco, 2009. p. 35.

188 Human rights watch. Some transparency, no accountability: the use of oil revenue in Angola and its impact on human rights. New York, 2004. p. 91. Disponível em: <http://www. hrw.org/sites/default/files/reports/angola0104.pdf>. Acesso em: 4 set. 2013. 
Flávio Rubinstein anota os efeitos positivos da transparência para "estabilidade, eficiência e equidade", ${ }^{189}$ "para a sustentabilidade macroeconômica, para a boa gestão dos recursos públicos e para a disciplina fiscal", ${ }^{190}$ sendo que "facilita e incentiva a adoção de políticas públicas melhores à estruturação de instituições mais adequadas à promoção dos interesses da sociedade". ${ }^{191}$

No mesmo sentido, e referindo especialmente o papel da transparência na luta contra a Maldição dos Recursos Naturais, são veementes as conclusões apresentadas por Joseph Stiglitz, Jeffrey Sachs e Macartan Humphreys, ao final de obra inteiramente reservada ao assunto. Afirmam:

Fechamos este volume com uma nota especial sobre o papel da transparência na reversão da maldição dos recursos naturais. Um número notável de capítulos nesse volume identificou a importância da transparência na resolução dos múltiplos problemas que emanam das atividades de petróleo e gás. Isso é ainda mais impressionante já que os autores são oriundos de uma gama de diferentes profissões, disciplinas e perspectivas $[\ldots]$

Transparência de fato leva a melhores efeitos? Os resultados são impressionantes. Embora a teoria seja variada, as análises empíricas sustentam muito claramente o argumento por maior transparência [...]

Em resumo, os argumentos em favor da transparência variam dos impactos que pode ter na competição entre empresas quando buscando direitos de exploração e perfuração; à maior eficiência dos processos de negociação; à credibilidade da posição negocial de um governo e sua habilidade para garantir a longevidade de um acordo; à estabilidade de um ambiente político e os efeitos disso no acesso aos mercados de capitais e nos incentivos aos líderes para gastar otimamente no tempo; às posturas das populações perante os governos; à habilidade dos mecanismos básicos de responsabilização e prestação de contas, sejam eles governamentais ou não governamentais. Esses argumentos são convincentes e são suportados por trabalhos empíricos sobre transparência. Eles sugerem que o primeiro passo em direção à reversão da maldição dos recursos naturais é a remoção das camadas de segredo que continuam a rondar vários aspectos da indústria. Esse segredo, enquanto imensamente benéfico a alguns poucos, vem com grande custo às populações dentro e fora dos países produtores e em última análise aos governos e empresas que os promovem. ${ }^{192-193}$

189 RUBINSTEIN, Flávio. Notas sobre a transparência fiscal no direito financeiro. In: CONTI, José Maurício; SCAFF, Fernando Facury (Org.). Orçamentos públicos e direito financeiro cit., p. 878.

190 Idem, ibidem.

191 Idem.

192 HUMPHREYS, Macartan; SACHS, Jeffrey D.; STIGLITZ, Joseph E. Future Directions for the Management os Natural Resources. In: HUMPHREYS, Macartan; SACHS, Jeffrey D.; STIGLITZ, Joseph E. (Org.). Escaping the resource curse cit., p. 328 e 331-332. Tradução livre.

193 Outros autores, sobre o mesmo tema, repetem essas recomendações. Como exemplo, cite-se Van der Ploeg, que escreve (VAN DER PLOEG, Frederick. Challenges and opportunities for resource rich economies cit., p. 50): "The best would be to improve the quality of institutions and the legal system and to insist on accountability and transparency of resource revenues, but vested interests will probably oppose that". 
Mas é também conveniente lembrar que a transparência, por si só, não é suficiente para boa governança, devendo ser defendida em conjunto com outras medidas que levam a boas e seguras práticas. Apenas para exemplificar uma situação: não é suficiente a pressão pela maior divulgação de dados e fatos, sem a capacitação da sociedade civil para que os leia e interprete, a partir daí exigindo, de forma organizada e efetiva, as mudanças que precisam ser feitas. ${ }^{194}$ Ivar Kolstad e Arne Wiig pontuam diversos efeitos salutares da transparência, ${ }^{195}$ embora conectando tais efeitos diretamente com a melhor educação da população para que compreenda exatamente os dados e informações acessados, interpretando-os de forma a proporcionar sua efetiva participação na Administração pública. ${ }^{196}$ Contudo, indicam também que muitos estudos que põem a transparência como prioridade absoluta na luta contra a maldição podem estar equivocados (preferem debitar os efeitos especialmente ao rentismo e à corrupção). Nessa linha, opinam pelo equívoco de instituições como a EITI ao focarem suas análises na receita dos países ricos em recursos naturais quando, entendem, o foco deveria estar nas despesas. ${ }^{197}$

194 Interessante a colocação do Diretor Executivo do Fundo Soberano Norueguês ao New York Times, abordado a ênfase dada à transparência, em contraponto a outros Fundos, que prezam o sigilo quanto a seus dados e operações: "From our perspective, the positives are greater than the negatives. Part of that is a reflection of how transparent we need to be toward the Norwegian public, which is the ultimate owner of the fund. But another thing this kind of disclosure gives is an enormous performance pressure. If you disclose it in detail, there's nowhere to hide. The results are visible to everyone". ROTH, Gregory. Norway finds virtue (and value) in transparency. New York Times, 26 de setembro de 2008. Disponível em: <http://www.nytimes.com/2008/09/27/business/worldbusiness/27interview.html?_r=0>. Acesso em: 4 set. 2013.

195 KOLSTAD, Ivar; WIIG, Arne. Is transparency the key to reducing corruption in resource-rich countries? World Development, v. 37, n. 3, Elsevier, 2008, p. 529. “Transparency, or access to information, can have an effect on corruption. Transparency can reduce bureaucratic corruption by making corrupt acts more risky, by making it easier to provide good incentives to public officials, and by easing the selection of honest and efficient people for public service. Transparency can reduce political corruption by helping make politicians more accountable to the public. More generally, transparency can facilitate cooperation over opportunistic rent-seeking and help maintain norms of integrity and trust".

196 Idem, ibidem, p. 529. "Agents whose access to information is increased, must also have an ability to process the information, and the ability and incentives to act on that information. The impact of transparency therefore depends on the level of education of an electorate, the extent to which key stakeholders have the power to hold a government to account, and the private or collective nature of the goods about which information is provided".

197 Idem, p. 529. "If transparency in some form is sufficiently important as to merit priority, increased access to information should focus on the areas most important to curbing corruption and alleviating the resource curse. Current approaches, such as the EITI, have tended to focus on transparency in public revenues. Given the centrality of public expenditures in patronage politics in resource-rich countries, the focus on revenues is not necessarily the most effective one in addressing corruption. In view of the resource curse literature, the emphasis of the EITI on revenues rather than on expenditures, thus appears misplaced". 
A transparência é ferramenta de diagnóstico, mas (embora possa ser em alguns casos) não é o remédio que implicará diretamente na solução contra as más práticas, se não levada a efeito junto com outras ações. ${ }^{198}$

1.b.iii.6. Outros efeitos. Conduta antidemocrática, Desigualdade, Guerras Civis, Liberdades das Mulheres.

Para além dos já acima mencionados, outros efeitos deletérios, decorrentes da exploração de recursos naturais não renováveis, podem ser encontrados na literatura.

Diz-se que a exploração dos recursos naturais não renováveis implica prejuízos ao estabelecimento ou prosseguimento da democracia no país explorador. Que favorece regimes autoritários a se instalar ou se manter. ${ }^{199}$

Essa tese é sustentada especialmente por Michael Ross, ${ }^{200}$ que investiga três efeitos, identificados por ele na literatura, para que assim ocorra: [i] o efeito rentista, focado na atuação dos governos, que utilizariam medidas fiscais para manter a população politicamente desmobilizada; [ii] o efeito repressivo, focado no gasto público, que seria direcionado ao aumento das forças militares e de repressão, mantendo a população desmobilizada; e [iii] o efeito modernizador, que explica essa desmobilização através de forças sociais, especialmente defendendo que a exploração de petróleo não promove melhoras nos níveis educacionais e de especialização do trabalho, estes que conduziriam a uma maior democratização. ${ }^{201} \mathrm{O}$ Autor, utilizando análises estatísticas, conclui que as descobertas de jazidas petrolíferas não têm efeitos antidemocráticos em países de industrialização avançada, mas podem prejudicar ou desestabilizar a democracia em países mais pobres. ${ }^{202}$ Afirma que suas análises sustentam a validade, generalidade e robustez da

198 O'SULLIVAN, Diarmid. What's the point of transparency? - the extractive industries transparency initiative and the governance of natural resources in liberia, timor leste and other countries. Disponível em: <http://publishwhatyoupay.org/sites/publishwhatyoupay.org/files/What\%27s\%20the\%20point\% 20of\%20transparency\%20April\%202013.pdf >. Acesso em: 2 set. 2013.

Abdelkader Sid Ahmed (AHMED, Abdelkader Sid. Celso Furtado e o desenvolvimento a partir da exportação de recursos naturais não renováveis. In: FURTADO, Celso. Ensaios sobre a Venezuela... cit., p. 161 [arquivos Celso Furtado, v. 1]), referindo a análise de Celso Furtado sobre a Venezuela, que previu vários dos efeitos que vieram a se tornar correntes na literatura, afirma que nos estudos de Furtado, "ficava em destaque o elo entre a capacitação das rendas centralizadas pelo Estado e os regimes autoritários, de par com a dependência notadamente tecnológica e a vulnerabilidade externa crescente, assim como a grande dificuldade para promover reformas em face dos interesses adquiridos nesse tipo de economia".

200 ROSS, Michael L. Does oil hinder democracy? cit.

201 Idem, ibidem, p. 332 e ss.

202 Idem, p. 343-344. 
correlação entre petróleo e democracia, ${ }^{203}$ já descontadas outras possíveis influências a viciar o estudo. Afirma que há consistência (no mínimo, fraca) em todos os três efeitos, acima referidos, que conduziriam à ligação entre democracia e petróleo, com especial destaque para o efeito rentista. ${ }^{204}$ Embora registre que as conclusões são mais fluidas quando se trata de exploração de minérios. ${ }^{205}$

O mesmo Michael Ross reiterou sua conclusão principal em revisitação do tema, ${ }^{206}$ afirmando que são fortes as evidências que a riqueza do petróleo tende a prolongar os governos autoritários. Mudou, porém, parte de suas conclusões: apontou não mais encontrar suporte para os efeitos repressivo e modernizador, acima referidos, mas seguiu entendendo persuasiva a hipótese do efeito rentista. ${ }^{207}$ Essa percepção tornou-se majoritária, a ponto de o jornalista Thomas L. Friedman ter escrito sobre a "Primeira Lei da Petropolítica": "o preço do petróleo e a marcha das liberdades sempre se movem em direções opostas nos Estados ricos em petróleo". ${ }^{208}$

Mas a posição referida acima não passou livre de críticas, especialmente diante da falha em identificar os mecanismos pelos quais transitaram diversos países, ricos em recursos naturais, e ao mesmo tempo com sólidos governos democráticos - destacando-se a Noruega.

Foi especialmente influente a crítica de Stephen Haber e Victor Menaldo ${ }^{209}$ à referida proposição. Os autores negam peremptoriamente que haja influência da exploração dos recursos minerais em um regime político mais ou menos democrático (afirmam que, quando muito, as evidências sugerem que o efeito é de majorar os níveis de democracia $^{210}$ ), e o fazem com base também em pesquisas empíricas que, sustentam, corrigem dados utilizados por Michael Ross (estes que alcançariam uma conclusão enviesada através de condução por variáveis omitidas). Para melhor explicar sua posição, em crítica às pesquisas anteriores como a de Ross, e especialmente das explicações

203 ROSS, Michael L. Does oil hinder democracy? cit., p. 346 e 356.

204 Idem, ibidem, p. 356.

205 Idem, p. 357.

206 ROSS, Michael L. But seriously: does oil really hinder democracy?. 2008. Versão preliminar. Disponível em: <http://www.yale.edu/leitner/resources/papers/ButSeriously.pdf〉. Acesso em: 2 set. 2013.

207 Idem, ibidem, p. 22.

208 FRIEDMAN, Thomas L. The first law of petropolitics. Foreign Policy, 1. ${ }^{\circ}$ maio 2006. Disponível em: <http://www.foreignpolicy.com/articles/2006/04/25/the_first_law_of_petropolitics>. Acesso em: 4 set. 2013. Tradução livre.

209 HABER, Stephen H.; MENALDO, Victor A. Do natural resources fuel authoritarianism? A reappraisal of the resource curse cit.

210 Idem, ibidem, p. 3. 
fundadas na consideração de dados culturais e políticos específicos, afirmam com muita verve e ironia que "a presunção por trás da maioria das regressões na literatura é que, não tivesse a Arábia Saudita se tornado dependente do petróleo, poderia ter desenvolvido as mesmas instituições políticas que a Dinamarca, desde que tivesse alcançado a mesma renda per capita e tivesse menos muçulmanos" ${ }^{211}$ - criticando pesadamente as análises que comparam países com panos de fundo muito diversos como se fossem unidades homogêneas, salvo pelo petróleo. Sua análise, então, dá-se em relação a cada país, comparando-o com ele mesmo antes da dependência dos recursos naturais, e comparandoo também com países que se apresentam em circunstâncias similares, salvo pela dependência $^{212}$ à exploração dos recursos naturais. E os resultados indicam que essa dependência não promove o autoritarismo..$^{213}$

Thad Dunning, embora não contradiga a afirmativa de que há uma direta correlação entre exploração de petróleo e democracia, em que esta sai prejudicada, vai além, e propõe algumas alterações significativas nessa equação. ${ }^{214}$ Sustenta, por exemplo, que embora exista essa correlação positiva entre petróleo e autoritarismo, existe também uma relação positiva entre petróleo e democracia, ${ }^{215}$ isto é: em alguns casos, a situação é revertida de forma que a exploração do bem mineral incentiva a maior democratização do Estado. ${ }^{216}$ Sua análise parte da observação do comportamento das elites nesses países. Assim, o autoritarismo é promovido porque há mais razões para que os detentores do poder sigam nessa posição, controlando esses recursos vastos, e assim obtendo os benefícios decorrentes. ${ }^{217}$ Mas, de outra banda, o petróleo promove a democracia quando as elites utilizam dessa receita "extra" para promover a redistribuição de renda, que atende aos anseios da maioria pobre; a ideia subjacente é de que essas elites assim evitariam que a redistribuição ocorresse mediante uma política tributária que atingisse seu (das elites)

211 HABER, Stephen H.; MENALDO, Victor A. Do natural resources fuel authoritarianism? A reappraisal of the resource curse cit., p. 2. Tradução livre.

212 Idem, ibidem, p. 25.

213 Idem.

214 DUNNING, Thad. Crude democracy: natural resource wealth and political regimes. New York: Cambridge University Press, 2008.

$215 \mathrm{O}$ autor ressalva expressamente que sua análise não contempla a qualidade da democracia, admitindo que essa pode não ser a "plena democracia econômica ou social que teóricos políticos têm em mente", mas que ainda assim atinge os requisitos mínimos para que assim se chame. Também por isso o nome da obra, que se refere às democracias "cruas" (DUNNING, Thad. Crude democracy cit., p. 12-13 e 290. Tradução livre).

216 Idem, ibidem, p. 11: "On the one hand, a resource boom may increase the incentives to control the distribution of resource rents and decrease the attractiveness of democracy to elites. [...] On the other hand, a resource boom may also mitigate the redistribution of private income through taxation and thereby increase the attractiveness (or reduce the disutility) of democracy".

217 Idem, p. 100-101. 
patrimônio pessoal diretamente: estaria disposta a redistribuir a riqueza para não ter de redistribuir a renda. ${ }^{218}$ Dessa forma, "o empoderamento político de uma maioria relativamente pobre é menos custoso às elites ricas". ${ }^{219}$ A democracia será por eles preferida quando não lhes for demais ameaçadora. ${ }^{220}$ Daí que o "efeito democratizante" deve ser observado em sociedades em que o setor privado da economia é mais desigual; e quando a economia é menos dependente desses recursos naturais.

Interessante notar - o que é ressaltado pelo mesmo autor ${ }^{221}$ - que são fortes as evidências negando qualquer efeito deletério da riqueza mineral na democracia da América Latina, concluindo, em média, por ligeira melhora democrática. Exemplo comum é o da Venezuela, que justamente quando mais fortemente se apoiou nessa indústria extrativa (durante o boom dos anos 1980), fortaleceu sua democracia. O próprio texto de Dunning, contudo, não fixa posição sobre se isso sé um reflexo de sua "maldição condicionada" ou se se trata de uma confirmação da hipótese sustentada por Haber e Menaldo, de que não existe, nesse aspecto democrático, qualquer maldição. Ross, embora aceitando que as análises assim indicam, suscita duas possíveis explicações para o fato: uma é o "efeito vizinhança", em que os meios antidemocráticos decorrentes da exploração petrolífera são sobrepostos pelas pressões oriundas dos países vizinhos não produtores; outra é temporal, em que os meios antidemocráticos são frustrados por uma prévia mobilização política da sociedade. ${ }^{222}$ - 223 Concordando com as conclusões de Dunning especificamente direcionadas à América Latina, mas resistindo a ampliar suas causas subjacentes para outros lugares do mundo, Ross adota uma solução de compromisso ao afirmar que "Dunning está certo: petróleo é associado com mais democracia na América Latina, mas com menos democracia no resto do mundo em desenvolvimento" ${ }^{224}$ - assim, parece confessar a fraqueza de sua tese, desprovida que é de generalidade.

Vale lembrar, aqui, que a democracia é um bem em si mesma. Embora o tema seja polêmico, com ressalvas ao necessário respeito ao multiculturalismo, fique-se com a

218 DUNNING, Thad. Crude democracy cit., p. 104.

219 Idem, ibidem, p. 101.

220 Idem, p. 290.

221 DUNNING, Thad. Natural resources and democracy in latin america ... cit.

222 ROSS, Michael L. Oil and democracy revisited. 2009. Versão preliminar. Disponível em: <http://www.sscnet.ucla.edu/polisci/faculty/ross/Oil\%20and\%20Democracy\%20Revisited.pdf>. Acesso em: 5 set. 2013, p. 9

223 ROSS, Michael L. The oil curse cit., p. 86, em outra oportunidade, face à posição e estudos apresentados por Dunning, especialmente relacionados à América Latina, reitera esta última alternativa, colocando que a exploração de recursos naturais não renováveis impede a democracia apenas nos países sem prévia experiência democrática.

224 Idem, ibidem. 
doutrina de Comparato, para quem a democracia é o "único regime político compatível com o pleno respeito aos direitos humanos". 225

Nos Estados em que se dá a atividade de exploração de recursos naturais não renováveis nota-se um menor nível de igualdade social, sendo a distribuição de renda mais precária. Nesse sentido, Gylfason e Zoega sugerem que se trata de uma consequência de esse setor da economia atrair trabalhadores em detrimento das atividades com maior grau de tecnologia. ${ }^{226}$ Afirmam que o índice GINI de desigualdade de renda e de gênero varia diretamente conforme a parcela dos recursos naturais na riqueza nacional. ${ }^{227}$ Auty compartilha dessa ideia, apontando que o setor extrativo atrai trabalhadores a uma atividade que demanda menos qualificação, o que aumenta a desigualdade. ${ }^{228}$

Já Ross, embora concordando com suas premissas - sustentando que deve ser uma prioridade do governo evitar que os trabalhadores mudem dos setores "transacionáveis" aos "não transacionáveis", como o setor extrativo, inclusive utilizando contramedidas, quando esse movimento for detectado -, nega que os dados existentes sejam suficientes para afirmar que a maior desigualdade é um efeito típico da exploração de recursos naturais. ${ }^{229}$

Goderis e Malone, por sua vez, não são da mesma opinião das acima referidas. Sustentam que os níveis de desigualdade são em verdade reduzidos quando das altas nos

225 COMPARATO, Fábio Konder. A afirmação histórica dos direitos humanos cit., p. 246. Cabe mencionar, contudo, a existência de opiniões no sentido de que nem sempre a democratização leva a melhores resultados econômicos - COLLIER, Paul; HOEFFLER, Anke. Testing the neocon agenda: democracy in resource-rich societies. European Economic Review, n. 53, Elsevier, 2009. Afirmam: "In the absence of resource rents democracies outperform autocracies, in the presence of large resource rents autocracies outperform democracies", p. 293. Os mesmos autores ponderam ainda, em outro texto (COLLIER, Paul; HOEFFLER, Anke. Democracy and resource rents. Global Poverty Research Group Working Paper Series, n. 016, 2005), que "o antídoto" para o baixo crescimento associado à democracia nos países de grande renda oriunda da exploração mineral está no fortalecimento dos freios e contrapesos, especialmente na liberdade de imprensa, e com menos ênfase na competição eleitoral. É evidente que isso não torna a democracia indesejável. Mas é um fator a ser considerado, especialmente buscando conhecer suas causas com o objetivo de superá-las.

226 GYLFASON, Thorvaldur; ZOEGA, Gylfi. Inequality and economic growth: do natural resources matter? CESifo Working Paper Series, n. 712, 2002: "the more time workers devote to natural resource extraction, the more unequal the distribution of income". p. 6.

227 Idem, ibidem, p. 25.

228 AUTY, Richard M. Natural resources, development models and sustainable development. Environmental Economics Programme Working Paper, n. 03-01, 2003, p. 5.

229 ROSS, Michael L. How mineral-rich states can reduce inequality. In: HUMPHREYS, Macartan; SACHS, Jeffrey D.; STIGLITZ, Joseph E. (Org.). Escaping the resource curse cit. 
preços dos recursos naturais, mas que em longo prazo são reconduzidos ao patamar original. ${ }^{230}$

Também é dito que a exploração de petróleo e/ou minérios aumento o risco de ocorrência de guerras civis e outras espécies de conflitos internos. A explicação básica seria a exaltação dos interesses de grupos diversos e heterogêneos dentro de um mesmo país, já amansados pela passagem do tempo, em disputa pela riqueza natural que se espera seja iminentemente transformada em riqueza material e desenvolvimento econômico e social.

Essa correlação é sustentada por Collier e Hoeffler, para quem a conexão entre os temas está na capacidade dos grupos internos rebeldes para se financiar através da extorsão de riqueza de commodities, geralmente controlando ilegalmente a produção ou transporte desses bens em áreas rurais, como ocorre com os diamantes de Serra Leoa e de Angola. ${ }^{231}$ Paul Collier desenvolveu mesmo um "bordão" para sustentar essa hipótese: afirmou, para o deleite da imprensa internacional, que os "diamantes são os melhores amigos das guerrilhas" (“diamonds are a guerrilla's best friend"). ${ }^{232}$ Apontam os autores, de outro lado, que em países com alto grau de dependência dos recursos minerais esse risco de guerra civil tende a cair, o que interpretam como sendo evidência do aumento das receitas do Governo, com a consequente possibilidade de melhor arquitetar suas forças internas de repressão.

James Fearon objeta em várias formas. Concorda que exista uma relação positiva entre alto nível de dependência da exportação de petróleo e guerras civis. Mas nega que essa relação seja extensível a outras commodities. E, embora preste homenagens à ideia de avaliar as fontes de financiamento dos grupos rebeldes e até mesmo concorde que se trate de uma questão relevante, contesta fortemente que essa seja a causa primária, especialmente porque o caixa das forças contrainsurgentes também é aumentado, dando-se uma anulação de uma pela outra. Ao reverso, foca sua interpretação do fenômeno no já

230 GODERIS, Benedikt; MALONE, Samuel W. Natural resource booms and inequality: theory and evidence. OxCarre Research Paper 08, Oxford University, 2010.

231 COLLIER, Paul; HOEFFLER, Anke. Greed and grievance in civil war. Centre for the Studies of African Economies Working Paper Series, n. 2002-01, 2002, p. 6. Os autores também encontram ligação entre guerras civis e o papel das diásporas nos países. Referem que suas análises apontam para uma correlação direta, mesmo excluindo variáveis que indicam ser a migração populacional uma consequência - e não causa - da guerra. Encontram evidências que o papel das diásporas é relevante no financiamento dos grupos rebeldes.

232 FERGUSON, Niall. The least among us. New York Times, 1. ${ }^{\circ}$ jul. 2007. Disponível em: <http://www.nytimes.com/2007/07/01/books/review/Ferguson-t.html?pagewanted=all>. Acesso em: 7 set. 2013. 
referido enfraquecimento institucional causado pela exploração, que importa em menos capacidades administrativas e burocráticas. ${ }^{233}$ Acresce ainda que a riqueza natural aumenta o "prêmio" pelo sucesso insurgência, tornando-a mais recompensadora.

Em verdade, as causas para que a exploração de recursos minerais conduza a guerras civis, já descritas na literatura, são várias. Macartan Humphreys ${ }^{234}$ listou 06 (seis) dessas causas, submetendo-as a testes analíticos. São elas: [i] o mecanismo dos rebeldes ganaciosos $^{235}$ (o próprio Autor objeta os termos ora traduzidos como "ganância" e "mágoa", afirmando que são infelizes, dado que implicam conotação moral ${ }^{236}$ ), em que (a) esses grupos praticam atividades criminais para obter rendas apartadas do poder do Estado, e/ou em que (b) os prêmios aos rebeldes são maiores, e/ou em que (c) os grupos rebeldes, especialmente quando a exploração se dá em locais afastados dos centros urbanos, passam a crer na viabilidade e prosperidade (a partir dos recursos oriundos da atividade mineral) de um Estado autônomo; [ii] o mecanismo dos forasteiros gananciosos,${ }^{237}$ em que os conflitos são estimulados por terceiros, como Estados vizinhos e empresas com interesses econômicos contrariados - hipótese que tem na República do Congo um bom exemplo; [iii] o mecanismo da mágoa $^{238}$ (de alguns grupos face ao governo central), em que (a) decorre da desigualdade de renda interna, e/ou (b) da instabilidade e insatisfação dos grupos mais afetados pelos choques externos (como a queda dos preços do mineral) frequentemente causados pela alta volatilidade dos recursos, e/ou (c) da migração forçada, que ocorre, por exemplo, nos casos de desapropriação de imóveis ou de prejuízos ambientais que inviabilizam o prosseguimento de uma atividade econômica como a agricultura, e/ou (d) pela percepção de que a riqueza dos recursos naturais é distribuída de forma mais desigual do que as demais fontes, especialmente quando a região produtiva se vê com relevante papel na economia nacional, mas recebendo poucos investimentos em comparação com outras regiões nacionais; [iv] o mecanismo da viabilidade, ${ }^{239}$ em que os recursos naturais servem apenas como modo de financiamento dos grupos que já se

233 FEARON, James. Primary commodities exports and civil war. 2004. Disponível em: <http://isites.harvard.edu/fs/docs/icb.topic244653.files/Fearon_J_Prim_Commod_Exports_Civ_War_20 04.pdf>. Acesso em: 7 set. 2013. p. 6 e 17.

234 HUMPHREYS, Macartan. Natural resources, conflict, and conflict resolution: uncovering the mechanisms. Journal of Conflict Resolution, v. 49, n. 4, 2005.

235 Idem, ibidem, p. 511.

236 Idem, p. 511, nota de rodapé n. 10.

237 Idem, p. 511.

238 Idem, p. 511-512

239 Idem, p. 512. 
revelavam insurgentes por outras razões; [v] o mecanismo dos Estados frágeis, ${ }^{240}$ em que (a) há menor conexão entre sociedade e Estado quando este é financiado pelas receitas oriundas da exploração, deixando de tributar seus cidadãos em nível ótimo, assim reduzindo o interesse da sociedade de fiscalizar o Estado, e reduzindo o interesse do Estado de prestar contas à sociedade, e/ou em que (b) a exploração dos recursos naturais importa em reduzidos incentivos para criar instituições burocráticas sólidas; e [vi] o mecanismo das relações esparsas, ${ }^{241}$ em que a exploração de minério ou petróleo torna tênues as relações internas, especialmente porque o empresariado foca em atividade extrativa, com pouco comércio interno - o argumento está fundado na ideia de que as relações comerciais importam em melhor conhecimento da cultura de uns pelos outros, tornando ambos mais compreensíveis e menos violentos.

Apesar de observar todos os referidos mecanismos para que a exploração dos recursos naturais não renováveis torne mais provável a ocorrência de guerras civis, suas análises indicam que apenas 2 (dois) deles encontram amparo: dos Estados frágeis e da mágoa. $^{242}$ Os demais não retornaram resultados positivos.

Por ultimo, cabe referir a existência de estudos que indicam que a exploração de petróleo e minérios conduz a menores liberdades políticas das mulheres. ${ }^{243}$

A ideia desenvolvida na hipótese é de que esse tipo de atividade provoca a mudança da economia do país, migrando do setor transacionável (agricultura/manufatura) ao não transacionável (construção e serviços), vinculando as atividades empresariais ao setor extrativo de recursos naturais e exportador. ${ }^{244}$ Ocorre que, por diversas razões (segregação ocupacional de gênero, diferenças salariais, aumento dos salários aos chefes de família, aumento dos salários indiretos aos chefes de família, incluindo menor tributação, assim majorando os incentivos para cuidar da casa e dos filhos) essa mudança provoca o afastamento das mulheres da força de trabalho. ${ }^{245} \mathrm{E}$ a redução de mulheres dos postos de emprego traz consequências ruins para suas liberdades políticas, ${ }^{246}$ relacionadas

240 HUMPHREYS, Macartan. Natural resources, conflict, and conflict resolution... cit., p. 512-513.

241 Idem, ibidem, p. 513.

242 Idem, p. 526.

243 ROSS, Michael L. Oil, Islam and women. American Political Science Review, v. 102, n. 1, 2008.

244 BOADWAY, Robin; SHAH, Anwar. Fiscal federalism... cit., p. 216.

245 ROSS, Michael L. Oil, Islam and women cit., p. 110: "In many developing countries, women are largely employed in the traded sector, in low-wage jobs in export-oriented factories and agriculture; and they are excluded from many parts of the nontraded sector, such as construction and retail, since these jobs typically entail heavy labor, or contact with men outside the family".

246 Idem, ibidem, p. 110. "when the fraction of female citizens in the work force rises, it should enhance women's political influence through dynamics at an individual level (as their exposure to the work place 
à sua emancipação da casa paterna e do arbítrio do marido, ao seu nível de escolaridade, às taxas de fertilidade, à criação de laços com outras mulheres, difundindo experiências, à sua influência na família e, finalmente, à sua participação política, inclusive medida consoante o número de assentos tomados por mulheres no Parlamento e outros órgãos governamentais diretivos. ${ }^{247}$

O autor afirma que, para concluir que há uma relação positiva entre a exploração de petróleo e a redução das mulheres nos postos de trabalho, suas análises foram blindadas da influência, potencialmente deturpadora dos resultados, do Islamismo e da cultura árabe e do Oriente Médio.

Não é essa a opinião, contudo, de Pippa Norris. ${ }^{248}$ Iniciando por afirmar que caiu parcialmente em desuso a ideia de que as liberdades das mulheres estão vinculadas à sua participação no mercado de trabalho, a autora critica a seleção de países para comparação utilizada por Ross; a ausência de considerações temporais; ${ }^{249}$ os modelos econométricos utilizados, inclusive recordando que é comum verificar nações em que os recursos naturais não renováveis são deveras significantes observando sua proporção no PIB, nas receitas públicas e nas exportações, mas o número de empregos que demanda é muito baixo considerando essa predominância econômica (atividade capital-intensiva); e a não consideração (embora afirmando o inverso) efetiva de influências culturais e da identidade religiosa, inclusive deixando de se dirigir às largas diferenças entre culturas e crenças abarcadas pelo mesmo título islâmico (sunitas e xiitas, árabes e asiáticos, etc.).

As conclusões de Norris são contundentes. Sustenta que a tese de que as liberdades das mulheres sofre uma maldição dos recursos naturais não resiste ao escrutínio. Que não é um fator relevante nos problemas de disparidade de gênero nos Estados Árabes (em verdade podendo até mesmo existir uma relação inversa). Debita esses

affects their identities and perceptions), a social level (as their density in the labor force rises, so does the number of formal and informal female networks), and an economic level (as their growing role in the economy forces the government to take their interests into account)".

247 ROSS, Michael L. Oil, Islam and women cit., p. 107-108.

248 NORRIS, Pippa. Perhaps petroleum perpetuates patriarchy? A response and critique to Ross. Harvard Kennedy School. Disponível em: <http://www.hks.harvard.edu/fs/pnorris/Acrobat/Culture,\%20 Islam\%20and\%20Oil.pdf>. Acesso em: 7 set. 2013. O texto foi publicado em: NORRIS, Pippa. Petroleum patriarchy? A response to ross. Politics and Gender 5.4, nov. 2009, p. 553-560. A consulta realizada foi através do sítio acima indicado, e não à revista Politics and Gender.

249 NORRIS, Pippa. Perhaps petroleum perpetuates patriarchy? A response and critique to Ross. p. 6. "Patriarchal cultures in Arab states did not spring up overnight in the mid-nineteenth century as the result of the discovery and commercial exploitation of refined petroleum; they have enduring historical roots which predate the discovery and production of oil". 
fatores, no Oriente Médio, à influência cultural e religiosa, ${ }^{250}$ afirmando que a pesquisa empírica sustenta fartamente essa conclusão. Sustenta que as mulheres têm mais sucesso em alcançar cargos legislativos ou ministeriais em sociedades não islâmicas, sejam elas ricas ou pobres em recursos naturais, sendo também verdadeiro que alcançam menos sucesso nesse sentido nas sociedades islâmicas, ricas ou pobres em recursos naturais.

E ironiza: "[segundo Ross] comprar aquela bicicleta nova não é somente saudável para você e para o planeta; também facilita a igualdade para as mulheres. Quem diria?".251

\section{1.c. Doença Holandesa.}

A denominação de Doença Holandesa faz referência à exploração de gás natural naquele país europeu - e o aumento vertigionoso das exportações do produto. Registre-se, desde já, contudo, que não se trata de fenômeno exclusivamente relacionado aos recursos naturais não renováveis: diz respeito também a outros recursos naturais (como café e chá) e mesmo, como sustenta Bresser-Pereira em um conceito ampliado, a situações de farta e barata mão de obra. ${ }^{252}$

O mesmo Bresser-Pereira, em destacado texto sobre o tema, conceitua a doença holandesa como

a sobreapreciação crônica da taxa de câmbio de um país causada por este para explorar recursos abundantes e baratos, cuja produção comercial é compatível com uma taxa de câmbio claramente menor do que a taxa de câmbio médica que viabiliza setores econômicos de bens comercializáveis que utilizam tecnologia no estado da arte. ${ }^{253}$

O ponto fulcral do fenômeno é cambial. A exploração dos recursos naturais, com especial relevo para as rendas extraordinárias daí decorrentes, promove uma

250 NORRIS, Pippa. Perhaps petroleum perpetuates patriarchy? cit., p. 16. "It seems more plausible to conclude that long-standing religious traditions leave an enduring mark on the norms and beliefs, the attitudes and values, which characterize different societies. These cultural values leave a deep imprint upon the way that men and women see the most appropriate division of labor for men and women in the home, family and public sphere - including the role of women in elected office".

251 Idem, ibidem, p. 4.

252 BRESSER-PEREIRA, Luiz Carlos. Doença holandesa e sua neutralização: uma abordagem ricardiana. In: BRESSER-PEREIRA, Luiz Carlos (Org.). Doença holandesa e indústria. Rio de Janeiro: FGV, 2010. p. 146 e ss.

253 Idem, inidem, p. 123. Mister ressaltar que o referido autor trata "Doença Holandesa" e "Maldição dos Recursos Naturais" de forma única. Nada obstante reconheça-se que existem diversas interligações entre os temas, optou-se, neste trabalho, por utilizá-los indicando fenômenos diversos, a primeira vinculada à questão cambial enquanto que a segunda apontando efeitos econômicos e políticos diversos, já referidos. 
valorização da moeda do país onde se dá a atividade. ${ }^{254}$ Isso gera uma consequência nefasta nas demais atividades, especialmente de manufatura, em face da dificuldade de exportação desses bens (que se tornam mais caros no exterior) e da facilitação da entrada de bens importados, que vêm competir com a produção nacional. ${ }^{255-256}$ As empresas nacionais, dadas as dificuldades, acabam por se tornar meras indústrias "maquiladoras". 257 ${ }^{258}$ Ainda, o protagonismo da indústria extrativa ${ }^{259}$ conduz a uma mudança do panorama

254 O fenômeno é comumente descrito, mas não é automático. Como ressalta Van der Ploeg (VAN DER PLOEG, Frederick. Challenges and opportunities for resource rich economies cit., p. 19), "there are a variety of reasons why a natural resource boom may be associated with depreciation rather than appreciation of the real exchange rate".

255 Frankel (FRANKEL, Jeffrey. The natural resource curse cit., p. 22) resume o tema da macroeconomia da doença holandesa em 05 (cinco) passos: [i] grande valorização real da moeda; [ii] aumento do gasto público; [iii] aumento do preço dos bens não transacionáveis em relação aos bens transacionáveis; [iv] deslocamento de trabalhadores e terras dos setores transacionáveis não ligados à exportação de commodities, atraídos pelos melhor retorno desse setor exportador e dos setores de bens e serviços não transacionáveis; [v] déficit em conta corrente.

256 Ensina Celso Furtado (FURTADO, Celso. O desenvolvimento recente da economia venezuelana, 1957. In: FURTADO, Celso. Ensaios sobre a Venezuela... cit., p. 54): "Mas o que importa reter de todo esse processo é que a absorção da oferta crescente de divisas se fez com uma forte sobrevalorização externa da moeda e que dessa sobrevalorização resultou que os salários monetários na Venezuela passaram a ser tão elevados ou até mais do que naqueles países em que a produtividade média é muito superior à da economia venezuelana e que concorrem no mercado venezuelano com a produção local. A consequência prática disso foi a seguinte: qualquer atividade econômica em que existisse a possibilidade de concorrência de importações só pôde subsistir mediante forte proteção". Em outro texto (FURTADO, Celso. Notas sobre a economia venezuelana e suas perspectivas atuais, 1974. In: FURTADO, Celso. Ensaios sobre a Venezuela... cit., p. 123), o mesmo Celso Furtado afirma: "Em 1972, do total de bens disponíveis destinados ao consumo e à capitalização, cerca de $40 \%$ foram importados, e nada impede que essa participação das importações na oferta global se eleve nos próximos anos. É concebível, por exemplo, que a oferta interna triplique até o final do decênio dos 70 e que paralelamente as importações se multipliquem por cinco". Carlos Aguiar de Medeiros (MEDEIROS, Carlos Aguiar de. Celso Furtado na Venezuela. In: FURTADO, Celso. Ensaios sobre a Venezuela... cit., p. 142) complementa: "Assim, os efeitos desse padrão de crescimento ampliavam o subdesenvolvimento". BRESSER-PEREIRA, Luiz Carlos. Doença holandesa e sua neutralização: uma abordagem ricardiana. In: BRESSER-PEREIRA, Luiz Carlos (Org.). Doença holandesa e indústria cit., p. 138.

258 Abdelkader Sid Ahmed (AHMED, Abdelkader Sid. Celso Furtado e o desenvolvimento a partir da exportação de recursos naturais não renováveis. In: FURTADO, Celso. Ensaios sobre a Venezuela... cit., p. 164-165) ressalta: "Essencialmente, a doença holandesa atesta que importantes setores de hidrocarbinetos são a causa de uma sobrevalorização da taxa de câmbio. O preço das exportações cresce, enquanto baixa o das importações, nas condições de Marshall-Lerner. O volume das exportações de outros setores, diferentes do petróleo, diminui, ao passo que cresce substancialmente o volume das importações, o que afeta negativamente o balanço de pagamentos, fenômeno por um tempo ocultado pelas receitas derivadas do petróleo. Isso significa a contração do setor produtivo e não petroleiro na economia, e, portanto, no caso dos países desenvolvidos, uma desindustrialização".

259 "A consequência mais marcante da MRN [Maldição dos Recursos Naturais] é a especialização econômica, em que a maior parte do PIB é gerada somente pelo setor extrativista mineral com vistas à exportação. Essa é a descrição aproximada do que se chama de doença holandesa, em que ocorrem efeitos de crowding out da produção de manufaturados para o setor primário". Por isso, então, que a questão deveria ser contraposta pela diversificação econômica, que "é um dos principais pontos a serem buscados por políticas que visam minimizar os impactos dos recursos naturais na economia. A diversificação é fundamental para evitar os malles descritos anteriormente, advindos da dependência, e por permitir a criação de estratégias de saída para quando a produção entrar em seu ciclo de depleção". PERIARD, Thiago; LOSEKANN, Luciano. Petróleo, doença holandesa e dependência da renda petrolífera. In: MONIÉ, Frédéric; BINSZTOK, Jacob (Org.). Geografia e geopolítica do petróleo. Rio de Janeiro: Mauad X, 2012. p. 135 e 141. 
econômico, promovendo a migração do PIB não relacionado à atividade exploratória de uma base industrial para uma base de prestação de serviços, o que pode não ser tão relevante no aspecto nacional, mas que pode sim influenciar muito no plano local ou regional. ${ }^{260}$ Como coloca Mikesell, "na maioria dos casos, ocorrem distorções que tendem a debilitar a produção e o investimento de setores-chave". ${ }^{261}$

E promove, por consequência, a migração de trabalhadores e capital para a atividade extrativa ou outras atividades (principalmente serviços) que lhe são marginais, que inclusive passam a ofertar melhores salários. ${ }^{262}$

Posto em outros termos, o tema está relacionado às maiores externalidades ${ }^{263}$ positivas oriundas do setor manufatureiro/industrial em comparação com a atividade de exploração de recursos naturais: a migração de pessoas a esta atividade prejudica aquela, restringindo essas externalidades. ${ }^{264-265}$ Tudo o que traz efeitos indesejados, ${ }^{266}$ sendo um deles a pior distribuição de renda. ${ }^{267}$

260 CASELLI, Francesco; MICHAELS, Guy. Do oil windfalls improve living standards? Evidence from Brazil. cit., p. 27.

261 MIKESELL, Raymond F. Explaining the resource curse, with special reference to mineral-exporting countries. Resources Policy, v. 23, n. 4, Elsevier, 1998, p. 193.

${ }^{262}$ O que Leite e Weidmann (LEITE, Carlos; WEIDMANN, Jens. Does mother nature corrupt? Natural resources, corruption, and economic growth cit., p. 8) referem como "resource pull effect".

263 A identificação dessas externalidades e o impacto positivo delas deve ser central ao estudo. Destaca Van der Ploeg (VAN DER PLOEG, Frederick. Challenges and opportunities for resource rich economies cit., p. 19-21) que os países devem se especializar naquilo em que têm vantagem comparativa, daí por que a mudança de trabalhadores e capital ao setor extrativista não é necessariamente deletéria. Contudo, o mesmo autor explica que se as externalidades positivas assim justificarem, deve haver intervenção estatal para evitar essa mudança. Exemplifica esse melhor impacto do setor manufatureiro com a melhora do capital humano através do desenvolvimento de expertise no trabalho (learning by doing).

264 Leite e Weidman (LEITE, Carlos; WEIDMANN, Jens. Does mother nature corrupt? Natural resources, corruption, and economic growth cit.) sustentam que o encadeamento relatado na literatura da doença holandesa pode ser descrito como uma "resposta racional da economia" ao boom de recursos naturais. O que não impede que essa resposta traga consequências nefastas, considerando a falta das externalidades positivas já mencionadas. Tudo o que reconfirma a ideia de que o tema deve ser dirigido especialmente pela estrutura do Estado, e não simplesmente deixado às forças de mercado. O mesmo destaca Jeffrey Sachs (SACHS, Jeffrey D. How to handle the macroeconomics of oil wealth?. In: HUMPHREYS, Macartan; SACHS, Jeffrey D.; STIGLITZ, Joseph E. (Org.). Escaping the resource curse cit., p. 183): "these resource shifts can become a true 'disease' or market failure if there is something special about the traded goods sector that is being squeezed".

265 Bresser-Pereira, embora afirmando que não há razão determinista para afirmar que o setor extrativo é menos capaz de gerar bons frutos, parece indicar que a concentração de capital e trabalho nesse setor é um mal em si, independentemente das externalidades do setor prejudicado: "Não há nada que torne a produção agrícola e mineral intrinsecamente menos produtiva ou eficiente do que a manufatureira [...] Entretanto, ainda que essa exploração possa implicar valor adicionado per capita alto, o país estará renunciando a outras atividades que já têm condições de produzir com conteúdo científico e tecnológico ainda maior, e - o que é ainda mais grave - a todas as outras atividades que potencialmente possa vir a produzir com valor adicionado per capita mais alto" (BRESSER-PEREIRA, Luiz Carlos. Doença holandesa e sua neutralização: uma abordagem ricardiana. In: BRESSER-PEREIRA, Luiz Carlos (Org.). Doença holandesa e indústria cit., p. 144-145). 
Ainda mais sensível é a questão quando consideradas as características básicas dos recursos minerais: a sua não renovabilidade e a sua marcada volatilidade. É dizer: considerando que a extração é, por definição, restrita no tempo e sujeita a altos e baixos, a ideia de não desenvolvimento de outros setores econômicos ou de seu encolhimento é mais preocupante porque quando finda a extração, ou quando os preços caírem, o país restará improdutivo, desindustrializado ${ }^{268}$ - e pode "nunca recuperar a taxa de crescimento experimentada antes do período de expansão das exportações". ${ }^{269}$

Contudo, assim como na maldição acima referida - e apesar da carga conotativa pesada também presente no termo -, a doença holandesa não é inevitável ou irreversível, ou mesmo, na visão de alguns, um fenômeno tão relevante a causar sérios prejuízos à economia do país. ${ }^{270-271}$

Jeffrey Sachs, por exemplo, sustenta que o medo da doença holandesa é exagerado. Para ele, os efeitos deletérios ocorrem apenas quando a expansão econômica é utilizada para financiar consumo em vez de investimento. Sustenta que os recursos oriundos da exploração dos recursos naturais devem ser investidos como parte de uma estratégia nacional de desenvolvimento, especialmente em infraestrutura. Em seu entender, essa estratégia não apenas evita a mudança de trabalhadores e capital em direção ao setor

266 Negando que a mudança entre setores da economia seja, por si, deletéria - e que esse efeito negativo depende das consequências associadas ao setor econômico desprivilegiado -, Haussman e Rigobon (HAUSMANN, Ricardo; RIGOBON, Roberto. An alternative interpretation of the "resource curse". In: DAVIS, J.; OSSOWSKI, R.; FEDELINO, A. (Org.). Fiscal policy formulation and implementation in oil-producing countries cit., p. 16) afirmam: "it is not obvious that learning by doing or technological development is slower in resource-based industries relative to others".

267 HUMPHREYS, Macartan; SACHS, Jeffrey D.; STIGLITZ, Joseph E. Introduction: What is the problem with natural resource wealth?. In: HUMPHREYS, Macartan; SACHS, Jeffrey D.; STIGLITZ, Joseph E. (Org.). Escaping the resource curse cit., p. 6; SACHS, Jeffrey D. How to handle the macroeconomics of oil wealth?. In: HUMPHREYS, Macartan; SACHS, Jeffrey D.; STIGLITZ, Joseph E. (Org.). Escaping the resource curse cit., p. 184.

268 Bresser-Pereira. "No momento em que um país de renda média se vê ameaçado pela doença holandesa, o que está sob ameaça é a demanda para todo um enorme setor industrial de bens comercializáveis. Considerar que o país possa sofrer sem grandes custos desindustrialização e voltar à condição de especialização em indpustrias intensivas em recursos naturais não é realista". BRESSER-PEREIRA, Luiz Carlos. Doença holandesa e sua neutralização: uma abordagem ricardiana. In: BRESSERPEREIRA, Luiz Carlos (Org.). Doença holandesa e indústria cit., p. 144.

269 MIKESELL, Raymond F. Explaining the resource curse, with special reference to mineral-exporting countries cit., p. 194. Tradução livre.

270 Essa é a opinião de Sala-i-Martin e Subramanian, em análise da economia nigeriana. SALA-I-MARTIN, Xavier; SUBRAMANIAN, Arvind. Addressing the natural resource curse: an illustration from Nigeria cit.

271 Afirma Raymond Mikesell: "The Dutch Disease was not the major factor in explaining the growth pattern for more than half of the countries reviewed" (MIKESELL, Raymond F. Explaining the resource curse, with special reference to mineral-exporting countries cit., p. 197). 
explorador, como eleva a produtividade dos setores econômicos, transacionáveis e não transacionáveis, não relacionados à exploração ${ }^{272}$ - havendo ou não elevação cambial.

O mesmo autor, de outra banda, defende também que já estando instalados os primeiros estágios da doença, com a sobreapreciação da taxa de câmbio, cabe ao Estado controlá-la, o que pode fazer seja através da manutenção de uma taxa de câmbio flutuante; seja por meio da indexação da moeda nacional com o dólar ou o euro.

Bresser-Pereira explica que a neutralização da doença holandesa cabe ao Estado através da administração da taxa de câmbio, o que deve fazer basicamente através da tributação dos bens que geram a doença holandesa, de forma "equivalente à diferença percentual entre a taxa de câmbio de equilíbrio corrente que seu custo mais baixo proporciona e a taxa de câmbio de equilíbrio industrial que viabiliza setores comercializáveis no estado da arte da tecnologia”. ${ }^{273}$ Os recursos arrecadados com essa tributação devem ser mantidos em fundo internacional, "de forma a evitar que sua entrada no país reaprecie a taxa de câmbio". ${ }^{274}$ Interessante ainda sua colocação quanto à existência, nos anos 1970, de tal tributação oblíqua ("confisco cambial”, como era chamada pelo setor cafeeiro). Isto é: embora não fosse instituído claramente o tributo, eram concedidos incentivos à indústria manufatureira para exportação (e gravadas as importações), o que era negado à indústria extrativa causadora da doença holandesa. Essa solução, embora menos racional e menos transparente, era a politicamente viável. ${ }^{275}$

Eis, então, que a doença pode ser ultrapassada.

E a tarefa de conduzir para que assim ocorra cabe à estruturação de Estado e de Governo, elaborando e pondo em prática políticas compatíveis para combater os males da apreciação cambial. Como destaca Mikesell, "os sintomas da doença holandesa podem ser moderados ou amplamente evitados pela adoção de políticas governamentais apropriadas". ${ }^{276-277}$

272 SACHS, Jeffrey D. How to handle the macroeconomics of oil wealth? In: HUMPHREYS, Macartan; SACHS, Jeffrey D.; STIGLITZ, Joseph E. (Org.). Escaping the resource curse cit., p. 181-186.

273 BRESSER-PEREIRA, Luiz Carlos. Doença holandesa e sua neutralização: uma abordagem ricardiana. In: BRESSER-PEREIRA, Luiz Carlos (Org.). Doença holandesa e indústria cit., p. 132.

274 Idem, ibidem, p. 132.

275 Idem, p. 143.

276 MIKESELL, Raymond F. Explaining the resource curse, with special reference to mineral-exporting countries cit., p. 194. E ainda: "All countries experience shocks from a loss of major export markets [...] How the shocks are handled determines whether they will prevent sustainable development". p. 195.

277 Van der Ploeg vê a necessidade de intervenção estatal apenas se demonstradas as externalidades positivas dos setores econômicos diversos da atividade que dá causa à doença holandesa: VAN DER PLOEG, Frederick. Challenges and opportunities for resource rich economies cit., p. 50. 


\section{1.d. Redução da carga tributária.}

Michael Ross sustenta que "quando os governos recebem mais receita de petróleo, eles tendem a responder coletando menos receitas de tributos". ${ }^{278}$ Segundo o autor, essa relação é desproporcional: esses governos se tornam desproporcionalmente mais dependentes da receita de recursos minerais e desproporcionalmente mais liberados do poder/dever de tributar. ${ }^{279}$

"O efeito da receita de hidrocarbonetos no esforço de obtenção de receita doméstica é estatisticamente significante e negativo em todas as especificações”, dizem Bornhorst, Gupta e Thornton. ${ }^{280}$ Afirmam que, na média dos 30 (trinta) países pesquisados, o aumento de $1 \%$ da receita oriunda de hidrocarbonetos (em relação ao PIB) rebaixa em $0,2 \%$ a arrecadação da receita não relacionada à indústria extrativa de recursos naturais. ${ }^{281}$ Os autores negam, segundo suas análises, que essa relação seja influenciada pelos índices de corrupção governamental.

McGuirk corrobora a existência dessa relação entre a exploração dos recursos minerais e a redução da carga tributária. E vai além: afirma que essa relação é ainda mais forte às vésperas de eleições; e que suas medições confirmam a proposição da ciência política de que a menor tributação conduz à menor accountability do governo perante seus jurisdicionados, havendo uma relação causal em que a maior execução tributária aumenta a demanda por responsabilização (accountability) do Poder Público. ${ }^{282}$ Então, "quando as rendas dos recursos naturais crescem, os líderes políticos abrandam o fardo da tributação nos cidadãos como meio de torná-los mais complacentes". ${ }^{283-284}$

ROSS, Michael L. The oil curse... cit., p. 31.

279 Idem, ibidem.

280 BORNHORST, Fabian; GUPTA, Sanjeev; THORNTON, John. Natural resource endowments, governance, and the domestic revenue effort: evidence from a panel of countries. IMF Working Paper, n. 08/170, 2008, p. 9.

281 Michael Ross (ROSS, Michael L. The oil curse cit.), por sua vez, aponta que os países produtores de petróleo são aproximadamente $30 \%$ menos dependentes da tributação de bens e serviços do que os países não produtores. Afirma, mais, que na média o setor petrolífero implica $19 \%$ da economia mas financia 54\% do Orçamento. p. 31.

282 McGUIRK, Eoin F. The illusory leader: natural resources, taxation and accountability. Institute for International Integration Studies Discussion Paper, n. 327, 2010.

283 Idem, ibidem, p. 17.

284 AUTY, Richard M. Natural resources, capital accumulation and the resource curse cit., p. 5: "Natural resources allow governments to win political support by capturing and distributing the rents, so they neglect wealth creation. In this way, a longer reliance on primary product exports engenders predatory political states rather than developmental ones. It also delays competitive industrialisation so that urbanisation is retarded, the demographic cycle is delayed and each worker must support more dependants. The rate of saving therefore increases more slowly than in resource-poor countries. 
Os autores acima citados destacam-se porque efetuaram pesquisas destinadas a comprovar especificamente que há uma relação (negativa) de causa e efeito entre a exploração dos recursos naturais não renováveis e a tributação dos demais setores da economia. McGuirk vai além para demonstrar que essa menor tributação provoca efeitos deletérios na relação entre o Estado e os cidadãos. Mas estão longe de ser os únicos a expor esse fenômeno. Asfaha, por exemplo, afirma que como os recursos entram diretamente nos cofres do Governo, há desincentivo para estabelecer sistemas e instituições robustos para arrecadação tributária (e diversificação da base produtiva), que é mais custosa tanto econômica quanto politicamente. E, como o Estado depende menos do cidadão, também se vê menos impelido a atender suas necessidades. ${ }^{285-286}$ Observa ainda que países ricos em recursos naturais comumente citados como aqueles que superaram a maldição (Noruega e

Meanwhile, the lag in labour-intensive manufactured exports causes surplus labour to persist in rural areas, while skills accumulate more slowly. This heightens income inequality and social tensions". Diz ainda Ross (ROSS, Michael L. The oil curse... cit., p. 31-33): "Governments find it bureaucratically easier and politically more popular to collect revenues from their oil sectors than to collect taxes from the population at large".

285 ASFAHA, Samuel G. National revenue funds: their efficacy for fiscal stability and inter-generational equity. International Institute for Sustainable Development, 2007. Disponível em: <http://ssrn.com/abstract=1032877>. Acesso em: 7 set. 2013, p. 10.

Dizem Jonathan Isham, Michael Woolcock, Lant Pritchett e Gwen Busby (ISHAM, Jonatham; WOOLCOCK, Michael; PRITCHETT, Lant; BUSBY, Gwen. The varieties of resource experience: how natural resource export structures affect the political economy of economic growth cit.): "the state has less need for taxation of the population, and without the pressure for taxation the state has less need to develop mechanisms of deep control of the citizenry. By the same token, citizens have less incentive to create mechanisms of accountability and develop the deep 'civil society' and horizontal social associations that many feel are the 'preconditions' of democracy”. Birdsall e Subramanian (BIRDSALL, Nancy; SUBRAMANIAN, Arvind. Saving Iraq from its oil cit.) afirmam que uma das diversas formas pelas quais o petróleo faz funcionar o seu "veneno" é: "The state is relieved of the pressure to tax and has no incentive to promote the protection of property rights as a way of creating wealth. As for the country's citizens, because they are not taxed, they have little incentive and no effective mechanism by which to hold government accountable. This can lead to the unchecked abuse of state power and undermine the process by which political systems reconcile conflicting interests and demands". p. 81. Van der Ploeg (VAN DER PLOEG, Frederick. Challenges and opportunities for resource rich economies cit., p. 49) aponta: "Resource rich countries should not spend their windfall profits and aim to maintain their revenues from income taxes in line with growth in national income, even though taxes may be difficult to collect, unpopular and distortionary. Slashing regular tax revenues tends to weaken the linkages between the government and its people". Para Humphreys (HUMPHREYS, Macartan. Natural resources, conflict, and conflict resolution... cit., p. 512), "State structures may be weaker in naturalresource dependent economies. There are two prominent variants of the argument, both of which focus on the strength of state-society linkages. One variant focuses on the society side of weak society-state relations and holds that when citizens are untaxed by governments, they have less power over them: they may have less information about government activity, weaker incentives to monitor government behavior, and fewer instruments at their disposal to withdraw support from governments; accordingly, resource-dependent states may have little compulsion to respond to the demands of their citizens or create structures that engage their citizens". 
Botsuana) adotam medidas voltadas diretamente ao tema, demandando a plena instituição e arrecadação dos tributos voltados aos setores não extrativos. ${ }^{287}$

Terry Lynn $\operatorname{Karl}^{288}$ aponta para a existência, nos gestores públicos desses países, do "alívio do fardo de tributar seus próprios eleitores", o que conduz à ausência da pressão social por uma Administração eficaz e transparente. Afinal,

conceder um direito é mais simpático que impor um dever. Quando se concede um direito, todos imaginam que estão compreendidos nele. Quando se impõe um dever, todos sabem quem está compreendido nele. Conceder um direito é uma forma de ganhar votos; impor deveres é uma forma de perdê-los. ${ }^{289}$

Karl segue no tema. Afirma que essa tendência - padrão de menor tributação dos setores desligados da indústria extrativa - é recorrente nos países dependentes das rendas de recursos minerais, representando um dos fatores que levam ao péssimo desempenho (não só econômico, mas político e social) de Venezuela, Irã, Nigéria e Argélia: "na medida em que o dinheiro do petróleo entrava nos cofres públicos de maneira sempre crescente, tornou-se politicamente mais e mais difícil de elevar a tributação doméstica" ${ }^{290}$ E prossegue, utilizando esse mesmo fator como relevante na explicação da razão pela qual a Indonésia saiu-se algo melhor ${ }^{291}$ e a Noruega saiu-se muito melhor. ${ }^{292}$ A autora põe o tema como significante para formação da "infeliz distância entre jurisdição e autoridade" 293 nesses países. Isto é: observando a relevância da tributação na formação dos Estados europeus, afirma que "nos petro-estados, essa ruptura do ciclo de construção do Estado foi especialmente aguda, em razão de padrões de tributação essencialmente diferentes uma vez que se tornaram exportadores". ${ }^{294}$ E coloca:

287 ASFAHA, Samuel G. National Revenue Funds: Their efficacy for fiscal stability and inter-generational equity. International Institute for Sustainable Development, 2007. Disponível em: <http://ssrn.com/abstract=1032877>. Acesso em: 7 set. 2013, p. 21-22.

288 Em: KARL, Terry Lynn. Ensuring fairness: the case for a transparent fiscal social contract. In: HUMPHREYS, Macartan; SACHS, Jeffrey D.; STIGLITZ, Joseph E. (Org.). Escaping the resource curse cit., p. 262. Tradução livre.

289 FARREL, Martin Diego. Filosofia del derecho y económia. Buenos Aires: La Ley, 2006. p. 15. Tradução livre.

290 KARL, Terry Lynn. The paradox of plenty... cit., p. 198-199.

291 Idem, ibidem, p. 211. "Rather the being totally permeated by rent seeking and institutional rigidity, its policy patterns were based on fiscal austerity and domestic taxation as well as monetary influx".

292 Idem, p. 220. "As corporate revenues from pretroleum shot up, it resisted the strong temptation to permit oil revenues to replace its normal revenue base by lowering taxes. Unlike all other exporters, it managed to sustain its domestic tax base, although it did suffer some erosion".

293 Idem, p. 58

294 Idem, p. 60. 
Essa pobre história de construção de Estado foi perpetuada no período pós-colonial. Dado seu fácil acesso ás receitas do petróleo, poucos governantes buscaram suplementar as rendas do Estado através de crescimento substancial na tributação doméstica. Em vez disso, eles cederam à tentação permanente de evitar decisões domésticas impopulares, tributando as companhias petrolíferas estrangeiras. Os tipos de resultados administrativos locais, que em outros países menos desenvolvidos asseguraram entradas tributárias e proveram o Estado de penetração no território nacional, foram negligenciados. Não foram sequer desenvolvidos no primeiro momento, ou, mesmo que tenham existido, restaram subsequentemente murchados. Governantse se tornaram adeptos da arte política em outra arena, entretanto, eventualmente demonstrando habilidades incomuns em monitorar, regular e promover a indústria petrolífera tanto no nível nacional como no internacional. Mas a alta estatalidade ${ }^{295}$ nessa arena ocorreu às custas, no longo prazo, de sua capacidade de construir burocracias extensivas, penetrantes e coerentes que pudessem formular e implementar políticas públicas com sucesso. ${ }^{296}$

Então, também na visão de Karl, a reduzida tributação do setor não extrativo compromete o desenvolvimento institucional, inclusive turvando a diferença entre o que é público do que é privado e seus reflexos no Erário (o que indica maior espaço para corrupção e comportamento rentista), e prejudicando os elos entre cidadãos e Estado. ${ }^{297}$

É de se recordar também que a menor tributação doméstica aumenta o grau de dependência do Estado diante da exploração mineral e aumenta os perigos da já mencionada volatilidade dos recursos minerais.

Collier põe a questão como fundamental para compreender os fracos sistemas de freios e contrapesos nos países que dependem da receita de exploração de riqueza mineral. E contraria as colocações de que esses países gastam demais: para ele, "os governos das economias petrolíferas não gastam mais, eles tributam menos". ${ }^{298}$

Martin Sandbu tenta adotar conceitos da "psicologia social da tributação" para observar o mesmo fenômeno. Também ele afirma que "os seres humanos são inclinados a se importar de forma muito mais forte com dinheiro que passou por suas mãos do que com dinheiro que eles simplesmente nunca veem". ${ }^{299}$ E desenvolve a ideia, a partir de três

295 Ou Estatidade. Do original "stateness", a referir o papel do Estado como protagonista na condução de assuntos de alta relevância.

296 KARL, Terry Lynn. The paradox of plenty... cit., p. 61. Tradução livre.

297 Idem, ibidem, p. 62.

298 COLLIER, Paul. Is aid oil? An analysis of whether Africa can absorb more aid. 2005. Disponível em: <http://economics.ouls.ox.ac.uk/11503/1/uuidbe263d06-c5a9-4e2e-a29c-16e80cdd7bc0-

ATTACHMENT01.pdf>. Acesso em: 14 set. 2013, p. 4. Tradução livre.

299 SANDBU, Martin E. Natural wealth accounts: a proposal for alleviating the natural resource curse. World Development, v. 34, n. 7, Elsevier, 2006, p. 1154. 
padrões de tomada de decisões individuais, ${ }^{300}$ para concluir que a "posse de uma quantia aumenta seu valor percebido pelo indivíduo", daí que os "pagamentos tributários são geralmente percebidos como um custo que pessoas têm que pagar tirando de seus ganhos, e então têm incentivos para responsabilizar o governo por como gasta o 'seu' dinheiro",301 em contraste com a riqueza oriunda dos recursos naturais, que mesmo se for desperdiçada ou roubada será "percebida como um ganho não realizado uma vez que nunca passou pelas mãos da população e então nunca foi auferido ou possuído". ${ }^{302}$

A questão também é revestida de grandes implicações a partir da ótica federalista. Isto é: assim como se alega que as receitas de recursos naturais conduzem a uma menor tributação, também é verdadeiro que os repasses intergovernamentais verticais causam efeito semelhante, acentuadamente incidente no caso da partilha de royalties. Daí que, como ressalta Gobetti, "os entes dependentes desses repasses podem não ter incentivos a explorar as bases tributárias sob sua competência", ${ }^{303}$ gerando resultados indesejados que Ahmad e Mottu reconhecem e põem no contexto da competição perniciosa entre entes federados, suscitando a ocorrência dos fenômenos econômicos "beggar-thyneighbor" e "race to the bottom". ${ }^{304-305}$ E então esses repasses federativos devem também incluir uma variável de "capacidade de arrecadação" ou "esforço de arrecadação", justamente visando combater os efeitos deletérios desse comodismo tributário (que pode

300 SANDBU, Martin E. Natural wealth accounts... cit., p. 1159-1160. São eles: [i] "Reference dependence. When evaluating monetary outcomes, people pay much more attention to changes in income levels than to those levels themselves"; [ii] "Loss aversion. Not only do people generally evaluate changes from a reference point, rather than levels, but the evaluation is also asymmetric. In general, 'losses loom larger than gains': a loss of a certain size is more hurtful than a gain of the same size which is beneficial, in terms of psychological satisfaction"; [iii] "Framing. The third relevant phenomenon is that the reference points on which people base their decisions are extremely labile and susceptible to manipulation by framing. The same change can be framed as a gain (if the frame involves a reference point that is worse) or as a loss (if the frame involves a reference point that is better). Behavior has been shown to depend dramatically on the triggered frame".

301 Idem, ibidem, p. 1160.

302 Idem.

303 GOBETTI, Sérgio Wulff. Federalismo fiscal e petróleo no Brasil e no mundo. IPEA, 2011. Texto para discussão n. 1669, p. 15.

304 AHMAD, Ehtisham; MOTTU, Eric. Oil revenue assignments: country experiences and issues. In: DAVIS, J.; OSSOWSKI, R.; FEDELINO, A. (Org.). Fiscal policy formulation and implementation in oil-producing countries cit., p. 3 e 12. Os Autores afirmam, por exemplo, que o não exercício da capacidade tributária dos entes federados, ligado diretamente à partilha da receita de recursos naturais, pode ser vista na Colômbia. p. 14.

305 Também enfatizando esse aspecto de competição: BROSIO, Giorgio. Oil revenue and fiscal federalism. In: DAVIS, J.; OSSOWSKI, R.; FEDELINO, A. (Org.). Fiscal policy formulation and implementation in oil-producing countries cit., p. 251. 
ser também comissivo, visando deliberadamente enfraquecer os laços de cobrança entre cidadãos e governantes). ${ }^{306}$

Vale notar que, embora a relação entre tributação e accountability seja frequente e sólida na literatura, ela não passa sem críticas - Michael Herb, por exemplo, sugere que os cidadãos têm "muitas razões para querem que seus governantes sejam responsabilizados, mesmo se não forem tributados". ${ }^{307}$ Michael Ross concorda com essa afirmação, mas mantém as conclusões anteriores. Isto é: afirma que os cidadãos dos países que exploram recursos minerais sabem da elevada receita pública daí oriunda e se importam com ela - e não só com a tributação a que estão submetidos. Logo, não haveria, aí, uma razão para menor accountability.

Contudo, para Ross o cerne está na característica peculiar da receita de recursos naturais não renováveis, que é a sua falta de transparência - diferente da receita tributária que é melhor conhecida porque, afinal, sai das carteiras dos cidadãos. Eis que as informações referentes a essa receita de recursos minerais não são bem conhecidas, a população tem uma percepção equivocada do volume dessas receitas, e consequentemente da razão entre gasto público que veem nas ruas e a receita pública ${ }^{308}$ - esta razão, segundo o Autor, é a de maior interesse da população. Logo, “como os cidadãos podem observar a receita tributária mas não a do petróleo, autocratas em países produtores de petróleo podem elevar sua popularidade escondendo uma porção das receitas de petróleo do público". ${ }^{309}$ Segundo defende Ross, assim é que haveria menos cobrança direcionada aos governantes: manipulando as informações para parecer, segundo os critérios racionais de avaliação dos cidadãos (receita x despesa), que o governo atua melhor do que efetivamente o faz (os

306 GOBETTI, Sérgio Wulff. Federalismo fiscal e petróleo no Brasil e no mundo cit., p. 15. Escreve: “a literatura de federalismo fiscal sugere que os sistemas de equalização fiscal entre os entes da federação se baseiem não nas receitas efetivamente obtidas por cada governo, mas nas capacidades de arrecadação, que diferem pelo nível de esforço ou eficiência de cada um. Isso significa que, se um determinado governo relaxar na sua arrecadação própria, ele não será beneficiado por isso, bem como também não será punido caso consiga aperfeiçoar sua eficiência".

307 HERB, Michael. All in the family: absolutism, revolution and democracy in the middle eastern monarchies. Albany: State University of New York Press, 1999. p. 256-59 apud HERB, Michael. No representation without taxation? Rents, development, and democracy. Comparative Politics, v. 37, n. 3, abr. 2005.

308 ROSS, Michael L. The oil curse... cit., p. 71.

309 Idem, ibidem. 
cidadãos não deixam de cobrar melhores ações do governo porque não têm interesse em fazê-lo; mas porque entendem, ainda que constrangidos por falsa percepção, que os resultados são bons).

Independente das razões para tanto, contudo, é seguro afirmar que é frequente o fenômeno de redução da tributação nos países (ou entes subnacionais) onde se dá vasta exploração de recursos naturais não renováveis. Como se verá adiante - buscando identificar a institucionalidade brasileira -, trata-se de prática deletéria, que pode e deve ser endereçada para evitar seus efeitos nocivos. 


\section{A PERSPECTIVA INTERGERACIONAL}

2. A perspectiva intergeracional.

a. Recursos naturais não renováveis, finitude, e as gerações futuras: um elo necessário. A finitude como elemento intrínseco e inafastável da exploração e que se reflete na receita pública decorrente

b. Por quê vincular royalties de recursos naturais não renováveis à ideia de equidade intergeracional

i. Explorar para quê? Uma breve menção ao pensamento furtadiano

ii. Economia dos Recursos Naturais: Hotelling, Solow, Hartwick

iii. A Filosofia política de John Rawls e o problema da justiça entre gerações

1. Aspectos fundamentais da justiça como equidade;

2. A justiça entre gerações em Rawls;

c. O quêe é equidade intergeracional: o que devemos às gerações futuras?

d. Equidade intergeracional, estrutura constitucional e representação;

e. Equidade intergeracional, finanças públicas e direit financeiro.

\section{A perspectiva intergeracional}

2.a. Recursos naturais não renováveis e as gerações ${ }^{310}$ futuras: ${ }^{311}$ um elo necessário. A finitude como elemento intrínseco e inafastável da exploração e que se reflete na receita pública decorrente.

310 “The term 'generation' is to be understood anthropologically”. HÄBERLE, Peter. A constitutional law for future generations - the 'other' form of the social contract: the generation contract. In: TREMMEL, Joerg (Ed.). Handbook of intergenerational justice. Cheltenham, UK: Edward Elgar, 2006. p. 221.

311 Para clareza metodológica, utilize-se o conceito de "geração" de Joerg Tremmel (TREMMEL, Joerg. A theory of intergenerational justice. London: Earthscan, 2009. p. 24): "In this book, a generation is referred to as a 'future generation' if none of its members is alive at the time the reference is made". Para uma outra perspectiva sobre o conceito de geração, v. ROCHA, Joaquim Freitas da. Breves reflexões sobre responsabilidade colectiva e finanças públicas. In: ROCHA, Joaquim Freitas da (Coord.). Anuário publicista da Escola de Direito da Universidade do Minho - Responsabilidade e cidadania. Braga: Universidade do Minho, 2012. t. I, ano 2012, p. 133. O autor concorda com Tremmel, na Nota acima, em que o conceito pode ser apenas entendido a partir de um determinado ponto de referência temporal, não se podendo tratar de duas pessoas em uma e outra geração em termos absolutos. Discorda de Tremmel, contudo, no que distingue não apenas as pessoas viventes e as por viver; mas, entre as viventes, distingue entre as maiores e as menores de idade. Afirma: "Importa começar por salientar que o próprio conceito de geração se apresenta de um modo inevitavelmente convencional, no sentido de se revelar um conceito útil apenas no contexto em que está a ser utilizado, não sendo possível um conceito analítico, preciso e determinado 10. Como já foi várias vezes salientado, as pessoas pertencentes a um grupo não nascem nem morrem ao mesmo tempo, além de que podem não desenvolver um sentimento de pertença que as faça sentir como parte de uma mesma geração. Em todo o caso, para os presentes propósitos e de um modo simples, entender-se-á por geração o conjunto amplo de pessoas nascidas num mesmo lapso temporal que outras, de modo a que se possa distinguir os que já não vivem (gerações passadas), os 
Já se referiu acima que a finitude é caráter intrínseco, definidor dos recursos naturais não renováveis. Não se desconhece que essa afirmação é redundante, um pleonasmo (afinal, dizer-se que os recursos são não renováveis já destaca sua finitude). Mas o reforço se reputa devido para os fins dessa dissertação, considerando a pouca atenção que vem sendo devotada ao tema.

Boadway e Keen ressaltam essa característica, indicando ser a finitude aquilo que é único, por definição, à produção potencial desses recursos naturais, pelo que "mais extração agora significa menos potencial extração depois". ${ }^{312}$ Postali indica que "a noção de renda mineral apresenta especificidades que merecem uma atenção especial, já que sua natureza está ligada, basicamente, à exauribilidade de sua fonte geradora". 313-314

maiores que vivem (geração presente), e os menores que vivem e os que ainda nascerão (geração e gerações futuras)".

312 BOADWAY, Robin; KEEN, Michael. Theoretical perspectives on resource tax design. In: DANIEL, Philip; KEEN, Michael; McPHERSON, Charles (Ed.). The taxation of petroleum and minerals cit., $\mathrm{p}$. 14. Tradução livre.

313 POSTALI, Fernando Antonio Slaibe. Renda mineral, divisão de riscos e benefícios governamentais na exploração de petróleo no Brasil. Rio de Janeiro: BNDES, 2002. p. 20-21. O autor escreve da perspectiva econômica, revisando a fundo a literatura do tema. Dentre os doutrinadores revisitados, vale mencionar por ora a crítica da Cairns, que "critica a noção de exauribilidade [...] não apenas pelo fato de a humanidade nunca ter se deparado com uma situação dessas, mas também porque o estoque de reservas minerais disponíveis na natureza não é propriamente uma variável exógena, pois ele também depende de descobertas resultantes de decisões de investimento em pesquisa". Prossegue, contudo: "A despeito da crítica de Cairns, a teoria econômica atribui à limitação física do recurso a emergência de um dos componentes de sua renda. A ideia de que a extração presente impossibilita que gerações futuras usufruam dos benefícios do recurso traz à tona questões de justiça intergeracional e eqüidade, no sentido de se perguntar o que deve ser feito com a renda de Hotelling obtida pelo proprietário do recurso, para não prejudicar os futuros consumidores".

314 Interessante a crítica ao conceito de finitude de Hochstetler (HOCHSTETLER, Richard Lee. Recursos naturais e o mercado: três ensaios. 2002. Tese (Doutorado) - Departamento de Economia da Faculdade de Economia e Administração da Universidade de São Paulo. São Paulo. p. 20): “A literatura econômica geralmente trata os recursos naturais dividindo-os em duas classes: recursos renováveis e recursos exauríveis. Neste modelo opta-se por não dividir os recursos naturais nessas duas categorias porque reconhece-se que há uma substitutibilidade relativamente alta entre essas duas classes de recursos naturais no seu uso final. Além disso, os recursos normalmente classificados como exauríveis podem ser renováveis na medida que são reutilizados ou reciclados [...] A diferenciação relevante é a de como os recursos naturais são utilizados, ou seja, a diferenciação relevante não é entre os recursos naturais e sim a tecnologia empregada". No mesmo sentido, ver as ponderações de Frankel (FRANKEL, Jeffrey. The natural resource curse cit., p. 9-10): "As Sheik Ahmed Zaki Yamani, the former Saudi oil minister, famously said, 'The Stone Age came to an end not for a lack of stones and the oil age will end, but not for a lack of oil.' Malthusians do not pay enough attention to the tendency for technological progress to ride to the rescue. On the other hand, the fact that the Malthusian forecast has repeatedly been proven false in the past does not in itself imply the Panglossian forecast that this will always happen in the future. One must seek, rather, a broad perspective in which all relevant reasoning and evidence are brought to bear in the balance". Nada obstante, entendemos que a crítica, mesmo que tomada como acertada, não prejudica as premissas que se está tentando firmar, já que a diferenciação quanto à tecnologia não infirma que a finitude dos recursos naturais não renováveis é certa e definidora desses bens, mas apenas conduz a hipóteses diferentes do quão finitos são esses recursos e de qual seu impacto econômico. Principalmente quanto ao eixo central que se pretende analisar (o reflexo dessa finitude nas receitas públicas), em contraste com a razão básica da crítica (reutilização e reciclagem), entendemos que uma e outra ideias não são conflitantes. 
Nada obstante, a ênfase que ora se propõe não está na decisão de extrair ou não, ou quanto extrair, ${ }^{315}$ mas na decisão de como consumir ${ }^{316-317}$ esses recursos e, especialmente, a receita pública que advém da extração. É dizer: entende-se perfeitamente lícita e válida a decisão de simplesmente não explorar os bens (entesourar), por ora, se assim se entender melhor política, econômica e socialmente. ${ }^{318-319}$ As razões que ora enfrentamos, contudo, não dirigem esta questão (explorar ou não; quanto explorar) senão deveras marginalmente (e ocasionalmente).

Interessa-nos, pois, abordar a questão de que os recursos naturais em comento são finitos, exauríveis - e a certeza de que o são atrai essa característica básica para dentro dos debates sobre exploração e, principalmente, consumo, tornando-se item relevante na interpretação das normas relacionadas e das opções políticas e/ou econômicas disponíveis ao Estado.

Stiglitz, Humphreys e Sachs, como já mencionado, destacam a não renovabilidade dos minérios e do petróleo como sua característica essencial, a diferenciar essa riqueza de outras, especialmente quando se traduz em receita pública. Afirmam, então, que, de uma visão econômica, são "menos como uma fonte de renda e mais como um

315 Embora este - verificação dos níveis ótimos de extração, ou até mesmo a decisão por não extrair também seja um tema de interesse, que pode vir a ser tratado em outra oportunidade.

316 É de se registrar também, em respeito ao recorte metodológico e às limitações deste trabalho, que o termo consumo não é utilizado seguindo rigorosas definições econômicas, mas de forma lata.

317 Para uma análise sobre os níveis atuais de consumo - que, contudo, se refere aos recursos naturais em geral, não só aos não renováveis - e os critérios para avaliar se são ou não excessivos, ver: ARROW, Kenneth; DASGUPTA, Partha; GOULDER, Lawrence; DAILY, Gretchen; EHRLICH, Paul; HEAL, Geoffrey; LEVIN, Simon; MÄLER, Karl-Göran; SCHNEIDER, Stephen; STARRETT, David; WALKER, Brian. Are we consuming too much? cit., p. 151. Sobre o consumo dos recursos minerais, afirmam: "Even if some resources such as stocks of minerals are drawn down along a consumption path, the sustainability criterion could nevertheless be satisfied if other capital assets were accumulated sufficiently to offset the resource decline". Os autores concluem pela existência de evidências de que o consume atual é, sim, excessivo, embora façam ressalvas quanto às variáveis que podem levar a conclusões opostas.

318 Como destacam Stiglitz, Humphreys e Sachs (HUMPHREYS, Macartan; SACHS, Jeffrey D.; STIGLITZ, Joseph E. Introduction: What is the problem with natural resource wealth? In: HUMPHREYS, Macartan; SACHS, Jeffrey D.; STIGLITZ, Joseph E. (Org.). Escaping the resource curse cit., p. 15): "We assume in particular that governments are willing to take sometimes bold and difficult steps to try to succeed where most states have failed. If states are unable or unwilling to take such steps, then the best solution may well be to leave the oil and gas in the ground. The fact is that oil in the ground is a nonwasting asset. Although leaving oil in the ground means that interest is forgone, the ground just might be the safest place for the asset, especially if there exists the risk that governments may use revenue for their purposes rather than for the god of society, as has happened so often already".

319 Em sentido contrário, cético quanto às vantagens de manter os minérios nas jazidas: HEAL, Geoffrey. Are oil producers rich?. In: HUMPHREYS, Macartan; SACHS, Jeffrey D.; STIGLITZ, Joseph E. (Org.). Escaping the resource curse cit., p. 157. Para ele, "oil in the ground earns no income and contributes nothing to welfare, however envious the rest of the world may be of this asset. Envy, however, does not pay interest, whereas money in an investment fund does, so it clearly pays (from a financial point of view) to turn oil in the ground into money in a bank account". 
ativo". ${ }^{320}$ Daí que "devem ser empregados padrões nacionais de contabilidade que reflitam corretamente a real economia da produção de petróleo e gás, registrando simultaneamente os ganhos e o esgotamento dos recursos". ${ }^{321}$ Sachs destaca que, por causa dessa característica intrínseca, "o fluxo das rendas petrolíferas é na verdade a conversão de capital natural em capital financeiro, e daí ao consumo ou a outras formas de capital como capital humano ou capital físico reprodutível”. ${ }^{322-323}$

É precisamente esse o ponto destacado por Geoffrey Heal. ${ }^{324}$ Arguindo que a renda derivada de recursos naturais não renováveis, precisamente por ser exaurível, é deveras diferente daquela oriunda de outras fontes no que concerne à riqueza fundamental de uma nação, ${ }^{325} \mathrm{o}$ autor se dirige à sustentabilidade ${ }^{326}$ econômico-financeira do país rico em recursos minerais - insustentabilidade quando dependente de uma renda marcadamente finita. ${ }^{327}$ Ataca as medições mais utilizadas de renda ou riqueza de um país (como as medidas segundo o PIB), quando deixam de observar esse fator determinante: a redução do

320 HUMPHREYS, Macartan; SACHS, Jeffrey D.; STIGLITZ, Joseph E. Introduction: What is the problem with natural resource wealth?. In: HUMPHREYS, Macartan; SACHS, Jeffrey D.; STIGLITZ, Joseph E. (Org.). Escaping the resource curse cit., p. 4.

321 HUMPHREYS, Macartan; SACHS, Jeffrey D.; STIGLITZ, Joseph E. Future Directions for the Management os Natural Resources. In: HUMPHREYS, Macartan; SACHS, Jeffrey D.; STIGLITZ, Joseph E. (Org.). Escaping the resource curse cit., p. 325.

322 SACHS, Jeffrey D. How to handle the macroeconomics of oil wealth. In: HUMPHREYS, Macartan; SACHS, Jeffrey D.; STIGLITZ, Joseph E. (Org.). Escaping the resource curse cit., p. 180.

323 No mesmo sentido, aponta Paulo Springer de Freitas (FREITAS, Paulo Springer de. Rendas do petróleo: questão federativa e instituição de Fundo Soberano. Artigo apresentado no IV Fórum Senado Debate Brasil. Nova fronteira do petróleo: os desafios do pré-sal. Brasília, 3 e 4 de dezembro de 2008, p. 37): “a extração do petróleo nada mais representa do que uma troca de ativos: o ativo que estava depositado no subsolo, na forma de óleo cru, transformou-se em ativo financeiro, por meio do pagamento das participações governamentais. Portanto, o patrimônio do setor público não se altera quando o governo passa a receber receitas oriundas da exploração do petróleo. E o impacto final sobre esse patrimônio dependerá da forma como os recursos serão gastos. Se o forem com despesas correntes (que representam consumo e não criam instrumentos de geração de riqueza futura), o patrimônio público irá se reduzir ao longo do tempo. Já se o governo investir os recursos oriundos do petróleo, então sua situação patrimonial, em princípio, não irá se alterar".

324 HEAL, Geoffrey. Are Oil Producers Rich?. In: HUMPHREYS, Macartan; SACHS, Jeffrey D.; STIGLITZ, Joseph E. (Org.). Escaping the resource curse cit.

325 Idem, ibidem, p. 156.

326 Kenneth Arrow, o já mencionado Geoffrey Heal, Partha Dasgupta, entre outros que assinam obra coletiva (ARROW, Kenneth; DASGUPTA, Partha; GOULDER, Lawrence; DAILY, Gretchen; EHRLICH, Paul; HEAL, Geoffrey; LEVIN, Simon; MÄLER, Karl-Göran; SCHNEIDER, Stephen; STARRETT, David; WALKER, Brian. Are we consuming too much? cit., p. 150), utilizam definição de "desenvolvimento sustentável" como "desenvolvimento que atende às necessidades da presente geração sem comprometer a habilidade das futuras gerações para atender suas próprias necessidades". No citado artigo, utilizam "sustentabilidade" para significar que o "bem-estar social intertemporal deve não ser reduzido com o tempo". Tradução livre.

327 HEAL, Geoffrey. Are Oil Producers Rich?. In: HUMPHREYS, Macartan; SACHS, Jeffrey D.; STIGLITZ, Joseph E. (Org.). Escaping the resource curse cit., p. 157. 
patrimônio natural, ${ }^{328}$ e sua contrapartida sustentável: a construção de outras formas de capital. $^{329-330}$ Essas medições criticadas, então, superestimam estatísticas e até mesmo uma análise que assim não perceba pode ser utilizada para explicar parte dos efeitos deletérios da exploração. ${ }^{331-332}$ A conclusão principal de Heal diz respeito à relevância dos mercados

328 Idem, ibidem, p. 165: "resource depletion must be deducted from national income. This is not conventionally done and, as a result, national income figures are too high and the growth of national income is overstated".

329 Idem, ibidem, p. 170: “A proper measure of income allows for resource depletion. Conventional measures of investment will greatly overstate the real investment rate in resource-based economies. And a measure of the sustainability of welfare is based on the value of the changes in all forms of capital, natural and other".

330 Estudo do Banco Mundial (WORLD BANK. Where is the wealth of nations? Measuring capital for the $21^{\text {st }}$ century. Washington DC: World Bank, 2006.) segue no mesmo sentido, defendendo a adoção do critério de medição batizado de Genuine Savigns. Afirma: "Genuine saving provides a much broader indicator of sustainability by valuing changes in natural resources, environmental quality, and human capital, in addition to the traditional measure of changes in produced assets provided by net saving. Negative genuine saving rates imply that total wealth is in decline; policies leading to persistently negative genuine saving are unsustainable. In addition to serving as an indicator of sustainability, genuine saving has the advantage of presenting resource and environmental issues within a framework that finance and development planning ministries can understand. It makes the growth-environment trade-off explicit, since those countries pursuing economic growth today, at the expense of natural resources, will be notable by their depressed rates of genuine saving. Of the 140 countries where genuine saving is estimated for 2003, just over 30 have negative saving rates. [...] Genuine saving provides an indicator of sustainability”. p. 35-36 e 46. Por sua vez, Auty (AUTY, Richard M. Natural resources, capital accumulation and the resource curse cit., p. 9 e 11) igualmente critica as medições tradicionais, advogando o uso de uma "Contabilidade do meio ambiente e recursos naturais" (tradução livre): "environmental and natural resource accounting (EARA) can also help by providing a rationale for sustainable deployment of the mineral rents. EARA recognises that the GNP identity of the standard national accounts (SNA) overstates investment and output because each year some produced (manmade) capital is scrapped (depreciated) [...] The key policy implication from EARA is that many resource-rich governments need to shift resources away from consumption and towards investment to competitively diversify the economy away from reliance on the consumption of finite natural resources". Neil Buchanan (BUCHANAN, Neil H. What kind of environment do we owe future generations?. Lewis \& Clark Law Review, v. 15, n. 2, 2011) é outro que critica a análise do tema fundada em verificações do PIB. Para ele, há evidentes insuficiências na verificação do Produto Interno Bruto para tomar quaisquer decisões que digam respeito ao binômio exploração x preservação (p. 356-357). Não advoga que seja abandonado o uso do PIB, mas apenas que este seja utilizado apenas para referir aquilo que, efetivamente, mede (o tamanho da economia), e não usado para medir o que, evidentemente, não mede (felicidade humana ou bem-estar humano).

331 No tema da sustentabilidade econômico-financeira e orçamentária e sua medição, vale mencionar a contribuição trazida por Alan Auerbach, Jagadeesh Gokhale e Laurence J. Kotlikoff. Os autores, criticando a multiplicidade de conceitos e métodos utilizados pelo Poder Executivo Federal estadunidense, propuseram um sistema de medição que demonstrasse efetivamente o déficit passado às gerações futuras. O sistema por eles desenvolvido, que veio a se tornar deveras influente, foi chamado de Generational Accounting, e é assim descrito em linhas gerais: "Generational accounts indicate, in present value, what the typical member of each generation can expect to pay, now and in the future, in net taxes (taxes paid net of transfer payments received). Generational accounting indicates not only what existing generations will pay, but also what future generations must pay, given current policy and the government's intertemporal budget constraint. This constraint requires that those government bills not paid by current generations must ultimately be paid by future generations" (AUERBACH, Alan J.; GOKHALE, Jagadeesh; KOTLIKOFF, Laurence J. Generational accounting: a meaningful way to evaluate fiscal policy. The Journal of Economic Perspectives, v. 8, n. 1, 1994, p. 75).

332 No mesmo sentido da nota anterior, vale mencionar a posição de Daniel Shaviro, que se dirige à "fenda fiscal" revelada pela contabilidade de Auerbach, Gokhale e Kotlikoff. O autor pretende se posicionar sobre qual o tratamento a ser dado ao tema, especialmente questionando se as razões de justiça intergeracional demandam que seu país aumente a tributação atual, para não sobrecarregar as gerações 
de capitais nessa equação: o investimento da receita derivada dos recursos naturais não renováveis permite alterar o perfil da renda ("transformação de ativos não rentáveis em ativos rentáveis", ${ }^{333}$ podendo convertê-la "em um estoque de riqueza de outro tipo, que gera renda e pode em princípio ser preservada indefinidamente" ${ }^{334}$ ), tornando-a sustentável trazendo "um nível positivo de consumo que pode ser mantido indefinidamente". ${ }^{335}$ Assim, “apesar de a base física da receita permanecer inalterada, seu potencial de bem-estar é aumentado". ${ }^{336}$ Daí que a desconsideração da intrínseca finitude desses recursos naturais, direcionando a receita deles decorrente ao consumo é "desperdício de capitais", 337 é "como aumentar a renda familiar pela venda da prataria da família: isso não pode durar e é em verdade uma forma de alienar seus ativos - não uma fonte de renda". ${ }^{338-339}$

Quer-se destacar, pois, que todo e qualquer regramento a respeito do tema deve necessariamente abordar essa característica e dirigir-se às suas consequências. ${ }^{340}$

E, ao assim fazer, emerge intuitiva a preocupação com as consequências a serem arcadas pelas futuras gerações. ${ }^{341-342}$

futuras. Utiliza, para fundamentar suas razões, uma perspectiva marcada e confessadamente utilitarista direta. Suas conclusões são de que os EUA deveriam iniciar imediata e progressivamente a fechadura da "fenda", com aumento de tributação. Contudo, sua conclusão é fundada em razões de eficiência econômica, e não de equidade intergeracional. SHAVIRO, Daniel. The long-term U.S. Fiscal gap: is the main problem generational inequity?. George Washington Law Review, v. 76, 2008, p. 1327. HEAL, Geoffrey. Are Oil Producers Rich?. In: HUMPHREYS, Macartan; SACHS, Jeffrey D.; STIGLITZ, Joseph E. (Org.). Escaping the resource curse cit., p. 161.

334 Idem, ibidem, p. 165.

335 Idem, p. 163.

336 Idem, p. 161.

337 BERCOVICI, Gilberto. Direito econômico do petróleo e dos recursos minerais cit., p. 338.

338 HEAL, Geoffrey. Are Oil Producers Rich?. In: HUMPHREYS, Macartan; SACHS, Jeffrey D.; STIGLITZ, Joseph E. (Org.). Escaping the resource curse cit., p. 170.

339 VAN DER PLOEG, Frederick. Challenges and opportunities for resource rich economies cit., p. 39: "consuming rents from exhaustible resources is literally consuming capital".

340 "The design of the fiscal framework should be guided by an assessment of long-term fiscal sustainability-i.e., whether a government can sustain current spending, tax, and other policies in the long run without threatening its solvency or defaulting on its liabilities or promised expenditures. In the case of resource-rich countries, such an assessment needs to take into account the exhaustibility of the resource revenue" (BAUNSGAARD, Thomas; VILLAFUERTE, Mauricio; POPLAWSKI-RIBEIRO, Marcos; RICHMOND, Christine. Fiscal frameworks for resource rich developing countries cit., p. 8).

341 "Future generations need to be protected because they are in a disadvantaged position with respect to the present generation which has the power to affect badly their quality of life by overpopulating the earth, by spoiling the delicate balance of the biosphere, by storing nuclear waste which are disastrous to the genetic heritage of posterity, by depleting the earth's natural resources and by using genetic engeneering to affect the unity of the human species. They are disadvantaged because they are 'downstream' in time from us and thus subject to the long-term consequences of our actions. Even their very existence is threatened! The scope of their choices is restricted by decisions taken by their predecessors. Moreover, future generations are inherently disadvantaged since they are 'mute', having no representatives among the present generation, and so their interests are often neglected in present socio-economic and political planning. They cannot plead or bargain for equal treatment since they have no voice and nothing they do 
Essa intuição é fundamentada. A utilização dos recursos naturais não renováveis hoje, por definição, importa na impossibilidade de sua utilização futuramente.

Daí se faz presente a questão: é lícito e justo que a geração atual aproveite dos bônus oriundos dessa exploração em detrimento de outros? É imperiosa a observação dos interesses das futuras gerações? Devemos algo a elas? Da mesma forma, é esperado que as gerações atuais se perguntem se as gerações passadas assim agiram.

De outro lado, se se concluir que devemos observar seus interesses, isso implica vedação de exploração dos recursos naturais não renováveis? Se devemos algo, o que devemos? Como observar seus interesses de maneira eficaz e suficiente ${ }^{343}$

Vale notar que a questão que ora se põe não se vincula, necessariamente, com a existência ou não, futuramente, do próprio bem mineral. Diz respeito também - e principalmente, no que cabe a esta dissertação - à governança da receita pública oriunda da exploração desses bens.

Não se trata tão somente de observar direitos individuais. O tema é relevante do ponto de vista do Direito Financeiro e das finanças públicas: a governança das receitas públicas que derivam da exploração ditará se as gerações futuras estão ou não incluídas nos proveitos da atividade, ou se seus interesses foram desprezados em prol de um uso insustentável pelas gerações presentes; é como ponderam Fernando Facury Scaff e Francisco Sérgio Rocha, para quem a equidade intergeracional surge como "nova compreensão dos direitos fundamentais", a impor limites à atividade financeira do Estado. ${ }^{344} \mathrm{O}$ tema é importante também em um viés econômico-institucional: como já

will affect the present generation" (AGIUS, Emmanuel. Intergenerational justice. In: TREMMEL, Joerg (Ed.). Handbook of intergenerational justice cit., p. 319).

342 "In that fundamental way, all generations are the product of the decisions of those who preceded them. At any moment, a choice can be made in the belief that its consequences will not be so momentous as to affect future generations significantly; but the distinction is a matter of degree. We know that decisions today will change the future, even if we do not yet know the form or extent of those effects". BUCHANAN, Neil H. What kind of environment do we owe future generations? cit., p. 343.

343 "Making such choices involves comparing costs and benefits [...]. There is no intrinsically right answer to any question involving choices" (BUCHANAN, Neil $\mathrm{H}$. What kind of environment do we owe future generations? cit., p. 353).

344 "A dimensão da pessoa humana é projetada no futuro, não apenas como a dimensão civilista do nascituro, mas de toda uma futura (e ainda nem mesmo gestada) geração de pessoas humanas [...] $\mathrm{O}$ interesse protegido não é o da atual geração, mas sua preservação para as futuras gerações. Não é mais um interesse do indivíduo contra o Estado, ou inerente apenas a certa coletividade, mas um interesse difuso e que abrange não apenas as atuais, mas as futuras gerações. É esta nova dimensão dos direitos fundamentais que deve estar presente em nossa mente ao interpretar a norma do equilíbrio orçamentário como um instrumento de sustentabilidade financeira e não como uma equação contábil-matemática. Não se pode deixar o direito das futuras gerações ser violado pelo jogo político do aqui e agora, das lutas políticas do presente" (SCAFF, Fernando Facury; ROCHA, Francisco Sérgio Silva. Equilíbrio 
referido, os recursos naturais não renováveis, por sua inequívoca relevância ${ }^{345}$ mundial, e nada obstante sua exploração ser recheada de "armadilhas" (representadas nos efeitos deletérios que se tentou acima revisar), representam ativos valorosos, capazes de ajudar substancialmente no crescimento ou estabilização da economia de uma nação - daí que o tema não pode ser visto apenas na perspectiva interrupta e rival (conflito entre a geração que se encerra e outras que começam sucessivamente), mas também de modo unitário e sequencial (da nação que, independente das sucessivas gerações de cidadãos, busca sempre prover melhor desempenho social aos seus, ininterruptamente). Como acertadamente colocado pelo ex-Ministro do Supremo Tribunal Federal Ayres Britto, os recursos minerais, "são da Nação, esta enquanto realidade atemporal, incorporando, a um só tempo, a ancestralidade, a contemporaneidade e a posteridade". 346

Então, a característica intrínseca de finitude dos recursos naturais não renováveis remete à consideração dos interesses das futuras gerações. ${ }^{347}$

Assim é que Barnett e Ossowski apontam que "a finitude do petróleo levanta questões complexas de sustentabilidade e alocação intergeracional dos recursos", ${ }^{348}$ acrescendo que "o desafio de longo prazo para a política fiscal é decidir como alocar a riqueza estatal (incluindo a riqueza petrolífera) entre gerações", ${ }^{349}$ o que reflete "preocupações quanto à equidade intergeracional, que devem ser atendidas mirando uma política fiscal que preserve a riqueza estatal". ${ }^{350-351}$ Os mesmos Barnett e Ossowski, em

orçamentário e sustentabilidade financeira: anotações sobre o Brasil. Revista dos Tribunais, v. 925, São Paulo: RT, nov. 2012).

345 BERCOVICI, Gilberto. Direito econômico do petróleo e dos recursos minerais cit., p. 234: "o controle estatal sobre as fontes de energia consiste em um eixo central de um projeto democrático em que a política macroeconômica esteja a serviço dos interesses nacionais, além de poder propiciar um planejamento energético de logo prazo".

346 ADI 3273, rel. Min. Carlos Britto, rel. p/ Ac Min. Eros Grau, Tribunal Pleno, j. 16.03.2005, DJ 02.03.2007, p. 141.

347 Engel e Valdés trazem a correlação entre finitude e futuras gerações de forma bem simples e direta: "since oil wealth is exhaustible, intergenerational equity considerations must also be taken into account". ENGEL, Eduardo; VALDÉS, Rodrigo. Optimal fiscal strategy for oil exporting countries. IMF Working Paper, n. 00/118, 2000, p. 4.

348 BARNETT, Steven; OSSOWSKI, Rolando. Operational aspects of fiscal policy in oil-producing countries. In: DAVIS, J.; OSSOWSKI, R.; FEDELINO, A. (Org.). Fiscal policy formulation and implementation in oil-producing countries. Washington, D.C.: International Monetary Fund, 2003. p. 45.

349 Idem, ibidem, p. 47.

350 Idem.

351 O texto de Bresser-Pereira, já citado (BRESSER-PEREIRA, Luiz Carlos. Doença holandesa e sua neutralização: uma abordagem ricardiana. In: BRESSER-PEREIRA, Luiz Carlos (Org.). Doença holandesa e indústria cit., p. 135), que se dirige basicamente à doença holandesa, argumenta que neutralizada esta, "as duas taxas de câmbio de equilíbrio passam a ser razoavelmente iguais. O país estará vivendo o seu dia a dia como qualquer outro país e estará usando suas rendas ricardianas para constituir um fundo no exterior que lhe renderá benefícios futuros". 
outro texto, que escrevem com Davis e Daniel, apresentam o argumento intuitivo acima referido da seguinte forma: "se toda a receita de recursos naturais não renováveis fosse consumida, isso deixaria menos riqueza e menos oportunidades de consumo para as futuras gerações. Isto seria, em geral, considerado como indesejável nas bases da equidade intergeracional". ${ }^{352-353}$ As futuras gerações, note-se, podem ser atendidas não apenas com a manutenção da substância mineral inexplorada; mas, especialmente, pela manutenção/criação/desenvolvimento de fontes de renda, antes inexistentes, a partir do impacto inicial trazido pela exploração dos recursos minerais.

É nesse mesmo sentido que caminham os ensinamentos de Celso Furtado, para quem as "sociedades que vivem da renda auferida sobre um patrimônio que receberam como dádiva" "não vivem do próprio trabalho, de hoje ou do passado. Nasceram sobre uma mina de ouro. Quanto mais alto o nível de vida das gerações presentes, maiores problemas deverão enfrentar as futuras quando começar a esgotar-se o tesouro que receberam". 354

Então, com Sachs, deve-se sustentar que "há um forte argumento contra a transferência de recursos esgotáveis somente às gerações atuais, em vez de distribuir os benefícios entre gerações presentes e futuras". ${ }^{355-356}$

352 DAVIS, Jeffrey; OSSOWSKI, Rolando; DANIEL, James A.; BARNETT, Steven. Stabilization and savings funds for nonrenewable resources: experience and fiscal policy implications. In: DAVIS, J.; OSSOWSKI, R.; FEDELINO, A. (Org.). Fiscal policy formulation and implementation in oil-producing countries cit., 2003. p. 277.

353 COLLIER, Paul; VAN DER PLOEG, Frederick; VENABLES, Anthony J. Managing resource revenues in developing economies. Disponível em: <http://users.ox.ac.uk/ econpco/research/pdfs/ ManagingResourceRevenuesinDevelopingEconomies.pdf $>$. Acesso em: 18 set. 2013, p. 27-28. "Consumption of resource revenues should be smoothed, beginning early (perhaps before revenue flows) and certainly extending well beyond the period of peak resource revenues". Ainda: "The life of natural resources tends to span many generations, so some account must be taken of the intergenerational consequences of resource depletion, if only implicitly" (BOADWAY, Robin; SHAH, Anwar. Fiscal federalism cit., p. 211).

354 FURTADO, Celso. Globalisation et exclusion: Le Brésil dans l'ordre mondial émergent. Paris: Publisud, 1995. p. 40 apud AHMED, Abdelkader Sid. Celso Furtado e o desenvolvimento a partir da exportação de recursos naturais não renováveis. In: FURTADO, Celso. Ensaios sobre a Venezuela... cit., p. 168.

355 SACHS, Jeffrey D. How to handle the macroeconomics of oil wealth?. In: HUMPHREYS, Macartan; SACHS, Jeffrey D.; STIGLITZ, Joseph E. (Org.). Escaping the resource curse cit., p. 178. Também p. 192-193.

356 Humphreys e Sandbu (HUMPHREYS, Macartan; SANDBU, Martin E. The political economy of natural resource funds. In: HUMPHREYS, Macartan; SACHS, Jeffrey D.; STIGLITZ, Joseph E. (Org.). Escaping the resource curse cit., p. 197 e 198), revisando brevemente as particularidades da economia dos recursos minerais, apresentam algumas "implicações importantes": "One is that spending should be stabilized and should not track revenues closely. Another is that temporarily large revenues - such as those deriving from depletable natural resources - ought to be saved so as to benefit future generations [...] The need to separate the pattern of spending from the pattern of income means that good fiscal policy in countries with large natural resource wealth typically involves accumulating large amounts of revenues for future use". Expondo a questão de forma a vincular este tema (atenção às gerações futuras) 
Por isso mesmo é que a análise da instituição e funcionamento de políticas públicas relacionadas aos recursos naturais não renováveis não pode prescindir da ótica intergeracional. ${ }^{357-358}$ Como alertam José Roberto Afonso e Sérgio Gobetti, “o ideal é que as decisões de políticas públicas em torno da matéria tenham por objetivo básico proporcionar às gerações futuras uma compensação pela exploração presente de um recurso exaurível". ${ }^{359}$ De forma semelhante opina Paul Collier, ao apontar que "para respeitar os interesses das futuras gerações, uma porção substancial dos bens extraídos deve ser compensada com a acumulação de outros ativos", de conformidade com a vida útil das jazidas, de forma que "quanto mais próximo o recurso natural estiver da exaustão, maior deve ser a poupança das receitas decorrentes". ${ }^{360}$ Daí que "se há uma decisão do

com a já referida preocupação relacionada ao consumo das rendas derivadas dos recursos naturais não renováveis, o Banco Mundial assim apresenta o assunto: "Stocks of exhaustible resources such as oil represent a potential source of development finance. The question for countries with resource endowments is whether to consume these resource rents, providing current welfare but at a cost to future generations, or to invest the rents in other assets". WORLD BANK. Where is the wealth of nations? Measuring capital for the $21^{\text {st }}$ century cit., p. 43.

357 São veementes as colocações de Rodrigo Valente Serra: “A promoção da justiça intergeracional, ou pelo menos, o não comprometimento das gerações futuras, deve ser alvo de toda política de desenvolvimento. Os investimentos em saúde, educação, infraestrutura básica e produtiva, qualificação profissional, modernização da máquina administrativa, diversificação produtiva, entre outros, poderiam, rigorosamente, ser defendidos como ações de desenvolvimento, e por que não, ações também sensíveis em relação às gerações futuras. Se 'não me escapa que o verdadeiro desenvolvimento dá-se nos homens e nas mulheres e tem importante dimensão política', não há, portanto, como eleger uma única forma de alcançar a promoção da justiça intergeracional, pois esta se confunde com o próprio desenvolvimento. Assim, se o estudo chama atenção para algumas políticas específicas é com intuito de oferecer parâmetros para o debate acerca da aplicação dos royalties. No Brasil, onde a propriedade do subsolo é da União, é de se esperar que os tributos e outros benefícios arrecadados pela atividade petrolífera sejam aplicados em atividades que proporcionem alguma renda no futuro quando o petróleo e o gás natural exaurirem, pois as gerações futuras não mais terão esta fonte de renda. E quanto às esferas de governo subnacionais (GSNs): seriam estas justas beneficiárias dos royalties? Entre as diferentes possibilidades analíticas sobre a utilização dos royalties desenvolvidas neste capítulo, somente uma poderia justificar o pagamento dos royalties às esferas de governo subnacionais (GSNs) impactadas pelo segmento de E-P: a compensação por uma trajetória de crescimento baseada em um recurso não renovável. Trata-se esta compensação, na verdade, de uma aplicação, ao nível dos GSNs, das políticas de promoção da justiça intergeracional" (SERRA, Rodrigo Valente. Contribuições para o debate acerca da repartição dos royalties petrolíferos no Brasil. 2005. Tese (Doutorado) - Instituto de Economia, Universidade Estadual de Campinas. p. 70-71).

358 INTERNATIONAL MONETARY FUND. Guide on resource revenue transparency cit., p. 40: "The budget framework should incorporate a clear policy statement on the rate of exploitation of natural resources and the management of resource revenues, referring to the government's overall fiscal and economic objectives, including long-term fiscal sustainability [...] since the resources are finite, it is important to take into account alternative options concerning possible exploitation rates and the intergenerational distribution of income flows, as well as the distribution of spending and the immediate social impact of resource industries". p. 29-30. E ainda: "A central issue for countries rich in nonrenewable resources is how best to use revenue derived from the resource to promote a diversified economy and share the benefits with future generations".

359 AFONSO, José Roberto Rodrigues; GOBETTI, Sérgio Wulff. Rendas do petróleo no Brasil: alguns aspectos fiscais e federativos. Revista do BNDES, Rio de Janeiro, v. 15, n. 30, p. 231- 269, dez. 2008, p. 233.

360 COLLIER, Paul. Small countries and big resources: harnessing natural resources for development in the g7+ countries. Paper prepared for the g7+ high level ministerial retreat. 2012. Disponível em: 
governo sobre a qual cada cidadão deve estar ciente é a proporção da receita de recursos naturais que é usada para investimento no futuro, em contraponto ao consumo atual". ${ }^{361}$

Há de se concluir, pois, com Leal e Serra, que ensinam que "o objetivo singular ou específico desse instrumento arrecadatório [royalty] relaciona-se à promoção da justiça intergeracional e, portanto, sua administração deve seguir as regras adequadas à gestão de ativos de longo prazo". ${ }^{362}$ E, ainda, com Hirdan Costa e Edmilson Moutinho dos Santos, que afirmam que "a justiça intra e intergeracional deverá ser parâmetro de destinação das rendas derivadas da extração econômica de hidrocarbonetos". 363

Daí também que se dá mais uma aproximação do tema em debate com o direito ambiental, especialmente no conceito de sustentabilidade (já referida acima de perspectiva econômico-financeira, mas que, ao menos em nosso país, está mais relacionada ao meio ambiente), que também exige uma visão temporal alargada, orientada ao futuro. Ora, "seja como for definido o desenvolvimento sustentável, atingi-lo é, no cerne, o processo de manter a riqueza para as futuras gerações". 364-365

<http://www.g7plus.org/news-feed/2013/1/10/small-countries-and-big-resources.html〉. Acesso em: $1 .^{\circ}$ out. 2013 , p. 8 .

361 Idem, ibidem, p. 13. O autor não desconhece que as pressões populares são determinantes nessa hipótese. Isto é: vê que, em geral, prevalece o entendimento de que as necessidades atuais já são enormes, sendo inviável a aplicação dos benefícios em prol das gerações futuras. Daí que Collier sustenta uma ação comunicativa proativa, por parte do Governo. Cita como exemplo de sucesso nesse quesito a campanha realizada em Botsuana, que tinha por objetivo sensibilizar a população da oportunidade histórica de proteger os interesses de seus filhos. Relata: "Its overarching theme, which was made part of every government policy for many years, was 'because we are poor we must carry a heavy load'. The imagery of a heavily laden peasant woman was designed to resonate with ordinary people and in essence said: 'don't expect too much too soon, we are going to have to work hard and save to build the future'. It effectively punctured the counter-narrative of 'we've discovered diamonds so we're all rich'. As this narrative took hold, it created the political space for the accumulation of assets for which Botswana is rightly celebrated" (p. 19).

362 LEAL, José Agostinho; SERRA, Rodrigo. Uma investigação sobre os critérios de repartição dos royalties petrolíferos. In: PIQUET, Rosélia (Org.). Petróleo, royalties e região. Rio de Janeiro: Garamond, 2003. p. 179.

363 COSTA, Hirdan Katarina de Medeiros; SANTOS, Edmilson Moutinho dos. Justiça e sustentabilidade: a destinação dos royalties de petróleo. Estudos avançados, v. 27, n. 77, 2013, p. 148. Afirmam, mais, os mencionados autores: "Não se trata de entender que as rendas decorrentes da extração econômica de hidrocarbonetos resolverão todos os problemas de certa sociedade, mas de aproveitar a existência desse recurso público financeiro para destinar tais rendas de forma a criar e revisar conceitos e parâmetros desenvolvimentistas atuais para possibilitar a continuidade da vida com qualidade sobre o planeta Terra. Portanto, o princípio da justiça intra e intergeracional absorve a justiça intergeracional para construir a percepção da unicidade da espécie humana e da sua relação com o seu território e/ou com a natureza, o que inclui o uso, o manejo e a gestão dos recursos naturais" (p. 149).

364 Tradução livre. No original: "However sustainable development is defined, achieving it is, at heart, the process of maintaining wealth for future generations" (WORLD BANK. Where is the wealth of nations? Measuring capital for the $21^{\text {st }}$ century cit., p. 35). E ainda: "Saving effort is of course not the whole story in sustaining development. Saving must be channeled into productive investments that can underpin future welfare, rather than high-profile but ultimately nonremunerative projects" (p. 56). 
Tratando-se de sustentabilidade relacionada à exploração dos recursos naturais não renováveis, analisa-se especialmente a governança dada às receitas públicas derivadas destes bens, especialmente observando os níveis de poupança, investimento e consumo. É dizer: o país que se utiliza dessas receitas marcadas pela não renovabilidade para consumo atual, sem promover a criação ou incremento de fontes de renda, sem investir em capital reprodutível, em geral sem observar o caráter intrínseco de finitude dos recursos que conduz à observação dos interesses das gerações futuras, está se tornando mais pobre ano após ano e privando que os cidadãos de amanhã possam se utilizar dessa riqueza consumida ou mesmo que possam escolher dar outro rumo à exploração, fazendo suas próprias escolhas. ${ }^{366}$

\section{2.b. Por quê vincular royalties de recursos naturais não renováveis à ideia de equidade intergeracional.}

Tentou-se no item acima adentrar neste texto a ideia da proteção dos direitos das futuras gerações, criando, ainda que de forma tênue, um elo entre [i] a exploração dos recursos naturais não renováveis; [ii] sua característica intrínseca (e redundante) de finitude; e [iii] a atenção aos interesses das gerações vindouras.

365 Ficamos com as definições trazidas pelo Relatório da Organização das Nações Unidas sobre o tema: "O desenvolvimento sustentável é aquele que atende às necessidades do presente sem comprometer a possibilidade de as gerações futuras atenderem a suas próprias necessidades [...] em essência, o desenvolvimento sustentável é um processo de transformação no qual a exploração dos recursos, a direção dos investimentos, a orientação do desenvolvimento tecnológico e a mudança institucional se harmonizam e reforçam o potencial presente e futuro a fim de atender as necessidades e aspirações humanas" (NOSSO FUTURO COMUM. Comissão mundial sobre meio ambiente e desenvolvimento. 2. ed. Rio de Janeiro: Fundação Getulio Vargas, 1991. p. 46 e 49). Vale ainda mencionar a doutrina de Ana Maria Nusdeo: "a ideia de um desenvolvimento sustentável diz respeito à exploração dos recursos naturais no presente sem comprometer os recursos à disposição das gerações futuras. Relaciona-se, assim, com todas as políticas públicas voltadas ao estímulo de formas de utilização dos recursos naturais no processo de produção econômica e reprodução social que permita sua conservação ou renovação para o uso futuro das presentes e próximas gerações" (NUSDEO, Ana Maria. Desenvolvimento sustentável do Brasil e o protocolo de Quioto cit.). O artigo contém ainda excelenete análise sobre outros conceitos propostos, além de críticas aos conceitos mais utilizados. E ainda: AUTY, Richard M. Natural resources, capital accumulation and the resource curse cit., p. 9: "sustainability requires that the capacity to sustain the income stream from the mineral asset needs to be passed on to future generations. This calls for the income generating capacity of the depleted mineral to be replaced with alternative wealth-generating assets (for example, factories or an educated workforce)". Para outras concepções de sustentabilidade: WOLF, Clark. Intergenerational justice. In: FREY, R. G.; WELLMAN, Cristopher Heath (Ed.). A companion to applied ethics. Oxford: Blackwell Publishers, 2003. p. 288 e ss.

366 VAN DER PLOEG, Frederick. Challenges and opportunities for resource rich economies cit., p. 40: "This means that many resource rich countries become poorer each year despite large natural resources. They effectively squander their natural resources at the expense of future generations without investing in other forms of intangible or productive wealth". 
Esse elo partiu de fortes intuições e de trabalhos (relacionados à atividade de extração de recursos minerais) com objetivos diversos, a oferecer suporte para a hipótese sobre a qual ora se disserta.

Tendo sido apresentado o tema e afirmado o referido elo, de início em bases mais genéricas e partindo de afirmações sempre diretamente relacionadas aos recursos naturais não renováveis, entende-se que é o momento de um passo seguinte, em busca de bases sólidas para responder por quê o tema em comento merece ser avaliado na perspectiva intergeracional.

\section{2.b.i. Explorar para quê? Uma breve menção ao pensamento furtadiano.}

Já se referiu que o objeto destas linhas é a análise da governança da receita pública oriunda dos recursos naturais não renováveis, especialmente sob a lente do Direito Financeiro. Ao momento, contudo, convém endereçar - ainda que brevemente - uma questão que subjaz ao debate, e emerge de forma recorrente. Ela está presente, por exemplo, quando se questiona: se a exploração contém armadilhas, porquê não abandonála? Ou ainda: se a exploração pode violar os direitos das gerações futuras, porquê não manter os recursos naturais, pura e simplesmente, entesourados?

E, de outro lado, essas questões podem se desdobrar de forma ainda mais ampla: para quê explorar os recursos naturais não renováveis?

Vale considerar que o Estado brasileiro é detentor soberano desses recursos naturais (como se verá adiante). Então, certamente, a exploração dessa atividade não se justifica na liberdade individual de iniciativa empresarial (CF, art. 170), por mais que se garanta ao concessionário a propriedade do produto da lavra, no caso dos recursos minerais (CF, art. 176), e por mais que se possa contratar com empresas estatais ou privadas essa exploração, no caso do petróleo e seus derivados $\left(\mathrm{CF}\right.$, art. $\left.177, \S 1 .^{\circ}\right)$.

Assim é que, de partida, devem ser totalmente rejeitadas as ideias ultraliberais (de fato, libertárias) de John Brätland, para quem a exploração dos recursos naturais não renováveis é toda explicada e fundada na propriedade privada, pelo que acusa Solow e Hartwick (referidos adiante) de defender uma agenda intervencionista ambiciosa com "flagrantes falhas éticas". Suas ferozes palavras incluem a afirmação de que "os governos não têm, em geral, qualquer propriedade legítima às terras que carregam recursos exauríveis"; e ainda que os royalties são "confisco" e um "roubo da propriedade 
privada". ${ }^{367}$ Tais afirmações, que são deveras passíveis de críticas nos ambitos da filosofia política e da economia política, revelam-se, no campo do direito, absolutamente despropositadas, negando a evolução do papel do Estado e sua tradução constitucional, enfim rejeitando princípios e regras não apenas dos direitos internos, como o brasileiro, mas igualmente do direito internacional, que reconhece a relevância estratégica dos recursos naturais aos Estados. Não se aprofundará na crítica, por desnecessário, máxime dados os fundamentos nos capítulos posteriores.

Em verdade, o que se investiga nesta oportunidade é anterior às colocações do modo de exploração (arts. 176-177 da CF/1988), valendo mesmo questionar por quais razões o Estado brasileiro deverá, por si próprio ou mediante concessão (ou autorização ou permitissão ou mesmo mediante contratação de serviços) a terceiros privados, efetivamente dar início a essa exploração.

E, em face desta questão, sobressai o pensamento de Celso Furtado, que, como buscaremos relacionar, acresce às demais razões já expostas e a expor neste trabalho, que comandam uma orientação da governança dos recursos públicos oriundos da exploração dos recursos naturais não renováveis.

Celso Furtado, em Formação Econômica do Brasil, consigna:

A destruição dos solos que, do ponto de vista social, pode parecer inescusável, do ponto de vista de um empresário privado, cuja meta é obter o máximo de lucro de seu capital, é perfeitamente concebível [...] a situação pode ser perfeitamente assimilada à de uma indústria extrativa, pois o esgotamento de uma reserva mineral representa a alienação de um patrimônio cuja ausência poderá ser lamentada pelas gerações futuras. Mas, se o aproveitamento da reserva esgotável se faz para dar início a um processo de desenvolvimento econômico, não somente a geração presente mas também as futuras - que receberão a reserva transformada em capital reprodutível - serão beneficiadas. ${ }^{368}$

A referência às futuras gerações não é isolada, mas está contida na teoria de Furtado, especialmente em suas lições sobre o desenvolvimento e, principalmente, o subdesenvolvimento. Sua doutrina postula inicialmente que são subdesenvolvidas "as regiões cuja produtividade aumenta ou poderia aumentar pela simples implantação das técnicas já conhecidas", de forma que "o crescimento das economias subdesenvolvidas é,

367 BRÄTLAND, John. Rawlsian investment rules for "intergenerational equity": breaches of method and ethics. The journal of libertarian studies: an interdisciplinary review, v. 21, n. 04, 2007.

368 FURTADO, Celso. Formação econômica do Brasil. 34. ed. São Paulo: Companhia das Letras, 2007. p. 234. 
sobretudo, um processo de assimilação da técnica prevalecente na época", ${ }^{369}$ pelo que o desenvolvimento resulta "da introdução de combinações mais produtivas dos fatores de produção"370 - admitindo "o progresso tecnológico como uma dimensão do processo de acumulação de capital".371

Nada obstante, ensina que o subdesenvolvimento é um "processo histórico autônomo, e não uma etapa pela qual tenham, necessariamente, passado as economias que já alcançaram grau superior de desenvolvimento". ${ }^{372}$ Tomando de exemplo um país cuja economia está voltada à exportação (especialmente exploração mineira), pondera que a empresa capitalista que aí se insere "não se vincula, dinamicamente" porque "a massa de lucros por ela gerados não se integra na economia local". ${ }^{373} \mathrm{O}$ que revela, então, especialmente quando se observam os investimentos das empresas sediadas em países desenvolvidos nas economias dos países em desenvolvimento, não uma superação do subdesenvolvimento por estes últimos, mas a instalação de uma economia híbrida, onde o núcleo capitalista passa a "coexistir, pacificamente, com uma estrutura arcaica". ${ }^{374}$ Daí segue que mesmo o setor industrial da nação em desenvolvimento foca em competir com os bens manufaturados importados, e não em desenvolver tecnologia nova, direcionada aos demais setores econômicos nacionais, pelo que apresenta "uma estrutura ocupacional tipicamente pré-capitalista", de forma que "grande parte de sua população esteja alheia aos benefícios do desenvolvimento". 375

Então, adicionando ao conceito de desenvolvimento já acima mencionado, afirma que "é a heterogeneidade tecnológica entre setores ou departamentos de uma mesma economia que caracteriza o subdesenvolvimento". ${ }^{376}$

369 FURTADO, Celso. Desenvolvimento e subdesenvolvimento. Rio de Janeiro: Contraponto: Centro Internacional Celso Furtado, 2009. p. 85.

370 Idem, ibidem, p. 88.

371 Idem, p. 94. A relevância do processo de acumulação de capitais é referida com mais detalhes nas p. 106 e ss.

372 Idem, p. 161.

373 Idem, p. 163.

374 Idem, p. 164. Ainda: "O caso mais simples é o da coexistência de empresas estrangeiras, produtoras de uma mercadoria de exportação, com uma larga faixa de economia de subsistência, coexistência esta que pode perdurar, em equilíbrio estático, por longos períodos. O caso mais complexo - exemplo do qual nos oferece o estádio atual da economia brasileira - é aquele em que a economia apresenta três setores: um, principalmente de subsistência; outro, voltado sobretudo para a exportação e o terceiro, como um núcleo industrial ligado ao mercado interno, suficientemente diversificado para produzir parte dos bens de capital de que necessita para seu próprio crescimento" (p. 171).

375 Idem, p. 171-172.

376 Idem, p. 173. 
Por isso mesmo que o desenvolvimento ou subdesenvolvimento não se mede pelo PIB ou renda per capita. ${ }^{377}$ A movimentação econômica pode ser forte, mas se for concentrada em poucos setores (e capturada pela elite), não alcançando os demais "departamentos" da economia nacional, a alta renda per capita não se traduzirá em desenvolvimento. Foi exatamente o que Celso Furtado encontrou na Venezuela: "subdesenvolvimento com abundância de divisas", ${ }^{378}$ onde afirma expressamente que "a atual abundância de recursos financeiros não é causa suficiente para liquidar o subdesenvolvimento". 379

Aplicando essa doutrina ao caso brasileiro, o que se deve enfatizar é que o Brasil teve formação notadamente voltada à economia primária, extrativista e exportadora - arcaica, portanto -, como se vê de seus ciclos do ouro, da borracha, do açúcar, do café, enquanto que, por outro lado, importou produtos manufaturados e tecnologia. ${ }^{380}$ Essa formação marcou a estrutura econômica de maneira indelével, de modo que ainda hoje, e apesar das tentativas (mais ou menos corretas; mais ou menos bem sucedidas; mas ainda assim tentativas) de desenvolvimento de uma indústria nacional desenvolvida, com a produção de bens manufaturados, essa estrutura em grande parte subsiste. O que se vê refletido também nos números, já apresentados acima, que dizem da participação privilegiada do setor minerário (especialmente do minério de ferro) na balança comercial brasileira. Essas fortes marcas da formação econômica brasileira nos dias atuais são salientadas por Calixto Salomão Filho, Brisa Ferrão e Ivan Ribeiro. ${ }^{381}$

377 Sustenta: "o crescimento econômico, tal qual o conhecemos, vem se fundando na preservação dos privilégios das elites que satisfazem seu afã de modernização; já o desenvolvimento se caracteriza pelo seu projeto social subjacente. Dispor de recursos para investir está longe de ser condição suficiente para preparar um melhor futuro para a massa da população. Mas quando o projeto social prioriza a efetiva melhoria das condições de vida dessa população, o crescimento se metamorfoseia em desenvolvimento" (FURTADO, Celso. Os desafios da nova geração. Jornal dos economistas, n. 179, jun. 2004, p. 3-4).

378 FURTADO, Celso. Notas sobre a economia venezuelana e suas perspectivas atuais, 1974. In: FURTADO, Celso. Ensaios sobre a Venezuela... cit., p. 120-121). Afirma: "Em primeiro lugar, cabe assinalar a baixa produtividade do sistema econômico, se se exclui o setor que utiliza recursos não renováveis, vale dizer, petróleo. Comparando as taxas de investimento e de incremento do PIB comprova-se que a eficiência média do sistema tem estado abaixo do que seria de se esperar, tanto mais que o equipamento usado é quase sempre importado e incorpora tecnologia de vanguarda. $\mathrm{O}$ segundo ponto a assinalar diz respeito ao baixo nível da carga fiscal. Comparando-se o valor dos impostos efetivamente pagos pela população com a sua renda, depreende-se que a carga fiscal é menos da metade ou da terça parte da que se observa em outros países da América Latina de renda per capita inferior à da Venezuela".

379 Idem, ibidem, p. 125.

380 É o "desarollo hacia fuera", de que trata Gilberto Bercovici (BERCOVICI, Gilberto. Direito econômico do petróleo e dos recursos minerais cit., p. 17).

381 Relevantíssimas as lições sobre a força das estruturas jurídicas na perpetuação da concentração de renda nas mãos de poucos (SALOMÃO FILHO, Calixto; FERRÃO, Brisa Lopes de Mello; RIBEIRO, Ivan César. Concentração, estruturas e desigualdade: as origens coloniais da pobreza e da má distribuição de 
A evolução econômica, pois, conduziu o Brasil à incômoda situação de periferia econômica na propagação do progresso técnico, em contraponto à centralidade dos países desenvolvidos. É dizer, com Alessandro Octaviani: "É central a região que criou o avanço técnico, fazendo-o socialmente necessário para as outras regiões, que, então, são subordinadas à primeira. Aos que não chegaram na capacidade de produção do avanço técnico, resta suprir o centro com produtos de necessidade primária". ${ }^{382}$ É o que se passou a chamar de "relação centro-periferia", impondo efeitos diversos ${ }^{383}$ e antagônicos a um (centro ${ }^{384}$ ) e outro (periferia ${ }^{385}$ ), distanciando-os ainda mais em níveis de desenvolvimento. ${ }^{386}$

Esse relacionamento desigual e desvantajoso para os países exportadores de produtos primários é também identificado como fenômeno da "deterioração dos termos de troca", em que

renda. São Paulo: IDCID, 2006. p. 15-16.). Dentre outras passagens: “As estruturas excluem os agentes econômicos do mercado, limitam a liberdade da mão-de-obra, concentram o acesso ao capital (financeiro ou humano) e ao crédito, existindo inclusive evidência de sua maior importância na explicação de fenômenos econômicos quando comparadas às instituições [...] as estruturas jurídicas e econômicas têm uma explicação natural para a sua permanência. Tendo sido desenhadas para garantir a exclusão da maioria e a concentração econômica, com claros reflexos no acesso a todo e qualquer meio de participação social, sua permanência é natural e, mais do que isso, difícil de ser extinta. Os privilégios são apropriados de tempos em tempos pelos grupos mais diversos, sucedendo-se uns aos outros na posse do aparato destinado a garantir a concentração [...] o grau de concentração e, por conseqüência, os padrões de pobreza e de desigualdade observados entre as diversas regiões do Brasil e de outras excolônias podem ser rastreados até episódios da ocupação colonial e mesmo encontrados em atividades econômicas de desenvolvimento mais recente. A análise desses episódios ajuda a entender o atual estágio de desenvolvimento do país, assim como seus níveis de pobreza e a desigualdade de renda, e nesse processo vislumbra-se melhor a influência das estruturas econômicas e jurídicas sobre o fenômeno". LUIS, Alessandro S. Octaviani. Recursos genéticos e desenvolvimento: os desafios furtadiano e gramsciano. 2008. Tese (Doutorado) - Faculdade de Direito da Universidade de São Paulo. p. 150.

383 "O avanço na acumulação nem sempre produziu transformações nas estruturas sociais capazes de modificar significativamente a distribuição da renda e a destinação do novo excedente. A acumulação, que nas economias cêntricas havia conduzido à escassez de mão-de-obra, criando as condições para que se dessem a elevação dos salários reais e a homogeneização social, produziu nas regiões periféricas efeitos totalmente diversos: engendrou a marginalização social e reforçou as estruturas tradicionais de dominação ou substituiu-as por outras similares. Em verdade, a acumulação periférica esteve de preferência a serviço da internacionalização dos mercados, que acompanhou a difusão da civilização industrial" (FURTADO, Celso. A invenção do subdesenvolvimento. Revista de Economia Política, v. 15, n. 2 (58), abr.-jun. 1995, p. 6).

384 "Ser central é deter a chave do progresso técnico, encarnado contemporaneamente na industrialização. Logo, a tarefa fundamental da superação do subdesenvolvimento é a industrialização”. LUIS, Alessandro S. Octaviani. Recursos genéticos e desenvolvimento cit., p. 152.

385 "A estrutura produtiva do centro tem por características essenciais ser diversificada e homogênea, enquanto que a da periferia é especializada e heterogênea" (BERCOVICI, Gilberto. Direito econômico do petróleo e dos recursos minerais cit., p. 16).

386 Como afirma Celso Campilongo, "centro e periferia operam com fórmulas muito diversificadas de repressão da instância material, inclusão nos sistemas parciais e exclusão de direitos" (CAMPILONGO, Celso Fernandes. Celso Furtado e o desenvolvimentismo: ele pode não oferecer a melhor saída para os nossos dilemas. Porém, tomá-lo como referência a respeito de como o Brasil deve ser estudado é imperioso [homenagem]. Getulio, São Paulo, v. 1, n. 1, jan. 2007, p. 33). 
o poder de compra dos bens primários para a aquisição de bens manufaturados se reduz com o passar do tempo, o que, consequentemente, gera menor renda para a periferia, concentra os frutos do progresso técnico nas economias industrializadas e favorece a transferência de rendas da periferia para o centro, ${ }^{387}$

o que se conecta também com a já mencionada volatilidade dos recursos naturais não renováveis, dado que os preços desses bens podem frequentemente sofrer quedas acentuadas pelas movimentações do mercado internacional, enquanto que os preços dos bens manufaturados são muito mais equilibrados, beneficiando a estabilidade dos países mais desenvolvidos.

O que esta acanhada exposição quer apresentar, então, é o "desafio furtadiano", que objetiva a superação do subdesenvolvimento, ${ }^{388}$ dificultada pela condição de periferia econômica que nos foi legada desde o período colonial. Esta, como ressalta Bercovici, é a tarefa do direito econômico, ${ }^{389}$ e a principal política econômica fixada pela Constituição. ${ }^{390}$

E nesse processo de superação do subdesenvolvimento, destaca-se a necessidade de promover a industrialização, ${ }^{391-392}$ afastando a concentração da base econômica nos setores primário e extrativista-exportador, obtendo progresso tecnológico e diversificando a economia do país - portanto afastando-se da heterogeneidade tecnológica e da "deterioração dos termos de troca". ${ }^{393}$ O rompimento do ciclo de subdesenvolvimento,

387 BERCOVICI, Gilberto. Direito econômico do petróleo e dos recursos minerais cit., p. 17-18.

388 "Assegurar as condições de um aumento elevado e constante da renda nacional 'per capita' aparece hoje em dia, acima das querelas ideológicas e políticas, como a tarefa primeira e indeclinável do Poder Público. Nestas condições, a iniciativa, ou melhor, a responsabilidade do Estado na vida econômica deixa de ser a exceção para transformar-se em princípio”. COMPARATO, Fabio Konder. O indispensável direito econômico. Revista dos Tribunais, n. 353, São Paulo: RT, mar. 1965.

389 BERCOVICI, Gilberto. Política econômica e direito econômico. Revista Fórum de Direito Financeiro e Econômico, v. 1, 2012, p. 209-210. E também: BERCOVICI, Gilberto. Direito econômico do petróleo e dos recursos minerais cit., p. 14 e 304.

390 BERCOVICI, Gilberto. Política econômica e direito econômico cit., p. 218.

391 BERCOVICI, Gilberto. Direito econômico do petróleo e dos recursos minerais cit., p. 18 e 23.

392 FURTADO, Celso. O desenvolvimento recente da economia venezuelana, 1957. In: FURTADO, Celso. Ensaios sobre a Venezuela... cit., p. 60 e ss., especialmente p. 64, em que recomenda a "diversificação da estrutura econômica". Ainda: "Duas frentes seriam, em meu entender, capazes de suscitar uma autêntica mudança qualitativa no desenvolvimento do país: a reforma agrária e uma industrialização que facilite o acesso às tecnologias de vanguarda" (FURTADO, Celso. Os desafios da nova geração cit., p. 4). Ainda: "Por todas essas implicações e características, a produção de commodities continua a ser um problema, mais do que uma solução para o desenvolvimento de longo prazo dos países latinoamericanos. Desse ponto de vista, dado o nível de renda per capita desses países, a diversificação e, mais propriamente, a industrialização, continuam sendo os principais objetivos a perseguir" (CARNEIRO, Ricardo de Medeiros. Commodities, choques externos e crescimento: reflexões sobre a América Latina. Santiago: Nações Unidas, CEPAL, Div. de Desarrollo Económico, 2012. p. 44).

393 Nas palavras de Celso Furtado: "As experiências referidas deixam claro que, no mundo atual, certas condições devem ser cumpridas pelo país de economia periférica que pretenda superar o subdesenvolvimento. As de maior relevo são: (i) um grau de autonomia de decisões que limite o mais 
diretamente relacionado à estrutura econômica da nação, então, é que deve ser fortemente endereçado.

E isto diz diretamente com o objeto destas linhas: os recursos naturais não renováveis, destacando-se no Brasil o minério de ferro e o petróleo. Ao passo em que sua exploração - e os diversos benefícios que trazem, por ora nos interessando mais diretamente a receita pública arrecadada com a cobrança de royalties - pode servir para financiar as políticas públicas que visam superar o subdesenvolvimento, essa mesma exploração (de bens que são primários e, no caso do minério de ferro, voltados à exportação) importa em continuidade da estrutura econômica arcaica de que fala Furtado.

Daí, então, que se mostra especialmente relevante a ótica do Direito Financeiro no estudo do tema. Analisando a utilização, pelo Estado, dos recursos públicos relativos a essa exploração, pode-se cuidar para que a tarefa de quebra do ciclo de subdesenvolvimento seja endereçada, evitando que a exploração seja, ao fim e ao cabo, apenas uma nova etapa de mais do mesmo: primarização e patrimonialidade. ${ }^{394-395}$

Há de se concordar, pois, com Octaviani, quando postula que "o direito financeiro insere-se nesse programa constitucional de superação do subdesenvolvimento", de forma que "as despesas de capital e as correntes só guardarão legitimidade constitucional se estiverem adequadas a tal desiderato". 396

possível a drenagem para o exterior do potencial de investimento; (ii) estruturas de poder que dificultem a absorção desse potencial pelo processo de reprodução dos padrões de consumo dos países ricos e assegurem um nível relativamente alto de investimento no fator humano, abrindo caminho à homogeneização social; (iii) certo grau de descentralização de decisões empresariais requerido para a adoção de um sistema de incentivos capaz de assegurar o uso do potencial produtivo; (iv) estruturas sociais que abram espaço à criatividade num amplo horizonte cultural e gerem forças preventivas e corretivas nos processos de excessiva concentração do poder" (FURTADO, Celso. A invenção do subdesenvolvimento cit., p. 9).

394 As rendas petrolíferas, adverte Gilberto Bercovici, "podem ser facilmente dispersadas, quando deveriam seu utilizadas de modo que criassem ativos duráveis, para assegurar a sua continuidade" (BERCOVICI, Gilberto. Direito econômico do petróleo e dos recursos minerais cit., p. 29). O autor fecha seu estudo com contundentes palavras sobre a opção que se nos apresenta sobre a governança das rendas dos recursos minerais e sua utilização: "As alternativas são muito claras: ou este excedente contribuirá para manter o Brasil uma economia dependente e associada, a reboque das variações de preços do mercado internacional de produtos primários, consistindo o petróleo em mais um dos inúmeros ciclos econômicos vividos na história do país, mais um dos nossos 'milagres' para exportação; ou este excedente terá um papel decisivo no financiamento das políticas necessárias para a superação do subdesenvolvimento e, assim, completar a construção da Nação" (p. 360-361).

395 Interessantes as observações de André Nassif, negando que o Brasil sofra de desindustrialização ou de doença holandesa, mas advertindo dos riscos de que tais fenômenos se façam presentes: NASSIF, André. Há evidências de desindustrialização no Brasil? Textos para discussão, Revista do BNDES, n. 108, jul. 2006.

396 OCTAVIANI, Alessandro. A bênção de Hamilton na semiperiferia: ordem econômico-social e os juros da dívida pública. In: CONTI, José Maurício; SCAFF, Fernando Facury (Org.). Orçamentos públicos e direito financeiro cit., p. 1188. 
Daí que, na mesma toada, referindo-se aos royalties de recursos naturais não renováveis, Fernando Facury Scaff ensina:

os mecanismos financeiros devem ser estudados e manejados para um melhor proveito de toda a população, presente e futura, de um país. Mais importante do que a arrecadação - comparativamente baixa no Brasil - é a importância estratégica de sua gestão para o desenvolvimento e a soberania de cada país. ${ }^{397}$

Não por outras razões, Celso Furtado, referindo-se ao caso Venezuelano, forte na exploração do petróleo, reitera em diversas oportunidades essa posição. Afirma que a "orientação dos gastos públicos" é chave dos principais problemas; ${ }^{398}$ que "a inação ou omissão do Estado não constitui uma opção"; ;99 que os recursos do excedente petroleiro trazem uma "crescente responsabilidade do Estado na tomada de decisões econômicas", 400 sendo essencial sua transformação em capacidade produtiva. ${ }^{401}$

Então, compete ao Estado - e ora propõe-se essa atuação através do Direito Financeiro - exercer papel ativo na exploração e, especialmente, na governança das receitas públicas daí decorrentes, cuidando para que esses recursos sejam direcionados àquele fim referido: "transformar a sociedade, promovendo o desenvolvimento",402 "criar riqueza e gerar novas capacidades produtivas". ${ }^{403}$ Afinal, e retomando mais ativamente o já referido quanto à maldição dos recursos naturais e o que se verá adiante sobre a equidade intergeracional, "é o Estado que deve atuar, precipuamente, como o administrador responsável dos interesses das futuras gerações". ${ }^{404}$

Retome-se, então, à pergunta que deu nome a este item: explorar para quê? A resposta, com a teoria furtadiana, não pode ser outra: a exploração deve ocorrer tendo como fim último a superação do subdesenvolvimento. Isto deve se dar, principalmente, através da promoção da industrialização, diversificando a base produtiva, escapando ao

397 SCAFF, Fernando Facury. Royalties decorrentes da exploração de recursos naturais não renováveis cit., p. 128.

398 FURTADO, Celso. O desenvolvimento recente da economia venezuelana, 1957. In: FURTADO, Celso. Ensaios sobre a Venezuela... cit., p. 72.

399 FURTADO, Celso. Notas sobre a economia venezuelana e suas perspectivas atuais, 1974. In: FURTADO, Celso. Ensaios sobre a Venezuela... cit., p. 125.

400 Idem, ibidem, p. 134.

401 BERCOVICI, Gilberto. Direito econômico do petróleo e dos recursos minerais cit., p. 306.

402 Idem, ibidem, p. 13.

${ }^{403}$ Idem, p. 25.

404 COMPARATO, Fábio Konder. A afirmação histórica dos direitos humanos cit., p. 440. 
ciclo econômico periférico que, desde tempos coloniais, mantém o Brasil como mero exportador de bens primários. ${ }^{405}$

Em verdade, tendo iniciado essa breve exposição com a transcrição da doutrina de Celso Furtado, cabe também assim encerrar. Como que respondendo à mesma questão, Furtado afirma que "não existe nenhuma razão econômica" para que os recursos naturais não renováveis deixem de ser explorados. E estende sua opinião:

Pode-se argumentar que a utilização intensiva de recursos esgotáveis é economicamente condenável sempre que sirva principalmente para financiar gastos correntes. Um país ou região que não realiza inversões pelo menos no montante do valor das reservas esgotáveis utilizadas estará consumindo seu próprio capital. Mutatis mutandis, se o fruto da exploração das reservas esgotáveis é utilizado na constituição de outro ativo de valor econômico igual ou maior, a política de utilização intensiva de reservas poderá estar economicamente justificada. ${ }^{406}$

O pensamento furtadiano, pois, relaciona-se intrinsecamente, com o objeto central estudado.

O objeto primordial da exploração - superação do subdesenvolvimento - e, notadamente, seus meios - diversificação da base produtiva - referenda as posições necessárias para evitar as armadilhas da exploração: protege contra a volatilidade da receita, estimulando que outras atividades floresçam, contribuindo aos cofres públicos; combate o comportamento rentista, estimulando Governo e população a não se escorar na atividade extrativa; combate a doença holandesa.

E ainda, notadamente, revela-se um excelente receituário para endereçar o outro tema tomado como mote nessa exposição, a defesa dos interesses das gerações futuras. Furtado defende o investimento das receitas públicas decorrentes da exploração dos recursos naturais não renováveis em capital reprodutível. ${ }^{407}$ Que se revela forma não apenas de escapar do ciclo periférico de subdesenvolvimento, como, ao mesmo passo, de agir em cumprimento à equidade intergeracional acima referida.

405 As rendas dos recursos naturais não renováveis podem tem "um impacto político profundo". BERCOVICI, Gilberto. Direito econômico do petróleo e dos recursos minerais cit., p. 309-310. Mais: têm "a vantagem potencial de poder financiar investimentos públicos que sejam parte de uma estratégia de desenvolvimento coerente" - p. 345. E ainda: "O desafio histórico é aproveitar esta que, talvez, seja a última chance de termos condições efetivas e concretas para superar o subdesenvolvimento" - p. 360.

407 No mesmo sentido: BERCOVICI, Gilberto. Direito econômico do petróleo e dos recursos minerais cit., p. 346. 


\section{2.b.ii. Economia dos Recursos Naturais: Hotelling, Solow, Hartwick.}

Inicie-se a busca por mais fundamentos sólidos à ideia de direito (justiça, equidade) intergeracional pela perspectiva diretamente econômica.

Quer-se registrar os trabalhos de três economistas muito influentes no correr do século XX, que dirigiram suas análises à exploração dos recursos naturais (nem sempre aos não renováveis, embora sejam estes que nos interessem), e cujas conclusões, embora não sejam suficientes para construir uma teoria de direitos intergeracionais, são deveras relevantes para estabelecer a necessidade (de uma perspectiva econômica) de que o tema seja investigado a fundo.

Deve-se mais uma vez deixar explícito o corte metodológico, fixando que as considerações sobre os trabalhos destes economistas, abaixo contidas, não têm a pretensão de esgotar seus entendimentos, nem muito menos de analisá-los criticamente; por se entender relevante que sejam conhecidos, busca-se nos textos próprios e em comentários a eles trazer suas ideias centrais - no que se aplica aos objetos dessa dissertação - de forma expositiva, escapando-se à avaliação meritória de cada um deles.

Harold Hotelling publicou em 1931 o influente texto A Economia dos Recursos Exauríveis, ${ }^{408}$ que pretendeu responder às inquietações, à época já presentes, de que os recursos naturais não renováveis estariam sendo explorados de forma muito veloz e negociados em preços muito baixos, em detrimento das futuras gerações. Propôs-se identificar elementos concretos que ajudem a dirimir dúvidas ${ }^{409}$ sobre essa atividade exploratória, tanto do ponto de vista do Estado-explorador como do ator privado, e em resposta também aos grupos conservacionistas.

408 HOTELLING, Harold. The economics of exhaustible resources. Journal of Political Economy, v. 39, n. 1, 1931. Tradução livre.

409 "How much of the proceeds of a mine should be reckoned as income, and how much as return of capital? What is the value of a mine when its contents are supposedly fully known, and what is the effect of uncertainty of estimate? If a mine-owner produces too rapidly, he will depress the price, perhaps to zero. If he produces too slowly, his profits, though larger, may be postponed farther into the future than the rate of interest warrants. Where is his golden mean? And how does this most profitable rate of production vary as exhaustion approaches? Is it more profitable to complete the extraction within a finite time, to extend it indefinitely in such a way that the amount remaining in the mine approaches zero as a limit, or to exploit so slowly that mining operations will not only continue at a diminishing rate forever but leave an amount in the ground which does not approach zero? Suppose the mine is publicly owned. How should exploitation take place for the greatest general good, and how does a course having such an objective compare with that of the profit-seeking entrepreneur? What of the plight of laborers and of subsidiary industries when a mine is exhausted? How can the state, by regulation or taxation, induce the mine-owner to adopt a schedule of production more in harmony with the public good? What about import duties on coal and oil? And for these dynamical systems what becomes of the classic theories of monopoly, duopoly, and free competition?" (idem, ibidem, p. 139). 
Em Hotelling, a já referida peculiaridade da finitude dos recursos minerais é destacada, já que "a renda é multiplicada pela quantidade de minérios extraída conforme o estoque é exaurido". ${ }^{410}$ Daí que o Autor fortalece o conceito de "custo de uso" ("tipo particular de custo de oportunidade" ${ }^{411}$ ), que "é a diferença entre o preço do recurso e seu custo marginal de produção e faz parte da renda, que seria, dessa forma, uma compensação ao proprietário da jazida pela redução de seu valor devido à extração de seus recursos". ${ }^{412-}$ ${ }^{413}$ Afirma Postali:

Assim, a renda dos recursos minerais é conceitualmente diferente da renda da terra: mesmo sob competição e outras condições assumidas, e desde que os direitos de propriedade sejam claramente definidos, a renda de um projeto marginal não cai para zero, pois a extração no tempo presente impossibilita a extração futura, prejudicando as gerações posteriores. Ou seja, existe um custo de oportunidade que consiste em adiar a extração, sendo o custo de uso o valor dessa produção posterior. ${ }^{414}$

A análise considera que a finitude dos recursos provoca o aumento dos preços

do recurso natural não renovável no futuro: quanto mais próximo estiver da exaustão, maiores serão seus preços. ${ }^{415}$ Essa dinâmica entre exploração atual (maior volume,

410 BERCOVICI, Gilberto. Direito econômico do petróleo e dos recursos minerais cit., p. 28.

411 POSTALI, Fernando Antonio Slaibe. Renda mineral, divisão de riscos e benefícios governamentais na exploração de petróleo no Brasil cit., p. 17-18: "conceito de custo de uso, isto é, um tipo particular de custo de oportunidade, com características temporais: a extração de um recurso não renovável hoje acarreta um custo de oportunidade de extraí-lo amanhã".

412 Idem, ibidem, p. 18.

413 Rodrigo Valente Serra (SERRA, Rodrigo Valente. Contribuições para o debate acerca da repartição dos royalties petrolíferos no Brasil cit., p. 56-57): “como o recurso não é reproduzível, é necessário acrescermos ao preço o custo de oportunidade. A oportunidade de se explorar o recurso em algum tempo futuro e não hoje".

414 POSTALI, Fernando Antonio Slaibe. Renda mineral, divisão de riscos e benefícios governamentais na exploração de petróleo no Brasil cit., p. 19. Ainda: OTTO, James; ANDREWS, Craig; CAWOOD, Fred; DOGGETT, Michael; GUJ, Pietro; STERMOLE, Frank; STERMOLE, John; TILTON, John. Mining royalties cit., p. 28: "user costs can be shown to reflect the current market value of marginal resources in the ground and the expected costs of discovering new marginal resources. As a result, user costs reflect the value of mineral resources arising from the fact that they are nonrenewable".

415 Frankel (FRANKEL, Jeffrey. The natural resource curse cit., p. 6), dentre outros, credita a Hotelling "the important theoretical principle that the price of oil in the long run should rise at a rate equal to the interest rate". Contudo, sua análise estatística obtém resultados que podem ser considerados céticos, identificando ora uma trajetória crescente de preços, ora um rumo decrescente. Afirma que pode-se concluir por uma ou outra tendência, dependendo do específico período de tempo pesquisado (p. 8-9) ("there is no consistent trend either way", p. 37). Essas conclusões, contudo, não podem ser precipitadas: a doutrina de Hotelling não prega uma trajetória sempre crescente dos preços; mas que os preços subirão quanto mais se aproximar da exaustão. Como essa informação (quantidade de minerais restantes) é de afirmação difícil e polêmica, inclusive (ou especialmente) pela descoberta de novas jazidas ou a viabilização, por novas tecnologias, de outras jazidas, entendemos que não se pode ainda, a partir dos dados coletados no correr do século XX (ainda que apontem preços decrescentes dos recursos naturais não renováveis), refutar a ideia de Hotelling, como fazem, por exemplo, Gavin Wright e Jesse Czelusta (WRIGHT, Gavin; CZELUSTA, Jesse. Resource-Based Growth: Past and Present. In: LEDERMAN, Daniel; MALONEY, William F. (Ed.). Natural resources, neither curse nor destiny cit., p. 164: "Economists have known for some time that Harold Hotelling's theoretical prediction that the scarcity 
menores preços) e futura (menor volume, maiores preços) dá vazão à utilização do "custo de uso" ou "de oportunidade" acima referido. Afinal, o proprietário da jazida, público ou privado, deve considerar em seu planejamento que a venda atual do minério por um preço impede (reiterando a finitude) que esse mesmo bem seja explorado em valores superiores futuramente. ${ }^{416-417} \mathrm{O}$ que, sob outro olhar, atende (ainda que parcialmente) ideias conservacionistas ou de sustentabilidade, na medida em que representa elemento econômico de proteção do esgotamento célere e do aproveitamento irresponsável dos bens.

and relative prices of nonrenewable resources would rise inexorably over time has not been borne out by the facts of history", p. 204), embora deva-se firmar que os autores invectivam contra a própria ideia de não renovabilidade, de forma que "so-called nonrenewables can be progressively extended through exploration, technological progress, and investments in appropriate knowledge" (p. 207). Afinal, o próprio Hotelling [...] aponta que "by considering the influence of fixed investments and the cost of accelerating production at the beginning, we may be led to production curves which rise continuously from zero to a maximum, and then fall more slowly as exhaustion approaches. Certain production curves of this type have been found statistically to exist for whole industries of the extractive type, such as petroleum production".

416 HOTELLING, Harold. The economics of exhaustible resources cit., p. 162: "the quantity of a commodity which can be sold per unit of time depends ordinarily upon the rate of change of the price, as well as upon the price itself".

417 Rodrigo Valente Serra (SERRA, Rodrigo Valente. Contribuições para o debate acerca da repartição dos royalties petrolíferos no Brasil cit., p. 57-58) sustenta: "Há racionalidade para a manutenção de uma jazida inexplorada? Sim, se esta jazida, aos olhos de seu proprietário, prometer ganhos mais elevados no futuro. E como é possível ao proprietário da jazida processar este cálculo? Toma o proprietário o valor futuro do preço do mineral, e sobre este valor aplica uma taxa de desconto, trazendo este valor para o presente. Este valor futuro do mineral, trazido para o presente, e descontado o custo de produção, serve como parâmetro para o proprietário decidir-se sobre o momento da exploração". Para Carlos Augusto Góes Pacheco (PACHECO, Carlos Augusto Góes. Avaliação de critérios de distribuição e de utilização de recursos das participações governamentais no Brasil. 2007. Dissertação (Mestrado) - Universidade Federal do Rio de Janeiro), "ao optar por preservar as reservas inexploradas, o proprietário dos recursos poderá obter ganhos futuros conforme aumenta o preço dos recursos no decorrer do tempo. Isto demonstra que, para a economia dos recursos naturais, os recursos inexplorados (in the ground) são tratados como bens de capital". A abordagem do acadêmico, nesse item específico, é deveras similar créditos atribuídos - à de Rodrigo Valente Serra. Frankel (FRANKEL, Jeffrey. The natural resource curse cit., p. 6-7), sobre o posicionamento de Hotelling, ensina: "If the value of the oil in the ground is not expected to increase in the future, or not expected to increase at a sufficiently rapid rate, then the owner has an incentive to extract more of it today, so that he earns interest on the proceeds". Ainda James Otto et alii (OTTO, James; ANDREWS, Craig; CAWOOD, Fred; DOGGETT, Michael; GUJ, Pietro; STERMOLE, Frank; STERMOLE, John; TILTON, John. Mining royalties cit., p. 19 e 27): "mineral resources are nonrenewable on any time scale of relevance to the human race. As a result, an opportunity cost is incurred in consuming mineral resources today, since once exploited they are no longer available for use in the future. This means that future production will have to rely on poorer quality resources and, consequently, more expensive resources, or use alternative materials [...] Hotelling noted that firms incur an opportunity cost in addition to their production costs in the process of producing mineral commodities. This is because increasing output by one more unit today, rather than leaving the required mineral resources in the ground, reduces the mineral resources available in the future". 
Esse "custo de uso/oportunidade", que importa em uma renda adicional ${ }^{418}$ que remunera a não utilização do bem no futuro (sua exploração atual) deve ser apropriado pelo Estado, como destaca Bercovici, ${ }^{419}$ na análise da obra de Hotelling.

É o que dá fundamento à exigência dos royalties de recursos naturais não renováveis.

A mencionada análise ficou conhecida por Renda de Hotelling (“ou Regra de Hotelling"420): "uma compensação ao proprietário pela redução do valor de sua jazida, em decorrência da extração, que torna o recurso indisponível no futuro". ${ }^{421}$ Para Rodrigo Valente Serra, "o que a regra de Hotelling propõe é uma trajetória de extração que garantiria uma melhor alocação temporal dos recursos". ${ }^{422-423}$

Portanto, o trabalho de Hotelling é deveras relevante a esta dissertação - que confessadamente carece de pretensões puramente econômicas, quanto mais de definição de preços e avaliação de mercados - na medida em que é pioneiro na inserção do componente temporal no estudo da exploração dos recursos naturais não renováveis. ${ }^{424-425}$

418 SERRA, Rodrigo Valente. Contribuições para o debate acerca da repartição dos royalties petrolíferos no Brasil cit., p. 57.

419 BERCOVICI, Gilberto. Direito econômico do petróleo e dos recursos minerais cit., p. 28.

420 Ou ainda, como adverte Rodrigo Valente Serra, Renda de Gray-Hotelling (SERRA, Rodrigo Valente. Contribuições para o debate acerca da repartição dos royalties petrolíferos no Brasil cit., p. 55, nota $\mathrm{n}$. 38).

421 POSTALI, Fernando Antonio Slaibe. Renda mineral, divisão de riscos e benefícios governamentais na exploração de petróleo no Brasil cit., p. 20.

422 SERRA, Rodrigo Valente. Contribuições para o debate acerca da repartição dos royalties petrolíferos no Brasil cit., p. 61.

423 HOTELLING, Harold. The economics of exhaustible resources cit., p. 170: "any particular production schedule fixes the value of the mine at such a figure that the income at any time, after allowing for depletion, is exactly equal to the interest on the value of the investment at that time". Consoante Boadway e Keen (BOADWAY, Robin; KEEN, Michael. Theoretical perspectives on resource tax design. In: DANIEL, Philip; KEEN, Michael; McPHERSON, Charles (Ed.). The taxation of petroleum and minerals cit., p. 4), "one of the costs of extracting some resource this period is the revenue foregone by the consequent inability to extract it in the future: this is sometimes referred to as "Hotelling rent"". Van der Ploeg (VAN DER PLOEG, Frederick. Challenges and opportunities for resource rich economies cit., p. 33), ensina que "the Hotelling rule implies that the capital gain on natural resources must equal the world interest rate".

424 HOTELLING, Harold. The economics of exhaustible resources cit., p. 174-175: "The problems of exhaustible resources involve the time in another way besides bringing on exhaustion and higher prices, namely, as bringing increased information, both as to the physical extent and condition of the resource and as to the economic phenomena attending its extraction and sale".

425 Tratando de Hotelling, Hirdan Katarina de Medeiros Costa (COSTA, Hirdan Katarina de Medeiros. $O$ princípio da justiça intra e intergeracional como elemento na destinação das rendas de hidrocarbonetos: temática energética crítica na análise institucional brasileira. 2012. Tese (Doutorado) - Universidade de São Paulo, 2012. p. 296) consigna: “A característica temporal dos recursos naturais exauríveis é tratada como um diferencial no preço a ser obtido pelo proprietário quando da extração de minérios. O valor da renda mineral inclui a compensação pela indisponibilidade dos recursos no amanhã. As gerações futuras são colocadas, dessa forma, como sujeitos os quais as decisões de exploração dos recursos devem ponderar, pois o consumo do recurso exaurível pelas gerações atuais cria a necessidade 
Incorporando os interesses das futuras gerações na equação, Hotelling a um só tempo traz implicações ao desenho dos royalties, à formulação de políticas públicas de conteúdo integeracional, às reivindicações dos grupos conservacionistas, dentre outras questões comumente associadas à extração de recursos naturais não renováveis.

Então, o paradigmático artigo de Hotelling, embora puramente econômico, é deveras relevante em outras diversas searas, inclusive a do Direito Financeiro, especialmente quando voltada às considerações intergeracionais.

Robert Solow publicou em 1974 o artigo Equidade Intergeracional e Recursos Exauríveis, ${ }^{426}$ em que parte de uma crítica às teorias de crescimento econômico que identifica como conceitualmente utilitaristas (identificadas pelo autor nas ideias de Frank Ramsey), eis que "a perda de utilidade para um indivíduo (ou geração) pode ser mais que compensada pelo incremento para outro", ${ }^{427-428}$ Invectivando contra ideias utilitaristas, é explícita e diretamente influenciado pela doutrina de John Rawls (cujas ideias serão melhor tratadas adiante) sobre a equidade entre gerações. O referido trabalho pretende analisar os níveis de investimento e consumo das rendas de recursos naturais não renováveis a partir do critério maximin (defendido por Rawls, mas não quanto à perspectiva intergeracional, como também será referido adiante), e o faz principalmente montando regressões a partir dos critérios populacional (aumento ou não da população no tempo), tecnológico (melhora significativa no tempo) e da exauribilidade (ou não) dos recursos naturais, buscando definições de justiça distributiva intergeracional. Para Solow, considerando constantes tecnologia e níveis populacionais e considerando também recursos naturais renováveis, a política pública de ponto ótimo está em cada geração manter o estoque de capitais intacto, consumindo o produto nacional líquido. ${ }^{429}$

de se pensar em caminhos de compensação das gerações futuras". Vale considerar que Hotelling, embora introduzindo a questão temporal, "analisou a formação do preço do bem sob uma ótica econométrica, não tratando de outros aspectos, tais como o da justiça intergeracional", consoante adverte Fernando Facury Scaff (SCAFF, Fernando Facury. Royalties decorrentes da exploração de recursos naturais não renováveis cit.).

426 SOLOW, Robert M. Intergenerational equity and exhaustible resources. The Review of Economic Studies, v. 41, Symposium on the economics of exhaustible resources, 1974. Tradução livre.

427 Idem, ibidem, p. 29.

428 Não é objeto deste trabalho avaliar criticamente as correntes da filosofia política.

429 SOLOW, Robert M. Intergenerational equity and exhaustible resources cit., p. 31. Contudo, alteradas as variáveis, as conclusões se alteram. Solow entende que o critério maximin é razoável ao planejamento de decisões intertemporais, embora apresente dificuldades consideráveis: requer uma acumulação inicial de capital; pode conduzir a conclusões equivocadamente conservadoras. Deve-se apontar que a geração que acumula e não consome é prejudicada, cabendo ainda considerar que a geração atual pode compensar as futuras por eventuais condutas danosas a seus interesses, mas o inverso não é verdadeiro: as gerações futuras nunca poderão devolver o bem-estar que recebem, por mais que seja superior ao que se entenda 
No que ora interessa, o autor conclui: "as gerações anteriores têm o direito de extrair das reservas (otimamente, é claro!) desde que elas adicionem (otimamente, é claro!) ao estoque de capital reprodutível". ${ }^{430}$ É dizer: observando o interesse das gerações futuras, o consumo das rendas decorrentes dos recursos naturais não renováveis deve ser limitado, exigindo-se o investimento em fatores que permitam a reprodução do capital.

Asheim e Buchholz põem a lição de Solow da seguinte forma: "os recursos naturais exauríveis podem ser substituídos por capital produzido pelo homem de forma que o esgotamento desses recursos naturais não prejudique as futuras gerações. A substitutibilidade entre os capitais natural e feito pelo homem então, apesar da finitude dos recursos naturais, pode permitir o consumo equitativo para todas as gerações". 431

Solow voltou ao tema em 1986, com o artigo Sobre a alocação intergeracional dos recursos naturais. ${ }^{432}$ Neste, posiciona a questão historicamente observando que a alta de preços provocada pela OPEC chamou a atenção do mundo para a finitude dos recursos. E que isso se traduziu, "no nível popular", em discussão sobre equidade intergeracional, basicamente tomando a forma de uma pergunta: "quanto é justo, do dote de recursos naturais não renováveis do mundo - ou de um país -, a geração presente utilizar e quanto deve ser deixado às gerações vindouras que não têm voz ativa nas decisões contemporâneas?". ${ }^{433}$ Ressaltou que esta não é a pergunta adequada a se fazer: a contribuição dos economistas para o tema, segundo ele, é justamente alertar que se trata de uma questão insuficiente porque as gerações

não devem às suas sucessoras uma parte deste ou daquele recurso natural em particular. Se devem algo, é a capacidade produtiva genérica ou, ainda mais genericamente, o acesso a um certo padrão de vida ou nível de

adequado, em comparação temporal. Solow, contraria essa premissa (de que as gerações futuras nada podem fazer pelas passadas), apontando que "There is something the future can do for the past: it can inherit less capital. All the more so, if technical progress favours later periods over earlier, the later generation can compensante the earlier by inheriting even less capital than that. The asymmetry is more subtle. If capital goods were not productive, I think there would apper no difficulty of principle. The problem arises because capital formation exploits nature; if the earlier generations dissaves for the sake of equity, the future pays more - in ouput foregone - than the past has gained. If the initial standard of consumption were high enough, then the principle of diminishing marginal utility suggest that the future does not pay more, not in terms of the coin that really counts" - Nota de rodapé n. 1, p. 34. O argumento parece apenas retórico, na medida em que a geração não escolhe o quanto herda da anterior - embora um sistema presente de representação (consideração) dos interesses das gerações futuras na tomada de decisões dos Estados pudesse se ocupar de ideias desse calibre.

430 SOLOW, Robert M. Intergenerational equity and exhaustible resources cit., p. 41.

431 ASHEIM, Geir B.; BUCHHOLZ, Wolfgang. The hartwick rule: myths and facts. CESifo Working Paper Series, n. 299, 2000, p. 2. Disponível em: <http://ssrn.com/abstract=258960>. Tradução livre.

432 SOLOW, Robert M. On the intergenerational allocation of natural resources. The Scandinavian Journal of Economics, v. 88, n. 1, Growth and Distribution: Intergenerational Problems, mar. 1986.

433 Idem, ibidem, p. 141. 
consumo. Quer a capacidade produtiva deva ser transmitida entre gerações na forma de depósitos de minerais ou equipamentos ou conhecimento tecnológico é mais uma questão de eficiência do que de equidade. $^{434}$

Seguindo na crítica às ideias utilitaristas, ${ }^{435}$ refere seu trabalho anterior - em que, por sua própria interpretação, definiu "o critério de bem estar como sendo o padrão de consumo alcançado pela geração menos abastada. Em outras palavras, a geração presente tem sempre o direito de tomar o máximo que puder da reserva comum intertemporal, desde que deixe a possibilidade de que cada geração sucessora possa ser tão abastada quanto esta" ${ }^{436}$ e em que definiu como melhor caminho o que tenha "níveis de consumo constantes" e com "o maior nível de consumo que possa ser mantido permanentemente". ${ }^{437}$ Buscou incrementar essas questões também a partir das ideias (então já publicadas) de John Hartwick - referido a seguir.

A preocupação de Solow, contudo, muda de foco: não investiga se as gerações presentes podem consumir em detrimento das futuras; mas se as futuras, considerando que "o investimento das rendas de recursos naturais em capital reprodutível causará o crescimento do consumo por cabeça", têm direito a um maior padrão de vida. ${ }^{438}$ É nesse ponto que questiona (embora timidamente) a doutrina de Hartwick, especialmente indicando a ausência, na sua doutrina, de incorporação dos elementos crescimento populacional e desenvolvimento tecnológico em um horizonte temporal largo. O que faz, contudo, sem deixar de louvar o mencionado autor por recordar a todos da "antiquada" obrigação de manter intacto o capital, e de que há fatores outros além da utilidade imediata que devem ser considerados quando se analisa a economia dos recursos naturais. ${ }^{439}$

Finalmente, ainda com Robert Solow, convém referir trabalho seu publicado em 1993, decorrente de palestra proferida em outubro/1992 por ocasião do $40 .^{\circ}$ aniversário da instituição Resources For The Future, ${ }^{440}$ em que prega:

se "sustentabilidade" significa algo mais que um slogan ou a expressão de uma emoção, ela deve importar em uma prescrição de preservar a capacidade produtiva para o futuro indefinido. Isto é compatível com o

\footnotetext{
434 SOLOW, Robert M. Intergenerational equity and exhaustible resources cit., p. 142.

435 Idem, ibidem, p. 143.

436 Idem, p. 143.

437 Idem, p. 144.

438 Idem, p. 145.

439 Idem, p. 148-149.

440 SOLOW, Robert M. An almost practical step towards sustainability. Resources Policy, v. 19, 1993, p. 162-172.
} 
uso de recursos naturais não renováveis apenas se a sociedade como um todo substituir os recursos utilizados com outra coisa. ${ }^{441-442}$

No texto, o autor advoga fortemente o desenvolvimento de modos (mais confiáveis dos que então conhecia) de introduzir na contabilidade nacional ${ }^{443}$ a exploração dos recursos naturais não renováveis. Assim, criticou as medidas tradicionais (como o PIB) ${ }^{444}$ que podem indicar movimentação econômica sem demonstrar as condições - no que tange ao impacto no meio ambiente e nos recursos minerais - com que esta movimentação econômica ocorre e que a amparam.

No mais, trabalhando a ideia de sustentabilidade, ${ }^{445}$ indica que sua promoção demanda uma conduta enviesada em direção ao investimento, este que deve ser suficiente para manter intacto o estoque de capital, aceitando trocas e substituições entre os bens que formam este capital. ${ }^{446}$

Sintetiza sua opinião com uma pergunta e uma resposta:

O quê cada geração deve dar em troca dos recursos explorados se quiser respeitar a ética da sustentabilidade? Nós agora temos uma resposta em princípio. Ela deve adicionar ao capital social de outras formas, o suficiente para manter intacto o capital social agregado. Em outras palavras, ela deve repor os recursos utilizados com outros bens de igual valor $[\ldots]^{447}$

441 SOLOW, Robert M. An almost practical step towards sustainability cit., p. 163.

442 SUNSTEIN, Cass R.; ROWELL, Arden. On discounting regulatory benefits: risk, money, and intergenerational equity. U Chicago Law \& Economics, Olin Working Paper, n. 252, maio 2005, p. 24. "Robert Solow defines sustainability to require each generation to have the capacity to attain the same levels of welfare as those that preceded it".

443 O tema da contabilidade pública dos recursos naturais não renováveis, e especialmente a sua aplicação no Brasil atual, é de extrema relevância, embora escape ao objeto desta dissertação.

444 Sobre o tema, é interessante a proposta de Carlos Rojas em: ROJAS, Carlos. Valoración de recursos minerales bajo la teoria del desarrollo sostenible. Revista EIA, n. 13, p. 65-75, 2010.

445 SOLOW, Robert M. An almost practical step towards sustainability cit., p. 167-168: "If sustainability means anything more than a vague emotional commitment, it must require that something be conserved for the very long run. It is very important to understand what that something is: I think it has to be a generalized capacity to produce economic well-being [...] For the rest of this talk, I will assume that a sustainable path for the national economy is one that allows every future generation the option of being as well off as its predecessors. The duty imposed by sustainability is to bequeath to posterity not any particular thing - with the sort of rare exception I have mentioned - but rather to endow them with whatever it takes to achieve a standard of living at least as good as our own and to look after their next generation similarly. We are not to consume humanity's capital, in the broadest sense [...] A sustainable path for the economy is thus not necessarily one that conserves every single thing or any single thing. It is one that replaces whatever it takes from its inherited natural and produced endowment, its material and intellectual endowment. What matters is not the particular form that the replacement takes, but only its capacity to produce the things that posterity will enjoy. Those depletion and investment decisions are the proper focus".

446 Idem, ibidem, p. 170.

447 SOLOW, Robert M. An almost practical step towards sustainability cit., p. 170. Tradução livre. 
O autor sustenta que tais ideias, se aceitas, podem ser transformadas em políticas públicas, especialmente adotando a racionalidade de que "o comprometimento com a sustentabilidade é traduzido em comprometimento com um montante especificável de investimento produtivo". ${ }^{448} \mathrm{E}$ até mesmo, nessa toada, apresenta sua opinião sobre a já mencionada maldição da exploração dos recursos naturais não renováveis - que entendemos ir de acordo com o que foi apresentado acima: "o pecado capital não é minerar; é consumir as rendas da mineração". ${ }^{449}$

Finalmente, convém mencionar a contribuição daquele que é provavelmente o mais influente dos economistas a contribuir com pesquisa específica sobre a exploração dos recursos naturais não renováveis e seu impacto nas futuras gerações: John Hartwick. No curto artigo Equidade intergeracional e o investimento das rendas de recursos exauríveis, ${ }^{450}$ já inicia apresentando sua ideia central:

Investir todos os lucros ou rendas de recursos exauríveis em capital reprodutível como máquinas. Esta prescrição parece resolver o problema ético da geração presente enganar gerações futuras por "sobreconsumir" o produto atual, parcialmente imputável ao uso corrente de recursos exauríveis. ${ }^{451}$

Argumenta, tomando de partida a doutrina de Solow, ${ }^{452}$ que a medida impede o esgotamento dos recursos naturais não renováveis, inexistindo "consumo" das máquinas. Assim, nenhuma geração estará em melhor posição que outra - alcançando a equidade intergeracional. A partir de seus cálculos, Hartwick oferece como regra: "o investimento dos retornos de recursos exauríveis em capital reprodutível implica consumo per capita constante". ${ }^{453-454}$

448 SOLOW, Robert M. An almost practical step towards sustainability cit., p. 171.

449 Idem, ibidem

450 HARTWICK, John M. Intergenerational equity and the investing of rents from exhaustible resources. The American Economic Review, v. 67, n. 5, dez. 1977, p. 972-974.

451 Idem, ibidem, p. 972.

452 Hartwick aponta que Solow define equidade intergeracional como sendo: "per capita consumption remaining constant over time" (idem, p. 973).

453 Idem, p. 974. O autor voltou a tais ideias em outro artigo, publicado no ano seguinte (mas já referido, no prelo, no artigo antes abordado), abandonando a situação hipotética de uma sociedade com apenas uma espécie de recurso natural não renovável para analisar o tema na presença de uma multiplicidade de recursos. O texto, embora totalmente voltado aos cálculos diferenciais, conclui pela possibilidade de aplicação da regra considerando múltiplos recursos exauríveis. HARTWICK, John M. Substitution among exhaustible resources and intergenerational equity. The Review of Economic Studies, v. 45, n. 2, jun. 1978, p. 347-354.

454 O conteúdo da regra de Hartwick, contudo, não é totalmente pacífico. Há, ainda no presente, debate sobre o que está e o que não está contido na doutrina do referido autor. Asheim e Buchholz (ASHEIM, Geir B.; BUCHHOLZ, Wolfgang. The hartwick rule: myths and facts. CESifo Working Paper Series, jun. 2000, n. 299), por exemplo, se dedicaram a contrariar duas noções, que têm como equivocadas 
Essa regra chegou a ser indicada como "regra de ouro" ("rule of thumb"), dada sua relevância. ${ }^{455}$

A conclusão, embora possa parecer singela, é de grande relevância. Não apenas porque segue trazendo os direitos intergeracionais ao debate, como porque oferece uma regra para o tratamento das receitas de recursos naturais não renováveis, objetivando respeitar aqueles direitos. ${ }^{456}$ Como alerta Postali, "o resultado de Hartwick é mais a

(consideram-nas "mitos") sobre o texto de Hartwick: uma, de que a sua regra indica sustentabilidade; e outra, de que a regra presume que os recursos naturais não renováveis são passíveis de perfeita substituição por bens criados pelo homem, sendo então adequada apenas à noção de "sustentabilidade fraca". Também analisam as críticas a Hartwick de que sua teoria é meramente descritiva, e não prescritiva. Para Hamilton, Ruta e Tajibaeva (HAMILTON, Kirk; RUTA, Giovanni; TAJIBAEVA, Liaila. Capital accumulation and resource depletion: a hartwick rule counterfactual cit.), a questão sobre a prescritividade ou descritividade da doutrina diz com a impossibilidade de se vincularem as futuras gerações com os mesmos padrões de investimento/consumo decididos hoje. Com base em Hartwick, Richard Lee Hochstetler (HOCHSTETLER, Richard Lee. Recursos naturais e o mercado... cit., p. 142) afirma: "Para que o desenvolvimento seja sustentável no longo prazo é necessário que uma proporção das rendas seja direcionada à acumulação de capital físico e humano, para compensar a depreciação do capital natural, e que esses investimentos em capital físico e humano sejam produtivos e não dependentes da indústria de extração dos recursos naturais (em termos do modelo do Dutch Disease, isso significaria investimentos nos setores de bens comercializáveis)". O trabalho de Hartwick, segundo Maria Amélia Enríquez (ENRÍQUEZ, Maria Amélia Rodrigues da Silva. Equidade intergeracional na partilha dos benefícios dos recursos minerais: a alternativa dos fundos de mineração. Revista Iberoamericana de Economía Ecológica, v. 5, 2006, p. 63) "demonstra que o custo de uso, ou renda da escassez resultante da extração dos minerais, deve ser reinvestido em outras formas de capital com a finalidade de manter o nível de produção econômica e preservar o nível de bem-estar social”. Nas palavras de Hirdan Costa e Edmilson Moutinho (COSTA, Hirdan Katarina Medeiros; SANTOS, Edmilson Moutinho dos. Sustentabilidade e a destinação dos royalties de petróleo: uma contribuição teórica. Documento apresentado ao evento Cleaner production initiatives and challenges for a sustainable world, 3rd International Workshop - Advances in cleaner production. 2011. Disponível em: <http://www.advancesincleanerproduction.net/third/files/sessoes/6A/8/Costa_HKM\%20-\%20Paper\%20\%206A8.pdf>. Acesso em: 30 set. 2013, p. 2): "Hartwick [...] estabeleceu a seguinte regra: o investimento do retorno da atual exploração de recursos naturais não renováveis em capital reprodutível implica um consumo per capita constante. Apesar da ausência do recurso natural em si, os investimentos realizados, com as rendas geradas, garantiriam uma riqueza futura consistente na manutenção da renda individual e na riqueza social". Finalmente, ensina Sollow (SOLOW, Robert M. An almost practical step towards sustainability cit., p. 170): "This is sometimes known as Hartwick's rule: a society that invests aggregate resource rents in reproducible capital is preserving its capacity to sustain a constant level of consumption".

455 WORLD BANK. Where is the wealth of nations? Measuring capital for the $21^{\text {st }}$ century cit., p. 49. E: SOLOW, Robert M. On the intergenerational allocation of natural resources cit., p. 148, "Hartwick's rule is a better-than-average rule of thumb".

456 Como colocam Cruz e Ribeiro (CRUZ, Bruno de Oliveira; RIBEIRO, Márcio Bruno. Sobre maldições e bençãos: é possível gerir recursos naturais de forma sustentável? Uma análise sobre os royalties e as compensações financeiras no Brasil. Rio de Janeiro: IPEA, 2009. Texto para discussão n. 1412, p. 17): "A regra de Hartwick garante que o consumo entre gerações, na ausência de crescimento populacional e progresso tecnológico, seja constante ao longo do tempo. Logo, seria necessário transformar as riquezas naturais em insumo produtivo para que as gerações futuras não sejam penalizadas pelo consumo do recurso esgotável no presente". Para Serra (SERRA, Rodrigo Valente. Contribuições para o debate acerca da repartição dos royalties petrolíferos no Brasil cit., p. 67-68), "a ideia é que a atual deixe para a geração futura capital reprodutível, o suficiente para que seja mantido um padrão de vida satisfatório. Segundo Hartwick, é possível manter um nível de consumo per capita constante no decorrer do tempo e garantir a eqüidade entre gerações. Para isso, a geração atual deve converter parte da renda gerada (renda de Hotelling) pela extração de recursos não renováveis em máquinas e trabalho. É a transferência de estoque de recursos não renováveis em estoques de capital reprodutível". E afirmam Asheim e Buchholz 
indicação do investimento mínimo necessário para evitar a queda no padrão de vida da população que poderia resultar da crescente escassez do recurso não renovável, do que o estabelecimento de um nível ótimo de investimento" ${ }^{457-458}$ Complementa Hirdan Katarina de Medeiros Costa: "Apesar da ausência do recurso natural em si, os investimentos realizados, com as rendas minerarias geradas podem garantir uma riqueza futura consistente, permitindo a manutenção da renda individual e da riqueza social". ${ }^{459} \mathrm{Ou}$ ainda na leitura de Maurício de Carvalho Amazonas: "para a manutenção de uma utilidade não declinante, posta em termos de um consumo não declinante, requer-se um reinvestimento das rendas provenientes do uso dos recursos exauríveis em capital reprodutível". ${ }^{460}$

A referida doutrina é útil também na tomada de decisão quanto à comum dualidade "gasto social x investimento", como alertam Gobetti e Serra. ${ }^{461}$

E, mais, a regra de Hartwick se presta a indicar, com suas razões e fundamentos econômicos, aquilo que já parece intuitivo (e será melhor tratado adiante): a diversificação produtiva se revela como chave nas sociedades em que a indústria mineral se faz relevante. ${ }^{462}$ Aliás, "uma vez que consumir as rendas dos recursos exauríveis é

(ASHEIM, Geir B.; BUCHHOLZ, Wolfgang. The hartwick rule: myths and facts cit., p. 2. Disponível em: <http://ssrn.com/abstract=258960>): "Hartwick's result became so attractive because it gave an extension to a basic message of neoclassical resource economics [...]: Exhaustible natural resource inputs can be substituted by manmade capital in a way that depleting these natural resources does not harm future generations. Substitutability between natural and manmade capital thus, in spite of the exhaustibility of natural resources, may allow for equitable consumption for all generations, and Hartwick (1977) seemed to have found the investment policy that would bring about sustainability in this way".

457 POSTALI, Fernando Antonio Slaibe. Renda mineral, divisão de riscos e benefícios governamentais na exploração de petróleo no Brasil cit., p. 21.

458 SOLOW, Robert M. On the intergenerational allocation of natural resources cit., p. 146. "The policy of investing resource rents in reproducible capital suggests irresistibly that some appropriately defined stock is being maintained intact, and that consumption can be regarded as the 'interest' on that stock. This interpretation turns out to be quite right".

459 COSTA, Hirdan Katarina de Medeiros. O princípio da justiça intra e intergeracional como elemento na destinação das rendas de hidrocarbonetos: temática energética crítica na análise institucional brasileira. 2012. Tese (Doutorado) - Universidade de São Paulo. p. 33.

460 AMAZONAS, Mauricio de Carvalho. Valor e meio ambiente: elementos para uma abordagem evolucionista. 2001. Tese (Doutorado) - Faculdade de Economia da Universidade Estadual de Campinas. p. 41.

461 GOBETTI, Sérgio Wulff; SERRA, Rodrigo Valente. Novo marco regulatório do petróleo: desafios na transição do regime de concessão para o regime de partilha. Brasília: ESAF, 2011. Monografia premiada com o segundo lugar no XVI Prêmio Tesouro Nacional, 2011. p. 50. Tópicos Especiais de Finanças Públicas. Brasília (DF).

462 POSTALI, Fernando Antonio Slaibe. Renda mineral, divisão de riscos e benefícios governamentais na exploração de petróleo no Brasil cit., p. 21-22: "Em outras palavras, a Regra de Hartwick estabelece que um país deve usar a renda de seus recursos para financiar a diversificação da economia na direção de atividades mais dependentes de trabalho e capital físico do que de recursos naturais". Edmilson Santos e Giovani Loss (SANTOS, Edmilson Moutinho dos; LOSS, Giovani R. Resource curse thesis e a regulação das participações governamentais do petróleo e gás no Brasil. Revista de Direito Público da Economia - RDPE, Belo Horizonte, ano 1, n. 4, Belo Horizonte: Fórum, out.-dez. 2003) afirmam: "Por 
literalmente consumir capital, a regra de Hartwick de investir as rendas em outras formas de capital tem apelo para os preocupados com o desenvolvimento sustentável". ${ }^{463}$

Tampouco a referida singeleza percebida das conclusões pode nublar sua grande relevância: Hamilton, Ruta e Tajibaeva se dedicaram a investigar como (economicamente) estariam no presente alguns países exploradores de recursos naturais não renováveis que deixaram de observar a regra de Hartwick $^{464}$ (aplicam sua metodologia desde 1970). ${ }^{465}$ Reputam a existência de uma relação inversamente proporcional entre a abundância de recursos naturais não renováveis e o uso dessas receitas consoante da regra de Hartwick; ${ }^{466}$ e apontam alguns países, como Nigéria e Venezuela, que poderiam ter hoje estoques de "capitais produzidos" até 05 (cinco) vezes maiores, ou comparáveis aos níveis da Coreia do Sul, passando assim a depender muito menos da exploração mineral. Mas que escolheram por aplicar suas receitas em consumo. ${ }^{467-468}$ Botsuana, por outro lado, é um dos

essa regra, portanto, os países ricos em petróleo e gás devem aplicar as rendas provenientes desses recursos no financiamento da diversificação da economia em direção a atividades mais dependentes de trabalho e capital físico do que do petróleo e gás, a fim de evitar os malefícios já citados da resource curse e a fim de garantir que os benefícios desses recursos perpetuem para as gerações futuras [...] Sua implementação na prática, naturalmente, deve ser por meio da regulação das rendas petroleiras governamentais, buscando-se limitar ou até mesmo direcionar a aplicação dessas rendas pelos Governos”. Já Maria Amélia Enríquez (ENRÍQUEZ, Maria Amélia. Mineração: maldição ou dádiva. Os dilemas do desenvolvimento sustentável a partir de uma base mineira. São Paulo: Signus, 2008. p. 61) consigna: “Os meios financeiros para os investimentos devem vir da 'renda de escassez' dos recursos não-renováveis. Este princípio ficou conhecido como 'regra de Hartwick'. Para que essa regra seja satisfeita, é necessário haver uma política deliberada de incentivo ao investimento em bens de capital". VAN DER PLOEG, Frederick. Challenges and opportunities for resource rich economies cit., p. 39.

464 HAMILTON, Kirk; RUTA, Giovanni; TAJIBAEVA, Liaila. Capital accumulation and resource depletion: a hartwick rule counterfactual cit., p. 3. Dizem os autores: "we limit ourselves to comparing an estimate of the current stock of produced capital with a hypothetical estimate of how large this stock could be if resource rents had been invested in produced capital. We assume that all resource rents are invested in produced capital for simplicity, although the theory suggests more generally that resource rents could be invested in a range of assets, including human capital - if any of the countries highlighted below had in fact been investing their resource rents in human capital (quite unlikely given the observed levels of per capita income) then our methodology would produce a biased picture of their investment performance".

465 Em suas palavras, o que querem responder é: "How rich would countries be in the year 2000 had they followed the Hartwick Rule since 1970?" Observando também que "The countries shown in this table are those having both exhaustible resources and a sufficiently long time series of data on gross investment and resource rents" (idem, ibidem, p. 5).

466 Idem, ibidem, p. 6: "high negative correlation between resource abundance and the difference between baseline and counterfactual capital accumulation - a simple regression shows that a $1 \%$ increase in resource dependence is associated with a $9 \%$ increased difference between counterfactual and actual capital".

467 Idem, ibidem, p. 6-7. Deve-se ressaltar que o Brasil é apresentado nesse estudo como país não dependente dos recursos naturais não renováveis; e que está, junto com um conjunto de países que inclui Tailândia e Índia, dentre aqueles que investiram até mais do que comanda a regra de Hartwick.

468 Vale mencionar que os autores concluem com algumas ressalvas. A principal delas é de que "o mundo real é mais complexo": embora o artigo seja manifestamente favorável à observação da regra de Hartwick, nem sempre a sua rejeição (aplicação das rendas em consumo) deve ser condenada. Como observam, nos países mais pobres a aplicação dos valores em consumo é, muitas vezes, imperativa, já que "a alternativa pode ser a inanição". Finalmente, mencione-se que, embora se trate de opinião deveras 
países - sempre mencionado como exemplo dos que souberam melhor gerir suas receitas de recursos naturais não renováveis - que segue rigorosamente a regra de Hartwick e apresenta desempenho econômico destacado. ${ }^{469-470}$

Cabe referir, também, um outro aspecto positivo da doutrina de Hartwick, esse relacionado à transparência: trata-se de política de sustentabilidade útil na medida em que é aberta ao monitoramento e à fiscalização ${ }^{471}$ - sujeito, é claro, a discordâncias quanto aos métodos de cálculo dos investimentos e mesmo quanto à identificação precisa daquele montante que deverá ser investido.

Embora não se pretenda nesta oportunidade analisar os conceitos (e graus) de sustentabilidade, vale mencionar que Hartwick é frequentemente associado à ideia de "sustentabilidade fraca". $472-473$

Hotelling, Solow e Hartwick, todos economistas influentes na formação do pensamento sobre a exploração de recursos naturais não renováveis, dão destaque à questão intergeracional. Embora muitas vezes sem o apoio de melhores definições sobre a "justiça" ou "equidade" entre gerações, é certo que o aspecto temporal foi decisivo na formação de suas ideias e foi cuidadosamente inserido em seus modelos.

Muito mais do que os cálculos e métodos por ele utilizados, e as muitas críticas e elogios recebidos, a consideração (e até mesmo priorização) dos interesses das futuras gerações é o que nos importa, por ora.

Sobre o tema, e introduzindo o que se pretende tratar adiante, uma observação se faz útil: os trabalhos dos economistas acima citados (aqueles posteriores a 1971), quase todos, ${ }^{474}$ fazem referência a John Rawls ou sua obra (Uma Teoria da Justiça). O que parece

interessante, e que, pretendendo demonstrar a relevância da contribuição de Hartwick, aplica métodos e premissas que não são avaliados como corretos ou incorretos nesta dissertação.

WORLD BANK. Where is the wealth of nations? Measuring capital for the $21^{\text {st }}$ century cit., p. 49.

$470 \mathrm{O}$ mesmo estudo foi apresentado como capítulo de livro publicado pelo Banco Mundial: Idem, ibidem, p. 49-60.

471 Idem, ibidem, p. 102.

472 ENRÍQUEZ, Maria Amélia Rodrigues da Silva. Equidade intergeracional... cit., p. 63: “A ideia de sustentabilidade fraca admite que o capital natural e o capital produzido pelo homem são perfeitamente substituíveis [...] De acordo com esse enfoque, a redução do estoque de capital natural é aceitável se ele for convertido em renda sustentável, ou seja, em investimentos alternativos que garantam um fluxo de rendimento no futuro".

473 A noção de sustentabilidade "fraca" ou "forte" diz respeito à possibilidade de substituição entre diferentes tipos de capital. Sobre o tema, v. TREMMEL, Joerg. A theory of intergenerational justice cit., p. 69 e ss.

474 SOLOW, Robert M. Intergenerational equity and exhaustible resources cit., p. 45; SOLOW, Robert M. On the intergenerational allocation of natural resources cit., p. 143; HARTWICK, John M. 
referendar, na afirmação de Amartya Sem, que a economia "pode tornar-se mais produtiva se der uma atenção maior e mais explícita às considerações éticas que moldam o comportamento e o juízo humanos". 475

\section{2.b.iii. A Filosofia política de John Rawls e o problema da justiça entre gerações.}

2.b.iii.1. Aspectos fundamentais da justiça como equidade.

Ronald Dworkin, reconhecido jurista, falou sobre John Rawls na Universidade de Harvard, quando dos ritos do falecimento deste, em fevereiro de $2003:{ }^{476}$

Uma Teoria da Justiça juntou-se ao cânone de obras que qualquer pessoa propriamente educada era esperada a ao menos reconhecer; ela apareceu de imediato nas listas de leitura de direito, economia, história e teoria social assim como de filosofia, e três décadas depois as ideias principais de Rawls - a posição original com seu véu de ignorância como uma estratégia para pensar sobre justiça e o objetivo de tornar aqueles entre nós que estão em pior posição tão melhores quanto possam estar - são até mais como uma moeda comum: elas são agora a propriedade intelectual comum de milhões de pessoas [...] A experiência de pensamento de Rawls, instantaneamente memorável, sobre o quê as pessoas decidiriam por elas mesmas em condições equânimes, que olha para a sociedade de dentro, do ponto de vista dos indivíduos, um por um [...] deu às suas ideias a mais intensa força que um argumento filosófico pode ter: a pegada de pertinência e o choque de reconhecimento.

O trecho transcrito dá perspectiva à obra, contextualizando sua relevância não apenas para a filosofia política, mas - e talvez aí sua maior importância - para diversas outras áreas de conhecimento, o direito (e não apenas na filosofia do direito) incluído.

É manifesto que nesta oportunidade não há espaço - ou pretensão - de se estudar em profundidade a obra de Rawls. Interessa aos objetivos desta dissertação trazer suas ideias sobre um ponto específico: a justiça entre gerações. Nada obstante, antes de adentrar nela, cabem algumas considerações, ainda que breves e perfunctórias, sobre a Teoria de Justiça de John Rawls, mesmo para possibilitar que melhor se entenda o quadro no qual inserido o item específico de análise.

Intergenerational equity and the investing of rents from exhaustible resources cit., p. 974; HARTWICK, John M. Substitution among exhaustible resources and intergenerational equity cit., p. 354.

475 SEN, Amartya. Sobre ética e economia. Trad. Laura Teixeira Motta. rev. técnica Ricardo Doninelli Mendes. São Paulo: Companhia das Letras, 1999. p. 25.

476 DWORKIN, Ronald. John Rawls. The Harvard Review of Philosophy, v. 11, 2003, p. 7-8. Tradução livre. 
A referida obra de Rawls parte de uma tentativa confessa ${ }^{477}$ de contrapor a visão utilitarista, ${ }^{478}$ então predominante, da filosofia moral e política, adentrando a ideia de justiça e arraigada especialmente nas instituições do Estado. ${ }^{479-480}$

Pretendeu "generalizar e elevar a uma ordem mais alta de abstração a teoria tradicional do contrato social representada por Locke, Rousseau e Kant", ${ }^{481}$ de forma que “o pacto social é substituído por uma situação inicial que incorpora certas restrições de conduta baseada em razões destinadas a conduzir a um acordo inicial sobre os princípios da justiça". ${ }^{482}$

Assim, o que propõe - e que chamou de justiça como equidade ${ }^{483}$ - é a aplicação de uma concepção de justiça na estrutura básica da sociedade, ${ }^{484-485}$ para fixação

477 RAWLS, John. Uma teoria da justiça. Trad. Almiro Pisetta e Lenita M. R. Esteves. São Paulo: Martins Fontes, 1997. p. 21-22 (Prefácio).

478 "À primeira vista, parece pouco provável que pessoas que se vêem como iguais, com direito a fazer exigências mútuas, concordariam com um princípio que pode exigir para alguns expectativas de vida inferiores, simplesmente por causa de uma soma maior de vantagens desfrutadas por outros. Uma vez que cada um busca proteger seus próprios interesses, sua capacidade de promover sua concepção do bem, ningupem tem razão para aceitar uma perda duradoura para si mesmo a fim de causar um saldo líquido maior de satisfação [...] Assim, parece que o princípio da utilidade é incompatível com a concepção da cooperação social entre iguais para a vantagem mútua" (RAWLS, John. Uma teoria da justiça cit., p. 15-16). E também: "o princípio da eficiência sozinho não pode servir como uma concepção da justiça" (p. 75).

479 VITA, Álvaro de. A justiça igualitária e seus críticos. 2. ed. São Paulo: WMF Martins Fontes, 2007. p. 195-196: "Estamos agora em condições de precisar o sentido da célebre afirmação de Rawls de que 'o utilitarismo não leva a sério a distinção entre as pessoas'. Existem circunstâncias sob as quais o utilitarismo, em qualquer de suas variantes, seria levado a recomendar que o bem-estar de algumas (e mesmo muitas) pessoas seja tratado de forma instrumental à elevação máxima do benefício total ou da utilidade per capita. E Rawls recusa isso com base em uma interpretação do imperativo kantiano segundo o qual não devemos tratar os outros somente como meios mas sempre também como fins em si mesmos. Mas levar a sério a distinção entre as pessoas, isto é, considerar que o bem-estar de cada um tem valor, não nos compromete com a suposição - como pensa Nozick - de que também o sacrifício de cima para baixo não possa ser justificado".

480 GARGARELLA, Roberto. As teorias da justiça depois de Rawls: um breve manual de filosofia política. Trad. Alonso Reis Freire. rev. trad. Elza Maria Gasparotto; rev. téc. Eduardo Appio. São Paulo: WMF Martins Fontes, 2008. p. 1: "Rawls orienta boa parte de seu trabalho para responder à pergunta sobre quando podemos dizer que uma instituição funciona de modo justo".

481 RAWLS, John. Uma teoria da justiça cit., p. 22 (Prefácio).

482 Idem, ibidem, p. 3.

483 A locução "transmite a ideia de que os princípios da justiça são acordados numa situação inicial que é equitativa. A frase não significa que os conceitos de justiça e eqüidade sejam a mesma coisa, assim como a frase 'poesia como metáfora' não significa que os conceitos de poesia e metáfora sejam a mesma coisa" (RAWLS, John. Uma teoria da justiça cit., p. 14).

484 Essa atuação sobre a estrutura básica pode ser entendida como regulação da "escolha de uma constituição política e os elementos principais do sistema econômico e social". RAWLS, John. Uma teoria da justiça cit., p. 8. E explica mais adiante em sua obra: "A estrutura básica é um sistema público de regras que definem um esquema de atividades que conduz os homens a agirem juntos no intuito de produzir uma quantidade maior de benefícios e atribuindo a cada um certos direitos reconhecidos a uma parte dos produtos. O que uma pessoa faz depende do que as regras públicas determinam a respeito do que ela tem direito de fazer, e os direitos de uma pessoa dependem do que ela faz. Alcança-se a distribuição que resulta desses princípios honrando os direitos determinados pelo que as pessoas se comprometem a fazer à luz dessas expectativas legítimas" (p. 90). 
de princípios básicos a reger as relações entre os indivíduos. Princípios esses que se prestarão "para escolher entre as várias formas de ordenação social que determinam essa divisão de vantagens e para selar um acordo sobre as partes distributivas adequadas" ${ }^{\text {486 }}$ ou, em outras palavras, para fixar direitos e deveres no cerne dessa sociedade. A justiça a que se refere o título da obra de Rawls, "se define pela atuação de seus princípios na atribuição de direitos e deveres e na definição da divisão apropriada de vantagens sociais". 487

Então, "a idéia norteadora é que os princípios da justiça para a estrutura básica da sociedade são o objeto do consenso original. São esses princípios que pessoas livres e racionais, preocupadas em promover seus próprios interesses, aceitariam numa posição inicial de igualdade como definidores dos termos fundamentais de sua associação". 488

Daí é que Rawls começa a apresentar os caracteres centrais de sua tese.

Um desses elementos é a noção de posição original ${ }^{489}$ (não como uma verificação histórica, mas como situação hipotética argumentativa), assemelhada ao estado de natureza de Hobbes. ${ }^{490} \mathrm{~A}$ ideia é questionar: nessa posição original, pré-formação da sociedade, ${ }^{491}$ quais seriam os princípios de justiça que os indivíduos (pressupondo-os racionais e mutuamente desinteressados ${ }^{492}$ ) elegeriam ${ }^{493-494}$ para formação da sociedade e,

485 Sociedade, segundo Rawls, "é uma associação mais ou menos autossuficiente de pessoas que em suas relações mútuas reconhecem certas regras de conduta como obrigatórias e que, na maioria das vezes, agem de acordo com elas" (RAWLS, John. Uma teoria da justiça cit., p. 4).

486

487

488

489 nele estabelecidos sejam eqüitativos. Esse fato delimita o conceito de 'justiça como eqüidade' [...] As concepções da justiça devem ser classificadas por sua aceitabilidade perante essas pessoas nessas circunstâncias" (idem, p. 19).

490 Vale mencionar a lição de Häberle: "Taking into account the dimension of time, the 'social contract' presents itself as a 'generational contract' [...] The 'people' per se is a cooperation, a coexistence, and a succession of several generations. The constitutional state builds the 'body' and millions of smaller and larger contract conclusions in private business as well as in public politics create a part of the real basis for 'generational' or respectively 'intergenerational' 'harmonious' behavior ate the macro level". HÄBERLE, Peter. A constitutional law for future generations - the 'other' form of the social contract: the generation contract. In: TREMMEL, Joerg (Ed.). Handbook of intergenerational justice cit., p. 224.

491 "Naturalmente a finalidade dessas condições é representar a igualdade entre os seres humanos como pessoas éticas, como criaturas que têm uma concepção do seu próprio bem e que são capazes de ter um senso de justiça [...] Precisamos de uma concepção que nos capacite a visualizar nosso objetivo à distância: a noção intuitiva da situação inicial deverá fazê-lo" (RAWLS, John. Uma teoria da justiça cit., p. 21-24).

492 Idem, ibidem, p. 15.

493 Daí que se diz que a doutrina de John Rawls é voluntária e contratualista, pois "vai ao encontro dos princípios que pessoas livres e iguais aceitariam em circunstâncias equitativas [...] A situação inicial deve ser caracterizada por acordos totalmente aceitos" (idem, p. 15). E ainda: "o conteúdo do consenso pertinente não consiste em formar uma determinada sociedade ou adotar uma determinada forma de governo, mas em aceitar certos princípios morais. Além disso, os compromissos a que nos referimos são puramente hipotéticos: uma visão contratualista acredita que certos princípios seriam aceitos numa 
especialmente, de suas instituições, e para regência das regras distributivas? Como coloca

o Autor, "dizer que uma certa concepção da justiça seria escolhida na posição original

equivale a dizer que a deliberação racional que satisfaz certas condições e restrições atingiria uma certa conclusão". ${ }^{495-496}$

Indissociável desta é a utilização do conceito de véu da ignorância, a determinar que os indivíduos, na posição original, não conhecem "seu lugar na sociedade, a posição de sua classe ou o status social e ninguém conhece sua sorte na distribuição de dotes e habilidades naturais, sua inteligência, força e coisas semelhantes". ${ }^{497-498}$ Assim,

situação inicial bem definida. O mérito da terminologia do contrato é que ela transmite a ideia de que princípios da justiça podem ser concebidos como princípios que seriam escolhidos por pessoas racionais e que assim as concepções da justiça podem ser explicadas e justificadas" (p. 18). E também: "O objetivo da abordagem contratualista é o de estabelecer que tomados em seu conjunto esses pressupostos estabelecem parâmetros adequados para os princípios de justiça aceitáveis” (p. 20).

494 Em relação à nota anterior, vale mencionar que a doutrina de Rawls é contratualista, mas "seu modelo particular de contrato hipotético implica uma óbvia e direta rejeição às versões não idealizadas do contratualismo", estas que tratam de um acordo "real", aceitando que todos os assuntos podem ser transacionados, não dependendo "de outra coisa senão dos desejos ou preferências das pessoas", e sujeitos ao menor ou maior poder de negociação de cada uma. Já a ideia de Rawls "vem negar, e não refletir - como parece ocorrer nos contratos hobbesianos -, nossa desigual capacidade de negociação. Portanto, o contratualismo hobbesiano e o rawlsiano surgem comprometidos com uma ideia diferente de igualdade: a igualdade que interessa a Rawls não tem a ver com o igual poder físico (capaz de nos forçar a firmar um contrato mutuamente benéfico), mas com nosso igual status moral, que nos força, em todo caso, a desenvolver uma preocupação com a imparcialidade - pelo fato de se considerarem imparcialmente as preferências e interesses de cada um" (GARGARELLA, Roberto. As teorias da justiça depois de Rawls cit., p. 15-18).

495 E ainda: "a posição original deve ser interpretada de modo que possamos, a qualquer tempo, adotar a sua perspectiva. Deve ser indiferente a ocasião em que alguém adota esse ponto de vista, ou quem o faz: as restrições devem ser tais que os mesmos princípios são sempre escolhidos". RAWLS, John. Uma teoria da justiça cit., p. 149. Afirmou Rawls em outra oportunidade: "One feature of it might be put this way: injustice exists because basic agreements are made too late (Richard Zeckhauser). People already know their social positions and relative strength in bargaining, their abilities and preferences, and these contingencies and knowledge of them cumula-tively distort the social system. In an at-tempt to remedy this difficulty, contract theory introduces the notion of the original position" (RAWLS, John. Some reasons for the maximin criterion. The American Economic Review, v. 64, n. 2, Papers and Proceedings of the Eighty-sixth Annual Meeting of the American Economic Association, maio 1974, p. 141).

496 VITA, Álvaro de. A justiça igualitária e seus críticos cit., p. 184: “A posição original deve ser concebida de forma que um acordo razoável sobre princípios possa ser alcançado; concebê-la assim, por sua vez, é uma forma de exprimir a ideia de que uma sociedade bem-ordenada é aquela na qual a igualdade humana fundamental é apropriadamente reconhecida. Esse argumento não deixa de ser circular, mas, como afirma Brian Barry, trata-se de um círculo não vicioso".

497 RAWLS, John. Uma teoria da justiça cit., p. 13. Ainda: "Supõe-se, então, que as partes não conhecem certos tipos de fatos particulares. Em primeiro lugar, ninguém sabe qual é o seu lugar na sociedade, a sua posição de classe ou seu status social; além disso, ninguém conhece a sua sorte na distribuição dos dotes naturais e habilidades, sua inteligência e força, e assim por diante. Também ninguém conhece a sua concepção do bem, as particularidades de seu plano de vida racional, e nem mesmo os traços característicos de sua psicologia, como por exemplo a sua aversão ao risco ou sua tendência ao otimismo ou ao pessimismo. Mais ainda, admito que as partes não conhecem as circunstâncias particulares de sua própria sociedade. Ou seja, elas não conhecem a posição econômica e política dessa sociedade, ou o nível de civilização e cultura que ela foi capaz de atingir [...] $\mathrm{Na}$ medida do possível, o único fato particular que as partes conhecem é que a sua sociedade está sujeita às circunstâncias da justiça e a qualquer consequência que possa decorrer disso. Entretanto, considere-se como um dado que elas conhecem os fatos genéricos sobre a sociedade humana. Elas entendem as relações políticas e os 
cobertos pelo mencionado véu, as partes na posição original "não sabem como as várias alternativas irão afetar o seu caso particular, e são obrigadas a avaliar os princípio (sic) unicamente com base nas considerações gerais"; ${ }^{499}$ os sujeitos estarão despidos de preconceitos e impossibilitados de fazerem escolhas que lhes beneficiem especificamente.

Daí resultará, segundo Rawls, um "consenso ou ajuste equitativo", 500 possibilitando "a escolha unânime de uma concepção particular da justiça". 501

A partir dessa equação é que Álvaro de Vita se refere à teoria de Rawls como "contratualismo ${ }^{502}$ iluminista": porque oferece "justificações inteligíveis para os arranjos sociais básicos (e para as formas de autoridade que constituem)". 503

princípios da teoria econômica; conhecem a base da organização social e as leis que regem a psicologia humana. De fato, presume-se que as partes conhecem quaisquer fatos genéricos que afetem a escolha dos princípios da justiça” (idem, ibidem, p. 147-148).

498 GARGARELLA, Roberto. As teorias da justiça depois de Rawls cit., p. 22: “esse 'véu' não os impede de reconhecer certas proposições gerais, tais como as descobertas básicas que as ciências sociais fizeram em matéria de economia, psicologia social etc. Em suma, o que os citados agentes desconhecem é qualquer informação que lhes permita orientar a decisão em questão a seu próprio favor”. Ainda: VITA, Álvaro de. A justiça igualitária e seus críticos cit., p. 182: "Rawls sustenta que os fatores que respondem pelo acesso desigual a recursos sociais escassos são arbitrários de um ponto de vista moral. Esses fatores, por isso, não podem ter nenhum peso no acordo sobre os princípios da justiça que deverão vigorar em uma sociedade constituída por cidadãos livres e iguais".

499 RAWLS, John. Uma teoria da justiça cit., p. 147.

500 Idem, ibidem, p. 13. E: "O objetivo é excluir aqueles princípios cuja aceitação de um ponto de vista racional só se poderia propor, por menor que fosse sua probabilidade de êxito, se fossem conhecidos certos fatos que do ponto de vista da justiça são irrelevantes. Por exemplo, se um homem soubesse que era rico, ele poderia achar racional defender o princípio de que vários impostos em favor do bem-estar social fossem considerados injustos; se ele soubesse que era pobre, com grande probabilidade proporia o princípio contrário. Para representar as restrições desejadas imagina-se uma situação na qual todos estejam privados desse tipo de informação. Fica excluído o conhecimento dessas contingências que criam disparidades entre os homens e permitem que eles se orientem pelos seus preconceitos. Desse modo chega-se ao véu da ignorância de maneira natural" - p. 21.

501 Idem, ibidem, p. 151.

502 GARGARELLA, Roberto. As teorias da justiça depois de Rawls cit., p. 14. "Em linhas gerais, poderíamos dizer que a especial importância do contratualismo deve-se ao fato de nos ajudar a responder, de modo interessante, a duas perguntas básicas de qualquer teoria moral: a) $\mathrm{O}$ que a moral exige de nós? E b) Por que devemos obedecer a certas regras? À primeira pergunta, o contratualismo responde: a moral exige que cumpramos aquelas obrigações que nos comprometemos a cumprir. E, ante a segunda pergunta, o contratualismo afirma que a razão pela qual devemos obedecer a certas regras é porque nos comprometemos a isso. Não é por acaso, nesse sentido, que o contratualismo, como proposta teórica, tenha surgido e se tornado popular depois de uma época em que perguntas como as mencionadas só encontravam respostas por meio da religião".

503 VITA, Álvaro de. A justiça igualitária e seus críticos cit., p. 178. Prossegue: "O contratualismo rawlsiano não pode justificar os princípios de justiça que recomenda argumentando, como fazem os adeptos da perspectiva hobbesiana, que cada um dos membros da sociedade seria racionalmente levado a aceitá-los consultando apenas seu interesse próprio. Em vez de nos perguntarmos pelo que cada um pode aceitar, tendo em vista somente seu interesse próprio, perguntamo-nos pelo que cada um não tem como rejeitar se considerar eqüitativamente os interesses de todos aqueles (incluindo a si próprio) que deverão conduzir sua vida sob uma mesma estrutura institucional. A justificação deve ser conduzida, agora, de um ponto de vista adequadamente construído de imparcialidade moral. Estamos nos aproximando, como não é difícil de perceber, do dispositivo concebido por Rawls para testar as justificações oferecidas a diferentes princípios substantivos da justiça". 
Dadas essas condições iniciais, referidas acima, Rawls apresenta quais seriam os princípios de justiça que os indivíduos escolheriam para reger o Estado e as instituições: a concepção de justiça aplicada sobre a estrutura básica da sociedade.

São 02 (dois) ${ }^{504}$ estes princípios da justiça, conectados por uma "noção mais geral de justiça" ${ }^{505} \mathrm{O}$ primeiro (ligado a direitos e liberdades fundamentais) fixa: "cada pessoa deve ter um direito igual ao mais abrangente sistema de liberdades básicas iguais que seja compatível com um sistema semelhante de liberdades para todos". ${ }^{506} \mathrm{O}$ segundo (ligado a benefícios econômicos e sociais) dispõe:

as desigualdades econômicas e sociais devem ser ordenadas de tal modo que, ao mesmo tempo: (a) tragam o maior benefício possível para os menos favorecidos, obedecendo às restrições do princípio da poupança justa, e (b) sejam vinculadas a cargos e posições abertos a todos em condições de igualdade equitativa de oportunidades. ${ }^{507}$

O segundo princípio da justiça - que ora mais nos interessa -, especialmente no item (a), segundo Rawls, deve obedecer ao princípio da diferença, segundo o qual "as maiores expectativas daqueles em melhor situação são justas se, e somente se, funcionam como parte de um esquema que melhora as expectativas dos membros menos favorecidos da sociedade". ${ }^{508}$ Então, as vantagens de um são aceitas na sociedade apenas na medida em que importam na melhoria do menos afortunado: a estrutura básica é afetada "de modo que

504 Obedecem a uma "ordenação serial", de forma o primeiro antecede o segundo, não podendo o primeiro ser violado em razão de maior efetividade do segundo: as liberdades básicas só podem ser restringidas quando em confronto com outras liberdades básicas. RAWLS, John. Uma teoria da justiça cit., p. 65.

505 A "noção mais geral" é assim formulada: "Todos os valores sociais - liberdade e oportunidade, renda e riqueza, e as bases sociais da autoestima - devem ser distribuídos igualitariamente a não ser que uma distribuição desigual de um ou de todos esses valores traga vantagens para todos”. Idem, ibidem, p. 66.

506 Idem, ibidem, p. 333.

507 Idem. Ainda: "O segundo princípio insiste que cada pessoa se beneficie das desigualdades permissíveis na estrutura básica. Isso significa que cada homem representativo definido por essa estrutura, quando a observa como um empreendimento em curso, deve achar razoável preferir as suas perspectivas com a desigualdade às suas perspectivas sem ela. Não se permite que diferenças de renda ou imposições de autoridade e responsabilidade sejam justificadas pela alegação de que as vantagens de uns em uma posição são compensadas pelas maiores vantagens de outros em posições diferentes. Muito menos ainda podem infrações à liberdade ser contrabalançadas desse modo". Idem, ibidem, p. 69.

508 RAWLS, John. Uma teoria da justiça cit., p. 79-80. Prossegue na p. 80: "A ideia intuitiva é de que a ordem social não deve estabelecer e assegurar as perspectivas mais atraentes dos que estão em melhores condições a não ser que, fazendo isso, traga também vantagens para os menos afortunados [...] o princípio da diferença é uma condição fortemente igual no sentido de que, se não houver uma distribuição que melhore a situação de ambas as pessoas (limitando-nos, para simplificar, ao caso de duas pessoas), deve-se preferir uma distribuição igual [...] Não importa o quanto a situação de cada pessoa seja melhorada; do ponto de vista do princípio da diferença, não há ganho algum a não ser que o outro também ganhe". E na p. 81: "De acordo com o princípio da diferença, a desigualdade é justificável apenas se a diferença de expectativas for vantajosa para o homem representativo que está em piores condições". 
as contingências trabalhem para o bem dos menos favorecidos". ${ }^{509}$ O princípio da diferença é expressão do que os economistas se referem como critério (de eleição em casos de incerteza) maximin, a dizer: a escolha do que trará maximização (max) aos menos favorecidos (min), o que efetivamente se apresenta na doutrina rawlsiana. ${ }^{510}$

Nada obstante, o próprio autor inicialmente reconheceu a semelhança (entre o princípio da diferença e o critério maximin), mas assim justificou a terminologia diferenciada: "não é recomendável usar o mesmo nome para duas coisas tão diferentes": uma simples regra de escolha, de um lado; e um princípio da justiça, de outro. Argumentou, mais, que chamar o princípio da diferença de critério maximin sugeriria equivocadamente que a eleição desse princípio da justiça "deriva de uma suposição de uma aversão muito alta ao risco". É dizer: o critério maximin é identificado na economia como adequado para escolha de indivíduos com aversão ao risco; mas a doutrina de Rawls sustenta que o princípio da diferença seria eleito sem atitudes extremas, dos participantes da posição original, frente ao risco..$^{511-512}$

RAWLS, John. Uma teoria da justiça cit., p. 108.

510 Roberto Gargarella (GARGARELLA, Roberto. As teorias da justiça depois de Rawls cit.) apresenta o critério maximin como utilizado em Rawls como critério de racionalidade a "empregar em situações de incerteza", assim fazendo sua incidência na posição original, e desvinculando de uma relação direta com o princípio da diferença (que é um dos princípios da justiça derivados do acordo hipotético alcançado na posição original) - seriam, um e outro, coisas diversas, aplicáveis à teoria em momentos diversos. Sobre o critério maximin, afirma: "Rawls também diz alguma coisa sobre a regra de racionalidade a ser utilizada pelos sujeitos na 'posição original', em caso de dúvidas quanto à escolha que enfrentam. Rawls pensa na chamada 'regra maximin'- que passarei agora a descrever -, que parece apropriada a situações em que se deve escolher só uma entre diferentes alternativas a princípio atraentes. A mencionada regra afirma que, nesses momentos de incerteza, devem ser hierarquizadas as diferentes alternativas de acordo seus piores resultados possíveis. Nesse sentido, deverá ser adotada a alternativa cujo pior resultado for superior ao pior dos resultados das outras alternativas" - p. 23-24. Sobre o princípio da diferença, diz o autor: "se mostra associado à ideia de igualdade [...] O princípio da diferença, tal como está exposto, implica a superação de uma ideia de justiça distributiva, habitual em sociedades modernas, segundo a qual o que cada um obtém é justo se os benefícios ou posições em questão também forem acessíveis aos demais. Dado que nesse caso e, como vimos, entende-se que ninguém merece seus maiores talentos ou capacidades, o esquema de justiça não se considera satisfeito com uma mera igualdade de oportunidades. Afirma-se, em contrapartida, que as maiores vantagens dos mais beneficiados pela loteria natural só são justificáveis se elas fazem parte de um esquema que melhora as expectativas dos membros menos favorecidos da sociedade. Ou seja, as violações de uma ideia estrita de igualdade só são aceitáveis no caso de servirem para incrementar as parcelas de recursos em mãos dos menos favorecidos, e nunca de as diminuir" - a p. 25-26. Martín Diego Farrel (FARREL, Martin Diego. Filosofia del derecho y económia cit., p. 29) concorda com essa abordagem de aplicação em momentos distintos, afirmando: "Vale decir que el maximin aparece dos veces en la teoria de Rawls: como principio de elección en las circunstancias de la posición originaria, y como principio elegido como consecuencia de aplicar el principio de elección". O próprio John Rawls já afirmou: "I should emphasize that the maximin equity criterion and the so-called maximin rule for choice under uncertainty are two very different things" (RAWLS, John. Some reasons for the maximin criterion cit., p. 141).

511 RAWLS, John. Uma teoria da justiça cit., p. 80. Contudo, Rawls afirmou em outra oportunidade: "From the standpoint of the original position, the parties will surely be very considerably risk-averse; if we ask how risk-averse, we might say not less than that of most any normal person" (RAWLS, John. Some 
O princípio da diferença, segundo Rawls, teria uma grande vantagem, especialmente se comparado ao princípio utilitarista da eficiência: ele "exige menos de nossos julgamentos sobre bem-estar" ${ }^{\prime 513}$ (medida de utilidade), considerando que demanda apenas a identificação dos sujeitos representativos de cada camada social: "não importa o quanto esse indivíduo representativo é menos favorecido em relação aos outros". 514

Mencionado princípio está relacionado ao princípio da reparação, ${ }^{515}$ mas com ele não se confunde:

ele não exige que a sociedade tente contrabalançar as desvantagens como se fosse esperado de todos que competissem numa base equitativa. Mas o princípio da diferença alocaria recursos na educação, por exemplo, a fim de melhorar as expectativas a longo prazo dos menos favorecidos. ${ }^{516}$

Finalmente, o princípio da diferença "expressa uma concepção de reciprocidade": ${ }^{517}$ reconhece aos mais afortunados o direito de manter as vantagens obtidas "por meio de contingências naturais e sociais" ("lugar inicial de partida na sociedade", 518 sobre o qual não têm direito prévio ${ }^{519}$ ), por outro lado favorecendo os menos afortunados na medida em que se exige que sua condição seja melhorada para que sejam atingidos os princípios de justiça.

reasons for the maximin criterion cit., p. 143). Vale notar que no referido artigo, como se vê mesmo de seu título, Rawls abandona a rejeição pela utilização da expressão "maximin" de sua tese.

512 SANDEL, Michael J. Justiça: o que é fazer a coisa certa. 4. ed. Trad. Heloísa Matias e Maria Alice Máximo. Rio de Janeiro: Civilização Brasileira, 2011. p. 190. "Há quem questione se não seria possível que as pessoas, mesmo sem saber onde se inseririam na sociedade, ainda assim escolhessem o princípio da diferença. Como Rawls pode garantir que, sob o véu da ignorância, as pessoas não iriam querer arriscar a sorte em uma sociedade altamente desigual, na esperança de conseguir um lugar no topo da pirâmide? Talvez alguns até optassem por uma sociedade feudal, dispostas a correr o risco de ser servos sem terra na esperança de, quem sabe, ser reis. Rawls não acredita que ao escolher os princípios que devem governar sua vida as pessoas fossem correr tais riscos. A não se que soubessem que eram pessoas que gostam de correr riscos (característica ocultada pelo 'véu da ignorância'), elas não arriscariam tanto. Mas a tese de Rawls do princípio da diferença não se baseia totalmente na presunção de que as pessoas do contrato original fossem avessas a riscos. A ideia subjacente ao artifício do 'véu da ignorância' é um argumento moral que pode ser apresentado independentemente de tal artifício. Sua ideia principal é que a distribuição de renda e oportunidades, não pode ser fundamentada em fatores arbitrários do ponto de vista moral".

513 RAWLS, John. Uma teoria da justiça cit., p. 97.

514 Idem, ibidem.

515 Segundo o princípio da reparação: “desigualdades imerecidas exigem reparação [...] a fim de tratar as pessoas igualitariamente, de proporcionar uma genuína igualdade de oportunidades, a sociedade deve dar mais atenção àqueles com menos dotes inatos e aos oriundos de posições sociais menos favoráveis. A ideia é de reparar o desvio das contingências na direção da igualdade" (idem, p. 107).

516 Idem, p. 107-108.

517 Idem, p. 109.

518 Idem, p. 111.

519 Idem, p. 110. 
Vale consignar que o princípio da diferença (muitas vezes identificado na literatura apenas por "critério maximin") é um dos principais alvos dos críticos da teoria de John Rawls. ${ }^{520-521-522}$ Argumenta-se, especialmente, que ele seria escolhido na posição original apenas se se presumir que os indivíduos nessa situação têm aversão ao risco. A ideia central da doutrina utilitarista é que, nas mesmas condições expostas por Rawls (posição original e véu da ignorância), a escolha seria por um princípio de maximização da utilidade média, ${ }^{523}$ e não da utilidade dos menos favorecidos. Mas não só utilitaristas atacam o princípio da diferença. Como destaca Álvaro de Vita, "a concepção de justiça distributiva de Rawls também é criticada por ser insuficientemente igualitária". 524

Não se desconhece que John Rawls promoveu diversas modificações em suas ideias originais, muito em resposta às críticas, culminando no seu Liberalismo Político. ${ }^{525}$ Contudo, considerando que ora nos interessam suas premissas básicas, constantes da

520 Para uma demonstração de diversos critérios de escolha em face da incerteza, é interessante a leitura do Capítulo II ("Rawls, el criterio maximin y la utilidad promedio"), Seção II ("La plausibilidad del criterio maximin") de: FARREL, Martin Diego. Filosofia del derecho y económia cit., p. 38-62. Claro que o referido doutrinador defende a perspectiva utilitarista, aquela a que Rawls se contrapõe. Nada obstante, é enriquecedora a exposição sobre as diferenças entre "situações de risco" e "situações de incerteza", assim como sobre outros possíveis critérios de tomada de decisão.

521 Rawls, inclusive, fez publicar artigo frontalmente contrapondo essas críticas: RAWLS, John. Some reasons for the maximin criterion cit.

522 Joerg Tremmel postula que os participantes da posição original, cobertos pela véu da ignorância, rejeitariam o critério maximin para eleger um princípio "do valor esperado" sob certas cirunstâncias ("principle of expected value under the given circumstances"). TREMMEL, Joerg. A theory of intergenerational justice cit., p. 153.

523 VITA, Álvaro de. A justiça igualitária e seus críticos cit., p. 180-181 e 194 e ss. Álvaro de Vita, um confesso defensor das ideais de Rawls, defende o princípio da diferença, embora sem sustentar que se trata da escolha oriunda da posição original. Para o autor, o princípio é de ser justificado de uma perspectiva motivacional, para o cumprimento (dos critérios de justiça já escolhidos) depois de levantado o "véu da ignorância", já depois da finalizado o contrato de formação da sociedade e de suas instituições. Então, afirma que para defender o princípio da diferença, "seria preciso supor que o contrato rawlsiano tem uma segunda rodada na posição original, em que as partes, depois de terem acordado os princípios de justiça, examinariam a razoabilidade do compromisso que assumiram".

524 Idem, ibidem, p. 237. Prossegue: “Às vezes se afirma que o princípio da diferença sanciona vastas desigualdades socioeconômicas, uma vez que, se nele nos baseássemos, teríamos de considerar justo um estado de coisas em que enormes melhorias nas expectativas dos mais privilegiados produzissem apenas melhorias mínimas no bem-estar dos que se encontram na pior posição. Se fosse esse o caso, quaisquer níveis de desigualdade poderiam ser justificados com base nesse princípio". Vale recordar que o autor não concorda, em absoluto, com tais críticas. Assim é que afirma: "Como afirmei, no início desta discussão, a objeção de que o princípio de diferença autoriza desigualdades excessivas, desde que pequenas melhorias ocorram nas expectativas dos que se encontram na posição mais desfavorável, não tem nenhum fundamento. Esse equívoco, muito ao gosto dos economistas, decorre de considerar a justiça maximin à parte da concepção da qual ela é apenas um dos seus componentes", observando ainda que "o maximin é a última coisa que pode ser proposta antes de se defender alguma versão da estrita igualdade de resultados [...] É preferível um arranjo institucional que garanta um quinhão maior em termos absolutos, ainda que não igual, de bens primários para todos, a outro no qual uma igualdade de resultados é assegurada à custa de reduzir as expectativas de todos" (p. 251), finalizando com a consideração de que Rawls "acredita, e também é isso que estou tentando evidenciar, que uma estrutura básica que satisfaça os dois princípios de justiça não dará lugar a disparidades excessivas” (p. 252, nota de rodapé n. 87).

525 RAWLS, John. Political liberalism. Nova York: Columbia University Press, 1993. 
primeira parte d'Uma Teoria de Justiça, e que essa parte passou praticamente inalterada em suas obras posteriores, ${ }^{526}$ restringe-se a descrição aos elementos já postos.

\section{2.b.iii.2. A justiça entre gerações em Rawls.}

Sobre estas bases teóricas, John Rawls preocupou-se diretamente com a questão da justiça entre gerações, ${ }^{527-528}$ defendendo uma ética ${ }^{529}$ que vincule as atuações das gerações atuais com o bem-estar das futuras - ressaltando que também nessa análise a concepção utilitarista se revela frágil e insuficiente. ${ }^{530} \mathrm{E}$ o fez contra as ideias de Kant (para quem era "desconcertante o fato de que as gerações anteriores devessem carregar os seus fardos apenas para o bem das gerações posteriores, e que estas últimas devessem ter a boa sorte de residir no prédio já terminado") e Herzen (para quem "o desenvolvimento humano é um tipo de injustiça cronológica, pois aqueles que vivem mais tarde lucram com o trabalho de seus predecessores"). ${ }^{531}$ Afinal, argumenta, sua teoria entende que os dotes naturais, ainda que arbitrários e que portanto podem beneficiar uns em detrimento de

526 GARGARELLA, Roberto. As teorias da justiça depois de Rawls cit., p. 223 e ss., especialmente p. 225.

527 A preocupação com a justiça entre gerações remonta a Platão e Edmund Burke, embora Rawls destaquese por trazer o assunto dentro de sua influente e abrangente Teoria da Justiça, sistematizando-o dentro dos princípios aplicáveis à estrutura básica da sociedade: SARTOR, Vicente Volnei de Bona. Justiça intergeracional e meio ambiente. Florianópolis: Ed. do Autor, 2002. p. 48 e ss.

528 São recorrentes as críticas à justiça entre gerações de Rawls, não só com base na pouca explanação sobre o tema, como sobre a opacidade dos termos por ele utilizados. Por exemplo, diz Wolf: "Rawls is much less specific in what he says about intergenerational justice, and what he does say is confusing" (WOLF, Clark. Intergenerational justice. In: FREY, R. G.; WELLMAN, Cristopher Heath (Ed.). A companion to applied ethics cit., p. 285).

529 Embora tenha-se eleito Rawls como fio condutor dessa explanação, vale mencionar que a ideia pode ser encontrada também em outros autores. Por ora, observe-se como o eticista Peter Singer aborda o tema: "se deixarmos intactas todas as extensões naturais que hoje existem, as gerações futuras pelo menos terão a opção de deixar de lado os seus jogos de computador e sair para ver um mundo que não foi criado pelos seres humanos. Se destruirmos essas áreas naturais, essa opção deixará de existir para sempre [...] Portanto, uma ética centrada no homem pode ser a base de poderosos argumentos a favor do que poderíamos chamar de 'valores ambientais'. Tal ética não implica que o crescimento econômico seja mais importante do que a preservação da natureza; pelo contrário, é bastante compatível com uma ética centrada no homem o ponto de vista que vê o crescimento econômico baseado na exploração dos recursos não-renováveis como algo que traz benefícios à presente geração, e talvez a mais uma ou duas gerações, mas a um preço que terá de ser pago por todas as gerações que vierem depois [...] Os contornos gerais de uma ética verdadeiramente ambiental são fáceis de estabelecer. Em seu nível mais fundamental, essa ética incentiva a consideração dos interesses de todas as criaturas sensientes, inclusive das gerações que habitarão o planeta num futuro remoto" (SINGER, Peter. Ética prática. Trad. Jefferson Luiz Camargo. 3. ed. São Paulo: Martins Fontes, 2002. p. 288, 289 e 301).

530 RAWLS, John. Uma teoria da justiça cit., p. 316-317. Isto porque "as maiores vantagens das gerações futuras serão suficientemente grandes para superar em valor quase todos os sacrifícios presentes", de forma que "a doutrina utilitarista pode nos levar a exigir grandes sacrifícios das gerações mais pobres em nome de maiores vantagens das gerações posteriores que estarão em situação muito melhor [...] devemos ser capazes de evitar esse tipo de exagero".

531 Ambas as opiniões são referidas por Rawls (idem, ibidem, p. 317-318). Mas o autor afirma que "esses sentimentos, embora inteiramente naturais, estão deslocados. Pois embora a relação entre gerações tenha um caráter especial, ela não dá origem a nenhuma dificuldade insuperável". 
outros, não são justos ou injustos em si. O que é justo ou injusto, e isto se aplica à questão em análise, é "o modo como as instituições lidam com as limitações naturais e a maneira como elas são estruturadas para tirar vantagens das possibilidades históricas". 532

A questão intergeracional surge naturalmente dos elementos centrais da justiça como equidade. Afinal, na posição original, cobertos pelo véu da ignorância, ${ }^{533}$ os indivíduos não sabem sequer a que geração pertencerão ${ }^{534}$ - em que altura da linha temporal estarão -, sendo natural que, agindo racionalmente em defesa de seus interesses, prevejam princípios de justiça que impeçam que uns esgotem a riqueza que servirá também aos outros.

Contudo, impõe-se notar que Rawls promove ajustes, neste tema específico, de seus conceitos principais: a uma, vê-se na necessidade de alterar as características da posição original, demandando que os indivíduos naquela situação representem linhagens familiares e que estejam preocupados com o bem-estar de seus descendentes próximos. ${ }^{535-}$ 536 A duas, vê o princípio da diferença como inadequado para aplicar à justiça entre gerações porque "ele acarreta ou nenhuma poupança ou uma poupança que não basta para

532 RAWLS, John. Uma teoria da justiça cit., p. 318. Ainda (p. 325): "a posição temporal diferente das pessoas e das gerações por si não justifica que lhes seja dispensado um tratamento diferente".

533 Rawls lembra ainda que "A mera diferença de localização no tempo, o fato de algo ser anterior ou posterior, não é em si mesmo um motivo racional para que tenhamos por ele mais ou menos interesse" Idem, ibidem, p. 324.

534 Idem, p. 147.

535 Para Rawls, o véu da ignorância se revela um problema na formulação. Isto porque sua teoria pressupõe que as pessoas na posição original "sabem que são contemporâneas (interpretando o tempo presente como o tempo de inscrição na posição original)" - Idem, ibidem, p. 150. Daí que poderiam beneficiar sua própria geração em comum, em detrimento das demais, inclusive considerando que não há garantias de que as gerações anteriores pouparam. Então, Rawls inclui na equação: "para lidar com a questão da justiça entre gerações, eu modifico a suposição motivacional e acrescento mais uma restrição ( $\$ 22$ ). Com esses ajustes, nenhuma geração é capaz de formular princípios especialmente destinados a promover a sua própria causa, e alguns limites importantes para a poupança podem ser deduzidos ( $\$ 44)$. Não importa qual seja a posição de uma pessoa no tempo, cada uma é forçada a escolher por todas" - p. 151. Ainda: "Para que um resultado razoável seja atingido, supomos, primeiro, que as partes representam linhagens familiares, digamos assim, que se preocupam pelo menos com seus descendentes mais próximos; segundo, que o princípio adotado deve ser tal que elas desejem que as gerações anteriores o tenham seguido (§ 22). Essas restrições, juntamente com o véu da ignorância, têm por função garantir que qualquer geração se preocupe com todas as outras" (RAWLS, John. Uma teoria da justiça cit., p. 318).

536 Vale mencionar a reflexão de Doran: "Although parents may look out sharply for the interests of their children in the political process, it is doubtful that they are nearly so vigilant on matters that would affect their more distant descendants [...] The notion that current generations inevitably will take the interests of future generations into account through parental concern and affection suggests at most that current generations will look one or two generations forward. But perhaps that is sufficient. Current and future generations overlap continuously, and the tie between current and future generations is continuously renewed as chi ldren grow to adults and have their own children [...] If each generation looks out for the interests of the immediately following generation until that following generation is able to protect its own interests, the problem of equity between the generations will have been at least partly addressed" (DORAN, Michael. Intergenerational equity in fiscal policy reform. Tax Law Review, n. 61, 2008, p. 291-292). 
melhorar minimamente as condições sociais, de modo que todas as liberdades iguais

possam ser efetivamente exercidas". ${ }^{537-538}$ Esses ajustes não passaram sem críticas. ${ }^{539}$

537 RAWLS, John. Uma teoria da justiça cit., p. 317. Considera: "não há como as gerações posteriores possam ajudar a situação das gerações anteriores menos afortunadas. Dessa forma, o princípio da diferença não se aplica à questão da justiça entre gerações, e o problema da poupança deve ser tratado de alguma outra forma". Então, promove um ajuste (não uma exclusão). O princípio da poupança justa, visto adiante, deve ser combinado com o princípio da diferença; em verdade, aquele funciona como uma restrição deste: "esse princípio [poupança justa] é definido a partir do ponto de vista dos menos favorecidos em cada geração. São os homens representativos desse grupo estendido ao longo do tempo que, por arranjos virtuais, devem especificar a taxa de acumulação. Encarregam-se, na verdade, de limitar a aplicação do princípio da diferença. Em qualquer geração, suas expectativas devem ser maximizadas obedecendo à condição de fazer a poupança que seria objeto do acordo" (idem, ibidem, p. $323)$.

538 Steven Wall entende que essa exceção se dá porque Rawls identifica, numa perspectiva geracional, que as gerações menos favorecidas são as primeiras: WALL, Steven. Just savings and the difference principle. Philosophical studies. An International Journal for Philosophy in the Analytic Tradition, v. 116 , n. 1 , out. 2003, p. 85-86: "Rawls's point here is that, on the assumption of positive economic and technological development over time, the worst-off group will be in the first generation. Maximin reasoning then will favor a savings schedule that requires no savings from this generation, since to do so would be to benefit latter (and better off) generations at the expense of the worst-off group in the first generation. The same will hold true of subsequent generations - they too will not be required to make sacrifices to benefit latter generations better off than they are - and so no net savings will be required". Clark Wolfe credita essa exceção ao entendimento de Rawls de que seria necessária para o desenvolvimento econômico, ainda que às custas das gerações menos favorecidas: "it has sometimes been objected that this proccess requires those who are worse off (the earlier generations who do not have sufficient resources) to make sacrifices for those who are better off (the later generations who are wealthy enough to implement just institutions). Such sacrifices run contrary to the spirit of justice that animates the difference principle, but Rawls was convinced that they were necessary to make economic growth possible. This is his expressed reason for abandoning the difference principle in his account of intergenerational distributive justice [...] Rawls was convinced that the difference principle would make it impossible, under some adverse circumstances, ever to implement just institutions. The implementation of just institutions typically requires saving and accumulation during early stages of development. So the poorer early generations must simply bear the cost for the sake of the wealthier generations that follow”. WOLF, Clark. Intergenerational justice and climate policy. In: GOSSERIES, Axel; MEYER, Lukas H. (Coord.). Intergenerational justice. New York: Oxford University Press, 2009. p. 360.

539 Jane English foi pioneira na crítica às alterações promovidas por Rawls aos conceitos de posição original e véu da ignorância, quando tratou da justiça entre gerações. Mostrou, especialmente, que tais ideias sempre tiveram (e permaneceram tendo, nos demais assuntos não intergeracionais) o ponto de partida de indivíduos não altruístas ou benevolentes e que escolheriam aqueles princípios de justiça no interesse próprio (ENGLISH, Jane. Justice between generations. Philosophical studies. An International Journal for Philosophy in the Analytic Tradition, v. 31, n. 2, fev. 1977, p. 92-93) - e estas premissas impediriam que se concebessem os indivíduos na posição original como preocupados com seus descendentes. Argumentou que a colocação dos indivíduos na posição original como representantes de linhagens familiares - em diversas acepções possíveis dessa locução - poderia facilmente resultar em princípios de justiça bem diversos da poupança justa (Idem, ibidem, p. 96.). E que a limitação trazida por Rawls, para explicar a razão pela qual alterou a posição original (que as partes não saberiam se as gerações anteriores pouparam), seria desconectada do resto da teoria - que não é real, mas hipotética. Tudo a indicar que um princípio de poupança não seria contrário à atuação do indivíduo como em defesa do interesse próprio (Idem, ibidem, p. 98.). As críticas da referida autora foram fulcrais na reformulação do princípio da poupança justa, posteriormente, por John Rawls. Para Daniel Attas, a mudança da posição original para adequar a justiça entre gerações enfraqueceu a tese de Rawls metodologicamente. Mas sua opinião é de que o acréscimo dessa motivação adicional (chefes de família preocupados com seus herdeiros) é simplesmente inócuo, porque seus efeitos derivariam da posição original, em sua concepção primeira. E mais: Attas vê razões para considerar a poupança justa como apenas um estágio de aplicação do princípio da diferença - "uma cláusula em sua articulação plena", para "melhorar a situação dos menos favorecidos em uma dimensão intertemporal, da mesma forma que a desigualdade trata a dimensão 
Daí que propõe, para a hipótese, um princípio justo de poupança (ou poupança justa), em que "cada geração faz uma contribuição em favor daqueles que vêm depois e a recebe de seus predecessores". ${ }^{540}$ Ou ainda: se "assegure que cada geração receba de seus predecessores o que lhe é devido e faça sua parte justa em favor daqueles que virão depois". ${ }^{41-542}$ Numa analogia, "imaginando-se no papel de pais, devem definir o quanto deveriam poupar para seus filhos e netos, com referência ao que se acreditam no direito de reivindicar de seus pais e avós". ${ }^{543}$ É claro que isto ainda deixa muitas dúvidas, especialmente quanto à definição do quanto é justo poupar. Sobre isso, Rawls afirma:

As partes devem perguntar-se o quanto estariam dispostas a poupar a cada estágio de desenvolvimento, supondo que todas as gerações pouparam, ou vão poupar, de acordo com o mesmo critério. Elas devem considerar a sua disposição para poupar em qualquer fase dada de civilização, sabendo que as taxas que propõem devem regular o total acumulado. É essencial notar que um princípio de poupança é uma regra que atribui uma taxa apropriada (ou um limite para a avariação [sic] de taxas) a cada nível de desenvolvimento, ou seja, uma regra que determina uma programação das taxas de poupança. Podemos supor que taxas diferentes serão atribuídas a estágios diferentes. Quando as pessoas são pobres e poupar é difícil, deve-se exigir uma taxa mais baixa; ao passo que, em uma sociedade mais rica, maiores poupanças podem ser racionalmente esperadas, já que o ônus real da poupança é menor. Por fim, depois de firmemente estabelecidas as instituições, e efetivamente implementadas todas as liberdades básicas, o acúmulo líquido exigido cai para zero. Ao atingir esse ponto, uma sociedade terá cumprido o seu dever de justiça, mantendo instituições justas e preservando a sua base material. O princípio justo de poupança se aplica ao que a sociedade deve poupar por uma questão de justiça. Se seus membros desejarem poupar para outros propósitos, essa já é uma outra questão. É impossível ser muito específico a respeito do programa de taxas (ou do limite de taxas) que seria reconhecido; o máximo que podemos esperar dessas considerações intuitivas é que certos extremos sejam excluídos. ${ }^{544}$

intrageracional" (ATTAS, Daniel. A transgenerational difference principle. In: GOSSERIES, Axel; MEYER, Lukas H. (Coord.). Intergenerational justice cit., p. 216-217.). Ou ainda: a poupança justa deveria ser vista como "estendendo a racionalidade intrageracional do princípio [da diferença] para considerar e fazer uso do aspecto transgeracional visando melhor refletir os interesses dos menos favorecidos" (Idem, ibidem, p. 192.).

540 RAWLS, John. Uma teoria da justiça cit., p. 317. Reiterando o descabimento do princípio da diferença (critério maximin) na análise da justiça entre gerações: RAWLS, Some reasons. "Maximin is a macro not a micro principle. I should add that the criterion is unsuitable for determining the just rate of savings; it is intended to hold only within generations (Rawls, sec. 44, p. 291-92, Kenneth J. Arrow, 1973a, and Robert M. Solow)" (p. 142).

541 RAWLS, John. Uma teoria da justiça cit., p. 318.

542 Idem, ibidem, p. 321: "O princípio da poupança representa uma interpretação, formulada na posição original, do dever natural previamente aceito de defender e promover instituições justas".

543 Idem, p. 320.

544 Idem, p. 319. 
"As partes desejarão que todas as gerações economizem um pouco", sustenta Rawls. ${ }^{545-546}$ Mas isso não implica dizer que todas economizarão o mesmo. ${ }^{547} \mathrm{O}$ Autor observa que devem ser respeitadas diferenças entre gerações nesse quesito, especialmente no que concerne à ideia da acumulação primitiva de capitais. ${ }^{548}$ Ora, as primeiras gerações deverão manter capitais ${ }^{549-550}$ que, no futuro, já estarão presentes. Deverão gastar para tanto - sendo-lhes lícito poupar menos (embora considerando a especial carência de legitimidade de uma decisão feita por uma geração, mas que atinge outras ${ }^{551}$ ). Assim, "cada geração, exceto possivelmente a primeira, ganha com a manutenção de uma taxa razoável de poupança. O processo de acumulação, uma vez iniciado e levado adiante, traz benefícios para todas as gerações subsequentes". ${ }^{552-553}$ Mas isso não pode ser confundido com um mero dever de tornar as gerações posteriores mais ricas que suas antecessoras.

545 RAWLS, John. Uma teoria da justiça cit., p. 319. Ainda (p. 321): "Cada uma lega a outra um equivalente justo em capital real, que é definido por um princípio justo de poupança [...] Esse equivalente é a recompensa pelo que foi recebido das gerações precedentes, e possibilita que as posteriores tenham uma vida melhor em uma sociedade mais justa".

546 SUNSTEIN, Cass R.; ROWELL, Arden. On discounting regulatory benefits: risk, money, and intergenerational equity cit., p. 20-21. "This savings principle has the advantage of treating all generations the same, thus protecting against the dual problems of impoverishing the present and impoverishing the future. An approach that harmed the most disadvantaged members of current generations, for the sake of the future, would therefore be disfavored; and so too with an approach from which current generations benefit at the expense of the most disadvantaged members of posterity (as, on one view, is the case of emissions of greenhouse gases) [...] For present purposes we want to bracket the most controversial questions, and simply suggest that any ethical obligations are satisfied if the present can make it worthwhile for future generations to run the risk or risks to which it subjects them. This suggestion is in the same family as Rawls' claims about the uses of the veil of ignorance; it also fits with what welfarists would require". Deve-se notar que os autores parecem atribuir a Rawls a necessidade de aplicação do critério maximin na apreciação de questões intergeracionais. O que, como já visto, não é acurado.

547 "Estabelecido o princípio da poupança justa, a taxa a ser poupada varia de acordo como o estágio de desenvolvimento de cada sociedade" (SARTOR, Vicente Volnei de Bona. Justiça intergeracional e meio ambiente cit., p. 68).

548 RAWLS, John. Uma teoria da justiça cit., p. 329: “O princípio da poupança justa age como uma restrição à taxa de acumulação. Cada época deve fazer a sua respectiva parte para que se atinjam condições necessárias à implementação de instituições justas e do valor eqüitativo da liberdade; mas além disso, nada se pode exigir".

549 Idem, ibidem, p. 321: "Devemos ter em mente que esse capital não consiste apenas em fábricas e máquinas, e assim por diante, mas também em conhecimento e cultura, assim como em técnicas e habilidades, que possibilitam instituições justas e o valor equitativo da liberdade".

550 Sobre o quê deve ser deixado por uma geração às posteriores, v. TREMMEL, Joerg. A theory of intergenerational justice cit., p. 66. O autor postula que é incorreto tratar da questão sob a perspectiva de poupança de capitais, mas que as gerações devem legar às posteriores uma medida de bem-estar (referindo-se especialmente ao bem-estar medido pelo Índice de Desenvolvimento Humano - IDH). Para Tremmel, capitais são apenas meios de incrementar o bem-estar.

551 RAWLS, John. Uma teoria da justiça cit., p. 327-328: "De fato, a ausência das partes prejudicadas, ou seja, as gerações futuras, torna essa decisão ainda mais passível de questionamento".

552 Idem, ibidem, p. 321.

553 Como afirma Jane English (ENGLISH, Jane. Justice between generations cit.): “any saving principle will have a cumulative effect which may improve the position of later generations substantially, but cannot 
Afinal, essas lições estão amarradas pelo "objetivo do processo de acumulação": "uma condição social com uma base material suficiente para estabelecer instituições justas efetivas, dentro das quais as liberdades básicas possam todas ser implementadas", 554 ou ainda, simplesmente, "definir uma sociedade justa". ${ }^{555}$ Assim cada geração carrega "a sua respectiva parte do ônus de realizar e preservar uma sociedade justa". ${ }^{556}$ A poupança serve para a "plena realização das instituições justas e das liberdades iguais". 557

Portanto, para Rawls, "as pessoas de diferentes gerações têm deveres e obrigações em relação umas às outras exatamente como as têm as pessoas que vivem numa mesma época", ${ }^{558}$ o que sustenta lembrando que "os homens têm um dever natural de defender e promover o crescimento das instituições justas, e para isso a melhoria da civilização até um certo nível é exigida". ${ }^{559}$

Sunstein e Rowell destacam em Rawls que o princípio da poupança justa não demanda necessariamente que as ações das gerações presentes (estão referindo impactos ambientais) devam ser totalmente compensadas com benefícios às gerações futuras - "é possível imaginar situações nas quais a total compensação pode perfeitamente ser demais exigente". ${ }^{560}$ Essa lição liga-se, em verdade, com a já referida em que Rawls critica a noção utilitarista aplicada à matéria, por exigir demais das gerações presentes, baseadas na ideia de que a soma das utilidades futuras será superior.

Vale considerar que Rawls alterou algumas de suas ideias sobre a poupança justa quando da publicação de Justiça como Equidade: uma reformulação ${ }^{561}$ Embora

help the first generation, since they are asked to sacrifice for the future without gaining from the past (288). From behind a veil of ignorance, the choosers do not know which generation they are in, but they do know that they are all contemporaries $(137,140)$. This 'present time of entry' interpretation makes the choosers in effect the first generation to which the saving principle applies (140). Their choice of moral principles cannot change the past [...] So they can only lose by acknowledging any saving principle. Unless we stipulate that they already, in the original position, have affections for their offspring, no saving will result. Contrary to other applications of the difference principle (291), a saving principle asks the worst-off to sacrifice for the benefit of later persons who may be better off (292). Hence Rawls must, he thinks, devise a way to make the parties not self-interested in this respect. It is to incorporate this 'motivational assumption' that he construes the parties as family lines rather than individuals (128)". p. 92.

554 RAWLS, John. Uma teoria da justiça cit., p. 320.

555 Idem, ibidem, p. 321.

556 Idem, p. 321.

557 Idem, p. 322.

558 Idem, p. 323.

559 Idem, p. 324.

560 On discounting regulatory benefits: risk, money, and intergenerational equity cit., p. 21. Tradução livre.

561 RAWLS, John. Justiça como equidade: uma reformulação. Trad. Claudia Berliner; rev. téc. e da trad. Álvaro De Vita. São Paulo: Martins Fontes, 2003. 
reafirmando que este princípio "vigora entre gerações, ao passo que o princípio da diferença vigora dentro de uma geração", ${ }^{562}$ sua nova formulação do princípio altera as circunstâncias da posição original: desta forma, "as partes devem concordar com um princípio de poupança com a condição de quererem que todas as gerações anteriores o tivessem seguido". ${ }^{563}$ Então, "como nenhuma geração conhece seu lugar entre as gerações, isso implica que todas as gerações posteriores, inclusive a presente, têm de segui-lo". ${ }^{564}$

Como o próprio autor explica, a distinção está em que, nesta reformulação da tese, abandona-se a ideia de exigir dos indivíduos na posição original que se preocupem com seus descendentes, o que "apresenta certas dificuldades, pois muda a premissa da motivação (de desinteresse mútuo) para obter um princípio de poupança". ${ }^{565}$ Tais alterações à tese original foram objeto de aguerridos debates. ${ }^{566}$

562 RAWLS, John. Uma teoria da justiça cit., p. 225.

563 Idem, p. 227.

564 Idem.

565 RAWLS, John. Justiça como equidade:... cit., nota de rodapé n. 39.

566 Steven Wall dirige-se à reformulação do princípio da poupança justa, apresentada posteriormente por Rawls, considerando-a mais adequada, mesmo porque a inclusão, na posição original (em Uma teoria da justiça), de uma preocupação do sujeito com seus descendentes, parece-lhe feita ad hoc - WALL, Steven. Just savings and the difference principle cit., p. 81. Contudo, entende que o estabelecimento do critério guardar às gerações posteriores aquilo que entende que deveria ter sido guardado pelas anteriores, embora formulado de forma atraente, não oferece direções para que se responda o quanto deve ser poupado (p. 86). Nada obstante, o artigo de Wall dirige-se mesmo a questionar o que vê como uma tensão irreconciliável entre as ideias de justiça intra e intergeracional - o que, a seu ver, culmina em reconhecer as ideias de Rawls como menos igualitárias do que parecem, e mais comprometidos com o que chama de justiça prioritária (p. 87 e 88). Claus Dierksmeier concorda com a crítica à mudança na posição original, que considera casuísta (DIERKSMEIER, Claus. John Rawls on the rights of future generations. In: TREMMEL, Joerg (Ed.). Handbook of intergenerational justice cit., p. 77). Mas tampouco referenda a mudança na teoria de Rawls (em Justiça como equidade: uma reformulação), entendendo que traz novos problemas. Sua posição crítica reside na rejeição, por Rawls, de utilização de conceitos morais (apesar de sua fundamentação em Kant). Assim, "tudo o que o sistema de Rawls pode oferecer são acordos meramente condicionais entre pessoas que dão apenas na condição de receber, que contribuem apenas enquanto se beneficiam, que ajudam apenas enquanto isso promove seus interesses" (p. 80, Tradução livre). Já David Heyd, contrariando os autores acima referidos, embora reconhecendo que a alteração da posição original (para incluir que os indivíduos são representantes de linhagens familiares, preocupados com o bem-estar de sua prole) é "quase ad hoc" (HEYD, David. A value or an Obligation? Rawls on Justice to Future Generations. In: GOSSERIES, Axel; MEYER, Lukas H. (Coord.). Intergenerational justice cit., p. 175), vê uma versão enfraquecida dessa "suposição motivacional" como "não apenas necessária para a justiça intergeracional, mas uma condição essencial também para a justiça doméstica intrageracional" (p. 187, Tradução livre), o que aponta sustentando, contudo, que isso deriva de deveres morais, assim afastando-se da teoria rawlsiana que se pretende política no cerne. Assim, opinando que a justiça intergeracional é também uma forma de promoção da justiça intrageracional (p. 177), Heyd afirma que o princípio da poupança justa deve ser entendido como um princípio que assegura a justiça, em vez de um princípio da justiça (p. 187). Sobre a reformulação, diz Wolf: "This change is an improvement since, appropriately interpreted, it can avoid some of the problems that plagued the original account. Most importantly, it recovers concern for future generations as a function of rational choice from behind a veil of ignorance in the original position". WOLF, Clark. Intergenerational justice. In: FREY, R. G.; WELLMAN, Cristopher Heath (Ed.). A companion to applied ethics cit., p. 286. 
Como nota final à exposição das ideias de Rawls quanto à justiça entre gerações, vale observar que a exclusão do princípio da diferença (critério maximin), como elemento aplicável à questão intergeracional, foi objeto de diversas análises. Nesse sentido, o já citado Robert Solow, criticando a vagueza com que exposto o princípio da poupança justa, considerou-se "mais rawlsiano que Rawls", ${ }^{567}$ propondo que o critério maximin seja também aplicado à justiça entre gerações - e assim alcançando a conclusão, já acima referida, de que "as gerações anteriores têm o direito de extrair das reservas (otimamente, é claro!) desde que elas adicionem (otimamente, é claro!) ao estoque de capital reprodutível". ${ }^{568}$ Enquanto Solow critica Rawls pela não utilização do critério maximin nas análises intergeracionais, ${ }^{569}$ outros o fazem exatamente pelo oposto, ignorando sua ressalva de que referido critério, na sua teoria da justiça, não se dá entre gerações. ${ }^{570}$

Também criticando a poupança justa rawlsiana está Emmanuel Agius, que vê a essa doutrina como insuficientemente protetiva, chegando a afirmar que o referido princípio, em alguns casos, é uma ameaça, e não uma defesa dos direitos das futuras gerações (especialmente quando se refere ao futuro mais distante). ${ }^{571}$ Joerg Tremmel vai além e afirma quais, em sua opinião, são os princípios da justiça entre gerações que derivariam da posição original: (i) maximização do bem-estar médio de todos os indivíduos de todas as gerações; e (ii) nenhuma geração é obrigada a guardar mais do que a

567 SOLOW, Robert M. On the intergenerational allocation of natural resources cit., p. 29-30. Clark Wolf é de opinião semelhante. Para ele, Rawls foi precipitado em descolar o princípio da diferença quando da análise da justiça entre gerações, para além de tê-lo feito por razões equivocadas - entende que a necessidade de acumulação de capital e a consequente possibilidade de crescimento econômico não é incompatível com a estratégia de beneficiar as pessoas e gerações menos favorecidas. Então, rejeita o princípio da poupança justa, que em seu entender promove injustiças contra as gerações anteriores, menos favorecidas, defendendo a aplicação do princípio da diferença também na ótica intergeracional. WOLF, Clark. Intergenerational justice and climate policy. In: GOSSERIES, Axel; MEYER, Lukas H. (Coord.). Intergenerational justice cit., p. 363.

568 SOLOW, Robert M. On the intergenerational allocation of natural resources cit., p. 41.

569 Também postulando pela aplicação do princípio da diferença na questão entre gerações, e afirmando que Rawls e outros economistas (como Arrow) estão errados em considerar que a aplicação desse princípio importa em deixar as gerações anteriores em desvantagem, impedindo o processo de acumulação e o desenvolvimento econômico: WOLF, Clark. Intergenerational justice and Saving. In: LAMONT, Julian; FAVOR, Christi; GAUS, Gerald (Coord.). Values, justice and economics. Palo Alto/CA: Stanford University Press, 2010.

570 Rebatendo essas críticas com veemência: LONG, Ngo Van. A mixed Bentham-Rawls criterion for intergenerational equity. CIRANO Working Papers, 2007s-08, Montreal: CIRANO, 2007, p. 13-14. O autor, após revisão de uma série de critérios de bem-estar em longo espaço de tempo, propõe seu próprio critério, em parte utilitarista, em parte rawlsiano. Apresentando seu critério em termos econométricos, não será apreciado no mérito, seja por fugir ao escopo dessa dissertação, seja por faltar-nos capacidade técnica para tanto.

571 Afirma: "In concrete terms, there appears to be a point in the course of the 'development' process as it has historically occurred, at which added material consumption plainly becomes worth much less in terms of welfare than a healthier natural environment". AGIUS, Emmanuel. Intergenerational justice. In: TREMMEL, Joerg (Ed.). Handbook of intergenerational justice cit., p. 324. 
geração anterior. ${ }^{572}$ Segundo Tremmel, o resultado de seguir esses princípios seria de que "os membros das gerações mais tardias iriam necessariamente estar em melhores condições que os das gerações iniciais, ou, dito de outra forma, a humanidade iria progredir em condições normais". 573

Importa, por ora, fixar que esta dissertação não tem a pretensão de analisar a filosofia política de Rawls e seus críticos, ${ }^{574}$ mas tão somente registrar a relevantíssima contribuição dada ao tema, pondo em evidência a preocupação - até então algo negligenciada - com as disputas (mesmo que hipotéticas) entre gerações.

Quando Rawls trouxe à tona suas ideias sobre a justiça entre gerações, motivou centenas de pensadores mundo afora a debater o tema, inclusive aplicando-o nos mais diversos campos de trabalho.

É o que se pretende nesta ocasião, embora com as limitações trazidas pelo corte metodológico: utilizar esse referencial teórico para aplicação em considerações intergeracionais da governança da receita oriunda da exploração de recursos naturais não renováveis no Brasil.

\section{2.c. O que é equidade intergeracional: o que devemos às gerações futuras?}

Vistas as noções intergeracionais oriundas da economia dos recursos naturais e, por outro lado, da filosofia política rawlsiana, cabe dar um passo adiante, indo mais diretamente ao cerne da questão.

Isto é: importa-nos, por ora, não mais observar as ideias específicas derivadas da economia; ou a fundamentação político-moral de uma ideia de justiça entre gerações. Mas, tendo observado a existência desses pleitos por maiores considerações com os direitos das futuras gerações, identificar mais precisamente o conteúdo daquilo que chamamos de equidade intergeracional ${ }^{575}$ - considerando, primeiramente, que "as questões

\footnotetext{
TREMMEL, Joerg. A theory of intergenerational justice cit., p. 170. Idem, ibidem.

574 Para diversas abordagens filosóficas sobre a justiça entre gerações, incluindo sob as perspectivas marxista, comunitarista, libertária, dentre outras, recomenda-se a consulta a: GOSSERIES, Axel; MEYER, Lukas H. (Coord.). Intergenerational justice cit.

575 Deveras interessante o estudo de Julia Puaschunder, que buscou compreender, em 110 discursos, entrevistas e conversas, do quê mais frequentemente se trata quando se fala de equidade intergeracional. Em sua conclusão (o estudo foi realizado após a crise de 2008), as menções mais frequentes à equidade intergeracional diziam respeito ao sistema previdenciário, ao endividamento excessivo, e à sustentabilidade ecológica. PUASCHUNDER, Julia M. On the social representations of
} 
fundamentais de justiça intergeracional surgem quando as ações da geração presente restringem as opções das gerações futuras". ${ }^{576-577}$

E, assim sendo, é de se iniciar (e tomar por fio condutor) aquela que é talvez a mais influente obra sobre o tema, de autoria da estadunidense Edith Brown Weiss ${ }^{578}$ - que escreveu sobre o assunto no final da década de 1980, de uma perspectiva mais internacionalista ${ }^{579}$ e, marcadamente, mais ambientalista do que é objetivo central dessa dissertação. Mas, que nada obstante, buscou fixar as linhas mestras para a aplicação do tema, partindo da tese central de que "cada geração recebe um legado natural e cultural em guarda de gerações passadas e o mantém em guarda para as gerações futuras" gera direitos e deveres que devem ser observados por todos. Essa mesma concepção é apresentada por Bruce Auerbach, para quem "a não ser que estejamos preparados para voltar para um regime de subsistência, devemos trabalhar para manter a construir sobre o que herdamos de nossos ancestrais". 582

intergenerational equity. 2012. Disponível em: 〈http://ssrn.com/abstract=2011359〉. Acesso em: 19 nov. 2013.

576 SARTOR, Vicente Volnei de Bona. Justiça intergeracional e meio ambiente cit., p. 48.

577 De forma semelhante, Annika Oskarson coloca a questão como resultante de uma assimetria no relacionamento entre gerações. Afirma: "The problem at hand is a result of asymmetry in the relationship between current and future generations. The current generation can consume resources, degrade environmental quality and limit access to environmental goods and services without being touched by the consequences that such a behavior brings. Intergenerational equity tries to deal with this problem, and is not a new or isolated concept. It can be seen as a mechanism for reaching the goal of sustainable development and is closely linked to the developments under international environmental law during the last few decades. It is also closely tied to the debate regarding environmental human rights". OSKARSON, Annika. Intergenerational equity - Protecting future generations through domestic action. 2009. Dissertação (Mestrado) - Faculdade de Direito da Universidade de Lund. p. 19.

578 WEISS, Edith Brown. In fairness to future generations cit. Vale mencionar a menção de Cass Sunstein ao trabalho de Weiss, afirmando que se trata de posição, assim como a de Solow, que vai além do que é exigido pelo princípio da poupança justa de Rawls. SUNSTEIN, Cass R.; ROWELL, Arden. On discounting regulatory benefits: risk, money, and intergenerational equity cit., p. 24, nota de rodapé $n$. 107.

579 Para outra abordagem da justiça intergeracional internacional, especialmente considerando um dever de compensação entre as gerações anteriores dos países mais ricos e as gerações posteriores dos países em desenvolvimento, ver: BONIN, Pierre-Yves. La justice internationale et le partage des ressources naturelles. Québec Les Presses de L’Université Laval, 2010. p. 135 e ss.

580 WEISS, Edith Brown. In fairness to future generations cit., p. 2. Tradução livre. No mesmo sentido: WESTON, Burns H. The theoretical foundations of intergenerational ecological justice: an overview. Human Righs Quarterly, v. 34, 2012.

581 Referindo especificamente a governança dos recursos naturais, Kofi Annan também fala em "guarda" ou "administração" ("steward"), pelas gerações atuais, em atenção às futuras: "The Africa Progress Panel is convinced that Africa can better manage its vast natural resource wealth to improve the lives of the region's people. And we hope this report will make a contribution. We all stand to win from an Africa that is truly prosperous, stable and fair. We are all stewards of Africa's natural resource wealth for future generations" (ANNAN, Kofi A. Foreword. Africa Progress Report 2013: Equity in extractives stewarding Africa's natural reosurces for all. Africa Progress Panel, 2013. p. 7).

582 AUERBACH, Bruce E. Unto the thousandth generation: conceptualizing intergenerational justice. New York: Peter Lang, 1995. p. 234. 
A exposição de Weiss é aberta contradizendo uma intuição comum - inclusive nas exposições acima, de Solow, Hartwick e Rawls - mas que, em certos aspectos, pode não ser totalmente correta: a de que as gerações futuras terão melhores condições que as anteriores. Afirma Weiss: "Supusemos em séculos recentes que as condições seriam melhores para nossos descendentes do que para nós, mas agora somos forçados a questionar isso. Hoje temos o poder de alterar o planeta Terra irreversivelmente, numa escala global, de diferentes maneiras. Enquanto podemos desenvolver novas tecnologias para prevenir alguns desastres ambientais, não é de forma alguma certo que a tecnologia nos proverá de uma resposta suficiente". $583-584$

Vale considerar, mais, que não temos apenas o poder de alterar o planeta irreversivelmente. Temos também, hoje - diferente de 100 (cem) anos atrás - o conhecimento (embora não pleno, mas muito avançado, se comparado com o que existia há um século) sobre a extensão dos impactos de nossas ações, bem como sobre métodos para minorá-los ou, por vezes, até mesmo evitá-los. Isso, vale dizer, importa em aumento de nossa responsabilidade. ${ }^{585}$

583 WEISS, Edith Brown. In fairness to future generations cit., p. 1. Tradução livre.

584 De forma semelhante: AGIUS, Emmanuel. Intergenerational justice. In: TREMMEL, Joerg (Ed.). Handbook of intergenerational justice cit., p. 317. Para Neil Buchanan, "if we do not at least take the steps necessary to guarantee the inhabitability of the planet for future generations, then there is no reason to pretend that we are doing them a favor by preventing their incomes from falling" - BUCHANAN, Neil H. What kind of environment do we owe future generations? cit., p. 364. Nada obstante, referindose à questão intergeracional fiscal, Buchanan parece concordar com a ideia geral, combatida por Weiss, de que as condições futuras serão melhores (necessária ou, ao menos, previsivelmente), em: BUCHANAN, Neil H. Four out of four panelists agree: U.S. Fiscal policy does not cheat future generations. George Washington Law Review, v. 77, 2009. Tremmel, por sua vez, questiona: "How meaningful is theory of intergenerational justice if it does not take into account a possible loss in wellbeing due to ecological destruction?" - TREMMEL, Joerg. A theory of intergenerational justice cit., p. 155. Vicente Sartor, em interessante exposição, contextualiza historicamente essas crenças - fundadas ou não, que o referido autor chama de "ingênuas" - de que o futuro será automaticamente melhor em termos de bem-estar, crenças posteriormente questionadas, especialmente em razão de degradação ambiental de vários matizes ("Não se colocava na balança o benefício da acelerada produção tecnológica em contraposição caos malefícios de suas externalidade"). SARTOR, Vicente Volnei de Bona. Justiça intergeracional e meio ambiente cit., p. 55-57.

585 Dieter Birnbacher, por exemplo, sustenta que, diferente de gerações anteriores, a atual possui ferramentas para controlar os impactos que as suas ações causam sobre o futuro; especialmente, a geração atual, diferente das anteriores, diante do progresso científico-tecnológico, é capaz de prever com mais exatidão quais os impactos prospectivos de suas ações e assim detectar seus perigos e riscos. Estas mudanças conduzem a uma extensão de nossa responsabilidade, aí incluindo a responsabilidade para com o bem-estar das futuras gerações. BIRNBACHER, Dieter. Responsibility for future generations scope and limits. In: TREMMEL, Joerg (Ed.). Handbook of intergenerational justice cit., p. 23. Também trabalhando o tema sob o prisma da responsabilidade: ROCHA, Joaquim Freitas da. Breves reflexões sobre responsabilidade colectiva e finanças públicas. In: ROCHA, Joaquim Freitas da (Coord.). Anuário publicista da Escola de Direito da Universidade do Minho cit., p. 133. Afirma: "é possível afirmar-se que a responsabilidade intergeracional é um tipo de responsabilidade que se impõe em primeira linha como consequência de um dever de natureza ética, um imperativo moral que impende sobre a sociedade no seu todo e sobre cada um dos seus elementos em particular, no sentido de acautelar um projecto de 
Weiss identifica, nas concepções de desenvolvimento e sua relação com o uso de recursos naturais, três problemas de equidade entre gerações ${ }^{586}$ (os dois primeiros relacionados a benefícios das gerações presentes em detrimento das futuras; o terceiro discutindo limitação do acesso, pelas gerações presentes, aos recursos naturais), que reputa interrelacionados: (i) a exaustão de recursos; ${ }^{587}$ (ii) a degradação da qualidade dos recursos; ${ }^{588}$ e (iii) o acesso discriminatório ao uso e aos benefícios dos recursos pelas gerações presentes. $^{589}$

Partindo da identificação desses três problemas é que desenvolve sua teoria da equidade intergeracional. Para Weiss, que traz em seus fundamentos interessantes exemplos de concepções sobre a natureza de diversas culturas e mesmo religiões (além de

felicidade que supere as contingências temporais inerentes ao ciclo de existência de cada um. Tal componente ética é - rectius: deve ser - posteriormente revestida por um invólucro jurídico, em consequência do processo de desenvolvimento da consciência humana e da maturidade cultural de um povo, fazendo impender sobre uma geração o resultado das actuações de outra ou outras. Esta juridificação do imperativo resulta verdadeiramente imprescindível, na medida em que as actuações espontâneas (v.g., o mercado), só por si não reconhecem os direitos do futuro, havendo necessidade da sua imposição normativa, designadamente ao nível constitucional, como linha de comportamento".

586 WEISS, Edith Brown. In fairness to future generations cit., p. 6.

587 Que por sua vez se divide em outras três partes: (1) consumo dos recursos de alta qualidade (deixando às futuras gerações recursos de qualidade inferior e preço mais alto); (2) consumo dos recursos ainda não identificados como valiosos (sendo exemplos o gás natural desperdiçado em flares no passado e o hélio); (3) exaustão de recursos (finitude pura e simples, total ou parcial). WEISS, Edith Brown. In fairness to future generations cit., p. 6-9.

588 Valendo especial atenção às práticas de eliminação de resíduos, que por sua vez trazem três problemas: (1) uso do meio ambiente como lugar barato ou grátis para despejo de resíduos, assim passando adiante não apenas os problemas ambientais e de saúde decorrentes, como efetivamente transferindo os custos pela limpeza dos locais degradados; (2) ações que degradam a qualidade do ambiente de forma a inviabilizar determinados usos deste pelas futuras gerações (por exemplo, lagos poluídos que não mais servem para recreação); (3) ações poluidoras que conduzem ao esgotamento de vida animal ou vegetal. Vale mencionar ainda o problema cultural de degradação da qualidade de recursos, como a degradação das páginas dos livros, que pode importar em perdas irremediáveis e prejuízos consideráveis às futuras gerações. WEISS, Edith Brown. In fairness to future generations cit., p. 9-13.

589 A autora identifica três problemas concernentes ao acesso e uso dos recursos naturais pelas gerações atuais: (1) as necessidades das futuras gerações, que limitam o amplo consumo dos recursos recebidos do passado - o que está relacionado à perspectiva mais radicalmente preservacionista e que, levada ao extremo, despe as gerações presentes de seus direitos de acesso aos recursos (concepção não referendada pela autora, para quem "preserving all resources for future generations would seriously aggravate the problems of access that those in need already have, and would be untenable. Moreover, it would exacerbate the inequities among members of future generations, because the great disparities in poverty and wealth would be passed on to future generations" - o que está de acordo com a perspectiva desta dissertação, que não defende o entesouramento dos recursos minerais); (2) o empobrecimento de comunidades, que os impede de usufruir igualmente dos recursos, o que pode resultar em perpetuidade das desigualdades, com os mais abastados (com maior acesso aos recursos) passando para seus próprios descendentes este acesso privilegiado; (3) ações de parte das gerações atuais que impedem o uso dos recursos por outros membros da mesma geração, como por exemplo a degradação de determinados ecossistemas por uns, impedindo as práticas de agricultura, pecuária ou piscicultura por outros. WEISS, Edith Brown. In fairness to future generations cit., p. 13-15. Como se vê, os itens (2) e (3), em verdade, dizem respeito mais à equidade intrageracional do que propriamente ao problema entre gerações. 
instituições de direito público e privado, como a copropriedade), 590 “a qualquer tempo, cada geração é concomitantemente depositária e gestora do planeta para as futuras gerações e beneficiária de seus frutos. Isto impõe obrigações sobre nós para cuidar do planeta e nos dá certos direitos de usá-lo". ${ }^{591-592}$ A noção central, portanto, envolve uma parceria $^{593-594}$ entre gerações, onde ambas devem se respeitar ${ }^{595}$ - usufruir dos recursos

590 Também para uma perspectiva cultural e religiosa: OSKARSON, Annika. Intergenerational equity Protecting future generations through domestic action cit.

591 WEISS, Edith Brown. In fairness to future generations cit., p. 17. Tradução livre.

592 Interessante é a metáfora utilizada por Axel Gosseries para referir este tema. O autor utiliza, para fins didáticos, a imagem de nossa estada no planeta como "montanhistas", considerando a Terra como "um refúgio de montanha no qual aqueles que praticam montanhismo em áreas remotas podem descansar, cozinhar e aquecer-se". Essa metáfora teria a vantagem de ressaltar de as gerações "se sucederem umas às outras, sem que tenham necessariamente a oportunidade de se conhecerem ou encontrarem", de forma que "o refúgio é um espaço de passagem", e é ainda relevante "o facto de eles não terem um guarda. Consequentemente, o comportamento dos sucessivos ocupantes terá um impacto fundamental no estado do refúgio. Podem ocorrer efeitos cumulativos, como no caso da acumulação de lixo ou quando utensílios úteis são abandonados por montanhistas que não necessitam mais deles. Os efeitos decorrentes do exemplo desempenham um papel neste contexto. Isto implica, por exemplo, que a existência de gerações negligentes tenderá a não encorajar as gerações seguintes a agir de forma cuidadosa. Pode-se naturalmente tentar assegurar desde o início que o refúgio seja arquitecturalmente tão robusto quanto possível, resistindo em caso de degradação voluntária por parte de alguns dos sucessivos grupos". GOSSERIES, Axel. A justiça intergeracional e a metáfora do refúgio de montanha. Disponível em: $\langle$ http://www.uclouvain.be/cps/ucl/doc/etes/documents/Refugio_de_Montanha.pdf $>$. Acesso em: $30 \mathrm{dez}$. 2013.

593 A autora, vale apontar, adota claramente a perspectiva de Rawls da posição original em que os sujeitos não sabem a qual geração pertencerão. WEISS, Edith Brown. In fairness to future generations cit., p. 2324.

594 Bruce Auerbach, de forma semelhante, invoca um entendimento de comunidade entre gerações: "Our civilization is built on the achievements and the failures of past generations, and our actions, in turn, affect the lives o four descendants. Unless we undesrtand ourselves to be a part of a community which extends from past to future, we are unlikely to devote sufficient attention or resources to policies which shape that community and its future [...] The changes we make should be judged for how they are likely to affect remite members of our community; for only by treating future generations as members of our community do we make it possible for future generations actually to be members of that community, who will choose to honor our commitments and build on our moral traditions" (AUERBACH, Bruce E. Unto the thousandth generation cit., p. 231 e 235).

595 Essa ideia de parceria, mutatis mutandis, está presente também nas lições de Axel Gosseries, quando se dispõe a responder à questão de Brian Barry: por quê receber algo (recurso natural, recebido das gerações anteriores) justifica uma obrigação, que incide sobre o recipiente? Gosseries soma às investigações sobre o tema suscitando uma noção econômica bem conhecida: o desincentivo ao comportamento free-rider, identificado na geração que recebe os recursos naturais em certo nível, mas não se sente no dever de repassá-los às gerações seguintes em nível assemelhado. Argumenta: "Let me begin with the assumption that free-riding obtains whenever a person derives a net benefit from the fruits of someone else's labor, the latter being fully voluntary, without diminishing in any sense the enjoyment that this other person derives from this good [...] the concept of free-riding has to do with the productionconsumption relationship (rather than focusing merely on consumption) that is still capable of identifying injustices even if the good is non-rival [...] The hypothesis here is that any rival good whose beneficiary would not be its producer belongs to the potential scope of the concept of free-riding, understood as referring to a contribution insufficient once we consider the voluntary production effort by others regarding this good [...] However [referindo-se à metáfora de construção de um castelo pelas gerações anteriores], it could be meaningful to claim that by destroying the castle or even by letting it fall apart, the present generation would be free-riding on earlier generations. For it would take advantage, without adding anything itself, of the efforts they would voluntarily have put in this castle [...] The obligation to reciprocate to the next generation would thus result from an obligation not to free-ride to 
naturais sem com isso impedir que os demais também o façam -, daí por que muitos se referem ao assunto não como justiça ou equidade, mas como solidariedade intergeracional. ${ }^{596} \mathrm{E}$, mais, a teoria estabelece a necessidade de fixação de um nível

the detriment os earlier generations". GOSSERIES, Axel. Three models of intergenerational reciprocity. In: GOSSERIES, Axel; MEYER, Lukas H. (Coord.). Intergenerational justice cit., p. 130-135.

596 Essas noções de herança comum do patrimônio natural e de solidariedade entre gerações, mencionadas por Weiss, encontram eco também em: AGIUS, Emmanuel. Intergenerational Justice. In: TREMMEL, Joerg (Ed.). Handbook of intergenerational justice cit., p. 320-321 e 330-331. Sobre o tema da solidariedade entre gerações, vale consultar o voto-vista de Antonio Augusto Cançado Trindade, na Corte Interamericana de Direitos Humanos, proferido no caso Bámaca-Velásquez v. Guatemala, julgado em novembro de 2000. Afirma: "22. The human kind, that is, the unity of the human kind, ought, thus, in my understanding, to be better appreciated in its essentially temporal (and not static) dimension, comprising in the same way also future generations (who begin to attract the attention of the contemporary doctrine of international law). No one would dare to deny the duty that we have, the living beings, to contribute to construct a world in which future generations find themselves free from the violations of human rights which victimized their predecesors (the guarantee of non-repetition of past violations). 23. Human solidarity manifests itself not only in a spacial dimension - that is, in the space shared by all the peoples of the world, - but also in a temporal dimension - that is, among the generations who succeed each other in the time, taking the past, present and future altogether. It is the notion of human solidarity, understood in this wide dimension, and never that of State sovereignty, which lies on the basis of the whole contemporary thinking on the rights inherent to the human being" p. 6. Disponível em: 〈http://www.corteidh.or.cr/docs/casos/articulos/seriec_70_ing.pdf〉. Acesso em: 18 nov. 2013. Relevante sobre o tema, também, a lição de Alberto do Amaral Júnior: AMARAL JÚNIOR, Alberto do. Comércio internacional e a proteção do meio ambiente. São Paulo: Atlas, 2011. “A proteção do meio ambiente propõe o tema da justiça das normas internacionais a partir da compreensão do valor do tempo para o relacionamento entre as gerações [...] Os tratados internacionais sobre a proteção do meio ambiente, ao abordarem a relação entre as gerações presentes e futuras, trouxera à baila uma nova dimensão da justiça, inconfundível com as dimensões já reveladas pelo direito internacional moderno. A alusão às gerações futuras apareceu, nos últimos tempos, em várias áreas do direito internacional, notadamente nos tratados ambientais firmados na última década. O Preâmbulo da Carta das Nações Unidas expressamente mencionou a resolução de preservar as gerações vindouras do flagelo da guerra como motivo para a existência de uma nova organização internacional encarregada de limitar o uso da força e promover o progresso da humanidade [...] A tutela dos interesses das gerações futuras, convertida em objetivo a ser alcançado, altera a perspectiva tradicional que informa as regras jurídicas [...] A preocupação com o futuro introduz a importância do fator tempo para a finalidade do direito em geral e do direito internacional em particular [...] Os princípios da justiça intergeracional moldam o conteúdo das gerações presentes, determinando em cada caso o âmbito das ações possíveis”. p. 110. Destaca-se, ainda, das lições de Alberto do Amaral Jr., a indicação de que as gerações atuais não têm apenas o poder de atuar em favor das gerações futuras, mas o dever/obrigação de assim fazer, inclusive deixando de fazer escolhas que lhes impactem irremediavelmente mas, tanto quanto possível, possibilitando que as gerações posteriores tenham substrato e meios de alcançar suas próprias decisões. Tudo passando pela "consciência de que a geração presente é apenas um simples elo de uma cadeia mais ampla". E tudo conectado com as dimensões da solidariedade humana. AMARAL JÚNIOR, Alberto do. Comércio internacional e a proteção do meio ambiente cit., p. 110. Diz mais: "A proteção do meio ambiente propõe o tema da justiça das normas internacionais a partir da compreensão do valor do tempo para o relacionamento entre as gerações [...] Os tratados internacionais sobre a proteção do meio ambiente, ao abordarem a relação entre as gerações presentes e futuras, trouxera à baila uma nova dimensão da justiça, inconfundível com as dimensões já reveladas pelo direito internacional moderno. A alusão às gerações futuras apareceu, nos últimos tempos, em várias áreas do direito internacional, notadamente nos tratados ambientais firmados na última década. O Preâmbulo da Carta das Nações Unidas expressamente mencionou a resolução de preservar as gerações vindouras do flagelo da guerra como motivo para a existência de uma nova organização internacional encarregada de limitar o uso da força e promover o progresso da humanidade [...] A tutela dos interesses das gerações futuras, convertida em objetivo a ser alcançado, altera a perspectiva tradicional que informa as regras jurídicas [...] A preocupação com o futuro introduz a importância do fator tempo para a finalidade do direito em geral e do direito internacional em particular [...] Os princípios da justiça intergeracional moldam o conteúdo das gerações presentes, determinando em cada caso o âmbito das ações possíveis". 
mínimo de equidade entre as gerações - a ser fixado segundo padrões ambientais mínimos, que não podem decrescer. ${ }^{597}$

Os limites da equidade intergeracional, em Weiss, revelam-se em concepções antagônicas e radicais: de um lado, o modelo preservacionista, que demanda que as presentes gerações nada consumam, de tal forma que as futuras gerações se beneficiem às expensas das anteriores $;{ }^{598}$ de outro lado, o que chama de modelo da opulência, em que as gerações atuais consumem o quanto podem, “seja porque não há certeza que as futuras gerações existirão, seja porque maximizar o consumo hoje é a melhor forma de maximizar a riqueza das futuras gerações", ignorando questões de degradação, de extinção de espécies e de esgotamento de recursos não renováveis. ${ }^{599}$

Ambos os modelos são identificados como limítrofes porque estão fora da concepção de equidade intergeracional, notadamente porque privilegiam uma(s) geração(ões) em detrimento de outra(s). Para Weiss, “o propósito da sociedade humana deve ser realizar e proteger o bem-estar e a prosperidade de cada geração". ${ }^{600}$ E os modelos referidos claramente não acompanham esse propósito.

Este ponto reputa-se relevante, demandando ênfase. O que se defende - e já teve ter ficado evidente pelas razões expostas até aqui - é a defesa dos direitos das futuras gerações, a consideração de que essas gerações devem ser efetivamente protegidas, e para isso alguns institutos jurídicos (e também econômicos e políticos) devem ser ajustados ou, ao menos, devem levar em consideração esse aspecto temporal.

O que não se propõe, especialmente quando da aplicação direta dessas noções à exploração de recursos naturais não renováveis, é a paralisação das atividades econômicas

597 WEISS, Edith Brown. In fairness to future generations cit., p. 24-25. É uma espécie de mínimo existencial, muito debatido no Brasil quanto à justiça distributiva e a concretização dos direitos e garantias constitucionais, aplicado à justiça entre gerações. Isso "provê um piso para todas as gerações e assegura que cada geração tenha ao menos o mesmo nível de base planetária de recursos que seus ancestrais".

598 Idem, ibidem, p. 22-23. A autora afirma que esse modelo "é consistente com uma economia de subsistência, mas não com um mundo industrializado" (tradução livre). Vê semelhanças desse modelo com o regime de desenvolvimento Stalinista e com as posturas Calvinistas.

599 Idem, p. 23. Tradução livre. Vale ainda notar que os direitos e deveres intergeracionais, adiante delineados, funcionam como balança entre esses extremos. Diz Weiss: "They balance the extreme positions of the preservationist and the opulent models. Rights of access and equitable use serve as a brake on the preservationist model; obligations to conserve quality and diversity act as constraints on the opulent model. They are designed to ensure that each generation will inherit an environment in no worse condition than previous generations and will have an opportunity to use this environment to improve its economic and social well-being. They find roots in the cultural and religious traditions of the world" $-\mathrm{p}$. 46.

600 Idem, ibidem. Tradução livre. Destaque acrescido. 
(entesouramento dos minérios, por exemplo) hodiernas em prol desses interesses. Buscase, com Neil Buchanan, as escolhas públicas ("win-win choices") em que não apenas o respeito às futuras gerações é levado adiante, como também as gerações atuais utilizem (responsavelmente, sustentavelmente) esses recursos naturais na economia. ${ }^{601}$

Voltando às ideias de Weiss, cabe questionar: que objetivos derivam das noções fixadas? São eles: (i) cada geração deve passar adiante o meio ambiente em condição não pior daquela que recebeu, proporcionando acesso equânime das gerações futuras aos recursos e benefícios, ${ }^{602}$ (ii) as melhoras na base natural e cultural, realizadas pelas gerações anteriores, devem ser mantidas; (iii) reparar os danos, ainda que seja custoso, e ainda que tenha sido causado pelas gerações anteriores, embora podendo distribuir o custo de fazê-lo entre as gerações posteriores. ${ }^{603-604}$

601 "The analysis then broadens to ask whether there are policies that can help both current and future generations. Happily, the answer to that question is a resounding 'yes', meaning that the presumed conflict between generations is often more theoretical than real [...] There is, in other words, a broad range of win-win choices" (BUCHANAN, Neil H. What kind of environment do we owe future generations? cit., p. 343).

602 No mesmo sentido: AUERBACH, Bruce E. Unto the thousandth generation cit., p. 234. Também afirma Buchanan: "the broadest area of agreement seems to coalesce around an intuitive notion that people should make sure that 'my kids will do better than me'. To be sure, this answer still offers little quantitative guidance, but it does at least create a crude baseline: Each generation should make sure that it leaves future generations no worse off than current generations" - BUCHANAN, Neil H. What kind of environment do we owe future generations? cit., A ideia defendida por Joerg Tremmel é similar, embora não idêntica. Para ele, "the core element of a convincing theory of intergenerational justice, however, is the demand for making improvement possible for the next generation”. Por detrás dessa noção, está o fundamento, segundo Tremmel, de que a desigualdade entre gerações, estando as posteriores em melhores condições, não é apenas desejada como é o rumo natural da humanidade. TREMMEL, Joerg. $A$ theory of intergenerational justice cit., p. 204.

603 WEISS, Edith Brown. In fairness to future generations cit., p. 24. A autora postula também a existência de obrigações intergeracionais entre países. Isto é: considerando que muitos países de desenvolvimento mais avançado atualmente alcançaram essa condição com ampla exploração natural, é correto afirmar que eles hoje são responsáveis por compensar os jurisdicionados de outros países, que não promoveram essa exploração? A autora entende que sim. Contudo, essa dimensão da questão não será abordada nessa dissertação. Idem, ibidem, p. 26 e ss. A autora também promove considerações sobre o impacto intergeracional da má distribuição de renda (e acesso aos recursos naturais) intrageracional, questionando: "como podemos esperar que uma comunidade empobrecida cuide das futuras gerações, se ela não consegue nem mesmo cuidar de seu próprio povo hoje? A pobreza é a causa primária da degradação ecológica". Nada obstante, também a questão da má distribuição de riqueza na mesma geração, embora relevantíssima, não será abordada, senão marginalmente, nessa ocasião. Idem, ibidem, p. 27. Tradução livre.

604 No mesmo sentido da Nota anterior, é a lição de Buchanan: "intergenerational justice is not just a matter of looking at the changes in income between generations. It is also tied up very directly with distributive justice [...] For current generations to continue to ignore the most vulnerable among those alive, while also harming the health and well-being of future people, would be to the height of arrogance and selfishness [...] Intergenerational justice without distributive justice is no justice at all". BUCHANAN, Neil H. What kind of environment do we owe future generations? cit., p. 361, 366 e 367. Também Buchanan, em outra oportunidade: "the pressing issue from an egalitarian standpoint is not justice between generations but distributive justice within and across generations" (BUCHANAN, Neil H. Four out of four panelists agree: U.S. Fiscal policy does not cheat future generations cit., p. 1405). 
Vistas essas ideias gerais, cabe galgar mais degrau, questionando-se mais concretamente sobre o conteúdo da equidade intergeracional.

Weiss sistematiza os princípios aplicáveis à justiça entre gerações, desde já elegendo a equidade como princípio normativo básico ${ }^{605}$ - o que "assenta a fundação para o desenvolvimento dos princípios de equidade intergeracional". ${ }^{606}$

Esses princípios, vinculados diretamente aos propósitos da teoria da equidade intergeracional e seus objetivos, devem obedecer a 04 (quatro) critérios: (i) devem encorajar a equidade entre gerações; (ii) não devem requerer que uma geração preveja quais valores serão protegidos pelas próximas; (iii) devem ser claros para aplicação em situações previsíveis; e (iv) devem ser, em geral, compartilhados por tradições culturais diversas e, em geral, aceitáveis por sistemas políticos e econômicos diversos. ${ }^{607}$

Os princípios são: (i) conservação de opções, em que a cada geração se requer a conservação da diversidade da base de recursos natural e cultural, de forma a não restringir as opções das gerações futuras; ${ }^{608}$ (ii) conservação da qualidade, em que cada geração deve manter a qualidade dos recursos, passando o ambiente em condições não piores das recebidas pelas gerações anteriores; ${ }^{609-610}$ e (iii) conservação do acesso, em que

605 WEISS, Edith Brown. In fairness to future generations cit., p. 34. A Autora recorre ao Direito Internacional para definir o conteúdo do referido princípio. Diz: "In the North Sea Continental Shelf Cases, the Court [International Court of Justice] sets forth the classic description of equity: 'Whatever the legal reasoning of a court of justice, its decisions must by definition be just, and therefore in that sense equitable. Nevertheless, when mention is made of a court dispensing justice or declaring the law, what is meant is that the decision finds its objective justification in considerations lying not outside but within the rules, and in this field it is precisely a rule of law that calls for the application of equitable principles. There is consequently no question in that case of any decision ax aequo et bono, such as would only be possible under conditions prescribed by Article 38, paragraph 2, of the Court's Statute'. In its decision on the maritime boundary between Tunisia and Libya the Court invoked equity and noted that 'Equity as a legal concept is a direct emanation os the idea of justice [...] While it is clear that no rigid rules exist as to the exact weight to be attached to each element in this case, this is very far from being an exercise of discretion or conciliation"'. Finalmente, Weiss parece fixar sua concepção de equidade assim considerando: "Increasingly equity is being invoked to mean "equitable standards for the allocation and sharing of resources and benefits"” (p. 35-36). Idem, ibidem, p. 37.

607 Idem, p. 38

608 O princípio está ligado à noção de legitimidade: as futuras gerações devem ter resguardado seu direito de decidir quais valores promover e quais políticas seguir. Logo, as diversas opções devem se fazer presentes. Vale destacar também que o princípio não demanda que a diversidade de um ecossistema, como verificada em um ponto qualquer da história, deva ser intocada; mas que a diversidade, em gênero, o seja, independente da quantificação da vida lá presente. Não se pretende que, para a conservação das opções, tudo permaneça intocado. Uma analogia interessante é a de manutenção de diversidade como num portfólio de investimentos: não se exige que sejam os mesmos investimentos mantidos, mas que a estratégia de maximizar riqueza e a pulverização do risco, contidos nesse portfólio, deve sê-lo. Mesmo a estratégia de criar substitutos para os recursos naturais, através de novas tecnologias, é de ser aceita com base nesse princípio. WEISS, Edith Brown. In fairness to future generations cit., p. 40-42.

609 Novamente aqui vale comentar que não se adota o modelo conservacionista, mas uma ideia sustentável. Trade-offs são inevitáveis e esperados: "we may exhaust more reserves of a natural resource and cause 
cada geração deve prover a seus membros o acesso equânime aos recursos naturais

herdados das gerações anteriores, conservando tal acesso às futuras gerações. Como se vê, a formulação do princípio encampa também noções de equidade intrageracional. ${ }^{611}$

Weiss - no que se vê acompanhada por outros, como Clark Wolf ${ }^{612}-$ sustenta $^{2}$ que esses princípios obedecem à noção de desenvolvimento sustentável, na forma fixada pelo documento Nosso futuro comum, aprovado pela Comissão mundial sobre meio ambiente e desenvolvimento. Afinal, este documento igualmente prevê um princípio de

modest levels of pollution, but pass on a higher level of income, capital and knowledge sufficient to enable future generations to develop substitutes for the depleted resource and methods for abating or removing pollutants. Framework must be developed in which such balancing can take place". WEISS, Edith Brown. In fairness to future generations cit., p. 42-43. Vale observar que, nesse ponto, Weiss faz uma análise já referida, acima, na obra de Solow: a necessidade de desenvolver melhores índices e medições ambientais e referentes aos recursos naturais não renováveis, para que as escolhas políticas e a análise dos trade-offs seja transparente e fundamentada.

610 No mesmo sentido da Nota anterior: "It can be difficult to judge the value of our contributions to the inheritance of future generations. Because this is the case, it is important to articulate standards by which we may measure the quality of the world we inherited and that of the world we will pass on to future generations. Not everything we inherit is desirable, and not every change we make is an improvement". AUERBACH, Bruce E. Unto the thousandth generation cit., p. 235. Bonin (BONIN, Pierre-Yves. La justice internationale et le partage des ressources naturelles cit., p. 130-131) encampa uma versão do referido princípio: "Il est comparable au principe d'égalité des chances adopté par une société en vue d'assurer à tous ses membres la possibilité de réaliser leurs projets de vie. Dans les deux cas, l'objectif fondamental est de laisser à chaque individu ou à chaque génération la liberté de choisir son destin". O princípio deve ser entendido como "une condition minimale de justice pour toutes les générations". O autor, contudo, entende que o princípio importa em obstáculo ao crescimento econômico, pelo que oferta uma reformulação interpretativa, dando ênfase não à situação dos recursos naturais mas às circunstâncias que permitam prover "condições de vida" equivalentes em cada geração. Afirma: "Ce qui importe n'est pas de s'assurer que les générations futures auront une situation aussi proche que possible de la situation de la génération actuelle, mais de ne pas les placer dans une position inférieure" (p. 132). Nessa interpretação favorecida por Bonin, o princípio "n'exige pas que le niveau de vie des générations reste constant, mais uniquement que la quantité et la qualité des ressources se maintiennent. Comme il a été souligné précédemment, il s'agit d'un principe d'égalité des chances entre les générations et non d'un principe d'égalité de bien-être" (p. 133).

611 WEISS, Edith Brown. In fairness to future generations cit., p. 43-45.

612 WOLF, Clark. Intergenerational justice. In: FREY, R. G.; WELLMAN, Cristopher Heath (Ed.). A companion to applied ethics cit., p. 292. "Is there any reason to regard human sustainability as a requirement - perhaps a minimal requirement - of intergenerational justice? There are several ways in which such a claim might be supported. First, we may note that future generations are vulnerable to our choices. and that it is typically regarded as 'unjust' when some people needlessly deprive others of the ability to meet basic needs. The requirement of human sustain ability is violated only if we leave future generations worse off than we are ourselves with respect to the satisfaction of needs. so violation of the requirement of human sustain ability would make later generations worse off in order to benefit previous better-off generations" - p. 292. Vale mencionar que o referido autor acredita que essa noção de sustentabilidade corresponde ao princípio rawlsiano da poupamça justa, sendo o que seria escolhido pelas partes na posição original: "it is arguable that parties to a Rawlsian original position choice that included generation blindness would choose human sustainability as a minimal requirement of intergenerational justice. For alternative principles would increase the risk that parties to the choice would be unable to meet basic needs. Rawls argues that parties to the original position choice will be unwilling to consider principles that raise this downside risk". 
equidade intergeracional: "os Estados devem conservar e utilizar o meio ambiente e os recursos naturais para o benefício das presentes e futuras gerações". 613

Dos princípios da equidade intergeracional, e dando-lhes concretude, derivam direitos e deveres intergeracionais, na visão de Weiss. ${ }^{614-615}$ São direitos e deveres coletivos, na medida em que são definidos e aplicados consoante uma posição temporal; são aplicados a gerações, e a indivíduos enquanto membros de uma geração. ${ }^{616} \mathrm{E}$ dada a continuidade das gerações, direitos e deveres coexistem numa mesma geração, que é

613 NOSSO FUTURO COMUM. Comissão mundial sobre meio ambiente e desenvolvimento cit.

614 Nada obstante, a autora registra que, ao tempo da publicação de sua obra, "our concern for future generations can be considered as a moral protection of interests", não configurando direitos e deveres legais - WEISS, Edith Brown. In fairness to future generations cit., p. 103. Defenderemos adiante que, ao menos na análise do ordenamento brasileiro, estas considerações intergeracionais não são apenas morais, mas que configuram direitos de matriz constitucional. No mesmo sentido, que entendemos por demais tímido, especialmente por se tratar de um trabalho desenvolvido já em 2009 (em contraponto com o texto de Weiss, que data de 1989): "Do we have a responsibility to safeguard the environment for future generations? The answer is both yes and no. There is a firm basis for claiming that we have moral responsibility to do so; both the extension of Rawls theory of justice and the argumentation based on communitarianism, viewing all of humanity as a whole, suggest that we do. [...] Whether or not we have a legal responsibility to safeguard the interests of posterity is more unclear, however. Parallels can be drawn to the evolution of sustainable development as well as the development of international environmental law and human rights law. [...] Looking at the support that has been shown for the concept in various international declaration and agreements, no legally binding obligation for states to respect intergenerational equity has so far been established. A legal responsibility towards posterity has, however, been accepted in the domestic legal system of a number of countries around the world". OSKARSON, Annika. Intergenerational equity - Protecting future generations through domestic action cit., p. 50.

615 Sobre a Nota acima, vale referir as conclusões de Burns Weston: "Ample social justice theory distributive, reciprocity-based, and respect-based - establishes that future generations have legal as well as moral rights to protection from environmental threats and harms, especially such as are embodied in climate change" (WESTON, Burns H. The theoretical foundations of intergenerational ecological justice: an overview cit., p. 266).

616 Embora não negue que os interesses das futuras gerações devam ser observados, Casalta Nabais nega que elas tenham direitos. Para o autor, quando se fala em direitos das futuras gerações, quer-se falar de deveres das gerações presentes para com a humanidade, esta que compreende também as pessoas ainda não nascidas: "Aqui se devem integrar, a nosso ver, os deveres para com nossos companheiros da aventura humana - os animais, as plantas e até os rios, os mares - que, ao contrário do que por vezes se ousa afirmar, não constituem direitos (humanos!) dos animais, das plantas, dos rios e dos mares. Evidentemente que em tais domínios se trata dum conjunto de deveres indirectos para com a humanidade, ou mais precisamente, de exigências correspondentes a um equilibrado e adequado ambiente natural necessário à preservação da vida (digna de ser vivida) da espécie humana, integrada esta tanto pela geração actual como pelas gerações futuras. Diferentemente se passam as coisas relativamente aos deveres para com as gerações futuras frequentemente referenciados por direitos das gerações futuras, o que, a nosso ver, é inadequado, uma vez que não descortinamos quem sejam os actuais titulares (activos) desses direitos. Pois que estes ou são as futuras gerações, o que não é factível, ou se reconduzem à geração actual, o que originaria a curiosa categoria de direitos a que futuras gerações tenham direito(s) a uma vida digna de ser vivida. O que não deixa de ser uma forma bastante equívoca de dizer que sobre a actual geração, quer na forma de tarefas estaduais, quer na forma de diversos deveres (sem direitos) dos indivíduos, grupos e organizações, recaem exigências para com os vindouros orientadas no sentido da preservação no futuro da comunidade actual através da preservação de riscos e perigos que possam vir a inviabilizar ou onerar excessivamente a vida das gerações futuras". NABAIS, José Casalta. O dever fundamental de pagar impostos. Coimbra: Livraria Almedina, 1998. p. 53-54. Para uma opinião negando com veemência que as gerações vindouras têm ou possam ter quaisquer direitos: BECKERMAN, Wilfred. The impossibility of a theory of intergenerational justice. In: TREMMEL, Joerg (Ed.). Handbook of intergenerational justice cit., p. 53 e ss. 
simultaneamente titular dos direitos (em face das gerações anteriores) e dos deveres (em face das gerações posteriores). ${ }^{617}$ Os Estados, enquanto entidades contínuas, representam gerações passadas, atuais e futuras, no que refere direitos e deveres. ${ }^{618}$ Afinal, como lembra Beleeiro, "o Estado não morre, não incorre em falência e goza de perenidade do grupo humano ao qual serve de personalidade jurídica e política" ${ }^{619}$ E, diz José Souto Maior Borges, "os fins colimados pela atividade estatal são variáveis no tempo e no espaço e nisto consiste, precisamente, a sua relatividade histórica". ${ }^{620}$ Daí então que, com Comparato, deve-se reconhecer que "é o Estado que deve atuar, precipuamente, como o administrador responsável dos interesses das futuras gerações". ${ }^{621}$

Quais são os deveres? (i) dever de tomar ações para conservar os recursos; ${ }^{622}$ (ii) dever de garantir acesso equânime ao uso e aos benefícios desses recursos; ${ }^{623}$ (iii) dever de prevenir ou mitigar impactos adversos nos recursos e na qualidade ambiental; ${ }^{624}$ (iv) dever de minimizar desastres e prover assistência emergencial; e (v) dever de suportar os custos de compensar o dano aos recursos e à qualidade ambiental. ${ }^{625}$ Para além desses deveres, deriva dos princípios acima referidos, também, a responsabilidade que recai sobre os Estados não apenas para seguir os deveres por seus diversos agentes e órgãos, mas para estabelecer regras aos agentes privados, bem como para fazer com que sejam cumpridas. Os Estados são os avalistas do cumprimento dos deveres intergeracionais. ${ }^{626-627}$

617 WEISS, Edith Brown. In fairness to future generations cit., p. 45.

618 Idem, ibidem, p. 48.

619 BALEEIRO, Aliomar. Uma introdução à ciência das finanças cit., p. 460.

620 BORGES, José Souto Maior. Introdução ao direito financeiro cit., p. 14.

621 COMPARATO, Fábio Konder. A afirmação histórica dos direitos humanos cit., p. 438-440.

622 No caso dos recursos naturais não renováveis, esse dever se traduz em utilização eficiente dos recursos e no dever de estimular pesquisa científica visando encontrar substitutos a esses recursos. WEISS, Edith Brown. In fairness to future generations cit., p. 51.

623 Interessante a menção não apenas ao acesso aos recursos, mas às informações coletadas a partir deles. É uma vertente do direito à transparência e ao acesso à informação.

624 Embora sejam impactos que não se manifestam exatamente nos recursos naturais e no meio ambiente, senão marginalmente, vale mencionar que os efeitos da maldição dos recursos naturais e da doença holandesa, já acima referidos, são também impactos que devem ser evitados.

625 WEISS, Edith Brown. In fairness to future generations cit., p. 80: "From the perspective of future generations, it is important to minimize harm to the natural and cultural environment. In theory, either the present generation could be responsible for avoiding harm, or future generations could be given resources with which to undo damage or to mitigate the effects. The principle that should govern is that the party who can avoid the harm at least cost should be responsible for doing so".

Idem, ibidem, p. 86. A responsabilidade atribuída aos Estados é da mesma natureza da atribuída pela Declaração de Estocolmo de 1972 sobre o Meio Ambiente Humano, que estabelece, em seu Princípio 21: "Em conformidade com a Carta das Nações Unidas e com os princípios de direito internacional, os Estados têm o direito soberano de explorar seus próprios recursos em aplicação de sua própria política ambiental e a obrigação de assegurar-se de que as atividades que se levem a cabo, dentro de sua jurisdição, ou sob seu controle, não prejudiquem o meio ambiente de outros Estados ou de zonas situadas fora de toda jurisdição nacional". 
E quanto aos direitos intergeracionais ${ }^{628}$ ? Naturalmente, são compatíveis com e diretamente ligados aos deveres já elencados. ${ }^{629} \mathrm{O}$ estabelecimento desses direitos como interesses juridicamente protegidos - tem por cerne garantir que cada geração receba o planeta da geração anterior em condições não inferiores às que esta recebeu da antecedente. Não se trata de direitos possuídos por indivíduos, mas "podem apenas ser concebidos em nível de grupo", que "não dependem de conhecer o número ou tipo de indivíduos que podem por fim existir em qualquer das futuras gerações". ${ }^{630}$

A efetiva aplicação desses direitos é que gera maior dificuldade. Weiss sugere a designação de um representante - um ombudsman - dos interesses das futuras gerações perante as instituições estatais presentes. Esta medida serviria para endereçar o problema da carência de legitimidade que os governantes atuais têm para definir políticas que afetam profundamente as gerações futuras, sem que estas possam se manifestar. O ombudsman das gerações pósteras serviria para tentar reduzir esse gap de legitimidade, atuando em proteção aos sujeitos do porvir, tanto quanto possível. Vale considerar, nesse tema, que os Estados têm natureza de entidades contínuas, pelo que podem servir de protetores desses interesses (instalando e financiado o mencionado representante), inclusive fazendo-o, perante Cortes internacionais, ${ }^{631}$ em relação às transgressões de outros Estados nacionais.

Finalmente, Weiss traz formas de implementação das responsabilidades das gerações atuais em face das futuras, introduzindo a perspectiva de longo prazo em instituições, incentivos econômicos, instrumentos legais, consciência pública e vontade política. As estratégias para essa implementação são: ${ }^{632}$ (i) representação das futuras

627 O que não importa dizer, contudo, que apenas no Estado em suas políticas é que se respeita ou deixa de respeitar a equidade intergeracional. Como lembra Michael Doran, há um sensível número de atividades não governamentais que têm impacto entre gerações e que devem ser consideradas no tema. DORAN, Michael. Intergenerational equity in fiscal policy reform cit., p. 254-255. Afirma: "In other words, intergenerational equity is not a question specifically for government policy; it is fundamentally a question of political and moral philosophy". p. 259.

628 Weiss invoca diferentes perspectivas teóricas sobre os direitos, especialmente as de MacCormick e Kelsen, que objetariam a existência de direitos intergeracionais, seja porque bens públicos não podem ser objeto de direitos individuais; seja ante a falta de indivíduos determinados que possuam tais direitos. Contudo, a autora sustenta a existência desses direitos, ainda que contra a teoria trazida por estes e outros teóricos, notadamente invocando a diferença fundamental da matéria em debate, fundada que está em uma distância temporal. WEISS, Edith Brown. In fairness to future generations cit., p. 95-103.

${ }^{629}$ A autora elabora uma lista de categoria de ações que podem ser vistas como infringentes dos direitos intergeracionais, sem, contudo, listá-los como faz com os deveres. Essas ações incluiriam formas de disposição de rejeitos, danos aos solos, destruição das florestas tropicais, poluição do ar, entre outros. Idem, ibidem, p. 104.

630 Idem, p. 96. Tradução livre.

631 O sistema de proteção dos direitos intergeracionais sugerido por Weiss é todo fundado no sistema internacional de proteção aos Direitos Humanos.

632 WEISS, Edith Brown. In fairness to future generations cit., p. 119. 
gerações no processo de tomada de decisões ${ }^{633-634}$ - que pode ser através de uma comissão legislativa ou, sendo a mais promissora forma de assim alcançar, o estabelecimento de um ombudsman; (ii) uso sustentável dos recursos renováveis; (iii) manutenção de instalações e serviços para conservação de recursos naturais e culturais, incluindo produção, armazenamento e recuperação de dados; (iv) monitoramento da diversidade e da qualidade dos recursos ambientais; (v) avaliação de impactos; ${ }^{635}$ (vi) pesquisa científica e desenvolvimento tecnológico para melhor identificar os efeitos das ações das gerações atuais, melhorar a eficiência da utilização dos recursos e desenvolver recursos alternativos; ${ }^{636}$ (vii) codificação de direitos e obrigações; e (viii) educação global para criar consciência para a necessidade de conservação para as gerações futuras. ${ }^{637}$

633 "States should be encouraged to give standing in their national courts and administrative bodies to a representative of future generations, who might function like a guardian ad litem" (idem, ibidem, p. 123).

634 Nesse sentido, apreciando as pressões de grupos ambientais em contraponto com o desenvolvimento de projetos econômicos, Neil Buchanan afirma: "Those choices would be difficult enough if everyone who would be affected by those choices could be included in the decision-making process [...] The fundamental difference in setting environmental policy, of course, is the nagging problem that decisions today affect just the people currently involved in the political process but those who cannot participate as well. Because there is no way to bring those future parties into the process directly, the political process must somehow find a way to represent their interests in juxtaposition to the interests of those who are currently voting adults". BUCHANAN, Neil H. What kind of environment do we owe future generations? cit., p. 341-342. E ainda: "because it is not possible to ask future generations what they would prefer, current generations must speak for them. Ultimately, that is what the policy-making process is all about. Moreover, because of the irreversibility noted above, any decision to take away environmental options must be weighed more seriously than decisions that can be changed at any point in the future with relative ease" - p. 355. Alguns doutrinadores, embora reconhecendo que são relevantes as dificuldades que advêm da impossibilidade de chamar gerações futuras a participar da tomada de decisões, expondo suas preferências, buscam minorar esse problema. Como afirma Clark Wolf, não se pode supervalorizar o tema, eis que é razoável crer que suas preferências serão similares às nossas: "But it would be misleading to overemphasize our present ignorance about what future persons will want. We can more reliably, if fallibly, predict that their basic needs will be similar to our own. It is surely implausible to suggest that we should frame social policy around the possibility that future generations will be so different from ourselves that they will not have similar basic needs". WOLF, Clark. Intergenerational justice. In: FREY, R. G.; WELLMAN, Cristopher Heath (Ed.). A companion to applied ethics cit., p. 291. No mesmo sentido: "the seriousness of the nonrepresentation problem should not be overstated. Current generations generally do take into account the interests of future generations to the extent that parents and grandparents, when participating in the political process, assess the effects of their policy decisions on their children and grandchildren who are not yet able to vote or otherwise participate in representational government" (DORAN, Michael. Intergenerational equity in fiscal policy reform cit., p. 291).

635 "It would complement traditional environmental impact assessments. While the latter are supposed to consider long-term effects, they often do not. Their primary focus is always on present environmental effects. The intergenerational conservation assessment would rectify this imbalance by requiring separate, detailed attention to future impacts. Intergenerational conservation assessments would require those initiating actions or making loans to analyze how these will affect the diversity and the quality of natural and cultural resources and the access of people to these resources on the time-scale of a decade and beyond" (WEISS, Edith Brown. In fairness to future generations cit., p. 132).

636 "Only through such research can we give future generations the understanding and the tools they will need to manage their environmental legacy. Such research will help present and future generations to monitor our planet, assess the risks to its long-term environmental health, increase the efficiency of the exploitation and conservation of resources, develop alternatives to scarce resources and design products that use less scarce resources, and develop new technologies for gathering and maintaining information 
Para implementar essas estratégias, Weiss aponta para a necessidade de iniciativas institucionais. Sugere a criação de uma Comissão para o Futuro do Planeta, independente, como órgão intergovernamental ou não governamental, que teria como atribuições, dentre outras, alertar para os perigos à saúde dos recursos naturais e culturais.

Ainda, são relevantes suas considerações sobre aspectos econômico-financeiros da equidade intergeracional, isto é, sobre a necessária avaliação e contabilização dos tradeoffs entre o uso hodierno dos recursos e seus impactos futuros: não apenas, como já referido, a contabilização dos recursos é falha, como os métodos de tomada de decisões (como a utilização de taxas de desconto social) muitas vezes leva a decisões enviesadas em prol da exploração presente. ${ }^{638-639}$ Tudo o que leva a pleitear outros meios de condução, como mediante a utilização de trust funds.

regarding the environment and natural and cultural resources" (WEISS, Edith Brown. In fairness to future generations cit., p. 141).

637 "The greatest need is for a new ethos, planetary in scope and encompassing all generations. We need to develop a sense of belonging to a community of past, present and future generations" (idem, ibidem, p. 145).

638 Sobre a medição do fardo financeiro-orçamentário legado ao futuro, Alan Auerbach, Jagadeesh Gokhale e Laurence J. Kotlikoff propuseram um sistema de medição que demonstrasse efetivamente o déficit passado às gerações futuras. V. AUERBACH, Alan J.; GOKHALE, Jagadeesh; KOTLIKOFF, Laurence J. Generational accounting: a meaningful way to evaluate fiscal policy cit. Interessante também consultar a obra de Peer Ederer, Philipp Schuller e Stephan Willms, que defendem a utilização do Indicador de Sustentabilidade Econômica, justamente visando completar essa lacuna, ofertando medidas de transferências intergeracionais. O Indicador proposto analisa 5 (cinco) tipos de capital que são recebidos das gerações anteriores e mede o quanto desses bens está sendo repassado ao futuro. Os tipos de capital avaliado são: capital real (maquinário produtivo e imóveis comerciais), capital humano (número de pessoas empregadas multiplicado pelo custo da sua educação formal e informal), capital natural (todos os recursos naturais utilizados no processo produtivo), capital estrutural (regras e instituições formais e informais que organizam a sociedade), e dívida intergeracional (todas as promessas de pagamento futuro, deixadas em aberto pela geração analisada, para pagamento pelas futuras). Afirmam: "The Economic Sustainability Indicator measures how much capital any given generation is handing down to future generations, in terms of how much capital it has inherited from its parent generation. This tool goes beyond similar tools available today and encompasses all spheres of economic activity. It can furthermore not only be applied to generational cohorts but also to shorter time frames, such as election cycles. It is applicable not only to the economy as a whole but also to individuals or individual interest groups within it" (EDERER, Peer; SCHULLER, Phillip; WILLMS, Stephan. The Economic Sustainability Indicator. In: TREMMEL, Joerg (Ed.). Handbook of intergenerational justice cit., p. $131 \mathrm{e}$ 145-146). Embora não estejamos na posição de avaliar criticamente os critérios de medida utilizados pelos referidos pesquisadores, resta fixar, com aprovação, que esse tipo de análise vem sendo desenvolvida, buscando suprir a lacuna indicada por Weiss e permitindo que o processo de tomada de decisões seja decididamente mais fundamentado em questões desta natureza. Vale ainda consultar a doutrina de Tremmel (TREMMEL, Joerg. A theory of intergenerational justice cit., p. 90-91) para uma abordagem ceticista sobre este tipo de medição. Para ele, não sabemos quais tipos de capital devem ser incluídos na "herança geracional" e não temos como medir ou quantificar cada um desses tipos de capital. Tremmel favorece, quando o assunto é "o que devemos deixar às gerações futuras", outras medidas, notadamente o IDH - Índice de Desenvolvimento Humano.

Embora de forma algo diferente do proposto por Weiss, cabe mencionar, no tema de medição ou classificação voltado aos interesses das gerações futuras, que a organização britânica Intergenerational Foundation divulgou em 2012 um Índice de Justiça Intergeracional, em que pretende medir o impacto de políticas públicas do Reino Unido, em um intervalo de tempo, sobre as próximas gerações. O Índice 


\section{2.d. Equidade intergeracional, estrutura constitucional e representação.}

Tomando por base as lições de Weiss, ${ }^{640}$ cabe prosseguir tentando identificar como se estrutura a equidade intergeracional. Conforme já referido acima, um dos principais engasgos quando das considerações sobre os direitos e deveres entre gerações está na legitimidade das gerações atuais para decidir - ainda que levando em conta os interesses futuros - casos sensíveis e protraídos vastamente no tempo.

O problema da legitimidade reside no fato, simplesmente posto, de que as gerações futuras (máxime as mais distantes) não dispõem de representantes no processo de tomada de decisões atual. Daí surgem algumas considerações interessantes, especialmente relacionadas às instituições existentes na maioria dos países ocidentais - o Brasil incluído.

Joerg Tremmel inicia explanação sobre o tema suscitando a insuficiência do princípio democrático $^{641}$ - ou de sua forma contemporânea usual - para lidar com a justiça entre gerações. Isto é: as eleições periódicas, por tempo determinado, cabendo aos cidadãos elegerem aquele que melhor lhes representa, traz incentivos para que as políticas adotadas sejam apenas e tão somente dirigidas às gerações atuais. Então, não apenas as futuras gerações não participam dessa tomada de decisão como os gestores públicos têm maiores razões - máxime diante do interesse na reeleição em quatro anos - para dirigir

aponta, por exemplo, que de 2000 a 2011, o fardo imposto sobre as pessoas mais jovens foi sucessivamente aumentado, especialmente após a crise econômica de 2008. O documento foi elaborado em atenção a 09 (nove) indicadores: desemprego, pensões, dívida, participação democrática, saúde, renda, impacto ambiental e educação. Em todos eles analisou-se se as próximas gerações estarão em vantagem ou desvantagem em relação à atual. LEACH, Jeremy; HANTON, Angus. Intergenerational fairness index: measuring changes in intergenerational fairness in the united kingdom. Intergenerational foundation, 2012. Disponível em: <http://www.if.org.uk/wpcontent/uploads/2012/06/IFIndex_defin.pdf>. Acesso em: 30 dez. 2013.

640 Cabe mencionar que, nada obstante a influência do texto de Edith Brown Weiss, e sua profundida sistemática, que ora utiliza-se para apresentação do problema, é claro que suas ideias não passam sem críticas. Para uma revisão breve dessas críticas: OSKARSON, Annika. Intergenerational equity Protecting future generations through domestic action cit., p. 27. Afirma: "The theory of Weiss is not without problems and critique. There is uncertainty regarding the preferences and situation of future generations, the temporal extension of our obligations is being questioned and it is criticized for not sufficiently taking the needs of developing countries and historical factors such as colonization into account. Yet the theory manages to establish a coherent theoretical basis for the protection of future generations. It may not provide all the answers or be completely developed in all aspects, but can serve as a foundation for measures to safeguard the interests of posterity. The understanding of what matters are possible to control through legislation, or which interests that can be given legal significance, is under constant evolution. If agreement can be reached regarding the existence of moral responsibilities towards posterity, the translation of those into legal obligations may very well be the next rational step to take”.

641 TREMMEL, Joerg. Establishing intergenerational justice in national constitutions. In: TREMMEL, Joerg (Ed.). Handbook of intergenerational justice cit., p. 188-190. 
seus esforços àquele grupo votante. Não a gerações posteriores. É claro que isso não comanda a rejeição da democracia, mas uma adequação ao caso em debate.

Essa adequação poderia se dar de algumas formas. Tremmel advoga a positivação dos direitos das gerações futuras nas Constituições de cada país. ${ }^{642}$ Mas não apenas: prega a institucionalização ${ }^{643}$ concreta desses direitos através dessa positivação constitucional.

Então, identifica três tipos correntes de cláusulas constitucionais ${ }^{644}$ em diversos países pesquisados ao redor do mundo (cláusulas gerais de justiça intergeracional, cláusulas ecológicas, e cláusulas financeiras), assim como alguns modelos de instituições (Ombudsmen, Comitês parlamentares, Conselhos específicos) direcionadas ao tema, observando que no caso de adição de regra à Constituição, o Tribunal Constitucional passaria a ser o protetor desses direitos; no caso das instituições, seriam elas mesmas. O primeiro caso (cláusulas constitucionais guardadas pela Corte Constitucional) parece ser mais adequado, na visão do autor (daí por que prossegue tratando dele mais especificamente), já que seus membros costumam ter cargos vitalícios, não necessitando da aprovação direta dos indivíduos da geração atual. No caso de órgãos como Comissões, terse-ia o dilema: se eleitos democraticamente, poderiam incorrer nos mesmos equívocos do Executivo ou Legislativo; se não eleitos, podem ter seus poderes questionados justamente por isso: a falta de uma aprovação popular. ${ }^{645}$

642 No mesmo sentido: ROCHA, Joaquim Freitas da. Sustentabilidade e finanças públicas responsáveis Urgência de um direito financeiro equigeracional. Mimeo. O texto foi publicado em CORREIA, Fernando Alves; MACHADO, Jónatas E. M.; LOUREIRO, João Carlos (Org.). Estudos em homenagem ao Prof. Doutor José Joaquim Gomes Canotilho. Coimbra: Ed. Coimbra, 2012.

643 Institucionalização entendida como: "measures to safeguard the interests of future generations through institutions or written law". TREMMEL, Joerg. Establishing intergenerational justice in national constitutions. In: TREMMEL, Joerg (Ed.). Handbook of intergenerational justice cit., p. 189.

644 A divisão entre temas estanques de proteção intergeracional não é referendada por Peter Häberle, para quem a referência a cláusulas ecológicas e culturais são mais efetivas do que as cláusulas de proteção geral das futuras gerações porque se referem à toda a vida - e não apenas à vida humana, significado comumente extraído da mera referência às "futuras gerações". Afirma: "It is also necessary to broaden the perspective towards indirect generation protection, which is accomplished by nature and culture. The human generations are not conceivable without the protection of the 'nature' surrounding them and the 'culture' created by them; both nature as well as culture constitute their 'life world'. Generation protection is simultaneously always protection of nature and culture" (HÄBERLE, Peter. A constitutional law for future generations - the 'other' form of the social contract: the generation contract. In: TREMMEL, Joerg (Ed.). Handbook of intergenerational justice cit., p. 218-219). Com essa defesa veemente da proteção do meio ambiente e da cultura como uma proteção da própria raça humana, portanto, o autor põe a questão no mesmo patamar, tornando prescindível a análise diferenciada entre os temas.

645 TREMMEL, Joerg. Establishing intergenerational justice in national constitutions. In: TREMMEL, Joerg (Ed.). Handbook of intergenerational justice cit., p. 196 e 198. 
Contudo, apesar de favorecer a inclusão de regras intergeracionais nos textos constitucionais, Tremmel critica as redações atualmente encontradas, diante de sua abstração, indeterminação, vagueza, e não estabelecimento de direitos imediatamente reclamáveis, mas de objetivos estatais. ${ }^{646}$ Por isso, chega mesmo a propor uma redação de cláusula intergeracional ecológica, a ser incluída nas constituições nacionais, exigindo em diversos âmbitos que sejam respeitadas as noções de sustentabilidade. ${ }^{647}$ Em relação às cláusulas financeiras de justiça intergeracional, critica sua redação (tendo como alvo a cláusula alemã), também utilizando conceitos vagos (como a exigência de um orçamento balanceado) e permitindo exceções demais discricionárias para o endividamento. Por essas razões, Tremmel engloba as sugestões de alteração da constituição alemã propostas pelo FRFG (grupo não governamental Foundations of the Rights for Future Generations), seja incluindo uma cláusula intergeracional geral, ${ }^{648}$ seja melhorando a redação da cláusula intergeracional financeira. ${ }^{649}$

Tratando de uma perspectiva assemelhada - a análise de textos constitucionais no que concerne à proteção das gerações futuras -, mas tomando premissas diversas, Peter Häberle analisa o tema a partir da teoria constitucional. Sustenta que "cláusulas de proteção geracional e de proteção natural-/cultural no direito constitucional são obrigações

646 TREMMEL, Joerg. Establishing intergenerational justice in national constitutions. In: TREMMEL, Joerg (Ed.). Handbook of intergenerational justice cit., p. 204.

647 "Article: Protection of the Ecologic Rights of Succeedings Generations. (1) The state protects the rights and interests of succeeding generations within the bounds of the constitutional order through the legislative and according to law through the executive and the jurisdiction. (2) It guarantees that harmful substances will pollute nature, soil, air, water and the atmosphere only to the extent to which they can decompose due to their natural regenerative capabilities in the respective time period. (3) It guarantees that renewable resources are not exploited to a greater extent than they are capable of renewing themselves. Non-renewable raw materials and energy resources must be used as economically as possible by a justifiable expenditure. (4) It guarantees that no sources of danger are constructed which could lead to harm that cannot be undone or only undone by unjustifiable expenditure. (5) It guarantees that the existing variety of fauna and flora as well as ecological systems is not diminished by human activity. (6) Offenses against paragraphs 2 and 5 are allowed when they are compensated for by a quantitatively and qualitatively comparable compensation abroad" (idem, ibidem, p. 205). Vale mencionar que o mesmo Tremmel procura distinguir a justiça intergeracional da sustentabilidade: "sustainability can be defined as a concept that gives intergenerational justice the same weight as intregenerational justice on a normative level. The demand for intergenerational justice leads to two fields of activity: ecology and finances ('ecological' and 'financial' sustainability). Intragenerational justice mainly aims at international justice (adjustment of the living conditions in the North and the South), justice between the poor and the rich within a country, and justice between men and women". TREMMEL, Joerg. A theory of intergenerational justice cit., p. 7.

648 "The state must observe the principle of sustainability and safeguard the interests of future generations". TREMMEL, Joerg. Establishing intergenerational justice in national constitutions. In: TREMMEL, Joerg (Ed.). Handbook of intergenerational justice cit., p. 211.

649 "When making decisions with regard to the budgetm the Federal Republico f Germany and its states must pay attention to the macroeconomic balance, to the principle of sustainability and the interests of future generations" (acrescendo as partes em italic ao resto do texto, já existente) (idem, ibidem). 
em um estágio constitucional e endereçadas a todas as três funções estatais". ${ }^{650}$ Nada obstante, sua preocupação não está direcionada apenas à maior proteção de futuras gerações nos textos constitucionais, mas, muito ao inverso, a um adequado balanço da carga normativa imposta. Isto é: busca um meio termo entre um insuficiente "direito constitucional geracional", em que o presente é tido por absoluto e as decisões afetam o futuro sem conscientizar com seus impactos de longo prazo; e um demasiado "direito constitucional geracional”, em que as normas são trazidas de forma imutável, amarrando as gerações futuras, sob a mesma constituição (de cuja formação não participaram) - o que se revela vicioso, já que cada geração tem o direito de definir suas próprias regras, não podendo ser forçada a seguir as regras trazidas pelas anteriores. ${ }^{651-652}$

650 HÄBERLE, Peter. A constitutional law for future generations - the 'other' form of the social contract: the generation contract. In: TREMMEL, Joerg (Ed.). Handbook of intergenerational justice cit., p. 220.

651 Häberle, considerando uma noção geracional de povo, advoga a ideia de que a observância dos direitos intergeracionais demanda que as constituições sejam revisitadas periodicamente, permitindo a participação de cada geração, e observando as eventuais mudanças sociais a demandar a alteração no contexto jurídico-constitucional: "Within all these time processes or time periods not only the people living in the highly selective present are involved: rather the 'people' is included in advance as the 'sum of generations' - integrating present and past. In other words, the respective national people (founded by culture) is the beginning, subdivided into generations, which is fixed in the constitutional state. This beginning 'repeats' and renews this constituting process consistently in different ways and with different intensity. Thus, a constitution is normally drafted and enforced not only according to the demand of the generations living today but also for future ones. In order to enable the people and their representatives to participate in order to handle the 'social change' 'over and over again', also within shorter time units of 15 or 30 years (henceforth probably more), the model of the constitutional state has developed and differentiated appropriate procedures" (HÄBERLE, Peter. A constitutional law for future generations the 'other' form of the social contract: the generation contract. In: TREMMEL, Joerg (Ed.). Handbook of intergenerational justice cit., p. 223-224).

652 Víctor Muñiz-Fraticelli não compartilha dessa crítica ao longo alcance temporal das constituições. Refutando escritos de Thomas Jefferson (para quem a constituição e as leis de uma sociedade deveriam expirar automaticamente quando a geração que as escolheu deixa de ser maioria da população) e Michael Otsuka (que retoma a ideia de Jefferson, pondo ênfase na legitimidade das normas com base no consentimento, expresso ou tácito, daqueles que estão submetidos à sua autoridade), o autor defende a validade do que chama de constituições perpétuas - não no sentido de sua imutabilidade, mas no sentido de que, como tradicionalmente, suas normas "are assumed to be valid and biding without need to reenacted or ratified periodically with the appearance of each new generation". Muñiz-Fraticelli refuta essas ideias, seja com base em questões práticas (a dificuldade de renovar todo o ordenamento jurídiconormativo a cada 20 ou 30 anos), seja diante dos perigos que trariam para formação de um sistema próspero e estável (considerando que muitas das estipulações mais relevantes de um governo se dirigem ao futuro e dependem, para implementação, de ações continuadas, observando que muitos dos feitos que beneficiariam as futuras gerações seriam prejudicados, já que as gerações anteriores deixariam de aplicálos sem qualquer segurança de sua continuidade), ou ainda considerando que essa estabilidade normativa é diretamente ligada à ideia de autogoverno , inclusive pelo poder de liberar as gerações seguintes do fardo de discutir, de alto a baixo, novamente, toda a associação civil. A perpetuidade da constituição, então, garante condições mínimas de pluralismo, equidade e ordem. Para o autor, "it is not too alarmist to warn that expiring constitutions are a recipe for perpetual revolution”. Então, entende não apenas que o texto constitucional perpétuo (nas suas palavras) não viola os direitos das futuras gerações, como entende também que as gerações anteriores têm o dever - justamente em honra das futuras - de poupar a posteridade da discussão extensa dos pilares estatais básicos, legando-lhes uma constituição que garanta legitimidade política. MUÑIZ-FRATICELLI, Víctor M. The problema of a perpetual constitution. In: GOSSERIES, Axel; MEYER, Lukas H. (Coord.). Intergenerational justice cit., p. 377-408. 
Esta relevante objeção ao conteúdo das normas constitucionais de proteção às futuras gerações - a insuscetibilidade de sua alteração pelas gerações vindouras, assim impedindo que exerçam seus legítimos direitos políticos - tem um viés não apenas legislativo (normas imutáveis pelo processo legislativo ordinário), mas hermenêutico: é como alertam Bruce Auerbach e Michelle Reinhart, criticando o radical processo de interpretação levado a efeito principalmente por Antonin Scalia, na Suprema Corte estadunidense. O referido magistrado defende ardorosamente o que chamam de "textualismo constitucional", ou "originalismo textual", uma forma robustecida de interpretação histórica, em que os textos constitucionais (inclusive conceitos como "devido processo legal" e "punição cruel e incomum") devem ser lidos de acordo com seu sentido original, explicitamente com o intuito de evitar a dualidade de sentidos a ser dada pelas gerações futuras. Essa corrente de pensamento - além das objeções a serem formuladas pela hermenêutica jurídica - revela-se viciada na medida em que "a habilidade das futuras gerações para reinterpretar a Constituição por si própria é essencial à legitimidade intergeracional da Constituição". ${ }^{653}$ Muñiz-Fraticceli, embora defendendo a perfeita validade dos textos constitucionais em longo espaço de tempo, concorda com os mencionados autores. Para ele, a interpretação dos textos constitucionais (junto com a possibilidade de sua emenda) é justamente um dos pontos que garantem que a continuidade dos textos constitucionais não é ofensiva às gerações posteriores: a interpretação "não deve ser feita em abstração da história da cláusula e da maneira pela qual ela modelou nossa sociedade; mas deve ser feita em tudo considerando que nós somos plenos participantes nessa história". ${ }^{654-655}$

653 Afirmam ainda Auerbach e Reinhart: "Future generations cannot be consulted about the terms of a constitution, nor can they give their consent to that document, except long after it was written and adopted. At that point consent to the Constitution is not free and voluntary, but constrained by the very existence of the Constitution and the institutions that rest upon it, and by the dangers posed by abandoning those institutions [...] justice to future generations generally requires that the present generation not seek to limit the choices and options of their descendants whenever possible. Justice to future generations certainly requires that the present generation not seek to enforce its preferences on future generations, assuming that were possible. Although we should not be indifferent to the types of choices future generations may face, we have an obligation to respect the autonomy of future persons, and not to seek to limit their choices unnecessarily, nor to make choices for them that they are capable of making for themselves [...] It would not have been legitimate for the Framers of the Constitution to have attempted to impose their values on future generations, by deliberately restricting the choices of their descendants, as Scalia argues they did [...] There is good reason to conclude that Antonin Scalia's position is wrong both historically and ethically, and should be rejected" (AUERBACH, Bruce E.; REINHART, Michelle. Antonin scalia's constitutional textualism: the problem of justice to posterity. Intergenerational Justice Review, n. 01, 2012, p. 17-22).

654 Diz também: "people should be mindful of the historical development of the of their collective identity, and not succumb either to blind deference to the past, or to atemporal abstraction" (MUNIZ- 
Tratando ainda do tema legitimidade das decisões hodiernas que afetam as futuras gerações, impõe-se mencionar que já existem algumas iniciativas - em geral tidas por bem sucedidas, mas com graus de efetividade diversos - destinadas a minorar o déficit de participação dos indivíduos vindouros e que, por questões óbvias, não participam diretamente do processo de tomada de decisões. ${ }^{656}$ São elas: (i) a Comissão para as Futuras Gerações do Knesset (o Parlamento unicameral israelense); ${ }^{657}$ (ii) o Ombudsman para as futuras gerações húngaro; ${ }^{658}$ e (iii) o Escritório para análise de Política Econômica (CPB) holandês. ${ }^{659-660}$ Independente de maiores considerações sobre sua eficácia, é de se registrar

FRATICELLI, Víctor M. The problema of a perpetual constitution. In: GOSSERIES, Axel; MEYER, Lukas H. (Coord.). Intergenerational justice cit., p. 404 e 408).

655 Também numa reflexão sobre a validade da Constituição - e especialmente das cláusulas pétreas - em face dos interesses das futuras gerações, a partir da teoria constitucional, ver: NOGUEIRA, Cláudia de Góes. A impossibilidade de as cláusulas pétreas vincularem as gerações futuras. Revista de Informação Legislativa, ano 42, n. 166, Brasília: Senado Federal, Subsecretaria de Edições Técnicas, abr.-jun. 2005, p. 79 e ss.

656 Emmanuel Agius defende a criação de um órgão supraestatal legitimado como "guardião" das futuras gerações: AGIUS, Emmanuel. Intergenerational Justice. In: TREMMEL, Joerg (Ed.). Handbook of intergenerational justice cit., p. 322-323.

657 A Comissão é primordialmente legislativa, tendo os poderes de demandar informações de qualquer órgão estatal ou estabelecimento controlado, e de requisitar a outras comissões legislativas, na análise de leis, lhe seja concedido tempo razoável para preparar uma opinião fundamentada sobre seu impacto nas futuras gerações. Nada obstante esses poderes conferidos pela sua lei instituidora, na prática a Comissão tornou-se um catalisador de interesses de ONGs, iniciativas públicas, representações ministeriais executivas, e mesmo grupos do setor privado, todos concernentes às futuras gerações, não apenas representando esses interesses no Parlamento, como atuando para conscientização pública e até mesmo na produção de dados e informações relevantes. O Comissário será eleito por um comitê formado por profissionais e políticos. O Comissário será um cidadão com formação acadêmica, experiência profissional, que não tenha sido ativo politicamente nos dois anos anteriores à sua candidatura a Comissário, e que não tenha sido condenado criminalmente. Seu mandato é de cinco anos. A Comissão, em verdade, busca atuar como verdadeira conselheira do Governo, em suas diversas esferas. Interessante notar que, diferente do que ocorre em outros lugares, em Israel a Comissão ora referida não foi objeto de pressões populares e de grupos de interesses, mas resultou das ideias de um indivíduo, Joseph Lapid, então líder do Shinui, partido liberal de classe média, em um modelo top-down. Estas e outras informações relevantes estão em: SHOHAM, Shlomo; LAMAY, Nira. Comission for Future Generations in the Knesset: lessons learnt. In: TREMMEL, Joerg (Ed.). Handbook of intergenerational justice cit.

658 A Hungria mantinha a estrutura de Ombudsmen para outros assuntos, como direitos civis, direitos das minorias étnicas, e proteção de dados e liberdade de informações. Assim, uma organização não governamental húngara propôs a criação de um Ombudsman para as futuras gerações, para funcionar, como os demais, junto ao Poder Legislativo, protegendo os interesses das futuras gerações no processo de tomada de decisões de forma institucional. Segundo essa proposta, a função seria fundada em três pontos básicos para atuação eficiente: independência funcional (especialmente em face da administração pública), competência larga e proatividade (o que incluiria, além da investigação fática sobre violações aos interesses das futuras gerações, e a manifestação sobre processo de leis, quando provocado, também a atuação para prevenção de ações danosas, e a legitimidade para apresentação de projetos de leis e regulamentos). Maiores detalhes sobre a proposta inicialmente feita podem ser encontrados em: JÁVOR, Benedek. Institutional Protection of succeeding generations - Ombudsman for Future Generations in Hungary. In: TREMMEL, Joerg (Ed.). Handbook of intergenerational justice cit. Nada obstante, referido artigo foi publicado em 2006, quando o processo de criação permanecia na burocracia legislativa. Ele veio a se tornar realidade no final de 2007 , tendo a função sido efetivamente criada e permanecendo atuante até 2011, quando o cargo veio a ser acoplado ao Comissariado para os direitos fundamentais, como se vê em: 〈http://www.ajbh.hu/en/web/ajbh-en/>. Acesso em: 14 nov. 2013.

659 Trata-se de um órgão de pesquisa fundamentalmente econômico, suprindo dados aos agentes públicos especialmente sobre os efeitos de logo prazo das políticas em debate. Embora não se trata de um órgão 
que demonstram a preocupação dos Estados nacionais israelense, húngaro e holandês quanto aos interesses das gerações pósteras, dando um passo adiante, para além da mera previsão normativa programática.

Ainda sobre a participação das futuras gerações no processo político, há outras sugestões na literatura, que dizem respeito à extensão e melhoramento do processo democrático atual para minorar os efeitos da ausência das gerações futuras. Michael Doran, citando James Fishkin, menciona a utilização de uma "pesquisa de opinião deliberativa", que busca não apenas saber o que os jurisdicionados pensam, mas o que pensariam se estivessem sujeitos a condições hipotéticas ideais de intenso processo deliberativo. ${ }^{661}$ Tratar-se-ia de um "método prescritivo para determinar o que o corpo político decidiria sobre uma questão se fosse viável se envolver no tipo de processos deliberativos profundos que são viáveis apenas em pequenos grupos". ${ }^{662}$ Doran sustenta que esse processo incrementaria a democracia deliberativa, fazendo com que as gerações atuais estejam hábeis a compreender os interesses das gerações futuras e os representar.

No mesmo sentido - extensão e melhora do processo democrático como forma de representar as futuras gerações - Raymond Kopp e Paul Portney propuseram um "referendo simulado", destinado especificamente ao processo de tomada de decisões com base numa análise intergeracional de custo-benefício. Esse método seria aplicado a um grupo restrito de votantes, devendo ser reiterado em espaços de tempo regulares - de forma que os indivíduos que iniciariam a tomar o fardo das políticas, ainda que em suas primeiras gerações, fossem ouvidos. ${ }^{663}$

que formule políticas - mas apenas trabalhe nos impactos daquelas decisões a serem tomadas por quem de direito, inclusive quanto aos planos apresentados nas plataformas eleitorais, evitando julgamentos -, sua independência em face do governo central (embora faça parte dele formalmente) permite que funcione como catalisador das preocupações intergeracionais. Suas opiniões econômicas englobam vasto espectro, desde os rendimentos dos investimentos públicos até os impactos do envelhecimento da população (e as políticas a lidar com o tema) nas finanças públicas e a já mencionada análise préeleitoral dos planos apresentados pelos partidos políticos em disputa. O CPB tem seu trabalho detalhado em: VAN OPSTAL, Rocus; TIMMERHUIS, Jacqueline. The role of CPB in Dutch economic policy. In: TREMMEL, Joerg (Ed.). Handbook of intergenerational justice cit.

Para uma exposição sobre estas e outras instituições destinadas a promover os direitos das futuras gerações, v. OSKARSON, Annika. Intergenerational equity - Protecting future generations through domestic action cit.

661 DORAN, Michael. Intergenerational equity in fiscal policy reform cit., p. 287.

662 Idem, ibidem.

663 "Under the mock referendum approach, however, appeal is made directly to the citizenry for the evaluation of the policy option in question. First, a representative random sample of U.S. households is drawn, a sample that could be partitioned in any number of ways, to be discussed below. This sample would then be presented with a detailed description about what is known about the likely effects of the policy change, and--importantly--what is likely to happen if nothing is done. Among other things, that description would spell out the beneficial effects expected to result from the intervention, and where and 
Eis, portanto, que existem formas - algumas mais concretas e já testadas, outras sugeridas e ainda abstratas - de institucionalizar a proteção das futuras gerações, como se faz imperativo para uma defesa efetiva desses interesses.

A questão da justiça entre gerações, note-se, sofre um tipo especial de resistência: a carência de motivação social concreta para agir de acordo com os referidos preceitos jurídicos e morais. Essa carência se revela latente por algumas razões. A uma, as futuras gerações (especialmente as mais distantes) não têm o apelo de um rosto que possa ser reconhecido pelos cidadãos. Então, os pleitos em prol desses sujeitos ainda não nascidos, identificados e tampouco conhecidos, revelam-se na prática sensivelmente menos passíveis de aceitação social, especialmente quando comparados a outros, imediatamente identificados e conhecidos - como, por exemplo, tragédias naturais, reveladas pelos meios de comunicação com nomes e faces. A duas, os pleitos em prol das gerações futuras são inevitavelmente abstratos: para usar o mesmo exemplo acima, uma tragédia natural pode demandar um valor certo para reconstrução de casas, aparelhamento de hospitais, fornecimento de alimentos; mas a poupança justa (para usar o termo de Rawls) tem valor incerto, dependente de uma diversidade de variáveis, presentes, passadas e futuras, para que se chegue até o que é de ser considerado correto. A três, finalmente, vê-se esse problema de motivação aumentado porque, ainda que se queira atender aos interesses das futuras gerações, esse(s) ato(s) está(ão) sujeito(s) a uma série de incertezas: sobre o quê nossos descendentes irão valorizar; sobre o impacto que nossas ações atuais terão no longo

when they will occur. [...] It is important that the sample households be presented with the best information possible about where these effects will be felt. [...] The descriptive material presented to the sample population would also include a description of how the proposed policy intervention would work. That is, it would explain how a tax on carbon equivalents, say, would translate into increased prices for gasoline, home heating oil, electricity, and other products not initially subject to the tax but making use of the taxed products as inputs [...] It is quite important that the temporal distribution of impacts be described as carefully as possible. Households would have to be told what favorable and unfavorable impacts are likely to occur immediately, which ones could be expected later in their lives (say, over the next twenty to thirty years), and which impacts are not likely to manifest themselves for hundreds of years. It is equally important that households be given a sense of the uncertainties that attach to the various effects [...] The most important respect in which the descriptive material would vary concerns the description of the costs that the household itself is likely to bear, now and in the future. By confronting households with identical information on the likely beneficial effects of the program in space and time, and identical information on the costs that others are likely to bear, while varying for different respondents the description of the costs that they are likely to face, one can sketch out a willingness-topay locus for the policy by observing the way their (hypothetical) votes vary with the cost of the program. This is the kernel of our proposed mock referendum approach [...] It places the burden of valuation and discounting for intergenerational projects squarely on the shoulders of those who would begin to bear the burdens associated with project implementation--those in the here and now. If repeated regularly, it could be updated as old generations die off and are replaced by new ones" (KOPP, Raymond J.; PORTNEY, Paul R. Mock referenda for intergenerational decisionmaking. Resources For The Future Discussion Paper, 97-48, Washington, DC: Resources for the Future). 
prazo (considerando, também, que variáveis como o tamanho da população e a evolução tecnológica são deveras incertos e certamente de grande relevância numa perspectiva temporal), e até mesmo incertezas sobre se as gerações imediatamente posteriores às nossas também cooperarão nesse esforço de respeitar a equidade intergeracional. ${ }^{664-665}$ Tudo, cumpre sempre recordar, em um ambiente de recursos escassos ${ }^{666}$ onde são necessárias escolhas trágicas. ${ }^{667}$ Cada unidade monetária dirigida a uma ação importa em uma unidade monetária não dirigida a outra.

${ }^{664}$ O tema é bem desenvolvido por Dieter Birnbacher: BIRNBACHER, Dieter. What motivates us to care for the (Distant) Future?. In: GOSSERIES, Axel; MEYER, Lukas H. (Coord.). Intergenerational justice cit., p. 273-298. No texto, o autor toma de empréstimo os conceitos e elementos da motivação oriundos da psicologia, em suas diversas fases (aceitação, adoção, aplicação e ação). Sustenta: "Apart from some of the members of the generations of our children and grandchildren, future generations are faceless and invisible. Future people are object of thought and calculation. They come into view only as abstract recipients of goods and potential victims of harms, as anonymous items, and do not offer themselves as concrete and experientially accessible objects of attitudes such as love, friendship, reverence or solidarity. But it seems that our moral sensibilities are primarily attuned to 'identified' and not to 'statistical' beneficiaries and victims [...] One important aspect of the necessary abstractness pf future generations is that it is more difficult to presente a vivid and realistic picture of future situations than of present situations in the media" - p. 282-283. E ainda: "Acting for the future is inherently more risky than acting for the present or for the immediate future. It essentially involves the risk of squandering moral resources on projects that fail to achieve their intended aims by factors beyond the agent's control. That these risks have a considerable psychological impact on behavior has been shown in several relevant areas. On of the preconditions for action motivation seems to be a relevant 'control belief', i.e. the belief of appropriate action will be effective in attaining the desired goal. Without relevant 'control beliefs', the motivation to entre upon a course of action can be expected to be unstable" - p. 284 .

665 Tema semelhante é tratado por alguns não como motivação, mas como um problema de empatia, conforme referido por Paul Bloom, em matéria jornalística que destinada à crítica de livros sobre o assunto. BLOOM, Paul. The baby in the well. The New Yorker. 20 de maio de 2013. Afirma: "Such are the paradoxes of empathy. The power of this faculty has something to do with its ability to bring our moral concern into a laser pointer of focused attention. If a planet of billions is to survive, however, we'll need to take into consideration the welfare of people not yet harmed - and, even more, of people not yet born. They have no names, faces, or stories to grip our conscience or stir our fellow-feeling".

666 FARREL, Martin Diego. Filosofia del derecho y económia cit., p. 93: "Que lós recursos son limitados no me parece una aserción controvertible. Hume ló dijo de manera convincente: "nunca se tiene una cantidad tal de bienes que satisafagan a cada uno de nuestros deseos y necesidades'".

667 Sobre as escolhas trágicas, ver: CALABRESI, Guido; BOBBIT, Philip. Tragic choices: the conflicts society confronts in the allocation of tragically scarce resources. New York: W. W. Norton \& Company, 1978. O tema é assim brevemente resumido por Regis de Oliveira: "As necessidades são ilimitadas e infinitas. Diante da assunção, pelo Estado, de inúmeras atribuições, o que se verifica pela só análise da Constituição, o agente público deve identificar onde alocará os recursos disponíveis. Não tem como atender a tudo e a todos. Logo, elege prioridades". OLIVEIRA, Regis Fernandes de. Gastos públicos. São Paulo: RT, 2012. p. 123. Ainda, diz Gilmar Mendes: "Há sempre uma decisão financeira detrás de cada atuação estatal que demande recursos". MENDES, Gilmar Ferreira. Tributação e finanças públicas na Constituição Federal de 1988. In: MENDES, Gilmar Ferreira; BRANCO, Paulo Gustavo Gonet. Curso de direito constitucional. 6. ed. rev. e atual. São Paulo: Saraiva, 2011. p. 1451. Mister, finalmente, destacar o duplo aspecto da despesa pública, realçado por Baleeiro: "Em todos os tempos e lugares, a escolha do objetivo da despesa envolve um ato político, que também se funda em critérios políticos, isto é, nas ideias, convicções, aspirações e interesses revelados no entrechoque dos grupos detentores do poder. Tanto mais lúcidos, cultos e moralizados sejam os governantes quanto mais probabilidades existem de que se realize aquele cálculo da máxima vantagem social. Isso põe em contraste o aspecto político e o aspecto técnico da despesa pública. A despesa pública deve ser encarada sob esse duplo aspecto" (BALEEIRO, Aliomar. Uma introdução à ciência das finanças cit., p. 78). 
Portanto, essas limitações quanto à motivação social tornam mais urgente a criação de instituições destinadas ao trato da matéria: sejam elas de direito positivo (como a inclusão de cláusulas constitucionais), de criação de consciência pública (principalmente através da educação), por meio de órgãos governamentais diretamente dirigidos ao tema (como a Comissão e o Ombudsman, acima citados, ou até mesmo mediante atribuição específica de poderes ao Ministério Público), sejam ainda através da sociedade civil (como think tanks e afins), ou até mesmo através de órgãos internacionais (como propõe Weiss, no modelo das Cortes destinadas à proteção dos Direitos Humanos ${ }^{668}$ ).

\section{2.e. Equidade intergeracional, finanças públicas e direito financeiro.}

Cabem ainda algumas observações sobre a aplicação da ideia de equidade entre gerações diretamente às finanças públicas e à política fiscal - e ao Direito Financeiro.

Isto é: embora grande parte das razões já acima apresentadas, apesar de dirigirse à matéria ambiental, se aplique de forma direta ou de forma principiológica à questão financeira, algumas diferenças devem ser anotadas. Afinal, não apenas de meio ambiente viverão as gerações futuras. Como consta da doutrina suprarreferida de John Rawls, é importante que deixemos instituições boas e justas. ${ }^{669}$

Como bem pondera Michael Doran, ${ }^{670}$ há uma multiplicidade de programas e ações, na esfera fiscal, que podem ser analisados sob a perspectiva de sua adequação ou não à justiça entre gerações. Na esfera ambiental, não se dá essa multiplicidade: embora seja evidente que há diversas formas de interação entre homem e natureza, a ratio é a mesma - evitar a degradação irreversível; permitir que as gerações futuras tenham acesso aos recursos naturais e/ou à riqueza deles oriunda.

Nas finanças públicas, podem ser analisados individualmente alguns programas - como a Seguridade Social -, apontando que são insustentáveis no tempo, e que deixarão

668 "The policies underlying international human rights law-the apotheosis of respect-based justice in the modern world-similarly provide a foundation for building intergenerational justice, the more so when they are internalized into national legal systems" (WESTON, Burns H. The theoretical foundations of intergenerational ecological justice: an overview cit., p. 261).

669 Como afirma Clark Wolf: "By working to secure peace, by extending the scope of democracy and the protection of rights, we make it more likely that their lives will be secure. By expanding knowledge and promoting appropriate technologies, we may provide them with opportunities we cannot even imagine. Our present choices can constrain opportunities as well, and there are increasing grounds for concern that our way of life might create serious hardships in the future" (WOLF, Clark. Justice and intergenerational debt. Intergenerational Justice Review, n. 1, 2008, p. 13).

670 DORAN, Michael. Intergenerational equity in fiscal policy reform cit., p. 291-292. 
dívidas para serem pagas por outrem, no futuro. Mas essa análise nunca será completa se não feita em conjunto com todas as demais políticas fiscais que tenham efeitos de longo prazo, algumas que certamente podem ser tidas como beneficiando as futuras gerações à custa das atuais, como é o caso do investimento em pesquisa e tecnologia. ${ }^{671}$

Essa característica multidimensional, contudo, embora possa importar numa cautela extra quando o tema é de equidade intergeracional na política fiscal, certamente não significa que tais análises não devam ser levadas adiante. Como Doran assevera, uma vez feitas essas ressalvas - inclusive como forma de clareza metodológica e honestidade intelectual -, tais análises, de políticas específicas, podem e devem ser feitas. ${ }^{672}$

Então, ainda que se tomem como corretas as críticas de Daniel Shaviro, para quem não podemos nos amparar em considerações intergeracionais para o desenho de questões fiscais e financeiras, ${ }^{673}$ isso não pode impedir que o tema se desenvolva. A uma, porque suas análises da equidade intergeracional são marcadamente utilitaristas, portanto

671 Doran refere até mesmo os gastos levados a efeito em decorrência da 2. ${ }^{\text {a }}$ Guerra Mundial. Para o autor, embora as gerações da primeira metade do século XX tenham deixadas dívidas para serem pagas pelas gerações futuras, também deixou-lhes como legado a liberdade e a prosperidade custeados com dinheiro e vidas na guerra. $\mathrm{O}$ argumento revela-se procedente, embora deva ser apartado da análise crítica do mérito da guerra e das virtudes dos vencedores (DORAN, Michael. Intergenerational equity in fiscal policy reform cit., p. 253-254).

672 "Those observations imply that, even if we cannot make broad assessments about the intergenerational equity of government fiscal policy or government policy as a whole, we can make normative evaluations at the margins about whether a particular government program or a potential reform to a particular government program is more or less equitable in its intergenerational effects" (idem, ibidem, p. 259).

673 Para ele, "evaluating this distribution question is extremely difficult. Even if one narrows the potential normative landscape by assuming a utilitarian view of generational equity, a number of important considerations suggest tilting overall distribution toward future generations, while others suggest tilting it toward us. We are thus left with far greater normative uncertainty in addressing generational equity than typically arises in addressing intragenerational equity [...] The problems that make generational equity so much harder, even under a straight utilitarian norm, are twofold. First, we know much less about the future than the present and cannot confidently say, for example, how much wealthier our society will grow or for how long it will continue. Second, over a long period of time the world may change enough to undermine standard assumptions, such as that a dollar has the same marginal utility for two individuals who, by measures such as lifetime income, appear to be equally well-off. Technological and environmental changes, for example, may plausibly have systematic effects on marginal utility that cannot comfortably just be ignored. The fact that it is so hard to reach any firm conclusions about the implications of generational equity for long-term budgetary policy does not reduce such equity's potential importance or suggest that we should simply forget about it. The uncertainty does, however, impede relying on considerations of equity to draw confident conclusions regarding how we ought to share between current and future generations the burden of putting fiscal policy on a sustainable course". SHAVIRO, Daniel. The long-term U.S. Fiscal gap: is the main problem generational inequity? cit., p. 1327. Também por isso, Neil Buchanan (citando a concordância de outros, especialmente Daniel Shaviro) entende que não há razões para se afirmar que a política fiscal atual dos EUA prejudica as futuras gerações: "there is no convincing case that current generations are being somehow unfair to future generations while coddling themselves [...] intergenerational justice is not the appropriate lens through which to discuss fiscal policy". BUCHANAN, Neil H. Four out of four panelists agree: U.S. Fiscal policy does not cheat future generations cit., p. 1406 e 1410. O autor contraria frontalmente a opinião de Laurence Kotlikoff, para quem a política fiscal estadunidense pratica "abuso infantil fiscal" p. 1406 , nota de rodapé n. 9 . 
limitando suas conclusões a essa escola de pensamento, que certamente não é a única - e, acreditamos, não é a que deve ser tomada como fio condutor do tema, como se viu acima, na exposição da obra de John Rawls. Segundo, porque mesmo suas conclusões não indicam que o tema deve ser abandonado: se temos dificuldade em compreender quais serão as condições populacionais ou tecnológicas no futuro, ou mesmo conhecer quais serão as preferências das pessoas nesse futuro, isso certamente não impede que hodiernamente os Governos adotem medidas para possibilitar o desenvolvimento dessas pessoas ou para possibilitar que essas escolham encontrem meios de realização. ${ }^{674} \mathrm{Em}$ verdade, a dificuldade de conhecer as preferências dos cidadãos no futuro, embora de certa forma insolúvel, pode ser mitigada - e é isso o que se tentou demonstrar acima, com a apresentação de modelos institucionais destinados a guardar, no processo político atual, que seus interesses sejam considerados.

Também por isso é que se deve louvar a iniciativa de Joaquim Freitas da Rocha ${ }^{675}$ quanto à necessidade de "enaltecer a transtemporalidade", desenvolvendo um "Direito Financeiro Equigeracional", ${ }^{676}$ em que é o "Estado que ainda continua a cumprir satisfazer necessidades de natureza colectiva e, por outro lado, que as suas decisões devem ser sempre tomadas tendo por base uma visão temporal alargada". 677

Rocha toma como premissa (dentre outras), para focar seu pleito de direção do Direito Financeiro a tais questões:

Segunda premissa: a decisão financeira pública exige uma visão temporal alargada. Com efeito, afirmar que os actores jurídico-financeiros deverão agir na prossecução do Interesse público, no sentido que aqui se apontou, significa afirmar que deverão agir sempre no sentido da consecução de um projecto de comunidade, no quadro do qual a satisfação das necessidades colectivas se erige a imperativo constitucional e legal incontornável. Mas mais do que isso. Um Direito financeiro responsável e actualisticamente entendido reclama igualmente uma exigência de intertemporalidade e de equigeracionalidade - alguma doutrina refere-se

674 Em outra oportunidade, Daniel Shaviro afirmou, em crítica à política de isenções fiscais: "The younger generations keep having to pick up the tab for the older generations' expanding benefits" (SHAVIRO, Daniel. Editorial: how tax cuts feed the beast. The New York Times, $21 \mathrm{dez}$. 2004).

675 Agradecemos ao Prof. Joaquim Rocha por ter gentilmente fornecido cópia do trabalho adiante referido. Esperamos ter feito jus às suas ideias, honrando-o com a busca, através dessa dissertação, de suscitar a ideia de um Direito Financeiro que se ocupa dos desequilíbrios entre gerações.

676 ROCHA, Joaquim Freitas da. Sustentabilidade e finanças públicas responsáveis - Urgência de um direito financeiro equigeracional. Mimeo. O texto foi publicado em CORREIA, Fernando Alves; MACHADO, Jónatas E. M.; LOUREIRO, João Carlos (Org.). Estudos em homenagem ao Prof. Doutor José Joaquim Gomes Canotilho cit. Nesta dissertação, contudo, foi utilizada (e a ela se farão referências) a minuta não publicada do artigo.

677 CORREIA, Fernando Alves; MACHADO, Jónatas E. M.; LOUREIRO, João Carlos (Org.). Estudos em homenagem ao Prof. Doutor José Joaquim Gomes Canotilho cit., p. 3. 
a um imperativo moral - que o concreto pensamento casuístico ou a simples redução a um ciclo político-eleitoral não permite, porque não consegue, atingir. Significa isto que os actores e decisores jurídicofinanceiros devem ser dotados de uma visão temporal de longo prazo, que ultrapasse o momento decisório e permita projectar positivamente os efeitos da decisão num âmbito temporal alargado, abrangendo sujeitos que não tomaram partido na decisão. Como já foi referido em outros quadrantes, trata-se de "consider the future consequences of present actions". ${ }^{678}$

A tese suscitada pelo Autor lusitano revela não apenas enunciados gerais, mas a preocupação analítica de fixar conceitos concretos à sua aplicação. Assim, apresenta as dimensões positiva e negativa na qual se estabelece esse "Direito Financeiro equigeracional”: (i) positiva: "imperativo que os bens públicos e semi-públicos ${ }^{679}$ produzidos no presente sejam aptos a projectar as suas utilidades em momentos futuros temporalmente afastados, de modo a que as gerações vindouras possam retirar vantagens da sua efectivação", ${ }^{680}$ a exigir que se priorizem despesas de capital e em itens de natureza reprodutiva; (ii) negativa: "exige-se que as gerações futuras não sejam desproporcionalmente oneradas com os encargos inerentes à satisfação das necessidades colectivas da geração presente", ${ }^{681}$ evitando contração de dívidas de longo prazo para realização de despesas com limitado alcance temporal. ${ }^{682}$ Vale recordar, sobre este último

678 CORREIA, Fernando Alves; MACHADO, Jónatas E. M.; LOUREIRO, João Carlos (Org.). Estudos em homenagem ao Prof. Doutor José Joaquim Gomes Canotilho cit., p. 6.

679 Bens semipúblicos ou meritórios são "um caso intermediário entre os bens públicos e os privados". "Tais bens, embora submetidos ao princípio da exclusão, são freqüentemente - e cada vez com mais intensidade - produzidos publicamente, tendo em vista a importância que a sociedade atribui a sua produção. Inclui-se nessa categoria a maior parte dos 'serviços sociais', como Educação, Saúde, Nutrição e Saneamento Básico. A característica essencial dos bens semipúblicos é seu elevado conteúdo de externalidades, isto é, os benefícios advindos do seu consumo não são totalmente internalizados pelo indivíduo que os consome, espalhando-se uma parcela considerável deles por toda a coletividade. Assim, por exemplo, o consumo de serviços de vacinação contra moléstias infecto-contagiosas beneficia tanto o indivíduo que se submete à vacinação quanto toda a coletividade, que fica menos exposta ao contágio. Vantagens para a comunidade de um maior consumo individual de educação são também freqüentemente assinaladas, com base em melhoria na produtividade e elevação dos padrões culturais". REZENDE, Fernando Antonio. Finanças públicas. 2. ed. São Paulo: Atlas, 2001. p. 86. Com Sousa Franco, vê-se que os bens públicos (ou "colectivos") "são aqueles em que, para um determinado nível de existência ou provisão do bem, a utilização por uma pessoa não prejudica minimamente a utilização por qualquer outra: é o caso de um farol, da defesa nacional, do serviço de patrulha costeira, do funcionamento geral dos órgãos de soberania". Contrapõem-se aos bens privados (ou individuais), que "se são consumidos por uma pessoa em determinada quantidade, não podem ser consumidos por outra: o pão que A come não pode ser comido por B" (FRANCO, Antonio L. de Sousa. Finanças públicas e direito financeiro. Coimbra: Almedina, 2007. v. 1, p. 26).

680 ROCHA, Joaquim Freitas da. Sustentabilidade e finanças públicas responsáveis - Urgência de um direito financeiro equigeracional. Mimeo. p. 7.

681 Idem, ibidem.

682 "Just as individuals need to plan for different needs at varying stages in their lifecycle, nations and global communities also need to plan consumption and saving to accommodate for expected needs [...] Still, it would be a mistake to think of our legacy to the future only in terms of the debts we accrue. We provide 
ponto, a lição de Ferreiro Lapatza, para quem "a ideia de tempo aparece, assim, colocada no núcleo de toda operação de crédito, até tal ponto que, podemos dizer, toda operação de crédito consiste na troca de um bem presente por uma riqueza futura". ${ }^{683}$ No mesmo sentido é a exposição de Baleeiro, que apresenta o crédito público como "a técnica pela qual as gerações futuras partilham de despesas da atualidade". ${ }^{684}$

Rocha estabelece ainda 4 (quatro) regras mínimas para cumprimento desses princípios financeiros, e que devem ser positivadas. São elas: (i) "regra de exigência de equilíbrio orçamental substancial - apelando à distinção entre certo tipo de receitas e certo tipo de despesas (v.g., ordinárias, não ordinárias; efectivas, não efectivas) - e secundarizando o equilíbrio meramente formal ou aritmético; (ii) "limites máximos de gasto, ou tectos para a despesa pública, nomeadamente as despesas com o pessoal”; (iii) “fixação de limites máximos para a dívida pública (Schuldenbremse), principalmente a de médio e longo prazo"; e (iv) "restrição ou mesmo proibição do recurso ao crédito". ${ }^{685}$

Outrossim, advoga sejam fortalecidos os instrumentos de planejamento e previsão orçamentária, que classifica como hodiernamente "debilitados", ${ }^{686}$ impondo-se seu cumprimento substancial, inclusive criando vínculo destes com outros instrumentos políticos e legislativos. É esse o ponto também ressaltado por Émerson Gomes, que, comentando as normas de contabilidade pública da Lei n. 4.320/1964, sustenta que

a equidade entre gerações determina que as entidades governamentais não devem transferir os custos dos serviços atualmente prestados para as gerações futuras e a equidade intertemporal enfatiza que as entidades governamentais não devem transferir os custos dos serviços atualmente prestados para o futuro. ${ }^{687}$

future generations with knowledge and capital improvements, not just with debts. These benefits constitute at least partial compensation for the disadvantages represented by the debts we pass on. But it is appropriate for us to ask whether our capital improvements constitute effective and appropriate compensation for the burdens we leave behind" (p. 15). WOLF, Clark. Justice and intergenerational debt cit., p. 13. O texto advoga a ideia também de que os impactos ambientais devem ser tidos tal e qual a dívida deixada para as próximas gerações, afinal as despesas com sua reconstrução, ou mesmo os prejuízos com sua ausência, podem (e devem) ser calculados monetariamente.

683 LAPATZA, José Juan Ferreiro. Instituticiones de derecho financiero. Madrid: Marcial Pons, 2010. p. 107. Tradução livre. Ainda: LAPATZA, José Juan Ferreiro. Curso de derecho financiero español. 14. ed. rev. Madrid, Marcial Pons, 1992. p. 536.

684 BALEEIRO, Aliomar. Uma introdução à ciência das finanças cit., p. 475.

685 ROCHA, Joaquim Freitas da. Sustentabilidade e finanças públicas responsáveis - Urgência de um direito financeiro equigeracional. Mimeo. p. 8.

686 Idem, ibidem.

687 GOMES, Emérson César da Silva. Arts. 83 a 100. In: CONTI, José Maurício (Coord.). Orçamentos públicos: a Lei n. 4.320/1964 comentada. 2. ed. São Paulo: RT, 2010. p. 288. 
João Ricardo Catarino concorda com a inclusão do elemento temporal/geracional na sistemática financeira, lançando a equidade intergeracional como princípio. Apresentando os princípios do processo orçamentário (princípios do consentimento, da legalidade tributária, da autorização anual para o lançamento e cobrança dos impostos, da autorização prévia para a contração de empréstimos públicos, da universalidade do imposto, do equilíbrio orçamentário, da centralização financeira e da repartição e da interdependência de poderes), afirma que eles são "hoje complementados por outros que, entretanto, se lhes juntaram, como os princípios da equidade intergeracional, da estabilidade, da solidariedade recíproca entre órgãos públicos e da transparência orçamental". ${ }^{688}$

Abordagem semelhante, trazendo a igualdade entre gerações para o Direito Financeiro (e Tributário), é levada a cabo por Luciano Rezzoagli e Bruno Rezzoagli. ${ }^{689}$ Embora o cerne de sua exposição esteja vinculado ao princípio da igualdade, seu artigo conduz a questões semelhantes às trazidas por Joaquim Rocha, bem como a respostas semelhantes. Vale transcrever:

Se a igualdade é a base do imposto e dos encargos públicos, então o planejamento relativo à arrecadação dos fundos públicos que recai sobre e obriga a população a contribuir (impostos e encargos públicos) não deve estruturar-se tendo como base a busca de uma pressão tributária geracionalmente equitativa? Pode aplicar-se o princípio da igualdade de maneira intergeracional?

Por nossa parte estamos convencidos que o Estado, em uma economia de escala (nacional, provincial e municipal), deve atender à Igualdade Intergeracional para planejar da maneira mais eficiente $o$ desenvolvimento de um sistema financeiro e tributário que garanta a menor pressão fiscal para cada geração. Mais, ainda, o adequado planejamento no endividamento e na criação ou desenvolvimento de impostos e encargos públicos justifica que em momentos de crise, como, por exemplo, a crise financeira internacional de meados de 2008, seja combatida e resolvida racionalmente entre várias gerações de contribuintes, com uma adequada e equitativa pressão tributária, não recaindo todo o peso do colapso na geração atual. ${ }^{690}$

É relevante pontuar que essas observações, embora estejam de acordo com as acima apresentadas, são focadas em outro aspecto, trazendo racionalidade ao princípio da

688 CATARINO, João Ricardo. Processo orçamental e sustentabilidade das finanças públicas: o caso europeu. In: CONTI, José Maurício; SCAFF, Fernando Facury (Org.). Orçamentos públicos e direito financeiro cit., p. 795.

689 REZZOAGLI, Luciano Carlos; REZZOAGLI, Bruno Ariel. Teoría de la igualdad intergeneracional: una perspectiva financiera y tributaria en la República Argentina. Revista Brasileira de Direito Tributário e Finanças Públicas, n. 33, jul.-ago. 2012, p. 171 e ss.

690 Idem, ibidem, p. 181-182. Tradução livre. 
equidade intergeracional aplicado ao Direito Financeiro: os autores mencionados querem evitar que a aceitação da ideia de justiça (ou igualdade) entre gerações imponha restrições proibitivas ao acesso ao crédito e à dívida pública. Fixam, portanto, que embora seja necessário distribuir a "pressão fiscal" entre gerações - e esta é sua ideia central, de distribuição dessa "pressão" -, isto não quer dizer que as gerações atuais devem ser sobreoneradas, arcando com os custos (especialmente tributários), por exemplo, de financiamento de obras públicas que servirão à posteridade (e, talvez, diante do tempo necessário para construção dessas obras, só à posteridade).

Então, se é injusto que as gerações atuais recorram a empréstimos que serão pagos apenas no futuro, utilizando as verbas para seu consumo desenfreado e deixando para que outros "paguem a conta", é também injusto que as gerações atuais, por seus tributos, financiem obras que serão gozadas por muitas gerações porvir; "se as inversões aumentem o nível de bem-estar ou o nível de vida das gerações futuras, a igualdade intergeracional exige que ditas gerações arquem com os custos daquelas, e um dos caminhos possíveis pode ser o endividamento". ${ }^{691-692}$

A presença das futuras gerações no direito financeiro é, com vigor, realçada por Fernando Facury Scaff e Francisco Sérgio Rocha. Trabalhando os conceitos de equilíbrio orçamentário e sustentabilidade financeira, os autores encontram nessa relação uma evolução do sistema de proteção dos direitos fundamentais; segundo Scaff e Rocha, já não é mais suficiente proteger direitos coletivos ou difusos, ingressando a equidade

691 REZZOAGLI, Luciano Carlos; REZZOAGLI, Bruno Ariel. Teoría de la igualdad intergeneracional... cit., p. 183-184. Tradução livre. Interessantes ainda suas ponderações quanto ao reflexo dessas ideias no conceito de capacidade contributiva: este também se revelaria maculado com a exigência de impostos na atualidade para financiar gastos públicos que seriam gozados pela posteridade (p. 186).

692 A contração de dívida, vale sempre recordar, pode ser fundamental para o planejamento de um país. Como observa Regis Fernandes de Oliveira: "Toda pessoa, física ou jurídica, tem capacidade para obter empréstimos e deles necessita para sua sobrevivência. $\mathrm{O}$ crédito revela-se através da fidúcia que está presente no relacionamento humano. Se entre as pessoas físicas tal afirmativa é verdadeira, diga-se o mesmo entre as pessoas jurídicas e, especialmente, entre as pessoas jurídicas de direito público. Logo, os Estados, para sua sobrevivência, dependem de financiamentos de toda ordem, para cumprir seus objetivos e finalidades. Não só buscam recursos junto a instituições financeiras, bem como perante outras pessoas jurídicas de direito público. Da mesma forma, procuram receitas financeiras no âmbito interno do Estado, como também o fazem internacionalmente, seja perante entidades financeiras, seja perante outros Estados. Em suma, é da vida normal dos entes públicos que estes se relacionem e busquem recursos perante outros, para a subsistência dos Estados e para desenvolvimento de suas atividades" (OLIVEIRA, Regis Fernandes de. Dívida pública e operações de crédito. Revista Tributária e de Finanças Públicas, v. 64, 2005). 
intergeracional como uma "nova compreensão dos direitos fundamentais", a impor limites à atividade financeira do Estado. ${ }^{693}$

Em outra oportunidade, Joaquim Freitas da Rocha volta ao tema, embora tomando a responsabilidade entre gerações como cerne. ${ }^{694}$ Essa responsabilidade das gerações correntes para com as futuras é de se materializar nas dimensões preventiva e repressiva.

Na dimensão preventiva, exige-se (i) "Selectividade da despesa pública e não oneração excessiva", em que "a geração presente deva procurar garantir um modelo de existência adequado para as gerações que se lhe seguirão", exigindo que "não se limitem (irresponsavelmente) a incluir no processo motivacional apenas os efeitos circunscritos ao momento em que a decisão está a ser tomada" 695 e, na forma como acima já exposto, modelando o gasto público e a contração de dívida pública; (ii) manifestação dessa responsabilidade nos domínios de educação (significando não apenas a priorização desse tipo de gasto, mas a conscientização da população sobre os impactos atuais às gerações

693 "Porém a evolução dos estudos jurídicos constatou ser insuficiente a preocupação com o coletivo, sendo também necessário que o Direito se ocupasse dos interesses difusos da sociedade, que são aqueles que atingem um grupo indeterminado, e indeterminável, de pessoas. São tais as lesões causadas por poluição atmosférica, congestionamentos de tráfego etc. que não se pode determinar a quantidade de pessoas alcançadas pelo dano. O mesmo ocorre com o endividamento público excessivo, ocasionando a insustentabilidade financeira de diversos países que, interconectados em nosso mundo globalizado podem ocasionar problemas além das fronteiras nacionais. A solução individual e a coletiva não conseguem resolver este tipo de questão, sendo necessário desenvolver mecanismos adequados para operacionalizar sua prevenção e sustentabilidade. Some-se à questão dos interesses difusos o conceito de futuras gerações. E aí surge uma nova compreensão dos direitos fundamentais. Passam a ser considerados também os direitos dos que ainda não nasceram. A dimensão da pessoa humana é projetada no futuro, não apenas como a dimensão civilista do nascituro, mas de toda uma futura (e ainda nem mesmo gestada) geração de pessoas humanas. É dentro deste preceito que se encontra o direito ao desenvolvimento econômico, que é "um direito humano inalienável e que a igualdade de oportunidade para o desenvolvimento é uma prerrogativa tanto das nações quanto dos indivíduos que compõem as nações" (Declaração sobre o Direito ao Desenvolvimento, ONU, 1986, preâmbulo). O interesse protegido não é o da atual geração, mas sua preservação para as futuras gerações. Não é mais um interesse do indivíduo contra o Estado, ou inerente apenas a certa coletividade, mas um interesse difuso e que abrange não apenas as atuais, mas as futuras gerações. É esta nova dimensão dos direitos fundamentais que deve estar presente em nossa mente ao interpretar a norma do equilíbrio orçamentário como um instrumento de sustentabilidade financeira e não como uma equação contábil-matemática. Não se pode deixar o direito das futuras gerações ser violado pelo jogo político do aqui e agora, das lutas políticas do presente. É necessário que sejam adotados limites financeiros para a sustentabilidade econômica dos Estados nacionais a fim de evitar que estas gerações sejam obrigadas a arcar com enormes custos para a manutenção do Estado latu senso. [...] Decorre desta constatação que as regras atinentes às relações entre Governo e Parlamento devem deixar de se subordinar apenas à política do tempo presente, mas ter os olhos voltados também a esta sustentabilidade financeira, que possui uma lógica intergeracional" (SCAFF, Fernando Facury; ROCHA, Francisco Sérgio Silva. Equilíbrio orçamentário e sustentabilidade financeira: anotações sobre o Brasil cit.).

694 ROCHA, Joaquim Freitas da. Breves reflexões sobre responsabilidade colectiva e finanças públicas. In: ROCHA, Joaquim Freitas da (Coord.). Anuário publicista da Escola de Direito da Universidade do Minho cit.

695 Idem, ibidem, p. 135. 
futuras), recursos naturais e ambiente ("sobrelevar o direito que cada pessoa tem a uma capacidade económica e ecológica não deteriorada pelas actuações dos antecessores", e direcionando os recursos públicos para consecução desses fins, incluindo normas fiscais indutoras de comportamento), proteção social (sistema de segurança social que atue tanto evitando despesas, como na sua redução, por exemplo verificando mais minuciosamente o sistema de concessão de benefícios, seja ainda atuando no nível da receita) e saúde (também atuando na contenção de despesas desnecessárias e ineficientes e no incremento de receitas, inclusive eventualmente com imposição de taxas dos usuários). ${ }^{696}$

$\mathrm{Na}$ dimensão repressiva, Rocha defende a responsabilização como "um verdadeiro dever jurídico e até constitucionalmente ancorado e positivado, embora dificilmente justiciável. Em todo o caso, não tratará de um 'direito sem sanção', na medida em que podem advir consequências jurídicas relevantes, sendo os sujeitos futuros chamados a suportar todo um conjunto de restrições de direitos". 697

Quando tratamos da justiça, equidade, ou solidariedade intergeracional, deixamos de fora alguns temas recorrentes na literatura (vide bibliografia ao final) sobre os temas mas que - embora possam ser tratados em outra oportunidade - certamente não dizem diretamente com o objeto desta dissertação. ${ }^{698}$

Para ficar em três exemplos: (i) são recorrentes as dúvidas sobre a própria existência de deveres das gerações correntes às gerações futuras, baseadas numa concepção filosófica segundo a qual, se nossas ações atuais podem prejudicar a própria existência desses seres humanos. Assim, a modificação do meio ambiente não pode prejudicar uma pessoa porque a própria pessoa deixará de existir se tomada essa ação, dando espaço a outra, esta vinculada com as ações passadas. Ou, em outras palavras, pessoas diferentes existirão dependendo de nossas práticas. O tema é conhecido por non-identity problem; (ii) são frequentes críticas à questão intergeracional tendo por suporte o desconhecimento do tamanho da população nas gerações futuras, o que poderia alterar o consumo dos recursos naturais hodiernamente, em atenção à poupança justa rawlsiana; e (iii) são também comuns

${ }^{696}$ ROCHA, Joaquim Freitas da. Breves reflexões sobre responsabilidade colectiva e finanças públicas. In: ROCHA, Joaquim Freitas da (Coord.). Anuário publicista da Escola de Direito da Universidade do Minho cit., p. 137 e ss.

697 Idem, ibidem, p. 144.

698 Para uma breve abordagem das questões filosóficas envolvidas, v. o verbete "Justiça Intergeracional" escrito por Lukas Meyer à Enciclopédia Stanford de Filosofia. MEYER, Lukas. "Intergenerational justice". The Stanford Encyclopedia of Philosophyc. Spring 2010 Edition. Edward N. Zalta (Ed.). Disponível em: <http://plato.stanford.edu/archives/spr2010/entries/justice-intergenerational/>. Acesso em: 18 nov. 2013. 
as reflexões sobre a caracterização de direitos das futuras gerações, baseadas na afirmação pura e simples de que pessoas que não existem não têm direitos.

Todas são questões reconhecidamente relevantes e citadas na doutrina, em muitos dos trabalhos referidos ao fim. Nada obstante, optando por um corte metodológico que exponha as premissas básicas da equidade intergeracional e seguindo com o seu conteúdo e, tanto quanto possível, a observação de seus caracteres essenciais, tais questões não foram ou serão abordadas. 


\section{ROYALTIES NO BRASIL. FEDERALISMO FISCAL E ASPECTOS}

\section{DO ORDENAMENTO PARA A GOVERNANÇA DOS ROYALTIES, SOB ANÁLISE DA EQUIDADE ENTRE GERAÇÕES E DOS EFEITOS DELETÉRIOS DA EXPLORAÇÃO.}

3. Como o Brasil se comporta perante a receita pública de recursos naturais não renováveis. Federalismo Fiscal e outras instituições, instrumentos e aspectos do ordenamento jurídico para a governança dos royalties. Superando os efeitos deletérios da exploração e observando as futuras gerações.

a. A equidade intergeracional nos ordenamentos internacional e brasileiro. As disposições do direito financeiro brasileiro

b. Sobre o domínio dos recursos naturais não renováveis no Brasil

c. Sobre a justificação e identidade dos royalties no direito brasileiro

d. Royalties e federalismo fiscal. Notas sobre a partilha espacial e sobre uma orientação temporal à partilha espacial.

i. Sobre a teoria do federalismo fiscal.

ii. A partilha espacial dos royalties de recursos naturais não renováveis no Brasil. A recente batalha legislativa e a corrente batalha judicial.

1. São procedentes as reivindicações dos Estados do Rio de Janeiro, do Espírito Santo e de São Paulo?

iii. Crítica à atual partilha espacial dos royalties. E: uma orientação de natureza temporal.

iv. Crítica às vinculações a órgãos da União.

e. Racionalidade no trato dos royalties e classificação financeiro-orçamentária

i. Receita originária, patrimonial

ii. Receita de capital

f. Fundos.

i. Os Fundos brasileiros. O Fundo Social da União.

ii. Críticas ao Fundo Social da União.

g. Exploração de recursos naturais não renováveis e tributação. A relação entre a receita proveniente da exploração do patrimônio público e o financiamento das despesas estatais. Notas sobre a realidade brasileira.

h. Constrangimentos na perspectiva do gasto e suas burlas. Nota sobre a qualidade do gasto. Necessidade de regras de vinculação/afetação do gasto público da receita de royalties

i. Transparência fiscal

j. Uma crítica aos novos marcos regulatórios das explorações mineral e petrolífera. Oportunidades desperdiçadas. Ausência de instituições que tragam as futuras gerações ao debate.

3. Como o Brasil se comporta perante a receita pública de recursos naturais não renováveis. Federalismo Fiscal e outras instituições, instrumentos e aspectos do 


\section{ordenamento jurídico para a governança dos royalties. Superando os efeitos deletérios da exploração e observando as futuras gerações}

No ano de 2012, as receitas tributárias brasileiras (totais, somando União, Estados, Distrito Federal e Municípios) foram superiores a R\$ 1,5 trilhão. No mesmo ano, os royalties oriundos da exploração de recursos naturais não renováveis foram de $\mathrm{R} \$ 33,5$ bilhões. A tabela abaixo demonstra a evolução, nos últimos anos, dessas duas grandezas:

$\begin{array}{ccccc}\text { (Em milhões de reais) } & \text { Tributos }^{699-700} & \begin{array}{c}\text { Royalties } \\ \text { petróleo }^{701}\end{array} & \text { CFEM }^{702} & \begin{array}{c}\text { Total royalties } \\ \text { recursos naturais } \\ \text { não renováveis }\end{array} \\ \mathbf{2 0 0 9} & 1.078 .414 & 16.435 & 742 & 17.177 \\ \mathbf{2 0 1 0} & 1.254 .324 & 21.599 & 1.083 & 22.682 \\ \mathbf{2 0 1 1} & 1.486 .679 & 25.628 & 1.560 & 27.188 \\ \mathbf{2 0 1 2} & 1.559 .118 & 31.674 & 1.834 & 33.508\end{array}$

Então, em 2012, as receitas de recursos naturais não renováveis representaram apenas $2,14 \%$ da receita tributária total $(1,82,1,80$, e $1,59 \%$, respectivamente, nos anos de 2011, 2010 e 2009).

699 Os números apresentados são retirados dos relatórios Contas do Governo da República, publicados anualmente pelo Tribunal de Contas da União. Os números de 2009, 2010, 2011 e 2012 estão disponíveis respectivamente em: <http://portal2.tcu.gov.br/portal/page/portal/TCU/comunidades/ contas/contas_governo/contas_09/index.htm>; <http://portal2.tcu.gov.br/portal/page/portal/TCU/ comunidades/contas/contas_governo/contas_10/index.html>; <http://portal2.tcu.gov.br/portal/page/ portal/TCU/comunidades/contas/contas_governo/Contas2011/index.htm>; <http://portal2.tcu.gov.br/ portal/page/portal/TCU/comunidades/contas/contas_governo/Contas2012/index.htm>. Acesso em: 22 nov. 2013.

700 Vale mencionar que os números de carga tributária total (toda a receita tributária, independente do Ente Político arrecadador) são apresentados por diversas fontes segundo metodologias diversas, alcançando resultados diferentes. Nada obstante, para fins desta breve exposição, as diferenças não são significativas. Outros números podem ser encontrados nos sítios do IBGE (até 2009), da Receita Federal (até 2011), e do IBPT - Instituto Brasileiro de Pesquisas Tributárias (até 2012 - referências datadas ao dia 22/11/2013, quando essas pesquisas foram levadas a efeito). Disponível respectivamente em: <http://www.ibge.gov.br/home/estatistica/economia/contasnacionais/2009/tabelas_pdf/tab20.pdf, $<$ http://www.receita.fazenda.gov.br/Publico/estudoTributarios/estatisticas/CTB2010.pdf>; $<$ http://www.receita.fazenda.gov.br/Publico/estudoTributarios/estatisticas/CTB2011.pdf>; <https://www.ibpt.org.br/img/uploads/novelty/estudo/559/CargaTributaria2012IBPT.pdf>. As diferenças metodológicas estão brevemente mencionadas no Relatório do IBPT, já acima referido. Os números apresentados por cada uma dessas fontes são (todos em milhões de reais): 2009 - IBPT: 1.095.933; RF: 1.055.440; IBGE: 1.091.812 /// 2010 - IBPT: 1.290.123; RF: 1.264.148 /// 2011 - IBPT: 1.492.144; RF: 1.462.951/// 2012 - IBPT: 1.597.016.

701 Somados os royalties propriamente ditos e as participações especiais. Disponível em: $<\mathrm{http}: / / \mathrm{www} \cdot$ anp.gov.br/?pg=62402\&m=\&t1=\&t2=\&t3=\&t4=\&ar=\&ps=\&cachebust=1365430612820>.

702 Disponível em: <https://sistemas.dnpm.gov.br/arrecadacao/extra/Relatorios/arrecadacao_cfem.aspx>. 
Nada obstante os números da arrecadação de royalties sejam comparativamente baixos, isto não importa em sua insignificância. Muito ao inverso, as atividades de exploração de recursos naturais não renováveis são relevantíssimas à economia nacional (como se viu na Introdução, especialmente no que concerne à participação do setor no total de exportações). E os valores de royalties são, igualmente, relevantes - o que se faz manifesto, especialmente depois das batalhas legislativas referentes à sua partilha.

O que se quer enfatizar, contudo, neste momento, é que esta dissertação busca analisar esta grandeza econômica (os royalties de recursos naturais não renováveis) específica. Isso implica algumas exclusões necessárias: considerações quanto às questões ambientais, sociais e econômicas das atividades minerária e petrolífera como um todo não resistirão ao corte metodológico, sendo referidas apenas marginalmente. $\mathrm{O}$ objeto de análise são os royalties.

Por royalty, entenda-se o "preço público pago ao proprietário do recurso natural não renovável que for extraído, inserido ou consumido por processo produtivo", conforme ensina Fernando Facury Scaff. ${ }^{703}$

Tomando por base as referências teóricas expostas acima, quer-se analisar criticamente a governança desses royalties, especialmente questionando: como o modelo adotado no Brasil se comporta perante as armadilhas já referidas acima - a "maldição" dos recursos naturais principalmente? E ainda: como esse mesmo modelo responde à necessidade de promover a equidade entre gerações?

É claro que muitas vezes essas duas questões estarão diretamente relacionadas. Fique-se com o exemplo mais óbvio: os Estados exploradores de recursos naturais não renováveis devem investir na diversificação de sua base produtiva, como medida de mitigar os efeitos da doença holandesa, evitar o comportamento rentista, e de forma ampla lutar contra as referidas armadilhas. No mesmo passo, essa diversificação importa em forma de beneficiar as futuras gerações, legando-lhes uma economia saudável e indepente desses mesmos recursos naturais não renováveis - que, vale lembrar apesar do pleonasmo, são exauríveis por definição - portanto permitindo a criação de novas riquezas. É nesse sentido que deve ser entendida, para aplicação ao caso, a proposta rawlsiana de uma poupança justa.

703 SCAFF, Fernando Facury. Royalties decorrentes da exploração de recursos naturais não renováveis cit., p. 137. 
Vale aqui ainda outra observação sobre o corte metológico afirmado. Em se tratando específica e direcionadamente de royalties, evitam-se algumas dificuldades do debate quanto à equidade intergeracional, já delineadas acima: se é certo que o debate quanto à promoção dos interesses das futuras gerações não deve ser feito isoladamente quando o assunto é política fiscal (porque alguns programas podem ser entendidos como usurpadores desses direitos, mas devem ser verificados no contexto geral, observando se outros programas fiscais não compensam essa "usurpação"704), a análise proposta, tendo por objeto apenas a receita de royalties, pode dar-se isoladamente porque essa receita pública tem natureza especial e especificamente relacionadas a esses recursos naturais.

É dizer: a característica da intertemporalidade desses bens, e por consequência da receita pública obtida a partir de sua exploração, tem intrínseco e umbilical relacionamento com a perspectiva intergeracional. E isso autoriza que a análise da governança de royalties se dê sob esse viés, ainda que feita independentemente de outras políticas públicas eventualmente existentes.

Portanto, o que se defende é que ainda que o Estado brasileiro promova os interesses das futuras gerações mediante programas financiados com a receita tributária, a característica básica desses royalties de recursos naturais não renováveis exige que sua governança seja diferente, orientada para compensar a exploração rival (no sentido de que cada tonelada ou barril explorado hoje não o será no futuro) atual.

O inverso seria equivocado. Permitir que o Estado promova a fusão dessas receitas públicas de naturezas diversas (tratando ambas as receitas como apenas dinheiro, e assim bem marcadamente fungível) seria ignorar as características intrínsecas da exploração dos recursos naturais não renováveis, ${ }^{705}$ autorizando seu tratamento indistinto, o que já argumentou-se ser um grande equívoco - como também ressalta Maria Amélia Enríquez quando condena a prática do caixa único. ${ }^{706}$

${ }^{704}$ Como sustentou Michael Doran, em: DORAN, Michael. Intergenerational equity in fiscal policy reform cit., 2008.

705 Note-se a lição de Paul Laband sobre a alienação do patrimônio do Estado: "Es de toda congruencia y de plena lógica que los ingresos procedentes de tales ventas no vayan a parar a los recursos generales del Estado, o a la Caja General del mismo, sino que se queden en el sector de la Administración, o em los fondos especiales, a que hayan pertenecido los objetos enajenados" (LABAND, Paul. Derecho presupuestario. Madrid: Instituto de estudios fiscales, 1979. p. 46).

706 ENRÍQUEZ, Maria Amélia. Mineração.... cit., p. 364. 
3.a. A equidade intergeracional nos ordenamentos internacional e brasileiro. As disposições do direito financeiro brasileiro.

Cabe iniciar com questão deliberadamente deixada de fora no capítulo anterior: podemos afirmar que o ordenamento jurídico brasileiro dá bases de sustentação para que se protejam os direitos ou interesses das gerações futuras? A resposta há de ser inequivocamente positiva.

E, para alcançar tal resposta, convém começar não exatamente pela produção jurídico-legislativa interna, mas pela observação da legislação internacional. Um curto passeio pelas referências intergeracionais nessas normas dá contexto à questão.

A preocupação com os direitos das gerações posteriores pode ser encontrada já no art. 28 da Declaração dos Direitos do Homem e do Cidadão da Constituição Francesa de 1793, quando dispõe que uma geração não pode sujeitar às suas Leis as gerações futuras (o que está de acordo com o debate, acima referido, quanto à eficácia temporal e à interpretação dos textos constitucionais). ${ }^{707}$

Contudo, apenas no século XX, e mais precisamente em sua segunda metade, é que o tema vai ganhando relevância e sua presença vem sendo reiterada. A verificação da evolução dessas referências - que se esboça adiante - parte de alusões genéricas e abstratas, ou contidas em temas específicos, progressivamente, até menções mais diretas quanto à proteção dos interesses das futuras gerações.

A Carta das Nações Unidas de 1945, assinada em junho/1945 (portanto marcada tematicamente pela recém-finda 2. ${ }^{a}$ Guerra Mundial), refere, na primeira linha de seu preâmbulo, o objetivo de "preservar as gerações vindouras do flagelo da guerra", 708 portanto manifestando especial interesse em tutelar não apenas o imediato. A Declaração Universal dos Direitos Humanos - ainda no final da primeira metade do século XX, em 1948 -, também em seu preâmbulo, aponta como fundamentos "da liberdade, da justiça e da paz" o reconhecimento da dignidade não apenas dos homens viventes, mas de "todos os

707 COMPARATO, Fábio Konder. A afirmação histórica dos direitos humanos cit., p. 176.

708 Disponível em: <http://www.un.org/spanish/Depts/dpi/portugues/charter/>. Acesso em: 23 nov. 2013. 
membros da família humana", ${ }^{709}$ o que imprime ao texto uma dimensão temporal, como nos lembra Edith Brown Weiss. ${ }^{710}$

A Declaração dos Princípios da Cooperação Internacional Cultural, de 1966, refere (art. 1. ${ }^{\circ}$, item 3) o patrimônio cultural como "herança comum pertencente a toda a humanidade", então ressaltando - "herança", algo necessariamente deixado por uns a seus sucessores - seu caráter transtemporal. E no art. 10 refere a cooperação cultural como modo de favorecer a formação profissional das novas gerações. ${ }^{711}$

Na Declaração da Conferência das Nações Unidas sobre o Meio Ambiente Humano (ou Declaração de Estocolmo), de 1972, as referências já não são tão sutis. Proclama (item 6): "A defesa e o melhoramento do meio ambiente humano para as gerações presentes e futuras se converteu na meta imperiosa da humanidade, que se deve perseguir, ao mesmo tempo em que se mantém as metas fundamentais já estabelecidas, da paz e do desenvolvimento econômico e social em todo o mundo, e em conformidade com elas". Dessa afirmação decorre a preocupação intergeracional manifestada expressamente em seus Princípios 1, 2, 5 e 11, ${ }^{712}$ com destaque, no que tange especificamente ao objeto ora perquirido, ao Princípio 5, que trata do compartilhamento dos benefícios da utilização dos recursos naturais não renováveis com as gerações futuras. Tais determinações tiveram influência em outras normas internacionais, como a Convenção sobre Prevenção da

709 Disponível em: 〈http://portal.mj.gov.br/sedh/ct/legis_intern/ddh_bib_inter_universal.htm〉. Acesso em: 23 nov. 2013.

710 WEISS, Edith Brown. In fairness to future generations cit., p. 25. Deve-se também a Weiss parte do roteiro das referências à proteção das gerações futuras ora delineado.

711 Disponível em: <http://portal.unesco.org/en/ev.php-URL_ID=13147\&URL_DO=DO_TOPIC\&URL_ SECTION=201.html>. Acesso em: 23 nov. 2013. Tradução livre.

712 Princípio 1: $\mathrm{O}$ homem tem o direito fundamental à liberdade, à igualdade e ao desfrute de condições de vida adequadas em um meio ambiente de qualidade tal que lhe permita levar uma vida digna e gozar de bem-estar, tendo a solene obrigação de proteger e melhorar o meio ambiente para as gerações presentes e futuras. A este respeito, as políticas que promovem ou perpetuam o apartheid, a segregação racial, a discriminação, a opressão colonial e outras formas de opressão e de dominação estrangeira são condenadas e devem ser eliminadas.

Princípio 2: Os recursos naturais da terra incluídos o ar, a água, a terra, a flora e a fauna e especialmente amostras representativas dos ecossistemas naturais devem ser preservados em benefício das gerações presentes e futuras, mediante uma cuidadosa planificação ou ordenamento.

Princípio 5: Os recursos não renováveis da terra devem empregar-se de forma que se evite o perigo de seu futuro esgotamento e se assegure que toda a humanidade compartilhe dos benefícios de sua utilização.

Princípio 11: As políticas ambientais de todos os Estados deveriam estar encaminhadas para aumentar o potencial de crescimento atual ou futuro dos países em desenvolvimento e não deveriam restringir esse potencial nem colocar obstáculos à conquista de melhores condições de vida para todos. Os Estados e as organizações internacionais deveriam tomar disposições pertinentes, com vistas a chegar a um acordo, para se poder enfrentar as consequências econômicas que poderiam resultar da aplicação de medidas ambientais, nos planos nacional e internacional.

Disponível em: 〈http://www.onu.org.br/rio20/img/2012/01/estocolmo1972.pdf〉. Acesso em: 23 nov. 2013. 
Poluição Marinha por Alijamento de Resíduos e outras matérias, de Londres, assinada em 1972; ${ }^{713}$ a Convenção relativa à Proteção do Patrimônio Mundial, Cultural e Natural, assinada em Paris, também em 1972; ${ }^{714}$ e a Convenção para o Comércio Internacional das Espécies da Flora e Fauna Selvagens em Perigo de Extinção, firmada em Washington, em $1973^{715}$ - todas as Convenções foram ratificadas pelo Brasil, promulgadas, respectivamente, pelos Decretos n. 87.566/1982, 80.978/1977, e 76.623/1975. A Carta dos Direitos e Deveres Econômicos dos Estados, de 1974, pode igualmente ser referida como levando adiante a linguagem protetiva das gerações posteriores. ${ }^{716}$

Em 1976, foi dado um passo adiante na proteção dos interesses das futuras gerações. A linguagem trazida pela legislação internacional já não trazia reconhecimento, afirmação, ou proclamação. Dando tal proteção como fato consolidado, a Convenção para a Proteção do mar Mediterrâneo contra a Poluição (Barcelona, 1976) trouxe em seu preâmbulo a afirmação de que as partes já estavam "totalmente conscientes de sua responsabilidade de preservar essa herança comum para o benefício e proveito de presentes e futuras gerações". 717

A Carta Mundial da Natureza (1982) reafirmou que "o homem deve adquirir o conhecimento para manter e aumentar sua habilidade para utilizar os recursos naturais de

713 Para reconhece que "o meio marinho e os organismos vivos que mantém, são de importância vital para a humanidade e que a todos interessa assegurar que seja administrado de modo a que não sejam prejudicados nem sua qualidade nem seus recursos". Disponível em: $<\mathrm{http}$ //legis.senado.gov.br/legislacao/ListaNormas.action?numero=87566\&tipo_norma=DEC\&data=198 20916\&link=s>. Acesso em: 23 nov. 2013.

714 art. 4. : Cada um dos Estados parte na presente Convenção deverá reconhecer que a obrigação de assegurar a identificação, protecção, conservação, valorização e transmissão às gerações futuras do patrimônio cultural e natural referido nos arts. $1 .^{\circ}$ e $2 .^{\circ}$ e situado no seu território constitui obrigação primordial. Para tal, deverá esforçar-se, quer por esforço próprio, utilizando no máximo os seus recursos disponíveis, quer, se necessário, mediante a assistência e a cooperação internacionais de que possa beneficiar, nomeadamente no plano financeiro, artístico, científico e técnico. Disponível em: <http://whc.unesco.org/archive/convention-pt.pdf>. Acesso em: 23 nov. 2013.

715 Onde se reconhece que "a fauna e flora selvagens constituem em suas numerosas, belas e variadas formas um elemento insubstituível dos sistemas naturais da terra que deve ser protegido pela presente e futuras gerações". Disponível em: <www.ibama.gov.br/category/49-_-_?download=1163\%3A_1115.pdf>. Acesso em: 23 nov. 2013.

716 Article 30: The protection, preservation and enhancement of the environment for the present and future generations is the responsibility of all States. All States shall endeavour to establish their own environment and development policies in conformity with such responsibility. The environmental policies of all States should enhance and not adversely affect the present and future development potential of developing countries. All States have the responsibility to ensure that activities within their jurisdiction or control do not cause damage to the environment of other States or of areas beyond the limits of national jurisdiction. All States should co-operate in evolving international norms and regulations in the field of the environment. Disponível em: <http://www.undocuments.net/a29r3281.htm>. Acesso em: 23 nov. 2013.

717 Disponível em: <http://www.unep.ch/regionalseas/regions/med/t_barcel.htm>. Tradução livre. Acesso em: 23 nov. 2013. 
forma a garantir a preservação das espécies e ecossistemas para o benefício das presentes e futuras gerações". ${ }^{718}$ E a Declaração de Nairóbi, do mesmo ano de 1982, ratifica as previsões da Declaração de Estocolmo, instando "todos os Governos e povos do mundo a assumir sua responsabilidade histórica, coletiva e individualmente, de garantir que nosso pequeno planeta seja passado adiante para as futuras gerações em condições que garantam uma vida de dignidade humana para todos".719

Essa evolução levou ao Relatório Nosso Futuro Comum (Relatório Brundtland), de 1987, elaborado sob a chefia de Gro Harlem Brundtland para a Comissão Mundial do Ambiente e do Desenvolvimento, criada em dezembro/1983 por Assembléia Geral da Organização das Nações Unidas - ONU. O documento, dirigido à temática do desenvolvimento sustentável, é pleno de referências aos interesses das futuras gerações desde o conceito de desenvolvimeno sustentável lá proposto. ${ }^{720}$

A Declaração do Rio de Janeiro sobre Meio Ambiente e Desenvolvimento, de 1992, previu que "o direito ao desenvolvimento deve ser exercido de modo a permitir que sejam atendidas equitativamente as necessidades de desenvolvimento e de meio ambiente das gerações presentes e futuras". ${ }^{721}$

No mesmo ano, a Convenção-Quadro das Nações Unidas sobre a Mudança do Clima afirmou a necessidade de equitativa preservação dos sistemas climáticos para benefício das gerações futuras, ${ }^{722}$ a Convenção sobre Diversidade Biológica também previu expressamente a proteção das gerações futuras, ${ }^{723-724}$ assim como o fez a Convenção

718 Disponível em: <http://www.un.org/documents/ga/res/37/a37r007.htm>. Tradução livre. Acesso em: 23 nov. 2013.

719 Disponível em: <http://www.un-documents.net/nair-dec.htm>. Tradução livre. Acesso em: 23 nov. 2013.

720 "O desenvolvimento sustentável é aquele que atende às necessidades do presente sem comprometer a possibilidade de as gerações futuras atenderem a suas próprias necessidades [...] em essência, o desenvolvimento sustentável é um processo de transformação no qual a exploração dos recursos, a direção dos investimentos, a orientação do desenvolvimento tecnológico e a mudança institucional se harmonizam e reforçam o potencial presente e futuro a fim de atender as necessidades e aspirações humanas". NOSSO FUTURO COMUM. Comissão mundial sobre meio ambiente cit., p. 46 e 49.

721 Disponível em: <http://www.onu.org.br/rio20/img/2012/01/rio92.pdf>. Acesso em: 24 nov. 2013.

722 Disponível em: <http://unfccc.int/resource/docs/convkp/conveng.pdf〉. Acesso em: 24 nov. 2013.

723 Disponível em: <http://www.cbd.int/doc/legal/cbd-en.pdf>. Acesso em: 24 nov. 2013.

724 Afirma Fábio Comparato, quanto à Convenção sobre a Diversidade Biológica: "Ela regula o direito da humanidade à preservação da biosfera, ou seja, da harmonia ambiental do planeta. Trata-se de aplicar, na esfera planetária, o princípio fundamental da solidariedade, tanto na dimensão presente quanto na futura; isto é, solidariedade entre todas as nações, povos e grupos humanos da mesma geração, bem como solidariedade entre a geração atual e as futuras. É evidente que a geração presente tem o dever fundamental de garantir às futuras gerações uma qualidade de vida pelo menos igual à que ela desfruta atualmente. Mas não é menos evidente que esse dever para com as gerações pósteras seria despido de sentido se não cuidasse de superar, desde agora, as atuais condições de degradação ambiental em todo o planeta, as quais representam desde já um sério risco para a biosfera como um todo e para o gênero humano em especial [...] Como foi pertinentemente observado, o cumprimento do dever universal de 
das Nações Unidas de Combate à Desertificação e Mitigação dos Efeitos da Seca. ${ }^{725}$ Todas as Convenções foram ratificadas pelo Brasil, promulgadas, respectivamente, pelos Decretos n. 2.652/1998, 2.519/1998, e 2.741/1998. Como se vê, a referência aos direitos das gerações futuras tornou-se comum na linguagem das normas internacionais, especialmente as de caráter ambiental. Em 1993, sobreveio a Declaração e Programa de Ação de Viena, adotada na Conferência Mundial de Direitos Humanos da ONU, que estabelece (item I.11) que "o direito ao desenvolvimento deve ser exercido de forma a satisfazer equitativamente as necessidades de desenvolvimento e ambientais das presentes e futuras gerações". 726

Tudo o que culminou, em novembro/1997, com a adoção, pela UNESCO braço da ONU que voltada para ciência, educação e cultura -, da Declaração sobre as Responsabilidades das Gerações Presentes em Relação às Gerações Futuras. ${ }^{727} \mathrm{O}$ documento, em que a UNESCO se diz "preocupada com o destino das gerações futuras diante dos desafios vitais do próximo milênio", contém 12 (doze) artigos em que é ressaltada a responsabilidade das gerações presentes de "garantir que as necessidades e os interesses das gerações presentes e futuras sejam plenamente salvaguardados” (art. 1), garantindo também que essas gerações pósteras tenham "liberdade de escolha com relação a seu sistema político, econômico e social e sejam capazes de preservar sua diversidade cultural e religiosa" (art. 2. ${ }^{\circ}$ ), e asseverando que "as gerações presentes podem fazer uso do patrimônio comum da humanidade, como definido na direito internacional, desde que isso não signifique o seu comprometimento irreversível" (art. 8), dentre outras disposições.

Finalmente, vale mencionar a Declaração de Joanesburgo sobre Desenvolvimento Sustentável, de $2002,{ }^{728}$ em que é proposta a abertura de uma temporada

desenvolvimento sustentável não pode ser deixado por conta do livre funcionamento dos mercados. O Prograna das Nações Unidas para o Meio Ambiente afirmou num relatório intitulado 'GEO 4', publicado em 25 de outubro de 2007, que a privatização generalizada da exploração dos recursos naturais e dos serviços públicos representa o pior cenário para o futuro próximo. É o Estado que deve atuar, precipuamente, como o administrador responsável dos interesses das futuras gerações”. COMPARATO, Fábio Konder. A afirmação histórica dos direitos humanos cit., p. 438-440.

725 Disponível em: <http://www.unccd.int/en/about-the-convention/Pages/Text-overview.aspx>. Acesso em: 24 nov. 2013.

726 Disponível em: <http://www.unhchr.ch/huridocda/huridoca.nsf/\%28symbol\%29/a.conf.157.23.en>. Tradução livre. Acesso em: 24 nov. 2013.

727 Disponível em: <http://unesdoc.unesco.org/images/0011/001108/110827por.pdf〉. Acesso em: 24 nov. 2013.

728 A propósito dessa reunião, escreveram os então Chefes de Estado do Brasil, da África do Sul, e da Suécia: "Hoje, abusamos dos recursos da Terra. Estamos nos alimentando de porções que pertencem às gerações ainda não nascidas. Os filhos de nossos filhos correm o risco de entrar neste mundo já carregando o peso da dívida criada por seus antepassados. Não é uma opção, e sim um imperativo 'satisfazermos as necessidades do presente sem comprometermos a capacidade das gerações futuras de 
em que se façam investimentos, "já muito atrasados", na sobrevivência e na segurança das futuras gerações. ${ }^{729} \mathrm{E}$, já em 2012, o documento final da Conferência das Nações Unidas sobre Desenvolvimento Sustentável (Rio+20), chamado de O Futuro que Queremos, deixa clara a opção por um desenvolvimento que seja economicamente, socialmente e ambientalmente (embora, cabe notar, esteja ausente a dimensão financeira) sustentável, "para o nosso planeta e para as futuras gerações". ${ }^{730-731}$

Como se vê, portanto, há diversas referências aos interesses das futuras gerações na legislação internacional, inclusive em várias normas formalmente internalizadas pelo Brasil, assim como em outras, como a Declaração sobre as Responsabilidades das Gerações Presentes em Relação às Gerações Futuras, adotada pela UNESCO, onde o Brasil mantém Delegação Permanente e é membro desde sua fundação. Então, há regras concernentes à proteção dos interesses das futuras gerações na legislação internacional internalizada. Assim como há normas, nesse sentido, de conteúdo não vinculativo, mas que ainda assim se prestam, no mínimo, a funcionar como vetores interpretativos, orientando a aplicação do direito interno pátrio. São mais que meras recomendações, integrando e complementando o ordenamento interno brasileiro. ${ }^{732}$

Ainda que aceitando a observação de Emmanuel Agius de que a Declaração de 1997 possui "força moral e ética, em vez de ser um instrumento legal", ${ }^{733}$ ficamos, no tema, com a mais apropriada abordagem de Joerg Tremmel, para quem "o direito positivo

satisfazer as deles', conforme dizia o Relatório Brundtland, em 1987” (CARDOSO, Fernando Henrique; MBEKI, Thabo Mvuyelwa; PERSSON, Goran. Podemos trabalhar juntos. Folha de S. Paulo - opinião, 1. ${ }^{\circ}$ set. 2002).

729 Disponível em: <http://www.un.org/jsummit/html/documents/summit_docs/131302_wssd_report_ reissued.pdf>. p. 155. Tradução livre. Acesso em: 24 nov. 2013.

730 Disponível em: <http://daccess-dds-ny.un.org/doc/UNDOC/GEN/N11/476/10/PDF/N1147610. pdf?OpenElement>. Acesso em: 24 nov. 2013.

731 Para referências às futuras gerações no âmbito das normas internacionais da União Europeia, ver: HÄBERLE, Peter. A constitutional law for future generations - the 'other' form of the social contract: the generation contract. In: TREMMEL, Joerg (Ed.). Handbook of intergenerational justice cit., p. 219 e ss.

732 "Em síntese, o direito internacional dos direitos humanos pode reforçar a imperatividade de direitos constitucionalmente garantidos - quando os instrumentos internacionais complementam dispositivos nacionais, ou quando estes reproduzem preceitos enunciados da ordem internacional - ou ainda estender o elenco dos direitos constitucionalmente garantidos - quando os instrumentos internacionais adicionam direitos não previstos pela ordem jurídica interna [...] os direitos internacionais constantes dos tratados de direitos humanos apenas vêm aprimorar e fortalecer, nunca restringir ou debilitarm o grau de proteção dos direitos consagrados no plano normativo interno" (PIOVESAN, Flávia. Direitos humanos e o direito constitucional internacional. 12. ed. rev. e atual. São Paulo: Saraiva, 2011. p. 156 e 163).

733 AGIUS, Emmanuel. Intergenerational justice. In: TREMMEL, Joerg (Ed.). Handbook of intergenerational justice cit., p. 318. 
deve se ajustar aos conceitos prevalescentes de moralidade na sociedade", ${ }^{734}$ apontando estar convencido de que é correto falar na existência de direitos das futuras gerações. ${ }^{735-736}$

Em verdade - e ainda sem entrar no direito interno brasileiro -, o fato é que a equidade intergeracional pode e deve ser defendida, conclusão a que se alcança por diversos meios, como a já referida teoria de justiça trazida pela filosofia política ou justificando-lhes através da legislação dos Direitos Humanos. ${ }^{737}$

Visto que a legislação internacional dá amparo para que se afirme a necessidade de observar os interesses das futuras gerações, cabe perguntar em seguida se o ordenamento jurídico brasileiro encampa esse dever. A resposta é igualmente positiva.

Já a Lei n. 6.938/1981 (Lei da Política Nacional do Meio Ambiente), como ensina Consuelo Yoshida, trouxe um "aperfeiçoado sistema de responsabilidade civil em prol dos interesses transindividuais", incentivando a "tutela preventiva baseada na cultura da observância das normas ambientais [...] propiciando a sadia qualidade de vida à presente e às futuras gerações"738 - denotando, pois, já no início da década de 1980 a preocupação com as gerações pósteras.

Na Constituição Federal de 1988, a mais evidente referência às futuras gerações está no seu art. 225, caput, tratando do meio ambiente. Dispõe:

Art. 225. Todos têm direito ao meio ambiente ecologicamente equilibrado, bem de uso comum do povo e essencial à sadia qualidade de vida, impondo-se ao Poder Público e à coletividade o dever de defendê-lo e preservá- lo para as presentes e futuras gerações.

734 TREMMEL, Joerg. Establishing intergenerational justice in national constitutions. In: TREMMEL, Joerg (Ed.). Handbook of intergenerational justice cit., p. 207.

735 Idem, ibidem, p. 203.

736 No mesmo sentido: "the person-affecting language of rights is an attractive and appropriate vehicle for understanding our relations with future individuals. Recognizing future people's rights is not a radical proposition requiring revolutionary changes to current moral categories and legal practices; rather, such a recognition is consistent with widely accepted (and analytically sound) understandings of rights" (BRUHL, Aaron-Andrew P. Justice unconceived: how posterity has rights. Yale Journal of Law \& the Humanities, v. 14, Iss. 2, article 4, p. 397).

737 "The existence of our moral obligations towards future generations may be approached in several ways. The moral responsibility to provide coming generations with the conditions for life can be justified through the broadening interpretation of general human rights, through the general comprehension of democratic principles, by the concept of common heritage of human kind or by relying on Rawls's theiry of justice". JÁVOR, Benedek. Institutional Protection of succeeding generations - Ombudsman for Future Generations in Hungary. In: TREMMEL, Joerg (Ed.). Handbook of intergenerational justice cit., p. 282.

738 YOSHIDA, Consuelo Y. M. TAC, TCA e composição prévia: a reparação do dano e medidas compensatórias no contexto da PNMA. Revista de Direito Ambiental, v. 64, 2011. 
Talvez porque a referência constitucional seja direcionada à questão ambiental, é nessa seara que se encontram no Brasil maiores debates sobre o tema. ${ }^{739}$ Relevantes são as contribuições de Celso Antonio Pacheco Fiorillo e Renata Marques Ferreira, ${ }^{740}$ de Édis Milaré - falando de uma solidariedade "diacrônica ('através do tempo')",741 -, bem como de Patrick Ayala ${ }^{742}$ - este que defende "novos direitos fundamentais biodifusos", com especial atenção às gerações posteriores, em que deve ser reconhecida a incompatibilidade

739 Interessante notar, contudo, que em diversas outras áreas a noção intergeracional pode ser aplicada. Tome-se de exemplo a doutrina de Canotilho e Machado, que invoca essa lógica para tratar de propriedade intelectual: "Essa necessária protecção exige a realização de ponderações que tenham em conta, não apenas uma visão estática de tutela de interesses de curto prazo, mas também uma perspectiva dinâmica de consideração sustentada dos interesses de médio e longo prazo, sendo que ao longo prazo não é alheia a própria protecção dos direitos das gerações futuras, hoje cada vez mais considerados essenciais a uma constitucionalmente adequada formulação de políticas públicas" (CANOTILHO, J. J. Gomes; MACHADO, Jónatas. A questão da constitucionalidade das patentes "pipeline” à luz da Constituição Federal brasileira de 1988. Coimbra: Almedina, 2008. p. 17).

740 FIORILLO, Celso Antonio Pacheco; FERREIRA, Renata Marques. Curso de direito da energia - tutela jurídica da água, do petróleo, do biocombustível, dos combustíveis nucleares e do vento. 2. ed. São Paulo: Saraiva, 2010. “A Carta de 1988, ao garantir pela primeira vez na história constitucional brasileira um direito direcionado às presentes e às futuras gerações, apontou para a necessidade de se assegurar a tutela jurídica do meio ambiente, não só em decorrência da extensão de tempo médio entre o nascimento de uma pessoa humana e o nascimento de seu descendente (dentro de sua estrutura jurídica, fundamentada na dignidade da pessoa humana), mas também devido à concepção de geração como grupo de organismos que têm os mesmos pais ou, ainda, como grau ou nível simples numa linha de descendência direta, ocupada por indivíduos de uma espécie, que têm um ancestral em comum e que estão afastados pelo mesmo número de crias de seu ancestral. Indicou ainda a Constituição de 1988 uma tutela jurídica voltada para o valor da solidariedade e da fraternidade, estipulando a necessidade de se preservar e se defender o meio ambiente hoje, para uso futuro das próximas gerações, ou como a doutrina, assevera a Constituição de 1988, em seu art. 225, acabou por positivar o princípio da equidade intergeracional ao lado do princípio do desenvolvimento sustentável, ou seja, é necessário e possível que se atendam às necessidades presentes, sem se comprometerem as reais possibilidades de as gerações futuras satisfazerem as suas próprias necessidades. O Estado, dessa forma, por determinação constitucional, deve prosseguir no desenvolvimento lógico do ciclo capitalista, mas preservando diretamente o meio ambiente, de maneira a permitir a formação de um círculo virtuoso de preservação para as futuras gerações; o desenvolvimento econômico, por assim dizer, não pode, de forma alguma, dilapidar os recursos naturais. Reforçou, assim, juridicamente, a Constituição, no âmbito material, a necessidade de se tutelar o direito ambiental a partir do conceito de patrimônio genético, observando-se, no plano jurídico processual, um critério preventivo como o único meio possível de se garantir um direito ambiental efetivamente direcionado às futuras gerações" (p. 56-57).

741 MILARÉ, Édis. Direito do ambiente: a gestão ambiental em foco - doutrina, jurisprudência, glossário. 6. ed. rev. atual. e ampl. São Paulo: RT, 2009. p. 820.

742 AYALA, Patryck de Araújo. Direito e incerteza: a proteção jurídica das futuras gerações no estado de direito ambiental. 2002. Dissertação (Mestrado) - Faculdade de Direito da Universidade Federal de Santa Catarina, 2002. "O estudo dos novos direitos fundamentais exige uma proposta epistemológicamente diferenciada de leitura do ambiente pelo direito ambiental, que deve ser, também, jurídica, mas essencialmente ecológica, uma proposta que é transdisciplinar. A solução proposta reside na atualidade da consideração jurídica de uma nova ética de interação entre os sujeitos relacionados, que passa por uma ética da alteridade; ética do cuidado. Suas características estão reunidas especialmente em torno da valorização cada vez mais acentuada do respeito, do cuidado, da interdição da lesão, do dano e dos estados de periculosidade potencializada, que encontram justificação direta na conservação da qualidade de vida de todos os envolvidos nessa relação e, sobretudo, em tomo de um novo significado de responsabilidade. Afirmar a existência de uma responsabilidade, estruturada em deveres perante as futuras gerações, implica mudanças no sentido jurídico genericamente vinculado à sua compreensão. A responsabilidade de que aqui se trata em nada pode ser relacionada à imputação por faltas, reparação por prejuízos ocorridos em algum momento no passado ou, ainda, culpar alguém por 
do princípio da reciprocidade -, por novos paradigmas naquela seara jurídica, orientados pelos direitos das futuras gerações. Também em perspectiva ambientalista, mas demonstrando cuidado com as futuras gerações, é a doutrina de Ingo Sarlet e Tiago Fensterseifer, ${ }^{743}$ além de Paulo Affonso Leme Machado, que pugna pelo abandono do ceticismo em relação ao princípio da equidade intergeracional, que, argumenta, deve ser ponderado pelos axiomas da razoabilidade e da proporcionalidade. ${ }^{744}$

\section{Sobre o dispositivo, ensina Consuelo Yoshida:}

O emblemático art. 225 da Constituição Federal, ao mesmo tempo em que assegura o direito intergeracional a um ambiente equilibrado, como forma de se garantir a sadia qualidade de vida, e, em última análise, a

atos passados, mas importa uma missão assumida coletivamente perante a proteção de um bem comum e perante as futuras gerações, e de forma compartilhada (e não acumulada) entre as gerações que se sucedem [...] Somente a partir do reconhecimento de que a alteridade está vinculada à responsabilidade, e de que a atuação responsável não pode ser limitada ao presente, é que se pode iniciar uma nova postura de leitura do ambiente, que é também uma nova leitura da eqüidade, que ultrapassa os limites espaciais do respeito pelo alter, para assumir dimensões intergeracionais. Essa afirmação recupera o padrão de deveres e obrigações assimétricos que qualifica a relação jurídica típica dos novos direitos fundamentais biodifusos, que é essencialmente, por essa razão, uma relação de imputação. Constata-se com a evidência da assimetria desses deveres e seu vínculo com a responsabilidade, a revisão das bases da moral tradicional -que funda relações baseadas no princípio da reciprocidade - invertendo sua lógica de atividade, justificada, em grande parte, pelo problema da ausência de atualidade dos sujeitos das novas relações, o que toma incompatível a aplicação da reciprocidade, que se amolda melhor com decisões imediatas e instantâneas. [...] Evidencia-se a necessidade de integração do discurso ético do respeito à alteridade, mas, sobretudo, da alteridade intergeracional, como elementos de revisão do moderno discurso ecológico, que é, atualmente, um discurso de inclusão do outro, propulsor de urna democracia ambiental, qualificada pelo novo Estado democrático do ambiente. A proteção da eqüidade intergeracional, a modificação do significado do outro, a atuação responsável do homem em face do outro, e o respeito (reconhecimento) da dignidade desse outro é que permitem o reconhecimento de um novo ethos para a definição dos sujeitos envolvidos nas novas relações jurídicas. Esse conjunto de condições se insere no espectro global da proteção de condições adequadas para o desenvolvimento $e$ conservação da vida, e não simplesmente da vida qualificada pelo elemento humano. Assim, ao tratar da proteção dos interesses das futuras gerações, pretende-se desenvolver uma proposta de proteção integral da vida, compreendendo aqui, como sujeitos, todos os seres vivos" (p. 165-167).

743 SARLET, Ingo Wolfgang; FENSTERSEIFER, Tiago. O papel do Poder Judiciário brasileiro na tutela e efetivação dos direitos e deveres socioambientais. Revista de Direito Ambiental, São Paulo: RT, v. 13, n. 52, out.-dez. 2008, p. 97. "há que partir da premissa de que deve prevalecer a proteção ambiental quando a ação degradadora combatida comprometa ou coloque em risco o âmbito de proteção da dignidade humana e as bases naturais indispensáveis para o equilíbrio ecológico em geral. [...] é de suma importância que seja sempre considerada a responsabilidade para com as existências humanas (e mesmo não humanas!) futuras, conforme dispõe a Constituição brasileira (art. 225) e o sistema internacional dos direitos humanos, razão pela qual, com razão, se apontou para a importância de se 'tomar a sério os interesses das futuras gerações"”.

744 MACHADO, Paulo Affonso Leme. Direito ambiental brasileiro. 18. ed. rev. atual. e ampl. São Paulo: Malheiros, 2010. p. 136-137. "O relacionamento das gerações com o meio ambiente não poderá ser levado a efeito de forma separada, como se a presença humana no planeta não fosse uma cadeia de elos sucessivos [...] A inserção de um princípio - abrangente e prospectivo - como a responsabilidade ambiental entre gerações pode ser motivo de crítica, pela dificuldade de sua implementação. A razoabilidade e a proporcionalidade hão de ajudar na fundamentação dos atos legislativos, administrativos e jurisdicionais, para evitar arbitrariedades. Não se pode negar o merecimento de um mandamento constitucional que não permitirá mais a ausência de um balanceamento dos interesses das gerações, onde num prato da balança estará a geração dos que, por não poderem falar ou votar, nem por isso são menos amados ou menos importantes". 
dignidade da pessoa humana, deixa claro que a responsabilidade pelos desafiantes desideratos é solidária e compartilhada por todos (poderes públicos e coletividade em geral). ${ }^{745}$

Não à toa, as manifestações do Supremo Tribunal Federal contendo o termo “intergeracional" - ou o anglicismo incompreensível "intergeneracional" - são, todas, referentes à matéria ambiental. ${ }^{746}$

Se há menção constitucional expressa para proteção dos interesses das futuras gerações na dimensão ambiental, o mesmo não pode se dizer da dimensão financeira. Mas isso não importa em dizer que essa proteção não existe.

Ora, o art. 167, III, da CF/1988 traz a "regra de ouro", assim disposta:

Art. 167. São vedados:

$[\ldots]$

III - a realização de operações de créditos que excedam o montante das despesas de capital, ressalvadas as autorizadas mediante créditos suplementares ou especiais com finalidade precisa, aprovados pelo Poder Legislativo por maioria absoluta;

A norma prevê - embora com linguagem algo embotada - que os Entes Federados estão proibidos de contrair dívidas para financiar despesas correntes, não reprodutíveis. Isto é: não lhes é permitido endividar-se para financiar seu consumo, sua atuação corriqueira, máxime no funcionamento regular da Administração. Como ensina James Giacomoni, essa "regra de ouro" "quer que cada unidade governamental tenha seu endividamento vinculado apenas à realização de investimentos e não à manutenção da máquina administrativa e demais serviços". ${ }^{747}$ Baleeiro afirma se tratar, a vedação de acesso ao crédito para custeio de gastos ordinários, uma "elementar regra de moral infensa ao egoísmo" - tais ingressos deveriam ser reservados a "investimentos duráveis", já que

745 YOSHIDA, Consuelo Y. M. A efetividade e a eficiência ambiental dos instrumentos econômicofinanceiros e tributários: ênfase na prevenção. A utilização econômica dos bens ambientais e suas implicações. In: TORRES, Heleno Taveira (Org.). Direito tributário ambiental. São Paulo: Malheiros, 2005. p. 528.

746 Referências ao termo "intergeracional": ADPF 101, rel. Min. Cármen Lúcia, Tribunal Pleno, j. 24.06.2009; RE 628821, rel. Min. Celso de Mello, j. 12.12.2011; AI 805276, rel. Min. Cármen Lúcia, j. 02.08.2010; RE 576425, rel. Min. Carlos Britto, j. 30.09.2009. Referências ao termo "intergeneracional": ADI 3540 MC, rel. Min. Celso de Mello, Tribunal Pleno, j. $1^{\circ} .09 .2005$; AI 802389, rel. Min. Dias Toffoli, j. 25.02.2013; AI 805417, rel. Min. Dias Toffoli, j. 25.02.2013; AI 805417, rel. Min. Dias Toffoli, j. 25.02.2013; ARE 715977, rel. Min. Dias Toffoli, j. 18.02.2013; RE 569223, rel. Min. Dias Toffoli, j. 14.09.2010; MS 27558, rel. Min. Joaquim Barbosa, j. 27.08.2010; AC 1255 MC, rel. Min. Celso de Mello, j. 16.06.2006; e STA 214, rel. Min. Presidente, Decisão Proferida pela Min. Ellen Gracie, j. 05.03.2008.

747 GIACOMONI, James. Orçamento público. 14. ed. ampl. rev. e atual. 3. reimpr. São Paulo: Atlas, 2009. p. 82 . 
assim "a gerações futura ficaria onerada com a amortização, ou com os juros da dívida, mas receberia, como compensação desse ônus", os benefícios oriundos do investimento, de forma que "o sacrifício da posteridade seria praticamente nulo pelo ativo que se conservaria até a época em que viesse a suportar os ônus financeiros correspondentes". ${ }^{748}$

A disposição é secundada por regras da Lei de Responsabilidade Fiscal: o art. $12, \S 2 .^{\circ}$ ("o montante previsto para as receitas de operações de crédito não poderá ser superior ao das despesas de capital constantes do projeto de lei orçamentária"), que embora tenha sido dito que "apenas reproduz o texto constitucional", ${ }^{749}$ foi impugnado perante o Supremo Tribunal Federal por não prever as exceções contidas na Constituição; ${ }^{750} \mathrm{e} o$ art. 44 ("é vedada a aplicação da receita de capital derivada da alienação de bens e direitos que integram o patrimônio público para o financiamento de despesa corrente, salvo se destinada por lei aos regimes de previdência social, geral e próprio dos servidores públicos”), que, na mesma toada, visa impedir que as receitas públicas decorrentes da alienação do patrimônio estatal sejam utilizadas em despesas da máquina administrativa. ${ }^{751}$

O que se quer enfatizar, por ora, contudo, é que a "regra de ouro" (e seus consectários) traz em seu conteúdo evidente carga intergeracional. Ao impedir que sejam contraídas dívidas para utilização em despesas correntes, evita-se que o consumo das gerações atuais seja custeado pelas gerações posteriores. Afinal, a dívida será paga no futuro - e seu adimplemento será provido pela arrecadação dos impostos das futuras gerações. Então, a "regra de ouro" nos diz que é injusto consumir os recursos atualmente, passando a "conta" para as futuras gerações.

Registre-se que essa vinculação (entre crédito público e os interesses das futuras gerações) não é desconhecida, muito ao inverso.

748 BALEEIRO, Aliomar. Uma introdução à ciência das finanças cit., p. 477.

749 NASCIMENTO, Carlos Valder do. Arts. 1. ${ }^{\circ}$ a 17. In: MARTINS, Ives Gandra da Silva; NASCIMENTO, Carlos Valder do (Org.). Comentários à lei de responsabilidade fiscal. 2. ed. rev. e atual. São Paulo: Saraiva, 2007. p. 92.

750 O STF, em decisão liminar, fixou: “[...] Art. 12, § $2 .^{\circ}$ : medida cautelar deferida para conferir ao dispositivo legal interpretação conforme ao inciso III do art. 167 da Constituição Federal, em ordem a explicitar que a proibição não abrange operações de crédito autorizadas mediante créditos suplementares ou especiais com finalidade precisa, aprovados pelo Poder Legislativo. [...]" (ADI 2238 MC, rel. Min. Ilmar Galvão, Tribunal Pleno, j. 09.08.2007).

751 "Portanto, no art. 44, quer-se impedir a alienação do patrimônio público sem contrapartida em novos investimentos. Alienar bens para custear as despesas cotidianas da Administração equivale a dilapidar o patrimônio público. É norma de franca proteção do patrimônio estatal, que somente cede quando se trata da previdência social" (DERZI, Misabel Abreu Machado. Arts. 40 a 47. In: MARTINS, Ives Gandra da Silva; NASCIMENTO, Carlos Valder do (Org.). Comentários à lei de responsabilidade fiscal cit., p. 326). 
Está contida em milhares de textos de Direito Financeiro, embora sob a terminologia de equilíbrio ou sustentabilidade financeiro-orçamentária ${ }^{752-753-754}$ conceitos que, como ensinam Fernando Facury Scaff e Francisco Sérgio Rocha, devem partir "da distinção entre os diferentes tipos de receitas, despesas e créditos públicos que devem ser observados à luz dos diferentes períodos de tempo orçamentário, que obrigatoriamente deve ultrapassar o rigoroso intervalo de 12 meses", evitando que se confundam com meros encontros de receitas e despesas; o equilíbrio orçamentário, segundo os autores, é meio para alcançar "a satisfação dos interesses sociais através da realização de despesas públicas", e exige analisar se os planos financeiros do Estado são "sustentáveis a médio e longo prazo e não comprometerão as despesas que deverão ser realizadas". 755

752 Afinal, como pontua Daniel Shaviro: "For centuries, concern about deficits has focused on the issue of burdening future generations. Proponents of addressing the fiscal gap often share this concern. The underlying idea is that, the more we defer addressing the fiscal shortfall however measured and labeled, the more we are leaving it for younger and future generations" (SHAVIRO, Daniel. The long-term U.S. Fiscal gap: is the main problem generational inequity? cit., p. 1311).

753 Vale notar, não como contraponto - que de fato não é - mas como ponderação do dever de manter as finanças públicas equilibradas, as ponderações de Cesar Augusto Seijas de Andrade, a respeito da possibilidade, dentro do sistema constitucional financeiro brasileiro, de elaboração de proposta orçamentária com resultado deficitário, com objetivos anticíclios. As excelentes colocações do autor conduzem a mais uma reflexão sobre a equidade intergeracional, que nem sempre demandará que as finanças públicas sejam anualmente superavitárias, podendo mesmo exigir o inverso - temporariamente, é claro. Ver: ANDRADE, Cesar Augusto Seijas de. Orçamento deficitário. In: CONTI, José Maurício; SCAFF, Fernando Facury (Org.). Orçamentos públicos e direito financeiro cit.

754 Sobre o conceito de "sustentabilidade financeira", ver: PEREIRA, Manuel Henrique de Freitas. Sustentabilidade das finanças públicas na União Europeia. In: CATARINO, João Ricardo; TAVARES, José F. F. (Coord.). Finanças públicas da União Europeia. Coimbra: Almedina, 2012. p. 287 e ss. O autor identifica duas correntes centrais de conceituação, "em ambos os casos procurando responder a uma questão central: há ou não limites para o crescimento da dívida pública?". Na primeira corrente, "o rácio da dívida pública (relação entre dívida pública e PIB) deverá convergir para um valor finito de modo a evitar que o nível de fiscalidade (relação entre receitas públicas e PIB) cresça indefinidamente". Pela segunda corrente, "a sustentabilidade das finanças públicas impõe que o valor atual de todos os futuros excedentes orçamentários primários (ou seja os saldos orçamentais sem juros) seja igual ao valor existente da dívida pública". Daí que, mesmo sem se posicionar, Freitas Pereira indica a relevância do conceito de dívida pública no tema, que deve ser tomado de forma abrangente. Afirma: "devem ser incluídas não só a chamada dívida explícita, derivada de obrigações contratuais e representada normalmente por títulos ou empréstimos bancários, mas também a dívida implícita, ou seja a que resulta de obrigações que, com grande probabilidade, os governos serão chamados a honrar em face das políticas em vigor, mesmo se tais obrigações não resultem propriamente de contratos, estabelecidos de forma legal. Entre estas últimas estão as obrigações ligadas ao pagamento de pensões de reforma, para mais num ambiente caracterizado por um acentuado envelhecimento demográfico. Obrigações semelhantes estão ligadas às despesas de saúde e de proteção social, pressupondo que as mesmas se mantêm de acordo com o seu enquadramento atual" - p. 289-291.

Os autores, contudo, não tomam equilíbrio e sustentabilidade como sinônimos: "Sustentabilidade financeira, portanto, é um termo mais amplo que equilíbrio orçamentário, na leitura contábil-matemática do termo. Para que ocorra sustentabilidade financeira é necessário que seja estabelecido um período de tempo de médio e longo prazo, e que todos os elementos financeiros que estejam à disposição daquele ente público sejam analisados de forma conjunta, podendo mesmo haver déficits públicos periódicos visando alcançar certas metas sociais, e obter o necessário equilíbrio orçamentário, dentro do período de tempo estabelecido. Trata-se de uma análise dinâmica do fenômeno financeiro, e não uma análise 
Apenas recentemente é que a linguagem vem se alterando para fazer constar expressamente a equidade, solidariedade ou justiça intergeracional, ou simplesmente, a preocupação com as futuras gerações ${ }^{756}$ - alteração de linguagem essa que fica nítida com a supra referida evolução da legislação internacional e dos Direitos Humanos.

Assim, Ricardo Lobo Torres chega mesmo a apresentar a "equidade entre gerações" como princípio geral do Direito Financeiro, afirmando que "os empréstimos públicos e as despesas governamentais não devem sobrecarregar as gerações futuras, cabendo à própria geração que deles se beneficia arcar com o ônus respectivo", ademais referindo o já transcrito art. 167, III, da CF/88 como expressão desse princípio, evitando a transferência de "carga fiscal para outra geração". ${ }^{757}$ O mesmo faz João Ricardo Catarino. $^{758}$

Eber Santa Helena vê na "regra de ouro" um vínculo estabelecido pela Constituição entre o Direito Financeiro e as futuras gerações: com Lobo Torres, afirma que a fixação do grau de endividamento público deve ser entendida como expressão direta da ideia de justiça entre gerações e do princípio da poupança justa, trazidos na doutrina de John Rawls. ${ }^{759-760}$ Para Émerson Gomes,

estática, limitada a um período de 12 meses. Esta noção de sustentabilidade financeira está mais próxima de um filme que de uma fotografia, esta mais condizente com a lógica do equilíbrio orçamentário considerado como uma equação contábil-matemática". SCAFF, Fernando Facury; ROCHA, Francisco Sérgio Silva. Equilíbrio orçamentário e sustentabilidade financeira: anotações sobre o Brasil cit.

756 Afirma Peter Häberle: "the generation contract marks off the limits of national debts" (HÄBERLE, Peter. A constitutional law for future generations - the 'other' form of the social contract: the generation contract. In: TREMMEL, Joerg (Ed.). Handbook of intergenerational justice cit., p. 225).

757 TORRES, Ricardo Lobo. Curso de direito financeiro e tributário. 15. ed. atual. até 31.12.2007. Rio de Janeiro: Renovar, 2008. p. 105.

758 João Ricardo Catarino igualmente inclui a equidade intergeracional como princípio. CATARINO, João Ricardo. Processo orçamental e sustentabilidade das finanças públicas: o caso europeu. In: CONTI, José Maurício; SCAFF, Fernando Facury (Org.). Orçamentos públicos e direito financeiro cit., p. 795. Em outra oportunidade, o mesmo autor sugere: "A melhoria da sustentabilidade das finanças públicas, tal como vem sendo preconizada pelo FMI, elaborando-se um relatório sobre tal sustentabilidade de cinco em cinco anos com informações projetadas para uma década" (CATARINO, João Ricardo. Problemas e perspetivas da governação financeira em ambiente aberto. Revista Fórum de Direito Financeiro e Econômico-RFDE, Belo Horizonte, ano 1, n. 1, mar.-ago. 2012, p. 105).

759 SANTA HELENA, Eber Zoehler. Justiça distributiva na teoria da justiça como eqüidade de John Rawls. Revista de Informação Legislativa, v. 45, n. 178, Brasília, abr.-jun. 2008. "Uma aplicação prática do princípio da poupança justa apresenta-se na fixação do grau de endividamento público, que Torres (1995, p. 176) considera como expressão da eqüidade entre gerações, ou seja, significa que os empréstimos públicos e as despesas governamentais não devem sobrecarregar as gerações futuras, cabendo à própria geração que deles se beneficia arcar com o ônus respectivo. Inegável que o endividamento excessivo repercute sobre o futuro, transferindo a carga fiscal para outra geração. Prevenindo tal ônus, o constituinte brasileiro de 1988 impôs a regra de ouro do art. 167, II, que limita os empréstimos públicos ao montante das despesas de capital (investimentos e inversões financeiras), que também são realizadas com vista ao futuro. Além desse limite, só por meio de autorização legislativa específica e com quorum qualificado da maioria absoluta" (p. 345). 
segundo a regra de ouro, é possível transferir às gerações/anos futuros os ônus do pagamento de empréstimos/financiamentos, se eles tiverem associados às despesas de capital (por exemplo, infraestrutura), uma vez que as gerações futuras também usufruirão dos benefícios advindos destas despesas. $^{761}$

Ferreiro Lapatza, como já mencionado, sustenta que a noção temporal é nuclear no tema da dívida e do crédito público. ${ }^{762}$ Manuel Henrique de Freitas Pereira é outro que, de forma didática, promove esse vínculo entre a ética intergeracional e o controle da dívida pública. Com muita razão, não postula a vedação da contração de dívidas públicas; mas postula, isto sim, que esses créditos estejam vinculados com despesas públicas que beneficiem as gerações futuras, estas que irão arcar, por meio da imposição tributária, com o saldo desses débitos deixados. ${ }^{763}$ No mesmo sentido é a lição de Fernando Facury Scaff e Francisco Sérgio Rocha. ${ }^{764}$

No mais, o relacionamento entre a dívida pública e as futuras gerações, com base no Direito Financeiro (e Tributário), pode ser verificado em Michael Doran, Neil

760 Jane English já havia sugerido o mesmo quando afirmou (ENGLISH, Jane. Justice between generations cit., p. 97): "Governmental deficit spending is a similar form of temporally reversed 'saving' which can extend over many generations".

761 GOMES, Emérson César da Silva. Arts. 83 a 100. In: CONTI, José Maurício (Coord.). Orçamentos públicos cit., p. 288.

762 LAPATZA, José Juan Ferreiro. Instituticiones de derecho financiero cit., p. 107. Também: LAPATZA, José Juan Ferreiro. Curso de derecho financiero español cit., p. 536.

763 "É que a dívida pública é afinal uma repartição no tempo do financiamento de uma despesa, o que, repercutindo-se sobre gerações futuras, só será legítimo se essas gerações, que no todo ou em parte a vão pagar com impostos, puderem beneficiar de algum modo da realização dessa despesa. Assim, importará ter sempre presente que contrair dívida hoje é inevitavelmente lançar impostos amanhã e que se a esperança de vida dos cidadãos que autorizam uma dívida é inferior à maturidade dos empréstimos (incluindo a da sua sucessiva renovação, qual bola de neve), com esses empréstimos a geração presente está a lanãr impostos sobre as gerações futuras - ou, para utiliza a linguagem sugestiva de Friedich List, a sacar letras sobre as gerações futuras. E este ónus é-lhes lançado sem que elas se tenham pronunciado sobre a justeza das razões que levaram à contracção da dívida. O consentimento dos impostos pelos cidadãos que os vão pagar - que há muito está enraizado na ordenação política das sociedades e que num Estado de direito democrático tem ainda mais razão de ser - fica totalmente comprometido. Daí que a resposta à questão posta é, em geral, que contrair dívida a pagar pelas gerações futuras é uma via que pode ser censurável no plano ético, especialmente no caso de essa dívida servir para financiar despesas que apenas beneficiam a geração presente" (PEREIRA, Manuel H. de Freitas. Ética e fiscalidade. Revista de Finanças Públicas e Direito Fiscal, ano 4, n. 3, p. 22).

764 "Crédito público é imposto diferido. Renúncia fiscal equivale a despesa pública. Serão as futuras gerações que arcarão com os custos dos gastos realizados hoje com base em empréstimos que serão pagos no porvir. O caráter intergeracional da sustentabilidade financeira é que deve ser o foco do problema. Governos irresponsáveis, que aumentam gastos públicos rígidos, custeados a partir de empréstimos públicos - mesmo que de longo prazo - devem ser coibidos de fazê-lo. Aqui o foco é a qualidade do gasto público, visando seu equilíbrio". SCAFF, Fernando Facury; ROCHA, Francisco Sérgio Silva. Equilíbrio orçamentário e sustentabilidade financeira: anotações sobre o Brasil cit. 
Buchanan, Clark Wolf, Luciano e Bruno Rezzoagli, e, principalmente, Joaquim Freitas da Rocha, todos já mencionados acima e que podem ser consultados sobre o tema. ${ }^{765-766}$

O que se quer fixar, portanto, nesta oportunidade, é que o sistema jurídicoconstitucional brasileiro, embora não refira expressamente as futuras gerações na perspectiva financeira, efetivamente contém disposições protetivas da equidade intergeracional também nesse âmbito.

E, para finalizar a busca por dispositivos da Constituição brasileira que encerrem a proteção das gerações futuras, cumpre lembrar que o art. 3..$^{\circ}$ da Carta prevê, como objetivo fundamental ${ }^{767}$ da República Brasileira, a construção de uma sociedade que, para além de livre e justa, é solidária.

A menção à solidariedade pode e deve ser tomada em confronto com as ideias, já acima apresentadas, de que a condição temporalmente contínua da passagem de todos pelo planeta - a unidade raça humana deve ser compreendida em sua dimensão temporal ${ }^{768}$ - invoca uma solidariedade entre gerações.

Então, pode-se mesmo afirmar, com Patryck Ayala, ${ }^{769}$ que não apenas nos arts. 225 e 167, III, da Constituição Federal de 1988, está a proteção das futuras gerações. Mas

765 Respectivamente: DORAN, Michael. Intergenerational equity in fiscal policy reform cit.; BUCHANAN, Neil $\mathrm{H}$. What kind of environment do we owe future generations? cit.; WOLF, Clark. Intergenerational justice and saving. In: LAMONT, Julian; FAVOR, Christi; GAUS, Gerald (Coord.). Values, justice and economics cit.; REZZOAGLI, Luciano Carlos; REZZOAGLI, Bruno Ariel. Teoría de la igualdad intergeneracional... cit.; ROCHA, Joaquim Freitas da. Breves reflexões sobre responsabilidade colectiva e finanças públicas. In: ROCHA, Joaquim Freitas da (Coord.). Anuário publicista da Escola de Direito da Universidade do Minho cit.; ROCHA, Joaquim Freitas da. Sustentabilidade e finanças públicas responsáveis - Urgência de um direito financeiro equigeracional. Mimeo - texto publicado em CORREIA, Fernando Alves; MACHADO, Jónatas E. M.; LOUREIRO, João Carlos (Org.). Estudos em homenagem ao Prof. Doutor José Joaquim Gomes Canotilho cit.

766 Para uma perspectiva da Economia Política: SÜSSMUTH, Bernd; VON WEIZSÄCKER, Robert K. Institutional determinants of public debt: a political economy perspective. In: TREMMEL, Joerg (Ed.). Handbook of intergenerational justice cit.

767 Cabendo, sobre o ponto, lembrar da lição de Bercovici: "Dispositivos como o art. 3. ${ }^{\circ}$ da Constituição de 1988 são o que doutrinadores constitucionais como o espanhol Pablo Lucas Verdú denominam de 'cláusulas transformadoras'. A 'cláusula transformadora' explicita o contraste entre a realidade social injusta e a necessidade de eliminá-la. Deste modo, impede que a Constituição considerasse realizado o que ainda está por se realizar, implicando na obrigação do Estado em promover a transformação da estrutura econômico-social. Sua concretização não significa a imediata exigência de prestação estatal concreta, mas uma atitude positiva, constante e diligente do Estado [...] $\mathrm{O}$ art. 3..$^{\circ}$ da Constituição de 1988 é um instrumento normativo que transformou fins sociais e econômicos em jurídicos, atuando como linha de desenvolvimento e de interpretação teleológica de todo o ordenamento constitucional" (BERCOVICI, Gilberto. Política econômica e direito econômico cit., p. 213).

768 Cf. Antonio Augusto Cançado Trindade, em voto-vista proferido na Corte Interamericana de Direitos Humanos, caso Bámaca-Velásquez v. Guatemala, julgado em novembro de 2000. Disponível em: <http://www.corteidh.or.cr/docs/casos/articulos/seriec_70_ing.pdf>. Acesso em: 25 nov. 2013.

769 "O futuro deixa de ser reproduzido como mera promessa institucional irresponsável, para que possa enfim ser ser socialmente percebido como resultado de ações e atividades solidárias. Esse compromisso 
também deve ser compreendida como objetivo fundamental da nação, fundada no art. $3 .^{\circ}$, I.

E não apenas na categoria dos objetivos fundamentais esse dever de proteção pode ser enquadrado. Tiago Fensterseifer postula que as obrigações intergeracionais devem ser tidas como deveres fundamentais ${ }^{770}$ - categoria jurídica esta, explica, que resta doutrinariamente "atrofiada", o que se explica pela força das ordinárias concepções liberais do Estado, que postulam uma atuação mínima estatal, voltada para a proteção patrimonial $^{771}$-, assentadas na "responsabilidade comunitária dos indivíduos". $772-773$ (Para Fensterseifer, a teoria dos deveres merece lugar de destaque na doutrina dos direitos fundamentais; afirma que "a dimensão normativa dos deveres fundamentais determina tanto a limitação de direitos subjetivos como também a redefinição do conteúdo desses, como ocorre, por exemplo, na imposição constitucional do cumprimento da função social da propriedade", ${ }^{774}$ de forma que os deveres fundamentais "estão atrelados à dimensão comunitária ou social da dignidade humana, fortalecendo a atuação solidária do indivíduo situado em dada comunidade estatal, o que demanda por uma releitura do conteúdo normativo do direito à liberdade, amarrando-o à idéia de responsabilidade comunitária e vinculação social do indivíduo". ${ }^{775}$ Os deveres fundamentais são "instrumentos de efetivação dos direitos fundamentais" e "dirigem-se primordialmente ao legislador", na

encontra-se expresso com grande ênfase no art. 225, caput, do texto constitucional brasileiro, em que foi reconhecido o fundamento de justificação do princípio da equidade intergeracional, que, na experiência constitucional brasileira, é objetivo da República e expressão de nossa cultura constitucional. A concretização da solidariedade como objetivo da República brasileira (art. 3. ${ }^{\circ}$, I) não está submetida a limites temporais (art. 225, caput), pois a solidariedade constitucionalmente protegida é intergeracional, relacionando passado, presente e futuro". AYALA, Patryck de Araújo. A proteção jurídica das futuras gerações na sociedade do risco global: o direito ao futuro na ordem constitucional brasileira. In: LEITE, José Rubes Morato; FERREIRA, Heline Sivini; BORATTI, Larissa Verri (Org.). Estado de direito ambiental: tendências. 2. ed. Rio de Janeiro: Forense Universitária, 2010. p. 354.

770 FENSTERSEIFER, Tiago. Direitos fundamentais e proteção do meio ambiente: a dimensão ecológica da dignidade humana no marco jurídico constitucional do estado socioambiental de direito. Porto Alegre: Livraria do Advogado, 2008. p. 206-207.

771 Idem, ibidem, p. 191.

772 Idem, p. 192-193.

773 A menção apenas a deveres "dos indivíduos” é explicada por Alessandro Mendes Cardoso: "os deveres fundamentais são, essencialmente, vinculados aos indivíduos, ou pessoas humanas. $\mathrm{O}$ fato de pessoas coletivas também serem destinatárias de deveres fundamentais não contradiz esse fato, uma vez que estas são instrumentos de afirmação e realização da pessoa humana, sendo que por detrás das pessoas jurídicas estão indivíduos, cuja efetivação de seus direitos fundamentais decorre necessariamente da existência e do funcionamento da comunidade social, viabilizada pela observância dos deveres fundamentais" (CARDOSO, Alessandro Mendes. O dever fundamental de recolher tributos no estado democrático de direito. Porto Alegre: Livraria do Advogado, 2014. p. 37).

774 FENSTERSEIFER, Tiago. Direitos fundamentais e proteção do meio ambiente cit., p. 193.

775 Idem, ibidem, p. 196. 
visão de Alessandro Cardoso. ${ }^{776}$ A definição mais utilizada ${ }^{777}$ de deveres fundamentais é a de Casalta Nabais, para quem são "deveres jurídicos do homem e do cidadão que, por determinarem a posição fundamental do indivíduo, têm especial significado para a comunidade e podem por esta ser exigidos", sendo "posições jurídicas passivas, autónomas, subjectivas, individuais, universais e permanentes e essenciais" ${ }^{\text {778 }}$ ). Embora não seja objeto desta dissertação aprofundar no estudo da teoria dos direitos e deveres fundamentais, são relevantes as colocações acima, porquanto adicionam ainda mais uma dimensão jurídica em que pode ser enquadrada a equidade intergeracional, reiterando sua presença no ordenamento jurídico pátrio.

Como anunciado ao princípio do tópico, o que se averigua é se é possível afirmar que o ordenamento jurídico brasileiro dá bases de sustentação para que se protejam os interesses das gerações futuras.

Com base nas considerações acima, a resposta há de ser positiva. Há elementos suficientes para se afirmar que a equidade intergeracional é defendida no texto constitucional. Essa proteção se dá em alguns casos (como o meio ambiente) de forma mais explícita que em outros (como as finanças públicas). Mas é imperativo que se reconheça que o sistema jurídico-constitucional brasileiro dá amparo a tais preocupações, demandando dos intérpretes a aplicação das noções de equidade intergeracional.

O que se quer, nos itens adiante, a partir dessa conclusão, é analisar algumas instituições, instrumentos e aspectos do sistema brasileiro de governança dos royalties de recursos naturais não renováveis, primordialmente através da lente do Direito Financeiro, averiguando se tais itens estão ou não dando cumprimento à proteção constitucional dirigida às gerações pósteras.

776 CARDOSO, Alessandro Mendes. O dever fundamental de recolher tributos no estado democrático de direito cit., p. 38.

777 Para outra definição de deveres fundamentais, consultar: MARTINEZ, Gregorio Peces-Barba. Los deberes fundamentales. DOXA, n. 4, 1986, p. 336. Afirma que são "aquellos deberes jurídicos que se refieren a dimensiones básicas de la vida del hombre en sociedad, a bienes de primordial importancia, a la satisfacción de necesidades básicas o que afectan a sectores especialmente importantes para la organización y el funcionamiento de las Instituciones públicas, o al ejercicio de derechos fundamentales, generalmente en el ámbito constitucional. El ejercicio de un deber fundamental no reporta benefícios exclusivamente al titular del derecho subjectivo correlativo, cuando existe, sino que alcanza una dimensión de utilidad general, beneficiando al conjunto de lós ciudadanos y a su representación jurídica, el Estado. A diferencia de lós derechos fundamentales, cuya raiz ética previa (la moralidad de lós derechos fundamentales) es evidente, los deberes fundamentales son, en ocasiones, consecuencia de la convención y del ejercicio del poder soberano, titular de la producción normativa".

778 NABAIS, José Casalta. O dever fundamental de pagar impostos cit., p. 64. 
Ainda que se argumente - não sem alguma razão - que o texto constitucional não dirige diretamente à governança dos recursos naturais não renováveis o dever de orientá-la em observância do futuro, entende-se já ter sido fixado, com as razões já postas acima, (i) que o interesse das futuras gerações, por suas características intrínsecas, não pode ser dissociado dessa proteção; e (ii) que tais características, interpretadas em conjunto com o direcionamento, trazido pelo ordenamento jurídico brasileiro, para a defesa da equidade intergeracional, demanda que essa governança mantenha seguros os direitos e interesses das futuras gerações.

Tudo sob a recordação, com Fernando Facury Scaff, de que "em primeiro lugar, deve vir a pessoa humana, e o direito financeiro tem importante papel a desempenhar na análise e implementação desses direitos, seja para a presente, seja para as futuras gerações". 779

\section{3.b. Sobre o domínio dos recursos naturais não renováveis no Brasil.}

$\mathrm{Na}$ forma do art. 20, inciso IX, da Constituição Federal de 1988, os recursos minerais - expressão utilizada no sentido lato, referindo também petróleo e gás natural são bens da União.

O domínio da União Federal, convém lembrar, é reafirmado nos arts. 176 e 177 do texto constitucional - o primeiro, tratando de recursos minerais, consigna que esses bens pertencem à União; o segundo afirma, em relação apenas a petróleo e derivados, o monopólio da União na pesquisa e lavra.

Resta não menos que explicitado à obviedade que o texto constitucional estabeleceu o regime do patrimônio desses recursos minerais, trazendo-lhes o regime do Direito Público e conectando esses direitos reais à Administração Pública, na pessoa do Ente federativo central. ${ }^{780}$ Mister anotar, também, que se hoje o domínio dos recursos

779 SCAFF, Fernando Facury. Royalties decorrentes da exploração de recursos naturais não renováveis cit., p. 526.

780 Alexandre de Moraes afirma: "Em qualquer dessas hipóteses, porém, o legislador constituinte estabeleceu a dominialidade da União, no sentido dado por Marcello Caetano, para quem 'o domínio público corresponderá, pois, ao conjunto dos direitos reais que a Administração Pública tem por lei sobre o território e seus espaços, coisas próprias nele individualizadas ou bens alheios, conferidos para serem exercidos no regime peculiar do Direito Público'. Esse é o entendimento de Celso Bastos, para quem 'as jazidas petrolíferas compõem a dominialidade pública. São bens públicos que integram o patrimônio da União'. Também Ives Gandra, ao analisar o art. 20, IX, da CF, afirma que 'os recursos minerais são considerados bens da União'. No mesmo sentido, Pinto Ferreira, quando afirma que 'os recursos minerais são bens públicos da União" (MORAES, Alexandre de. Regime jurídico da concessão para 
minerais parece livre de maiores discussões, este é um avanço da Constituição de 1988 e, até sua promulgação, existiam sérios debates sobre o tema, inclusive pela aplicação do regime de res nullius alegadamente utilizado nas Constituições de 1934 e $1937^{781}$ (referidos textos estabeleciam a distinção entre a propriedade do solo e do subsolo, mas não estabeleciam diretamente a propriedade desses bens). ${ }^{782}$ Esta colocação do domínio dos bens minerais na pessoa do ente político central, aliás, deve ser vista também, numa perspectiva comparada, como decorrente da posição temporal (final do século XX) em que se encontra nossa Constituição Federal, como lembra George Anderson. ${ }^{783}$

A orientação trazida pelo texto constitucional vigente é de caráter nacionalista (embora não xenófobo), ${ }^{784}$ calcada na ideia de concessão mineral, que "atribui um direito exclusivo a um ente privado para explorar e usar uma determinada jazida, desde que este atenda a certos requisitos técnicos, jurídicos e econômicos previstos em lei”. ${ }^{785}$

exploração de petróleo e gás natural. Revista de Direito Constitucional e Internacional, n. 36, São Paulo: RT, jul.-set. 2001, p. 162-163).

781 É o que sustenta Nelson Ribeiro, escrevendo logo após a entrada em vigor da Constituição vigente: "Essa perspectiva [nacionalista] se fez manifestar em primeiro lugar na definição da propriedade do subsolo, quando no art. 20, IX, definiu, como bens da União, 'os recursos minerais, inclusive os do subsolo'. A redação caracteriza-se pela especificidade, tentando prevenir a ocorrência de quaisquer dúvidas quanto à propriedade dos bens minerais. Essa especificidade foi mais ostensiva no art. 176, quando estabeleceu a regra de que 'as jazidas, em lavra ou não, e demais recursos minerais e os potenciais de energia hidráulica constituem propriedade distinta da do solo para efeito de exploração ou aproveitamento, $e$ pertencem à União, garantida ao concessionário a propriedade do produto da lavra' (grifos do autor). A norma constitucional aqui é mais explícita, pois manteve, como propriedade da União, as jazidas mesmo em lavra, caracterizando-as como propriedade distinta da do solo. Ao concessionário da exploração da jazida garantiu a propriedade do produto da lavra, o que, sem dúvida alguma, é um dos avanços mais importantes da política mineral brasileira. Foi superado, dessa maneira, o questionamento no sentido de aplicar aos bens minerais o regime de res nullius que as Constituições de 1934 e 37 haviam preconizado. Reconheceu, assim, a Constituição que os recursos minerais são bens econômicos que pertencem à sociedade como um todo. Por isso mesmo, não podem ser tratados como propriedade daquele que os descobrir, no seu excluisvo interesse particular, pois, seria uma violência contra o interesse social que é inerente à natureza desses bens" (RIBEIRO, Nelson de F. As macroperspectivas do direito minerário a partir da nova Constituição. Revista de Informação Legislativa, n. 102, Brasília, Senado Federal, abr.jun. 1989, p. 70).

782 Para um breve histórico da evolução jurídico-constitucional do tema, ver: CÂMARA DOS DEPUTADOS: Setor mineral rumo a um novo marco legal: rel. Jaime Martins; coord. Paulo César Ribeiro Lima; Alberto Pinheiro de Queiroz Filho; Leonardo Costa Schüler; Roberto Carlos Martins Pontes. Brasília: Câmara dos Deputados, Edições Câmara, 2011, Série Cadernos de Altos Estudos, n. 8, p. 25 e ss.

783 ANDERSON, George. Reflections on oil and gas in federal systems. In: ANDERSON, George (Ed.). Oil \& gas in federal systems cit., p. 376.

784 RIBEIRO, Nelson de F. As macroperspectivas do direito minerário a partir da nova Constituição cit., p. 71.

785 BARBOSA, Alfredo Ruy. A natureza jurídica da concessão para exploração de petróleo e gás natural. In: PIRES, Paulo Valois (Org.). Temas de direito do petróleo e do gás natural II. Rio de Janeiro: Lumen Juris, 2005. p. 14. 
Cria-se um direito público subjetivo ao particular concessionário, que, contudo, em todo caso, está expressa e indissociavelmente vinculado ao interesse nacional. ${ }^{786}$

Finalmente, não é de se deixar passar em branco o relevantíssimo papel que o domínio sobre os recursos minerais exerce sobre a noção de soberania. O controle sobre as fontes de energia é fundamental ao livre desenvolvimento das nações, evitando dependência tecnológica, impulsionando a produção interna, e atuando também na saúde macroeconômica do país. ${ }^{787}$

No plano internacional, a vinculação dos recursos minerais com a soberania já foi reiteradamente afirmada (não sem o protesto dos grupos de interesse privados e suas nações de origem), com destaque para a Resolução da ONU n. 1.803/1962, que declara que "o direito dos povos e das nações à soberania permanente sobre as suas riquezas e recursos naturais deverá ser exercido no interesse do respectivo desenvolvimento nacional e do bem-estar do povo do Estado em causa". ${ }^{788}$ Da mesma forma, a Carta dos Direitos e Deveres Econômicos dos Estados, de 1974 sustenta (art. 2.1) que "cada Estado tem, e pode exercitar livremente, total e permanente soberania, incluindo na posse, uso e disposição sobre toda a sua riqueza, recursos naturais e atividades econômicas". ${ }^{789}$

Quer-se enfatizar essa distinção dos planos interno e internacional (ordem jurídica global). Em se tratando de federalismo e descentralização, os entes políticos internos (União, Estados, Distrito Federal e Municípios) são autônomos e independentes entre si. São pessoas jurídicas de direito interno, mas não de direito público externo - nesta

786 BARBOSA, Alfredo Ruy. A natureza jurídica da concessão para exploração de petróleo e gás natural. In: PIRES, Paulo Valois (Org.). Temas... cit., p. 15. Para Giberto Bercovici (BERCOVICI, Gilberto. Direito econômico do petróleo e dos recursos minerais cit., p. 289), "o petróleo e os recursos minerais são bens públicos de uso especial, bens indisponíveis cuja destinação pública está definida constitucionalmente: a exploração e aproveitamento de seus potenciais". Para Alfredo Ruy Barbosa, a concessão estatal para exploração de petróleo e gás importa em "direito real de exploração" (BARBOSA, Alfredo Ruy. A natureza jurídica da concessão para exploração de petróleo e gás natural. In: PIRES, Paulo Valois (Org.). Temas de direito do petróleo e do gás natural II cit., p. 14).

787 BERCOVICI, Gilberto. Direito econômico do petróleo e dos recursos minerais cit., p. 234. "A soberania energética é um componente essencial da soberania econômica nacional, pois abrange um setor chave da economia do país. O Estado deve tomar decisões autônomas sobre a produção e destino dos seus recursos energéticos, planejando o seu desenvolvimento e evitando a dependência tecnológica e de fatores externos para a produção de energia. Deste modo, o controle estatal sobre as fontes de energia consiste em um eixo central de um projeto democrático em que a política macroeconômica esteja a serviço dos interesses nacionais, além de poder propiciar um planejamento energético de logo prazo". Ainda: "Para garantir o controle público sobre aspectos essenciais da economia, como as fontes de energia, eles [recursos minerais] são declarados propriedade da coletividade" (p. 285).

788 Para evolução do tema perante as Nações Unidas, v. a obra de Alfredo Ruy Barbosa, p. 3-4. BARBOSA, Alfredo Ruy. A natureza jurídica da concessão para exploração de petróleo e gás natural. In: PIRES, Paulo Valois (Org.). Temas de direito do petróleo e do gás natural II cit.

789 Disponível em: <http://www.un-documents.net/a29r3281.htm>. Acesso em: 30 nov. 2013. Tradução livre. 
categoria, apenas está a nação brasileira, a República Federativa do Brasil (daí que o Presidente da República tem uma dupla função: representar a nação externamente - incisos VII e VIII do art. 84 da Constituição; e representar a União Federal internamente).

Por essa razão, e diante das considerações acima, é que não se pode concordar, por exemplo, com Pierre-Yves Bonin, quando propõe que as rendas dos recursos naturais não renováveis sejam repartidas entre todos os países e indivíduos do mundo, por serem "bens da humanidade". ${ }^{790}$ Que se ratifique, então: os recursos minerais e petrolíferos encontrados no subsolo brasileiro são, na ordem internacional, bens da nação brasileira, que os explora como bem entender, observada sua autonomia e sua soberania.

E também, com essas notas, é que se há de interpretar a posição manifestada por Yoshida, sustentando que os recursos minerais são "bens ambientais de natureza difusa"791 e por Comparato, quando afirma que "o petróleo, na verdade, não pertence à União. Pertence à nação brasileira". ${ }^{792}$ É dizer: estas razões revelam-se perfeitas quando dirigidas à ordem internacional. Mas, no direito interno, o petróleo, bem como o minério de ferro e qualquer outro bem mineral, é sim de domínio da União Federal, ente político central, por expressa e inequívoca disposição constitucional.

Por isso, também, que se equivoca o Supremo Tribunal Federal quando afirma que a receita de royalties é receita pública originária de Estados e Municípios (MS 24.312). O tema será melhor abordado em item posterior.

790 "Les ressources naturelles jouent un rôle capital dans le développement économique des pays et le bienêtre de leurs habitants. Elles servent à nourrir la population, sont utilisées comme sources énergétiques et, en tant que matières premières, elles entrent dans la fabrication de la plupart des biens de consommation. Étant donné qu'elles sont produites par la nature sans être le fruit d'un travail humain, il serait normal qu'elles appartiennent collectivement à l'humanité et qu'elles soient gérées au profit de tous. Or, distribuées au gré des forces de la nature, elles ne sont malheureusement pas réparties également sur toute la planète et des pays en profitent plus que d'autres. Certains jouissent de conditions environnementales avantageuses ou de ressources minérales prodigieuses, tandis que d'autres, fréquemment menacés par les éléments, manquent cruellement de matières premières. Au nom de l'équité, il importe de redresser la situation afin que les bénéfices tirés des ressources naturelles soient plus équitablement répartis. Le moyen le plus efficace d'y parvenir consisterait à imposer une taxe aux pays qui possèdent, exploitent ou consomment davantage de ressources, puis à répartir les sommes recueillies entre les 'véritables' propriétaires des ressources, soit l'ensemble des habitants de la planète". BONIN, Pierre-Yves. La justice internationale et le partage des ressources naturelles cit., p. 3.

791 YOSHIDA, Consuelo Y. M. A efetividade e a eficiência ambiental dos instrumentos econômicofinanceiros e tributários: ênfase na prevenção. A utilização econômica dos bens ambientais e suas implicações. In: TORRES, Heleno Taveira (Org.). Direito tributário ambiental cit., p. 550.

792 COMPARATO, Fabio Konder. Quem dá mais? Folha de S. Paulo - Opinião. 24 nov. 2004. Disponível em: <http://www1.folha.uol.com.br/fsp/opiniao/fz2409200409.htm>. Acesso em: 30 nov. 2013. 
3.c. Sobre a justificação e identidade dos royalties no direito brasileiro.

O que justifica a existência dos royalties?

Essa questão está presente em quase todos os debates atuais sobre o tema, e não encontra pacificação. A sua justificação é relevante, contudo, para determinar seus contornos, seja na quantidade de arrecadação, seja na partilha, seja ainda no gasto.

Algumas razões têm sido apresentadas sobre o assunto $^{793}$ e serão brevemente recordadas, doravante identificadas como: (i) histórica; (ii) ambiental; (iii) demográfica; e (iv) custo de oportunidade.

i. Verifique-se, de início, aquela de conotação histórica. É sustentada essencialmente pelo ex-Ministro do Supremo Tribunal Federal Nelson Jobim, que, antes de sê-lo, participou da Assembleia Constituinte. Ele sustenta que a inclusão do $§ 1 .^{\circ}$ do art. 20 na Constituição Federal de 1988 é justificada pela decisão política de cobrança de ICMS sobre petróleo (e seus derivados) e energia elétrica no Estado de destino - e não no Estado de origem $\left(\mathrm{CF}\right.$, art. $\left.155, \S 2 .^{\circ}, \mathrm{X}, b\right)$.

A adoção dessa justificação histórica conduziria a algumas consequências imediatas, sendo a primeira delas a aceitação de pronto das reivindicações dos Entes Subnacionais (especialmente dos Estados) quanto à prioridade na partilha dessas receitas. Ora, levando o raciocínio adiante, nada mais lógico do que destinar aos Estados essa receita, se ela existe para compensar uma perda de sua arrecadação.

Igualmente, em tratando de mero reparo a uma amputação havida no campo tributário, seria natural que esta compensação fosse tomada com a mesma natureza e o mesmo regime jurídico, de forma a vedar quaisquer constrangimentos na disciplina do gasto dessa verba - constrangimentos que não se fazem presentes quando o tema é o gasto da receita pública havida por meio de impostos.

Esta posição foi defendida em pelo menos duas oportunidades: quando do julgamento do MS n. 24.312; ${ }^{794}$ e no julgamento do RE n. $198.088 .{ }^{795}$

793 Algumas dessas justificações estão reunidas em: SILVA, Paulo Roberto Coimbra. Compensação Financeira pela Exploração de Recursos Minerais - CFEM: natureza jurídica e questões correlatas. São Paulo: Quartier Latin, 2010.

794 MS 24312, rel. Min. Ellen Gracie, Tribunal Pleno, j. 19.02.2003, DJ 19.12.2003. "Então, qual foi o entendimento político naquela época que deu origem a dois dispositivos na Constituição? Daí por que preciso ler o $\S 1 .^{\circ}$ do art. 20, em combinação com o inciso X do art. 155, ambos da Constituição Federal. $\mathrm{O}$ que se fez? Estabeleceu-se que o ICMS não incidiria sobre operações que se destinassem a outros 
Essa hipótese que justifica a existência dos royalties consoante seus contornos históricos é reconhecida (embora não acatada) também por José Roberto Afonso e Sérgio Wulff Gobetti, ${ }^{796}$ tendo sido levada adiante em outras oportunidades. ${ }^{797}$

Fernando Facury Scaff, em minuciosa análise das atas do processo constituinte,

chega à conclusão de que os debates demonstram claramente que ocorreu um "acordo

Estados - petróleo, inclusive lubrificantes, combustíveis líquidos, gasosos e derivados e energia elétrica -, ou seja, tirou-se da origem a incidência do ICMS. Vejam bem, toda a produção de petróleo realizada no estado do Rio de Janeiro, ou toda produção de energia elétrica, no Paraná e no Pará, eram decorrentes de investimentos da União, porque o monopólio era da União. Toda a arrecadação do país contribuiu para aquela produção. Assim, decidiu-se da seguinte forma: tira-se o ICMS da origem e se dá aos estados uma compensação financeira pela perda dessa receita".

795 RE 198088, rel. Min. Ilmar Galvão, Tribunal Pleno, j. 17.05.2000, DJ 05.09.2003. "Vejam bem o que se passou, basicamente, na questão do petróleo. O sistema tributário anterior tinha imposto específico para energia elétrica e petróleo, que eram os chamados impostos únicos de competência da União, ao qual ela teria uma distribuição entre os Estados, distribuíam parcelas de arrecadação do imposto único, que eram as do art. 21, VIII, da Constituição anterior, imposto sobre produção, importação, circulação, distribuição ou consumo de lubrificantes e combustíveis líquidos ou gasosos e de energia elétrica, e também imposto sobre minerais, aquelas alíquotas chamadas impostos únicos. O que se fez em 1988? Colocou-se, em 1988, na base do ICMS essas operações, destruiu-se os impostos únicos, desapareceu e ampliou-se a base do ICM. O ICM anterior a 1988 era restrito, excluídas todas essas mercadorias referidas, esses bens lubrificantes e petróleo, e também estavam excluídos os serviços. Em 1988, amplia-se a base do ICMS para incluir serviços não excludentes, depois, por uma questão decorrente da própria Constituição, não excludentes, depois, os serviços municipais, o imposto de serviço atribuído aos Municípios, e incluiu-se, também, todos aqueles bens que compunham a base do chamado imposto único. Aí, surge um problema, os Estados produtores de energia elétrica e de petróleo passariam, tendo em vista regras específicas do ICM, a perceber todos os ICMS nas operações interestaduais, ou seja, os Estados produtores, no caso específico, fundamentalmente Sergipe, Rio, São Paulo e Bahia, passariam a perceber integralmente todo o tributo. Resolveu-se o quê, aí? Resolveu-se estabelecer, exatamente, que para essas hipóteses, ou seja, nestas circunstâncias em que houvesse a circulação de bens, que eram bens produzidos pela União em territórios dos Estados, para o qual todos os Estados haviam contribuído. O que se estabeleceu? Estabeleceu-se o princípio puro do destino, qual seja o tributo, que poderia ser arrecadado na origem, passou a ser arrecadado integralmente no destino. [...] Como a União não poderia mais compensar a existência daquela produção nos seus Estados, criou-se um 'royalty', mencionado no art. $20, \S 1$. $^{\circ}$, da Constituição Federal de 88, ou seja, aquela compensação que se dava pela participação nos impostos únicos, foi estabelecida da seguinte forma: [...] Aquilo que era a participação dos Estados produtores, no imposto único, transformou-se em 'royalty'. Por quê? Porque a maioria dos Estados-federados brasileiros não poderiam pagar ICMS, ou seja, destinar ICMS a três Estados produtores".

796 AFONSO, José Roberto Rodrigues; GOBETTI, Sérgio Wulff. Rendas do petróleo no Brasil: alguns aspectos físcais e federativos cit., p. 231- 269, dez. 2008, p. 237. "O direito de estados e municípios 'à participação no resultado da exploração de petróleo ou gás natural' foi consagrada no corpo da própria Carta Magna de 1988 (art. 20, § 1. ${ }^{\circ}$ ). Embora conste do título que trata da Organização do Estado, essa é uma diretriz de natureza tributária (se entendida num conceito mais amplo de qualquer forma de extração compulsória de recursos pelo Poder Público), e que, nos debates constituintes, sempre esteve implicitamente vinculada à deliberação sobre a partilha da nova base do imposto estadual sobre mercadorias. Isso porque os royalties eram vistos como uma espécie de compensação aos governos das regiões produtoras de petróleo por estas não receberem uma parcela do ICMS incidente sobre as operações interestaduais com petróleo e derivados, totalmente destinada aos estados consumidores".

797 O Boletim petróleo, royalties \& região, n. 24, jun. 2009. Disponível em: <http://www. royaltiesdopetroleo.ucam-campos.br>, apresenta "uma hipótese interpretativa bastante instigante: a de que a Constituição de 1988 garantiu o benefício das participações governamentais aos estados e municípios como forma de compensar a não incidência do ICMS sobre as operações interestaduais com petróleo e gás, que traria prejuízo aos estados (e consequentemente aos seus municípios) produtores de petróleo e energia elétrica". 
político" no sentido suscitado por Nelson Jobim: de fato, o art. $20, \S 1 .{ }^{\circ}$, da CF/88, e o art. $155, \S 2 .^{\circ}, \mathrm{X}, b$, estão correlacionados no nascedouro. ${ }^{798}$

Mas a constatação (ocorrência desse acordo político) não conduz à conclusão que muitos querem: o reconhecimento de que os Estados produtores/confrontantes devem necessariamente ser privilegiados em grande escala na partilha da receita pública de royalties. Muito menos essa constatação se presta a autorizar conclusões no sentido da constitucionalidade ou inconstitucionalidade de normas infraconstititucionais que reduzam a parcela dos Estados produtores ou confrontantes nesse rateio. É dizer, mais: este acordo político não é suficiente para justificar a existência dos royalties, embora exista inegável interesse do ponto de vista da condução do processo legislativo-constituinte.

Ora, a interpretação histórica, embora se revele útil, acrescendo dados para compreensão do tema, é também manifestamente insuficiente ao processo hermenêutico ${ }^{799}$ - vale sempre lembrar a frase marcante de Aliomar Baleeiro, enquanto magistrado do Supremo Tribunal Federal: "Não me cabe, Sr. Presidente, psicanalisar os eminentes representantes da Nação" (RE 62.739, Tribunal Pleno, julgado em 23/08/1967). O conteúdo da norma não se resume à vontade do legislador - em verdade, por vezes nem sequer coincide, máxime considerando que o processo democrático não permite afirmar que determinada norma é fruto do entendimento de apenas um sujeito, por mais que seja ele o relator da proposta. Da mesma forma, a interpretação histórica não resiste ao fato de que o direito - e a hermenêutica jurídica - é dinâmico, evoluindo junto com a sociedade. Então, se em determinada época uma norma era entendida de uma forma, isto não quer

798 SCAFF, Fernando Facury. Royalties decorrentes da exploração de recursos naturais não renováveis cit., p. 203-234.

799 GRAU, Eros Roberto. Ensaio e discurso sobre a interpretação/aplicação do direito. São Paulo: Malheiros, 2002. p. 108-110-112. "Assim, a referência à 'vontade do legislador', que apenas se pode explicar como um caso de misoneísmo, perde qualquer sentido. A interpretação constitucional, no nível lingüístico, é interpretação semântica, voltada à determinação do significado das palavras e expressões contidos no texto da Constituição. Vale dizer: refere-se a 'normas reveladas por enunciados lingüísticos' - não a intenções ou vontades do texto ou do 'legislador constituinte' -, estando, como observa Canotilho, condicionada pelo contexto, na medida em que se opera em condições sociais historicamente caracterizadas, produtoras de determinados 'usos' lingüísticos, decisivamente operantes na atribuição do significado. A lei, aliás - o texto normativo, em verdade -, já foi dito, costuma ser mais inteligente do que o legislador [...] Ora, se todo texto pretende ser compreendido em cada momento e em cada situação concreta de uma maneira nova e distinta, tenho a interpretação - se não for nossa intenção predeterminada a de fraudá-la (para justificar a obtenção de uma solução que satisfaça a nossa conveniência individual) - como atividade que adapta o direito às necessidades presentes e futuras da vida social (= atualiza-o), na acepção mais ampla dessa expressão. Os textos de direito não veiculam enunciados semânticos cristalizados, congelados no tempo; esses enunciados passam por alterações decorrentes do evolver da vida social, ainda que a sua redação (do texto) não sofra modificação [...] É do presente, na vida real, que se tomam as forças que conferem vida ao direito. Assim, o significado válido dos textos é variável no tempo e no espaço, histórica e culturalmente". 
dizer que assim será dez, vinte ou cem anos depois, justamente porque o direito evolui junto com as normas sociais, sob pena se tornar-se obsoleto. Remeta-se ao debate, já acima apresentado, da interpretação constitucional como instrumento de equidade intergeracional: tomar a compreensão da norma de forma estática no momento do nascedouro é, também, uma violação dos interesses das futuras gerações.

Essas observações foram melhores desenvolvidas por Fernando Facury Scaff: trabalhando com os cânones da doutrina nacional sobre hermenêutica jurídica, identifica, nas decisões do Supremo Tribunal Federal que acataram as intervenções de Nelson Jobim, a adoção da "criticada e vetusta sistemática da mens legislatoris". ${ }^{800}$

Entende-se, pois, que o reconhecimento de que o art. $20, \S 11^{\circ}$, da Constituição Federal está ligado no nascedouro com a alteração da incidência do ICMS sobre petróleo não autoriza, em absoluto, que se possa afirmar que este trade off político justifique a existência dos royalties ou que oriente soberanamente sua partilha.

De outro lado, veja-se que a Lei n. 2.004, de 1953, já previa (art. 27) uma “indenização" de 5\% sobre o valor do óleo extraído. Esse valor seria pago diretamente aos Estados e Territórios, que deveriam partilhar 20\% com os Municípios onde ocorria a extração. Em 1957, através da Lei n. 3.257, foi alterada a redação do art. 27 da Lei n. 2.004, embora suas disposições não tenham sofrido mudanças significativas: passou-se a prever que a alíquota seria de $4 \%$ aos Estados e Territórios, e de 1\% aos Municípios, de forma com que estes pudessem cobrar diretamente, eliminando o "intermediário". O Decreto-Lei n. 523, de 1969, e depois o Decreto-Lei n. 1.288, de 1973, acresceram a possibilidade de cobrança da "indenização" na hipótese de exploração de petróleo na plataforma continental, ressalvando que nestes casos o valor seria devido ao DNPM e ao Ministério de Educação e Cultura (Decreto-Lei n. 523) e, posteriormente, ao Conselho Nacional do Petróleo, para "formação de estoques de combustíveis" (Decreto-Lei n. 1.288). Sobrevieram ainda, antes da Constituição Federal de 1988, mudanças no dispositivo trazidas pela Lei n. 7.483, de 1985.

Tudo a indicar, portanto, e de forma induvidosa, que por mais que a partilha dos royalties e a redação atual do art. $20, \S 1 .^{\circ}$, da $\mathrm{CF} / 88$, tenham relação com a mudança do ICMS sobre petróleo, esta relação definitivamente não explica ou justifica a existência dos royalties.

800 SCAFF, Fernando Facury. Royalties decorrentes da exploração de recursos naturais não renováveis cit., p. 256 . 
Note-se ainda que nas palavras do próprio ex-Ministro Jobim, a exploração daqueles recursos naturais é decorrente de investimentos realizados pela União, nos quais "todos os Estados haviam contribuído". Então, desde o primeiro momento não poderiam mesmo os Estados produtores serem detentores de todo o benefício fiscal-arrecadatório daí oriundo. A barganha política estaria, para dizer o mínimo, muito desequilibrada.

De outra banda, ignora-se o papel dos recursos minerais nesse cenário. A exploração de minérios (como o minério de ferro) também gera o pagamento de royalties, mas não está sujeita, como os derivados de petróleo e a energia elétrica oriunda dos cursos d'água, à exigência de ICMS no estado de destino. Teriam, então, uma justificação diversa? Como se afirmará adiante, a resposta deve ser negativa, na medida em que a ratio dos royalties deve ser relacionada à finitude dos bens explorados.

Recorde-se que a atual forma de cálculo dos royalties petrolíferos não leva em conta absolutamente nenhum critério que - ainda que vaga e abstratamente - se refira à arrecadação do ICMS nos Estados produtores, caso fosse estipulada a regra de cobrança na origem. Claro que não seria possível uma compensação exata. Mas a total ausência de comunicação entre as exações lhe retira qualquer similitude ou conexão. ${ }^{801}$

Não é desprezível lembrar, neste tema, que há no ordenamento jurídico uma outra "compensação por perda de arrecadação": aquela trazida pela Lei Complementar n. 87/1996, que visa reparar os Estados exportadores pelo afastamento da incidência de ICMS sobre as operações de exportação de mercadorias. Neste caso, embora seja procedente a afirmação de que os critérios de reparação deixaram de ser técnicos e foram relegados ao livre jogo de forças políticas, deve-se atentar ao fato de que, quando de sua criação, a divisão de valores foi realizada consoante cálculos técnicos que buscavam explicitamente recompor as receitas amputadas. Não é o caso dos royalties.

Em verdade, e mais ainda do que as razões já postas, essa justificativa histórica se revela inadequada não apenas pelo que sugere, mas pelo que deixa de sugerir: a relevância da não renovabilidade dos recursos naturais explorados na existência e cálculo dessa exação prevista pelo art. 20, $\S 1^{\circ}{ }^{\circ}$, da Constituição Federal.

801 Tome-se de empréstimo a aprofundada e irreprochável doutrina tributarista sobre a base de cálculo. Dentre outros, Paulo de Barros Carvalho (CARVALHO, Paulo de Barros. Curso de direito tributário. 19. ed. rev. São Paulo: Saraiva, 2007: "A grandeza haverá de ser mensuradora adequada da materialidade do evento”. p. 364) e Geraldo Ataliba (ATALIBA, Geraldo. Hipótese de incidência tributária. 6. ed. São Paulo: Malheiros, 2008. p. 111: "fica evidente a posição central da base imponível [...] pela circunstância de ser impossível que um tributo, sem se desnaturar, tenha por base imponível uma grandeza que não seja ínsita na materialidade de sua hipótese de incidência”). 
ii. Alguns autores justificam a existência e cobrança dos royalties como forma de reposição de cunho ambiental. ${ }^{802-803}$

Sustentam que o pagamento se dá como forma de recompor a profunda intervenção que essas atividades, embora lícitas, causam ao meio ambiente.

Esse posicionamento parece encontrar guarida no julgamento paradigma do Supremo Tribunal Federal sobre o tema (RE 228800). Basta lembrar que o voto condutor, do Min. Sepúlveda Pertence, acompanhado à unanimidade, indica que:

Com efeito, a exploração de recursos minerais e de potenciais de energia elétrica é atividade potencialmente geradora de um sem número de problemas para os entes públicos, especialmente para os municípios onde se situam as minas e as represas. Problemas ambientais - como a remoção da cobertura vegetal do solo, poluição, inundação de extensas áreas, comprometimento da paisagem e que tais -, sociais e econômicos, advindos do crescimento da população e da demanda por serviços públicos.

O Manual de Contabilidade aplicada ao Setor Público, igualmente, indica se tratar de compensar um dano, embora não o refira especificamente ambiental. ${ }^{804}$

$\mathrm{O}$ argumento é frequentemente utilizado para pleitear a descentralização da receita de royalties. Nada obstante, deve-se lembrar que na forma do art. 23, VI, da Constituição Federal, a todas as esferas de governo compete "proteger o meio ambiente $e$ combater a poluição em qualquer de suas formas", bem como que impõe-se ao "Poder Público e à coletividade o dever de defendê-lo e preservá-lo" (sem distinção entre Entes Federativos), na forma do art. 225, também do Texto Constitucional. Assim, não é acurada a afirmação de que o impacto é localizado ou regionalizado. Sendo preocupação comum e inespecífica, cabe a todos o dever de cuidar, prevenir e reparar os danos ambientais.

802 Camila de Morais Leite e Roberta Borella Marcuci (LEITE, Camila de Morais; MARCUCI, Roberta Borella. A CFEM como indenização ambiental. In: SILVA, Paulo Roberto Coimbra (Coord.). Compensação financeira pela exploração de recursos minerais. São Paulo: Quartier Latin, 2010. p. 114) afirmam: "se enquadra na hipótese de compensação financeira paga por aqueles que exercem atividades mineradoras, em razão dos danos causados ao meio ambiente pela prática de tal atividade".

803 PIRES, Adilson Rodrigues. Breve ensaio sobre as participações governamentais nas atividades de exploração e extração do petróleo. In: CARNEIRO, Daniel Dix; PEIXOTO, Marcelo Magalhães (Org.). Aspectos tributários relacionados à indústria do petróleo e do gás. São Paulo: Ed. MP, 2011. p. 89. "Trata-se de compensar Estados e Municípios pela perda de suas riquezas e degradação do solo".

804 BRASIL. Secretaria do Tesouro Nacional. Manual de contabilidade aplicada ao setor público. Parte I: procedimentos contábeis e orçamentários. 4. ed. Brasília: Ministério da Fazenda, 2011. Aprovado pela Portaria STN n. 406, de 20 jul. 2011. p. 22. "Elas [compensações] têm como finalidade recompor financeiramente os prejuízos ou danos causados (externalidades negativas) pela atividade econômica na exploração desses bens". 
Também esta justificação, contudo, revela-se frágil. Cabe lembrar, de início, como feito acima, que a base de cálculo dos royalties hoje existentes não leva em conta, em qualquer grau, o impacto causado no meio ambiente. ${ }^{805}$

De outro lado, também constitui um óbice a essa ideia o fato de que outras atividades econômicas tão impactantes quanto a mineração e a extração petrolífera - e por vezes até mais impactantes - não estão contempladas na cobrança dessa exação. Sugere-se, portanto, que não é este o elemento justificador da existência dos royalties.

Finalmente, quer-se considerar que a compensação por atividades lícitas porém ecologicamente invasivas tem previsão constitucional, mas não no art. $20, \S 11^{\circ}$. Trata-se do art. 225, que trata especificamente da proteção do meio ambiente. ${ }^{806}$ Essa previsão constitucional gerou a Compensação trazida pelo art. 36 da Lei n. 9.985/2000 (conhecida por Compensação SNUC), que dispõe:

Art. 36. Nos casos de licenciamento ambiental de empreendimentos de significativo impacto ambiental, assim considerado pelo órgão ambiental competente, com fundamento em estudo de impacto ambiental e respectivo relatório - EIA/RIMA, o empreendedor é obrigado a apoiar a implantação e manutenção de unidade de conservação do Grupo de Proteção Integral, de acordo com o disposto neste artigo e no regulamento desta Lei.

$\S 1 .^{\circ} \mathrm{O}$ montante de recursos a ser destinado pelo empreendedor para esta finalidade não pode ser inferior a meio por cento dos custos totais previstos para a implantação do empreendimento, sendo o percentual fixado pelo órgão ambiental licenciador, de acordo com o grau de impacto ambiental causado pelo empreendimento.

$\S 2 .^{\circ}$ Ao órgão ambiental licenciador compete definir as unidades de conservação a serem beneficiadas, considerando as propostas apresentadas no EIA/RIMA e ouvido o empreendedor, podendo inclusive ser contemplada a criação de novas unidades de conservação.

$\S 3 .^{\circ}$ Quando o empreendimento afetar unidade de conservação específica ou sua zona de amortecimento, o licenciamento a que se refere o caput deste artigo só poderá ser concedido mediante autorização do órgão responsável por sua administração, e a unidade afetada, mesmo que não pertencente ao Grupo de Proteção Integral, deverá ser uma das beneficiárias da compensação definida neste artigo.

805 Renata Silveira, tratando da CFEM, afirma: "O mais importante para se determinar a natureza jurídica desses instituto foi a determinação legal de que o valor a ser pago a título de compensação financeira deve ser calculado em função do faturamento, uma vez que a denominada base de cálculo da CFEM não possui qualquer relação com as perdas ambientais a que alude implicitamente o constituinte". SILVEIRA, Renata Marques da. Aspectos jurídicos da compensação financeira pela exploração de recursos minerais - CFEM. 2010. Dissertação (Mestrado) - Pontifícia Universidade Católica de São Paulo, 2010. p. 139.

806 É especialmente relevante o conteúdo do $\S 2 .^{\circ}$ do art. 225: $\$ 2 .^{\circ}-$ Aquele que explorar recursos minerais fica obrigado a recuperar o meio ambiente degradado, de acordo com solução técnica exigida pelo órgão público competente, na forma da lei. 
Esta, sim, é exação fundada na reparação à intervenção ambiental, e que leva em consideração, na fixação do quantum debeatur, os males trazidos à esfera ecológica, tecnicamente identificados através do EIA/RIMA.

Convém recordar que a norma foi objeto de contestação perante o Supremo Tribunal Federal em Ação Direta de Inconstitucionalidade (n. 3.378/DF). Aquela Corte considerou constitucional a cobrança, afirmando que "não é uma indenização, é um compartilhamento de despesas" 807 e que "é uma verba de natureza compensatória porque visa preservar o meio ambiente e eventual empreendimento que possa causar significativo impacto ambiental". ${ }^{808}$ Determinou, contudo, a supressão, no $\S 1 .^{\circ}$ do art. 36 , do percentual mínimo de compensação, de forma a remeter o valor diretamente aos impactos encontrados nos estudos técnicos.

Em verdade, merece ser lembrado que o meio ambiente não pode ou deve ser considerado divisível em unidades municipais ou estaduais (talvez nem mesmo federais) autônomas, tudo levando a crer que o prejuízo em determinado lugar afeta a todos. ${ }^{809}$ Daí por que não caberia ao Ente onde ocorre a lavra, mesmo se aceita esta justificação aos royalties, arrogar-se no direito ao recebimento de parcela dos royalties. ${ }^{810}$

Quer-se demonstrar, contudo, que a justificação de caráter ambiental dos royalties encontra empecilhos até mesmo na coexistência de exação de caráter idêntico.

Lembre-se, também, que o pagamento da referida Compensação Ambiental (SNUC) não confere a qualquer particular o direito de poluir. Trata-se de compensar pelo impacto da atividade lícita. Para além do pagamento, o particular seguirá sujeito ao cumprimento de toda a legislação ambiental (como a obtenção do Licenciamento), inclusive recolhendo a Taxa de Controle e Fiscalização Ambiental (TCFA - Lei n. 6.938/1981, art. 17-B).

807 Trecho da manifestação do Min. Ayres Britto durante a sessão.

808 Voto do Min. Menezes Direito.

809 FENSTERSEIFER, Tiago. Direitos fundamentais e proteção do ambiente cit., p. 107. "Na medida em que a proteção do ambiente é colocada na estrutura constitucional do Estado brasileiro como dever de proteção estatal, e também como direito fundamental da pessoa humana, há que se remodelar a estrutura do Estado no intuito de traçar, de forma 'transversal' e cooperativa, a atuação de todos os entes políticos, entes estatais, órgãos administrativos, instituições jurídicas (Ministério Público e Defensoria Pública), etc., a fim de perseguir e atingir tal objetivo".

810 Ainda: CRUZ, Bruno de Oliveira; RIBEIRO, Márcio Bruno. Sobre maldições e bençãos cit., p. 36, jul. 2009: "Não há qualquer sentido econômico de vincular um percentual da receita da produção como forma de compensação pelo dano ambiental". 
Finalmente, também é dever do particular explorador a recuperação da área degradada - conforme dispõe a Lei n. 6.938/81, art. 2. ${ }^{\circ}$, VIII, regulamentado pelo Decreto n. 97.632/1989. O Plano de Recuperação (PRADE) será submetido ao órgão ambiental juntamente com o EIA/RIMA. “A recuperação deverá ter por objetivo o retorno do sítio degradado a uma forma de utilização, de acordo com um plano preestabelecido para o uso do solo, visando a obtenção de uma estabilidade do meio ambiente" (art. 3. ${ }^{\circ}$ ).

Assim, também a variante da justificação ambiental - que dá ênfase na degradação posterior ao final da exploração - se vê prejudicada. ${ }^{811}$

iii. Há, ainda, os que entendem que os royalties se justificam para fazer frente ao crescimento da demanda por serviços públicos nos locais de exploração, em razão dos altos níveis de migração - o que acima se chamou de justificação demográfica. ${ }^{812}$

Também esta noção parece encontrar guarida no julgado paradigma do STF, RE 228.800, que afirma que os royalties deveriam funcionar como resposta a problemas "sociais e econômicos, advindos do crescimento da população e da demanda por serviços públicos".

Mais uma vez, contudo, há razões que sugerem descartar essa relação. Repetese nesse ponto a referida ausência de relação entre a base de cálculo da exação e qualquer medida de transformação no tamanho da população ou na pressão local pela prestação de serviços públicos.

Igualmente, a observação de que outras atividades podem causar o mesmo movimento migratório sem que exista qualquer instrumento determinando o pagamento pelo aumento populacional conduz ao descarte da ideia. Em verdade, é de bom alvitre lembrar que, naquilo que se convencionou chamar de Guerra Fiscal, Estados da Federação batalharam ferozmente pela presença de grandes empresas em seus territórios (destacam-se as montadoras de automóveis) sem que, nessas ocasiões, o aumento populacional tenha sido um óbice. Em verdade, a competição se deu (e dá) mesmo que o custo para tanto seja a renúncia de receita tributária (ainda que manifestamente transgredindo a Constituição

811 "Essas receitas públicas [...] não têm natureza jurídica indenizatória" (RUBINSTEIN, Flávio. Receitas públicas de recursos naturais no direito financeiro brasileiro cit., p. 195).

812 Dentre outros, Ricardo Lobo Torres (TORRES, Ricardo Lobo. Curso de direito financeiro e tributário cit., p. 191): "natureza de preços públicos pela utilização de recursos naturais situados em seus territórios, justificando-se como contraprestação pelas despesas que as empresas exploradoras de recursos naturais causam aos poderes públicos, que se vêem na contingência de garantir a infraestrutura de bens e serviços e a assistência às populações envolvidas em atividades econômicas de grande porte". 
Federal e a Lei de Responsabilidade Fiscal). ${ }^{813}$ Note-se, especificamente, que já se vê, em relação à exploração petrolífera do pré-sal, por iniciar, uma corrida por atração de investimentos, utilizando explicitamente reduções tributárias para tanto, ${ }^{814}$ apesar de permeada pela relativa rigidez locacional dos empreendimentos.

Convém consignar, ademais, que se a atividade extrativista é sucedida de migração extensiva de pessoas àquela região, o ordenamento jurídico brasileiro já possui instrumentos a fazer frente a esta modificação demográfica: destaca-se, nesse sentido, a competência tributária própria. ${ }^{815}$ Mais pessoas demandam mais serviços públicos - isto é correto. Contudo, mais pessoas consomem mais mercadorias - trazendo acréscimos na arrecadação de ICMS (e trazendo incremento ao VAF); prestam e consomem mais serviços - majorando a arrecadação de ISS; utilizam mais imóveis urbanos - aumentando o recolhimento de IPTU; ${ }^{816-817}$ utilizam mais veículos - aumentando a arrecadação de IPVA; mais pessoas significa maior quinhão no Fundo de Participação dos Municípios. ${ }^{818}$

813 Disponível em: <http://www1.folha.uol.com.br/poder/949701-estados-driblam-supremo-para-manterincentivos-fiscais.shtml>. Acesso em: 13 jul. 2012.

814 VALOR ECONÔMICO. Em SP, cidades se preparam para disputar cadeia do pré-sal. 02 de dezembro de 2013. p. A3. Consta: "Cidades do litoral paulista se articulam para disputar bases de apoio logístico às plataforms do pré-sal na Bacia de Santos". Embora a reportagem pontue que "ninguém admite abertamente a intenção de conceder benefícios fiscais para atrair unidades que alimentarão de insumos e pessoas às operações offshore", observa que "a cidade de Santos, onde a Petrobrás está construindo a nova sede administrativa da Bacia de Santos, trabalha para atrair toda uma cadeia de fornecedores. A Câmara Municipal aprovou, recentemente, um projeto de lei que estabelece incentivos fiscais às empresas voltadas à inovação que se instalarem no parque tecnológico do município, ao lado do futuro Centro de Pesquisa Tecnológica em Petróleo e Gás da Baixada Santista. A empresa será isenta de IPTU, ISS, ITBI, taxa de licença e taxa de aprovação nos primeiro cinco anos".

815 "Não faz sentido compensar estados e municípios pela necessidade de aumentar a oferta de serviços públicos para fazer frente à maior demanda provocada pelo aumento da população, que, por sua vez, decorreria da atração de migrantes provocada pela indústria petrolífera. Não há evidências de que a população dos municípios que recebem mais royalties e participações especiais cresça mais rapidamente que a dos demais municípios. E, mesmo que ocorra o aumento da população, a atividade de extração, ao aumentar a circulação de renda no município, permite um aumento da arrecadação" (FREITAS, Paulo Springer de. Rendas do petróleo... cit., p. 50).

816 Estudos recentes demonstram que há grande potencial tributário inexplorado na arrecadação do IPTU. Nesse sentido: AFONSO, José Roberto Rodrigues; ARAÚJO, Erika Amorim; NÓBREGA, Marcos Antonio Rios da. O Imposto Predial e Territorial Urbano (IPTU) no Brasil: um diagnóstico sobre o grau de aproveitamento do imposto como fonte de financiamento local. Final paper. Lincoln Institute of Land Policy, fev. 2010, p. 33. "Foi demonstrado que o IPTU não representa uma importante fonte de recursos tributários próprios para a maioria das prefeituras brasileiras. Embora a média de arrecadação nacional tenha alcançado US\$ 46,5 per capita, mais da metade dos municípios do país recolheu menos de US\$ 5 por habitante e, em um número considerável de cidades, a receita do imposto não chegou a US\$ 0,50 per capita. Um quadro de tamanha assimetria, por si só, sugere a existência de um enorme potencial tributário não explorado".

817 Os problemas e dificuldades na arrecadação do IPTU podem ser estudados em: INSTITUTO DE PESQUISA ECONÔMICA APLICADA. Política fiscal e justiça social no Brasil: o caso do IPTU. Brasília: IPEA, 2009. Comunicado da Presidência n. 28.

818 FREITAS, Paulo Springer de. Rendas do petróleo... cit., p. 22-23 e 29: "uma das principais justificativas para transferir royalties para os municípios produtores é o crescimento populacional, e o conseqüente aumento na demanda por serviços públicos, provocado pela indústria petroleira. Esse argumento torna-se 
Por isso, Bercovici aponta que a renda dos royalties não deve "servir para prover recursos aos governos atingidos para atender a demandas novas ou extraordinárias por serviços públicos", especialmente eis que a instalação da indústria extrativa "já contribui para aumentar consideravelmente a arrecadação de impostos municipais e estaduais". ${ }^{819}$ Vale lembrar a observação de Boadway e Shah, referindo o Estado-membro fictício de Petrolia, numa Federação em que o ente central é proprietário dos recursos naturais: "mesmo sem que as receitas dos recursos naturais sejam direcionadas a Petrolia, o impacto econômico do boom de petróleo e gás gerará significativas diferenças em capacidade fiscal entre esta e outras regiões". ${ }^{820}$ Daí que "o sistema de transferências fiscais tenderá a mitigar essas diferenças". ${ }^{821}$

Considere-se, mais, que uma vez que a economia local gira em torno da empresa mineradora ou petrolífera, os gastos com o aparelhamento do órgão de arrecadação restam deveras reduzidos, eis que há a possibilidade de, através de mecanismos de substituição tributária, concentrar a fiscalização naquela empresa extrativista, inclusive penalizando-a por eventual falha na retenção de tributos daqueles que lhes prestam serviços.

É conveniente lembrar ainda das observações - referidas em outro espaço neste trabalho - sobre o fenômeno, globalmente identificado, do pior desempenho arrecadatório dos Entes Políticos receptores da receita de royalties. ${ }^{822}$ Elas tendem a confirmar que não há déficit de capacidade de arrecadação própria, mas má gestão dos recursos e competências já alocadas.

A análise do tema sob uma perspectiva da repartição constitucional de competências tributárias leva a concluir que o sistema brasileiro está apto a enfrentar

mais frágil se a geração de renda proporcionada pela indústria do petróleo levar a um aumento da arrecadação tributária do município, o que viabilizaria o atendimento da maior demanda por serviços públicos [...] indiretamente, a atividade de extração, ao aumentar a circulação de renda no município, permite um aumento da arrecadação. Isso porque os salários e as encomendas locais da indústria petrolífera estimulam o comércio, contribuindo para maior pagamento de ICMS em atividades nãopetrolíferas, e aumentam a procura por serviços, imóveis e veículos, gerando maior arrecadação de ISS, IPTU e IPVA”. Também: Sobre o assunto: Boletim petróleo, royalties \& região, n. 26, dez. 2009. Disponível em: 〈http://www.royaltiesdopetroleo.ucam-campos.br/>.

819 BERCOVICI, Gilberto. Direito econômico do petróleo e dos recursos minerais cit., p. 338.

820 BOADWAY, Robin; SHAH, Anwar. Fiscal federalism cit., p. 225. Tradução livre.

821 Idem, ibidem, p. 227. Prosseguem os autores: "In context of a major oil and gas boom in Petrolia, fiscal competition likely favors Petrolia with its much higher fiscal capacity, and the competition can take various forms".

822 Nesse sentido: AHMAD, Ehtisham; MOTTU, Eric. Oil revenue assignments: country experiences and issues. In: DAVIS, J.; OSSOWSKI, R.; FEDELINO, A. (Org.). Fiscal policy formulation and implementation in oil-producing countries cit., p. 217. 
elevações demográficas - e as consequentes alterações na pressão por serviços públicos -, através do correspondente aumento das arrecadações própria e transferida.

Então, é de se rejeitar também a justificação demográfica.

iv. A quarta e última justificação para a existência dos royalties diz respeito à ideia de custo de oportunidade - conceito emprestado da teoria econômica. Bruno Salama assim explica o conceito de custo de oportunidade:

A escassez força os indivíduos a realizarem escolhas e a incorrerem em trade-offs. Os trade-offs são, na verdade, são "sacrifícios": para se ter qualquer coisa é preciso abrir mão de alguma outra coisa - nem que seja somente o tempo. Esse algo de que se abre mão é o chamado 'custo de oportunidade'. Todas as escolhas têm custos de oportunidade. Isso quer dizer que nem tudo pode ser feito ou produzido; tudo tem um custo; e cada centavo gasto em uma determinada atividade, é o mesmo centavo que não é gasto em todas as demais. ${ }^{823-824}$

Nessa perspectiva, os royalties representam a troca (trade-off) realizada pelo

Estado, onde abre mão dos recursos naturais, inviabilizando seu uso futuro, e ganha, por outro lado, valores em moeda.

Que não se confunda a ideia de custo de oportunidade com uma simples troca isto é, alienação, venda e compra (embora o negócio jurídico possa ser instrumentalizado desta forma, valendo considerar que as regras contratuais aplicáveis já são estranhas às presentes razões). A noção de custo de oportunidade ora enfatizada é acentuada pela condição intrínseca de finitude do bem; de patrimônio que, uma vez explorado, não estará mais disponível. Afinal, vale lembrar que a realização de receita de royalties é

823 SALAMA, Bruno. O que é direito e economia?. In: TIMM, Luciano Benetti. Direito e economia. 2. ed. Porto Alegre: Livraria do Advogado, 2008. p. 12-13. Para Adriano Cançado Trindade, custo de oportunidade "diz respeito à exploração de um bem que não mais poderá ser explorado no futuro. Em outras palavras, so se explorar um recurso não-renovável, estar-se-ia suprimindo essa possibilidade de exploração das gerações futuras. Daí a função do royalty de compensar Estados por recursos que foram usados, em vez de serem guardados par o futuro". O autor, contudo, não se posiciona para afirmar qual, em sua concepção, é o fundamento para cobrança desses valores (TRINDADE, Adriano Drummond Cançado. Royalties na mineração no direito comparado. In: SOUZA, Marcelo Mendo Gomes de (Coord.). A compensação financeira pela exploração dos recursos minerais - CFEM. Belo Horizonte: Del Rey, 2011. p. 72).

824 COOTER, Robert D.; ULEN, Thomas. Law and economics. 5. ed. Boston: Addison Wesley, 2007. "This term refers to the economic cost of an alternative that has been foregone. When you decided to attend a college, graduate school, or law school, you gave up certain other valuable alternatives, such as taking a job, training for the Olympics, or traveling around the world on a tramp steamer. In reckoning the cost of going to college, graduate school, or law school, the true economic cost was that of the next best alternative. This point is true of the decisions of all economic actors: when maximizing utility, the consumer must consider the opportunities given up by choosing one bundle of consumer goods rather than another; when maximizing profits, the firm must consider the opportunities foregone by committing its resources to the production of widgets rather than to something else. In general, the economic notion of opportunity cost is more expansive than the more common notion of accounting cost". 
assemelhada a "aumentar a renda familiar pela venda da prataria da família", ${ }^{825}$ e que "o consumo do capital nacional é economicamente condenável". 826

A aplicação do custo de oportunidade, aplicada aos recursos naturais não renováveis, é enfatizada por Harold Hotteling, em seu conceito de "custo de uso". Ela torna relevante o elemento temporal (que está no cerne quando se tratam de recursos não renováveis) na economia da exploração. Nesse sentido, portanto, os royalties representam "uma compensação ao proprietário pela redução do valor de sua jazida, em decorrência da extração, que torna o recurso indisponível no futuro". ${ }^{827-828}$ Reitere-se: esse modelo de justificação é direcionado especificamente aos recursos naturais não renováveis: é a sua natureza finita que explica a cobrança da exação.

Uma vez explorado o recurso mineral, o Estado não mais terá o domínio/propriedade desse bem; tampouco as gerações futuras terão o bem como parte do patrimônio público. ${ }^{829}$ Então, "qualquer geração que consuma esses recursos incorre em dívida perante as futuras gerações". 830

Assim é que Maria Amélia Enríquez acrescenta: "toda vez que um recurso é explotado, ele está sujeito a um custo de oportunidade, em vez de ser poupado para o futuro". ${ }^{831}$ A mesma Autora discorre ainda sobre o "uso da renda mineral enquanto um instrumento capaz de fazer a ligação entre a atual geração que terá os seus recursos minerais exauridos e as gerações futuras que poderão contar com outras possibilidades que compensem o esgotamento do mineral". ${ }^{832}$ É também como prevê Tilton, para quem "os recursos são intrinsecamente valiosos porque são não renováveis. Como resultado, um

825 HEAL, Geoffrey. Are oil producers rich?. In: HUMPHREYS, Macartan; SACHS, Jeffrey D.; STIGLITZ, Joseph E. (Org.). Escaping the resource curse cit., p. 170.

826 FURTADO, Celso. Desenvolvimento e subdesenvolvimento cit., p. 94-95, nota de rodapé n. 07.

827 POSTALI, Fernando Antonio Slaibe. Renda mineral, divisão de riscos e benefícios governamentais na exploração de petróleo no Brasil cit., p. 20.

828 Afirmam Postali e Nishijima: "a extração de um recurso não renovável hoje acarreta um custo de oportunidade de extraí-lo em algum momento futuro" (POSTALI, Fernando Antonio Slaibe; NISHIJIMA, Marislei. Distribuição das rendas do petróleo e indicadores de desenvolvimento municipal no Brasil nos anos 2000. Estudos econômicos, 2011, v. 41, n. 2, ISSN 0101-4161. Disponível em: <http://dx.doi.org/10.1590/S0101-41612011000200010〉. Acesso em: 1. ${ }^{\circ}$ dez. 2013).

829 Afirma Rubinstein: "se parte destas receotas não forem poupadas ou alocadas à geração de outras formas de capital, reduzir-se-á o patrimônio das futuras gerações". RUBINSTEIN, Flávio. Receitas públicas de recursos naturais no direito financeiro brasileiro cit., p. 207.

830 AUERBACH, Bruce E. Unto the thousandth generation cit., p. 181.

831 ENRÍQUEZ. Maria Amélia. Mineração... cit., p. 314.

832 Idem, ibidem, p. 311. 
custo de oportunidade, ou o que os economistas chamam de custo de uso, é incorrido quando esses recursos são explorados agora, em vez de poupados para o futuro". ${ }^{833}$

É esta renda, decorrente da deterioração patrimonial, em detrimento das gerações futuras, então, que justifica a existência e cobrança de royalties pelo Estado. ${ }^{834-835}$ Afinal, "os Estados devem ser compensados pela extração dessa sua propriedade e também pelos custos de oportunidade associados com o consumo do recurso hoje em vez de em algum momento no futuro". ${ }^{836}$

Quando cobra CFEM ou royalties petrolíferos, o Estado busca ser compensado por abrir mão de algo - a exploração futura desses bens. Essa justificação para existência e exigência dos royalties destaca também a diferença estrutural entre os recursos naturais não renováveis e os demais recursos naturais. É dizer: apenas em relação aos não renováveis é que se está inviabilizando a sua utilização futura. Portanto, é apenas em relação a eles que se exigem royalties, na conformação referida. ${ }^{837}$

E, mais, essa justificação é compatível com o conceito de royalty ora utilizado, ${ }^{838}$ bem como com a definição de James Otto e outros, para quem royalties são "pagamento ao proprietário dos recursos minerais em retorno pela remoção dos minérios da terra". ${ }^{839}$ É compatível ainda com a afirmação de Gilberto Bercovici, para quem "a

833 TILTON, John. Determining the optimal tax on mining. Natural Resources Forum, v. 28, 2004, p. 144. Tradução livre.

834 "O entendimento econômico acerca dessa renda seria de que ela deve ser, necessariamente, capturada pelo Estado, isso sob pena da atividade de exploração dos recursos naturais se tornar um prejuízo e não um benefício para a sociedade. A captura dessa renda de Hotelling no sistema brasileiro ocorre por meio das participações governamentais, previstas pela Lei do Petróleo, art. 46 e seguintes, sendo elas: os bônus de assinatura, os royalties, as participações especiais e o pagamento pela ocupação ou retenção da área”. SANTOS, Edmilson Moutinho dos; LOSS, Giovani R. Resource curse thesis e a regulação das participações governamentais do petróleo e gás no Brasil cit. Como já mencionado, contudo, discorda-se dos autores citados em relação à natureza jurídica do bônus de assinatura e do pagamento pela ocupação ou retenção de área - que, a nosso ver, são receitas de cunho administrativo, e não royalties.

835 Afirma Carlos Augusto Góes Pacheco: "a justificativa para o pagamento dos royalties reside no fato de que estes pagamentos decorrem da extração de um recurso natural não-renovável, onde há embutido, um custo de oportunidade”. PACHECO, Carlos Augusto Góes. Avaliação de critérios de distribuição e de utilização de recursos das participações governamentais no Brasil cit., p. 77. Ainda: "o custo de oportunidade específico da exploração dos recursos minerais que expressa a renda de Hotelling se iguala aos royalties pagos aos proprietários das jazidas minerais". SERRA, Rodrigo Valente. Contribuições para o debate acerca da repartição dos royalties petrolíferos no Brasil cit., p. 57.

836 INTERNATIONAL COUNCIL ON MINING \& METALS. Minerals taxation regimes: a review of issues and challenges in their design and application. London: ICMM, 2009. p. 20-21. Tradução livre.

837 Cabe repisar aqui o corte metodológico já referido acima quanto à CFURH: não se vislumbra nessa hipótese a característica da finitude; daí por que não está incluída nessa análise.

838 Por royalty, entenda-se o "preço público pago ao proprietário do recurso natural não renovável que for extraído, inserido ou consumido por processo produtivo", conforme ensina Fernando Scaff (SCAFF, Fernando Facury. Royalties decorrentes da exploração de recursos naturais não renováveis cit., p. 137).

839 OTTO, James; ANDREWS, Craig; CAWOOD, Fred; DOGGETT, Michael; GUJ, Pietro; STERMOLE, Frank; STERMOLE, John; TILTON, John. Mining royalties cit., p. 41-42. 
renda minerária, ou royalty, é uma compensação ou retribuição paga pelo uso de um direito, no caso, a exploração de um recurso natural exaurível". ${ }^{840}$ Essa compatibilidade se dá porque a justificação ora sugerida apenas especifica o escopo no qual esse pagamento é exigido, de resto observando seus critérios básicos. Assim como na hipótese ora sustentada, os autores citados tratam dos royalties afastando-os do conceito de venda/alienação do bem mineral ou da jazida ${ }^{841}$ Fernando Facury Scaff, posicionando a cobrança dos royalties na história, ainda, destaca a posição deste instrumento como a "própria afirmação da soberania" ${ }^{842}$ - o que, mutatis mutandis, ainda pode ser aplicado na atualidade, já que através da exigência de royalties, o Estado deixa clara sua posição de proprietário desses bens, soberano conforme sua legislação interna e consoante a legislação internacional, e que por isso deve ser compensado - assim como suas gerações pósteras pela exploração e especialmente por abrir mão do recurso finito.

Acreditamos que esta justificação é adequada e deve ser observada, inclusive nos efeitos diretos e indiretos decorrentes desse ângulo de análise. Defendemos que é esta a justificação que dá origem à cobrança de royalties. A exigência não se escora em quaisquer preceitos ambientais, sociais ou tributários.

Cabe referir que, utilizados os mesmos filtros referidos acima (para refutar as demais justificações), a ideia de custo de oportunidade não encontra a mesma resposta negativa. Assim, observa-se que: (i) a base de cálculo dos royalties minerais e petrolíferos é formada por grandezas tendentes (ou ao menos próximas) a medir o valor do recurso extraído - sendo adequada à noção de pagamento pela perda do patrimônio; (ii) o ordenamento jurídico brasileiro não possui qualquer outro instrumento que cumpra a mesma função - de compensar ou repor o patrimônio público (recursos naturais não renováveis) exaurido; (iii) não se vislumbram - como nas noções ambiental e demográfica, acima debatidas - outras atividades de mesma natureza (e neste item a característica marcante é a não renovabilidade do recurso natural) que não obedeçam ao pagamento dos royalties.

De outra banda, é de se ressaltar que a justificação ora sustentada está de acordo, também, com as classificações de receita pública expostas pela doutrina do direito

840 BERCOVICI, Gilberto. Direito econômico do petróleo e dos recursos minerais cit., p. 328.

${ }^{841}$ SCAFF, Fernando Facury. Royalties decorrentes da exploração de recursos naturais não renováveis cit., p. 134; OTTO, James; ANDREWS, Craig; CAWOOD, Fred; DOGGETT, Michael; GUJ, Pietro; STERMOLE, Frank; STERMOLE, John; TILTON, John. Mining royalties cit., p. 16.

842 SCAFF, Fernando Facury. Royalties decorrentes da exploração de recursos naturais não renováveis cit., p. 132. 
financeiro e trazidas pela Lei n. 4.320 - o que se observará melhor em item adiante: é receita originária, na classificação segundo a origem, porque decorre da exploração do patrimônio público; e é receita de capital, na classificação econômica da Lei n. 4.320, porque decorre da conversão, em espécie, de bens e direitos integrados ao patrimônio público.

O que se defende, pois, é que essa justificação é notoriamente mais adequada, na medida em que vincula os royalties decorrentes da exploração dos recursos naturais não renováveis com aquilo que efetivamente os distingue de outros bens, que é o seu caráter finito. Em verdade, tem-se que esta opção é consentânea com a evolução do tratamento concedido aos recursos minerais no Brasil.

Clèmerson Clève e Alessandra Martins, por exemplo, explicam que "o monopólio do petróleo constitucionalmente tutelado e de titularidade da União tem uma razão de ser muito clara, ligada à essencialidade e à finitude deste bem". ${ }^{843}$ Ousamos acrescer que também a regra que impõe o pagamento de royalties pelo particular tem a mesma razão de ser.

Finalmente, lembre-se que a justificação ora defendida segue também as razões expostas quanto ao domínio dos recursos naturais não renováveis: por direta determinação do texto constitucional, estes são bens da União.

Portanto, não se há de falar, como diversos doutrinadores e dentre eles Nelson Ribeiro, que "foi atribuída uma compensação aos Estados e Municípios pela perda de seus recursos naturais não renováveis", 844

Ora, a afirmação reputa-se equivocada na medida em que os recursos não são "seus" (dos Estados e Municípios). Tratando-se de bens da União, é esta a pessoa política compensada através dos royalties. É pela exploração do patrimônio da União que arca-se com o custo de oportunidade. "Os bens são todos da União, não cabendo, pois, qualquer espécie de indenização aos Estados, Distrito Federal ou Municípios". ${ }^{845}$

843 CLÈVE, Clèmerson Merlin; MARTINS, Alessandra Ferreira. Princípios constitucionais da atividade econômica petrolífera e Lei n. 9.478 de 1997. A \& C-Revista de Direito Administrativo $e$ Constitucional, n. 18, Belo Horizonte: Fórum, out.-dez. 2004, p. 50.

844 RIBEIRO, Nelson de F. As macroperspectivas do direito minerário a partir da nova Constituição cit., p. 73.

845 TORRES, Heleno Taveira. A compensação financeira devida pela utilização de recursos hídricos, exploração de recursos minerais ou produção de petróleo, xisto betuminoso e gás natural (art. 20, $\S 1$. $^{\circ}$, CF) - sua natureza jurídica. In: ROCHA, Valdir de Oliveira (Coord.). Grandes questões atuais do direito tributário. São Paulo: Dialética, 1998. p. 135. 
A receita é originária da União - e transferida aos demais Entes. O que se dá com a verba, após sua entrada nos cofres públicos (através da União), ainda que por disciplina constitucional ou legal, é exógeno a essas conclusões inarredáveis.

A justificação da existência e da cobrança dos royalties no ordenamento jurídico, ora defendida, vale dizer, é consentânea com as noções teóricas apresentadas nos capítulos anteriores.

É dizer: defende-se que a exploração, e a percepção das receitas públicas dela oriundas, deve necessariamente observar os efeitos deletérios ocorridos em situações análogas mundo afora para, compreendendo suas razões, evitar sua ocorrência no plano interno. Quando se entende os royalties como justificados pela necessidade de remunerar o custo de oportunidade da exploração atual do patrimônio público, em detrimento da exploração futura, relevam-se as propriedades intrínsecas dessa atividade: a finitude dos recursos explorados; e sua condição de patrimônio público, ativo estatal diretamente ligado à soberania nacional.

Destacando esses elementos, foge-se à noção dos royalties como mais uma receita pública, à disposição do gestor público para o consumo, tal e qual qualquer outra receita, especialmente a de impostos (necessariamente desvinculada, salvo disposições constitucionais).

Ao evitar considerar a receita de royalties como "mais uma à disposição", evitam-se também alguns efeitos deletérios da exploração, como a redução da arrecadação tributária própria, o comportamento rentista e mesmo a doença holandesa: compreendendo-se a natureza especial dos royalties, sua necessária ligação com o patrimônio do Estado, espera-se que seja abandonada a ideia de substitutibilidade entre uma (royalties) e outra (impostos) receitas públicas, então evitando a queda da arrecadação da última; espera-se que seja tomada consciência da insustentabilidade no longo prazo de se escorar nessa atividade exploradora, então condenando o comportamento rentista; e espera-se que sejam tomadas medidas de proteção e estímulo dos demais setores econômicos, então mitigando a doença holandesa.

Igualmente, a justificação dos royalties na forma proposta tem também a influência da equidade intergeracional, já que impõe no centro da ratio da exigência (e posteriormente, na ratio do gasto) o necessário elemento temporal, observando os interesses das gerações futuras. 
3.d. Royalties e federalismo fiscal. Notas sobre a partilha espacial e sobre uma orientação temporal à partilha espacial.

Como bem ressalta Fernando Facury Scaff, as receitas patrimoniais decorrentes da exploração dos recursos naturais não renováveis podem ser rateadas, dentro do país que as arrecada, no plano espacial - verticalmente, entre os níveis de governo da Federação, e horizontalmente, entre os diferentes Entes federados de mesmo nível - e, também, no plano temporal, "de modo de que uma geração obtenha e transfira às pósteras situações de bem estar superiores à que recebeu". 846

Já deve ter ficado evidente, a esta altura, que ocupamo-nos mais diretamente do rateio temporal, entre gerações, do que do rateio especial. Mas há de se reconhecer que, especialmente nos últimos anos no Brasil, é o critério espacial que tem prevalescido nos debates, especialmente através da teoria do Federalismo Fiscal. Vale aqui a objeção de Scaff de que o rateio temporal "não está contido na tradicional conceituação de federalismo fiscal". 847

Nada obstante, importa-nos por ora apresentar o debate de tão relevante e discutida questão - a partilha espacial, federativa - e, especialmente, buscar os pontos de cruzamento entre uma e outra espécie de rateio. É dizer: quer-se verificar o quê (se algo) a ideia de equidade intergeracional recomenda para a partilha federativa. As lições das armadilhas da exploração devem também ser utilizadas nessa investigação.

\section{3.d.i. Sobre a teoria do federalismo fiscal.}

A ideia de federação diz respeito à estruturação do Estado. ${ }^{848}$ Divide-se o poder estatal entre um ente central e outros entes subnacionais menores, que podem ser de dois níveis, como ocorre no Brasil: regional (Estados) e local (Municípios). Ao Estado Federal

${ }^{846}$ SCAFF, Fernando Facury. Royalties decorrentes da exploração de recursos naturais não renováveis cit., p. 376-381.

847 Idem, ibidem, p. 381.

848 "O respeito ao princípio federativo deve condicionar a legislação, as iniciativas e ações dos governos e também as decisões judiciais. Uma vez acolhido o federalismo pela Constituição todo ato com implicações jurídicas que for antifederativo será, por isso mesmo, inconstitucional. Não cabe, no momento da aplicação das normas e enquanto for essa a determinação constitucional, argumentar com eventuais inconvenientes do federalismo ou alegar que poderá ser mais vantajoso agir como se a Constituição não consagrasse o Estado Federal [...] obedecer a Constituição, no Brasil, significa, entre outras coisas, respeitar o princípio federativo e as normas constitucionais e legais que a ele se ligam ou dele decorrem" (DALLARI, Dalmo de Abreu. Implicações do pacto federativo. In: RAMOS, Dircêo Torrecillas (Coord.). O federalista atual: teoria do federalismo. Belo Horizonte: Arraes Editores, 2013. p. 590). 
se contrapõe o Estado Unitário, que é aquele em que um único ente governa. ${ }^{849-850}$ Neste caso, mesmo que haja a subdivisão em províncias, departamentos, ou similares, é o governo central que dá as cartas, tomando as decisões, exarando as ordens. ${ }^{851}$

A Teoria do Estado se ocupa de dizer dos pressupostos dessa descentralização do poder, suas vantagens e desvantagens, ${ }^{852}$ sua conveniência ou não. Por ora, cabe observar as lições de Baracho, para quem o processo de descentralização é relevante, importando numa atuação governamental mais eficiente. ${ }^{853}$ Baracho, citando doutrina estrangeira, apresenta o Federalismo como fórmula obrigatória de organizar a heterogeneidade das comunidades de base ${ }^{854-855}$ A atenção a essa heterogeneidade é

849 Convém observar o que pontuam Fernando Facury Scaff e Francisco Sérgio Rocha: "Embora o Federalismo seja considerado pelo Direito Constitucional como uma forma de Estado oposta ao Estado Unitário, constata-se que é muito mais um sistema de partilha de poder e de organização, independente do rótulo que se lhe aplica de 'federal'. Existem muitos Estados Unitários nos quais a descentralização é mais acentuada que em outros declaradamente Federativos" (SCAFF, Fernando Facury; ROCHA, Francisco Sérgio Silva. Princípios, elementos e conceito de Estado Federal. In: RAMOS, Dircêo Torrecillas (Coord.). Ofederalista atual cit., p. 67).

850 Também ensina Bercovici: "Em nenhuma concepção doutrinária o federalismo é entendido como oposto à unidade do Estado. Pelo contrário, o objetivo do federalismo é a unidade, respeitando e assimilando a pluralidade. Nem poderia ser diferente, afinal a unidade está na essência da orgaização estatal. Para garantir a unidade (fim), o Estado possui determinada forma de organização (meio), mais ou menos centralizada. Todo Estado, inclusive federal, neste sentido é unitário, pois tem como um de seus objetivos a busca da unidade" (BERCOVICI, Gilberto. Dilemas do estado federal brasileiro. Porto Alegre: Livraria do Advogado, 2004. p. 9-10).

851 OLIVEIRA, Regis Fernandes de. Curso de direito financeiro. 3. ed. rev. e atual. São Paulo: RT, 2010. p. 33.

852 Como ressalta Anderson: "El federalismo es adecuado para algunos países, no para todos. El federalismo es uma forma democratica de de gobierno, enraizada en el constitucionalismo y en el Estado de Derecho". ANDERSON, George. Una introducción al federalismo. Trad. Isabel Vericat y Celorio Morayta. Madrid: Marcial Pons, 2008. p. 30.

853 “A descentralização territorial tem justificações de ordem prática e política: - constitui uma receita para assegurar a diversidade na unidade, tendo em vista a variedade das necessidades locais, sendo que não se abandona certo controle do poder central; - contribui para descongestionar a administração central; possibilita à administração melhor conhecimento dos problemas administrativos de ordem local; - a descentralização territorial é sobretudo fruto de fator político, surge como conseqüência do princípio da democracia representativa, ralacionando (sic) a organização constitucional com a administrativa; [...] Apesar do seu constante aparecimento, a palavra descentralização acomoda muitos questionamentos, que começam a partir de sua definição precisa. Associa-se esse vocábulo a ideias como: - liberdades locais; rapidez; - iniciativa; - participação no processo de decisão" (BARACHO, José Alfredo de Oliveira. Teoria geral do federalismo. Rio de Janeiro: Forense, 1986. p. 117-118 e 120-121).

854 BARACHO, José Alfredo de Oliveira. Teoria geral do federalismo cit., p. 321.

855 REIS, Élcio Fonseca. Federalismo fiscal: competência concorrente e normas gerais de direito tributário. Belo Horizonte: Mandamentos, 2000. p. 32: "O elemento informador do princípio federativo é a pluralidade consorciada e coordenada de mais de uma ordem jurídica incidente sobre um mesmo território estatal, posta cada qual no âmbito de competências previamente definidas, a submeter um povo". Ainda, ensina Paulo Gonet Branco: "O federalismo tende a permitir a convivência de grupos étnicos heterogêneos, muitas vezes com línguas próprias, como é o caso da Suíça e do Canadá. Atua como força contraposta a tendências centrífugas. $\mathrm{O}$ federalismo, ainda, é uma resposta à necessidade de se ouvirem as bases de um território diferenciado quando da tomada de decisões que afetam o país como um todo. A fórmula opera para reduzir poderes excessivamente centrípetos". BRANCO, Paulo Gustavo Gonet. Estado Federal. In: MENDES, Gilmar Ferreira; BRANCO, Paulo Gustavo Gonet. Curso de direito constitucional cit., p. 832. 
essencial na doutrina desenvolvida por Charles Tiebout, nos anos 1950: para o autor, a divisão do governo em compartimentos menores permitiria a oferta de um pacote de bens e encargos públicos adequado para as preferências de cada cidadão, evitando, portanto, a homogeneização massificada. Daí sua famosa ideia de "votar com os pés": cada família buscaria estar sob a jurisdição do governo que oferecesse aquilo que é mais próximo de suas preferências. ${ }^{856}$ Wallace Oates, por sua vez, convencido dos benefícios da organização federal, apresenta o tema como uma soma das vantagens de um Estado Unitário com as vantagens da descentralização, cada um fazendo "o que faz de melhor". 857

É através do pacto federativo que o Estado se organiza da forma federativa, distribuindo as competências entre os vários entes. ${ }^{858-859}$ Esse pacto pressupõe a autonomia dos entes periféricos em relação ao poder central, não admitindo relação de dependência entre um e outro, e nem mesmo relação de hierarquia. A soberania permanece sendo do ente público geral; mas os entes descentralizados, embora não soberanos, são autônomos. ${ }^{860}$ Como afirma Regis Fernandes de Oliveira, "não há, como se pretendeu,

856 "Em Tiebout, o grande mérito da descentralização físcal está no estímulo à concorrência entre os governos locais (estados e municípios)" (MENDES, Marcos. Federalismo Fiscal. In: BIDERMAN, Ciro; ARVATE, Paulo Roberto (Org.). Economia do setor público no Brasil. Rio de Janeiro: Elsevier/Campus, 2005. p. 425).

857 "From an economic standpoint, the obvious attraction of the federal form of government is that it combines the strengths of unitary government with those of descentralization. Each level of government, rather than attempting to perform all the functions of the public sector, does what it can do best. The central government presumably accepts primary responsibility for stabilizing the economy, for achieving the most equitable distribution of income, and for providing certain public goods that influence significantly the welfare of all members of society. Complementing these operations, subcentral governments can supply those public goods and services that are of primary interest only to the residents of their respective jurisdictions. In this way, a federal form of government offers the best promise of a successful resolution of the problems that constitute the economic raison d'être of the public sector. It is in this sense that federalism may, in economic terms, be described as the optimal form of government". OATES, Wallace E. Fiscal federalism. Cheltanham: Edward Elgar Publishing, 2012. p. 14-15.

858 OLIVEIRA, Regis Fernandes de. Curso de direito financeiro cit., p. 38.

859 Para Gilberto Bercovici, "o grande objetivo do federalismo, na atualidade, é a busca da cooperação entre União e entes federados, equilibrando a descentralização federal com os imperativos da integração econômica nacional". BERCOVICI, Gilberto. Dilemas do estado federal brasileiro cit., p. 58.

860 "A caracterização de uma Federação é estabelecida pela reunião de um conjunto de requisitos, relevando a distinção entre soberania e autonomia como marco distintivo. A soberania, que é elemento privativo da União, outorga personalidade jurídica de direito público à União, sendo seu atributo exclusivo. Os Estados-membros não possuem este atributo, sendo-lhes conferido o elemento de autonomia, com competências delimitadas e definidas pela Constituição do estado federal". SCAFF, Fernando Facury; ROCHA, Francisco Sérgio Silva. Princípios, elementos e conceito de Estado Federal. In: RAMOS, Dircêo Torrecillas (Coord.). O federalista atual cit., p. 69. Daí também que os Estados-membros, autônomos mas não soberanos, recebem Poder Constituinte, que contudo não é originário, mas derivado da (e limitado pela) Constituição federal, conforme: RAMOS, Dircêo Torrecillas. Composição da federação brasileira. In: RAMOS, Dircêo Torrecillas (Coord.). O federalista atual cit., p. 85. 
pensar na divisão da soberania entre os entes federais. A soberania é, essencialmente, indivisível e, pois, entra na competência de apenas uma pessoa jurídica". 861

Os entes são constitucionalmente iguais, encontrando sua diferença no campo das competências. ${ }^{862}$ Nesse sentido é que Paulo Bonavides aponta como princípios ou leis que regem o federalismo: a autonomia e a participação. ${ }^{863} \mathrm{E}$ afirma que os Estados federais buscam: "institucionalizar-se por um modo mais perfeito e eficaz sob a forma de comunhão perpétua e indissolúvel, capaz de exprimir os altos valores da solidariedade, do amparo mútuo, do respeito, da colaboração e da liberdade". ${ }^{864}$ Os entes políticos subnacionais são autônomos e independentes entre si. São pessoas jurídicas de direito interno, mas não de direito externo. Deve manter-se a distinção entre a ordem jurídica global, em que atua a República Federativa do Brasil; e as ordens jurídicas parciais, onde atuam as pessoas jurídicas de direito público interno. ${ }^{865}$

Eis que a ideia de um Estado federal presume a distribuição de competências entre os diversos entes políticos internos. ${ }^{866} \mathrm{E}$, para exercer as atividades que lhe competem, o ente político deve alcançar meios de financiamento. ${ }^{867}$ Deve-se ter atenção à lição de Carmen Lúcia Antunes Rocha: "Pela subtração de recursos econômico-financeiros às entidades federadas, tem-se chegado à ruptura velada, mas não menos grave, e ao esvaziamento de algumas propostas da Federação". 868

861 OLIVEIRA, Regis Fernandes de. Federalismo fiscal e pacto federativo. Revista Tributária e de Finanças Públicas, v. 61, 2005.

862 REIS, Élcio Fonseca. Federalismo fiscal cit., p. 39-40.

863 BONAVIDES, Paulo. A Constituição aberta - temas políticos e constitucionais da atualidade, com ênfase no federalismo das regiões. 2. ed. São Paulo: Malheiros, 1996. p. 430.

864 Idem, ibidem, p. 418.

865 TORRES, Heleno Taveira. Tributos e convenções internacionais em matéria tributária e o federalismo fiscal brasileiro. Revista Dialética de Direito Tributário, n. 86, nov. 2002, p. 46: "Na composição federativa, por rigor, deve-se ter sempre em mente a distinção entre ordem jurídica global, inerente à República Federativa do Brasil, sujeito de direito público externo, definida como sistema de normas nacionais, e as ordens jurídicas parciais: central (a União) e periféricas (Estados-membros), que estão submetidas à discriminação constitucional de competências. Entre os entes formadores das ordens jurídicas parciais não há preeminência ou relação hierárquica de uma sobre a outra, visto serem autônomas e isônomas entre si e diferenciarem-se apenas pela distinção das competências materiais pertinentes a cada uma. Mas não se diga o mesmo quanto à relação entre a ordem jurídica global e soberana (representante dos interesses nacionais) e as ordens parciais. A ordem global soberana prevalece sobre as ordenes parciais autônomas".

866 OLIVEIRA, Regis Fernandes de. Curso de direito financeiro cit., p. 38.

867 "Afinal, partilhar atribuições (competências administrativas e legislativas) sem partilhar recursos é transformá-las em promessas vazias, obrigações inexequíveis”. MENDES, Gilmar Ferreira. Tributação e finanças públicas na Constituição Federal de 1988. In: MENDES, Gilmar Ferreira; BRANCO, Paulo Gustavo Gonet. Curso de direito constitucional cit., p. 1453.

868 ROCHA, Carmen Lúcia Antunes. República e federação no Brasil - Traços constitucionais da organização política brasileira. Belo Horizonte: Del Rey, 1997. p. 185. 
A autonomia do ente subnacional, manifestada no plano financeiro, ${ }^{869}$ é parte relevantíssima do arranjo institucional. ${ }^{870} \mathrm{~A}$ autonomia financeira está diretamente vinculada à capacidade de financiar as atividades a serem exercidas, fruto da outorga de competências administrativas. Como ensina José Maurício Conti, "a autonomia financeira é de fundamental importância. Não é exagero dizer ser ela quem garante a sobrevivência da federação. Sem recursos para se manter, as entidades federadas estão fadadas ao fracasso. Não poderão exercer as funções que lhe competem, e passarão a depender do poder central para financiar suas atividades, circunstância que aniquila todo e qualquer poder autônomo que se lhes atribua" ${ }^{871} \mathrm{E}$ ainda, com Sampaio Dória: "O poder político, distribuído pelas camadas da federação, encontra seu necessário embasamento na simultânea atribuição de poder financeiro, sem o qual de pouco vale: autonomia na percepção, gestão e dispêndio das rendas próprias". ${ }^{872}$

E é nesse contexto que se apresenta o federalismo fiscal. ${ }^{873}$ Ele se destina à compreensão dos meios de dotar cada um dos entes governamentais dos recursos necessários ao desenvolvimento das atividades que lhes competem. ${ }^{874}$ Em outras palavras: de "assegurar-lhes meios para a obtenção de seus fins". ${ }^{875}$ Segundo Conti, federalismo

869 "O equilíbrio federativo exige que haja correlação entre as competências, que são encargos, tarefas a serem executadas, e os meios financeiros indispensáveis para seu desempenho". DALLARI, Dalmo de Abreu. Implicações do pacto federativo. In: RAMOS, Dircêo Torrecillas (Coord.). O federalista atual cit., p. 593.

870 "Los acuerdos en torno a la recaudación, reparticipación y gasto del dinero son de crucial importancia, tanto política como económicamente, para el funcionamento de lós sistemas federales". ANDERSON, George. Una introducción al federalismo cit., p. 51.

871 CONTI, José Maurício. Federalismo fiscal e fundos de participação. São Paulo: Juarez de Oliveira, 2001.p. 14.

872 SAMPAIO DÓRIA, Antônio Roberto. Discriminação de rendas tributárias. São Paulo: José Bushatsky Editor, 1972. p. 11

873 'Nessa expressão, o adjetivo 'fiscal' restringe o tipo de 'federalismo' de que estamos falando. O termo federalismo, desacompanhado do adjetivo, diz respeito à divisão de poderes políticos e constitucionais entre os diferentes níveis de governo, indo muito além da mera divisão de tarefas administrativas". MENDES, Marcos. Federalismo Fiscal. In: BIDERMAN, Ciro; ARVATE, Paulo Roberto (Org.). Economia do setor público no Brasil cit., p. 422.

874 Segundo Marcos Mendes, o federalismo fiscal é definido como "a divisão de tarefas entre os diferentes níveis de governo: quem (que níveis de governo) deve arrecadar cada um dos tributos do país e quem deve ofertar cada um dos servoços públicos (saúde, saneamento, educação, limpeza, iluminação, segurança pública, estabilidade macroeconômica, assistência aos pobres etc.). A ideia principal é buscar uma divisão de tarefas que maximize a eficiência do setor público”. Idem, ibidem, p. 421.

875 OLIVEIRA, Regis Fernandes de. Curso de direito financeiro cit., p. 42. Prossegue o autor: "Faz-se um bolo arrecadatório, destinado a fornecer os meios para que o Estado cumpra suas finalidades, podendo atender aos serviços públicos, exercitando o poder de polícia, intervindo no domínio econômico, preservando situações através de documentos e mantendo sua estrutura, tais como adquirindo imóveis (por compra ou expropriação), móveis, objetos artísticos, monumentos, alugando imóveis, mantendo seu pessoal etc. Ao celebrar-se o pacto federativo através da elaboração do pacto político que é a Constituição, deve haver o sopesar das necessidades de cada ente autônomo e os recursos previstos no texto. Se não houver compatibilidade, o pacto é vesgo. Se não se estabelecer razoabilidade entre fins e meios, perecem as soluções democráticas, criando-se odiosa estrutura de dominação dos entes maiores 
fiscal é "o estudo da maneira pela qual as esferas de governo se relacionam do ponto de vista financeiro". ${ }^{876}$

O tema, então, é a distribuição de recursos no seio da federação. Nas palavras de Anwar Shah: "os princípios do federalismo fiscal estão preocupados com o desenho das constituições fiscais - isto é, como a tributação, o gasto e as funções regulatórias são alocadas entre governos e como transferências intergovernamentais são estruturadas. Esses arranjos são de fundamental importância para a provisão eficiente e equitativa dos serviços públicos", ${ }^{877}$ revelando, em verdade, "a questão mais fundamental de uma federação". ${ }^{878}$

A teoria do federalismo fiscal busca avançar no estudo dos fatores determinantes para essa distribuição de recursos e especialmente auxiliar no desenho das instituições fiscais, visando adequar a partilha das finanças públicas àquela decisão política que fixou quem fará o quê. ${ }^{879}$

E os instrumentos a serem utilizados nessa tarefa são diversos.

O primeiro (quiçá prévio) e mais óbvio destes é a própria partilha das competências administrativas. Isto é: quanto menos atividades governamentais forem descentralizadas a Estados e Municípios, menor será a necessidade de dotá-los de recursos. ${ }^{880}$ Mas não apenas quantitativamente a alocação das competências importa no

sobre os menores. Deixando de se atender a critérios equitativos na distribuição de recursos, instaura-se o desequilíbrio repugnante entre os centros federativos de poder. Logo, urge que as limitações ao poder de tributar não tornem exangues as fontes dos Municípios e Estados, nem se instituam mecanismos de imunidades de tal ordem que atinjam somente as esferas menores da federação". p. 42-43.

876 CONTI, José Maurício. Federalismo fiscal e fundos de participação cit., p. 24.

877 SHAH, Anwar. Introduction: principles of fiscal federalism. In: SHAH, Anwar (Ed.). The practice of fiscal federalism: comparative perspectives. A global dialogue on federalism. Canadá: McGill-Queen's University Press, 2007. v. 4, p. 3. Tradução livre.

878 Idem, ibidem, p. 9. Tradução livre.

879 "Six questions arise with respect to intergovernmental finance in any country [...]. The first five focus on content as follows:

- The question of expenditure assignment: Who should do what?

- The question of revenue assignment: Who should levy what taxes?

- The question of vertical imbalance: How should any imbalance between the revenues and expenditures of subnational government be resolved?

- The question of horizontal imbalance or equalization: To what extent should fiscal institutions attempt to adjust for differences in needs and capacities between different government units at the same level of government?

- The question of access to capital markets: What, if any, rules should existe with respect to subnational borrowing?

The sixth question concerns the process by which these questions are answered, that is, the institutional framework within which the technical problems of fiscal federalism are resolved" (BIRD, Richard M.; VAILLANCOURT, François. Introduction and summary. In: BIRD, Richard M.; VAILLANCOURT, François (Ed.). Perspectives on fiscal federalism. Washington: The World Bank, 2006. p. 2).

880 SILVA, Mauro Santos. Teoria do federalismo fiscal: notas sobre as contribuições de Oates, Musgrave, Shah e Ter-Minassian. Belo Horizonte: Nova Economia, 2005. "A principal questão relativa à 
desenho fiscal. Isso também ocorre qualitativamente: a eficiência é alcançada atribuindo a cada ente político a responsabilidade por realizar as atividades que afetem mais diretamete seus jurisdicionados, e também a quem esteja mais apto a escutar suas preferências. Mas observando também critérios de justiça redistributiva e de redução de desigualdades regionais. $^{881}$

Outro instrumento comum reside na responsabilidade por gerar receita. Seu foco primário é o tributário - mas não exclui as receitas patrimoniais. ${ }^{882}$ Através deste instrumento, é possível outorgar - como de fato ocorre no Brasil - a competência por instituir e arrecadar tributos a cada um dos Entes Políticos. É a chamada repartição das fontes de receita. ${ }^{883}$ Então, o desenho fiscal é ponderado para que a base impositiva outorgada seja de grandeza adequada às atribuições administrativas que cabem ao Ente.

Em um plano básico, deve-se escolher no tema uma de três opções: alocar todas as receitas nos entes subnacionais, determinando que estes entes transfiram parte dessa receita "para cima", para que o ente nacional possa satisfazer suas necessidades; outra opção é alocar toda a responsabilidade arrecadatória no ente central, financiando os

organização do sistema fiscal é a definição clara e precisa de competências que devem ser atribuídas a cada nível de governo, isto é, o grau de autonomia capaz de permitir o alcance de uma situação Paretoeficiente. No que diz respeito à função alocativa, a autonomia, sob o ponto de vista teórico-normativo, deve ser compartilhada entre os diferentes níveis de governo e diferentes unidades federadas, segundo o grau de correspondência entre as preferências relativas à contribuição tributária e à cesta de bens produzidos pelo setor público das comunidades componentes de cada jurisdição. [...] Em síntese, o conteúdo do Teorema da Descentralização de Oates (1977, p. 59) afirma que há maximização da eficiência econômica da ordenação federativa fiscal alocativa, sempre que for observada perfeita correspondência entre as ações do governo e a preferência dos grupos que o financiam. O governo central deve responder pela provisão de bens cujo consumo seja uniforme, em termos de preferência e em termos de quantidade individual demandada em todo o território federativo. Os governos estaduais assumiriam a responsabilidade pela provisão de itens com preferências regionais, e os governos locais responderiam pelos bens cujo perfil da demanda fosse especifico de uma localidade. [...] Pela ótica da despesa, os programas redistributivos podem ser operacionalizados por meio de dois mecanismos. Primeiro, a definição da composição da cesta de bens produzidos pelo governo, maior quantidade de bens destinados ao consumo das populações de renda inferior tende a implicar transferências de recursos em forma de produtos e serviços. Segundo, por meio de transferências diretas para as populações de renda mais baixa, de forma a possibilitar que os indivíduos beneficiados possam realizar suas próprias escolhas, ou seja, possam dispor dos recursos segundo suas próprias preferências. Essas ações são identificadas como tarefas primordialmente destinadas ao governo central do Estado federativo, por demandarem procedimentos em escala nacional e grau e uniformidade capazes de eliminar possibilidades de deslocamento espacial dos fatores produtivos. [...] As políticas redistributivas são tratadas pela teoria do federalismo fiscal como políticas preferencialmente nacionais. Ações locais, num cenário de mobilidade de fatores, tendem a alterar preferências localizacionais e produzir decisões ineficientes ao conjunto do sistema econômico. A participação de governos subnacionais em ações distributivas é desejável em circunstâncias especiais, quando as restrições supramencionadas não forem verificadas, criando, com isso, a possibilidade da adoção de medidas eficientes e eficazes". p. 120-124.

881 TER-MINASSIAN, Teresa. Intergovernmental fiscal relations in a macroeconomic perspective: an overview. In: TER-MINASSIAN, Teresa (Ed.). Fiscal federalism in theory and practice. Washington: International Monetary Fund, 1997. p. 4-7.

882 OLIVEIRA, Regis Fernandes de. Curso de direito financeiro cit., p. 42.

883 CONTI, José Maurício. Federalismo fiscal e fundos de participação cit., p. 36. 
entes subnacionais com transferências; e a terceira opção, mais comum, é alocar algum poder tributário nos entes subnacionais, complementando, quando necessário, as verbas necessárias para financiamento de suas atividades com transferências (de diversas tipologias) oriundas do ente central. ${ }^{884}$

Claro que há uma série de considerações que dizem respeito não apenas ao quantum de arrecadação. ${ }^{885-886}$ Especialmente, deve-se considerar que o tributo é meio de gerência macroeconômica (o que diz respeito à volatilidade da base), esta que, por seu caráter nacional abrangente, é pacificamente reconhecida como de atribuição preferencial ao Ente Central. Da mesma forma, o tributo é importante ferramenta de operação da justiça distributiva (o que diz respeito à uniformidade da base) - que é também uma tarefa preferencial da União. ${ }^{887}$ Distorções econômicas (como na circulação de bens e na movimentação de fatores de produção - o que diz com a mobilidade da base) devem ser consideradas, ${ }^{888}$ máxime em face da possível desigualdade da base imponível nos diversos locais do país. Idem em relação a fatores de eficiência na estrutura de arrecadação. A elasticidade da base imponível é igualmente relevante também nesse tema (para além da teoria da imposição fiscal - o princípio da neutralidade tributária ${ }^{889}$ ), especialmente quando

884 NORREGAARD, John. Tax Assignment. In: TER-MINASSIAN, Teresa (Ed.). Fiscal federalism in theory and practice cit., p. 50-51.

885 Afirma Bernard Dafflon: "in fiscal federalism, efficiency is not economic efficiency. Equity is not only redistributive: it encompasses equal access, the right of diversity, consideration for the minority, solidarity and equalization. The political economy of the assignment of responsabilities in federal and decentralized nations is concerned with the general relationships between government units and government levels". DAFFLON, Bernard. The assignment of functions to decentralized government: from theory to practice. In: AHMAD, Ehtisham; BROSIO, Giorgio. Handbook of fiscal federalism. Cheltenham: Edward Elgar Publishing, 2006. p. 299.

886 V. MENDES, Marcos. Federalismo Fiscal. In: BIDERMAN, Ciro; ARVATE, Paulo Roberto (Org.). Economia do setor público no Brasil cit., p. 430 e ss.

887 BOADWAY, Robin; SHAH, Anwar. Fiscal federalism cit., p. 167.

888 "Most forms of local and regional business taxes found in developing countries introduce serious economic distortions in a variety of ways". BIRD, Richard M. Local and regional revenues: realities and prospects. In: BIRD, Richard M.; VAILLANCOURT, François (Ed.). Perspectives on fiscal federalism cit., p. 191. Também: VARSANO, Ricardo; FERREIRA, Sérgio Guimarães; AFONSO, José Roberto. Fiscal competition: a bird's eye view. Rio de Janeiro: IPEA, 2002. Texto para discussão n. 887, p. 4-5. "When business, capital income or property taxes are in force in decentralized government units, depending on economic conditions, tax exporting may occur. Income and property taxes may be exported to foreign owners of domestic companies or land. Business taxes may be shifted, through increases in the prices of local output, to residents of other jurisdictions who consume the goods. Tax shifting is more likely when a locality produces a highly specialized commodity, like natural resources or touristic attractions. When tax exporting occurs, residents of a particular area do not bear the full cost of the public goods that the local government provides. This may give rise to inefficient overprovision of these goods".

889 "Outro requisito desejável ao sistema tributário é a neutralidade, a não-interferência ou a minimização da interferência dos tributos nas decisões alocativas realizadas pelos agentes econômicos. A introdução de um tributo no sistema produtivo pode produzir desequilíbrios de preços relativos e com isso provocar distorções no sistema informacional configurado no espaço de mercado, conduzindo os agentes a 
se trata de bases tributáveis compartilhadas entre entes federativos, já que o aumento das alíquotas por um reduz a base também do outro igualmente competente. ${ }^{890-891}$

O federalismo fiscal busca também, então, identificar qual (entre os muitos possíveis) é um "bom tributo local”, que possa ser atribuído aos entes descentralizados de forma eficiente, sem causar distorções econômicas, que tenha potencial de arrecadação adequado, que seja compatível com a estrutura de arrecadação a ser construída localmente, e que seja transparente aos jurisdicionados, ${ }^{892-893}$ promovendo a responsabilização (accountability) do ente tributante. ${ }^{894-895}$ Bird, embora não abordando diretamente essas condições, resume o tema apontando dois critérios que devem ser satisfeitos: (i) o valor arrecadado deve ser suficiente para que os entes subnacionais mais ricos sejam financeiramente autônomos; e (ii) esses tributos devem impor clara responsabilidade fiscal ao ente subnacional, sendo coletados dos jurisdicionados do ente tributante e preferivelmente relacionados aos benefícios que estes recebem do respectivo governo. ${ }^{896}$ Em outra oportunidade, afirma que no cerne do debate deve estar a responsabilização do ente subnacional: a arrecadação do tributo próprio deve ser clara, os cidadãos devem

decisões ineficientes do ponto de vista da maximização dos retornos esperados". SILVA, Mauro Santos. Teoria do federalismo fiscal cit., p. 127.

890 BOADWAY, Robin; SHAH, Anwar. Fiscal federalism cit., p. 169-170.

891 Como já pontuava Sampaio Dória: "A título ilustrativo, poder-se-iam nomear algumas dessas diretrizes informadoras de ideal discriminação de rendas: (a) receitas proporcionais aos encargos atribuídos ao órgão federado; (b) complementação, através de impostos, de competência regulatória material; (c) concentração, na União, de impostos de difusão econômica nacional, e, nos govêrnos locais, dos econômicamente restritos à sua esfera de influência; (d) distribuição equitativa dos impostos de equivalente produtividade e daquêles de base real e pessoal; (e) flexibilidade de acesso a novas fontes tributárias; (f) atribuição de impostos ao órgão que possa mais eficientemente coletá-los e administrá-los; (g) tentativa de integração dos sistemas; (h) eliminação de embaraços à circulação econômica entre as unidades federativas; (i) possibilidade de distensão do poder tributário federal em casos emergenciais, etc.”. SAMPAIO DÓRIA, Antônio Roberto. Discriminação de rendas tributárias cit., p. 17.

892 NORREGAARD, John. Tax Assignment. In: TER-MINASSIAN, Teresa (Ed.). Fiscal federalism in theory and practice cit., p. 52-53.

893 Para Shah, são 04 (quarto) os princípios norteadores: eficiência econômica, equidade nacional, viabilidade administrativa, e necessidade fiscal (também chamado de adequação de receita). SHAH, Anwar. Introduction: principles of fiscal federalism. In: SHAH, Anwar (Ed.). The practice of fiscal federalism cit., p. 20.

894 BOADWAY, Robin; SHAH, Anwar. Fiscal federalism cit., p. 165.

895 Para uma revisão dos critérios de alocação de tributos aos entes subnacionais, inclusive com análise das bases imponíveis mais comuns, ver: TALIERCIO, Robert R. Subnational own-source revenue: getting policy and administration right. In: WORLD BANK. East Asia decentralizes: makig local government work. Washington: The World Bank, 2005. p. 107 e ss.

896 BIRD, Richard M. Local and regional revenues: realities and prospects. In: BIRD, Richard M.; VAILLANCOURT, François (Ed.). Perspectives on fiscal federalism cit., p. 179. A responsabilidade fiscal mencionada por Bird deve ser interpretada como uma conexão entre aqueles que tomam as decisões sobre os tributos locais, aqueles que pagam esses tributos, e aqueles que se beneficiam dos recursos recolhidos ao Erário - cf. BIRD, Richard M.; VAILLANCOURT, François. Introduction and summary. In: BIRD, Richard M.; VAILLANCOURT, François (Ed.). Perspectives on fiscal federalism cit., p. 2. 
compreendê-la, e o governo deve poder ser cobrado pela exigência, assim como pelo bom uso dado à receita. ${ }^{897}$ Os tributos sobre a propriedade imobiliária são frequentemente reconhecidos como os melhores a serem alocados nas esferas de governo mais descentralizadas. ${ }^{898} \mathrm{Na}$ outra ponta, tributos sobre a renda são frequentemente tidos como melhor alocados no ente central.

Vale mencionar que as bases econômicas da imposição podem ser totalmente separadas por ente tributante (como ocorre no Brasil), assim como podem ser divididas entre entes diversos, cada um aplicando uma alíquota sobre a mesma base. ${ }^{899}$ É importante a lição de Martinez-Vazquez, McLure e Vaillancourt, apresentando quatro principais aspectos da alocação da responsabilidade pela geração de receitas, que devem ser definidos: (i) qual nível de governo escolhe os tributos com os quais os governos subnacionais receberão receitas; (ii) qual nível define as bases impositivas; (iii) qual nível estabelece as alíquotas; e (iv) qual nível administra esses tributos. ${ }^{900}$

Como se vê, são muitas as variáveis no design da repartição das bases tributárias que podem constranger uma adequada distribuição dos recursos públicos. ${ }^{901}$ Esses fatores costumam pesar em favor da União.

Daí que se revela também relevantíssimo outro grupo de instrumentos: as transferências intergovernamentais, ${ }^{902-903 ~ " i n s t r u m e n t o ~ m a i s ~ i m p o r t a n t e ~ d o ~ f e d e r a l i s m o ~}$

897 BIRD, Richard M. Subnational taxation in developing countries: a review of the literature. World Bank Policy Research Working Paper Series, n. 5.450, 2010, p. 44.

898 Interessante a defesa enfática desta base tributária por John Norregaard, que entende tratar-se de tributação mais eficiente, neutra, menos distorsiva, estável, previsível, transparente (o que, por outro lado, a torna impopular) e que também promove o uso eficiente da terra. NORREGAARD, John. Taxing Immovable property: revenue potential and implementation challenges. IMF Working Paper, n. 13/129, maio 2013.

899 TER-MINASSIAN, Teresa. Intergovernmental fiscal relations in a macroeconomic perspective: an overview. In: TER-MINASSIAN, Teresa (Ed.). Fiscal federalism in theory and practice cit., p. 8-11.

900 MARTINEZ-VAZQUEZ, Jorge; McLURE, Charles; VAILLANCOURT, François. Revenues and expenditures in an intergovernmental framework. In: BIRD, Richard M.; VAILLANCOURT, François (Ed.). Perspectives on fiscal federalism cit., p. 25.

901 "Even within the limited range of issues discussed in this paper, it is difficult to draw definitive conclusions about the 'ideal' subnational tax system for any particular country. To do so one must take into account not only the normal public finance trio of goals - efficiency (allocation), equity (distribution), and stabilization - but also the extent to which economic growth is emphasized as a policy goal as well as such nebulous but politically ressonante factors as regional balance and the maintenance of national unity and political stability. In addition, of course, policy change in any country must start from the existent situation. Existent fiscal institutions usually reflect the results of an accretionary process of policy change over time, and the inertia inherent in such institutions must not be underestimated. To understand, let alone to resolve, the intergovernmental fiscal puzzle in any country thus requires substantial institutional as well as analytical knowledge. In part for this reason, international comparisons of intergovernmental financial arrengemnts are both difficult to make and hard to interpret once made". BIRD, Richard M. Subnational taxation in developing countries: a review of the literature cit., p. 2. 
fiscal", ${ }^{904}$ que também podem ser instituídas sob diversos modelos. ${ }^{905}$ Dentre eles, destacam-se 906 (i) o compartilhamento de receitas (ou repartição do produto da arrecadação $^{907}$ ), como ocorre no Brasil com o ITR (art. 158, II, da CF/88) e o Imposto sobre a Renda na fonte dos servidores públicos federais (art. 158, I, da CF/88), sob um critério de derivação; e como ocorre com os Fundos de Participação (art. 159 da CF/88) sob um critério redistributivo; ${ }^{908}$ e (ii) as transferências por concessões ${ }^{909}$ (grants), que podem ser condicionais ou não, direcionadas (a obras, políticas públicas ou programas específicos) ou não, vinculadas ou não, e podem ou não exigir contrapartida do ente público receptor (por exemplo, demandando que a cada $\mathrm{R} \$ 100,00$ transferidos da União

902 "A literatura de finanças públicas cita as seguintes razões para as transferências intergovernamentais: i) internalização de externalidades a outras jurisdições; ii) melhoria do sistema tributário como um todo; iii) Correção de ineficiências na oferta de equilíbrio de bens públicos locais; e iv) equalização fiscal entre juridições". LIMA, Edilberto Carlos Pontes. Transferências da União para estados e municípios nãooriginárias de repartição de receitas: para que se destinam e o que determina o montante. Disponível em: 〈http://federativo.bndes.gov.br/bf_bancos/estudos/e001768pdf〉. Acesso em: 30 nov. 2013.

903 "Em tese, há ao menos duas justificativas econômicas para efetuar essas transferências. A primeira advém dos ganhos de eficiência obtidos na arrecadação dos tributos pelo governo central, que pela amplitude da base tributária concentra maior volume de recursos, e da capacidade dos governos locais de proverem a maior parte dos serviços públicos de forma mais eficiente. [...] A segunda, que é um tanto quanto subjetiva,3 mas não menos importante que a outra, justifica-se na provisão de serviços públicos com um padrão mínimo de qualidade em todas as UFs circunscritas a um mesmo país. [...] Portanto, as transferências intergovernamentais visam diminuir os desequilíbrios verticais e horizontais que surgem em uma federação". DUARTE, Angelo José Mont’alverne; SILVA, Alexandre Manoel Angelo da; LUZ, Everaldo Manoel; GERARDO, José Carlos. Transferências fiscais Intergovernamentais no Brasil: uma avaliação das transferências federais, com ênfase no Sistema único de Saúde. Rio de Janeiro: IPEA, 2009. Texto para discussão n. 1457, p. 7.

904 CONTI, José Maurício. O Estado e o imposto: federalismo financeiro e fiscal. In: CATARINO, João Ricardo; GUIMARÃES, Vasco Branco (Coord.). Lições de fiscalidade. Coimbra: Almedina, 2012. p. 409.

905 "Las federaciones varían en el grado de centralización de la recaudación de ingresos y en el gasto destinado a programas. Pero en todas las federaciones, el gobierno central recauda más ingresos (incluídos lós préstamos) de los que necesita para su proprio gasto directo, en parte debido a las ventajas de una recaudación de los ingresos sigificativamente centralizada. Los gobiernos centrales realizan transferencias fiscales a las unidades constitutivas - y a veces directamente a los gobiernos locales - para permitirles cumplir mejor con sus obligaciones. La importancia de estas transferencias varía: mientras en algunas federaciones las unidades constitutivas dependen casi exclusivamente de las transferencias, en la mayoria de ellas, las transferencias del centro a las unidades constitutivas cubren, de promedio, menos de la mitad de sus gastos. Em consecuencia, en la mayoría de federaciones existe uma medida justa de responsabilidad de lós gobiernos constitutivos ante sus respectivas poblaciones por los ingresos que recaudan en relación con los programas" (ANDERSON, George. Una introducción al federalismo cit., p. 56).

906 "There are two broad ways this transfer of funds can take place: by assigning a predetermined share of federal reveues to the states, or by making federal-state transfers whose magnitude is based on criteria other than federal revenues" (BOADWAY, Robin; SHAH, Anwar. Fiscal federalism cit., p. 293).

907 CONTI, José Maurício. Federalismo fiscal e fundos de participação cit., p. 37-38.

908 "The basic structure of revenue sharing can be described by three components: the type of federal revenues to be shared, the proportion of those revenues that Will go to the states as a whole, and the allocation of the shared revenues among the states" (BOADWAY, Robin; SHAH, Anwar. Fiscal federalism cit., p. 293).

909 Nomenclatura utilizada por Mauro Santos Silva (SILVA, Mauro Santos. Teoria do federalismo fiscal cit., p. 131). 
ao Município, este aplique R\$20,00 de seus próprios cofres na mesma finalidade). ${ }^{910-911}$ Também podem ser legais ou voluntárias. ${ }^{912-913}$

Cada um dos possíveis tipos de transferências traz efeitos macroeconômicos diversos e pode ser aplicado, com a ajuda da literatura, com objetivos diversos. Isto é: podem objetivar promover a estabilização das finanças da nação $;^{914}$ ou objetivar a redução de desigualdades regionais (equidade horizontal); ou incentivar a redistribuição de renda aos cidadãos mais pobres; ${ }^{915-916}$ ou simplesmente gerar maior eficiência na prestação de serviços públicos (especialmente aqueles que afetam cidadãos de mais de uma jurisdição ${ }^{917}$ ); ou promover padrões sociais mínimos na oferta de determinados serviços públicos (como educação - o caso do FUNDEB brasileiro). Algumas dificuldades serão encontradas no conflito entre esses diversos objetivos já que, como se faz evidente, em muitos casos vários deles serão endereçados através da mesma política de transferências. Outras dificuldades podem advir, também, de efeitos adversos dessas transferências, máxime aqueles relacionados à perda de interesse dos entes receptores dessas transferências no desenvolvimento de sua competência tributária própria; $;{ }^{918}$ e no chamado

910 Para uma revisão dessas variáveis: CONTI, José Maurício. Federalismo fiscal e fundos de participação cit., p. 39-40.

911 Detalhes sobre os tipos de transferências, seus prós e contras, podem ser encontrados em: BOADWAY, Robin; SHAH, Anwar. Fiscal federalism cit., p. 306 e ss.

912 TER-MINASSIAN, Teresa. Intergovernmental fiscal relations in a macroeconomic perspective: an overview. In: TER-MINASSIAN, Teresa (Ed.). Fiscal federalism in theory and practice cit., p. 13-15.

913 Sobre a relevância das transferências e seus possíveis modelos, v. REZENDE, Fernando. Os desafios do federalismo fiscal. In: REZENDE, Fernando (Coord.). Desafios do federalismo fiscal. Rio de Janeiro: FGV, 2006. p. 16 e ss.

914 "The design of grant systems and the mix of instruments used reflect the constitutional framework, institutional and political constraints, and forces underlying the division of responsabilities and resources ina country. The magnitude of the grants should be determined by overall fiscal sustainability exercises for 'general government', but the distribution of resources across regions often reflects political economy consideratons". AHMAD, Ehtisham; SEARLE, Bob. On the implementation of transfers to subnational governments. In: AHMAD, Ehtisham; BROSIO, Giorgio. Handbook of fiscal federalism cit., p. 402.

915 Essa dualidade (entre as medidas redistributivas direcionadas às pessoas pobres em contraponto às medidas direcionadas às comunidades pobres) é reconhecida por José Maurício Conti, que afirma: "Nada mais razoável, na busca do caminho que leve à Justiça Social, do que reconhecer ser aplicável esta noção da igualdade não apenas aos indivíduos como tais, considerados isoladamente, mas também às comunidades na qual vivem" (CONTI, José Maurício. Federalismo fiscal e fundos de participação cit., p. 30).

916 BOADWAY, Robin. Intergovernmental redistributive transfers: efficiency and equity. In: AHMAD, Ehtisham; BROSIO, Giorgio. Handbook of fiscal federalism cit., p. 358.

917 É o caso, por exemplo, de compensar uma unidade descentralizada de governo por ações, por ela custeadas, que têm efeitos benéficos (externalidades positivas) que se fazem presentes a cidadãos jurisdicionados em outras unidades. SHAH, Anwar. Introduction: principles of fiscal federalism. In: SHAH, Anwar (Ed.). The practice of fiscal federalism cit., p. 31. Tradução livre.

918 "Finally, transfer systems should be designed carefully to avoid undesirable behavior by recipient governments, such as redution in tax effort or skewed spending, while ensuring that they have the necessary resources to provide the desired level of public services" (MARTINEZ-VAZQUEZ, Jorge; McLURE, Charles; VAILLANCOURT, François. Revenues and expenditures in an intergovernmental 
flypaper effect, onde as verbas oriundas de transferências tendem a ser "aprisionadas" na máquina pública, traduzindo-se mais do que proporcionalmente em gasto público. ${ }^{919}$

Fala-se, mesmo, em um "federalismo fiscal de segunda geração", voltado a analisar os impactos eminentemente políticos dos desenhos fiscais, tais como os incentivos à má gestão, acima referidos. No campo das transferências intergovernamentais, por exemplo, essa "nova geração" recomenda que as transferências sejam orientadas privilegiando os entes subnacionais que promovem o crescimento econômico, em vez de permitir-se sucumbir à dependência (ou preguiça) fiscal. ${ }^{920}$

É prudente sempre lembrar, contudo, que o estudo do federalismo fiscal não prescinde da lição - já acima mencionada - da Teoria do Estado, que demanda a autonomia financeira dos entes subnacionais. Assim, por mais que transferências significativas sejam direcionadas a um ente (ou um nível de governo), é legítima a arguição de que apenas quando se aloca a competência impositiva neste ente é que se estará respeitando sua autonomia. ${ }^{921}$ Só então terá ele o poder de decidir quanto onerar a base, como fazê-lo, quais isenções estabelecer, etc. ${ }^{922-923}$ Por isso mesmo é que Sampaio Dória afirma que "a atribuição de competência tributária, sim, é requisito axiomático da federação, para assegurar independência política". ${ }^{924}$

Esse binômio tributação $x$ transferências, que pode ser tido como cerne do federalismo fiscal, envolve um sem-número de possíveis combinações de desenhos fiscais.

framework. In: BIRD, Richard M.; VAILLANCOURT, François (Ed.). Perspectives on fiscal federalism cit., p. 33).

919 AHMAD, Ehtisham; CRAIG, John. In: TER-MINASSIAN, Teresa (Ed.). Fiscal federalism in theory and practice cit., p. 77-84 e 95. Ainda: MENDES, Marcos. Federalismo fiscal. In: BIDERMAN, Ciro; ARVATE, Paulo Roberto (Org.). Economia do setor público no Brasil cit., p. 451 e 459.

920 WEINGAST, Barry R. Second generation fiscal federalism: the implications of fiscal incentives. Journal of Urban Economics, v. 65, Elsevier, 2009. Também: BIRD, Richard M. Subnational taxation in developing countries: a review of the literature cit., p. 8 e ss; OATES, Wallace E. Toward a secondgeneration theory of fiscal federalism. International Tax and Public Finance, 12, ago. 2005, p. 349 e ss.

921 NORREGAARD, John. Tax Assignment. In: TER-MINASSIAN, Teresa (Ed.). Fiscal federalism in theory and practice cit., p. 71.

922 "An important prerequisite for the exercise of subnational fiscal autonomy is therefore the ability to choose statutory tax rates [...] the capacity to set rates is clearly the most important of these [se refere aos quarto aspectos de definição da tributação subnacional], and also the most efficient. The choice of rates is what allows subnational governments to choose the level of public services while minimizing the compliance costs associated with collecting the required revenues". MARTINEZ-VAZQUEZ, Jorge. McLURE, Charles; VAILLANCOURT, François. Revenues and expenditures in an intergovernmental framework. In: BIRD, Richard M.; VAILLANCOURT, François (Ed.). Perspectives on fiscal federalism cit., p. 24 e 25.

923 Sobre o tema, convém consultar: SCAFF, Fernando Facury; SILVEIRA, Alexandre Coutinho da. Competência tributária, transferências obrigatórias e incentivos fiscais. In: CONTI, José Maurício; SCAFF, Fernando Facury; BRAGA, Carlos Eduardo Faraco (Org.). Federalismo fiscal: questões contemporâneas. Florianópolis: Conceito, 2010.

924 SAMPAIO DÓRIA, Antônio Roberto. Discriminação de rendas tributárias cit., p. 15. 
O que se busca é a ótima junção destes instrumentos, permitindo que cada nível de governo seja adequadamente financiado para o exercício de seu mister.

O último dos principais instrumentos dos quais se ocupa o federalismo fiscal é o controle do endividamento dos entes subnacionais, que pode se dar em variados graus e em variadas formas, e que se faz relevante dados os deletérios efeitos nacionais que a bancarrota de um ente subnacional pode causar. ${ }^{925}$

Dentro dessas categorias, diversas formulações podem ser defendidas como as melhores em um Estado hipotético e idealmente considerado. Quando se trata de uma nação real, então, essas opções - que conjugam os instrumentos acima referidos até um ponto ótimo - são ainda mais numerosas. E devem, necessariamente, observar as peculiaridades de cada país, sendo certo que não é o caso de se aplicar uma formulação one size fits all. Peculiaridades que vão desde a formação econômica, cultural e política de um país até, pura e simplesmente, as preferências de seus cidadãos, serão decisivas na definição do nível de descentralização de um país e, especialmente, no relacionamento fiscal entre cada um desses entes políticos. ${ }^{926}$

Tentou-se expor de forma breve os fundamentos gerais da teoria do federalismo fiscal, especialmente apresentando os instrumentos por ela utilizados para tratar do equilíbrio financeiro interno de um país que adota o modelo federativo, descentralizando competências administrativas e que, portanto, demanda que os entes subnacionais detenham os recursos necessários para levar a cabo suas atividades governamentais.

O que se deixou de fora nestas linhas - e é bom que fique explícito - é a aplicação do federalismo fiscal no Brasil. O tema se revela relevantíssimo e a análise dos diversos instrumentos - e seu maior ou menor êxito nos objetivos propostos, bem como a maior ou menor adequação desses instrumentos aos princípios constitucionais - é de grande interesse, embora não seja endereçada nesta oportunidade. Há vários trabalhos nacionais de referência sobre o tema, que podem e dever ser consultados. ${ }^{927}$

925 TER-MINASSIAN, Teresa. Intergovernmental fiscal relations in a macroeconomic perspective: an overview. In: TER-MINASSIAN, Teresa (Ed.). Fiscal federalism in theory and practice cit., p. 18-21.

926 SAMPAIO DÓRIA, Antônio Roberto. Discriminação de rendas tributárias cit., p. 16 e ss.

927 CONTI, José Maurício. Federalismo fiscal e fundos de participação cit. REZENDE, Fernando; OLIVEIRA, Fabrício Augusto de. Descentralização e federalismo fiscal no Brasil: desafios da reforma tributária; SCAFF, Fernando Facury. Aspectos financeiros do sistema de organização territorial do Brasil. Revista Dialética de Direito Tributário, n. 112, jan. 2005. TER-MINASSIAN, Teresa. Brazil. In: TER-MINASSIAN, Teresa (Ed.). Fiscal federalism in theory and practice cit. REZENDE, Fernando. 
Enfatize-se apenas, nessa oportunidade, que o federalismo fiscal brasileiro se pretende cooperativo ou participativo, a promover o equilíbrio socioeconômico entre os entes políticos, ${ }^{928-929}$ "em que, respeitada a autonomia dos entes federados, criam-se sistemas de interpenetração entre eles, que se manifestam de forma mais evidente no campo das finanças públicas, por mecanismos de partilhas de receitas e transferências intergovernamentais". ${ }^{930}$ Sobre o tema, não se pode passar sem a menção à recorrente crítica feita por Ives Gandra da Silva Martins de que, embora cooperativo em teoria, diante da persistente concorrência horizontal (especialmente entre Estados-Membros em matéria de ICMS), o caso brasileiro se torna, na prática, um de federalismo "fratricida". 931

Afastadas maiores considerações sobre a prática brasileira do federalismo fiscal (embora vistas as linhas mestras da teoria), cabe retomar ao objeto central ora trazido. Com isso, apresenta-se a seguir o federalismo fiscal brasileiro aplicado especificamente à matéria de royalties decorrentes da exploração de recursos naturais não renováveis.

Isto é: quer-se perquirir como se dá atualmente a partilha dessa receita pública patrimonial, visando daí tirar conclusões sobre a adequação ou não desse quadro institucional às ideias desenvolvidas nos capítulos anteriores.

3.d.ii. A partilha espacial dos royalties de recursos naturais não renováveis no Brasil. A recente batalha legislativa e a corrente batalha judicial.

Federal Republic of Brazil. In: SHAH, Anwar (Ed.). The practice of fiscal federalism cit. CONTI, José Maurício; SCAFF, Fernando Facury; BRAGA, Carlos Eduardo Faraco (Org.). Federalismo fiscal cit. Também: CONTI, José Maurício. Federalismo fiscal e fundos de participação cit. CONTI, José Maurício (Org.). Federalismo fiscal cit.; MENDES, Marcos. Federalismo Fiscal. In: BIDERMAN, Ciro; ARVATE, Paulo Roberto (Org.). Economia do setor público no Brasil cit.

928 SCAFF, Fernando Facury. Aspectos financeiros do sistema de organização territorial do Brasil cit., p. 21.

929 O federalismo cooperativo ou participativo tem como contraponto o federalismo competitivo ou concorrente, como lembra André Carvalho. CARVALHO, André Castro. Mecanismos para a otimização do federalismo fiscal brasileiro. In: CONTI, José Maurício; SCAFF, Fernando Facury; BRAGA, Carlos Eduardo Faraco (Org.). Federalismo fiscal cit., p. 165.

930 CONTI, José Maurício. Considerações sobre o federalismo fiscal brasileiro em uma perspectiva comparada. In: CONTI, José Maurício; SCAFF, Fernando Facury; BRAGA, Carlos Eduardo Faraco (Org.). Federalismo fiscal cit., p. 24. O autor ainda ressalta que a cooperação brasileira é vertical e assimétrica, esta voltada à redução de desigualdades. p. 25.

931 MARTINS, Ives Gandra da Silva. Grandes questões atuais do direito tributário - Palestra proferida durante o simpósio. São Paulo: Dialética, set. 2013. Ainda, vale mencionar o ensinamento de Regis de Oliveira sobre a realidade federalista brasileira: "O grande arrecadador é a União, que, disfarçadamente, mas com a anuência dos representantes dos Estados, criou as denominadas contribuições. Os Estados, no entanto, também querem a parte do leão e brigam por isso. Nasce aí o que se denominada [sic] guerra fiscal. Por aí bem se vê que a federação já é um ponto de litígio" (OLIVEIRA, Regis Fernandes de. Gastos públicos cit., p. 124-125). 
Já se consignou acima que, para os fins ora buscados, entendem-se por royalties de recursos naturais não renováveis, no ordenamento jurídico brasileiro: (i) a CFEM - Compensação Financeira pela Exploração de Recursos Minerais; e (ii) os royalties de petróleo, aí incluídos os royalties propriamente ditos (conforme terminologia legal) e também as participações especiais.

Importa agora ver como essas receitas públicas são partilhadas entre os entes federados no Brasil, sempre que possível cotejando esse rateio com a evolução políticolegislativa recente.

Inicie-se pela CFEM, que é de formatação muito mais simples. Até a presente data, ${ }^{932}$ a partilha federativa das receitas públicas arrecadadas sob tal rubrica é estabelecida pela Lei n. 8.001/1990, art. $2 .^{\circ}, \S 2 .^{\circ}$. O total arrecadado será dividido entre:

$\begin{array}{cc}\text { Ente federativo } & \text { Percentual } \\ \text { Municípios Mineradores } & 65 \% \\ \text { Estados Mineradores } & 23 \% \\ \text { União } & 12 \%\end{array}$

Na União Federal, a mesma Lei já estabelece vinculação plena de todos os valores arrecadados: $2 \%$ do total arrecadado (e não da parte que cabe à União) estão atrelados previamente ao Fundo Nacional de Desenvolvimento Científico e Tecnológico FNDCT; e os demais $10 \%$ estão vinculados ao Departamento Nacional de Produção Mineral (destes 10\%, 2\% deverão necessariamente ser destinados à "proteção mineral em regiões mineradoras, por intermédio do Instituto Brasileiro de Meio Ambiente e dos Recursos Naturais Renováveis - Ibama”).

Estes percentuais são os mesmos desde a edição da referida Lei, em 1990 (salvo pelas vinculações interna na União).

Contudo, depois de anos de promessas, em junho/2013 o Governo Federal finalmente submeteu ao Congresso Nacional (e liberou ao escrutínio da sociedade civil) o projeto de um "Novo Marco Regulatório da Mineração". O projeto, que recebeu na Câmara dos Deputados o n. 5.807/2013, foi inicialmente marcado pela Presidência da

932 Em 30 de novembro de 2013. 
República como de caráter urgente, mas após pressões do Poder Legislativo e de EstadosMembros, a Presidência retirou-lhe o rito de urgência. ${ }^{933}$

Ao que ora importa - a partilha entre entes subnacionais do produto da arrecadação -, o Projeto de Lei submetido pelo Executivo Federal manteve na íntegra os percentuais acima apresentados (art. 38, incisos I, II e III), alterando apenas os percentuais de vinculação dentro da parcela que cabe à União ( $\left.\operatorname{art.~38,~§1.~}{ }^{\circ}\right): 4,8 \%($ dos mesmos 12\%) caberiam ao FNDCT; os demais 7,2\% caberiam à nova Agência Nacional de Mineração ANM (que substituirá o DNPM, se aprovada a proposta), com repasse obrigatório de $2 \%$ ao IBAMA, embora não tenha ficado claro se esses $2 \%$ são retirados diretamente da alíquota de 7,2\% (ficando 5,2\% à ANM e 2\% ao IBAMA) ou se representam 2\% do total de recursos públicos destinados à ANM.

Em novembro/2013, contudo, no âmbito da Comissão legislativa para apreciação da proposta, o Deputado Federal Leonardo Quintão (PMDB/MG) submeteu ao Congresso uma proposta de substitutivo ao projeto 5.807/2013. Neste (art. 68), a partilha federativa das receitas públicas de CFEM passaria a ser feita da seguinte forma:

$\begin{array}{cr}\text { Ente federativo } & \text { Percentua } \\ \text { Municípios Mineradores } & 60 \% \\ \text { Municípios relacionados }^{934} & 10 \% \\ \text { Estados Mineradores } & 20 \% \\ \text { União } & 10 \%\end{array}$

A parcela que cabe à União seria dividida em: 20\% ao FNDCT; 20\% ao Centro de Tecnologia Mineral - CETEM, para a realização de pesquisas, estudos e projetos de tratamento, beneficiamento e industrialização de bens minerais; e 60\% à ANM, com repasse obrigatório de $2 \%$ ao IBAMA.

933 Notícia disponível em: <http://oglobo.globo.com/economia/dilma-retira-urgencia-de-codigo-demineracao-10092066>. Acesso em: 30 nov. 2013.

934 Estes municípios "relacionados" à mineração seriam aqueles (art. 68, IV): “a) cortados pelas infraestruturas rodoviária, ferroviária ou hidroviária, utilizadas para o transporte de minérios; b) afetados pelas operações de embarque e desembarque de minérios; ou c) onde se localizem as pilhas de estéril, barragens de rejeitos e instalações de beneficiamento de minérios, bem como demais instalações previstas no plano de aproveitamento econômico", com a Agência de Mineração definindo (art. 68, § 1. ${ }^{\circ}$ ) "o grau de impacto da mineração em cada Município [...] para fins de justa distribuição dos recursos". 
A grande alteração, trazida pelo substitutivo, é a inclusão de uma nova classe de beneficiários da receita pública de CFEM: os Municípios relacionados.

Outros debates que tocam o tema estão pendentes de apreciação no Poder Legislativo da União, onde multiplicam-se Projetos os mais diversos, mas que, especialmente, visam majorar alíquota e alterar base de cálculo visando maior volume de arrecadação. ${ }^{935-936}$ Esse é o caso da Emenda n. 66, apresentada pelo Senador Flexa Ribeiro (PSDB-PA) ao Projeto de Lei de Conversão n. 18/2012 (Medida Provisória n. 563/2012), em que estabelece também para a CFEM a disciplina já existente na seara tributária para os preços de transferência. ${ }^{937}$ Há outras propostas de revisão da distribuição federativa dessas receitas minerárias, embora em tom muito mais tímido do que ocorre com os royalties do petróleo. ${ }^{938}$

935 Os debates sobre a modificação no valor dos royalties minerais, que estão calcados especialmente na comparação do valor dos royalties no Brasil com outros países, além da comparação com o valor dos royalties da mineração em comparação com os do petróleo, podem ser resumidos em: CÂMARA DOS DEPUTADOS: Setor mineral rumo a um novo marco legal. rel. Jaime Martins; coord. Paulo César Ribeiro Lima; Alberto Pinheiro de Queiroz Filho; Leonardo Costa Schüler; Roberto Carlos Martins Pontes. Brasília: Câmara dos Deputados, Edições Câmara, 2011, Série cadernos de altos estudos, n. 8. Para uma refutação das ideias lá apresentadas, ver, na mesma obra: SCAFF, Fernando Facury. Gargalos tributários do setor mineral - notas para discussão. p. 171 e ss. E ainda, do ponto de vista da classe industrial mineradora, o Estudo produzido pela Ernst \& Young para o Instituto Brasileiro de Mineração - IBRAM. Disponível em: <http://www.ibram.org.br/sites/1300/1382/00001165.ppt> e em: <http://www.ibram.org.br/sites/700/784/00001269.pdf>, além dos artigos e apresentações firmados por Paulo Camillo Vargas Penna, ex-Diretor Presidente do IBRAM. Disponível em: $<$ http://www.ibram.org.br/150/15001002.asp?ttCD_CHAVE=130262> 〈http://www.senado.gov.br/comissoes/ci/ap/AP20111018_Paulo_Camillo.pdf〉.

936 Pode-se citar como exemplos o Projeto de Lei do Senado 01/2011, do Senador Flexa Ribeiro (PSDB-PA) alterando a base de cálculo da CFEM para que passe a ser o faturamento bruto (não mais líquido) resultante da venda do produto mineral.

937 O faz através do acréscimo ao art. 19-A da Lei n. 9.430/1996 de um $\S 6 .^{\circ}$ com esta redação: "O preço definido na forma deste artigo será adotado para fins de apuração da base de cálculo da Compensação Financeira pela Exploração de Recursos Minerais (CFEM), de que trata o art. 6. ${ }^{\circ}$ da Lei n. 7.990, de 28 de dezembro de 1989". Na Justificativa da Emenda, fez constar que se trata de medida com o propósito de "coibir manipulações de valores em operações de importações ou de exportações. Tais manipulações visam a transferir lucros para países com menor imposição tributária sobre a renda. Como medida de combate a essas práticas, que aviltam a base de tributação no Brasil transferindo-a para outros países, impõe-se ao contribuinte o dever de comprovar que os valores dessas operações não sofreram manipulações ou ajustes indevidos, o que é feito mediante o cálculo dos chamados preços parâmetros. As mesmas manipulações de preços vêm causando grandes prejuízos aos Estados exportadores de minérios, razão pela qual apresentamos esta emenda, que visa estender a aplicação do Preço sob Cotação na Exportação à apuração da base de cálculo da CFEM".

938 É o caso do Substitutivo apresentado, pelo Senador Aécio Neves (PSDB-MG) ao Projeto de Lei do Senado 01/2011, do Senador Flexa Ribeiro (PSDB-PA), que reduz o percentual de CFEM a ser destinado aos Municípios de 65 para 50\%, majorando a participação dos Estados, e criando um "fundo especial", a ser distribuído entre todos os Municípios do Estado arrecadador (8\%). Mencione-se, ainda, oriundos da Câmara dos Deputados, o Projeto de Lei n. 841/2011, que dispõe sobre a obrigatoriedade da destinação do percentual de 1,5\% sobre o valor bruto da CFEM para os estados da federação e municípios impactados no processo de mineração; o Projeto de Lei n. 3.854/2008, que visa destinar parcela da CFEM a um fundo nacional de exaustão de jazidas. 
Quando se passa à análise dos royalties petrolíferos, contudo, o tema se torna deveras mais complexo.

Isso porque são múltiplos os quadros de rateio, variando conforme: a exploração se dá em terra ou no mar; o valor partilhado é de royalties propriamente ditos ou de participação especial; nos royalties propriamente ditos, se o valor se refere à alíquota mínima $(5 \%)$ ou que excede este mínimo; e ainda varia conforme se trata do modelo de concessão (com base na Lei n. 9.478/1997) ou de partilha (com base na Lei $n$. $12.351 / 2010)$.

Fernando Facury Scaff apresentou esta divisão de forma didática, consoante se vê dos quadros abaixo, que ora se reproduzem na íntegra. ${ }^{939}$

ROYALTIES TERRESTRES

\begin{tabular}{|c|c|c|c|}
\hline & Partilha & $\begin{array}{c}\text { Concessão } \\
5 \% \\
\text { obrigatório }\end{array}$ & $\begin{array}{c}\text { Concessão } \\
\text { entre } \\
5 \% \text { e } 10 \%\end{array}$ \\
\hline Estados Produtores & $20 \%$ & $70 \%$ & $52,50 \%$ \\
\hline Municípios Produtores & $10 \%$ & $20 \%$ & $15 \%$ \\
\hline Municípios Afetados & $5 \%$ & $10 \%$ & $7,5 \%$ \\
\hline Rateio pelo sistema FPE adaptado & $25 \%$ & Zero & Zero \\
\hline Rateio pelo sistema FPM adaptado & $25 \%$ & Zero & Zero \\
\hline Fundo Social da União & $15 \%$ & Zero & $25 \%$ \\
\hline
\end{tabular}

ROYALTIES MARÍTIMOS

\begin{tabular}{|c|c|c|c|}
\hline & Partilha & $\begin{array}{c}\text { Concessão } \\
5 \% \text { obrigatório }\end{array}$ & $\begin{array}{c}\text { Concessão entre } \\
5 \% \text { e } 10 \%\end{array}$ \\
\hline Estados Confrontantes & $22 \%$ & $20 \%$ & $20 \%$ \\
\hline $\begin{array}{c}\text { Municípios } \\
\text { Confrontantes }\end{array}$ & $5 \%$ & $\begin{array}{c}17 \% \\
(\mathrm{em} 2019=4 \%)\end{array}$ & $\begin{array}{c}17 \% \\
(\mathrm{em} 2019=4 \%)\end{array}$ \\
\hline $\begin{array}{c}\text { Municípios Afetados } \\
\text { Fateio pelo sistema }\end{array}$ & $2 \%$ & $3 \%$ & $3 \%$ \\
\hline $\begin{array}{c}\text { Rateio pelo sistema } \\
\text { FPM adaptado }\end{array}$ & $24,5 \%$ & $20 \%$ & $20 \%$ \\
\hline $\begin{array}{c}\text { Fundo Social da União } \\
\text { Fudo } 2019=27 \%)\end{array}$ & $\begin{array}{c}20 \% \\
(\mathrm{em} 2019=27 \%)\end{array}$ \\
\hline
\end{tabular}

939 SCAFF, Fernando Facury. Royalties decorrentes da exploração de recursos naturais não renováveis cit., p. 424 e ss. Agradecemos imensamente ao Prof. Fernando Facury Scaff pela disponibilização das matrizes. 


\section{PARTICIPAÇÕES ESPECIAIS}

\begin{tabular}{|c|c|c|}
\hline & $\begin{array}{l}\text { Sistema } \\
\text { anterior }\end{array}$ & Sistema atual \\
\hline Estado Produtor ou Confrontante & $40 \%$ & $\begin{array}{c}34 \% \\
(\mathrm{em} 2018=20 \%)\end{array}$ \\
\hline Município Produtor ou Confrontante & $10 \%$ & $\begin{array}{c}5 \% \\
(\mathrm{em} 2019=4 \%)\end{array}$ \\
\hline Rateio pelo sistema FPE adaptado & Não tratava & $\begin{array}{c}9,5 \% \\
(\mathrm{em} 2019=15 \%)\end{array}$ \\
\hline Rateio pelo sistema FPM adaptado & Não tratava & $\begin{array}{c}9,5 \% \\
(\text { em } 2019=15 \%)\end{array}$ \\
\hline União - Fundo Social & Não tratava & $\begin{array}{c}42 \% \\
(\mathrm{em} 2016=46 \%)\end{array}$ \\
\hline $\begin{array}{l}\text { União - Ministério de Minas e Energia } \\
\text { e do Meio Ambiente }\end{array}$ & $50 \%$ & Não trata \\
\hline
\end{tabular}

Deve-se mencionar que por "sistema FPE adaptado" e "sistema FPM adaptado", refere-se a uma forma de partilha idêntica ao dos Fundos de Participação dos Estados e dos Municípios, previstos respectivamente nas alíneas $a$ e $b$ do art.159, I, da Constituição Federal. O adjetivo "adaptado" diz respeito às exclusões, determinadas pela Lei, dos entes subnacionais já beneficiados diretamente na partilha, na qualidade de produtores ou confrontantes (que poderão, contudo, optar por receber na qualidade de "produtores ou confrontantea" ou no monte geral dessa sistemática de fundo de participação). A qualificação do Fundo Social será melhor apresentada adiante.

Valem, contudo, algumas notas sobre o processo político-legislativo (e judiciário, como se verá) que conduziu até o quadro atual, exposto acima.

Nesta evolução, vale lembrar primeiro a lição de José Roberto Afonso e Sérgio Wulff Gobetti, que observam que a sucessão de normas no tempo (até 2008), com o crescente despertar de atenções sobre elas, conduziu a uma modificação esquizofrênica dos critérios de distribuição da receita, de forma a negar-lhe qualquer critério objetivo - isto é, deixando a questão ao pleno jogo de forças políticas envolvidas. ${ }^{940}$

940 "De modo geral, é possível verificar que dois conceitos têm norteado a distribuição de royalties para estados e municípios: o impacto sobre as localidades de embarque e desembarque de petróleo e gás natural e, principalmente, a produção. No caso da produção em terra, esse conceito é facilmente concretizado pela localização geográfica dos poços e/ou campos, e é natural presumir que essas localidades sejam as principais afetadas pela atividade petrolífera. No caso da produção em mar, entretanto, a definição das localidades com direito à compensação é absolutamente arbitrária e tem se baseado em um conceito acessório, o da 'confrontação' com poços ou campos de petróleo, ainda que esses poços e campos estejam - na sua maioria - a uma distância de quase 100 milhas da costa, onde diferentes prolongamentos de linhas podem implicar diferentes situações de 'direito à compensação'. Originalmente, nas primeiras legislações (1985 e 1989) que trataram da repartição dos royalties de mar, 
Quer-se focar, contudo, nas mudanças ocorridas a partir de 2011, onde o debate da distribuição federativa dessas receitas tomou fortes e abertas proporções. Em outubro/2011, o Senado Federal votou e aprovou o Projeto de Lei n. 448/2011, de autoria do Senador Wellington Dias (PT-PI), com o substitutivo do Senador Vital do Rêgo Filho (PMDB-PB) para introduzir modificações no regime jurídico dos royalties de petróleo, ${ }^{941}$ tanto no sistema de concessões, previsto desde a Lei n. 9.478/1997, quanto no sistema de partilha de produção, previsto na Lei n. 12.351/2010 - a norma continha originalmente previsão de rateio federativo dos royalties, que contudo restou vetada pelo então Presidente da República.

Dentre as alterações legais contidas no Projeto 448/2011, a mais debatida era a mudança na destinação destes royalties, antes concentrada nos Estados e Municípios produtores e confrontantes. Isto é: o Projeto previu que grande parte dessas receitas passaria a integrar um "Fundo Especial" exclusivamente destinado aos Estados e Municípios não produtores - o que já se chamou, acima, de "sistema FPE (ou FPM) adaptado". Note-se que as receitas atingidas não seriam apenas aquelas decorrentes do novo modelo de exploração (partilha, trazido pela Lei n. 12.276/2011), mas também as decorrentes do modelo anterior (concessão, da Lei n. 9.478/1997), tanto nas jazidas a serem concedidas sob esse modelo, quanto nas jazidas já em exploração. A norma modificaria os critérios de rateio aplicáveis à exploração marítima no sistema de concessões; e incluiria a previsão de rateio a ambos os tipos de exploração (terrestre e marítima) no sistema de partilha. Previu-se, contudo, um "regime de transição" para suavizar a mudança entre o sistema anterior de rateio, mais focado nos Estados produtores; e o novo modelo, acima apresentado.

definiu-se que a partilha se faria não apenas entre os municípios 'confrontantes', mas também entre os demais integrantes da sua área geoeconômica, constituída pelas localidades atravessadas por oleodutos e gasodutos e os limítrofes (fronteiriços). Esse critério mais amplo prevalece até hoje no rateio dos royalties derivados da alíquota básica de $5 \%$, mas não está presente, por exemplo, na partilha da alíquota excedente de $5 \%$ e da participação especial, instituídas pela Lei do Petróleo, em 1997. Sobre essa nova fatia dos royalties, impera de forma quase absoluta o critério de distribuição apenas para os municípios confrontantes. A cada nova modalidade de renda petrolífera sobre a atividade em plataforma criada desde a década de 1980, os critérios de partilha entre municípios foram se tornando mais restritivos e desvinculados dos impactos socioeconômicos da atividade petrolífera. A própria parcela distribuída universalmente a todos os municípios e estados, o FEP, também foi reduzida proporcionalmente: inicialmente (1985), representava $20 \%$ do royalty básico, em 1989 foi reduzida para $10 \%$ e, em 1997, com a Lei do Petróleo, foi fixada em 7,5\% para o royalty excedente e em $0 \%$ para a participação especial” (AFONSO, José Roberto Rodrigues; GOBETTI, Sérgio Wulff. Rendas do petróleo no Brasil: alguns aspectos fiscais e federativos cit., p. 231- 269, dez. 2008, p. 239-240).

941 Disponível em: <http://www.senado.gov.br/noticias/nova-distribuicao-dos-royalties-do-petroleo-eaprovada-pelo-senado-texto-vai-a-camara.aspx?parametros=royalties>. Acesso em: 14 jul. 2012. 
A notícia da aprovação, no Senado Federal, deste Projeto, foi recebida com grande revolta pelos dois principais Estados produtores de petróleo da federação: Rio de Janeiro e Espírito Santo. Ambos organizaram movimentos públicos contra o que chamaram de "injustiça" e "covardia". $942-943$

(Projeto de Lei semelhante já havia sido impugnado perante o Supremo Tribunal Federal pelo então Deputado Federal Geraldo Pudim, do PMDB/RJ, ${ }^{944}$ que requeria a sustação dos trâmites legislativos já que, em seu entender, criaria crise institucional federativa. O Estado do Rio de Janeiro irresignou-se perante o Supremo Tribunal Federal, também, quanto à não incidência de Participação Especial decorrente de exploração de petróleo nas áreas que foram objeto de Cessão Onerosa, nos termos da Lei n. $\left.12.276 / 2011^{945}\right)$.

Na Câmara dos Deputados, esse Projeto recebeu o n. 2.565/2011. Após muitos e acalorados debates, o Projeto, com algumas modificações (mas mantido o cerne acima referido, de distribuição mais ampla dos royalties arrecadados) veio a ser aprovado em 06/11/2012, após sessão parlamentar com dezenas de contramarchas.

As reações foram novamente exaltadas. O Governador do Estado do Rio de Janeiro foi a público afirmar que aquelas disposições trariam a falência das contas estaduais, exigindo o inadimplemento das obrigações e mesmo a não realização dos grandes eventos previstos para o futuro próximo: Copa do Mundo e Jogos Olímpicos. ${ }^{946}$ Rogou abertamente à Presidenta da República para que vetasse a Lei.

E assim ocorreu. A Chefe do Poder Executivo vetou parcialmente a norma aprovada pelo Congresso Nacional, na parte em que alterava a destinação dos royalties dos “contratos já em vigor". Foi promulgada, com os vetos, a Lei n. 12.734/2012. Concomitantemente, foi publicada a Medida Provisória n. 592/2012, que direcionou à educação a totalidade dos royalties de petróleo arrecadados em contratos de concessão (firmados a partir de dezembro/2012), além de incluir algumas disposições diretamente relacionadas às lacunas trazidas pelo veto.

942 Disponível em: <http://www.estadao.com.br/noticias/impresso,ato-oficial-reune-milhares-por-royalties,797334,0.htm>. Acesso em: 15 nov. 2011.

943 Disponível em: <http://www1.folha.uol.com.br/poder/1004834-com-samba-ato-contra-divisao-deroyalties-reune-5000-no-es.shtml >. Acesso em: 15 nov. 2011.

944 Mandado de Segurança n. 28.885, rel. Min. Rosa Weber. O pedido de liminar foi negado pela Relatora à época, Ministra Ellen Gracie.

945 Ação Direta de Inconstitucionalidade n. 4.492, rel. Min. Gilmar Mendes.

946 Disponível em: <http://oglobo.globo.com/economia/sergio-cabral-diz-que-com-nova-regra-dos-royaltiesrio-fecha-as-portas-nao-faz-copa-nem-olimpiadas-6657618>. 
O Congresso Nacional mobilizou-se para pôr à votação, de imediato, o veto presidencial. O Supremo Tribunal Federal então impediu, por decisão monocrática concessiva de medida liminar, que essa votação se realizasse (MS 31.816, Rel. Min. Luiz Fux). Mas passados quase 3 (três) meses, o Plenário do STF cassou a liminar e, por maioria, denegou a ordem pleiteada, assim liberando a apreciação da matéria pelo Legislativo.

O veto presidencial, autuado com o n. 38/2012, foi derrubado em sessão conjunta do Congresso Nacional iniciada em 06.03.2013. A Lei n. 12.734/2012 foi promulgada e republicada na forma original, isto é, consoante aprovada pela Câmara dos Deputados. Mais pressão política se seguiu, até mesmo com a ordem de suspensão de todos os pagamentos do Estado do Rio de Janeiro, excetuados os pagamentos a servidores.

A matéria foi levada ao Supremo Tribunal Federal (ADIs 4.916, 4.917, 4.918 e 4.920, todas relatadas pela Ministra Carmen Lúcia). Em decisão monocrática (proferida nos autos da ADI 4.917), concedeu-se medida liminar para suspender a eficácia dos dispositivos da Lei que dizem respeito à alteração da distribuição federativa dos royalties decorrentes das "concessões instituídas com base na legislação antes vigente". 947-948 Aguarda-se decisão final.

Mas cabe dar um passo atrás para questionar: quais os fundamentos suscitados pelos Estados produtores (especialmente Rio de Janeiro e Espírito Santo, mas também São Paulo) para impugnar perante o STF a Lei n. 12.734/2012?

947 Pontuou a Ministra, em sua decisão: "Das concessões acabadas decorreram direitos que ingressaram no patrimônio público das pessoas federadas e que, mesmo se desdobrando em recebimentos de valores no presente e parcelas no futuro, fundamentam-se em processos findos, válidos, que se formaram e se aperfeiçoaram segundo a legislação vigente no período em que se deram os seus atos. Aplicar a nova legislação àqueles atos e processos aperfeiçoados segundo as normas vigentes quando de sua realização seria retroação, dotar de efeitos pretéritos atos e processos acabados segundo o direito, em clara afronta à norma constitucional do inciso XXXVI do art. 5. , antes mencionado".

948 Vale recordar, em relação à nota anterior, a doutrina de Consuelo Yoshida, sobre a proteção do ato jurídico perfeito, do direito adquirido e da coisa julgada quando confrontados com direitos difusos: "O uso ilegítimo e fraudador destes prestigiosos institutos e instrumentos de segurança jurídica merecem especial atenção da Administração Ambiental, do Ministério Público e do Poder Judiciário, notadamente, que devem estar atentos para cercear, impedir e não contribuir para a disseminação dessas práticas deletérias que, na realidade, contribuem para o surgimento incessante de novos passivos ambientais. Não pode ser olvidada, nesta complexa empreitada, a observância do princípio da proibição do retrocesso, nos planos legislativo-normativo e de execução e implementação dos direitos fundamentais em geral, pelos poderes públicos e pela sociedade, através de seus diferentes setores, para a melhoria contínua dos padrões socioeconômico e ambientais, buscando a sustentabilidade do desenvolvimento humano em relação às presentes e futuras gerações. [...] Não podem, com efeito, ser toleradas práticas legislativas, administrativas e judiciais, bem como atividades econômicas, político-sociais e culturais dos diferentes setores da sociedade, que atentem contra o equilíbrio ecológico já tão ameaçado e atingido em escala planetária" (YOSHIDA, Consuelo Y. M. Ato jurídico perfeito, direito adquirido, coisa julgada e meio ambiente. Revista de Direito Ambiental, v. 66, 2012). 
Os argumentos mais comuns neste sentido podem ser sintetizados em três eixos básicos: ${ }^{949}$ (i) que os royalties petrolíferos, conforme referência do art. $20, \S 1 .^{\text {o }}$, da Constituição Federal, justificam-se como compensação aos Estados pela exclusão destes bens da base de incidência do ICMS (art. 155, § 2. ${ }^{\circ}, \mathrm{X}, b$ ); (ii) que os royalties são necessariamente atrelados aos Estados e Municípios onde se dá a extração (ou confrontantes) porque são estes os entes federativos responsáveis por arcar financeiramente com os custos trazidos pela atividade exploratória, notadamente sociais (relacionados à expansão populacional nas respectivas regiões) e ambientais; e (iii) que os royalties são receita pública originária destes entes subnacionais. No mais, argumenta-se que a alteração dos critérios de partilha em relação às jazidas já concedidas (lembrando que nenhum contrato sob o regime de partilha está em operação até esta data) viola direitos adquiridos, segurança jurídica, bem como os princípios constitucionais de programação orçamentária.

3.d.ii.1. São procedentes as reivindicações dos Estados do Rio de Janeiro, do Espírito Santo e de São Paulo?

Mister dirigir-se às queixas que têm por inconstitucional as mudanças no sistema de partilha de royalties petrolíferos (também consideradas as participações especiais), retirando grande parte das transferências de receitas públicas aos Estados produtores e confrontantes.

Cabe lembrar do teor do art. 20, $\$ 1 .^{\circ}$, da CF/88. Ele dispõe:

É assegurada, nos termos da lei, aos Estados, ao Distrito Federal e aos Municípios, bem como a órgãos da administração direta da União, participação no resultado da exploração de petróleo ou gás natural, de recursos hídricos para fins de geração de energia elétrica e de outros recursos minerais no respectivo território, plataforma continental, mar territorial ou zona econômica exclusiva, ou compensação financeira por essa exploração.

Como se vê, a redação é truncada e a interpretação, dificultada.

949 Estes argumentos podem ser encontrados em: TORRONTEGUY, Alessandra Folkze. A aplicação dos royalties do petróleo na efetividade dos direitos fundamentais sociais. São Paulo: LTr, 2011; MADUREIRA, Claudio. Royalties de petróleo e federação. Belo Horizonte: Fórum, 2012; FARIAS, Lindbergh. Royalties do petróleo: as regras do jogo - para discutir sabendo. Rio de Janeiro: Agir, 2011; BARROSO, Luís Roberto. Federalismo, isonomia e segurança jurídica: inconstitucionalidade das alterações na distribuição de royalties do petróleo. Parecer. 2010. Disponível em: <http://s.conjur.com.br/dl/parecer-luis-roberto-barroso-royalties.pdf〉. Acesso em: 30 nov. 2013. Além, estes argumentos estão delineados nas petições iniciais das Ações Diretas de Inconstitucionalidade 4.916, 4.917, 4.918 e 4.920, todas atualmente em trâmite perante o Supremo Tribunal Federal. 
Nada obstante, temos como induvidoso que a redação da norma garante, sim, aos Estados e Municípios produtores e confrontantes uma participação diferenciada (de forma benéfica) na partilha dos royalties petrolíferos. ${ }^{950}$

Isto porque o texto do dispositivo assegura que os entes subnacionais receberão parte dos valores quando a exploração se der (aí qualificando quais são os entes subnacionais) no respectivo território (indicando também que para esses fins, o "território" é aumentado por uma participação na plataforma continental, mar territorial ou zona econômica exclusiva).

A interpretação literal, então, garante aos entes subnacionais que sejam privilegiados no rateio dessas receitas públicas. A redação truncada do dispositivo, pelo que se pode dela extrair a partir apenas do texto, assegura participação no resultado da exploração que ocorre no respectivo território. ${ }^{951}$

É de se notar que, diferente do que fez em outros temas, neste a Constituição Federal não fixou os percentuais de distribuição. Assegurou essa participação prioritária "nos termos da Lei”, a dizer que é lícito ao legislador infraconstitucional determinar os percentuais de rateio, desde que sempre mantenha os produtores e confrontantes com uma parte diferenciada. O percentual exato dessa parte é de ser definido em lei.

Então, a Lei n. 12.734/2012 é constitucional na medida em que manteve, em todos os casos, a prioridade aos Estados e Municípios produtores e confrontantes. Seria inconstitucional se os tivesse tratado como todos os demais - incluindo-os no rateio apenas através do sistema de partilha assemelhado aos Fundos de Participação. Ou se, frustrando a norma constitucional, estipulasse percentual tão baixo - o que não poderia passar sem

950 LOUREIRO, Gustavo Kaercher. Participações governamentais na indústria do petróleo: evolução normativa. Porto Alegre: Sergio Antonio Fabris, 2012. p. 150. Afirma o autor: "Aflora dos debates - e redações - que levariam ao art. $20, \S 1^{\circ}$, a intenção muito clara de consagrar a participação diferenciada dos Estados/Municípios 'diretamente afetados' ('produtores' ou com áreas 'adjacentes' à plataforma continental), A Constituição insere-se decididamente na tradição imediatamente anterior, acolhendo-a e procurando reforçá-la, pela constitucionalização de tema que fora objeto, até então, de regulação por legislação ordinária". Prossegue afirmando que a CF/1988 "positivou, pela primeira vez em nossas Constituições, um direito aos Estados e Municípios, eliminando da esfera de disposição da União o que até então aí estava, i.e., a existência de direitos de apropriação das rendas da exploração de petróleo em favor de entes não proprietários. O que era derivado e dependente de iniciativa legislativa privativa da União tornou-se originário e obrigatório ex constutione. Originário e obrigatório em favor não de todos os Estados/Municípios do Brasil, mas daqueles entes da Federação que, desde 1953, batiam-se pelo reconhecimento de suas situações peculiares. Essa, pelo menos, parece ter sido a intenção dos constituintes".

951 Não se está propondo que a forma de interpretação literal prevalece sobre outras, nem que é a mais relevante forma hermenêutica. Mas é método útil de interpretar os comandos legais, e que pode ser decisivo na ausência de conclusões firmes a partir de outros modos interpretativos - como é o caso em análise. 
invocar os princípios da razoabilidade e da proporcionalidade - a ponto de, na prática, frustrar esse tratamento diferenciado de forma indireta.

Como nada disso ocorreu, continuando os produtores e confrontantes com valores muito superiores aos que receberão os demais entes nacionais, entende-se que o sistema diferenciado/prioritário estabelecido no art. $20, \S 1$. $^{\circ}$, da $\mathrm{CF} / 88$, restou obedecido. Valendo considerar, ademais, que há estudos ${ }^{952}$ a indicar que na sistemática anterior de partilha dos royalties petrolíferos (onde Estados e Municípios eram mais fortemente privilegiados), em muitos desses entes subnacionais identificam-se sintomas da Maldição dos Recursos Naturais, além da presença sobrefinanciamento, sendo os recursos a eles destinados superiores à sua capacidade de absorção.

Ainda assim, alguns Estados (Rio de Janeiro e Espírito Santo principalmente, mas também São Paulo) argumentam que a modificação dos percentuais de rateio dos royalties de petróleo (ou seu estabelecimento, no caso do regime de partilha) é inconstitucional porque sua leitura do ordenamento jurídico-constitucional indica que esse tratamento diferenciado e prioritário não está sendo observado. Para tanto, argumentam em torno dos três eixos básicos acima mencionados - (i) royalties são compensação pela alteração da incidência do ICMS; (ii) Estados e Municípios onde se dá a extração são responsáveis por arcar financeiramente com os custos trazidos pela atividade; e (iii) royalties são receita pública originária destes entes subnacionais -, além do argumento de que a alteração do rateio em relação às jazidas já concedidas viola direitos adquiridos.

Os reclames, contudo, improcedem. Embora visto que o art. 20, §1. ${ }^{\circ}$, da $\mathrm{CF} / 88$, efetivamente assegura-lhes tratamento diferenciado, a extensão desse direito não é a apresentada nas Ações Diretas de Inconstitucionalidade.

Ora, (i) já se argumentou acima que os royalties não se justificam como um trade off político-federativo, embora um acordo político tenha, de fato, ocorrido. Não apenas este acordo não é razão de existência dos royalties como a aceitação desse argumento importa em abraçar unicamente uma interpretação histórica que, como já se viu, é insuficiente de ser aplicada isoladamente. Portanto, repete-se que o acordo político que se revela nos trabalhos que conduziram à Constituição de 1988, embora seja útil considerar, certamente não deve ser determinante para interpretação da norma constitucional.

952 SERRA, Rodrigo Valente. Rendas petrolíferas no Brasil: critérios de distribuição distorcidos induzem ineficiência do gasto. In: MENDES, Marcos (Org.). Gasto público eficiente. Rio de Janeiro: Topbooks, 2006; AFONSO, José Roberto Rodrigues; GOBETTI, Sérgio Wulff. Rendas do petróleo no Brasil: alguns aspectos fiscais e federativos cit., p. 231- 269, dez. 2008. 
De outro lado, (ii) os royalties tampouco se explicam pelos impactos ambientais e demográficos ocorridos nas áreas de exploração, como também já se argumentou. Para estes impactos, o ordenamento jurídico brasileiro possui normas e instrumentos que lhes dirigem diretamente, como é o caso das obrigações de cunho especificamente ambiental.

Em verdade, e considerando que os debates ora travados no Supremo Tribunal Federal dizem respeito majoritariamente à exploração marítima, esses argumentos tornamse fragilíssimos, porque nem Estados nem Municípios serão responsáveis pelos danos ambientais lá ocorridos; e tampouco seus territórios se estendem até o mar, pelo que não arcarão com parte da variação da densidade populacional; e a parte que efetivamente enfrentarão poderá e deverá ser endereçada com as receitas tributárias, que esse aumento populacional necessariamente trará.

Finalmente, (iii) também não há que se falar que os royalties importam em receitas públicas originárias dos Estados e Municípios, especialmente porque é a União que detém o domínio sobre os bens. Assim, sendo os royalties "preço público pago ao proprietário do recurso natural não renovável”, este pagamento se dá à União. Tratando-se de receita originária, oriunda da exploração do patrimônio, fica claro - por ser esse patrimônio da União - que é receita originária da União.

Portanto, com essas razões, reputam-se improcedentes os pleitos apresentados nas Ações Diretas de Inconstitucionalidade 4.916, 4.917, 4.928 e 4.920.

Observe-se, por último, que as razões ora apresentadas podem parecer contraditórias: ao passo em que se afirma a existência de um direito à partilha diferenciada, previsto na Constituição Federal, afirma-se também a improcedência das razões trazidas pelos Estados justamente pleiteando essa "diferenciação".

Mas contradição não há. Efetivamente, entende-se que não há razões jurídicopolíticas externas à Constituição que demandem essa partilha diferenciada - nem mesmo o acordo político realizado no processo constituinte. Nada obstante, o texto constitucional optou por assegurar essa diferença no rateio. E, enquanto o fizer, de forma válida e legítima, esse preceito deve ser seguido; a razão que assim demanda é diretamente positiva e constitucional. ${ }^{953}$ No caso em análise, o comando foi seguido: apesar da redução dos

953 Nada obsta, inclusive, que o respectivo dispositivo constitucional venha a ser revogado ou modificado. Certamente, não se trata de cláusula pétrea nem deve ser intrinsecamente relacionado ao regime federal: as razões para assim entender devem ficar claras adiante. 
percentuais, está prevista uma diferença, em favor dos entes produtores, na Lei n. $12.734 / 2012$.

A análise do caso concreto - da dogmática jurídica que envolve o art. 20, §1. $^{\circ}$, da Constituição, a novel Lei n. 12.734, e os impactos a Estados e Municípios da Federação -, contudo, não é o objetivo central deste trabalho. Serve apenas para ilustrá-lo, sendo relevante enquanto demonstra como se dá o rateio espacial dos royalties no Brasil. Igualmente não é objeto destas linhas - e poderia ser de uma dissertação ou tese inteira - a análise dos argumentos que pugnam pela ocorrência de violação, levada a efeito pela referida Lei, de preceitos constitucionais relacionados à segurança jurídica, a direitos adquiridos, e à programação orçamentária.

O que se tem por escopo central, reitere-se, é a análise crítica dos institutos brasileiros de governança dos royalties, máxime diante das noções de equidade intergeracional e dos efeitos deletérios da exploração dos recursos naturais não renováveis, descritos mundo afora.

\section{3.d.iii. Crítica à atual partilha espacial dos royalties. E: uma orientação de natureza temporal.}

Já se referiu - e ora se retoma - como se dá a partilha dos royalties de recursos naturais não renováveis: (i) na CFEM, com os Municípios sendo deveras privilegiados (65\%), os Estados mantendo uma parcela razoável da arrecadação (23\%); e a União uma parcela bem inferior (12\%), totalmente vinculada a órgãos internos minerários e ambientais, além de $2 \%$ ao FNDCT; e (ii) nos royalties petrolíferos (aí incluídos os royalties propriamente ditos e participações especiais), com os Estados produtores ou confrontantes tendo uma participação destacada (em torno de $20 \%$, mas que chega a $70 \%$ nos royalties terrestres, alíquota mínima), os Municípios produtores ou confrontantes tendo uma participação forte, embora bem menor que os Estados (em geral em torno de 5\%, chegando a $20 \%$ nos royalties terrestres, alíquota mínima), os Municípios meramente afetados tendo uma parcela que também é significativa (embora inferior), a União com quocientes altos, destinados ao Fundo Social, e, finalmente, o rateio pelos sistemas de Fundos de Participação de Estados e Municípios, destinados a todos os entes subnacionais brasileiros, igualmente com percentuais relevantes (geralmente em torno de 20\%) no 
sistema de partilha e no sistema de concessão para exploração marítima, embora com nenhuma participação nos royalties terrestres submetidos ao sistema de concessão.

Cabe questionar - o que até o presente momento não foi feito: o que diz a teoria do federalismo fiscal sobre a atribuição de competências impositivas e rateio de receitas públicas, especificamente em relação às receitas de recursos naturais? A mais breve consulta a essa teoria dirá que é recomendável que essas receitas sejam concentradas no ente político central - a União.

São várias as razões para tanto. Notem-se algumas delas.

Inicie-se considerando a relevância dos custos de administrar e fiscalizar um tributo. ${ }^{954}$ Aquelas incidências que sejam mais difíceis (e, portanto, custosas) de administrar devem ser alocadas ao ente central, que para além de manter maior capacidade de financiamento desses serviços, replicará o conhecimento desenvolvido em todos os lugares - o que não acontece quando se dá a descentralização da exigência, exigindo de cada ente tributante o desenvolvimento da estrutura arrecadatória. Este ponto desaconselha que os royalties sejam atribuídos aos entes subnacionais, ${ }^{955}$ dada sua inerente complexidade, a iniciar pela diversidade de teores minerais e métodos de exploração em cada jazida. ${ }^{956}$ Embora não se aplique ao caso brasileiro - onde a União é responsável por toda a estrutura de arrecadação - é aspecto que deve ser considerado, especialmente diante de alguns pleitos (improcedentes ${ }^{957}$ ) recentes de Estados da federação pela fiscalização e arrecadação direta da CFEM. ${ }^{958}$

954 Aqui e doravante, enquanto tratar-se de federalismo fiscal, se utiliza o termo tributo de forma ampla, a indicar uma exação, uma base imponível capaz de gerar receita. Encampa também os royalties, embora seja de conhecimento geral - o que ainda se verá - que estes não são, tecnicamente, tributos.

955 Nesse sentido: BROSIO, Giorgio. The assignment of revenue from natural resources. In: AHMAD, Ehtisham; BROSIO, Giorgio. Handbook of fiscal federalism cit., p. 443. Vale mencionar posição divergente, no sentido de que a imposição sobre recursos naturais não demanda grandes custos de administração. Em: BOADWAY, Robin; SHAH, Anwar. Fiscal federalism cit., p. 187.

956 OATES, Wallace E. Fiscal federalism cit., p. 144; ANDERSON, George. Reflections on oil and gas in federal systems. In: ANDERSON, George (Ed.). Oil \& gas in federal systems cit., p. 375.

957 Afirmam Guilherme Ferreira e Guilherme Lima: "parece-nos evidente que a competência para cobrança, arrecadação e fiscalização da CFEM é prerrogativa única e exclusiva da União Federal”. FERREIRA, Guilherme Simões; LIMA, Guilherme Corrêa da Fonseca. Competência da União Federal para cobrança, arrecadação e fiscalização da CFEM. In: SOUZA, Marcelo Mendo Gomes de (Coord.). A compensação financeira pela exploração de recursos minerais - CFEM. Belo Horizonte: Del Rey, 2011. p. 141. E ainda Herbert Pereira da Silva: "a veiculação de normas de fiscalização, arrecadação e cobrança da CFEM por meio de leis estaduais e municipais é ofensiva à Constituição Federal”. SILVA, Herbert Pereira da. Inconstitucionalidade de leis estaduais e municipais que disciplinam a fiscalização, arrecadação e cobrança da CFEM. In: SOUZA, Marcelo Mendo Gomes de (Coord.). A compensação financeira pela exploração de recursos minerais cit., p. 184.

958 O Estado da Bahia aprovou a Lei n. 10.850/2007 que, dentre outras disposições, determina que o pagamento dos royalties seja efetuado diretamente ao Estado (art. 5. ${ }^{\circ}$ ). A norma foi objeto da Ação 
A mesma objeção (relacionada à competência impositiva, e não ao direcionamento das receitas) vale às considerações relacionadas à política nacional de exploração dos recursos naturais não renováveis. Mesmo por questões de soberania, é a União que estabelece essas políticas - não os Estados ou Municípios. No caso brasileiro, isso fica ainda evidente dado o domínio dos recursos minerais e petrolíferos (basta notar, ademais, que é a União quem estabelece o Plano Nacional de Mineração ${ }^{959}$ ). Então, considerando que as imposições tributárias e patrimoniais são relevantes na formação dessas políticas, impõe-se considerar que é a União quem deve cobrar os royalties. ${ }^{960}$

De outro lado, já se referiu que é parte relevante do desenho fiscal de um país a promoção da responsabilização (accountability) do ente tributante, ${ }^{961}$ de maneira que os cidadãos possam compreender o quanto está sendo recolhido e o quanto está sendo gasto, permitindo, então, a cobrança efetiva dos gestores públicos. ${ }^{962}$ Nesse sentido, são desaconselhadas fartas transferências de receitas públicas de royalties aos entes subnacionais porque não promovem essa responsabilização: o cidadão exige menos de um Ente público quando não está financiando diretamente suas atividades. Vale lembrar que essa faceta é dupla quando há a transferência da receita de royalties: o prejuízo à responsabilização nasce do fato de ser uma receita que decorre da exploração do patrimônio - portanto não sendo oriundo dos bolsos dos cidadãos; e também nasce do só fato de ser uma transferência - portanto quebrando o vínculo entre arrecadação e gasto

Direta de Inconstitucionalidade 4.606, ajuizada pela União. Os pareceres da AGU e do MPF foram no sentido de provimento da ação, que aguarda julgamento. O Estado do Pará aprovou a Lei n. 6.710/2005 que estabeleceu que o pagamento da CFEM deveria se dar diretamente aos cofres estaduais (art. $2 .^{\circ}$ ). A norma foi objeto de contestação judicial pelo DNPM - Departamento Nacional de Produção Mineral, através da Ação Cível Originária 845. A ação restou extinta por razões formais, sem apreciação do mérito. O Estado do Pará, contudo, não vem exigindo seu cumprimento no que tange à arrecadação direta dos royalties minerais. Há referências (FERREIRA, Guilherme Simões; LIMA, Guilherme Corrêa da Fonseca. Competência da União Federal para cobrança, arrecadação e fiscalização da CFEM. In: SOUZA, Marcelo Mendo Gomes de (Coord.). A compensação financeira pela exploração de recursos minerais cit., p. 133) a normas similares também nos Estados do Rio de Janeiro, Espírito Santo e Sergipe.

959 MME - MINISTÉRIO DE MINAS E ENERGIA (BRASIL). Plano Nacional de Mineração 2030 Geologia, mineração e transformação mineral. Brasília, 2013.

960 BROSIO, Giorgio. The assignment of revenue from natural resources. In: AHMAD, Ehtisham; BROSIO, Giorgio. Handbook of fiscal federalism cit., p. 444; BROSIO, Giorgio. Oil revenue and fiscal federalism. In: DAVIS, J.; OSSOWSKI, R.; FEDELINO, A. (Org.). Fiscal policy formulation and implementation in oil-producing countries cit., p. 251; ANDERSON, George. Reflections on oil and gas in federal systems. In: ANDERSON, George (Ed.). Oil \& gas in federal systems cit., p. 375.

961 BOADWAY, Robin; SHAH, Anwar. Fiscal federalism cit., p. 165; ANDERSON, George. Reflections on oil and gas in federal systems. In: ANDERSON, George (Ed.). Oil \& gas in federal systems cit., p. 398 e ss.

962 OATES, Wallace E. Fiscal federalism cit., p. 123; AHMAD, Ehtisham; CRAIG, John. In: TERMINASSIAN, Teresa (Ed.). Fiscal federalism in theory and practice cit., p. 94-95; BOADWAY, Robin; SHAH, Anwar. Fiscal federalism cit., p. 165; BROSIO, Giorgio. The assignment of revenue from natural resources. In: AHMAD, Ehtisham; BROSIO, Giorgio. Handbook of fiscal federalism cit., p. 444. 
pelo mesmo ente, novamente prejudicando a relação entre os jurisdicionados e essa receita pública, que não foi por eles provida.

As receitas públicas devem ser alocadas ao ente central quando sua base de incidência for caracteristicamente volátil, porque a União está melhor equipada (inclusive através de outros instrumentos tributários e regulatórios) para suportar grandes alterações nos níveis de arrecadação. ${ }^{963}$ Por isso, as receitas de recursos naturais não renováveis, marcadamente instáveis, devem ser preferencialmente vinculadas ao ente central.

A União deve manter consigo as receitas públicas daquelas bases imponíveis distribuídas desigualmente pelo território nacional ${ }^{964}$ - o que é claramente o caso dos minérios e do petróleo. Como colocam Boadway e Shah, "o tratamento dado aos recursos naturais está no coração do debate sobre balanço fiscal". ${ }^{965}$ Afinal, quer-se, explicitamente,

963 NORREGAARD, John. Tax Assignment. In: TER-MINASSIAN, Teresa (Ed.). Fiscal federalism in theory and practice cit., p. 68; BOADWAY, Robin; SHAH, Anwar. Fiscal federalism cit., p. 208 e 301; BROSIO, Giorgio. The assignment of revenue from natural resources. In: AHMAD, Ehtisham; BROSIO, Giorgio. Handbook of fiscal federalism cit., p. 443, 447-448 e 451, onde afirma: "When revenue diminishes abruptly, subnational units can only resort to expenditure cuts, thus endangering even the provision of minimum levels of essential services, such as education and health, where these are decentralized. During upturns in prices, subnational jurisdictions would be literally awash with funds they are unable to spend efficiently, or enter into spending commitments that might not be sustainable in the longer term, especially if pricess fall"; AHMAD, Ehtisham; MOTTU, Eric. Oil revenue assignments: country experiences and issues. In: DAVIS, J.; OSSOWSKI, R.; FEDELINO, A. (Org.). Fiscal policy formulation and implementation in oil-producing countries cit., p. 217; BROSIO, Giorgio. Oil revenue and fiscal federalism. In: DAVIS, J.; OSSOWSKI, R.; FEDELINO, A. (Org.). Fiscal policy formulation and implementation in oil-producing countries cit., p. 251; ANDERSON, George. Reflections on oil and gas in federal systems. In: ANDERSON, George (Ed.). Oil \& gas in federal systems cit., p. 375 e 393 e SS.

964 TER-MINASSIAN, Teresa. Intergovernmental fiscal relations in a macroeconomic perspective: an overview. In: TER-MINASSIAN, Teresa (Ed.). Fiscal federalism in theory and practice cit., p. 9; NORREGAARD, John. Tax Assignment. In: TER-MINASSIAN, Teresa (Ed.). Fiscal federalism in theory and practice cit., p. 68; BOADWAY, Robin; SHAH, Anwar. Fiscal federalism cit., p. 187-207 e ss; BIRD, Richard M.; VAILLANCOURT, François. Introduction and summary. In: BIRD, Richard M.; VAILLANCOURT, François (Ed.). Perspectives on fiscal federalism cit., p. 11; McKENZIE, Kenneth J. Fiscal federalism and the taxation of nonrenewable resources. In: BIRD, Richard M.; VAILLANCOURT, François (Ed.). Perspectives on fiscal federalism cit., p. 253 - o autor foca não apenas no apecto equitativo, mas igualmente em um critério de eficiência, é dizer: a manutenção dessas receitas no Estado explorador conduz a uma "migração populacional fiscalmente induzida", que se revela ineficiente numa perspectiva nacional; BROSIO, Giorgio. The assignment of revenue from natural resources. In: AHMAD, Ehtisham; BROSIO, Giorgio. Handbook of fiscal federalism cit., p. 447; AHMAD, Ehtisham; MOTTU, Eric. Oil revenue assignments: country experiences and issues. In: DAVIS, J.; OSSOWSKI, R.; FEDELINO, A. (Org.). Fiscal policy formulation and implementation in oil-producing countries cit., p. 217; BROSIO, Giorgio. Oil revenue and fiscal federalism. In: DAVIS, J.; OSSOWSKI, R.; FEDELINO, A. (Org.). Fiscal policy formulation and implementation in oil-producing countries cit., p. 250: "When oil rents are assigned exclusively to subnational governments, they tend to produce vast horizontal imbalances-that is, extremely large disparities in per capita revenues of subnational units"; ANDERSON, George. Introduction. In: ANDERSON, George (Ed.). Oil \& gas in federal systems cit., p. 3; ANDERSON, George. Reflections on oil and gas in federal systems. In: ANDERSON, George (Ed.). Oil \& gas in federal systems cit., p. 375.

965 BOADWAY, Robin; SHAH, Anwar. Fiscal federalism cit., p. 234. 
reduzir as desigualdades regionais ${ }^{966}$ - art. $3 .^{\circ}$, III, da CF/88. Logo, repudia a este objetivo fundamental da república que as exações com potencial para grande desigualdade entre entes subnacionais sejam descentralizadas. É, claramente, o caso dos royalties de recursos naturais não renováveis.

Note-se que não se trata apenas de evitar que as desigualdades já existentes cresçam (como no caso de Estados já economicamente privilegiados por fatores quaisquer e que ainda contam com grandes minas ou jazidas e portanto recebem vastas somas de royalties), mas igualmente se trata de promover a redução dessas desigualdades.

Isto é: apenas a União, através de suas transferências, é capaz de levar adiante a equidade fiscal. Apenas a União será capaz de privilegiar um Estado pobre em detrimento de outro rico, o que pode fazer através do desenho de um sistema de transferências fiscais (como já faz o FPE, embora os quoeficientes relacionados a essa redução de desigualdades possam ser considerados insuficientes) - e lembrando que no Brasil, diferente da Alemanha, não existe até o presente um sistema de transferências horizontais (dos entes subnacionais mais ricos aos mais pobres). ${ }^{967}$ Então, só a União pode manter um sistema fiscal horizontalmente equânime em face da exploração dos recursos naturais não renováveis, o que, vale refrisar, torna-a candidata preferencial na definição de quem deve gerir as receitas públicas daí decorrentes.

Há, finalmente, também, a questão da corrupção, que é facilitada quando os recursos públicos são geograficamente concentrados em proporções superiores à capacidade de absorção do ente público. ${ }^{968-969}$

966 "Decisions must be made not only on considerations of of economic efficiency and economic frowth at the national level but also on consequences for economic development in the different regions of the nation" (idem, ibidem, p. 218).

967 "From an economics perspective, a case can be made that the federal government has a role in addressing the inefficiencies and inequities resulting from an oil and gas boom in a particular state. This role could involve redistributive interstate transfers, the use of the federal spending power to influence state behavior via conditional grants, federal taxation and spending policies that might mute the consequences of inefficient state building, and serving as a coordinator to induce cooperative behavior among states" (BOADWAY, Robin; SHAH, Anwar. Fiscal federalism cit., p. 227).

968 BROSIO, Giorgio. The assignment of revenue from natural resources. In: AHMAD, Ehtisham; BROSIO, Giorgio. Handbook of fiscal federalism cit., p. 450.

969 "Moreover, the transparency in expenditure management needed to ensure an effective stabilization fund would be difficult to establish at the central level and more so at the subnational level, where expenditure management procedures and reporting practices are likely to be rudimentary". AHMAD, Ehtisham; MOTTU, Eric. Oil revenue assignments: country experiences and issues. In: DAVIS, J.; OSSOWSKI, R.; FEDELINO, A. (Org.). Fiscal policy formulation and implementation in oil-producing countries cit., p. 224; ANDERSON, George. Reflections on oil and gas in federal systems. In: ANDERSON, George (Ed.). Oil \& gas in federal systems cit., p. 398 e ss. 
Por todas essas razões, a teoria do federalismo fiscal recomenda que a cobrança dos royalties seja feita pelo ente central; e que as receitas públicas arrecadadas fiquem, principalmente, com o ente central.

Claro que existem algumas moderações. Especialmente, é frequente na literatura a lembrança de que os Estados e Municípios produtores arcam com os custos pelo fornecimento da infraestrutura necessária ao desenvolvimento dos projetos de exploração dos recursos naturais não renováveis. ${ }^{970}$ Esta é uma atribuição que muitas vezes recai sobre estes entes subnacionais, e que não é compartilhada com os demais da federação e que, por isso, fortalece seus pleitos por uma participação desigual em relação aos demais entes de mesmo nível na arrecadação dos royalties. É importante lembrar, contudo, que tais argumentos relacionados ao fornecimento de infraestrutura se tornam muito frágeis quando a extração é offshore, em que os serviços públicos demandados em terra são muito reduzidos. ${ }^{971}$

As noções acima referidas foram apresentadas de forma sintética e objetiva por Teresa Ter-Minassian. Consignou:

A distribuição das receitas dos recursos naturais não renováveis (royalties, acordos de partilha da produção ou dos dividendos de empresas estatais nesses setores) entre os diferentes níveis do governo é um dos temas mais controvertidos nas relações fiscais intergovernamentais. A literatura teórica sobre o assunto normalmente defende a centralização de tais recursos por razões econômicas (para evitar transmitir aos orçamentos subnacionais a alta volatilidade associada a este tipo de receita) e por razões de distribuição (porque os recursos naturais não renováveis (RNNR) estão frequentemente concentrados em algumas jurisdições subnacionais). No entanto, também é reconhecido que há justificação para transferir parte das receitas dos recursos às entidades subnacionais onde os recursos estão localizados, para compensá-las pelos danos ambientais resultantes da

970 BOADWAY, Robin; SHAH, Anwar. Fiscal federalism cit., p. 207 e ss.; McKENZIE, Kenneth J. Fiscal federalism and the taxation of nonrenewable resources. In: BIRD, Richard M.; VAILLANCOURT, François (Ed.). Perspectives on fiscal federalism cit., p. 257; BROSIO, Giorgio. The assignment of revenue from natural resources. In: AHMAD, Ehtisham; BROSIO, Giorgio. Handbook of fiscal federalism cit., p. 447; ANDERSON, George. Reflections on oil and gas in federal systems. In: ANDERSON, George (Ed.). Oil \& gas in federal systems cit., p. 376.

971 "The influence of resource-rich local jurisdictions is evidenced by the recent trend in allocation of revenue from off-shore petroleum. This resource, which is generally the property of the central government, is presently shared among neighbouring subnational governments in a number of countries, such as Canada, Australia, Brazil and Italy. Since there are much lower infrastructure costs and almost no externalities from offshore exploration and production, the sharing with subnational government shows the intensity of their pressures and the difficulty of resisting them" (BROSIO, Giorgio. The assignment of revenue from natural resources. In: AHMAD, Ehtisham; BROSIO, Giorgio. Handbook of fiscal federalism cit., p. 446). 
exploração dos recursos e para cobrir as necessidades de infraestrutura adicional para tais fins. ${ }^{972}$

Essas considerações seriam suficientes para - com base na teoria do federalismo fiscal - analisar criticamente o esquema atual brasileiro de partilha dos royalties do petróleo e dos royalties da mineração (CFEM).

Contudo, este ainda não é o objetivo final ora perquirido. Como anunciado antes, o que se quer é utilizar os instrumentos teóricos dos capítulos anteriores - tanto os relacionados às armadilhas da exploração dos recursos naturais como os relacionados à justiça entre gerações, e mais especificamente a zona de encontro entre ambos - para avaliar o federalismo fiscal brasileiro, aplicado aos royalties.

A teoria do federalismo fiscal, propriamente dita, pouco se importa com o caráter intrínseco da não renovabilidade dos recursos naturais - e os impactos daí decorrentes nos interesses das gerações pósteras. Por isso, do ponto de vista do federalismo fiscal, pode ser desenhado um sistema em que os royalties e os tributos entrecruzam-se para alcançar um equilíbrio federativo.

Assim não ocorre, contudo, segundo as bases que se procurou construir nos capítulos anteriores. Isto é: o que ora se pleiteia é que os royalties não podem ser considerados como mais uma receita pública; que suas características próprias exigem que se lhe dê tratamento diferenciado. E que, portanto, a governança dessa receita pública deve observar pressupostos específicos, trazidos pela finitude do bem, e que incorporem os interesses das futuras gerações.

Daí é que se pretende ofertar uma orientação temporal (oriunda da noção intergeracional) à partilha espacial (sistema de transferências - federalismo fiscal).

Já deve ter ficado claro pelas razões atrás expostas - embora ainda não colocado de forma enfática e direta, como se faz agora - que uma das formas ora favorecidas de governança das receitas públicas decorrentes da exploração de recursos naturais não renováveis é aquela que se dirige à diversificação da base produtiva.

A diversificação econômica importa em modo de proteção das finanças nacionais contra os possíveis efeitos deletérios da exploração mineral. Ela combate a dependência àquela atividade exploratória, estimulando a atuação de outros

972 TER-MINASSIAN, Teresa. Reforma do fundo de participação dos estados. BID: Texto para debate. IDB-DP-216, mar. 2012. p. 8. 
empreendimentos. Assim, confronta os efeitos perversos da volatilidade associada aos recursos naturais não renováveis, ao passo em que incrementa outras bases arrecadatórias, que podem (ajudar a) suportar a economia em tempos de baixa dos preços dos bens minerais ou petrolíferos; contrapõe o comportamento rentista, ofertando outras atividades lucrativas à sociedade, não apenas ligadas ao setor extrativista; enfrenta a doença holandesa, esta que tem como pressuposto a migração de bens à atividade exploratória; afronta o fenômeno da redução na carga tributária dos Entes beneficiados, estimulando que outras bases imponíveis sejam cultivadas. ${ }^{973}$

Da mesma forma, uma política de diversificação produtiva tem relevantíssima participação na questão intergeracional. Ela atende aos preceitos econômicos que demandam uma aplicação das rendas minerais em capital reprodutível, possibilitando a criação de riqueza nova, em substituição aos bens finitos explorados, para que esteja à disposição das futuras gerações ${ }^{974}$ Ela remete à poupança justa rawlsiana, ${ }^{975} \mathrm{em}$ que "cada geração faz uma contribuição em favor daqueles que vêm depois e a recebe de seus

973 "Perhaps most indicative of its different behavior, the Norwegian government sought to protect the state's non-oil fiscal capacity. As corporate revenues from petroleum shot up, is resisted the strong temptation to permit oil revenues to replace its normal revenue base by lowering taxes". KARL, Terry Lynn. The paradox of plenty cit., p. 220. Para Jeffrey Sachs, "the starting point of managing oil, therefore, is taking a long-term view of national development [...] First, development depends on a mixed economy". SACHS, Jeffrey D. How to handle the macroeconomics of oil wealth. In: HUMPHREYS, Macartan; SACHS, Jeffrey D.; STIGLITZ, Joseph E. (Org.). Escaping the resource curse cit., p. 175. Rodrigo Valente Serra destaca a relevância da diversificação produtiva, embora, de maneira muito diversa do que ora se pretende, vincula esta tarefa com o âmbito local, destacando que os royalties devem refletir a relevância da indústria exploradora no Município. A opinião parece deslocada, máxime diante da constatação de que estimula a maior dependência, não a reprime. Assim: "No nível subnacional a política de promoção da justiça intergeracional deve ser realizada, portanto, através da diversificação produtiva, ou de alguma outra estratégia que procure minimizar os efeitos depressivos sobre a região que ocorrerão quando do esgotamento econômico das jazidas. Assim, o pagamento de royalties a unidades subnacionais deveria ser feito na proporção da importância, para o município, da atividade econômica associada à indústria do petróleo" (SERRA, Rodrigo Valente. Rendas petrolíferas no Brasil: critérios de distribuição distorcidos induzem ineficiência do gasto. In: MENDES, Marcos (Org.). Gasto público eficiente cit., p. 212).

974 "Faz grande diferença gastar os recursos em despesas correntes e assistencialismo ou investir na diversificação produtiva e formação de capital humano. Um real empregado em novas alternativas para criação de emprego e renda tem a capacidade de se multiplicar, enquanto que um real empregado em despesas correntes simplesmente se consome na hora do gasto, ou seja, não tem a capacidade de se propagar pela economia. Ao contrário, por vezes ele cria novas obrigações que onerarão a receita futura" (ENRÍQUEZ. Maria Amélia. Mineração... cit., p. 347). Paulo Springer de Freitas recomenda "que sejam destinados a projetos que elevem o nível de produtividade da economia, como em educação e infraestrutura" (FREITAS, Paulo Springer de. Rendas do petróleo... cit., p. 5).

975 "When little or nothing is known about oil reserves and their value, a proponent of Rawls' theory of justice would suggest that these revenues should be centralized because of the large uncertainty concerning the distribution of oil reserves among the various areas of the country. In other words, every individual would vote for centralization, if he or she had to decide under a 'veil of ignorance' and faced with the possible risk of receiving no revenue, if it turns out that his or her region has no reserves at all and oil property rights are decentralized" (BROSIO, Giorgio. Oil revenue and fiscal federalism. In: DAVIS, J.; OSSOWSKI, R.; FEDELINO, A. (Org.). Fiscal policy formulation and implementation in oil-producing countries cit., p. 255). 
predecessores". ${ }^{976}$ E observa, igualmente, a noção de desenvolvimento (financeiramente) sustentável, legando ao futuro condições iguais ou melhores que as encontradas, atendendo ao princípio da conservação de opções de Weiss: ${ }^{977}$ embora comprometendo irremediavelmente uma opção (exploração do próprio recurso natural), deixa à posteridade opções outras de atividades econômicas. Como colocam Sunstein e Rowell, "quaisquer obrigações éticas são satisfeitas se o presente puder fazer valer a pena para as futuras gerações o risco ou riscos aos quais as sujeita". 978

E ainda, observando as lições de Celso Furtado, o investimento em diversificação econômica contribui para a superação do subdesenvolvimento, inclusive através da fuga da herança colonial que coloca o Brasil em condição periférica. ${ }^{979}$

Então, "é de se esperar que os tributos e outros benefícios arrecadados pela atividade petrolífera sejam aplicados em atividades que proporcionem alguma renda no futuro, quando o petróleo e o gás natural se exaurirem, pois as gerações futuras não mais terão esta fonte de renda". 980

Especialmente, a ideia de diversificar a economia brasileira é antagonizada por aquela que seria (e muitas vezes é) a forma deletéria de utilização das receitas públicas oriundas dos recursos naturais não renováveis: seu direcionamento ao consumo corrente, este que não gera frutos, incentiva abusos, aceita riscos, promove desequilíbrios, estimula dependência, frustra as gerações futuras, e perde a oportunidade de alterar estruturalmente as condições econômicas nacionais.

976 RAWLS, John. Uma teoria da justiça cit., p. 317.

977 WEISS, Edith Brown. In fairness to future generations cit., p. 40-42.

978 SUNSTEIN, Cass R.; ROWELL, Arden. On discounting regulatory benefits: risk, money, and intergenerational equity cit., p. 20-21. Tradução livre.

979 "O desenvolvimento da economia venezuelana exigirá no futuro uma diversificação da estrutura econômica relativamente mais intensa que a observada no passado. Isso significa que a produtividade tem que aumentar de forma mais igual no conjunto das atividades econômicas e que a estrutura ocupacional da população terá que se modificar fundamentalmente". FURTADO, Celso. O desenvolvimento recente da economia venezuelana, 1957. In: FURTADO, Celso. Ensaios sobre a Venezuela... cit., p. 64. Ainda: "Em relação à estrutura produtiva, as variáveis-chave na análise de Furtado eram a taxa de câmbio real e os salários, além da política de compras do governo. Historicamente, com o câmbio valorizado e os salários do setor formal refletindo parcialmente a riqueza do petróleo, a produção nacional de bens comercializados requeria elevada barreira protecionista, e a falta de política industrial congelava uma estrutura produtiva ineficiente. Parte dessa realidade permanece nos dias atuais, pois falta uma política de diversificação produtiva em condições de rápida recuperação do poder de compra dos salários". MEDEIROS, Carlos Aguiar de. Celso Furtado na Venezuela. In: FURTADO, Celso. Ensaios sobre a Venezuela... cit., p. 154.

980 SERRA, Rodrigo; PATRÃO, Carla. Impropriedades dos critérios de distribuição dos royalties no Brasil. In: PIQUET, Rosélia (Org.). Petróleo, royalties e região cit., p. 193. 
Com essas considerações, cabe tornar a questionar: a qual nível federativo devem ser atribuídas as receitas públicas decorrentes da exploração de recursos naturais não renováveis, observando o propósito preferencial de promoção da diversificação produtiva? Mais uma vez - e reiterando as conclusões oriundas da doutrina do federalismo fiscal -, esta alocação há de ser preferencialmente na União.

Ora, embora seja possível afirmar que os entes mais descentralizados têm melhores condições de identificar as preferências da população, deve-se fixar que a gestão destes valores nos entes públicos locais e regionais encontra sérias dificuldades quando o tema é diversificação produtiva. Os entes subnacionais possuem informações suficientes (sejam elas culturais, técnicas, fiscais, econômicas, etc.), se tanto, de um universo restrito. Os limites constitucionais materiais e legislativos lhes deixam pouca margem para inquirir em quê, quem, quando, onde e como se estimularia a produção de bens não relacionados à lavra. ${ }^{981}$ Vale lembrar também que há vários possíveis desenhos de mecanismos institucionais que permitem integrar a governança pelo ente central com as preferências coletadas pelos entes regionais. Por exemplos, esses mecanismos podem ser de gestão compartilhada (como ocorre com Fundos como o FUNDEB ${ }^{982-983}$ ), de fomento produtivo,

981 FREITAS, Paulo Springer de. Rendas do petróleo... cit., p. 30 - "sem dúvida, é desejável que uma região se prepare para o futuro. E o município, por ter uma economia menos diversificada do que os estados e a União, tenderia a sofrer mais com o declínio da atividade de extração do petróleo". Daniel Bregman (BREGMAN, Daniel. Um estudo sobre a aplicação dos royalties petrolíferos no brasil. Brasília: ESAF, 2007. p. 15) sustenta que: "Outra questão que emerge é o papel dos governos estaduais e municipais, maiores beneficiários dos royalties, como líderes da promoção de políticas públicas que promovam a diversificação das regiões produtoras. Pela proximidade com a população e o melhor conhecimento da economia das regiões, eles têm maior capacidade de diagnosticar as vocações econômicas, no entanto seu corpo técnico tem pouca experiência na promoção de amplas políticas públicas: papel historicamente destinado ao governo federal". Documento do Conselho Internacional de Mineração Metálica (ICMM. Minerals taxation regimes: a review of issues and challenges in their design and application. Report published with the Commonwealth Secretariat. Disponível em: <http://www.icmm.com/ page/12880/minerals-taxation-regimes-report-published-with-the-commonwealth-secretariat>. 2009. p. 47) indica: "A compromise lies in making financial resources available to the entire and broadly-defined region affected by resource development, rather than just to the administrative district where the mineral resource happens to be located. Compromises are always necessary, because there are no good solutions to the problem of how to define affected communities in terms of administrative boundaries".

982 AFONSO, José Roberto Rodrigues; GOBETTI, Sérgio Wulff. Rendas do petróleo no Brasil: alguns aspectos fiscais e federativos cit., p. 231- 269, dez. 2008, p. 264: "Já a alocação de recursos deveria seguir a lógica de um Fundo Soberano, cuja busca do interesse nacional poderia nortear mesmo aplicações realizadas dentro do país. Já existe uma experiência bem-sucedida de formação de poupança pública e aplicação na indução de investimentos produtivos e geração de empregos - o Fundo de Amparo ao Trabalhador (FAT) -, que alimenta um banco nacional de desenvolvimento e tem uma história e uma dimensão raramente encontrada em outras economias emergentes. Também há uma experiência mais recente na formação de um fundo que beneficia governos de diferentes esferas (estadual e seus respectivos municípios) e bem-sucedida em termos da operacionalização financeira - os fundos estaduais de valorização do ensino básico (Fundef e, agora, Fundeb). Aproveitando tais experiências, poderia ser constituído não apenas um fundo, mas diferentes fundos, de caráter regional ou mesmo local, para formação da poupança e sua aplicação, especialmente em investimentos em infraestrutura econômica e social". 
ou mesmo a imposição de uma localidade ou região onde a União deverá gastar - o que não significa entregar os recursos para que sejam gastos pelo Ente Descentralizado. ${ }^{984}$

Vale lembrar que compete à União "elaborar e executar planos nacionais e regionais de ordenação do território e de desenvolvimento econômico e social", consoante estabelece o art. 21, IX, do texto constitucional. A União "poderá articular sua ação em um mesmo complexo geoeconômico e social, visando a seu desenvolvimento e à redução das desigualdades regionais" (art. 43, caput). A União possui instrumento tributário específico para "intervenção no domínio econômico" (CIDE - art. 149). Outrossim, vê-se que as instituições de fomento municipais são poucas ou nulas; as Estaduais são limitadas; apenas no âmbito da União, especialmente em órgãos como SUDAM, SUDENE e BNDES, tal atividade ganha maior corpo.

A promoção da diversificação frequentemente exige parques industriais largos, que extrapolam as fronteiras estaduais (especialmente quando consideradas as regiões conforme sua vocação ou seu solo, ou quaisquer fatores externos aos limites políticos entre Estados) ou municipais (que podem inclusive já estar abarrotados com a indústria extrativista e todos os prestadores de serviços que os cercam), criando mais uma fonte de desinteresse para os gestores dos entes subnacionais.

Cabe concordar com Boadway e Shah, que utilizam a região fictícia de Petrolia para argumentar. Questionam: "Petrolia é necessariamente um bom lugar onde promover a diversificação?". E respondem: "Não é nem um pouco claro que a localização de valiosos depósitos de riqueza de recursos naturais deva ela própria ditar a localização de nódulos para o desenvolvimento e crescimento de atividade econômica diversificada. Pelo contrário, recursos naturais são frequentemente localizados em áreas remotas que não têm quaisquer outras vantagens naturais para o desenvolvimento econômico". 985

983 SERRA, Rodrigo Valente. Rendas petrolíferas no Brasil: critérios de distribuição distorcidos induzem ineficiência do gasto. In: MENDES, Marcos (Org.). Gasto público eficiente cit., p. 239. "Tomando-se como exemplo as normas de repasses municipais vigentes no Sistema Único de Saúde ou no FUNDEF, verifica-se a exigência legal de conselhos gestores e fiscalizadores das receitas destes programas. A importância dos recursos das participações governamentais para o destino das regiões petrolíferas e suas áreas de influência poderia também justificar mecanismos especiais, previstos em lei, de consulta e fiscalização sobre sua destinação".

984 ROSS, Michael L. How Mineral-rich States can reduce inequality. In: HUMPHREYS, Macartan; SACHS, Jeffrey D.; STIGLITZ, Joseph E. (Org.). Escaping the resource curse cit., p. 250: "giving subnational governments either the authority to levy mineral taxes or a fixed share of the nation's oil revenues should be avoided whenever possible. The best approach is for governments to collect revenues centrally, and make allocation decisions centrally, but with input from local and regional authorities".

985 BOADWAY, Robin; SHAH, Anwar. Fiscal federalism cit., p. 223. Tradução livre. 
Estas razões seriam suficientes para fixar que, do ponto de vista da diversificação produtiva, é recomendável que os recursos públicos sejam alocados primordialmente junto à União Federal.

Mas não é só.

Ultrapassando essas considerações, vale questionar: que implicaria outorgar essa responsabilidade - diversificação produtiva - para que seja levada a efeito pelos Estados, utilizando das receitas oriundas da exploração?

É evidente que isto implicará uma extensão das desigualdades regionais. O Estado produtor passará não apenas a ter benefícios naturalmente arbitrários (posição dos recursos minerais), como desenvolverá, apenas dentro de suas fronteiras, benefícios econômicos, sociais e tributários. ${ }^{986}$ Terá mais empregos, arrecadará mais tributos. E isto ofende frontalmente o objetivo fundamental da República de diminuir as diferenças entre regiões - e não exarcebá-los - para além de contrariar a noção rawlsiana de justiça, que desenvolve o conceito do véu da ignorância justamente para evitar que tais privilégios arbitrários sejam perpetuados.

Portanto, não apenas quanto às competências constitucionais e quanto à aptidão para promover a diversificação produtiva é que estes recursos estarão melhores alocados na União. ${ }^{987}$ A isonomia horizontal também assim demanda.

E há mais. Embora fundamentalmente diferente, ${ }^{988}$ a equidade intergeracional não prescinde da promoção da justiça redistributiva intrageracional. ${ }^{989}$ Afinal, cada geração carrega "a sua respectiva parte do ônus de realizar e preservar uma sociedade

986 Idem, ibidem, p. 208, 210, 227 e 228.

987 “A literatura econômica sugere, como vimos, que as receitas do petróleo sejam preferencialmente geridas de modo centralizado em decorrência da inaptidão dos governos subnacionais em lidar com o caráter volátil e intergeracional desses recursos". SERRA, Rodrigo Valente; GOBETTI, Sérgio Wulff. Petróleo, royalties e desenvolvimento: Brasil e experiências internacionais. In: MONIÉ, Frédéric; BINSZTOK, Jacob (Org.). Geografia e geopolítica do petróleo cit., p. 195.

988 Em sentido contrário, apontando para a existência de um mesmo príncípio de justiça intra $e$ intergeracional, mas de qualquer forma amparando a suscitada relação próxima existente entre um e outro ficos de justiça distributiva: "as interações entre tais tipos de justiça mostram que a forma adequada de compreendê-las é através de uma unicidade. Com tal sentido, enxerga-se a justiça intra e intergeracional como uma única justiça, de similar conteúdo e igual necessidade de concretude, porém com diversas formas de efetivação". COSTA, Hirdan Katarina de Medeiros; SANTOS, Edmilson Moutinho dos. Justiça e sustentabilidade: a destinação dos royalties de petróleo cit., p. 148.

989 "The theory of intergenerational equity outlined here asserts that all peoples also have a set of intragenerational planetary obligations and planetary rights designed to implement justice between generations [...] How can we expect an impoverished community to care about future generations, if it cannot even care for its own people today?". WEISS, Edith Brown. In fairness to future generations cit., p. 21 e 27. 
justa", 990 e "as pessoas de diferentes gerações têm deveres e obrigações em relação umas às outras exatamente como as têm as pessoas que vivem numa mesma época". ${ }^{991}$ Então, "o propósito da sociedade humana deve ser realizar e proteger o bem-estar e a prosperidade de cada geração".992

E, novamente, quando o tema é redistribuição de renda e riqueza, é o Ente central quem deve tomar a dianteira. ${ }^{993}$

Finalmente, cumpre retomar o tema da proteção macroeconômica do país, especialmente contra a supervalorização cambial que desemboca na doença holandesa. É tema de inequívoco interesse intergeracional, na medida em que pode, se mal administrado, prejudicar a acumulação de riqueza e mesmo o desenvolvimento de projetos - como a da diversificação econômica - que tornam duradoura a riqueza obtida a partir da exploração dos recursos naturais.

Mais uma vez, há de se reconhecer que é na União que residem os poderes de gerência macroeconômica. ${ }^{994}$ Basta ver que cabe ao Ente central "emitir moeda" (CF, art. 21, VII), "administrar as reservas cambiais do País e fiscalizar as operações de natureza financeira, especialmente as de crédito, câmbio e capitalização, bem como as de seguros e

990 RAWLS, John. Uma teoria da justiça cit., p. 321.

991 Idem, ibidem, p. 323.

992 WEISS, Edith Brown. In fairness to future generations cit., p. 23. Tradução livre. Destaque acrescido.

993 NORREGAARD, John. Tax Assignment. In: TER-MINASSIAN, Teresa (Ed.). Fiscal federalism in theory and practice cit., p. 53-54. "The literature on fiscal federalism and local government finance generally suggests that the following criteria and consideration should form the basis for decisions on which taxes can adequately be assigned to the subcentral level and which should remain at the national level. - To the extent that the tax in question is aimed at, and is suitable for, economic stabilization or income redistribution objectives, it should be left to the responsibility of the central government". Angelo Duarte, Alexandre Silva e Everelado Luz (DUARTE, Angelo José Mont'alverne; SILVA, Alexandre Manoel Angelo da; LUZ, Everaldo Manoel; e GERARDO, José Carlos. Transferências fiscais intergovernamentais no Brasil cit., p. 9-10) sustentam: "Conforme os princípios de eficiência propostos na teoria da tributação ótima, Mcluren (1983) elaborou um desenho de sistema tributário para um país organizado sob a forma de federação, cujas principais conclusões sobre a distribuição das competências tributárias são as seguintes: [...] • impostos sobre recursos naturais, mesmo que cobrados na origem, devem ser de competência federal; $\bullet$ a capacidade fiscal pode ter uma distribuição bastante desigual entre os governos subnacionais, havendo necessidade de mecanismos de equalização horizontal, em geral implementados por meio do governo central". Para Biadway e Shah (BOADWAY, Robin; SHAH, Anwar. Fiscal federalism cit.), "Decetralization of the delivery of poverty alleviation program poses a challenge for this coordination effort. The benefits of efficiency of delivery are achieved by giving local agencies the responsibility for delivering individual programs. They are not in the best position to coordinate with other agencies in other program areas", p. 460, E ainda, diz Ter-Minassian: "It must be recognized that a high degree of decentralization may come in serious conflict with distributional objectives". TER-MINASSIAN, Teresa. Intergovernmental fiscal relations in a macroeconomic perspective: an overview. In: TER-MINASSIAN, Teresa (Ed.). Fiscal federalism in theory and practice cit., p. 22. Oates aponta no mesmo sentido: OATES, Wallace E. Fiscal federalism cit., p. 150.

994 TER-MINASSIAN, Teresa. Intergovernmental fiscal relations in a macroeconomic perspective: an overview. In: TER-MINASSIAN, Teresa (Ed.). Fiscal federalism in theory and practice cit., p. 23. 
de previdência privada" (art. 21, VIII), legislar sobre "sistema monetário e de medidas, títulos e garantias dos metais" (art. 22, VI), "política de crédito, câmbio, seguros e transferência de valores" (art. 22, VII), “comércio exterior" (art. 22, VIII).

Assim é que Ahmad e Mottu revelam-se incisivamente contrários às transferências de receitas públicas decorrentes da exploração de recursos naturais não renováveis aos entes subnacionais. Para os autores, ao fazê-lo, a nação está fazendo-se desprotegida das intempéries macroeconômicas, prejudicando a utilização de instrumentos que estariam disponíveis apenas no nível central de governo. ${ }^{995}$

Tudo o que permite analisar criticamente a repartição, hoje existente, dos royalties minerais e petrolíferos brasileiros.

Inicie-se pela CFEM. Como já se viu, na partilha dessas receitas públicas, são fortemente privilegiados os Municípios. Reputa-se que este modelo de transferências é, a partir das noções aqui buscadas, deveras viciado. Os entes locais são inaptos, de fato e de direito, para promover diversificação produtiva. São inaptos a promover ações redistributivas. São também inaptos a utilizar instrumentos de proteção macroeconômica.

Daí que a priorização destes Entes na partilha da CFEM deixa o país desprotegido contra os efeitos deletérios da exploração; e é prejudicial aos interesses das gerações futuras.

Nos royalties petrolíferos (aí incluídas as participações especiais), a situação é melhor, embora não muito. As mesmas conclusões valem para as parcelas em que os

995 AHMAD, Ehtisham; MOTTU, Eric. Oil revenue assignments: country experiences and issues. In: DAVIS, J.; OSSOWSKI, R.; FEDELINO, A. (Org.). Fiscal policy formulation and implementation in oil-producing countries cit., afirmam: "The least preferred solution is oil-revenue sharing. By taking away large amounts of revenue from the central government, it precludes and complicates macroeconomic management. By fully transmitting the volatility of oil revenue to subnational governments, it does not provide stable financing of local public services, and it usually does not manage to diffuse separatist tendencies, since oil-producing regions can still be better off by keeping 100 percent of their oil revenues [...] The data also confirm that the volatility of total revenues is greater when the share of oil revenues in total revenues is higher" - p. 218; "Revenue sharing, however, has major drawbacks with regards to macroeconomic management and overall fiscal discipline (Ter-Minassian, 1997b). Revenue-sharing arrangements reduce the revenue base that the central government can use to stabilize the economy or to adjust the fiscal policy stance-they may distribute revenues that are not commensurate to subnational governments' spending needs-and they leave subnational governments vulnerable to potentially large swings in oil revenues. In addition, these arrangements tend to be politically controversial and unstable" - p. 229; "Because revenue-sharing arrangements take away large amounts of revenue from the central government, they complicate macroeconomic management. Sharing a large revenue source-such as oil taxation- reduces the capacity of the central government to run countercyclical fiscal policies or implement effective fiscal adjustment. The central government may be left with little revenue to exert a significant macroeconomic impact, and subnational governments may not be willing to follow a policy determined at the central level, especially in the case of fiscal adjustment" - p. 236-237. 
Estados e Municípios recebem a maior parte dessa receita pública. Mesmo que as maiores transferências se deem nas explorações terrestres, alíquotas que chegam a $70 \%$ para os Estados revelam-se demasiadas, em patamar superior ao do simples desiderato de referir os gastos com a infraestrutura a ser fornecida, considerando também que o sistema brasileiro já prevê, nas competências tributárias outorgadas a esses entes, uma resposta (ao menos parcial) à maior pressão por serviços públicos demandada nas áreas desses projetos.

Vale lembrar que, na verificação dos sistemas de rateio de 12 (doze) países federais de diferentes matizes, promovida por George Anderson, o Brasil é o único que compartilha receita de recursos naturais com os entes políticos locais (Municípios) ${ }^{996}-$ nos demais países selecionados, esta partilha alcança apenas os entes regionais (Estados).

Quando se trata de royalties marítimos, as participações dos Estados e Municípios caem para níveis bem menores (cerca de $20 \%$ e 5\%, respectivamente, em grossa média). Estes valores são mais adequados, embora ainda possam ser considerados excessivos, especialmente quando se observa que a pressão por serviços públicos é deveras reduzida, eis que a exploração sequer se dá em seus territórios. ${ }^{997}$

E há o sistema de repartição com todos os Estados e Municípios da federação, através de Fundos que imitam os critérios dos Fundos de Participação de Estados e Municípios. Os percentuais são relevantes (geralmente em torno de 20\%) no sistema de partilha e no sistema de concessão para exploração marítima, embora com nenhuma participação nos royalties terrestres submetidos ao sistema de concessão.

Este sistema amplo de repartição é tido como virtuoso por vários estudiosos. ${ }^{998}$ Cabe, respeitosamente, discordar.

Com a teoria do federalismo fiscal, as considerações trazidas pelas análises específicas da exploração de recursos naturais não renováveis, e também com a perspectiva intergeracional, já se sustentou que as receitas públicas devem ser direcionadas ao ente

996 ANDERSON, George. Reflections on oil and gas in federal systems. In: ANDERSON, George (Ed.). Oil \& gas in federal systems cit., p. 378 e 379.

997 Idem, ibidem, p. 379. O autor considera ainda, especificamente no caso do Brasil, que as linhas geodésicas ortogonais fixadas para definir quem são os entes "confrontantes" produzem uma fórmula arbitrária (p. 390), faltando ao regime de transferências brasileiro uma "arquitetuta coerente" (p. 391). Também entendendo que a exploração no mar não justifica (ou diminui sensivelmente sua razão) a participação diferenciada dos "confrontantes": BERCOVICI, Gilberto. Direito econômico do petróleo e dos recursos minerais cit., p. 343-344.

998 BERCOVICI, Gilberto. Direito econômico do petróleo e dos recursos minerais cit., p. 344; SCAFF, Fernando Facury. Royalties decorrentes da exploração de recursos naturais não renováveis cit., p. 480481; RUBINSTEIN, Flávio. Receitas públicas de recursos naturais no direito financeiro brasileiro cit., p. 197. 
político central. E a pulverização destas receitas nos demais entes subnacionais, por mais que possa ser defendida sob a égide da isonomia, não triunfa sobre aquelas razões certamente não as substitui.

$\mathrm{Na}$ forma de distribuição federativa que foi chamada de "sistema FPE (FPM) adaptado”, permanecem as causas pelas quais deitaram-se as críticas acima.

Os Estados e Municípios são incapazes, seja no plano de suas competências, seja pela falta de aptidão causada por suas limitações vocacionais e territoriais, a promover a diversificação da base produtiva. Os entes subnacionais, considerados amplamente - não apenas produtores e confrontantes - são ineficientes para conduzir programas de redistribuição de riqueza. E a partilha dos royalties entre todos os Estados e Municípios reproduz a fragilização da atuação da União no que concerne ao uso dos instrumentos macroeconômicos de proteção contra a volatilidade do mercado de bens minerais, bem como face aos distúrbios cambiais que levam à doença holandesa.

É bem verdade que pelo menos uma das objeções acima mencionadas seria endereçada: não se pode afirmar que a partilha dos royalties no "sistema FPE adptado" implicaria aumento das desigualdades regionais. Distribuindo a receita pública entre todos, é possível afirmar que essas iniquidades seriam mantidas ou reduzidas - dependendo de uma análise dos coeficientes que formam os Fundos de Participação.

Mas outras objeções podem também ser suscitadas para este sistema específico. É o caso daquela levantada por Celso Furtado que, analisando o processo de acumulação de capital e a distribuição do excedente de produção, afirma: "Se o fruto desse aumento de produção se distribuísse uniformemente com o conjunto da coletividade, logo seria consumido, sendo de efeito pouco persistente". ${ }^{999}$ Daí por que não seria alcançado o objetivo essencial do processo de acumulação: "a transformação do excedente em capacidade produtiva". ${ }^{1000}$

É dizer: a pulverização dos royalties em todos os Estados e Municípios, apesar de atender preceitos de isonomia, tem o efeito de minorar sua relevância, estimulando-lhe o consumo puro e simples, e dificultando-lhe transparência e controle. Estes, como já se

999 FURTADO, Celso. Desenvolvimento e subdesenvolvimento cit., p. 107. Furtado prossegue (p. 110) no mesmo sentido afirmando: "Por outro lado, se o fruto de um aumento, ocasional ou permanente, de produtividade fosse distribuído com o conjunto da população, o resultado seria apenas uma elevação ocasional ou permanente do nível de consumo, passando a economia de uma posição estacionária a outra, sem que se originasse um processo de crescimento".

1000 Idem, ibidem, p. 107. 
argumentou, são efeitos que, aplicados aos royalties de recursos naturais não renováveis, devem ser tidos por viciosos.

A receita de royalties, como tem se procurado enfatizar, é especial porque vinculada aos bens públicos finitos. E, por isso, deve ter tratamento diferenciado. Ao transferir essa receita de maneira ampla, inespecífica, em montantes necessariamente reduzidos (para alcançar todos os entes federativos), torna-se difícil ou mesmo despiciendo exigir sua aplicação orientada ao futuro; os entes públicos receptores não terão razões ou meios para desenvolver programas públicos nesse sentido.

Então, em face das referências teóricas ora adotadas, é de se concluir que também a distribuição dos royalties de recursos naturais não renováveis em sistemas assemelhados aos Fundos de Participação dos Estados e Municípios (assim como a distribuição que privilegia os entes subnacionais produtores ou confrontantes) merece críticas, falhando em formar um desenho de transferências fiscais que observe a equidade intergeracional e os possíveis (mas evitáveis) efeitos deletérios dessa atividade exploratória.

\section{3.d.iv. Crítica ao regime de vinculações ${ }^{1001}$ a órgãos da União.}

No atual sistema de partilha dos royalties petrolíferos, abandonou-se o sistema de vinculação a órgãos da União. Em vez disso, a parte que cabe ao ente político central será destinada ao Fundo Social da União, este que será referido mais adiante.

Contudo, nos royalties minerários (CFEM), a parte que cabe à União Federal ainda mantém este sistema de vinculações, de forma que todos os valores daí decorrentes estão previamente destinados, sendo: $2 \%$ do total arrecadado (e não da parte que cabe à União) ao Fundo Nacional de Desenvolvimento Científico e Tecnológico - FNDCT; demais 10\% ao Departamento Nacional de Produção Mineral; e, oriundos destes 10\%, $2 \%$ à “proteção mineral em regiões mineradoras”, por intermédio do IBAMA.

Vale lembrar que há quem considere inconstitucional o texto do art. $20, \S 1 .^{\circ}$, da Constituição Federal, mesmo tratando-se de norma constitucional originária. ${ }^{1002}$ Regis

1001 Entenda-se por "vinculação": "liame normativo (constitucional ou legal) estabelecido para a receita, unindo-a a certa despesa, órgão ou fundo". SCAFF, Fernando Facury. Royalties decorrentes da exploração de recursos naturais não renováveis cit., p. 394.

1002 "Em qualquer hipótese, cobra constatar que é norma inconstitucional (§ 1. $)$, quando estende os resultados dessa participação à exploração dos recursos da plataforma continental e da zona econômica 
Fernandes de Oliveira considera essas vinculações "sem sentido", eis que "órgão da União não pode receber recursos diretamente"; ${ }^{1003}$ Manoel Gonçalves Ferreira Filho as entende aberrantes. $^{1004}$

Mas este não é o objeto da crítica.

Quer-se verificar, com os mesmos instrumentos acima apresentados, se essas vinculações estão de acordo com a doutrina sobre os efeitos deletérios da exploração e, especialmente, com a observação da equidade intergeracional.

A vinculação ao FNDCT é uma que pode ser considerada de acordo com tais ideias. O Fundo tem como objetivo "financiar a inovação e o desenvolvimento científico e tecnológico com vistas em promover o desenvolvimento econômico e social do País", conforme dispõe o art. $1 .^{\circ}$ da Lei n. 11.540/2007. Os recursos que compõem o FNDCT deverão ser destinados a (art. 11) "apoio a programas, projetos e atividades de Ciência, Tecnologia e Inovação - C,T\&I, compreendendo a pesquisa básica ou aplicada, a inovação, a transferência de tecnologia e o desenvolvimento de novas tecnologias de produtos e processos, de bens e de serviços, bem como a capacitação de recursos humanos, intercâmbio científico e tecnológico e a implementação, manutenção e recuperação de infra-estrutura de pesquisa de C,T\&I".

Ora, o desenvolvimento científico e tecnológico é relevante na proteção dos interesses das futuras gerações. É o tipo de investimento público que dá frutos, construindo novos meios de produção ou aperfeiçoando os existentes, permitindo a reprodução da riqueza nacional, e buscando a superação do subdesenvolvimento.

Máxime em se tratando de recursos naturais não renováveis e de bens de relevância energética estratégica: a busca de meios alternativos de energia renovável é fundamental na perspectiva intergeracional, de forma a permitir que as gerações futuras

exclusiva: estes, nos precisos termos do inciso $\mathrm{V}$, pertencem à União. Não se vislumbra, aliás, de que modo a lei - cuja atuação é prevista - poderia contornar tal realidade. Além de tudo, soa como juridicamente inadmissível e igualmente inconstitucional a vinculação de receita contida na determinação de que, dos resultados da aludida exploração também participem os órgãos da administração direta da União: órgãos da administração direta não têm personalidade jurídica própria". SILVA, Paulo Napoleão Nogueira da. Artigos 20 ao 24. In: BONAVIDES, Paulo; MIRANDA, Jorge; AGRA, Walber de Moura. Comentários à Constituição Federal de 1988. Rio de Janeiro: Forense, 2009. p. 549-550.

1003 OLIVEIRA, Regis Fernandes de. Curso de direito financeiro cit., p. 247.

1004 FERREIRA FILHO, Manoel Gonçalves. Comentários à Constituição brasileira de 1988. São Paulo: Saraiva, 1992. p. 154. 
tenham acesso às mesmas condições atuais - e que não sejam frustradas com a utilização predatória dos meios energéticos.

Não por outra razão, Edith Brown Weiss considera que o desenvolvimento científico-tecnológico, direcionado a encontrar substitutos aos bens explorados, é obrigatório por parte das gerações atuais, devendo o Estado assegurar que este tipo de pesquisa seja levado a efeito; ${ }^{1005}$ assim como é obrigatória a pesquisa científica que se dirija a melhor conhecer (descobrir e avaliar) os impactos da exploração atual sobre o bemestar futuro, especialmente no meio ambiente. ${ }^{1006}$ A pesquisa científica, nesse viés, é um mandamento também de sustentabilidade financeira, como recorda Bouvier. ${ }^{1007}$

${ }^{1005}$ WEISS, Edith Brown. In fairness to future generations cit., p. 51.

${ }^{1006}$ Idem, ibidem, p. 66. Também Auerbach: "Not only is a policy of developing renewable energy resources desirable for its consequences, it is ethically mandatory for other reasons as well [...] Because these resources are non-renewable, any generation which consumes those resources incurs in a debt to future generations. This debt can be diminished by devolping technology which permits the remaining nonreneable resources to be exploited more efficiently ou by developing new sources of non-reneable energy [...] It is possible to repay our debt to posterity only by expanding the resource opportunities of all future generations. It is likely nthat this can be accomplished only by beginning immediately to convert from dependence on non-renewable energy resources to dependence on renewable energy sources". AUERBACH, Bruce E. Unto the thousandth generation cit., p. 240. E Pierre-Yves Bonin opina: "une génération serait justifiée d'épuiser totalement les réserves d'une source d'énergie (le pétrole), pour autant qu'elle fournisse aux générations suivantes une source équivalente d'énergie (le nucléaire). Les ressources énergétiques n'ont pas besoin d'être les mêmes, mais la nouvelle source d'énergie doit pouvoir rendre des services équivalents à l'ancienne" - p. 132 ; "Par conséquent, le seul espoir d'assurer aux générations futures un approvisionnement équivalent en ressources réside dans la recherche. Bien qu'un résultat positif ne soit pas garanti, on peut présumer que plus les investissements dans ce secteur seront importants, plus les chances de surmonter les difficultés à venir seront grandes. La justice entre les générations commande donc de substantiels investissements en recherche, qui devront être effectués par la génération actuelle des pays qui consomment le plus de ressources non renouvelables rares et précieuses" - p. 141; "La justice intergénérationnelle exige que chaque génération lègue à celles qui la suivent des conditions au moins similaires ou équivalentes à celles dont elle a elle-même bénéficié. Jusqu'aux années 1980, cette exigence a été relativement bien respectée. Pour continuer à s'y conformer, la génération actuelle des pays développés devrait investir dans la recherche scientifique et technologique et défrayer le coût du rétablissement et du maintien d'un environnement sain" - p. 145 . BONIN, Pierre-Yves. La justice internationale et le partage des ressources naturelles cit. Finalmente, considera Wolf: "Where the resources we consume, like Iowa topsoil, are regenerated at geological rates of time, we should consider them to be a non-renewing finite stock. Soil and oil are available to us in a fixed quantity, and if we consume them, we cannot expect to do so at a sustainable Hicksian rate. The best we can hope is that as we use these resources up, we may provide later generations with economic substitutes for them, so that our depletion will not leave the future worse off overall". WOLF, Clark. Justice and intergenerational debt cit., p. 16.

1007 "Il apparaît donc aujourd'hui que le capital immatériel constitue un facteur primordial de performance. Ce qui devrait, à notre sens, conduire les pouvoirs publics à s'intéresser à un facteur essentiel situé en amont du processus de production qui réside dans la qualité du dispositif de recherche et de formation, condition première d'une capacité créative. Il s'agit aussi d'un facteur qui devrait de plus en plus être considéré comme stratégique pour la mise en place d'une bonne gouvernance financière publique. Il est ainsi grand temps d'admettre qu'en elles-mêmes les techniques de gestion ne sont pas suffisantes pour assurer la soutenabilité des finances publiques et que les compétences, les savoirs humains sont essentiels". BOUVIER, Michel. Crise des finances publiques, crise d'un modèle politique et naissance de "l'Etat intelligent". Colóquio internacional a moderna gestão financeira pública: uma resposta à crise económica? Lisboa: Tribunal de Contas, 2009. p. 49. 
Gilberto Bercovici, por sua vez, dirige-se à faceta de soberania que envolve o tema, observando que mesmo os tipos de energia, bem como as formas de aproveitamento dos recursos naturais, hoje utilizados no Brasil, são desenvolvidos no exterior, não sendo necessariamente adequados à realidade nacional tampouco aos recursos que se encontram fartamente o território brasileiro. Daí que o investimento em ciência e tecnologia também é de ser considerado como etapa de fuga da dependência tecnológica, devendo ser priorizado na política de exploração dos recursos minerais. ${ }^{1008}$

Por todas essas razões, entende-se que a vinculação dos recursos de CFEM ao FNDCT é adequada da perspectiva intergeracional, assim como da sustentabilidade financeira e econômica, além da proteção da soberania energética nacional.

Mas o mesmo não se pode afirmar das demais vinculações.

Especialmente o direcionamento de recursos ao DNPM revela-se vicioso. Com Rodrigo Valente Serra, é de se concluir que "os recursos são aplicados de modo a estimular a intensificação da exploração do recurso não renovável, em vez de buscar alternativas a serem usadas pelas gerações futuras". 1009

Ora, basta verificar quais são as atribuições do DNPM. O órgão, na forma da lei atual, dá cumprimento ao Código de Minas (art. 3. ${ }^{\circ}, \S 2 .^{\circ}$, do Decreto-Lei n. 227/1967) e fiscaliza as "atividades concernentes à mineração, ao comércio e a industrialização das matérias-primas minerais" (art. 114 do Decreto n. 62.934/1968 - Regulamento do Código de Mineração). O Código de Minas foi elaborado (art. 1. ${ }^{\circ}$ ) no exercício da competência de "administrar os recursos minerais, a indústria de produção mineral e a distribuição, o comércio e o consumo de produtos minerais".

Eis que a destinação (vinculação) da receita de royalties ao DNPM retroalimenta o sistema de exploração mineral, estimulando-o a prosseguir mais e mais, ${ }^{1010}$

1008 BERCOVICI, Gilberto. Direito econômico do petróleo e dos recursos minerais cit., p. 356.

1009 SERRA, Rodrigo Valente. Rendas petrolíferas no Brasil: critérios de distribuição distorcidos induzem ineficiência do gasto. In: MENDES, Marcos (Org.). Gasto público eficiente cit., p. 227. O autor se refere às vinculações dos royalties petrolíferos, então vigentes. Nada obstante, entendemos que essas razões se aplicam diretamente à estrutura de vinculações da CFEM.

1010 Vale recordar a lição de Collier: "Often, it is unwise to invest heavily in adding value in this sector because it increases dependence upon the sector, and, once the resources are depleted, the adjustment needed in the economy will be all the greater". COLLIER, Paul. Small countries and big resources: harnessing natural resources for development in the g7+ countries. Paper prepared for the g7+ high level ministerial retreat. 2012. Disponível em: <http://www.g7plus.org/news-feed/2013/1/10/small-countriesand-big-resources.html >. Acesso em: 19 nov. 2013, p. 10. 
em vez de - como recomendam a equidade intergeracional e a governança voltada a ultrapassar os efeitos deletérios da exploração - promover outros segmentos econômicos.

Estas verbas públicas, ademais, serão fatalmente aplicadas em custeio do órgão de fiscalização mineral, passando longe do dever de investir em capital reprodutível.

Deve-se mencionar ainda que a vinculação dos proventos (ou das condições e estrutura de trabalho) do agente arrecadador à quantidade de recursos arrecadados cria inequívoco sistema de incentivos para que esta arrecadação seja inflada - o que pode ser pericioso aos agentes econômicos privados que investem, sob as regras do Estado, na atividade exploratória. É claro que os royalties são exigidos na forma estrita da Lei; mas não se há de negar que existem inúmeras formas transversas de majorar a arrecadação, inclusive por simples mudanças interpretativas veiculadas em atos infralegais.

Finalmente, é de se contrapor enfaticamente a vinculação dessa receita pública ao DNPM, já que tal liame transgride as razões mesmas pelas quais recomenda-se que tais recursos sejam concentrados na União: estando necessariamente ligada ao DNPM, não estará à disposição para promover diversificação produtiva, ou integrar programas de redistribuição, ou para servir de esteio a instrumentos de defesa macroeconômica.

Assim, entende-se que tal vinculação é viciosa.

Quanto à vinculação de percentual ao IBAMA, para "proteção mineral em regiões mineradoras", a conclusão é semelhante. Isto é: embora a proteção do meio ambiente seja especialmente favorecida no aspecto intergeracional, a vinculação é genérica; destina-se ao órgão, e não a programas, daí que pode ser utilizada em meras despesas de custeio; e mantém o ciclo de priorização da atividade extrativista na pauta econômica brasileira, destinando-se exclusivamente à "proteção mineral".

Não se defende, por evidente, que tais órgãos deixem de ser financiados pelo Estado brasileiro, através da União Federal. Mas apenas que o financiamento de suas atividades básicas se dê através do Orçamento geral - e não das receitas públicas oriundas da exploração dos recursos naturais não renováveis, estas que, em razão das peculiaridades dos bens explorados, devem necessariamente ser destacadas do "caixa único", observando governança específica, e não submetidas a um regime de simples verba pública descaracterizada e substituível por outras receitas quaisquer do Erário. 
3.e. Racionalidade no trato dos royalties e classificação financeiro-orçamentária.

Seguindo a análise do trato que o ordenamento jurídico brasileiro dá à questão dos royalties, prioritariamente na esfera financeira, cabe analisar o enquadramento dessa receita pública nas classificações mais comumente utilizadas.

\section{3.e.i. Receita originária, patrimonial.}

No doutrina de Direito Financeiro brasileiro, os métodos de classificação das receitas públicas parecem encontrar consenso.

Afastando classificações propostas por publicistas do início do século XX (Seligman, Jèze, Einaudi), a distinção que vem sendo utilizada é quanto à origem dos recursos, de forma a enquadrar a receita como originária ou derivada.

Regis Fernandes de Oliveira, assim, indica que "a receita originária decorre da exploração, pelo Estado, de seus próprios bens ou quando pode exercer atividade sob o que se denomina de direito público disponível"; e "a receita derivada provém do constrangimento sobre o patrimônio do particular". ${ }^{1011-1012}$ Inclui ainda a categoria das receitas transferidas, que são aquelas onde "o dinheiro ingressa nos cofres públicos de Estados e Municípios não em virtude de seu poder constritivo sobre o particular nem por exploração de seus próprios bens, mas recebem o dinheiro em decorrência do exercício da competência de outra unidade política que, por disposição constitucional, o transfere aos cofres de Estados e Municípios". ${ }^{1013}$

Para Geraldo Ataliba, "costuma a doutrina classificar as receitas em: originárias e derivadas, conforme provenham da exploração, pelo estado, de seus instrumentos (bens e serviços), ou provenham do uso de seu poder de constranger os submetidos à sua fôrça ao concurso compulsório". ${ }^{1014}$ E Souto Maior Borges indica que "a

1011 OLIVEIRA, Regis Fernandes de. Curso de direito financeiro cit., p. 122. "Em suma, as receitas originárias provêm do próprio patrimônio público do Estado ou de relação disciplinada pelo direito privado, ao passo que as derivadas advêm do patrimônio ou renda particulares".

1012 Para Sousa Franco, receitas patrimoniais são as "que resultam da administração do patrimônio do Estado ou da disposição de elementos do seu activo e que não tenham carácter tributário". FRANCO, Antonio L. de Sousa. Finanças públicas e direito financeiro cit., v. 1, p. 51. Alberto Deodato, por sua vez, afirma serem receitas originárias "aquelas que provêm do domínio privado do Estado: as patrimoniais, as industriais e as comerciais. Traduzem-se no que se chama de preços". DEODATO, Alberto. Manual de ciência das finanças. 20. ed. São Paulo: Saraiva, 1984. p. 34.

1013 OLIVEIRA, Regis Fernandes de. Curso de direito financeiro cit., p. 122.

1014 ATALIBA, Geraldo. Apontamentos de ciência das finanças, direito financeiro e tributário cit., p. 26. 
receita originária (patrimonial ou industrial) é obtida pelo Estado através da administração dos seus recursos e bens patrimoniais (jus gestionis). Esses ingressos decorrem do exercício de uma atividade estatal equiparável à atividade dos particulares", enquanto que "a receita derivada ou tributária é obtida pela arrecadação de impostos, taxas e contribuições e resulta do exercício por parte do Estado do seu poder de império (jus imperii)". 1015

Nesse diapasão é que os royalties recolhidos na forma do art. $20, \S 1 .^{\circ}$, da Constituição Federal, vieram a ser estudados pela doutrina.

Apontando que se trata de uma receita diretamente decorrente da exploração do patrimônio público - recorde-se que os recursos minerais são de domínio da União, consoante acima debatido -, a doutrina majoritária indica que se tratam de receitas originárias. É o caso das opiniões de Reynaldo Andrade da Silveira, ${ }^{1016}$ Fernando Facury Scaff, ${ }^{1017}$ Aurélio Pitanga Seixas Filho, ${ }^{1018}$ Heleno Taveira Torres, ${ }^{1019}$ Luiz Emygdio Rosa Jr., ${ }^{1020}$ Renata Marques da Silveira, ${ }^{1021}$ Geraldo Valentim Neto e Solange Maria Santos Costa $^{1022}$ e Ana Carolina Valladares Belisário ${ }^{1023}$ (com respeitosas divergências, para quem se trata de tributo/receita derivada, de Alberto Xavier, ${ }^{1024}$ Roque Carrazza ${ }^{1025}$ e Adriano

1015 BORGES, José Souto Maior. Introdução ao direito financeiro cit., p. 36.

1016 SILVEIRA, Reynaldo Andrade da. A compensação financeira: receita tributária ou patrimonial? Algumas questões. In: SCAFF, Fernando Facury (Org.). Ordem econômica e social. São Paulo: LTr, 1999. p. 331-336.

1017 SCAFF, Fernando Facury. Aspectos controvertidos sobre a CFEM - Compensação Financeira pela Exploração de Recursos Minerais (Royalties da mineração). In: SCAFF, Fernando Facury; ATHIAS, Jorge Alex Nunes (Coord.). Direito tributário e econômico aplicado ao meio ambiente e à mineração. São Paulo: Quartier Latin, 2009. p. 282-310; SCAFF, Fernando Facury. Royalties decorrentes da exploração de recursos naturais não renováveis cit., p. 129.

1018 SEIXAS FILHO, Aurélio Pitanga. Natureza jurídica da compensação financeira por exploração de recursos minerais. In: ROCHA, Valdir de Oliveira (Coord.). Grandes questões atuais do direito tributário. São Paulo: Dialética, 1998. p. 29-37.

1019 TORRES, Heleno Taveira. A compensação financeira devida pela utilização de recursos hídricos, exploração de recursos minerais ou produção de petróleo, xisto betuminoso e gás natural (art. $20, \S 1 .^{\text {o }}$ $\mathrm{CF}$ ) - sua natureza jurídica. In: ROCHA, Valdir de Oliveira (Coord.). Grandes questões atuais do direito tributário cit., p. 119-146.

${ }^{1020}$ ROSA JUNIOR, Luiz Emygdio. Manual de direito financeiro \& direito tributário. 14. ed. Rio de Janeiro: Renovar, 2000. p. 59-60.

1021 SILVEIRA, Renata Marques da. Aspectos jurídicos da compensação financeira pela exploração de recursos minerais cit., p. 140.

1022 VALENTIM NETO, Geraldo; COSTA, Solange Maria Santos. A compensação financeira pela exploração de recursos minerais (CFEM): os royalties da mineração. In: SOUZA, Marcelo Mendo Gomes de (Coord.). A compensação financeira pela exploração de recursos minerais cit., p. 90.

1023 BELISÁRIO, Ana Carolina Valladares. A natureza jurídica da compensação financeira pela exploração de recursos minerais - CFEM. In: SOUZA, Marcelo Mendo Gomes de (Coord.). A compensação financeira pela exploração de recursos minerais cit., p. 123.

1024 XAVIER, Alberto. Natureza jurídica e âmbito de incidência da compensação financeira por exploração de recursos minerais. Revista Dialética de Direito Tributário, n. 29, São Paulo: Dialética, 1998. 
Daleffe ${ }^{1026}$ ). Regis Fernandes de Oliveira ${ }^{1027}$ e Ricardo Lobo Torres ${ }^{1028}$ enxergam diferenças na natureza jurídica da receita pública, entre as figuras (art. $20, \S 1 .^{\circ}$, da $\mathrm{CF} / 88$ ) de participação e de compensação financeira. Nada obstante, concordam que de receita derivada/tributária não se trata.

Não foi outra a compreensão do Supremo Tribunal Federal, no julgado paradigmático sobre o tema, relatado pelo Min. Sepúlveda Pertence (Primeira Turma), nos autos do Recurso Extraordinário n. 228.800/DF:

EMENTA: Bens da União: (recursos minerais e potenciais hídricos de energia elétrica): participação dos entes federados no produto ou compensação financeira por sua exploração (CF, art. 20, e § 1..$\left.^{\circ}\right)$ : natureza jurídica: constitucionalidade da legislação de regência (L. 7.990/89, arts. $1 .^{\circ}$ e $6 .^{\circ}$ e L. 8.001/90). 1. O tratar-se de prestação pecuniária compulsória instituída por lei não faz necessariamente um tributo da participação nos resultados ou da compensação financeira previstas no art. $20, \S 1 .^{\circ}, \mathrm{CF}$, que configuram receita patrimonial. 2. A obrigação instituída na L. 7.990/89, sob o título de "compensação financeira pela exploração de recursos minerais" (CFEM) não corresponde ao modelo constitucional respectivo, que não comportaria, como tal, a sua incidência sobre o faturamento da empresa; não obstante, é constitucional, por amoldar-se à alternativa de "participação no produto da exploração" dos aludidos recursos minerais, igualmente prevista no art. $20, \S 11^{\circ}$, da Constituição. (RE 228800, Relator(a): Min. SEPÚLVEDA PERTENCE, Primeira Turma, julgado em 25/09/2001, DJ 16-11-2001 PP-00021 EMENT VOL02052-03 PP-00471).

Observe-se, ainda, que estes royalties adentram o patrimônio público da União como receita originária, mas são repassados para Estados e Municípios, no que, para esta operação, tomam forma de receita transferida, como observa Fernando Facury Scaff. ${ }^{1029}$ A 4. ${ }^{a}$ edição do Manual de Contabilidade Aplicada ao Setor Público (desenvolvido pela Secretaria do Tesouro Nacional, órgão do Ministério da Fazenda) corrobora este entendimento. ${ }^{1030}$

${ }^{1025}$ CARRAZZA, Roque Antonio. Natureza jurídica da compensação financeira pela exploração de recursos minerais. Sua manifesta inconstitucionalidade. São Paulo: Max Limonad, 1995. p. 306.

${ }^{1026}$ DALEFFE, Adriano. Ilegalidade da compensação financeira pela exploração de recursos minerais. Revista Dialética de Direito Tributário, n. 33, p. 07-15, São Paulo: Dialética, 06, 1998.

${ }^{1027}$ OLIVEIRA, Regis Fernandes de. Curso de direito financeiro cit., p. 245.

1028 TORRES, Ricardo Lobo. Curso de direito financeiro e tributário. 12. ed. Rio de Janeiro: Renovar, 2005. p. 191-192.

1029 SCAFF, Fernando Facury. Aspectos controvertidos sobre a CFEM - Compensação Financeira pela Exploração de Recursos Minerais (Royalties da mineração). In: SCAFF, Fernando Facury; ATHIAS, Jorge Alex Nunes (Coord.). Direito tributário e econômico aplicado ao meio ambiente e à mineração cit., p. 282-310.

1030 "Diante da necessidade de se classificar, no Município, a receita proveniente de royalties e deparando-se com as codificações de receita e seus respectivos desdobramentos: 1340.00.00 - Compensações 
Convém observar, contudo, que neste aspecto particular não há consonância entre as posições doutrinária e do Governo Federal, acima apresentadas, e a interpretação do tema pela Corte Constitucional Brasileira. Isto porque, nos autos do Mandado de Segurança n. 24.312/DF, o Supremo Tribunal Federal (Órgão Pleno), através da Relatoria da então Ministra Ellen Gracie, fez consignar que os royalties "são receitas originárias destes últimos entes federativos" ${ }^{\prime 1031}$ (naquela ocasião, o STF apreciou se os entes políticos subnacionais poderiam sofrer fiscalização do Tribunal de Contas da União no que se refere aos repasses de royalties, na forma do art. 71, VI, do texto constitucional ${ }^{1032}$ ).

Equivocou-se, claramente, o STF. Conforme acima consignado, os royalties são receitas originárias, isto é, decorrem da exploração dos bens próprios, pelo Estado. E consoante já se argumentou, mais acima, inclusive por disposições constitucionais

Financeiras; 1721.22.00 - Transferência da Compensação, pergunta-se: em qual situação os Municípios irão fazer uso das codificações acima? A receita dos royalties é repassada diretamente das empresas para os Municípios ou das empresas para o Estado ou União e estes transferem a respectiva cota para os Municípios? Podem ocorrer as duas situações? Os royalties incidentes sobre a exploração de recursos hídricos e minerais são recolhidos ao Tesouro Nacional e depois distribuídos aos Estados e Municípios por meio de transferências intergovernamentais. Assim, o grupo 1340.00.00 - Compensações Financeiras - é de uso da União. A União repassa as cotas-parte aos Estados e Municípios, que registram uma receita de transferência 1721.22.00 - Transferência de Compensação Financeira. Quando as transferências se derem dos Estados para os Municípios, estes registram no grupo 1722.22.00 Transferência da Cota-parte da Compensação Financeira". BRASIL. Secretaria do Tesouro Nacional. Manual de contabilidade aplicada ao setor público. Parte IV: perguntas e respostas. 4. ed. Brasília: Ministério da Fazenda, 2011. Aprovado pela Portaria STN n. 406, de 20 jul. 2011. p. 7.

1031 MANDADO DE SEGURANÇA. ATO CONCRETO. CABIMENTO. EXPLORAÇÃO DE PETRÓLEO, XISTO BETUMINOSO E GÁS NATURAL. PARTICIPAÇÃO, EM SEU RESULTADO, DOS ESTADOS, DISTRITO FEDERAL E MUNICÍPIOS. CONSTITUIÇÃO FEDERAL, ART. 20, § 1. . COMPETÊNCIA DO TRIBUNAL DE CONTAS DO ESTADO DO RIO DE JANEIRO PARA A FISCALIZAÇÃO DA APLICAÇÃO DOS RECURSOS ORIUNDOS DESTA EXPLORAÇÃO NO TERRITÓRIO FLUMINENSE. 1 - Não tendo sido atacada lei em tese, mas ato concreto do Tribunal de Contas da União que autoriza a realização de auditorias nos municípios e Estado do Rio de Janeiro, não tem aplicação a Súmula 266 do STF. 2 - Embora os recursos naturais da plataforma continental e os recursos minerais sejam bens da União (CF, art. 20, V e IX), a participação ou compensação aos Estados, Distrito Federal e Municípios no resultado da exploração de petróleo, xisto betuminoso e gás natural são receitas originárias destes últimos entes federativos $\left(\mathrm{CF}\right.$, art. $\left.20, \S 1^{\circ}{ }^{\circ}\right) .3-$ É inaplicável, ao caso, o disposto no art. 71, VI da Carta Magna que se refere, especificamente, ao repasse efetuado pela União mediante convênio, acordo ou ajuste - de recursos originariamente federais. 4 - Entendimento original da Relatora, em sentido contrário, abandonado para participar das razões prevalecentes. 5 - Segurança concedida e, ainda, declarada a inconstitucionalidade do arts. 1. ${ }^{\circ}$, XI e 198, III, ambos do Regimento Interno do Tribunal de Contas da União, além do art. 25, parte final, do Decreto n. 1, de 11 de janeiro de 1991. (MS 24312, rel. Min. Ellen Gracie, Tribunal Pleno, j. 19 fev. 2003, DJ 19.12.2003, p. 50 ement vol-02137-02, p. 350).

1032 Art. 71. O controle externo, a cargo do Congresso Nacional, será exercido com o auxílio do Tribunal de Contas da União, ao qual compete: [...] VI - fiscalizar a aplicação de quaisquer recursos repassados pela União mediante convênio, acordo, ajuste ou outros instrumentos congêneres, a Estado, ao Distrito Federal ou a Município; 
expressas, o domínio destes bens é da União. Então, é a União que explora os seus próprios bens. É dela a receita originária. Não se trata de receita originária dos Estados. ${ }^{1033}$

Deve-se observar que o fato de ser transferida a Estados e Municípios não retira daquela receita sua natureza jurídica primária - receita patrimonial; royalties. Quando se integram aos cofres dos entes subnacionais, devem continuar a observar as normas relacionadas a esta natureza; não podem ser confundidas por receitas derivadas, por exemplo. Mas isso não significa, por outro lado, que se trate de receita originária destes entes - a autorizar, v. g., que cobrem os valores diretamente dos concessionários da atividade de exploração, como já se tentou anteriormente. ${ }^{1034}$

Portanto, quando integram o Erário estadual, os royalties são receitas originárias (da União) e transferidas (aos Estados), um critério não anulando o outro. Como bem esclarece Scaff, impõe-se separar a classificação quanto ao vínculo que origina a receita (originária $\mathrm{x}$ derivada) da classificação quanto à fonte da receita (própria $\mathrm{x}$ transferida). ${ }^{1035}$ Nas contundentes palavras de Gilberto Bercovici, o julgado pelo STF no MS 24.312 é "uma decisão sem sentido algum que desnaturou a característica essencial da participação dos entes federados em uma receita pública originária federal". ${ }^{1036-1037}$

Assim, merece crítica e revisão o posicionamento tomado pelo Supremo Tribunal, não diante de sua conclusão (o art. 71, VI, da CF/88 não autoriza a fiscalização das receitas constitucionalmente transferidas), mas diante da afirmação já acima transcrita, que transgride cânones da classificação das receitas públicas, além de afrontar mesmo a dominialidade dos bens minerais e petrolíferos, constitucionalmente estabelecida.

\section{3.e.ii. Receita de capital.}

Cabe uma reflexão, ainda, sobre espécie de classificação que pouco chamou a atenção da doutrina, mas que tem se tornado deveras relevante. Trata-se da classificação

1033 SILVEIRA, Renata Marques da. Aspectos jurídicos da compensação financeira pela exploração de recursos minerais cit., p. 139.

1034 V. os já referidos casos da Lei n. 10.850/2007, da Bahia, que foi alvo da ADIN n. 4.606; da Lei n. 6.710/2005, do Pará, que foi alvo da ACO n. 845 - ambas perante o Supremo Tribunal Federal.

1035 SCAFF, Fernando Facury. Royalties decorrentes da exploração de recursos naturais não renováveis cit., p. 446.

1036 BERCOVICI, Gilberto. Direito econômico do petróleo e dos recursos minerais cit., p. 331.

1037 No mesmo sentido: HERNANDEZ, Fernanda Guimarães. Compensação financeira pela exploração de recursos minerais: regra matriz de incidência. 2010. Tese (Doutorado) - Faculdade de Direito da Universidade de São Paulo. 
segundo critério econômico, trazida pela Lei n. 4.320/1964, e que enquadra as receitas públicas em duas grandes categorias: as receitas correntes e as receitas de capital.

Vale observar, de princípio, que embora aquela classificação acima apresentada (entre receitas originárias e derivadas) seja a mais utilizada pela doutrina financeirista, esta classificação de que se tratará adiante é a que tem fundamento legal; por assim ser, as normas de direito financeiro, sempre que desejam identificar ou individualizar um tipo de receita, o fazem consoante a Lei n. 4.320/1964 (que "estatui normas gerais de direito financeiro para elaboração e contrôle dos orçamentos e balanços da União, dos Estados, dos Municípios e do Distrito Federal"), ${ }^{1038-1039}$ o que aumenta a sua relevância, porque é capaz de ditar os rumos da governança pública aplicada a determinadas entradas.

As classificações, é claro, "não são verdadeiras nem falsas, são úteis ou inúteis", como afirmou Genaro Carrió. ${ }^{1040}$

Nada obstante, quando os tipos de determinado diploma legal são transpostos para outros, integrando o ordenamento de forma sistemática - como é o caso da Lei de Responsabilidade Fiscal, que utiliza o mesmo enquadramento das receitas posto pela Lei $\mathrm{n}$. 4.320/64 -, impõe-se seja seguida a dinâmica trazida pela primeira norma. O mesmo se dá com as classificações: embora sua utilidade possa ser debatida, os efeitos legais diretos devem ser observados.

Exemplo disso está na própria Lei n. 4.320, que estabelece uma correlação entre receitas e despesas de cada tipo - receitas correntes fazem frente preferencialmente (embora não exista separação absoluta) a despesas correntes; receitas de capital fazem frente preferencialmente a despesas de capital. ${ }^{1041}$ Dispõe o art. 11 da mencionada Lei:

Art. 11. A receita classificar-se-á nas seguintes categorias econômicas: Receitas Correntes e Receitas de Capital.

$\S 1^{\circ}$ São Receitas Correntes as receitas tributária, de contribuições, patrimonial, agropecuária, industrial, de serviços e outras e, ainda, as provenientes de recursos financeiros recebidos de outras pessoas de

1038 Para um debate sobre as normas gerais de direito financeiro, ver: SCAFF, Fernando Facury. O que são normas gerais de direito financeiro?. In: MARTINS, Ives Gandra da Silva; MENDES, Gilmar Ferreira; NASCIMENTO, Carlos Valder do (Coord.). Tratado de direito financeiro. São Paulo: Saraiva, 2013. v. 1, p. 30 e ss. Também: CONTI, José Maurício. A autonomia financeira do Poder Judiciário. São Paulo: Ed. MP, 2006. p. 191 e ss. E ainda: OLIVEIRA, Regis Fernandes de. Curso de direito financeiro cit., p. 93-94.

1039 Para uma visão ampla da Lei n. 4.320/1964, v.: OLIVEIRA, Regis Fernandes de. A Lei n. 4.320, de 17.03.1964 (Lei Geral de Orçamento). Revista Tributária e de Finanças Públicas, v. 59, 2004.

1040 CARRIÓ, Genaro. Notas sobre derecho y lenguaje. 4. ed. Buenos Aires: Abeledo-Perrot, 1990. p. 99.

1041 Nesse sentido, dentre outros: ABRAHAM, Marcus. Curso de direito financeiro brasileiro. Rio de Janeiro: Elsevier, 2010. p. 77; REZENDE, Fernando Antonio. Finanças públicas cit., p. 153. 
direito público ou privado, quando destinadas a atender despesas classificáveis em Despesas Correntes.

$\S 2 .^{\circ}$ São Receitas de Capital as provenientes da realização de recursos financeiros oriundos de constituição de dívidas; da conversão, em espécie, de bens e direitos; os recursos recebidos de outras pessoas de direito público ou privado, destinados a atender despesas classificáveis em Despesas de Capital e, ainda, o superávit do Orçamento Corrente.

Assim, a questão que fica é: para os fins de classificação nos modelos apresentados pela Lei n. 4.320, os royalties são Receitas Correntes (o que teria embasamento na verificação de que, dentro deste gênero está a espécie das receitas Patrimoniais) ou são Receitas de Capital (o que teria embasamento uma vez que dentro deste gênero estão as provenientes de conversão, em espécie, de bens e direitos)?

A Administração Pública Federal os classifica como Receitas Correntes/Patrimoniais. ${ }^{1042}$

Ocorre que, como mencionado, a classificação mais usual (entre receitas originárias e derivadas) segue o critério da origem. Já a classificação tomada pela Lei n. 4.320/64 observa critério econômico. ${ }^{1043}$ Nela, a divisão por origem representa tão somente uma subcategoria da classificação principal que, repita-se, é econômica. ${ }^{1044}$ Isto é: o

1042 “3. Receita corrente - Patrimonial: São receitas provenientes da fruição do patrimônio de ente público, como por exemplo, bens mobiliários e imobiliários ou, ainda, bens intangíveis e participações societárias. São classificadas no orçamento como receitas correntes e de natureza patrimonial. Quanto à procedência, trata-se de receitas originárias. Podemos citar como espécie de receita patrimonial as compensações financeiras, concessões e permissões, dentre outras. A. Compensações Financeiras: A receita de compensação financeira tem origem na exploração do patrimônio do Estado, que é constituído por recursos minerais, hídricos, florestais e outros, definidos no ordenamento jurídico. Tais compensações são devidas à União, aos Estados e aos Municípios, de acordo com o disposto na legislação vigente, como forma de participação no resultado dessa exploração. Elas têm como finalidade recompor financeiramente os prejuízos ou danos causados (externalidades negativas) pela atividade econômica na exploração desses bens, assim como proporcionar meio de remunerar o Estado pelos ganhos obtidos por essa atividade". BRASIL. Secretaria do Tesouro Nacional. Manual de contabilidade aplicada ao setor público. Parte I: procedimentos contábeis e orçamentários cit., p. 22. No mesmo sentido: HERNANDEZ, Fernanda Guimarães. Compensação financeira pela exploração de recursos minerais: regra matriz de incidência cit.

1043 TORRES, Ricardo Lobo. Tratado de direito constitucional financeiro e tributário, volume V: o orçamento na Constituição. 2. ed. rev. e atual. Rio de Janeiro: Renovar, 2000. p. 79. "No que concerne à receita pública, adota a Lei n. 4.320/1964 (Anexo III) o critério da classificação por categorias econômicas". p. 79.

1044 É o que explicita o já citado Manual de contabilidade aplicada ao setor público. Parte I: procedimentos contábeis e orçamentários cit.): "O $\S 1 .^{\circ}$ do art. $8 .^{\circ}$ da Lei n. 4.320/1964 define que os itens da discriminação da receita, mencionados no art. 11 dessa lei, serão identificados por números de código decimal. Convencionou-se denominar este código de natureza de receita. Importante destacar que essa classificação é utilizada por todos os entes da Federação e visa identificar a origem do recurso segundo o fato gerador: acontecimento real que ocasionou o ingresso da receita no cofre público. Assim, a natureza de receita é a menor célula de informação no contexto orçamentário para as receitas públicas; por isso, contém todas as informações necessárias para as devidas alocações orçamentárias. A fim de possibilitar identificação detalhada dos recursos que ingressam nos cofres públicos, esta classificação é formada por 
critério legal de classificação não é, notadamente, aquele adotado pela doutrina majoritária. ${ }^{1045-1046}$

Então, os argumentos que defendem se tratar de receita corrente porque é receita patrimonial não sensibilizam: deve-se perquirir seu enquadramento no critério econômico para, só depois, verificar o critério da origem. Ser receita patrimonial em uma classificação não torna necessário que seja receita corrente em outra.

No caso da Lei n. 4.320/1964 "a finalidade do critério é evidenciar os recursos que se destinam ao atendimento das Despesas Correntes e os que viabilizam a realização das Despesas de Capital". ${ }^{1047}$

Assim é que a investigação quanto ao enquadramento dos royalties de recursos naturais não renováveis no critério de origem (receitas originárias $\mathrm{x}$ derivadas) não é conflitante, mas paralela à investigação quanto ao enquadramento no critério econômico (receitas correntes $\mathrm{x}$ de capital).

Contudo, uma vez que a Lei n. 4.320 não conceitua o que são receitas correntes e de capital, antes apenas os enumera, deve-se voltar à doutrina para melhor compreender as nuances básicas que relacionam os tipos enumerados. Ensina Flávio Rubinstein:

As receitas correntes são aquelas oriundas das atividades operacionais do Estado, para aplicação em despesas correspondentes (i.e., classificáveis como correntes), visando ao alcance das finalidades e metas dos diversos entes públicos, conforme previstas nos programas e ações de governo. $[\ldots]$

um código numérico de 8 dígitos que subdivide-se em seis níveis - Categoria Econômica, Origem, Espécie, Rubrica, Alínea e Subalínea: [...] O $\S \S 1 .^{\circ}$ e 2..$^{\circ}$ do art. 11 da Lei n. 4.320, de 1964, classificam as Receitas Orçamentárias em "Receitas Correntes" e "Receitas de Capital". [...] A Origem é o detalhamento das Categorias Econômicas "Receitas Correntes" e "Receitas de Capital", com vistas a identificar a natureza da procedência das receitas no momento em que ingressam no Orçamento Público" (p. 12-15).

1045 “A doutrina classifica as receitas públicas, quanto à procedência, em originárias e derivadas. Essa classificação possui uso acadêmico e não é normatizada; portanto, não é utilizada como classificador oficial da receita pelo poder público [...] A origem é o detalhamento das categorias econômicas Receitas Correntes e Receitas de Capital, com vistas a identificar a procedência das receitas no momento em que ingressam nos cofres públicos". BRASIL. Ministério do Planejamento, Orçamento e Gestão. Secretaria de Orçamento Federal. Manual técnico de orçamento MTO. Versão 2013. Brasília, 2012. p. 18 e 20.

1046 Ementário de Classificação das Receitas Orçamentárias (2012) - Brasília. Secretaria de Orçamento Federal - SOF (p. 45).

1047 GIACOMONI, James. Orçamento público cit., p. 140. Prossegue o autor: "Recorda-se que idênticas categorias econômicas são adotadas na classificação da despesa: Despesas Correntes e Despesas de Capital. Esse paralelismo classificatório possibilita elaborar quadro-resumo que destaca o Orçamento das Operações Correntes, formado pelas Receitas e Despesas Correntes, e o Orçamento das Operações de Capital, constituído pelas Receitas e Despesas de Capital, de especial utilidade nas análises econômicas e sobre o resultado das contas públicas". 
As receitas correntes, parece assentado admitir, incrementam somente o patrimônio não duradouro do Estado, ou seja, aquele patrimônio que se esgota dentro do período anual. ${ }^{1048}$

As receitas de capital são aquelas de natureza eventual, que alteram o patrimônio duradouro do Estado. Elas podem constituir meios para atingir-se a finalidade fundamental do ente respectivo que as aufere, ou até para o financiamento de atividades não operacionais visando à promoção de atividades primordiais de tal ente. [...]

Essas receitas são contabilmente representadas pela troca de elementos patrimoniais, isto é, um aumento no sistema financeiro (entrada de recursos financeiros) e uma baixa no sistema patrimonial (saída do patrimônio em troca de recursos financeiros). ${ }^{1049}$

Antonio Sousa Franco estabelece que "Receitas e despesas de capital são aquelas que alteram a situação ativa ou passiva do património duradouro do Estado, enquanto as receitas e despesas correntes são as que não oneram nem aumentam o valor do património duradouro do Estado". ${ }^{1050}$ Luiz Emygdio Rosa Jr. difere "operações correntes e operações de capital":

As primeiras consistem em todas as transações que o Governo realiza diretamente ou através de seus órgãos de administração indireta, e cujo esforço não resulta acréscimo no seu patrimônio ou na criação de bens de seu capital, consumindo-se no mercado as dotações para operações correntes ao se converterem em moeda. Daí ser o imposto uma receita corrente porque não se origina de qualquer bem de capital, mas da obrigação social dos cidadãos contribuírem para a manutenção da coisa pública [...] Por outro lado, considera-se todas as demais operações como de capital, e, por critério de natureza contábil, costuma-se entender como operações de capital aquelas que dão em resultado uma movimentação de registro no ativo e no passivo. ${ }^{1051}$

Carlos Alberto de Moraes Ramos Filho referenda opiniões que indicam que receitas de capital são as que promovem "alterações compensatórias" no patrimônio estatal, e que são esporádicas, descontínuas. ${ }^{1052}$ No mesmo sentido, Marcus Abraham utiliza um critério de continuidade ou estabilidade para encontrar a diferença entre os dois tipos de receita. Assim, as receitas correntes se caracterizariam por sua estabilidade, de maneira que "fazem parte da arrecadação estatal de forma ordinária e não eventual"; enquanto que as receitas de capital seriam eventuais, "pois para existirem dependem de

1048 RUBINSTEIN, Flávio. Arts. 9. 9 a 11. In: CONTI, José Maurício (Coord.). Orçamentos públicos: a Lei n. 4.320/1964 comentada. 2. ed. São Paulo: RT, 2010. p. 64.

1049 Idem, ibidem, p. 67.

${ }^{1050}$ FRANCO, Antonio L. de Sousa. Finanças públicas e direito financeiro cit., v. 1, p. 370.

${ }^{1051}$ ROSA JUNIOR, Luiz Emygdio Franco da. Manual de direito financeiro \& direito tributário cit., p. $62-$ 63.

173 
atos específicos e circunstâncias próprias". ${ }^{1053} \mathrm{O}$ critério de temporalidade é adotado por Fernando Rezende junto a um critério que relaciona a receita ao gasto, ensinando que a distinção entre receitas correntes e de capital "baseia-se na existência ou não de algum prérequisito para aplicação da receita, bem como no caráter recorrente ou não do ingresso", de forma que "as receitas de capital são aquelas cujos fluxos são mais irregulares". ${ }^{1054}$

Ferreiro Lapatza apresenta os gastos - definição útil na medida em que, como referido, impõe-se a paridade dentre receitas e despesas de cada categoria - correntes ou "de funcionamento" como aqueles "normais, necessários para a marcha dos serviços públicos e para a marcha do Estado", não implicando transferência de capital do setor público ao setor privado nem dentro do setor público, afetando apenas "o emprego das rendas do Estado e da Nação"; os gastos de capital, por outro lado, "afetam a riqueza da nação, seu capital e não suas rendas", aproximando-se da "velha noção de gastos extraordinários", mas não se equiparando a ela, já que "o que em outro tempo se considerava extraordinário foi convertido em normal". ${ }^{1055-1056}$

De todas essas conceituações e distinções - muitas vezes relacionadas mas não coincidentes -, pode-se extrair que as receitas de capital são aquelas que (i) alteram o patrimônio (ativos) do Estado; e (ii) não têm caráter de continuidade (habitualidade, estabilidade), sendo descontínuas, infrequentes.

Que se pode dizer, nesse quadro, dos royalties oriundos da exploração dos recursos naturais não renováveis? Essa receita pública (i) decorre de atividade que altera o patrimônio duradouro do Estado, representando um aumento no sistema financeiro decorrente de uma baixa no sistema patrimonial; e (ii) é passageira, descontínua no tempo porque esgotável.

\footnotetext{
1053 ABRAHAM, Marcus. Curso de direito financeiro brasileiro cit., p. 77.

1054 REZENDE, Fernando Antonio. Finanças públicas cit., p. 153.

1055 LAPATZA, José Juan Ferreiro. Instituticiones de derecho financeiro cit., p. 73. Tradução livre.

1056 Para Kleber Zanchim, em comentário à Lei n. 4.320/1964, “a opção legal pela separação das despesas públicas em categorias econômicas não é aleatória. Despesas correntes e despesas de capital distinguemse pelas consequências que produzem. As primeiras não agregam ativos para o ente que as realiza. Já as últimas têm exatamente essa finalidade [...] O critério econômico de classificação é, pois, a introdução de um ativo no patrimônio do ente público. As despesas correntes relacionam-se fundamentalmente à remuneração de serviços. São consideradas despesas meramente 'produtivas' por se referirem à manutenção de utilidades públicas promovidas pelo Estado. As despesas de capital, por sua vez, vinculam-se à aquisição ou produção de bens. Seriam 'reprodutivas' porque, além de criarem utilidades, aumentam a capacidade de produção do país. Daí as despesas correntes refletirem a ideia de 'aparelhamento do Estado', ou crescimento da máquina pública, enquanto as despesas de capital são vistas como fator de promoção do desenvolvimento econômico". ZANCHIM, Kleber Luiz. Arts. 12 a 21. In: CONTI, José Maurício (Coord.). Orçamentos públicos cit., p. 71-72.
} 
O primeiro ponto parece ser claro. Os bens minerais são parte do patrimônio nacional. São ativos brasileiros, alocados na União, pessoa jurídica de direito público interno. Ao explorá-los e receber royalties, a União esgota o ativo físico, substituindo-o por ativos financeiros. ${ }^{1057}$ Deve-se afirmar, com Fernando Facury Scaff, que

a cada barril de petróleo extraído e a cada tonelada de minério retirada do seio da terra, o Estado fica patrimonialmente mais pobre, e o preço direto que recebe por essa operação se caracteriza como royalty [...] a cada centavo recebido pelo Estado, uma parte do patrimônio público esgotável - recursos naturais não renováveis - é reduzido. ${ }^{1058}$

O segundo ponto (receita descontínua), contudo, demanda maior explicação. Uma verificação simples da arrecadação de royalties nos últimos anos apresentará valores anuais relativamente contínuos, daí podendo levar a crer que se trata de receita estável.

Contudo, como já extensamente argumentado acima, o que se propõe nessa oportunidade é observar a questão em horizonte temporal alargado.

E, nessa perspectiva, levando em conta o caráter de finitude, intrínseco aos recursos naturais ora debatidos, não renováveis por definição, conclui-se pela não perenidade dessas receitas. Uma mina ou jazida gerará apenas receitas públicas de royalties durante o tempo que for explorada. Em todos os demais momentos da história, anteriores e posteriores, não dará azo à arrecadação dessa receita.

Diferente da receita de impostos, que é de se esperar se faça presente hoje como nos próximos trezentos anos, a receita de royalties só existe durante o período em que for produtiva a mina ou jazida e o Estado decidir explorá-la. Esgotados os recursos, esgota-se a receita.

Portanto, a análise do tema sob uma visão temporal lata leva a afirmar que as receitas de royaties são descontínuas, instáveis. Os recursos naturais de que se trata são

1057 Segundo Paulo Springer de Freitas, “a extração do petróleo nada mais representa do que uma troca de ativos: o ativo que estava depositado no subsolo, na forma de óleo cru, transformou-se em ativo financeiro, por meio do pagamento das participações governamentais. Portanto, o patrimônio do setor público não se altera quando o governo passa a receber receitas oriundas da exploração do petróleo. E o impacto final sobre esse patrimônio dependerá da forma como os recursos serão gastos. Se o forem com despesas correntes (que representam consumo e não criam instrumentos de geração de riqueza futura), o patrimônio público irá se reduzir ao longo do tempo. Já se o governo investir os recursos oriundos do petróleo, então sua situação patrimonial, em princípio, não irá se alterar”. FREITAS, Paulo Springer de. Rendas do petróleo... cit., p. 37.

1058 SCAFF, Fernando Facury. Royalties decorrentes da exploração de recursos naturais não renováveis cit., p. 500-501. 
finitos. Portanto, enquanto as receitas de impostos são tendencialmente perenes, as receitas públicas de royalties são afirmativamente finitas.

Logo, trata-se de receita de capital - e não de receita corrente - decorrente da "conversão, em espécie, de bens e direitos", figura especificamente referida pela Lei n. $4.320 / 1964$, art. $11, \S 2 .^{\circ}$.

Vale mencionar que, na defesa da classificação dos royalties de recursos naturais não renováveis como receitas de capital, concorda-se com parte das conclusões alcançadas por Andressa Guimarães Torquato Fernandes, para quem, com base na análise da natureza jurídica dos contratos de concessão para a exploração de recursos minerais, os royalties (petrolíferos, no caso por ela analisado) são receita de capital e devem receber este tratamento pela Lei n. 4.320/1964 e por todos os demais diplomas (especialmente a LRF) que seguem o mesmo critério. ${ }^{1059}$

Nada obstante, a referida autora, para chegar à conclusão ora referida - tratamse, os royalties, de receitas de capital - defende que na atividade de exploração há uma alienação do bem público, sendo os royalties o resultante dessa venda. ${ }^{1060}$ Por se tratar da figura jurídica da alienação, aplicar-se-ia o teor do art. 44 da Lei de Responsabilidade Fiscal, que veda "a aplicação da receita de capital derivada da alienação de bens e direitos que integram o patrimônio público para o financiamento de despesa corrente". ${ }^{1061}$

Apesar dos amplos fundamentos suscitados por Andressa Fernandes - calcados especialmente nos direitos civil e administrativo, que ora não serão aprofundados, por fugir ao escopo destas linhas -, cabe uma inquietação: o enquadramento dos royalties no art. 44 da LRF pressupõe afirmar que os royalties são receitas públicas que derivam da alienação de bens públicos.

Para assim afimar, deve pressupor-se que os royalties se justificam pela alienação dos bens minerais e petrolíferos; que são contraprestação por essa alienação. Ou,

1059 FERNANDES, Andressa Guimarães Torquato. Direito financeiro aplicado ao setor do petróleo. 2013. Tese (Doutorado) - Faculdade de Direito da Universidade de São Paulo. p. 135.

1060 Idem, ibidem, p. 11.

1061 Interessante notar disposição mui semelhante na legislação argentina - Lei n. 25.917/2004, art. 12: "Articulo 12. El producido de la venta de activos fijos de cualquier naturaleza y el endeudamiento del Gobierno nacional, de las provincias y de la Ciudad Autónoma de Buenos Aires no podrán destinarse a gastos corrientes ni generar aumentos automáticos para el ejercicio siguiente, excepto operaciones de crédito para reestructurar deuda en condiciones más favorables a ellas, el financiamiento proveniente de Organismos Multilaterales de Crédito y el proveniente de programas nacionales de financiamiento con destino a obras públicas y fines sociales. Queda expresamente establecido, que la venta de activos fijos, podrá destinarse a financiar erogaciones de capital". Sobre o tema, ver também: REZZOAGLI, Luciano Carlos; REZZOAGLI, Bruno Ariel. Teoría de la igualdad intergeneracional... cit., p. 182-185. 
em outras palavras, que a exploração desses bens não passa, ao fim e ao cabo, de uma espécie sui generis de compra e venda.

E esta parece ser uma postura excessivamente privatista, tratando como mercadoria ordinária aqueles bens que, como já se expôs, são essenciais à soberania do Estado brasileiro, e que têm sua exploração vinculada aos objetivos constitucionais (especialmente de superação do subdesenvolvimento) e sujeita a processo de outorga estatal.

Ora, com Alfredo Ruy Barbosa, vê-se que "na concessão mineral, cabe ao Estado [...] administrar esse patrimônio nacional na condição de Poder Concedente e de agente fiscalizador das atividades desenvolvidas pelo concessionário, visando ao pleno atendimento do interesse coletivo". ${ }^{1062}$ Daí que, ao permitir a exploração da mina ou jazida pelo particular e exigir o pagamento de royalties, o Estado não aliena o bem público e exige uma contraprestação por essa alienação. Consoante o mesmo doutrinador, "a concessão minerária não envolve uma propriedade, por mais especial que seja, mas um direito real de exploração estruturado administrativamente". 1063

O que se extrai desta doutrina é que, por mais que se possa aceitar que a exploração é acompanhada por uma alienação (transferência de domínio, não necessariamente mediante compra e venda) de toneladas de minério ou de barris de petróleo (já que, ao menos no caso dos recursos minerais, a Constituição garante "ao concessionário a propriedade do produto da lavra" - art. 176), isto não implica dizer que a figura dos royalties represente uma contraprestação por essa alienação. Por consequência, não se aplica o art. 44 da LRF porque aquela receita de capital não é derivada da alienação dos bens, embora seja relacionada com a mesma atividade exploratória.

Ora, os royalties são "preço público pago ao proprietário do recurso natural não renovável que for extraído, inserido ou consumido por processo produtivo"; ${ }^{1064}$ mas seu conceito não encampa a noção de compra e venda dos bens. Daí por que não se fala mesmo em contraprestação nessa definição, mas, ao inverso, é focada a característica de

1062 BARBOSA, Alfredo Ruy. A natureza jurídica da concessão para exploração de petróleo e gás natural. In: PIRES, Paulo Valois (Org.). Temas de direito do petróleo e do gás natural II cit., p. 10.

${ }^{1063}$ Idem, ibidem, p. 14.

${ }^{1064}$ SCAFF, Fernando Facury. Royalties decorrentes da exploração de recursos naturais não renováveis cit., p. 137. 
inclusão dos bens no processo produtivo, o que ressalta a ideia de exploração do bem, mas não de uma troca pura e simples de bens minerais por dinheiro. ${ }^{1065}$

Igualmente, já se argumentou que os royalties se justificam como retenção, pelo Estado, do custo de oportunidade (ou "custo de uso", com Hotteling) envolvido na exploração dos bens; não como mercancia pura e simples desses bens.

Com estas colocações, então, é que se deve reiterar a inaplicabilidade do art. 44 da Lei de Responsabilidade Fiscal (LCP n. 101/2000) ao caso em estudo. O dispositivo legal traz uma vedação apenas àquelas receitas de capital que derivem da alienação de bens públicos; mas os royalties - embora sejam receitas de capital, e embora seja possível mesmo apontar a existência de uma alienação (transferência de domínio) de bens - não derivam dessa alienação, não se justificam como contraprestação por essa alienação, não podem ser entendidos como pura e simples expressão em dinheiro de uma operação de venda de recursos naturais não renováveis.

Vale recordar que a decisão do Estado brasileiro de conceder a exploração de uma mina ou jazida não é equivalente a uma decisão de venda daqueles depósitos. Ao permitir a atuação de particulares nesta atividade, Alexandre de Moraes aponta que o Estado promove "concessão de exploração de bem público". ${ }^{1066}$ Deve-se pontuar que o regime regulatório específico das concessões de exploração de minérios e petróleo ainda é muito disputado na doutrina, valendo notar, com Fernando Facury Scaff, a existência de elementos para indicar que os conceitos de direito administrativo não se aplicam com perfeição ao caso. ${ }^{1067}$ A questão merece ser melhor analisada pelos estudiosos do Direito Administrativo e regulatório, o que foge ao escopo destas razões.

Nada obstante, é de se considerar que, mesmo quando a Constituição garante ao concessionário a propriedade do produto da lavra, o faz em relação ao produto, e não à jazida ou mina. Então, é de se ver, com Floriano de Azevedo Marques Neto, que “o bem público (jazida) não é alienado ao particular, mas apenas objeto de um direito de

1065 Para Flávio Rubinstein, sequer se pode falar em "preço público", vez que neste está contido caráter contraprestacional. Então, os royalties exigidos no Brasil seriam "uma espécie singular de receitas patrimoniais". RUBINSTEIN, Flávio. Receitas públicas de recursos naturais no direito financeiro brasileiro cit., p. 106. O mesmo autor igualmente confirma que não se há de falar em preço pago pela alienação de bem público, mas também nega que os royalties sejam receitas de capital porque "há clara geração de riqueza nova pelo particular, com a peculiaridade de que esta riqueza tem origem no emprego do patrimônio público" - p. 229.

1066 MORAES, Alexandre de. Regime jurídico da concessão para exploração de petróleo e gás natural cit., p. 168.

1067 SCAFF, Fernando Facury. Royalties decorrentes da exploração de recursos naturais não renováveis cit., p. 80-81, nota de rodapé n. 129. 
exploração que implica na outorga de um uso privativo". ${ }^{1068}$ Afinal, "a autorização constitucional da apropriação pelo concessionário do produto da lavra diz respeito aos bens móveis extraídos, que não afeta a propriedade da União sobre os bens imóveis não extraídos", de forma que "a União, sem transmitir o domínio ou um direito real sobre o subsolo, outorga ao titular da concessão o direito de explorar o subsolo". ${ }^{1069}$

Para além das razões já acima colocadas, impõe-se considerar que a classificação dos royalties como receitas de capital é, certamente, a que é orientada pelas razões trazidas nos capítulos anteriores.

Em verdade, classificá-los como receitas correntes importaria em dizer que se prestam a "incrementar o patrimônio não duradouro do Estado", ${ }^{1070}$ exaurível em um exercício, o que é francamente ofensivo às ideias desenvolvidas acima. Isto é: compreender tais receitas como correntes (comuns, ordinárias, contínuas) é negar a própria razão de ser (justificação, conforme exposto) dessas entradas, ignorando aquilo que lhes confere status especial: a certeza de sua exaustão (mesmo desconhecido o momento em que ocorrerá).

Vale recordar que a classificação levada a efeito pela Lei n. 4.320/1964 busca uma paridade entre receitas e despesas: receitas correntes para custear despesas correntes; receitas de capital para custear despesas de capital. Basta ver que, na elaboração da proposta orçamentária, "as receitas e despesas de capital serão objeto de um Quadro de Recursos e de Aplicação de Capital” (art. 23 da mesma Lei).

Como já colocado, esta correlação não é absoluta; não há norma que comande a impossibilidade de custeio de despesas correntes a partir de receitas de capital, salvo o art. 44 da LRF, que contudo demanda que essas receitas de capital sejam qualificadas por serem derivadas de alienação, o que não é o caso dos royalties de recursos naturais não renováveis.

Despesas correntes, vale dizer, são (i) despesas de custeio e (ii) transferências correntes, estas que correspondem às "dotações para despesas as quais não corresponda contraprestação direta em bens ou serviços, inclusive para contribuições e subvenções destinadas a atender à manifestação de outras entidades de direito público ou privado" (Lei n. 4.320/1964, art. 12, § 2. ${ }^{\circ}$. A Lei as enumera como: Subvenções Sociais, Subvenções

1068 MARQUES NETO, Floriano Peixoto de Azevedo. Bens públicos: função social e exploração econômica. Belo Horizonte: Forum, 2009. p. 331.

1069 BERCOVICI, Gilberto. Direito econômico do petróleo e dos recursos minerais cit., p. 290.

1070 RUBINSTEIN, Flávio. Arts. 9. a 11. In: CONTI, José Maurício (Coord.). Orçamentos públicos cit., p. 64. 
Econômicas, Inativos, Pensionistas, Salário Família e Abono Familiar, Juros da Dívida Pública, Contribuições de Previdência Social, e Diversas Transferências Correntes.

O que deve ser ressaltado, contudo, é que este paralelismo, entre a natureza da receita e o tipo da despesa, é salutar e representa uma resposta interna ao ordenamento jurídico brasileiro a vários dos males relatados quanto à governança dos royalties de recursos naturais não renováveis.

Ora, o que se vem sustentando é que a utilização predatória dessas receitas (em consumo, custeio da máquina pública) põe em risco a economia nacional em face dos diversos efeitos da chamada maldição dos recursos naturais e quejandos. Mas também, especialmente, que esta utilização ofende a equidade intergeracional, trazendo benefícios na atualidade em prejuízo das gerações posteriores, estas que ficarão sem os recursos naturais a explorar e sem os efeitos de um gasto público orientado para ser duradouro. Para além disso, perder-se-ia a oportunidade de utilização dos recursos públicos oriundos da exploração no objetivo primário de sequer se explorar, qual seja a superação do subdesenvolvimento.

O citado comportamento é economicamente irresponsável e oportunista face à arbitrária posição temporal que ocupamos.

E é em direção a ele o incentivo que se extrai da classificação das receitas em debate como correntes: implica orientar seu gasto em direção às despesas correntes, que, como relatado acima, são aquelas ordinárias, destacando-se as despesas de custeio da máquina administrativa.

Como afirma Maria Amélia Enríquez:

Faz grande diferença gastar os recursos em despesas correntes e assistencialismo ou investir na diversificação produtiva e formação de capital humano. Um real empregado em novas alternativas para criação de emprego e renda tem a capacidade de se multiplicar, enquanto que um real empregado em despesas correntes simplesmente se consome na hora do gasto, ou seja, não tem a capacidade de se propagar pela economia. Ao contrário, por vezes ele cria novas obrigações que onerarão a receita futura. ${ }^{1071}$

Logo, a classificação dessas receitas como de capital orienta o gasto público e direção às despesas de capital, estas que são dirigidas a prazo mais longo, que podem repor

1071 ENRÍQUEZ. Maria Amélia. Mineração... cit., p. 347. 
o patrimônio explorado. Que estão mais aptas, enfim, a observar os interesses das futuras gerações e promover a poupança justa a que se refere John Rawls.

Eis que a institucionalidade brasileira, ao classificar a receita de royalties como corrente, merece críticas, especialmente a partir dos instrumentos teóricos com os quais se tem buscado desenvolver a análise da governança dessas receitas.

Como nota final: não se propõe interpretação que vincule absoluta e necessariamente a íntegra das receitas de royalties com aplicação em despesas de capital. Rejeitada a aplicação do art. 44 da LRF, sequer há fundamento legal que assim sustente.

Entende-se que, apesar da necessidade de privilegiar as despesas de capital, a impossibilidade de extrapolação de qualquer montante para as despesas correntes também relevante no funcionamento das instituições, inclusive aquelas voltadas ao futuro seria míope.

Nem sempre a separação rígida entre esses dois grandes gêneros de receitas e despesas é adequada para a promoção de equilíbrio nas finanças públicas. Como ensina Antonio Sousa Franco, essa postura "pode dar uma visão deformada das opções reais; privilegia as despesas que criam bens materiais duradouros, relativamente aos investimentos imateriais - educação, investigação científica e tecnológica - que serão financiados (em boa parte) por receitas correntes". ${ }^{1072}$

E é também como opinam Scaff e Rocha (embora referindo à regra de ouro e não aos royalties):

O conceito de despesas de capital nos leva ao de bens de capital - ou seja, quase equivalente ao de novas obras, prédios, construções; algo que seja incorporado valor imobilizado, que aumente o capital tangível. Ocorre que muitos investimentos públicos não se concretizam em bens de capital, mas em valores intangíveis, tais como educação, treinamento, capacitação tecnológica, prevenção de doenças etc. Logo, se o governo brasileiro decidisse obter um empréstimo público para erradicar doenças tropicais, tais como febre amarela, dengue, malária, estaria descumprindo a regra de ouro orçamentária prevista na Constituição, pois tais campanhas de saúde pública não se caracterizam como bem de capital, a despeito de seu inconteste valor em termos sociais. Este é um problema enfrentado pela aplicação desta regra. ${ }^{1073}$

${ }^{1072}$ FRANCO, Antonio L. de Sousa. Finanças públicas e direito financeiro cit., v. 1, p. 370-379.

${ }^{1073}$ SCAFF, Fernando Facury; ROCHA, Francisco Sérgio Silva. Equilíbrio orçamentário e sustentabilidade financeira: anotações sobre o Brasil cit. 
3.f. Fundos.

Quando o tema é governança e gestão dos recursos públicos oriundos de royalties de petróleo e mineração, tem sido bastante debatida a adoção de Fundos Soberanos, que nada mais são que instrumentos contábeis de reserva de valores fora (ao menos imediatamente) do alcance do Orçamento Geral, ${ }^{1074}$ bem como de vinculação ou afetação de recursos públicos, acreditando-se tratar-se de "instrumento eficiente para dinamizar a execução orçamentária e financeira". ${ }^{1075}$

Esses Fundos distinguem-se dos demais instrumentos fisco-contábeis por basicamente 02 (dois) motivos: [1] sua titularidade (estatal); e [2] seu prazo (longo). ${ }^{1076}$ Porém, como ensina $\mathrm{Xu} \mathrm{Yi-chong,} \mathrm{é} \mathrm{frequentemente} \mathrm{mais} \mathrm{fácil} \mathrm{definir} \mathrm{os} \mathrm{Fundos}$ Soberanos por exclusão (não são reservas internacionais, empresas públicas, fundos de pensão ou ativos explorados para o proveito de indivíduos). ${ }^{1077}$

Estas duas características importam em concluir que, diferentes de outros (como Fundos de Pensão ou hedge funds particulares), os Fundos Soberanos não buscam (ou não deveriam buscar) lucro imediato, mas levam em consideração, para formação de seu portfólio, outros objetivos - especialmente a promoção de valores entendidos como

1074 FREITAS, Paulo Springer de. Rendas do petróleo... cit., p. 38: "Embora não haja uma única definição que englobe todos os seus aspectos, pode-se definir Fundos Soberanos como veículos financeiros de propriedade de Estados, que investem recursos provenientes da poupança do setor público em variados tipos de ativos. Esses recursos podem decorrer de superávits nominais ou em conta-corrente do balanço de pagamentos". Ana Carla Bliacheriene, Marcos Funari e Renato Ribeiro (BLIACHERIENE, Ana Carla; FUNARI, Marcos Hime; RIBEIRO, Renato Jorge Brown. Natureza jurídica do Fundo Soberano brasileiro e do Fundo Fiscal de investimentos e estabilização. Revista Fórum de Direito Financeiro $e$ Econômico - RFDFE, Belo Horizonte, ano 1, n. 1, 2012) afirmam: "Genericamente, podem ser conceituados como fundos governamentais de aplicação financeira, normalmente constituídos por moeda estrangeira e geridos separadamente das reservas financeiras do Estado. Como regra, as soberanias que criam esses fundos apresentam superávit nominal no setor público ou superávit estrutural em contacorrente no balanço de pagamentos, decorrentes da exportação de uma commodity. Conseguem poupar mais do que investem ou então praticam políticas cambiais agressivas para valorização ou desvalorização de sua moeda. Assim, por meio destes fundos, estes países diversificam suas aplicações para além das tradicionais letras do tesouro norte-americano" - p. 180. Os Fundos Soberanos têm por missão "orientar o investimento e o uso destas receitas de modo a maximizar seu valor financeiro e o benefício delas extraído pela sociedade [...] os FSs possuem, gerem e administram ativos para atingir objetivos financeiros, além de fazerem uso de diversas estratégias de investimento que incluem investimentos em ativos estrangeiros", como se vê em: Relatório II. Fundos financeiros baseados em receitas de petróleo e gás. São Paulo: Bain \& Company, Tozzini Freire Advogados, 2009. p. 9-10.

1075 TORRES, Heleno Taveira; RODRIGUES, Felipe da Cunha. Fundo soberano do Brasil e finanças públicas: regime jurídico dos fundos públicos especiais, experiência internacional e a Lei n. 11.887/2008. Belo Horizonte: Fórum, 2012. p. 72.

1076 BOLTON, Patrick; SAMAMA, Frederic; STIGLITZ, Joseph. Introduction. In: BOLTON, Patrick; SAMAMA, Frederic; STIGLITZ, Joseph (Ed.). Sovereign wealth funds and long-term investing. New York: Columbia University Press, 2012. p. 3.

1077 YI-CHONG, Xu. The political economy of sovereihn wealth funds. In: YI-CHONG, Xu; BAHGAT, Gawdat. The political economy of sovereign wealth funds. Londres: Palgrave Macmillan, 2010. p. 3-5. 
relevantes à sociedade, como a proteção do meio ambiente. Claro que os gestores desses ativos têm o dever de maximizar o patrimônio gerido: embora não tenham acionistas que pressionem por lucros, têm sim cidadãos com seu patrimônio representado naqueles investimentos.

A existência de Fundos Soberanos ( $S W F$ na sigla em inglês, por Sovereign Wealth Funds) ao redor do mundo não é nova - registram-se Fundos dessa natureza desde os anos 1950. ${ }^{1078-1079}$ Mas apenas recentemente - anos 1990 e 2000 -, é que cresceram em número e, especialmente, em volume de recursos. ${ }^{1080}$ Para que se tenham parâmetros, o Sovereign Wealth Fund Institute, organização internacional destinada ao estudo da matéria, afirma que em janeiro/2013 esses Fundos somados representavam capital superior a US\$ 5,2 trilhões. ${ }^{1081}$ Isto é mais que o dobro do PIB brasileiro em 2012 (US\$ 2,253 trilhões ${ }^{1082}$ ). Contudo, "mesmo com esse gigantismo aparente, os fundos soberanos ainda constituem uma pequena parcela dos ativos e estoques de riqueza do mundo". ${ }^{1083}$

Não é coincidência que os fundos tenham crescido nos últimos 20 (vinte) anos: na forma dos dados já apresentados, foi neste período que os preços dos minérios e do petróleo cresceram solidamente - e, como se verá adiante, embora não sejam todos os Fundos Soberanos que se destinam a gerir receitas de recursos naturais não renováveis, os que o fazem têm se destacado. Dentre os 03 (três) maiores Fundos, 02 (dois) são de nações ricas em recursos naturais: Noruega e Emirados Árabes Unidos, nessa ordem, seguidos da China ${ }^{1084}$ em terceiro lugar.

$1078 \mathrm{Xu}$ Yi-chong afirma que a origem destes Fundos pode ser apontada no ano 1816, com a criação, na França, da Caisse des Dépôts et Consignations (CDC). YI-CHONG, Xu. The political economy of sovereihn wealth funds. In: YI-CHONG, Xu; BAHGAT, Gawdat. The political economy of sovereign wealth funds cit., p. 1.

1079 Para um compreensivo histórico da utilização de Fundos Soberanos, v. TORRES, Heleno Taveira; RODRIGUES, Felipe da Cunha. Fundo soberano do Brasil e finanças públicas cit., p. 81 e ss.

1080 "Thus, three trends interact to suggest that SWFs are here to stay: the expanding wealth of all societies, growing involvement of governments in managing that wealth, and increasing recognition of the benefits of international portfólio diversification. At the same time, SWFs are instruments of 'big money', and big money is distrusted whether in the hands of government, banks, hedge funds, or other private investment vehicles". TRUMAN, Edwin M. Sovereign Weakth funds: threat or salvation?. Washington D.C.: Peterson Institute for International Economics, 2010. p. 161.

1081 Disponível em: <http://www.swfinstitute.org/fund-rankings/>. Acesso em: 21 jan. 2013.

1082 Dados do Banco Mundial. Disponível em: <http://data.worldbank.org/country/brazil>. Acesso em: 5 dez. 2013.

1083 SIAS, Rodrigo. O Fundo Soberano brasileiro e suas implicações para a política econômica. Revista do $B N D E S$, Rio de Janeiro, v. 15, n. 30, dez. 2008, p. 110.

1084 Embora a China tenha grandes reservas de recursos naturais não renováveis, a ausência de uma participação decisiva destes bens na economia nacional leva a que não seja considerada "resource-rich". Nesse sentido: INTERNATIONAL MONETARY FUND. Guide on resource revenue transparency cit.; INTERNATIONAL MONETARY FUND. Macroeconomic policy frameworks for resource-rich developing countries cit. 
Nada obstante, não é apenas o aquecido mercado global de recursos naturais que explica o desenvolvimento dessas instituições. Os Fundos Soberanos são também a resposta de diversos países às crises financeiras internacionais e, especialmente, às exigências feitas pelo Fundo Monetário Internacional para auxiliar na recuperação econômica dessas nações. Vista muitas vezes como invasão e mácula à soberania desses países, a ação do FMI passou a ser temida e evitada, de forma que alguns países se utilizam dos Fundos Soberanos como poupanças para tempos de crise, evitando então submeter-se às regras daquela entidade. ${ }^{1085}$

A gestão dos Fundos pelo Estado, e a busca de benefícios públicos através dele, pode ser apontada como uma resposta dos anos 2000 à tendência liberal dos anos 1980-1990. “A mão visível do Estado não tinha sido tão aparente por algum tempo" como o é nos Fundos Soberanos. ${ }^{1086}$

Essa espécie de Fundo ainda encontra aceitação titubeante nos debates internacionais - especialmente por aqueles com conceitos prefixados na ideia da virtuose oriunda do mercado livre de amarras e, especialmente, de participação do Estado. É paradigmático, nesse sentido, o texto apresentado por Lawrence Summers no periódico Financial Times, ${ }^{1087}$ em que levanta uma série de preocupações sobre a existência dos

1085 GRIFFITH-JONES, Stephany; OCAMPO, José Antonio. Sovereign wealth funds: a developing country perspective. Trabalho apresentado no workshop sobre Fundos soberanos organizado pela Andean Development Corporation em Londres, 18 fev. 2008. Disponível em: <http://academiccommons.columbia.edu/download/fedora_content/download/ac:127037/CONTENT/So vereign_Wealth_Funds_GJ-O_final.pdf>. Acesso em: 25 fev. 2013, p. 11; MONK, Ashby H. B. Sovereignty in the era of global capitalism: the rise of sovereign wealth funds and the power of finance. Disponível em: <http://ssrn.com/abstract=1587327>. Acesso em: 16 fev. 2013, p. 6; BOLTON, Patrick; SAMAMA, Frederic; STIGLITZ, Joseph. Introduction. In: BOLTON, Patrick; SAMAMA, Frederic; STIGLITZ, Joseph (Ed.). Sovereign wealth funds and long-term investing cit., p. 6. Afirmam Heleno Torres e Felipe Rodrigues: "os fundos soberanos são reflexo do movimento dos Estados soberanos no sentido de atuação mais enérgica em papéis privados ou de consecução do interesse público por meios tradicionalmente utilizados pelos agentes econômicos privados, exercendo, simultaneamente, suas atividades tipicamente públicas". TORRES, Heleno Taveira; RODRIGUES, Felipe da Cunha. Fundo soberano do Brasil e finanças públicas cit., p. 281. Cabe ainda notar que: "Os programas de ajuste do FMI, além de provocarem desemprego e quedas acentuadas do PIB, embutiram o princípio explícito de superávits fiscais nos países afetados. O medo de novas crises, em contrapartida à abertura da conta financeira e capital, transformou os países asiáticos em 'acumuladores de reservas', mudança que resultou tanto dos superávits nominais fiscais maiores como da taxa de câmbio desvalorizada. Portanto, a atuação do FMI contribuiu para o que a literatura econômica passou a chamar de self insurance, e, por fim, para a proliferação dos fundos soberanos”. SIAS, Rodrigo. O Fundo Soberano brasileiro e suas implicações para a política econômica cit., p. 106.

1086 YI-CHONG, Xu. The political economy of sovereihn wealth funds. In: YI-CHONG, Xu; BAHGAT, Gawdat. The political economy of sovereign wealth funds cit., p. 21. Tradução livre. Ainda: "Governments worldwide, however, are are rethinking their roles and functions to ensure the smooth operayion of a market system" - p. 22.

1087 Em 29 de julho de 2007. "To the extent that SWFs pursue different approaches from other large pools of capital, the reasons have to be examined. The most plausible reasons - the pursuit of objectives other 
Fundos Soberanos, especialmente considerando sua titularidade governamental: para ele, a atuação de um agente com objetivos diversos daqueles puramente lucrativos demanda maiores atenções e até mesmo maiores regras. Afinal, esses Fundos "ficam na intersecção entre altas finanças e alta política". ${ }^{1088}$ Os Fundos Soberanos já foram chamados de "cavalos de Tróia", nos quais países não democráticos se infiltram nas economias desenvolvidas. ${ }^{1089}$ Em janeiro de 2008, um âncora de televisão dos Estados Unidos chegou a perguntar, a propósito dos investimentos de Fundos estrangeiros em bancos estadunidenses: “queremos que comunistas ou terroristas tomem nossos bancos?". ${ }^{1090}$ Esta preocupação excessiva parece ser descartada pela doutrina majoritária. ${ }^{1091}$

De outro lado, há céticos que simplesmente negam aos Fundos Soberanos qualquer papel relevante no atual panorama. ${ }^{1092}$ Há os que vêem riscos à segurança nacional oriundos do recebimento de investimentos de grande volume através de instrumentos comandados por Governos. ${ }^{1093-1094}$ Há os que enxergam tais Fundos como viciosos, especialmente quando (e é frequente) não integrados com o Orçamento geral. ${ }^{1095}$

E, especialmente, há os que ressalvam o otimismo de muitos em relação aos Fundos Soberanos, suscitando que, para que funcionem como desejado e tragam bom

than maximising risk-adjusted returns and the ability to use government status to increase returns - are also most suspect from the viewpoint of the global system".

1088 DREZNER, Daniel W. Sovereign Wealth Funds and the (in)security of global finance. Journal of International Affairs, v. 62, n. 1, 2008, p. 115. Tradução livre.

1089 Termo referido por Xu Yi-chong, embora deva-se mencionar que o autor entende que tais preocupações são alarmistas e infundadas: YI-CHONG, Xu. The political economy of sovereihn wealth funds. In: YICHONG, Xu; BAHGAT, Gawdat. The political economy of sovereign wealth funds cit., p. 1.

1090 Idem, ibidem, p. 19. Tradução livre.

1091 Para uma revisão dessa doutrina, v. TORRES, Heleno Taveira; RODRIGUES, Felipe da Cunha. Fundo soberano do Brasil e finanças públicas cit., p. 282. E afirmam ainda: "Os fundos soberanos, de modo geral, não representam risco sistêmico, ou seja, não têm capacidade de subversão dfos mercados financeiros" - p. 283.

1092 GILSON, Ronald J. Sovereign Wealth Funds: perhaps we see what we want to see. In: BOLTON, Patrick; SAMAMA, Frederic; STIGLITZ, Joseph (Ed.). Sovereign wealth funds and long-term investing cit., p. 208.

1093 JOHNSON, Simon. The rise of sovereign wealth funds. Finance and development, v. 44, n. 3, 2007. Disponível em: <http://www.imf.org/external/pubs/ft/fandd/2007/09/straight.htm>. Acesso em: 27 fev. 2013: "Of course, there are always some national security limitations on what foreigners can own. But recent developments in the world suggest there may be a perception that certain foreign governments shouldn't be allowed to own what are regarded as an economy's 'commanding heights'. This is a slippery slope, which leads quickly and painfully to other forms of protectionism. It's important to preempt such pressures".

1094 Richard Epstein e Amanda Rose, por outro lado, veem as opiniões que ressaltam esses riscos como exageradas e dramáticas, sustentando que o ordenamento (nos Estados Unidos) já prevê modos de evitar interferências indevidas. EPSTEIN, Richard A.; ROSE, Amanda M. The regulation of sovereign wealth funds: the virtues of going slow. The University of Chicago Law Review, v. 76, n. 111, 2009.

1095 DAVIS, Jeffrey; OSSOWSKI, Rolando; DANIEL, James A.; BARNETT, Steven. Oil funds: problems posing as solutions?. Finance and development, v. 38, n. 4. Disponível em: <http://www.imf.org/external/pubs/ft/fandd/2001/12/davis.htm>. Acesso em: 2 mar. 2013. 
retorno ao Estado, são necessárias instituições fortes, responsabilidade na sua governança e, principalmente, transparência. Mais sobre isso adiante.

Com base no crescente interesse por esse instrumento, um grupo de países, ligados ao FMI, OCDE e Banco Mundial, desenvolveu princípios gerais de organização dos Fundos Soberanos - são os chamados Princípios de Santiago (Santigo Principles), nomeados consoante a capital chilena, onde se realizaram as reuniões para debate do tema. A conclusão do grupo é de que "os investimentos dos fundos soberanos tendem a ser benéficos aos mercados internacionais, mas também suscitam preocupações", ${ }^{1096}$ daí por que buscam estruturas básicas comuns de aplicação e interpretação.

Os 24 (vinte e quatro) princípios podem ser repartidos em três áreas fundamentais ("[i] base jurídica; [ii] estrutura institucional e de governança; e [iii]

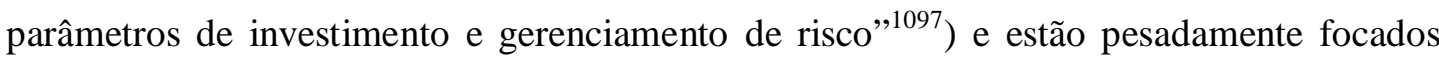
em governança, transparência, accountability, e em evitar o uso político dos Fundos por um país para invasão na soberania alheia. Tais princípios são apontados como tendo dissipado parte das preocupações internacionais com o uso destes Fundos. ${ }^{1098}$

Os Fundos Soberanos, portanto, afastando-se dos riscos que podem lhes acompanhar, são instrumentos valorosos, especialmente para os que acreditam e valorizam a promoção da justiça intergeracional.

Ao momento, interessa deixar de lado os Fundos formados por outros tipos de receitas, ${ }^{1099}$ focando nos Fundos Soberanos direcionados para governança das receitas públicas de recursos naturais não renováveis. ${ }^{100}$ É em atenção a estes que se prosseguirá embora, sempre que possível, trazendo considerações da literatura genérica dos Fundos Soberanos, quando assim se fizer útil.

1096 TORRES, Heleno Taveira; RODRIGUES, Felipe da Cunha. Fundo soberano do Brasil e finanças públicas cit., p. 215.

1097 Idem, ibidem, p. 217.

1098 TRUMAN, Edwin M. Sovereign Weakth funds cit. O autor, contudo, sustenta que esses princípios devem ser ainda reforçados para dissipar totalmente o a visão de que os Fundos podem ameaçar a ordem econômica internacional.

1099 Dos 25 (vinte e cinco) maiores Fundos Soberanos listados pelo Sovereign Wealth Fund Institute, 09 (nove) não estão diretamente relacionados a recursos naturais não renováveis.

1100 "A transformação de um recurso não renovável em recurso renovável se dá pelo investimento, doméstico ou no exterior, das rendas obtidas da extração mineral ou petrolífera de modo a aumentar a capacidade produtiva e elevar os padrões de vida da geração atual, assim como das gerações futuras. O método mais prático tem sido a criação de fundos de investimento nos quais a renda petrolífera ou mineral é canalizada. O fundo deve investir em ativos financeiros por meio dos quais incremente o capital produtivo real na forma de maquinário, construções, infra-estrutura ou conhecimentos destinados para o povo" (BERCOVICI, Gilberto. Direito econômico do petróleo e dos recursos minerais cit., p. 346). 
Os Fundos Soberanos direcionados à governança dos recursos naturais não renováveis são classificados, basicamente, em 02 (duas) espécies: ${ }^{1101}$ [i] aqueles que se prestam precipuamente a servir de instrumento de estabilização; e [ii] aqueles cuja principal função é de servir de poupança às gerações futuras. ${ }^{1102-1103}$

${ }^{1101}$ Vale considerar o constante entrecruzamento das duas funções referidas: "The general principle behind both stabilization and savings is the same. When revenues are front loaded, as is usually the case with natural resource revenue streams, a policy of constant public expenditures does double duty, as it fulfills both a savings function and a stabilization function" (HUMPHREYS, Macartan; SANDBU, Martin E. The political economy of natural resource funds. In: HUMPHREYS, Macartan; SACHS, Jeffrey D.; STIGLITZ, Joseph E. (Org.). Escaping the resource curse cit., p. 197).

1102 FREITAS, Paulo Springer de. Rendas do petróleo... cit., p. 51: "Quanto aos objetivos, os fundos soberanos podem ser classificados em duas categorias principais: fundos de estabilização e de poupança. Os primeiros têm por objetivo mitigar os efeitos dos ciclos econômicos, com o governo aportando recursos para o fundo em momentos de expansão, e sacando recursos durante as crises. Já os fundos de poupança têm por objetivo acumular ativos financeiros para as gerações futuras. As aplicações devem depender dos objetivos do fundo. Assim, fundos de estabilização requerem aplicações em ativos de menor maturação, menos arriscados, com maior liquidez e, preferencialmente, no exterior. Já fundos de poupança podem aplicar seus recursos em ativos que apresentam maior risco, porém maior retorno esperado no longo prazo". Para Ocampo e Griffith-Jones (GRIFFITH-JONES, Stephany; OCAMPO, José Antonio. Sovereign wealth funds: a developing country perspective. Trabalho apresentado no workshop sobre Fundos Soberanos organizado pela Andean Development Corporation em Londres, 18 fev. 2008. Disponível em: <http://academiccommons.columbia.edu/download/fedora content/download/ac:127037/CONTENT/Sovereign_Wealth_Funds_GJ-O_final.pdf>. Acesso em: 25 fev. 2013, p. 9): "Regarding their purposes, SWFs can be broadly categorized into two main types: savings and stabilization funds. Savings funds are intended as permanent funds and are generally associated with non-renewable natural resources. They create a store of wealth for future generations so that they can benefit from the resources after their depletion. They build on economic theory which implies that part of non-renewable resources should be saved to smooth the country's intertemporal consumption, in ways similar to individuals who save both for their retirement and to leave an inheritance to their children. A stabilization fund is a mechanism designed to reduce the impact of volatile fiscal revenues and/or foreign exchange receipts, linked to the pro-cyclical pattern of export prices or volumes. Stabilization funds often take the form of contingent funds, which accumulate resources when government revenues or the price of exports is high (above some threshold) and pay when they are low. A third category, sometimes mentioned separately (Davis et al., 2003) is a financing fund, whose operational rules are explicitly designed so it effectively absorbs a budget surplus or funds an overall budget deficit. An example is the Norwegian Fund, where the budget has to transfer to the fund revenues if the budget is in overall surplus; if the budget is in deficit, the latter is financed by the fund. A fourth category could be development funds, which allocate resources for funding priority socioeconomic projects, such as infrastructure. If we assume that, almost by definition, SWFs invest abroad, such development funds could, for example, invest in infrastructure and other projects in neighboring countries, possibly benefiting the source country through increased. This could be done bilaterally or through regional and sub-regional development banks. In practice, SWFs may have different purposes based on the source of funding. For example, Kimmitt (2008) notes that, while commodity-based funds are prone to multiple and changing objectives, including fiscal revenue stabilization and sterilization of foreign currency inflows, non-commodity-based funds are more commonly used to make stand-alone investments when a county has accumulated reserves in excess of the 'optimal' level". Ainda: DAVIS, Jeffrey; OSSOWSKI, Rolando; DANIEL, James A.; BARNETT, Steven. Stabilization and savings funds for nonrenewable resources: experience and fiscal policy implications. In: DAVIS, J.; OSSOWSKI, R.; FEDELINO, A. (Org.). Fiscal policy formulation and implementation in oil-producing countries cit., $\mathrm{p}$. 274.

1103 Utilizamos esta classificação simplificada, uma vez que melhor serve aos propósitos ora apresentados. Nada obstante, é correto observar que a divisão entre as espécies de fundos pode ser feita de diferentes formas, por exemplo com maior detalhamento de suas espécies, como a da citação da nota acima; ou mesmo pode ser feita consoante a fonte dos recursos depositados - como apontado por: MORGAN, J. P. Sovereign wealth funds: a bottom-up primer. J. P. Morgan, 2008. No mesmo sentido, a doutrina de Ana 
No primeiro caso, o objetivo principal é utilizar aqueles recursos de forma anticíclica, guardando nos tempos venturosos (por exemplo, na alta dos preços dos recursos naturais não renováveis) para utilização quando as receitas declinam. ${ }^{104}$ Permite lidar com a volatilidade da taxa de câmbio e com o desquilíbrio da balança de pagamentos. ${ }^{1105-1106}$ É instrumento de racionalidade e responsabilidade fiscal: afinal, de nada serviria a construção de escolas e hospitais hoje se amanhã, com a redução das receitas, não se tenham verbas orçamentárias suficientes para manter médicos e professores exercendo sua função, ${ }^{1107-1108}$ dessa forma, atua como promotor da previsibilidade

Carla Bliacheriene e outros (BLIACHERIENE, Ana Carla; FUNARI, Marcos Hime; RIBEIRO, Renato Jorge Brown. Natureza jurídica do Fundo Soberano brasileiro e do Fundo Fiscal de investimentos e estabilização cit.) aponta uma classificação em 5 (cinco) espécies, apoiada em definição tomada por documento do FMI e reproduzida por Rodrigo Sias (SIAS, Rodrigo. O Fundo Soberano brasileiro e suas implicações para a política econômica cit.). Também sobre as diversas definições, v. FUNDAÇÃO DO DESENVOLVIMENTO ADMINISTRATIVO DO ESTADO DE SÃO PAULO - FUNDAP. Fundos de riqueza soberana. São Paulo, 2008. Disponível em: <http://www.fundap.sp.gov. br/debatesfundap/pdf/conjuntura/Fundos\%20de\%20Riqueza\%20Soberana.pdf >. Acesso em: 7 dez. 2013.

${ }^{1104}$ Engel e Valdés (ENGEL, Eduardo; VALDÉS, Rodrigo. Optimal fiscal strategy for oil exporting countries cit., p. 38) defendem a utilização de fundos de estabilização para montar uma estratégia de "renda permanente" oriunda da exploração petrolífera e suavização dos choques. Mas ressalvam igualmente que, se o orçamento geral não seguir a estratégia de estabilização utilizada pelo fundo, os benefícios desse instrumento serão nulos. Afirmam: "And since money is fungible, the temptation to undo the restrictions on expenditures imposed by the stabilization fund will often be large. For instance, if expenditures out of oil wealth are stabilized completely, but fiscal expenditures continue to follow a pattern that is positively correlated with oil prices (e.g., due to procyclical access to financing in the international capital market), there will be no welfare gain from having a fund. The objective, at the end, is to stabilize expenditure, not a particular form of income. Thus, changes in the stabilization fund should represent the sum of all government incomes and expenditures, that is, the overall net fiscal asset position". A recomendação de prudência fiscal se faz relevante: "prudence would suggest that a negative shock should be seen as permanent, and a positive shock as temporary, until proven otherwise. The stronger a government's financial position, the less it needs to heed this advice because it can better afford to delay cutting expenditures. Also, the less costly expenditure is to adjust, the quicker it should be adjusted" - DAVIS, Jeffrey; OSSOWSKI, Rolando; DANIEL, James A.; BARNETT, Steven. Stabilization and savings funds for nonrenewable resources: experience and fiscal policy implications. In: DAVIS, J.; OSSOWSKI, R.; FEDELINO, A. (Org.). Fiscal policy formulation and implementation in oil-producing countries cit., p. 276. Outrossim, note-se a doutrina de Cagnin, Cintra, Farhi e Almeida (CAGNIN, Rafael Fagundes; CINTRA, Marcos Antonio Macedo; FARHI, Maryse; ALMEIDA, Júlio Sérgio Gomes de. $O$ debate em torno dos fundos cambiais: experiências internacionais. Texto para discussão IE/UNICAMP, 2008. n. 150, p. 17): “Em síntese, pode-se afirmar que os fundos de estabilização cumprem, direta ou indiretamente, as seguintes funções concomitantemente: (1) financiamento da política fiscal anticíclica, (2) estabilização da taxa de câmbio e (3) isolamento da política monetária".

1105 BERCOVICI, Gilberto. Direito econômico do petróleo e dos recursos minerais cit., p. 346.

1106 "Moreover, stabilization funds on their own cannot reduce the revenue uncertainty and volatility facing the public sector as a whole. The objective of rendering budget revenue more predictable and stable is achieved by transferring the uncertainty and volatility (or a portion of them) to the fund. Changing the revenue stream accruing to the public sector as a whole might be achieved by using commodity risk markets". DAVIS, Jeffrey; OSSOWSKI, Rolando; DANIEL, James A.; BARNETT, Steven. Stabilization and savings funds for nonrenewable resources: experience and fiscal policy implications. In: DAVIS, J.; OSSOWSKI, R.; FEDELINO, A. (Org.). Fiscal policy formulation and implementation in oil-producing countries cit., p. 280.

${ }^{1107}$ Relevantes, sobre o tema, as considerações a respeito do planejamento fiscal, não apenas da perspectiva formal (isto é, observando o Plano Plurianual e a Lei de Diretrizes Orçamentárias), mas observando as normas de transparência e accountability, e focando na qualidade do gasto público. Nesse sentido: 
indispensável à boa gestão pública, otimizando receitas e despesas, ${ }^{1109}$ contraindo as primeiras quando excessivas para permitir a sequência das últimas, quando insuficientes. ${ }^{1110} \mathrm{E}$ esta função é especialmente necessária em se tratando de receita de recursos naturais não renováveis, seja porque há a certeza de que os bens explorados são finitos, seja porque seus preços e demanda obedecem lógica própria e confusa, estando sujeitos a grandes altas, mas também a severas quedas. ${ }^{1111}$ São de curto e médio prazo, ${ }^{1112}$ e os valores reservados precisam estar à disposição para exercício de seu desiderato contracíclico tão logo necessário.

O Fundo estabelecido no Chile, construído a partir das vastas receitas adquiridas pela exploração do minério de cobre, pode ser tomado como exemplo de espécie de instrumento anticíclico, ${ }^{1113}$ sendo frequentemente louvado por suas

ALMEIDA, Carlos Otávio Ferreira de. O planejamento financeiro responsável: boa governança e desenvolvimento no Estado contemporâneo. In: CONTI, José Maurício; SCAFF, Fernando Facury (Org.). Orçamentos públicos e direito financeiro cit., p. 577 e ss.

1108 Vale mencionar a Lei de Responsabilidade Fiscal (Lei Complementar 101/2000, art. $1^{\circ}{ }^{\circ}, \S 1^{\circ}{ }^{\circ}$ ), que põe o planejamento financeiro no centro de uma conduta responsável: "A responsabilidade na gestão fiscal pressupõe a ação planejada e transparente, em que se previnem riscos e corrigem desvios capazes de afetar o equilíbrio das contas públicas, mediante o cumprimento de metas de resultados entre receitas e despesas e a obediência a limites e condições no que tange a renúncia de receita, geração de despesas com pessoal, da seguridade social e outras, dívidas consolidada e mobiliária, operações de crédito, inclusive por antecipação de receita, concessão de garantia e inscrição em Restos a Pagar".

${ }^{1109}$ Como afirmam Humphreys e Sandbu (HUMPHREYS, Macartan; SANDBU, Martin E. The political economy of natural resource funds. In: HUMPHREYS, Macartan; SACHS, Jeffrey D.; STIGLITZ, Joseph E. (Org.). Escaping the resource curse cit., p. 197): "spending should be stabilized and should not track revenues closely".

1110 "Em termos técnicos, o fundo de estabilização não reduz propriamente a volatilidade das receitas advindas da exploração de recursos naturais, mas transfere esta volatilidade, ou parte dela, ao fundo, impedindo que ela recaia diretamente sobre o orçamento. Amenizam-se, assim, as flutuações das receitas correntes disponíveis ao orçamento, reduzindo-se a incerteza e volatilidade das receitas decorrentes da atividade de exploração de recursos naturais". RUBINSTEIN, Flávio. Receitas públicas de recursos naturais no direito financeiro brasileiro cit., p. 241.

1111 Vale mencionar a posição de Collier, Van der Ploeg e Venables (COLLIER, Paul; VAN DER PLOEG, Frederick; VENABLES, Anthony J. Managing resource revenues in developing economies. Disponível em: $\quad$ http://users.ox.ac.uk/ econpco/research/pdfs/ManagingResourceRevenuesinDevelopingEcono mies.pdf $>$. Acesso em: 3 dez. 2013), para quem, nos países em desenvolvimento, é equivocado falar em fundos intergeracionais, dada a necessidade de investimentos de capital a atualidade. Defendem, contudo, um fundo destinado a garantir liquidez ao Estado, e que com essa definição teria características diferentes, como o curto-prazo de retiradas, para fazer frente a flutuações de preços. Assim, esse fundo: "would simply be to enable expenditure to stay on this path while actual revenues fluctuated around it" p. 2.

1112 Relatório sobre o tema consignou: "é esperado que um FS de estabilização, que tem tipicamente objetivos de curto e médio prazos, aloque uma parte maior de seus recursos em investimentos de horizonte mais curto, evitando exposição a ativos de baixa liquidez e de alto risco". Relatório II. Fundos financeiros baseados em receitas de petróleo e gás cit., p. 19.

1113 VELASCO, Andrés. Sovereign Wealth Funds as stabilizers. In: BOLTON, Patrick; SAMAMA, Frederic; STIGLITZ, Joseph (Ed.). Sovereign wealth funds and long-term investing cit., p. 35: "The idea was not simply to save the money, however, but to use it, and we used it quite actively when the crisis hit. We spent around $\$ 8$ billion in the course of the year and a half of the crisis to fund what was a pretty aggressive fiscal stimulus package". 
características e pela seriedade em sua condução, permitindo que seus objetivos sejam atingidos.

O segundo tipo de Fundo- de poupança - tem por objetivo primordial pura e simplesmente a reserva de valores em benefício das gerações futuras. Mais do que os Fundos de Estabilização, estão costumeiramente ligados aos recursos naturais não renováveis. A ideia é permitir o proveito dessa riqueza, pela sociedade a porvir, quando já não mais estarão disponíveis esses bens. Próximos aos fundos de pensão (de que divergem principalmente em objetivo e em gestão/aplicação dos ativos ${ }^{1114}$ ), têm a virtude imediatamente perceptível de evitar a "armadilha do caixa único" denunciada por Maria Amélia Enriquez; ${ }^{115}$ a só indisponibilidade desses recursos aos governantes de ocasião já alcança parte do objetivo, reduzindo os incentivos ao gasto por vezes pródigo já referido. Os recursos desses Fundos podem ou não estar diretamente vinculados com determinado propósito - previdência social, por exemplo. São de longo prazo ${ }^{1116}$ e, diferente dos Fundos de estabilização, não necessitam de grande liquidez - isto é, seu objetivo não exige o saque de valores em momentos de urgência.

Mas vale lembrar que tratar-se de um Fundo de poupança não implica dizer que os valores lá depositados devem permanecer inertes. Como outros instrumentos dessa natureza, devem ser aplicados de forma responsável, sem esquecer, contudo, que tais aplicações devem observar prazos muito mais longos e padrões menos agressivos e arriscados. ${ }^{1117}$

${ }^{1114}$ BOLTON, Patrick; SAMAMA, Frederic; STIGLITZ, Joseph. The state of Sovereign Wealth Funs: overview. In: BOLTON, Patrick; SAMAMA, Frederic; STIGLITZ, Joseph (Ed.). Sovereign wealth funds and long-term investing cit., p. 55.

1115 ENRÍQUEZ. Maria Amélia. Mineração... cit., p. 364: “a CFEM é um instrumento econômico que tem grande potencial para ajudar a contornar os problemas que os municípios mineradores enfrentam e, se bem aplicada, pode contribuir para a melhoria da eqüidade intergeracional na distribuição dos benefícios da extração mineral. [...] No entanto, esse instrumento está sub-utilizado por causa da 'armadilha do caixa único', ou seja, de problemas associados à governança". No mesmo sentido é a opinião de Joseph Bell e Teresa Faria, para quem se faz necessária a estruturação de uma conta especial (diferente da conta única do Tesouro) para receber as receitas de recursos naturais não renováveis. BELL, Joseph C.; FARIA, Teresa Maurea. Critical issues for a revenue management law. In: HUMPHREYS, Macartan; SACHS, Jeffrey D.; STIGLITZ, Joseph E. (Org.). Escaping the resource curse cit., p. 288 e ss.

1116 "espera-se que um FS de acumulação, com objetivos de transferência de renda entre gerações, tenha em sua carteira investimentos de maturação mais longa, admitindo maiores flutuações de seu patrimônio no curto prazo visando a um retorno superior no futuro". Relatório II. Fundos financeiros baseados em receitas de petróleo e gás cit., p. 19.

1117 "The fund's resources might be used to undertake domestic investment in physical assets rather than be sterilized abroad. Countries with pressing infrastructural needs or with perceived opportunities for productive domestic investment are particularly likely to consider this option. Such a strategy could also aim at enhancing the competitiveness (and promote the growth) of the nonresource tradables sector; in effect, part of the resource wealth would be given up for the prospect of higher nonresource wealth. There is, however, a danger that such spending may rise to an unsustainable level, or that too quick an 
O maior e mais bem sucedido exemplo de Fundo Soberano de poupança é o Fundo norueguês, que reúne a riqueza derivada da exploração petrolífera. ${ }^{1118}$ De acordo com suas regras, é permitida a retirada anual de até $4 \%$ (quatro por cento) do valor depositado para utilização pelo Governo aderindo ao orçamento. Curioso notar, entretanto, que apesar dessa permissão, as autoridades responsáveis pela sua gestão não têm sequer alcançado esse percentual.

Cumpre lembrar que a distinção entre as espécies de Fundos não é tão rígida. Embora sob críticas de alguns especialistas, ${ }^{1119}$ é comum que os Fundos Soberanos tenham elementos e objetivos vinculados a uma e outra dessas espécies - propósitos de estabilização e de poupança, além de outras várias, como o financiamento de determinados

increase may result in poor-quality projects”. DAVIS, Jeffrey; OSSOWSKI, Rolando; DANIEL, James A.; BARNETT, Steven. Stabilization and savings funds for nonrenewable resources: experience and fiscal policy implications. In: DAVIS, J.; OSSOWSKI, R.; FEDELINO, A. (Org.). Fiscal policy formulation and implementation in oil-producing countries cit., p. 296.

1118 "The Norwegian system has a number of advantages. It facilitates intergenerational wealth sharing; it avoids the creation of excessive current demand on the domestic economy; it shields the domestic economy against major changes in the industrial structure, the resource curse, ou the Dutch Disease; it reducs exchange rate appreciation that might be detrimental to the domestic economy; and it shelters the government from volatility that characterizes resource revenue. But, as mentioned, implementing the Norwegian system entails a leval of commitment that few governments show evidence of satisfying". BOADWAY, Robin; SHAH, Anwar. Fiscal federalism cit., p. 221.

1119 VELASCO, Andrés. Sovereign Wealth Funds as stabilizers. In: BOLTON, Patrick; SAMAMA, Frederic; STIGLITZ, Joseph (Ed.). Sovereign wealth funds and long-term investing cit., p. 36: "if your goal is macro stability, focus your SWF on that alone. Do everything else through the budget. If your country needs infrastructure, let the democratic process assign more money to infrastructure. If your country needs bigger social programs, have the budget through a democratic process, assign additional funds to social programs. Otherwise you will have a fund that is overburdened, and overburdened institutions tend to perform poorly". Afirma também Collier (COLLIER, Paul. Small countries and big resources: harnessing natural resources for development in the $\mathrm{g} 7+$ countries. Paper prepared for the $\mathrm{g} 7+$ high level ministerial retreat. 2012. Disponível em: <http://www.g7plus.org/news-feed/2013/1/10/small-countriesand-big-resources.html>. Acesso em: 27 ago. 2013): "The key institutions needed for harnessing resource revenues are funds for expenditure smoothing and asset accumulation. Where possible, distinct legal entities are desirable because smoothing requires that accumulated money should periodically be used to finance consumption, whereas accumulation to offset depletion should be legally protected from being raided for consumption" - p. 15. Cabe ainda notar, com Davis et alii, que: "Savings with the objective of preserving net government wealth are different from the financial savings designed to smooth expenditure adjustment discussed in the previous subsection. The former represents an economic concept of saving-that is, the excess of current revenue over current expenditure-and the theory is mute whether it should be invested in public works or held as financial assets, and thus whether the government should run an overall surplus or deficit. Savings to smooth expenditure adjustment, however, relate to financial savings. For example, if a government runs high economic savings but spends massively on public investment during 'good' times and fails to build up financial assets, this may not help it to finance expenditure adjustment during 'bad' times" - DAVIS, Jeffrey; OSSOWSKI, Rolando; DANIEL, James A.; BARNETT, Steven. Stabilization and savings funds for nonrenewable resources: experience and fiscal policy implications. In: DAVIS, J.; OSSOWSKI, R.; FEDELINO, A. (Org.). Fiscal policy formulation and implementation in oil-producing countries cit., p. 278. 
setores da economia do país. ${ }^{1120}$ O Fundo da Noruega, por exemplo, apesar de ser primordialmente um Fundo de poupança, contém instrumentos de estabilização. ${ }^{121-1122}$

Em qualquer caso, a missão primordial do Fundo é separar o padrão de gastos públicos do nível de receitas públicas ${ }^{1123-1124}$ nos países amplamente afetados pela exploração mineral. E, para fazê-lo, impõe-se a acumulação de grandes somas, suficientes a permitir que os gastos sejam relativamente mantidos ainda que as receitas tenham diminuído, como sói ocorrer nas épocas de baixa dos preços.

De acordo com documento elaborado por técnicos do Fundo Monetário Internacional, a estrutura básica dos Fundos Soberanos em países que exploram recursos naturais não renováveis pode ser assim resumida: (i) têm por objetivos políticos: a estabilização macroeconômica (suavização dos gastos tendo em vista a volatilidade e imprevisibilidade das receitas); formação de poupança (equidade intergeracional); e promoção de transparência na gestão das receitas de recursos naturais não renováveis e na fixação da política fiscal; e (ii) por objetivos operacionais: suavização da entrada de receita de recursos naturais não renováveis no orçamento, guardando uma parte dessa receita no

1120 "Na maioria das vezes, o caráter intergeracional dos saving funds também acompanha os fundos de estabilização. Esses fundos de estabilização que também têm a conservação da riqueza natural sob forma de ativos financeiros como um de seus objetivos faz com que, em termos ideais, o montante de recursos a ser utilizado como política de estabilização deva ser restringido ao retorno real sobre o patrimônio do fundo ou, pelo menos, convergir para esse valor ao longo do tempo". CAGNIN, Rafael Fagundes; CINTRA, Marcos Antonio Macedo; FARHI, Maryse; ALMEIDA, Júlio Sérgio Gomes de. O debate em torno dos fundos cambiais: experiências internacionais cit., p. 12.

1121 AFONSO, José Roberto Rodrigues; GOBETTI, Sérgio Wulff. Rendas do petróleo no Brasil: alguns aspectos fiscais e federativos cit., p. 231- 269, dez. 2008, p. 254: "Ou seja, além do componente de poupança, o fundo também é administrado numa perspectiva de estabilização fiscal, com os gastos públicos cumprindo um papel anticíclico".

1122 Especificamente sobre o Fundo norueguês, ver: SKANCKE, Martin. Fiscal policy and petroleum fund management in Norway. In: DAVIS, J.; OSSOWSKI, R.; FEDELINO, A. (Org.). Fiscal policy formulation and implementation in oil-producing countries cit.; TRAN $\varnothing \mathrm{Y}$, Bent Sofus. Norway - the accidental role model. In: YI-CHONG, Xu; BAHGAT, Gawdat. The political economy of sovereign wealth funds cit.

1123 HUMPHREYS, Macartan; SANDBU, Martin E. The political economy of natural resource funds. In: HUMPHREYS, Macartan; SACHS, Jeffrey D.; STIGLITZ, Joseph E. (Org.). Escaping the resource curse cit., p. 198.

1124 "When revenue falls sharply and unexpectedly, expenditure often falls sharply too, which is typically costly. Cutting current expenditures can be notoriously difficult and unpopular, and it may be socially damaging, especially if not done in the context of a medium-term comprehensive strategy of expenditure adjustment. Cutting capital spending might involve the abandonment of viable projects, where the return on some additional expenditure may be high. As a result, the productivity of public investment could be affected. But if expenditure is not reduced in the face of large permanent negative shocks, fiscal sustainability could be questioned". Davis e outros (DAVIS, Jeffrey; OSSOWSKI, Rolando; DANIEL, James A.; BARNETT, Steven. Stabilization and savings funds for nonrenewable resources: experience and fiscal policy implications. In: DAVIS, J.; OSSOWSKI, R.; FEDELINO, A. (Org.). Fiscal policy formulation and implementation in oil-producing countries cit., p. 275. Paulo Springer de Freitas afirma: "um fundo de estabilização é constituído com o objetivo de suavizar a trajetória de gastos do governo". FREITAS, Paulo Springer de. Rendas do petróleo... cit., p. 41. 
Fundo e fornecendo informação sobre o fluxo dessas receitas e sobre as mudanças nos ativos financeiros. As regras operacionais observam princípios específicos para a acumulação e retirada de recursos; princípios da gestão de ativos; e disposições sobre governança, transparência e prestação de contas. ${ }^{1125}$

No mais, é também característica comum o investimento de seus recursos no exterior, evitando a sobrevalorização da moeda do país de origem, ${ }^{1126-1127}$ e assim evitando a doença holandesa. ${ }^{1128}$ Não é, contudo, uma estratégia necessária para todos os recursos do Fundo: podem se fazer recomendáveis investimentos internos, especialmente aqueles

${ }^{1125}$ INTERNATIONAL MONETARY FUND. The role of fiscal institutions in managing the oil revenue boom. 2007. Disponível em: <http://www.imf.org/external/np/pp/2007/eng/030507.pdf>. Acesso em: 30 nov. 2013, p. 11. Tradução livre.

${ }^{1126}$ FREITAS, Paulo Springer de. Rendas do petróleo... cit., p. 43: "porque, dessa forma, o fundo estaria transferindo a volatilidade do preço do petróleo para a economia, o que é justamente o que se queria evitar". p. 44: "Se o fundo aplicar os recursos em ativos estrangeiros, o mais provável é que a exploração do petróleo tenha um impacto final nulo sobre a taxa de câmbio. Isso porque, entendendo a questão sob um ponto de vista estritamente financeiro, o aumento da oferta de divisas proporcionado pela maior exportação de petróleo será compensado pelo aumento da demanda por divisas provocado pelos investimentos do fundo em ativos no exterior".

${ }^{1127}$ Sustenta Rodrigo Sias: "os fundos soberanos propiciam fortes intervenções na taxa de câmbio para manter a competitividade externa de sua economia, evitando os riscos da apreciação cambial e dos movimentos bruscos dos fluxos de capitais, que, no passado, levaram a diversas crises cambiais e econômicas". SIAS, Rodrigo. O Fundo Soberano brasileiro e suas implicações para a política econômica cit., p. 125.

1128 "Investing profits abroad, rather than domestically, helps insulate the domestic economy from the adverse microeconomic effects that a mineral boom can cause, thereby reducing the prospect of what is commonly called the Dutch disease from occurring". OTTO, James; ANDREWS, Craig; CAWOOD, Fred; DOGGETT, Michael; GUJ, Pietro; STERMOLE, Frank; STERMOLE, John; TILTON, John. Mining royalties cit., p. 14-15. E afirma Bresser-Pereira: "os recursos desse imposto [sobre as vendas internas e a exportação de commodities] não deverão ser internalizados, mas ser usados para a constituição de um fundo internacional de ativos financeiros, de forma a evitar que sua entrada no país reaprecie a taxa de câmbio. Foi isso, essencialmente, o que fez a Noruega depois que descobriu e passou a exportar o petróleo do Mar do Norte. A Grã-Bretanha, que descobriu petróleo na mesma época, não neutralizou a doença holandesa e sua economia sofreu as consequências [...]. O Chile também neutraliza de forma adequada a doença holandesa ao taxar pesadamente as exportações de cobre, mas essa neutralização é parcial já que a receita do imposto não é destinada à constituição de um fundo internacional". BRESSER-PEREIRA, Luiz Carlos. Doença holandesa e sua neutralização: uma abordagem ricardiana. In: BRESSER-PEREIRA, Luiz Carlos (Org.). Doença holandesa e indústria cit., p. 132. Também Davis e outros (DAVIS, Jeffrey; OSSOWSKI, Rolando; DANIEL, James A.; BARNETT, Steven. Stabilization and savings funds for nonrenewable resources: experience and fiscal policy implications. In: DAVIS, J.; OSSOWSKI, R.; FEDELINO, A. (Org.). Fiscal policy formulation and implementation in oil-producing countries cit., p. 275. E ainda: "O potencial do Fundo Soberano para combater a 'doença holandesa' com menor custo político e menor grau de arbitrariedade pode ser observado no caso norueguês [...] o Fundo Soberano é um poderoso instrumento de política econômica constituindo-se, pois, em uma ferramenta valiosa para evitar os riscos da chamada 'doença holandesa' ou a sua forma mais agressiva, a 'maldição dos recursos naturais' -, diversificar a economia e atuar de forma anticíclica. Como foi visto no caso norueguês, o fundo tem uma atuação anticíclica na parte fiscal, ajuda as exportações resguardando-as da apreciação do câmbio e evita a "doença holandesa"” (SIAS, Rodrigo. O Fundo Soberano brasileiro e suas implicações para a política econômica cit., p. 112-125). 
destinados à diversificação produtiva - valendo considerar também, com Anderson, que as taxas de retorno no exterior são menores que as brasileiras. ${ }^{1129}$

Já os benefícios dos Fundos Soberanos, relatados na doutrina, são vários.

(i) Ajudam a diversificar a base de receitas públicas - geram-se novas receitas não apenas com os rendimentos dos investimentos dos valores reservados nos Fundos, como com os próprios juros do dinheiro reservado; (ii) atuam na proteção contra a doença holandesa; (iii) podem promover a disciplina ${ }^{1130}$ e a transparência fiscais. ${ }^{1131}$ Em certas situações, (iv) servem à busca de objetivos estratégicos, através do investimento em setores considerados prioritários ao desenvolvimento, inclusive com transferência de conhecimento e tecnologia. ${ }^{1132}$ Maria Amélia Enríquez afirma que

a criação de fundos para administrar as rendas provenientes da mineração atende a, pelo menos, três objetivos: 1) evitar os efeitos nefastos da 'maldição dos recursos'; 2) garantir benefícios às gerações atuais; e 3) promover o princípio de equidade intergeracional, gerando alternativas para a manutenção do nível de bem-estar socioeconômico após o esgotamento das reservas minerais [...] esses fundos também se constituem em instrumentos necessários para neutralizar os desequilíbrios provocados pela Dutch disease e, assim, garantir o padrão de vida das gerações atuais. Os fundos servem para enxugar liquidez do sistema (retirar o excesso de dinheiro que circularia se não houvesse essa opção), contribuindo para a manutenção dos preços internos. Isso contribui para

1129 ANDERSON, George. Reflections on oil and gas in federal systems. In: ANDERSON, George (Ed.). Oil \& gas in federal systems cit., p. 397.

${ }^{1130}$ FREITAS, Paulo Springer de. Rendas do petróleo... cit., p. 42: "reduzir as pressões políticas por aumento dos gastos públicos". Esta é foi também a conclusão alcançada na análise dos Fundos do Azerbaijão e do Kazaquistão: "Preliminary evidence suggests that both funds have contributed to improved transparency and accountability. In Azerbaijan, prior to the creation of the oil fund, no regular reporting took place on the use of oil bonus receipts. With the creation of the oil fund, quarterly reporting of oil fund revenues and expenditures and annual external audits have been put in place. Similarly, in Kazakhstan, before the establishment of the NFRK oil revenues were administered in an ad hoc, nontransparent manner. Now, any future expenditures of the oil fund will pass through the state budget, all inflows will pass through the treasury, and its portfolio balance will be published monthly". WAKEMAN-LINN, John; Mathieu, Paul; VAN SELM, Bert. Oil funds in transition economies: Azerbaijan and Kazakhstan. In: DAVIS, J.; OSSOWSKI, R.; FEDELINO, A. (Org.). Fiscal policy formulation and implementation in oil-producing countries cit., p. 356. E ainda, diz o relatório elaborado pelo banco J. P. Morgan: "SWFs also help enforce fiscal discipline and transparency, especially where funding and spending is governed by specific rules. This role is particularly important for newly emerging commodity economies that historically lacked fiscal discipline and transparency. A few countries use their SWFs as catalysts to promote the development of the domestic financial sector" (MORGAN, J. P. Sovereign wealth funds cit., p. 6).

1131 BAUNSGAARD, Thomas; VILLAFUERTE, Mauricio; POPLAWSKI-RIBEIRO, Marcos; RICHMOND, Christine. Fiscal frameworks for resource rich developing countries cit., p. 21. "The credibility and transparency of the fiscal policy framework can be supported by a well-designed resource fund, but the latter cannot be a substitute for an appropriate policy framework nor a panacea that obviates the need to strengthen overall fiscal management capacity".

1132 MORGAN, J. P. Sovereign wealth funds cit. 
assegurar o equilíbrio entre os preços relativos e, portanto, para não desestruturar os outros setores não mineiros da economia. ${ }^{1133-1134}$

Cumpre acrescer, contudo, que os Fundos podem vir a prejudicar a política fiscal caso não sejam integrados com o Orçamento do país. ${ }^{1135}$ Por integração, aqui, devese entender não uma identidade (Orçamento geral e Fundo se confundindo), mas uma coerência, ou coordenação, entre um e outro: o desenho da política de uso dos valores do Fundo não pode ser totalmente independente do desenho da política fiscal geral, levada a efeito através do Orçamento. Os riscos, caso assim não ocorra, são principalmente de eficiência fiscal: gastos duplicados (ordenados pelo Orçamento e também pelo Fundo) ou investimentos, realizados através do Fundo, que se revelam insuscetíveis de manutenção pelo Orçamento geral (de nada adianta construir 10 hospitais com os valores do Fundo se o Orçamento não puder suportar sua manutenção). ${ }^{1136}$

1133 ENRÍQUEZ, Maria Amélia Rodrigues da Silva. Equidade intergeracional... cit., p. 65 e 70.

1134 De forma semelhante, Ana Carla Bliacheriene et alii: "os fundos locais também podem ser utilizados como instrumento de contenção da valorização da moeda nacional em relação ao dólar [...] o Fundo Soberano é utilizado para conter o fluxo financeiro que pode produzir inflação monetária gerada pelo afluxo de recursos oriundos de alguma riqueza não renovável”. BLIACHERIENE, Ana Carla; FUNARI, Marcos Hime; RIBEIRO, Renato Jorge Brown. Natureza jurídica do Fundo Soberano brasileiro e do Fundo Fiscal de investimentos e estabilização cit., p. 182.

1135 "Governance risks are high because NRF financial flows can bypass the regular budget process and become vehicles for patronage and discretionary allocations". RESOURCE GOVERNANCE INDEX 2013. A measure of transparency and accountability in the oil, gas and mining sector. Revenue Waych Institute, 2013, p. 15.

1136 BAUNSGAARD, Thomas; VILLAFUERTE, Mauricio; POPLAWSKI-RIBEIRO, Marcos; RICHMOND, Christine. Fiscal frameworks for resource rich developing countries cit., p. 20: "Therefore, resource funds should be integrated into the budget to ensure its integrity and protect its role as the mechanism to set expenditure priorities and allocate public monies. Resource funds should not have authority to spend outside the budget. One particular practice to be avoided is the creation of 'development funds.' These funds are sometimes rationalized as parallel 'islands of excellence' to overcome public financial management (PFM) weaknesses in the budget process or to escape capture by powerful political groups. However, such development funds tend to fragment the budget process and policy decision-making, weaken the control of fiscal aggregates, as well as reduce the credibility and even the quality of the regular budget. Rather than looking for quick fixes, PFM weaknesses need to be tackled holistically. If there is nonetheless a strong need (particularly for political economy reasons) to visibly show that resource revenue and the resource fund's assets are 'directly' contributing to social welfare, development funds should be conceived only as a sort of "communication or transparency device' with no capacity to spend”. Também: DAVIS, Jeffrey; OSSOWSKI, Rolando; DANIEL, James A.; BARNETT, Steven. Oil funds: problems posing as solutions? cit.: "Oil funds can be poorly integrated with the budget, which can lead to a loss of overall fiscal control and create problems of expenditure coordination, such as duplication of expenditures or capital spending decisions being made without considering their implications for future recurrent spending" - o documento cita exemplos perniciosos de Nigéria e Venezuela, onde a não integração dos Fundos com o Orçamento levou a desperdício de recursos. Também: "Proper integration of the fund and the budget helps to maintain a unified control of fiscal policy and avoid problems in expenditure coordination, such as duplication of expenditure or capital spending decisions made without taking into account their impact on future recurrent spending”. DAVIS, Jeffrey; OSSOWSKI, Rolando; DANIEL, James A.; BARNETT, Steven. Stabilization and savings funds for nonrenewable resources: experience and fiscal policy implications. In: DAVIS, J.; OSSOWSKI, R.; FEDELINO, A. (Org.). Fiscal policy formulation and implementation in 
Mas não apenas isso. Há risco de prejuízos democráticos e de legitimidade, na medida em que, se não existir a referida coordenação entre o funcionamento dos Fundos e a política fiscal, o Fundo pode vir a sobrepor as decisões do Parlamento, substituindo-as pelas decisões do Poder Executivo ou daqueles investidos na função de ditar os rumos e efetuar os desembolsos desse instrumento. Daí que se postula que os "fundos necessitam ser completamente integrados ao orçamento e ao quadro fiscal". ${ }^{1137-1138}$

De outro lado, há o problema da fungibilidade. Isto é: dinheiro é bem fungível. Sua reserva em um Fundo pode passar ao público a impressão de uma gestão fiscal segura e precavida. Mas seus objetivos serão certamente frustrados se, concomitantemente, forem frágeis os limites à tomada de empréstimos. ${ }^{1139}$ Afinal, “os governos encontrarão empréstimos particularmente fáceis quando o preço do petróleo está em alta e os bens do fundo estão florescendo". ${ }^{1140}$ Assim, há críticos que indicam que a existência dos Fundos cria incentivos para que o governante contraia dívidas, portanto nulificando grande parte dos benefícios trazidos pelo instrumento, a começar pelo aspecto intergeracional.

Finalmente, há quem relacione os Fundos com os regimes autoritários, afirmando que sua instauração implica prejuízos ao esforço democrático, possibilitando que estados autocráticos e rentistas evitem movimentos oposicionistas. ${ }^{1141}$

oil-producing countries cit., p. 290. E ainda: RUBINSTEIN, Flávio. Receitas públicas de recursos naturais no direito financeiro brasileiro cit., p. 243.

${ }^{1137}$ BAUNSGAARD, Thomas; VILLAFUERTE, Mauricio; POPLAWSKI-RIBEIRO, Marcos; RICHMOND, Christine. Fiscal frameworks for resource rich developing countries cit., p. 21. Tradução livre.

1138 "Governance risks are high because NRF financial flows can bypass the regular budget process and become vehicles for patronage and discretionary allocations". RESOURCE GOVERNANCE INDEX 2013. A measure of transparency and accountability in the oil, gas and mining sector. Revenue Waych Institute, 2013, p. 15.

1139 "The government could borrow or run down assets to finance higher expenditures, leaving government savings unchanged even if the fund were to operate in accordance with its rules and if budget revenue were stabilized. Thus, if there is insufficient control of expenditure or deficits outside the fund, the advantages of operating a fund that stabilizes resources available to the budget would be limited. Indeed, governments will probably find borrowing particularly easy when the resource price is high and the fund's assets are burgeoning. The achievement of actual expenditure smoothing therefore requires additional fiscal policy decisions besides the operation of a fund". DAVIS, Jeffrey; OSSOWSKI, Rolando; DANIEL, James A.; BARNETT, Steven. Stabilization and savings funds for nonrenewable resources: experience and fiscal policy implications. In: DAVIS, J.; OSSOWSKI, R.; FEDELINO, A. (Org.). Fiscal policy formulation and implementation in oil-producing countries cit., p. 285.

1140 DAVIS, Jeffrey; OSSOWSKI, Rolando; DANIEL, James A.; BARNETT, Steven. Oil funds: problems posing as solutions? cit. Tradução livre.

1141 DREZNER, Daniel W. Sovereign wealth funds and the (in)security of global finance cit., p. 125. "The rise of sovereign wealth funds will also have some negative second order effects for American foreign policy. SWFs will impair democracy promotion efforts. These investment vehicles aid and abet in the persistence of 'rentier states' - governments that do not need their citizens to raise revenue. Democratization is a much more difficult policy for the United States to pursue when the target government is sitting on trillions of dollars in assets to buy off discontented domestic groups. 
Especialmente, contudo, impõe-se registrar que estes Fundos não são tão perniciosos quanto podem ser indiferentes. Isto é: a doutrina revela seguidas lições de que o Fundo Soberano não tornará o quadro fiscal de um país melhor. A relação de causa e efeito é inversa. Um melhor quadro fiscal é que fará do Fundo um instrumento mais eficiente e mais apto e produzir benesses ao seu Estado hospedeiro. Como destacam Humphreys e Sandbu, estudos sobre casos concretos indicam que de fato há uma correlação positiva entre a presença desses Fundos e uma menor sensibilidade dos gastos públicos em face das receitas de recursos minerais não renováveis; mas esses estudos expõem também que essa correlação já existia antes da instalação dos mesmos Fundos. ${ }^{1142-}$ 1143 Daí que se afirma que é a seriedade institucional do país que trará o melhor desempenho desse instrumento, e não o inverso. ${ }^{1144}$

Isto é: embora seja certo que muito se tem louvado a existência dos Fundos Soberanos, deve-se registrar que eles não são, manifestamente, instrumentos fáceis e rápidos de acesso a benefícios incontáveis. Não são tábua de salvação. Não transformam um país fiscalmente indisciplinado. ${ }^{1145-1146}$ Não produzem resultados milagrosos.

Authoritarian governments in the Middle East and East Asia will be more capable of riding out downturns that would otherwise have threatened their regimes. These funds are a means through which authoritarian regimes can guard against the vicissitudes of the free market. As the Asian financial crisis demonstrated a decade ago, market shocks can fell authoritarian governments. Sovereign funds, combined with ever increasing foreign reserves, can forestall economic crises before they topple authoritarian power structures". A opinião merece apresentação, mas deve-se registrar que, em nosso entender, não se revela correta. Não só está permeada pela ideia de que os Fundos Soberanos prejudicam o livre mercado, que seria a cura de todos os males, como guarda sérias passagens de nacionalismo estadunidense. No mais, seus fundamentos, ao menos nessa passagem, são notadamente falhos. A uma, porque o grande volume de recursos ingressado por fonte diversa da tributação não diz respeito propriamente aos Fundos, mas às receitas de recursos naturais não renováveis. Ainda, porque, como já referido acima, as pesquisas não têm encontrado relação positiva entre autoritarismo e exploração de recursos naturais. Finalmente, porque a prevenção contra crises econômicas não pode ser entendida como um vício, como o texto quer fazer parecer.

1142 HUMPHREYS, Macartan; SANDBU, Martin E. The political economy of natural resource funds. In: HUMPHREYS, Macartan; SACHS, Jeffrey D.; STIGLITZ, Joseph E. (Org.). Escaping the resource curse cit., p. 199.

1143 Davis et alii (DAVIS, J.; OSSOWSKI, R.; FEDELINO, A. (Org.). Fiscal policy formulation and implementation in oil-producing countries cit., p. 302), por outro lado, afirmam: "The empirical evidence suggests that the establishment of the NRF did not have an impact on government spending".

1144 AFONSO, José Roberto Rodrigues; GOBETTI, Sérgio Wulff. Rendas do petróleo no Brasil: alguns aspectos fiscais e federativos cit., p. 231- 269, dez. 2008, p. 254: “o fundamental é perceber que o país só terá um Fundo Soberano realmente poderoso se for capaz de superar a tentação de gastar no presente a maior parte dos recursos".

1145 Nesse sentido, são contundentes as afirmações de Macartan Humphreys e Martin Sandbu (HUMPHREYS, Macartan; SANDBU, Martin E. The political economy of natural resource funds. In: HUMPHREYS, Macartan; SACHS, Jeffrey D.; STIGLITZ, Joseph E. (Org.). Escaping the resource curse cit., p. 225-227.): "There is a simple reason why natural resource revenue funds do not on average contribute to better fiscal policy in countries heavily dependent on natural resource exports. The reason is that the economic considerations that are usually used to motivate funs support only a certain optimal fiscal policy, and are silent on what is the right institutional framework for implementing that policy [...] 
O que está no centro desses debates, portanto, não é tanto a criação de um Fundo; é a garantia de que seus efeitos positivos sejam observados. ${ }^{1147} \mathrm{E}$, como esses efeitos dependem excessivamente da institucionalidade desenvolvida, torna-se da maior relevância focar nos aspectos políticos. Especialmente, torna-se fundamental pleitear por estabilidade institucional - que certamente não será alcançada se a cada sessão legislativa as características legais dos Fundos forem alteradas.

Apesar de serem identificáveis bônus e ônus na criação desses Fundos Soberanos para governança das receitas públicas de recursos naturais não renováveis, não é difícil identificar que a opinião mais aceita tem sido pela virtuose do instrumento. Por isso é que, seja em número de Fundos, seja em quantidade de bens por eles geridos, o seu crescimento, especialmente na década de 2000, é notável. Por isso também que têm sido frequentes as observações de que o Fundo Soberano não é instrumento que, por si apenas, resolverá os problemas fiscais da nação que o institui. O fato é que as benesses trazidas pelos Fundos Soberanos estão intimamente relacionadas com a disciplina fiscal produzida. A "reserva" de valores no Fundo retira o montante do caixa único e da cobiçosa disponibilidade discricionária; as lições da ciência política indicam que a disponibilidade dos recursos no Orçamento cria incentivos para gastar além da necessidade, ${ }^{1148}$ o que se agrava no ambiente político competititvo: ainda que o gestor acredite que as verbas devem ser poupadas, gastará se não existirem normas que impeçam o próximo gestor de fazêlo. ${ }^{1149}$ A separação permite melhor acompanhar sua gestão e fiscalizar os fins que são

An NRF is not a panacea for these problems and the incentives to spend too rapidly persist wheter or not an NRF is established".

1146 FREITAS, Paulo Springer de. Rendas do petróleo... cit., p. 5/41-42. "deve-se deixar claro que os objetivos de um fundo - usualmente, amortecer os ciclos econômicos ou acumular um estoque de poupança para gerações futuras - podem ser atingidos por meio de um controle adequado de gastos públicos [...] Davis et al (2001), ao analisarem a experiência internacional, concluíram que a instituição de fundos não levou à maior disciplina fiscal, mas sim o contrário: países com maior disciplina fiscal instituíram fundos".

1147 "The establishment of NRFs may be justified on political economy grounds. Funds have been seen as potentially helpful instruments when governments have difficulty in maintaining stable expenditures". DAVIS, Jeffrey; OSSOWSKI, Rolando; DANIEL, James A.; BARNETT, Steven. Stabilization and savings funds for nonrenewable resources: experience and fiscal policy implications. In: DAVIS, J.; OSSOWSKI, R.; FEDELINO, A. (Org.). Fiscal policy formulation and implementation in oil-producing countries cit., p. 289.

1148 HUMPHREYS, Macartan; SANDBU, Martin E. The political economy of natural resource funds. In: HUMPHREYS, Macartan; SACHS, Jeffrey D.; STIGLITZ, Joseph E. (Org.). Escaping the resource curse cit., p. 200.

1149 Idem, ibidem, p. 196. Daí, também, que quanto menos estável for o Governo, maior será seu incentivo a gastar - p. 203. Sustentam os autores: "Inefficient overspending occurs because of incentives created by diverging interests and competition for power to advance those interests. The inefficiency can be overcome if policy makers can commit not to take full advantage of their power when they are in government" - p. 205. 
dados ao dinheiro - que, conforme ora se pleiteia, tem natureza e características que comandam sua utilização de forma diversa daquele ingressado pela receita de impostos.

Mas retome-se: o Fundo não é receita mágica e não garante, por sua só criação, estes benefícios. Ele pode ajudar na formação de um círculo virtuoso: o Fundo funciona bem porque as instituições e organização fiscal são sérias e respeitadas. E as instituições e organização fiscal são sérias e respeitadas porque o Fundo funciona bem. ${ }^{1150-1151}$

Contudo, se a cultura de disciplina fiscal ${ }^{1152}$ e de respeito às instituições não for promovida, então o Fundo é um mero substituto nominal e inepto ao caixa único. Como afirmam Davis e outros, pode ser que os fundos funcionem bem apenas quando não se precise deles. $^{1153}$

O maior exemplo disso, sempre referido nos textos sobre o tema, é o do Fundo estabelecido pela Noruega. A retirada dos valores lá depositados, para integração ao Orçamento e dispêndio regular, é permitida até o limite de $4 \%$ de seu valor total ao ano. ${ }^{1154}$ Mas lá a disciplina fiscal é de tal forma observada que, ano após ano, em vez que se verificar uma pressão sistêmica para dispor destes valores e aumentar este percentual - o que seria de se esperar, especialmente se tomado como paradigma o Parlamento brasileiro e a grande briga pelas emendas orçamentárias ${ }^{155}$-, o que se vê são exercícios fechados sem que sequer estes $4 \%$ sejam atingidos. Também não são conhecidas discussões para aumento desse percentual.

1150 "Simply holding the revenues in a fund, investing the fund in foreign assets, and drawing on that fund only to the extent that it generates income will ensure that induced financial effects will be largely suppressed. However, not all governments are able to exercise the self-discipline required to save all resource revenues" (BOADWAY, Robin; SHAH, Anwar. Fiscal federalism cit., p. 209).

1151 Como coloca Paulo Springer de Freitas: "é a disciplina fiscal que leva ao sucesso de um fundo, e não o contrário" (FREITAS, Paulo Springer de. Rendas do petróleo... cit., p. 3).

1152 Que não se resume ao comportamento do Poder Executivo, mas também do Legislativo, que pode decidir dispor dos recursos do Fundo da forma que melhor atenda suas políticas de ocasião.

1153 DAVIS, Jeffrey; OSSOWSKI, Rolando; DANIEL, James A.; BARNETT, Steven. Oil funds: problems posing as solutions? cit.

1154 New York: Columbia University Press, 2007. p. 200.

1154 HUMPHREYS, Macartan; SANDBU, Martin E. The political economy of natural resource funds. In: HUMPHREYS, Macartan; SACHS, Jeffrey D.; STIGLITZ, Joseph E. (Org.). Escaping the resource curse cit., p. 216.

1155 Interessante a lição de Regis de Oliveira: "Cada bancada de parlamentares quer levar para seu Estado o maior número possível de recursos. Nasce entre eles, não o digam ou não o percebam, a disputa para levar recursos a suas bases eleitorais. É do que vai ele viver futuramente, ao lado da necessidade de obtenção de recursos para bancar as respectivas campanhas. Tudo vai se passar, agora, dentro do orçamento. É aí que surgem os conflitos efetivos, embora disfarçados. Orçamento é uma peça de despesas e receitas em que se deliberam onde e como se vai gastar. É uma lei. Formal, não importa [...] $\mathrm{Na}$ elaboração do orçamento, os parlamentares se preocupam, em primeiro lugar, com as suas emendas, através das quais lograram fazer a alegria de suas comunidades ou, como se diz, de suas bases eleitorais”. OLIVEIRA, Regis Fernandes de. Gastos públicos cit., p. 116 e 118-119. 
Os benefícios e objetivos de um Fundo Soberano podem ser atingidos por outros meios. ${ }^{1156}$ Há meios conhecidos e sem quaisquer fórmulas mirabolantes, de instituir poupança pública. Há formas de promover a equidade intergeracional, seja mantendo recursos em moeda, seja investindo em capital reprodutível. Há modos de garantir, ou ao menos promover, a existência de instrumentos anticíclicos e de instrumentos de fixação de fluxos constantes (se não médios) de receitas públicas. A diversificação de fontes de receita e de produção, bem como o direcionamento de recursos a setores considerados prioritários, também, não dependem da estrutura dos Fundos Soberanos.

Por outro lado, há prejuízos possíveis oriundos da criação destes Fundos como os mencionados acima, em que se destacam a desvinculação com o Orçamento, e o desequilíbrio de poderes. E há custos certos: como qualquer estrutura mantida pela Administração Pública, demanda valores de manutenção, de pessoal, etc.

\section{Então por que instituí-los?}

Dos argumentos acima referidos, prós e contras, um parece se destacar, para aplicação ao caso brasileiro. É o que trata os Fundos como incentivadores de uma maior disciplina na governança das receitas públicas oriundas da exploração dos recursos naturais não renováveis. Já se argumentou da necessidade de tratar essas receitas públicas de modo apartado do caixa único. Mas não é o que se vê na situação atual.

Assim, a utilização de um Fundo específico para gerir a receita de royalties poderia conferir-lhes tratamento particular, impor-lhes regras e orientações específicas, proporcionar-lhes elevados níveis de transparência. É claro que o fundo "não desobriga o administrador público do dever de planejar, previamente, a alocação dos seus recursos". ${ }^{1157}$ Mas o instrumento minoraria o risco, sempre presente em se tratando de bens fungíveis, de confusão entre as receitas de royalties e aquelas oriundas de outras fontes, especialmente

1156 "The existence of a fund need not imply the creation of a new institutional mechanism. A nonrenewable resource "fund" may be a fund in name only. This accounting-only design is referred to as a "virtual fund' because there is no separate institutional structure for the management of the fund, and all revenues and expenditures are on-budget. Certain resources would be identified as belonging to the fund. These resources could be held in the government's main account or in a separate government account. Restrictions in line with the objectives of the fund would be placed on drawing down the fund's resources for expenditure. Any drawdown of government deposits, including the fund account, would appear as deficit financing. The assets that 'belong to the fund,' however, would be managed like other government assets". DAVIS, Jeffrey; OSSOWSKI, Rolando; DANIEL, James A.; BARNETT, Steven. Stabilization and savings funds for nonrenewable resources: experience and fiscal policy implications. In: DAVIS, J.; OSSOWSKI, R.; FEDELINO, A. (Org.). Fiscal policy formulation and implementation in oil-producing countries cit., p. 291.

1157 TORRES, Heleno Taveira; RODRIGUES, Felipe da Cunha. Fundo soberano do Brasil e finanças públicas cit., p. 56. 
de impostos - afinal, "a finalidade das leis ou dos atos administrativos não se queda como direito disponível de qualquer autoridade pública". ${ }^{1158}$ Permitiria que o debate (ora proposto) sobre a governança dos royalties fosse levado adiante, autorizando toda a sociedade a conhecer quais são os valores envolvidos e quais são os fins que lhes são dados, inclusive para que se possa promover objetivos relacionados à justiça entre gerações. Facilitaria a cobrança das Autoridades públicas para que esses fins fossem respeitados.

Em outras palavras: entende-se virtuosa a criação de um Fundo para governança dos royalties porque permite - tal qual se entende necessário - que esta receita pública seja tratada específica e apropriadamente, e não fique perdida em meandros contábeis e constrangimentos facilmente tergiversados (como se verá adiante), representando, ao fim e ao cabo, apenas mais alguns reais no Erário.

\section{3.f.i. Os Fundos brasileiros. O Fundo Social da União.}

No direito brasileiro, o Fundo financeiro é "um conjunto de recursos utilizados como instrumento de distribuição de riqueza, cujas fontes de receita the são destinadas para uma finalidade determinada ou para serem redistribuídas segundo critérios préestabelecidos", conforme definição de José Maurício Conti. ${ }^{1159}$

Para Heleno Torres e Felipe Rodrigues, que se dirigem aos "Fundos Especiais", estes são "instrumentos financeiros especiais que se prestam para permitir o financiamento de determinadas despesas públicas, sempre segundo disposição legal. Assim, pela própria natureza destes instrumentos, sua criação tem implicações tanto sobre os ingressos quanto sobre os gastos, pois cumpre saber quais recursos serão destinados ao fundo, e onde e como poderão ser empregados estes valores". ${ }^{1160}$ Os autores definem esses fundos como "alocação legal de recursos, sob a forma de patrimônio separado vinculado ao emprego em certos fins, orçamentários ou não, no atendimento de necessidades públicas ou como complementação financeira para a prestação de serviços públicos". ${ }^{1161}$

\footnotetext{
1158 TORRES, Heleno Taveira; RODRIGUES, Felipe da Cunha. Fundo soberano do Brasil e finanças públicas cit., p. 65.

1159 CONTI, José Maurício. Federalismo fiscal e fundos de participação cit., p. 76.

1160 TORRES, Heleno Taveira; RODRIGUES, Felipe da Cunha. Fundo soberano do Brasil e finanças públicas cit., p. 23.

1161 Idem, ibidem, p. 31.
} 
Esta definição tem a virtude de trazer ao primeiro plano a função de estabelecer "patrimônio separado", ${ }^{1162}$ portanto destacado, mantido em local diverso (embora deva-se recordar que se referem aos fundos "especiais", aí não incluídos os Fundos de Participação previstos na Constituição). Ainda segundo Torres e Rodrigues, estes fundos

demandam a necessidade de organizar as atribuições de certos recursos, por meio de procedimento técnico que sirva aos valores de redistribuição financeira, típicos do intervecionismo estatal na ordem econômica, para o atingimento de certos fins que não poderiam ser alcançados sem a atribuição do patrimônio em separado, sob gestão coordenada para atingir as finalidades legalmente estabelecidas. ${ }^{1163}$

Conti esclarece que os Fundos são "entes que não têm personalidade jurídica, mas são dotados de capacidade processual, ou seja, podem ser parte em juízo na defesa de seus interesses" 1164 (embora ressalve os Fundos de Participação dos Estados e dos Municípios, que não alcançam essa capacidade porque tratam-se de simples fórmulas matemáticas, sem autonomia de decidir como aplicar o dinheiro a ele destinado; existem "apenas e tão-somente como uma etapa intermediária - e necessária - entre as regras de recebimento dos recursos e as regras de distribuição dos mesmos recursos", ${ }^{1165}$ sendo em verdade "como as conta-correntes [...] figuras representativas de atos realizados por terceiros" $" 1166$ ).

Regis Fernandes de Oliveira referenda a ausência de personalidade jurídica dos Fundos financeiros, eis que "não têm direitos próprios, nem obrigações. Correspondem a meros lançamentos fiscais", ${ }^{1167}$ mas afirma a ausência também de personalidade judiciária, para tanto argumentando que o Fundo "não pratica atos jurídicos e, pois, não pode ser sujeito ativo ou passivo em relação processual". ${ }^{1168}$ O Autor, contudo, parece dirigir-se especificamente ao FPE e ao FPM, nesse tema.

${ }^{1162}$ Da mesma forma: “os fundos são recursos reservados, acumulação de riquezas, destinados para fins diversos e aplicação estabelecida pela Constituição ou por lei”. BALTHAZAR, Ezequiel Antonio Ribeiro. Fundos constitucionais como instrumento de redução das desigualdades regionais na federação. In: CONTI, José Maurício (Org.). Federalismo fiscal. Barueri: Manole, 2004. p. 109.

1163 TORRES, Heleno Taveira; RODRIGUES, Felipe da Cunha. Fundo soberano do Brasil e finanças públicas cit., p. 31.

1164 CONTI, José Maurício. Federalismo fiscal e fundos de participação cit., p. 78.

1165 Idem, ibidem, p. 79.

1166 Idem, p. 81.

1167 OLIVEIRA, Regis Fernandes de. Curso de direito financeiro cit., p. 316.

1168 Idem, ibidem, p. 317. Ainda: OLIVEIRA, Regis Fernandes de. Fundos públicos financeiros. Revista Tributária e de Finanças Públicas, v. 56, 2004. Afirma: "os fundos não são dotados seja de personalidade judiciária, seja de personalidade jurídica”. 
É possível afirmar, mesmo, que os Fundos não têm patrimônio. Em verdade, os fundos são o próprio patrimônio. ${ }^{1169}$

Na legislação brasileira, as disposições sobre os Fundos são localizadas na Lei n. 4.320/1964, Título VII, arts. 71 a 74:

\section{TÍTULO VII}

\section{Dos Fundos Especiais}

Art. 71. Constitui fundo especial o produto de receitas especificadas que por lei se vinculam à realização de determinados objetivos ou serviços, facultada a adoção de normas peculiares de aplicação.

Art. 72. A aplicação das receitas orçamentárias vinculadas a turnos especiais far-se-á através de dotação consignada na Lei de Orçamento ou em créditos adicionais.

Art. 73. Salvo determinação em contrário da lei que o instituiu, o saldo positivo do fundo especial apurado em balanço será transferido para o exercício seguinte, a crédito do mesmo fundo.

Art. 74. A lei que instituir fundo especial poderá determinar normas peculiares de contrôle, prestação e tomada de contas, sem de qualquer modo, elidir a competência específica do Tribunal de Contas ou órgão equivalente. ${ }^{1170}$

Destaque-se, na definição do art. 71, a possibilidade de "adoção de normas peculiares de aplicação". É dizer: tal como no caso de um Fundo para manejo dos royalties, é lícito - e até mesmo desejado - o estabelecimento de normas adaptadas para as finalidades específicas perquiridas, possibilitando gerir o dinheiro consoante os princípios que se entendam aplicáveis àquela receita específica e/ou àqueles fins específicos. Torres e Rodrigues pontuam que a definição legal combina "as opiniões formalista e a finalista, ao identificar a natureza dos fundos pela atribuição legal (formalista) a um certo fim específico (finalista)". 1171

A Constituição Federal, no art. 165, §9. ${ }^{\circ}$, II, exige que Lei Complementar seja editada para estabelecer "condições para a instituição e funcionamento de fundos".

1169 TORRES, Heleno Taveira; RODRIGUES, Felipe da Cunha. Fundo soberano do Brasil e finanças públicas cit., p. 36 .

1170 Sobre os dispositivos legais, afirma Cleucio Nunes: "Por meio desse conceito, não há dúvidas de que 'fundo público' é aplicação de recursos em determinado fim [...] Os fundos são instrumentos de gestão financeira do Estado, que podem estar inseridos nos fins de uma entidade de Administração indireta, e, neste caso, esse ente pode ter por insígnia o título de 'fundo', como é o caso do Fundo Nacional de Desenvolvimento da Educação - FNDE [...] O conceito de fundo, portanto, emerge da própria noção de orçamento público, na medida em que o 'fundo' serve para reunir receitas afetadas e dirigidas para determinadas finalidades. Somente a fixação das receitas e despesas em um orçamento é capaz de ensejar a instrumentalização de receitas públicas em torno de um fim específico". NUNES, Cleucio Santos. Arts. 71 a 74. In: CONTI, José Maurício (Coord.). Orçamentos públicos cit., p. 234-236.

1171 TORRES, Heleno Taveira; RODRIGUES, Felipe da Cunha. Fundo soberano do Brasil e finanças públicas cit., p. 34. 
Inexistindo essa Lei Complementar no ordenamento jurídico atual, entende-se que valem as disposições da Lei n. 4.320/64, acima transcritas, por recepção. ${ }^{1172}$

A instituição de quaisquer fundos pode apenas ser levada a efeito através de Lei - em sentido material e formal -, consoante exige expressamente o art. 167, IX, da $\mathrm{CF} / 88$, vedada a vinculação da receita de impostos (art. 167, IV).

A Lei de Responsabilidade Fiscal (Lei Complementar n. 101/2000) veda que os fundos sejam amparo para operações de crédito entre entes federativos (art. 35); e veda também que os órgãos da administração pública indireta prestem garantia, inclusive por meio dos fundos (art. 40, $\S 6^{\circ}$ ).

Cabe, finalmente, notar, que a estrutura jurídica dos Fundos tem sido pouco observada na doutrina, sendo a obras de José Maurício Conti e Regis Fernandes de Oliveira, já citadas acima, gratas exceções. Em geral, tais lições aparecem na análise de institutos específicos, especialmente com os Fundos de Participação dos Estados e Municípios, mas sem o nível de abstração exigido para uma visão abrangente da matéria.

Muitos dos conceitos correntemente utilizados, embora o sejam para todos os Fundos, são em verdade direcionados a estruturas específicas; os Fundos de Participação têm características diferentes do FUNDEB, que tem características diversas do Fundo Soberano e do Fundo Social da União. Embora um maior aprofundamento não seja levado adiante nesta oportunidade, cumpre registrar a crítica.

Vistas as disposições básicas da matéria no ordenamento jurídico brasileiro, cabe ir adiante com a identificação dos fundos soberanos no Brasil.

Pode-se arguir que o principal deles é o Fundo Soberano do Brasil (FSB), criado pela Lei n. 11.887/2008, de natureza contábil e financeira, "com as finalidades de promover investimentos em ativos no Brasil e no exterior, formar poupança pública, mitigar os efeitos dos ciclos econômicos e fomentar projetos de interesse estratégico do País localizados no exterior" (art. . $^{\circ}$ ). Como se vê, trata-se de instrumento multifacetado com as funções de poupar, estabilizar a economia, e promover investimentos estratégicos. Junto ao Fundo Soberano, e para sua operacionalização, foi criado o Fundo Fiscal de Investimentos e Estabilização - FFIE, de natureza privada e operacional, embora com o objetivo confuso (porque superposto) de "promover a aplicação em ativos no Brasil e no exterior, com vistas na formação de poupança pública, mitigação dos efeitos dos ciclos

1172 CONTI, José Maurício. Federalismo fiscal e fundos de participação cit., p. 76. 
econômicos e fomento a projetos de interesse estratégico do País localizados no exterior" $\left(\operatorname{art} .7 .^{\circ}, \S 3 .^{\circ}\right)$.

Chegou-se a argumentar pelo direcionamento das receitas públicas oriundas da exploração dos recursos naturais não renováveis ao Fundo Soberano, mas esta orientação foi abandonada, preferindo-se a criação de Fundo próprio, como se verá adiante.

Portanto, ausente a vinculação com o objetivo final ora perquirido, não serão tecidas maiores críticas ao FSB. A análise do Fundo Soberano do Brasil teria a vantagem de ofertar dados mais concretos para análise, visto que já está em operação, com portfólio de investimentos passível de verificação, assim como de críticas à sua governança. Caso este efetivamente gerisse as receitas de royalties, algumas críticas se fariam necessárias e imediatas; ${ }^{1173}$ especialmente, a composição de seus investimentos, fortemente (chegou a $80 \%$ ) calcada em participações acionárias na Petrobras, ${ }^{1174-1175}$ o que, tendo em vista a necessidade de evitar a dependência econômica do setor extrativista, direcionando os investimentos para outros setores, seria trágico. Por outro lado, deve-se mencionar que o FSB observa os Princípios de Santiago, como asseveram Torres e Rodrigues. ${ }^{1176}$

Então, a análise crítica que ora se levará adiante será apenas em relação ao fundo brasileiro que tem por missão gerir as receitas de royalties petrolíferos e outras receitas relacionadas à exploração, como os bônus de assinatura.

Trata-se do Fundo Social da União, criado pela Lei n. 12.351/2010 (art. 47 e seguintes) e, ainda sem ter entrado em operação, alterada (embora sem modificação expressa) pela Lei n. 12.858/2013.

É um Fundo de natureza contábil e financeira, “com a finalidade de constituir fonte de recursos para o desenvolvimento social e regional, na forma de programas e projetos nas áreas de combate à pobreza e de desenvolvimento" das áreas de educação,

1173 O fundo soberano teve relevantes perdas em 2011, o que deu diante da falta de diversificação da carteira de investimentos. Disponível em: <http://www.valor.com.br/opiniao/990726/fundo-soberano-perde-26em-cinco-meses>. Acesso em: 4 dez. 2013; O fundo soberano, cogitou-se, seria a origem dos valores envolvidos em eventual empréstimo aos países Europeus em crise. Disponível em: <http://economia.estadao.com.br/noticias/economia+geral-economia,eventual-ajuda-do-brasil-a-europaviria-do-fundo-soberano-fonte, 83928,0.htm>. Acesso em: 3 dez. 2013.

1174 A título de exemplo, note-se como o Fundo norueguês possui investimentos deveras diversificados em empresas brasileiras. Ver: TORRES, Heleno Taveira; RODRIGUES, Felipe da Cunha. Fundo soberano do Brasil e finanças públicas cit., p. 279.

1175 Disponível em: <http://www.brasileconomico.com.br/noticias/nprint/110851.html>. Acesso em: 7 dez. 2013.

1176 TORRES, Heleno Taveira; RODRIGUES, Felipe da Cunha. Fundo soberano do Brasil e finanças públicas cit., p. 339-340. 
cultura, esporte, saúde pública, ciência e teconologia, meio ambiente, e mitigação e adaptação às mudanças climáticas (art. 47). Esses investimentos "devem observar critérios de redução das desigualdades regionais" (art. 58, §5. ${ }^{\circ}$ ). A Lei ressalva explicitamente que os investimentos nessas áreas, realizados a partir do Fundo Social, observarão o tríduo de normas orçamentárias (PPA, LDO, LOA) (art. 47, $\left.\$ 1 .^{\circ}\right)$.

O Fundo Social tem objetivos de fundo de poupança e de fundo de estabilização, e ainda de fomento de investimentos estratégicos, como deixa claro o texto do art. 48 da referida Lei. ${ }^{1177}$ Será formado por recursos oriundos da parcela que cabe à União na exploração do petróleo nacional: bônus de assinatura, royalties, participação especial, e a receita da comercialização do petróleo. No mais, serão recursos do Fundo Social os rendimentos de suas aplicações e outros que a Lei assim dispuser (art. 49).

Seus investimentos buscam "a rentabilidade, a segurança e a liquidez de suas aplicações e assegurar sua sustentabilidade econômica e financeira", sendo "destinados preferencialmente a ativos no exterior, com a finalidade de mitigar a volatilidade de renda e de preços na economia nacional" (art. 50, caput e parágrafo único).

Mas - e isto será retomado adiante - os investimentos nas diversas áreas mencionadas no art. 47 serão oriundos não do valor do capital do fundo, mas apenas do “retorno sobre o capital”, isto é, dos rendimentos gerados pelo valor principal (art. 51), ressalvada a possibilidade de utilização do principal "na etapa inicial de formação de poupança do fundo" (art. 51, parágrafo único).

A Lei instituidora do Fundo Social prevê ainda sua estrutura organizacional, composta por um Comitê de Gestão Financeira (não remunerado), para definir a política de investimentos (art. 52), e um Conselho Deliberativo (igualmente não remunerado), para “propor ao Poder Executivo, ouvidos os Ministérios afins, a prioridade e a destinação dos recursos resgatados do FS para as finalidades estabelecidas no art. 47, observados o PPA, a LDO e a LOA" (art. 58).

Finalmente, a Lei n. 12.351/2010 traz previsões relacionadas à transparência e controle do Fundo Social. O Conselho Deliberativo “deverá submeter os programas e projetos a criteriosa avaliação quantitativa e qualitativa durante todas as fases de execução,

1177 Art. 48. O FS tem por objetivos: I - constituir poupança pública de longo prazo com base nas receitas auferidas pela União; II - oferecer fonte de recursos para o desenvolvimento social e regional, na forma prevista no art. 47; III - mitigar as flutuações de renda e de preços na economia nacional, decorrentes das variações na renda gerada pelas atividades de produção e exploração de petróleo e de outros recursos não renováveis. Parágrafo único. É vedado ao FS, direta ou indiretamente, conceder garantias. 
monitorando os impactos efetivos sobre a população e nas regiões de intervenção, com o apoio de instituições públicas e universitárias de pesquisa" (art. 58, §4. ${ }^{\circ}$ ); “As demonstrações contábeis e os resultados das aplicações do FS serão elaborados e apurados semestralmente", conforme estabelecido pela Secretaria do Tesouro Nacional (art. 59); e "o Poder Executivo encaminhará trimestralmente ao Congresso Nacional relatório de desempenho do FS" (art. 60).

A lei instituidora prevê que ato do Poder Executivo Federal regulamentará parte dessas disposições relativas ao Fundo Social. Este Regulamento, até a presente data, ainda não foi editado.

Sobreveio a Lei n. 12.858/2013, a alterar parcialmente - embora sem que se tenham promovidas alterações no texto - a Lei n. 12.351/2010. Especialmente, impactouse o art. 51, acima referido, que determina que os investimentos promovidos pelo Fundo Social serão custeados pelos rendimentos do capital poupado - e não pelo principal.

Pela Lei n. 12.858/2013, 50\% (cinquenta por cento) dos recursos do Fundo Social serão "destinados exclusivamente para a educação pública, com prioridade para a educação básica, e para a saúde" (art. 2. ), "até que sejam cumpridas as metas estabelecidas no Plano Nacional de Educação". O Plano Nacional de Educação atualmente vigente é o da Lei n. 10.172/2001, contendo metas diversas separadas por nível de ensino. Há outro Plano Nacional de Educação (2011-2020) em debate no Congresso Nacional.

Vale mencionar que a redação original da Lei n. 12.351/2010, enviada para sanção presidencial, previa uma afetação ${ }^{1178}$ dos valores para a educação. Dispunha que "50\% (cinquenta por cento) devem ser aplicados em programas direcionados ao desenvolvimento da educação pública, básica e superior, sendo o mínimo de $80 \%$ (oitenta por cento) destinado à educação básica e infantil” (art. 47, §2. ${ }^{\circ}$. Contudo, o dispositivo restou vetado pelo então Presidente da República, para tanto afirmando que "não é adequado fixar, previamente, quais as áreas a serem priorizadas dentre aquelas já contempladas, nas quais está incluída a educação".

1178 “A vinculação é um instrumento financeiro formal, enquanto a afetação é uma técnica financeira de conteúdo, pois cria um objetivo a ser alcançado com aquele recurso, usualmente de conteúdo social, de investimento ou de garantia”. SCAFF, Fernando Facury. Royalties decorrentes da exploração de recursos naturais não renováveis cit., p. 396. 
Como se vê, a disposição da Lei n. 12.858 passou por cima da disposição do art. 51 da Lei n. 12.351. Embora a proposta do Governo Federal ${ }^{1179}$ fosse de destinar à educação e saúde apenas os rendimentos do Fundo Social, este ponto restou modificado pelo Poder Legislativo, tendo a Presidenta da República sancionado a nova redação sem vetos.

Logo, a norma que previa que apenas o "retorno sobre o capital" do Fundo Social é que seria investido foi desprezada na primeira oportunidade possível.

\section{3.f.ii. Críticas ao Fundo Social da União.}

Entende-se que a criação de fundos para governança das receitas públicas decorrentes da exploração de recursos naturais não renováveis consiste em uma prática virtuosa. A principal razão pela qual a instituição de um Fundo é vantajosa em si própria isto é, ainda sem conhecer seu funcionamento concreto que é obviamente relevante e dirá se os objetivos abstratos expostos na Lei serão cumpridos - é que promove o destaque das receitas públicas do monte contábil/orçamentário geral. Ao separar essas receitas das demais, reconhece sua natureza especial, diversa das receitas ordinárias, e que assim merece tratamento específico, conforme sua natureza e características intrínsecas.

Portanto, a crítica, pela só instituição do Fundo Social, é positiva.

Da mesma forma, a análise da estrutura básica do Fundo Social da União, exposta na Lei, também conduz a concluir que se trata de um instrumento responsável, consoante os instrumentos teóricos apresentados nos capítulos anteriores.

Ora, no Fundo Social estabelecido pela Lei n. 12.351/2010, a finalidade de proteção intergeracional é evidente. A formação de poupança pública de longo prazo é objetivo explícito do Fundo (art. 48, I). O intuito de preservação dos interesses das gerações futuras, neste Fundo, é frequentemente realçado. ${ }^{180-1181} \mathrm{O}$ intento de combater as intempéries econômicas é também claro. Também se pode entender que o dever de

1179 Dispunha a Medida Provisória n. 591/2013: "Do total do resultado a que se refere o caput do art. 51 auferido pelo FS, cinquenta por cento deve ser aplicado obrigatoriamente em programas e projetos direcionados ao desenvolvimento da educação, na forma do regulamento".

${ }^{1180} \mathrm{O}$ veto presidencial à redação original da Lei mencionou: "O Fundo Social constitui uma poupança de longo prazo com vistas a assegurar os benefícios intergeracionais decorrentes da exploração do pré-sal".

1181 Referindo-se ainda ao Projeto de Lei, Torres e Rodrigues afirmam: "Nota-se no projeto clara preocupação com a transferência de riqueza entre as gerações". TORRES, Heleno Taveira; RODRIGUES, Felipe da Cunha. Fundo soberano do Brasil e finanças públicas cit., p. 320. 
promover a diversificação produtiva está endereçado, nos investimentos em educação e em ciência e tecnologia.

Os perigos associados aos Fundos, relatados na doutrina específica, parecem ter sido observados. Há expressa previsão de integração dos Fundos com a política orçamentária geral, representada na reiterada necessidade de observar as disposições das três Leis Orçamentárias. Há previsão (art. 50, parágrafo único) de investimento dos valores do Fundo preferencialmente no exterior, para "mitigar a volatilidade de renda e de preços na economia nacional". E também atende-se, parcialmente, ao problema da fungibilidade e da facilidade de acesso ao crédito, vedando que os recursos do Fundo sirvam de garantia, em qualquer modalidade. A legislação prevê regras de transparência e controle administrativo e social - dos investimentos do Fundo.

Contudo, não só elogios são merecidos.

Uma das principais - senão a principal - objeções, referidas acima, quanto à constituição de Fundos, está na sua indiferença ou prejudicialidade quando se deixa de obedecer aos padrões de disciplina fiscal e de respeito às instituições. De nada adiantam previsões valorosas na Lei instituidora se forem substituídas a cada comoção pública pelo que for conjunturalmente (e politicamente) mais favorável. Isto é: já se argumentou que os motivos de estabilização e autocontenção estão no cerne da ideia de um fundo para gerir as receitas de recursos naturais não renováveis.

E o que se vê no caso brasileiro, em relação a isso, não é alentador. Antes mesmo que o Fundo Social seja efetivamente instalado, já foram promovidas alterações substanciais em sua estrutura. As receitas oriundas do petróleo têm sido vistas como remédio para todos os males e, tal como ocorreu com sua destinação à educação e saúde, amanhã a frágil estrutura legislativa pode ser destinada a outros setores.

Por isso mesmo é que têm razão Bruno Cruz e Márcio Ribeiro, quando afirmam que

uma Emenda Constitucional garante maior institucionalidade ao fundo, evitando mau uso dos recursos e garantindo a ele uma fonte de recursos. O exemplo do Alaska mostra que um plebiscito pode conferir maior credibilidade ao fundo e o comprometimento dos gestores para a administração responsável dos recursos. ${ }^{1182}$

1182 CRUZ, Bruno de Oliveira; RIBEIRO, Márcio Bruno. Sobre maldições e bençãos cit., p. 36, jul. 2009: "Não há qualquer sentido econômico de vincular um percentual da receita da produção como forma de compensação pelo dano ambiental". 
No mesmo sentido é a opinião de Joseph Bell e Teresa Faria, para quem a manutenção da Lei representa um desafio, pelo que uma forma adequada de reforçar suas disposições seria adotar uma emenda constitucional endereçando alguns aspectos centrais, o que inibiria, ao menos em parte, a capacidade de partidos ou governantes de "mudar as regras em seu favor de forma arbitrária ou unilateral". ${ }^{1183}$

A governança das receitas petrolíferas seria beneficiada pela colocação de regras mais estáveis, como o são as emendas constitucionais, ${ }^{1184}$ ou pela utilização dos modos diretos de participação social - é como sugere Paul Collier que, consoante o exemplo de Botsuana, afirma que as pressões por gasto dessas receitas podem ser amenizadas através de ações de conscientização pública de sua relevância presente $e$ futura, o que ressalta a importância de evitar a alteração das regras postas. ${ }^{1185}$

É claro que tal sorte de estabilização normativa traz consigo também algum grau de engessamento que pode, se excessivo, ser pernicioso até mesmo para as futuras gerações, considerando o debate, já apresentando, sobre a legitimidade que cada geração tem para escolher quais as regras que deverão obedecer. Assim, outros mecanismos de estabilização podem ser pensados, tais como a introdução de um grau elevado de anterioridade e/ou a proibição de alterações dessas regras financeiras durante a vigência de um Plano Plurianual (4 anos).

${ }^{1183}$ BELL, Joseph C.; FARIA, Teresa Maurea. Critical issues for a revenue management law. In: HUMPHREYS, Macartan; SACHS, Jeffrey D.; STIGLITZ, Joseph E. (Org.). Escaping the resource curse cit., p. 311.

1184 Em sentido contrário: “Apesar de que o FS possa ser instituído por uma emenda constitucional acompanhada de lei e decreto complementares, esta forma de institucionalização é mais complexa e não traria vantagens significativas vis-à-vis a viabilização do FS por lei ordinária". Relatório II. Fundos financeiros baseados em receitas de petróleo e gás cit., p. 128.

1185 "Hence, a pro-active government counter-narrative is an urgent and important priority once prospecting is underway. How might such a narrative be framed? Whether a particular narrative takes hold depends upon whether it resonates with ordinary people, and so it is inevitably specific to each society. However, with this caveat I suggest two related approaches. The first approach is to frame the issue in terms of a historic opportunity for the children of the nation. Properly used, the depleting natural asset can transform the lives of the next generation. This places a correspondingly important responsibility on the shoulders of the present generation of adult citizens. If the natural asset is squandered, what will the next generation say about their parents? The Government of Botswana adopted a communications strategy along these lines. Its overarching theme, which was made part of every government policy for many years, was 'because we are poor we must carry a heavy load'. The imagery of a heavily laden peasant woman was designed to resonate with ordinary people and in essence said: 'don't expect too much too soon, we are going to have to work hard and save to build the future'. It effectively punctured the counter-narrative of 'we've discovered diamonds so we're all rich'. As this narrative took hold, it created the political space for the accumulation of assets for which Botswana is rightly celebrated". COLLIER, Paul. Small countries and big resources: harnessing natural resources for development in the g7+ countries. Paper prepared for the $\mathrm{g} 7+$ high level ministerial retreat. 2012. Disponível em: <http://www.g7plus.org/news-feed/2013/1/10/small-countries-and-big-resources.html〉. Acesso em: 27 nov. 2013, p. 19. 
Portanto, a já alteração de normas centrais da estrutura do Fundo Social revela que a sua institucionalidade merece reparos, para evitar que o caso brasileiro seja mais um de promessas vazias. Afinal, o exemplo norueguês, sempre tão incensado, "serve muito mais como parâmetro por seus procedimentos de accountability e transparência na gestão dos recursos do petróleo do que por sua fórmula bird-in-hand, que limita os gastos apenas aos rendimentos do fundo do petróleo, sem considerar as rendas futuras". 1186

Mas não apenas a instabilidade institucional deve ser objeto de crítica. Materialmente, a mudança levada a efeito pela Lei n. 12.858/2013 é deletéria.

A afetação dos valores à educação, propriamente, não é de ser condenada. Pode ser considerada como investimento público em capital humano, ${ }^{187}$ a elevar as liberdades pessoais, qualificando os cidadãos para o exercício de outras atividades produtivas. ${ }^{1188}$

Porém, a permissão de sacar metade do valor do principal contido no Fundo Social vai contra os princípios do mesmo do fundo. Dá-se prejuízo ao objetivo de buscar "a sustentabilidade econômica e financeira" (art. 50 da Lei n. 12.351/2010), o que demanda que o capital lá contido seja passível de reprodução. A perspectiva da equidade intergeracional também se revela, ao menos em parte, maculada. Isto é: por mais que se possa argumentar que o direcionamento dessas verbas públicas à educação tem o condão de beneficiar as gerações futuras - e de fato assim acreditamos -, é de se notar que a afetação trazida pela Lei se dá em relação a um setor social abrangente. Não há

${ }^{1186}$ GOBETTI, Sérgio Wulff. Política fiscal e pré-sal: como gerir as rendas do petróleo e sustentar o equilíbrio macrofiscal do Brasil. Brasília: ESAF, 2009. Monografia premiada com o segundo lugar no XIV Prêmio Tesouro Nacional - 2009: homenagem a Euclides da Cunha. Política fiscal e dívida pública. Brasília (DF). p. 40.

1187 "In a region where agricultural productivity is struggling to keep pace with population growth, where child malnutrition is declining far too slowly, where the number of out-of-school children is rising, and where high youth unemployment is endemic, it is vital that resource wealth is used not just to lift people out of poverty today but to finance the investments in human capital needed to create hope for future generations" (Africa Progress Report 2013... cit., p. 21).

1188 Cabe lembrar a doutrina de Jeffrey Sachs, para quem a estratégia de uso dessas receitas públicas deve ser diferente conforme o nível de desenvolvimento e renda do país. Para o autor: "For the poorest oil countries, the overriding goal is to use oil income to enable the economy to meet basic needs (food, safe drinking water, essential health services, basic education) and to put in place the infrastructure (power, irrigation, roads, ports, telecoms, the Internet) for private-sector-led economic growth. For middleincome oil countries, the overriding goal is tipically to promote the transition from a resource-based rural economy (including agriculture, oil and other mining) to a human-capital and knowledge-based urban economy. Key investments tipically need to be made in knowledge creation and diffusion (higher education, scientific institutions) as well as in infrastructure in fast-growing urban areas. For highincome oil countries (e.g., Norway), wich already have extensive physical infrastructure in addition to well-endowed systems of higher education and science, a priority for oil earnings may be to support the budget burdens of social insurance (e.g., pensions, low-income support, public-sector insurance)". SACHS, Jeffrey D. How to handle the macroeconomics of oil wealth?. In: HUMPHREYS, Macartan; SACHS, Jeffrey D.; STIGLITZ, Joseph E. (Org.). Escaping the resource curse cit., p. 178-179. 
especificações de que tipos de gasto público em educação deverão ser realizados, podendo sê-lo tanto para financiar uma melhor estrutura educacional inclusiva quanto para financiar gastos correntes que, por mais úteis que sejam na atualidade, não repercutem temporalmente, revelando-se consumíveis.

Nesse sentido, vale lembrar a lição de Sérgio Gobetti, para quem a

vinculação das receitas do petróleo a determinados gastos não é efetiva, como mostra a própria experiência brasileira com royalties, mas pode ser repensada de forma diferente, atrelando a renda não setorialmente, mas com foco nos investimentos em infraestrutura e em capital humano. ${ }^{1189}$

Não se pode aceitar que o Fundo Social seja uma extensão do Orçamento geral; que seja utilizado tão somente como uma reserva prioritária para investir em quaisquer setores que o Congresso entenda, na conjuntura, prioritários. Embora deva existir cooperação, integração entre Fundo e Orçamento, isto é muito diferente de fazer do Fundo mero repositório de valores ao Orçamento, sem considerar as particularidades da receita pública gerida em separado.

De outra banda, não se desconhece que o Fundo Social, nos estágios iniciais de acumulação, pode ter uma política diferente de retiradas - menos rígida. Assim dispõe mesmo a Lei n. 12.351/2010, no parágrafo único do art. 51. ${ }^{1190}$

Entretanto, a retirada de fatia tão alta do valor principal pode dificultar a acumulação inicial de valores no Fundo, esta que permitirá a formação de um volume capaz de gerar frutos para serem investidos.

Este defeito fica ainda mais claro quando se vê que a afetação, embora teoricamente temporária, está atrelada a metas por vezes abstratas, e até mesmo utópicas mencione-se a meta de "estabelecer um sistema de informações completas e fidedignas sobre a população a ser atendida pela educação especial, a serem coletadas pelo censo educacional e pelos censos populacionais" (item 25 do capítulo 8.3 do Plano Nacional de Educação), em que os conceitos de completude e fidedignidade revelam-se deveras subjetivos e sempre sujeitos a mais requisitos.

1189 GOBETTI, Sérgio Wulff. Política fiscal e pré-sal cit., p. 40.

1190 Também: "Neste aspecto, deve-se observar que se for feita, no caso brasileiro, uma opção por regras de retiradas conservadoras, que limitem os saques ao retorno real esperado dos investimentos do FS (aos moldes do POMV proposto pelo Alasca), pode ser válido abrir exceções para os saques dos primeiros anos de atividade do FS. Isto porque o montante acumulado nesses anos ainda será relativamente baixo, de modo que a retirada de parcela equivalente ao retorno do FS não será suficiente para financiar investimentos relevantes na economia doméstica". Relatório II. Fundos financeiros baseados em receitas de petróleo e gás cit., p. 175. 
A ausência de um prazo claro para que se dê o saque dos valores principais do Fundo prejudica, pois, a consecução dos seus objetivos.

Há de se considerar que o exaurimento dos capitais poupados no Fundo Social macula, também, a consecução dos fins de estabilização econômica e proteção cambial, assim como de suavização das entradas para combate à volatilidade. O Estado brasileiro necessita, para tanto, contar com reservas substanciais que permitam sua atuação em tempos de crise. Se não for possível acumular volume suficiente para que assim ocorra, o Fundo Social tornar-se-á tão somente uma poupança bancária pronta a ser objeto de interesses ocasionais.

Finalmente, registre-se que o excesso de liquidez introduzido no sistema pelo saque dos valores dos Fundos pode induzir efeitos econômicos adversos. É possível até mesmo que seja questionado um sobrefinanciamento da educação, especialmente considerando que há indícios de que o direcionamento constitucional de receitas de impostos ao setor já é deveras relevante e, quiçá, representa investimento suficiente para a melhora dos indicadores nacionais - cabendo, no presente, às políticas públicas focarem na qualidade do gasto, e não na quantidade da receita afetada. ${ }^{1191}$

Reputa-se, portanto, que a retirada de valores substanciais do Fundo Social, ainda que para aplicação na educação (e especialmente da forma como realizada pela Lei n. 12.858/2013, isto é, sem dirigir os investimentos a quaisquer aspectos do sistema educacional) viola os interesses das futuras gerações e deixa de atender às medidas necessárias para a fuga dos possíveis efeitos deletérios da atividade de exploração. ${ }^{1192}$

\section{3.g. Exploração de recursos naturais não renováveis e tributação. A relação entre a} receita proveniente da exploração do patrimônio público e o financiamento das despesas estatais. Notas sobre a realidade brasileira.

Já se expôs, acima, a associação, frequente na teoria da maldição dos recursos naturais, entre a exploração dos recursos naturais não renováveis e a queda dos níveis de

${ }^{1191}$ É a opinião de Mansueto Almeida, economista vinculado ao IPEA. ALMEIDA, Mansueto. Despesa com educação no Brasil - 1. 2013. Disponível em: <http://mansueto.wordpress.com/2013/09/05/despesa-emeducacao-no-brasil-1/>. Acesso em: 7 dez. 2013.

${ }^{1192}$ Há mesmo quem recomende, de lege ferenda, por essas razões, a eliminação do parágrafo único do art. 51 da Lei n. 12.351/2010: PIRES, Adriano; GIAMBIAGI, Fabio; LUCAS, Luiz Paulo Vellozo; SCHECHTMAN, Rafael. Conclusões e propostas para o setor. In: GIAMBIAGI, Fabio; LUCAS, Luiz Paulo Vellozo (Org.). Petróleo: reforma e contrarreforma do setor petrolífero brasileiro. Rio de Janeiro: Elsevier, 2013. p. 331-332. 
arrecadação tributária nos entes públicos - uma renúncia de receitas, expressa ou implícita (que pode se dar, por exemplo, pelo desaparelhamento dos órgãos de fiscalização tributária). As explicações para tanto, em geral, não são de fundo jurídico ou econômico, mas amparam-se especialmente na ciência política: os recursos da exploração permitem ao gestor público ver-se livre do "fardo" de tributar seus cidadãos, passando então a financiar o setor público pelas receitas oriundas do setor extrativo.

Essa conduta contém também uma estratégia política: a tributação é impopular e o gestor público, submetido periodicamente à avaliação das urnas, tem razões para mantê-la em níveis baixos. ${ }^{193}$ Há referências também ao fato de que as receitas públicas oriundas de impostos estão mais sujeitas ao escrutínio dos cidadãos, estes que passam a se importar mais com seu bom uso na máquina administrativa. No mais, o gestor que tributa pouco, mas gasto muito (isto é: valores oriundos de fontes não tributárias) pode vir a colocar-se como aquele que fez mais com menos.

Vale lembrar a lição de Regis Fernandes de Oliveira, analisando o gasto público (e, mais especificamente, o controle de despesas com pessoal, e os Municípios que "fazem política mesquinha de inchaço dos quadros públicos"). Ressalta a "expectativa sórdida de fazer 'média' com os recursos públicos". ${ }^{1194}$ A expressão se aplica ao caso analisado, na medida em que se observa que o desinteresse pela arrecadação tributária revela nada mais do que o interesse em "fazer média", através da renúncia de receita.

Importa, agora, fixar que esta prática - financiamento das funções do Estado por meio de receitas patrimoniais - é viciosa e deve ser combatida. Além, cabe verificar como o ordenamento jurídico brasileiro se comporta nesse sentido.

${ }^{1193}$ Vale lembrar que uma análise pode ser dirigida também internamente ao que se considera tributação; enquanto que os Impostos são suportados pela coletividade, as Taxas são exigidas apenas de contribuintes específicos, sujeitas à divisibilidade do serviço público ou poder de polícia. Portanto, também o seu uso pode significar maior arrecadação com menor custo político. Nesse sentido, vê-se que no Brasil, nos últimos anos, foram instituídas por entes subnacionais (Pará, Minas Gerais, Amapá, Mato Grosso) Taxas “de Fiscalização" da exploração mineral, apesar de os próprios governantes afirmarem, na imprensa, que a exação não se coaduna com os caracteres jurídicos específicos dessa espécie tributária. Essas Taxas, a nosso ver, são marcadamente inconstitucionais, como já se teve a oportunidade de coescrever em: SCAFF, Fernando Facury; SILVEIRA, Alexandre Coutinho da. Taxas de fiscalização sobre a exploração de recursos minerais. Revista Dialética de Direito Tributário, n. 210, mar. 2013. Fenômeno semelhante ao que se menciona é referido por Robert Taliercio. Afirma que os entes subnacionais frequentemente se utilizam de tributação não oficial, ilegal ou inconstitucional, para aumentar sua arrecadação, apesar dos efeitos adversos dessa prática ("these levies can undermine public trust in the tax system, which cannot be good for long-term compliance"): TALIERCIO, Robert R. Subnational own-source revenue: getting policy and administration right. In: WORLD BANK. East Asia decentralizes cit., p. 116-117.

1194 OLIVEIRA, Regis Fernandes de. Curso de direito financeiro cit., p. 280. 
Observar-se-á especialmente os entes políticos subnacionais: vale reafirmar que, embora a exploração de recursos minerais tenha papel destacado na economia nacional, o montante de receitas públicas que fica com a União não é de tal forma grande a ponto de permitir esta substituição entre uma e outra fontes de receitas. O mesmo não se pode dizer em relação a Estados e Municípios: os maiores recebedores de royalties minerais e petrolíferos contam com quantias significativas, o suficiente para promover, ao menos em alguns casos (especialmente alguns municípios do litoral fluminense e do interior do Pará e de Minas Gerais, mas também os Estados do Rio de Janeiro e do Espírito Santo, maiores beneficiados com os royalties petrolíferos), um trade off entre receita tributária e receita patrimonial.

Em breves linhas, a renúncia de receitas (ou gasto tributário) dá origem ao fenômeno da guerra fiscal, com todos os seus efeitos deletérios - que são observados não apenas nos níveis de arrecadação e no equilíbrio federativo, mas também no aumento das desigualdades regionais. ${ }^{1195}$ Como alerta Ricardo Lobo Torres, em artigo que põe em cheque toda a estrutura de incentivos fiscais, especialmente considerando que não há qualquer diferença entre deixar de receber (renúncia de receita) e gastar (subsídio), "a manipulação dos diversos incentivos tem sempre o objetivo político de encobrir os nomes dos beneficiários, excluindo-os do orçamento, para atender a certas conveniências políticas e evitar o controle do eleitor [...] o legislador muitas vezes opta pelas isenções porque sabe que a subvenção direta, aparecendo no orçamento, não contaria com a aprovação pública; esse comportamento é ilógico, porque a entidade que não merece a subvenção não poderia obter a isenção". ${ }^{1196}$

A Lei de Responsabilidade Fiscal - criticada por sua suposta invasão na esfera dos entes políticos subnacionais, mas principalmente louvada pelos diversos mecanismos de imposição de uma gestão fiscal séria e equilibrada - afirma que "constituem requisitos essenciais da responsabilidade na gestão fiscal a instituição, previsão e efetiva arrecadação de todos os tributos da competência constitucional do ente da Federação" (art. 11), ademais

1195 Para uma interessante abordagem do assunto, consultar: NÓBREGA, Marcos; FIGUEIREDO, Carlos Maurício. Renúncia de receita; guerra fiscal e tax expenditure: uma abordagem do art. 14 da LRF. In: FIGUEIREDO, Carlos Maurício; NÓBREGA, Marcos. Lei de Responsabilidade fiscal: aspectos polêmicos. Belo Horizonte: Fórum, 2006. p. 109 e ss.

1196 TORRES, Ricardo Lobo. Responsabilidade fiscal, renúncia de receitas e guerra fiscal no ICMS. In: SCAFF, Fernando Facury; CONTI, José Maurício. Lei de Responsabilidade Fiscal - 10 anos de vigência - Questões atuais. Florianópolis: Conceito, 2010. p. 13. 
trazendo sérias limitações e requisitos à instalação de renúncias fiscais (art. 14). ${ }^{1197}$ Também a Constituição Federal prevê (art. 165, §6. ${ }^{\circ}$ ) que o "projeto de lei orçamentária será acompanhado de demonstrativo regionalizado do efeito, sobre as receitas e despesas, decorrente de isenções, anistias, remissões, subsídios e benefícios de natureza financeira, tributária e creditícia".

Portanto, o só desrespeito a tais regras já demonstra que a conduta narrada, de redução da carga tributária para financiamento das despesas públicas por meio de receitas patrimoniais, merece ser combatida, não aplaudida. Mas não é só.

Como há muito ensina Jèze, "a princípio, as despesas públicas devem ser pagas com a receita do país, e não com o capital nacional". ${ }^{1198}$ Esta é uma regra básica que se vê violada: ao desprezar as receitas de impostos em prol da realização do gasto público por meio da receita de royalties, o Ente Público financia suas atividades com receitas decorrentes diretamente do patrimônio estatal. E pior: de uma receita pública originária (transferida) decorrente da exploração de recursos naturais não renováveis.

Ao fazê-lo, não só perde arrecadação de forma irresponsável, em termos absolutos; igualmente, deixa de criar uma base arrecadatória permanente e estruturada (especialmente aproveitando-se da circulação de bens e serviços que necessariamente acompanha os projetos de lavra de minérios e petróleo); e, ainda, perde a oportunidade de beneficiar as gerações futuras, que não terão à disposição os mesmos recursos (não renováveis) a impulsionar sua economia. Cabe verificar que a Noruega - sempre referida

1197 Art. 14. A concessão ou ampliação de incentivo ou benefício de natureza tributária da qual decorra renúncia de receita deverá estar acompanhada de estimativa do impacto orçamentário-financeiro no exercício em que deva iniciar sua vigência e nos dois seguintes, atender ao disposto na lei de diretrizes orçamentárias e a pelo menos uma das seguintes condições: I - demonstração pelo proponente de que a renúncia foi considerada na estimativa de receita da lei orçamentária, na forma do art. 12, e de que não afetará as metas de resultados fiscais previstas no anexo próprio da lei de diretrizes orçamentárias; II estar acompanhada de medidas de compensação, no período mencionado no caput, por meio do aumento de receita, proveniente da elevação de alíquotas, ampliação da base de cálculo, majoração ou criação de tributo ou contribuição. $\S 1 .^{\circ}$ A renúncia compreende anistia, remissão, subsídio, crédito presumido, concessão de isenção em caráter não geral, alteração de alíquota ou modificação de base de cálculo que implique redução discriminada de tributos ou contribuições, e outros benefícios que correspondam a tratamento diferenciado. 2. ${ }^{\circ}$ Se o ato de concessão ou ampliação do incentivo ou benefício de que trata o caput deste artigo decorrer da condição contida no inciso II, o benefício só entrará em vigor quando implementadas as medidas referidas no mencionado inciso.

$\S 3$. $^{\circ} \mathrm{O}$ disposto neste artigo não se aplica: I - às alterações das alíquotas dos impostos previstos nos incisos I, II, IV e V do art. 153 da Constituição, na forma do seu $\S 1$. ; II - ao cancelamento de débito cujo montante seja inferior ao dos respectivos custos de cobrança.

1198 No original: "en principe, lês dépenses publiques doivent être payées avec le revenu du pays et non avec le capital national". JĖZE, Gaston. Cours élémentaire de science des finances et de législation financière française: manuel à l'usage des étudiants des facultés de droit et des candidats au ministère des Finances, à la Cour des comptes, à l'Inspection des finances, etc. Nouvelle Édition. Paris: V. Giard \& E. Brière, 1909. p. 379. Tradução livre. 
como exemplo de virtuose no trato das receitas de recursos naturais não renováveis - é dos países exploradores o que tem maior receita não derivada da exploração; Angola (um dos que sofrem a maldição) é dos que menos arrecada receitas públicas não relacionada à exploração mineral. ${ }^{199}$

Impõe-se, sobre o tema, lembrar a dicotomia entre os Estados Fiscal e Patrimonial. Casalta Nabais se opõe severamente ao Estado Patrimonial (aquele que tem como suporte financeiro "as receitas do seu património ou propriedade" ${ }^{1200}$ ), afirmando que o Estado Fiscal (o que "tem nos impostos o seu principal suporte financeiro"1201) é o "instrumento que historicamente se revelou e continua a revelar como o mais adequado" à "realização da pessoa humana". ${ }^{1202-1203}$

Os conceitos de Estados Patrimonial e Fiscal foram melhores trabalhados por Fernando Facury Scaff, que busca uma classificação do Estado consoante a natureza do vínculo que origina a receita pública predominante. Para Scaff, nos Estados Patrominiais “as receitas públicas são predominantemente extraídas da exploração de seu patrimônio, considerado para tanto o da extração mineral, da agricultura, da indústria, do comércio ou dos serviços, o que corresponde aos três setores básicos da atividade econômica: primário, secundário e terciário. Portanto, as receitas advêm da exploração das próprias riquezas do Estado - em suma, de seu patrimônio"; ${ }^{1204}$ já os Estados Fiscais "tem suas receitas públicas advindas predominantemente dos tributos, que correspondem à imposição de arrecadação de valores, fruto do exercício do poder de império que possui". ${ }^{1205-1206}$

Mister lembrar que a evolução do financiamento das atividades estatais revela a utilização do patrimônio do próprio Estado ou Rei. Ensina Aliomar Baleeiro que "toda a economia e toda a estrutura medievais gravitam sobre a propriedade e a utilização das terras [...] Com as revoluções econômicas e políticas, desde o século

1199 BORNHORST, Fabian; GUPTA, Sanjeev; THORNTON, John. Natural resource endowments, governance, and the domestic revenue effort: evidence from a panel of countries cit., p. 5.

1200 NABAIS, José Casalta. Por um estado fiscal suportável - estudos de direito fiscal. Coimbra: Almedina, 2005. p. 27.

1201 Idem, ibidem, p. 24

1202 Idem, p. 24

1203 Para outras considerações sobre o Estado Patrimonial em comparação com o Estado Fiscal, ver: TORRES, Ricardo Lobo. A ideia de liberdade no estado patrimonial e no estado fiscal. Rio de Janeiro: Renovar, 1991.

1204 SCAFF, Fernando Facury. Royalties decorrentes da exploração de recursos naturais não renováveis cit., p. 24-25.

1205 Idem, ibidem, p. 25.

1206 Para uma compreensiva visão da evolução do Estado Fiscal na Europa e na Ásia, ver: YUNCASALILLA, Bartolomé; O'BRIEN, Patrick K. (Ed.). The rise of fiscal states: a global history, 15001914. Cambridge: Cambridge University Press, 2012. 
XVII, em todo o século XVIII e princípio do século XIX sobrevém a diferenciação entre o patrimônio pessoal do príncipe e os recursos do Estado, este alimentado a partir de então, precipuamente, pelos impostos"1207-1208 - embora deva-se recordar, com Scaff, que um e outro não são estágios históricos obrigatórios em qualquer nação. ${ }^{1209}$

Um retorno à situação de financiamento público pela receita decorrente da exploração do patrimônio (embora não se possa, efetivamente, afirmar que a apenas origem das receitas públicas explica e responde a todo o conjunto de prestações sociais) vem a ser pernicioso da perspectiva das liberdades formal e substancial: o Estado Fiscal privilegia o ambiente de defesa das liberdades, ${ }^{1210}$ valendo considerar que "tanto as leis orçamentárias quanto as tributárias foram inicialmente exigidas como limitações ao poder do soberano". ${ }^{1211}$ Vale consignar, com João Ricardo Catarino (por sua vez referindo Maurice Duverger), que "a história da democracia é a história do imposto". 1212-1213

${ }^{1207}$ BALEEIRO, Aliomar. Uma introdução à ciência das finanças cit., p. 139-142.

${ }^{1208}$ Geraldo Ataliba ensina: "De duas formas pode o estado obter recursos: auferindo lucros, na venda de bens e serviços, ou usando de seu poder para exigir o concurso compulsório das pessoas sujeitas a seu poder, para as necessidades públicas. Antigamente, predominava a primeira forma, com larga exploração, pelo estado, de seus bens. A crescente necessidade de dinheiro, consectária da progressiva ampliação da esfera de ação do poder público, reduziu a ínfima expressão de tais entradas. Hoje, no mundo todo, a receita pública é realizada pela segunda fórmula, em proporção quase total. É mesmo excepcional, nos dias atuais, a receita originária, além de relativamente inexpressiva". ATALIBA, Geraldo. Apontamentos de ciência das finanças, direito financeiro e tributário cit., p. 25. Por outro lado, consigna Flávio Rubinstein: "Ainda que as receitas patrimoniais jamais tenham deixado de exercer papel relevante no financiamento governamental, com a própria evolução do Estado, elas paulatinamente foram perdendo importância em favor da ascensão das receitas derivadas (especialmente os tributos), movimento que acompanhou a própria redução do papel intervencionista estatal na economia e as conquistas democráticas. Nesse passo, com o advento das conquistas liberais, as quais têm como marco essencial a Revolução Francesa, e das constituições modernas, as receitas tributárias foram impulsionadas à condição de pilar das finanças públicas. Nas últimas décadas, contudo, presenciou-se em diversos países - com destaque para o Brasil - um mpvimento de fortalecimento da importância das receitas originárias, especificamente daquelas decorrentes da exploração de recursos naturais". RUBINSTEIN, Flávio. Receitas públicas de recursos naturais no direito financeiro brasileiro cit., p. 5455. Há, contudo, de se contestar a afirmação de que o Brasil se destaca quanto à importância das receitas patrimoniais no financiamento do Estado. Como já demonstrado, os números dessa receita em relação à receita total ainda são tímidos (embora relevantes), especialmente quando confrontados com outros países - também já referidos - em que essa proporção é superior a 80\%, como são os casos de Angola e Nigéria (90 e 83\%, respectivamente).

1209 SCAFF, Fernando Facury. Royalties decorrentes da exploração de recursos naturais não renováveis cit., p. 33.

1210 Idem, ibidem, p. 39-42.

1211 MACHADO, Raquel Cavalcanti Ramos. A mudança do paradigma orçamentário: do controle do Estado para a implementação de políticas públicas. A função da receita pública no estado democrático e social de direito. In: CONTI, José Maurício; SCAFF, Fernando Facury (Org.). Orçamentos públicos e direito financeiro cit., p. 1048.

1212 CATARINO, João Ricardo. Processo orçamental e sustentabilidade das finanças públicas: o caso europeu. In: CONTI, José Maurício; SCAFF, Fernando Facury (Org.). Orçamentos públicos e direito financeiro cit., p. 794. 


\section{Ou, como coloca Casalta Nabais, o Estado Fiscal}

permite-nos falar de cidadania, mais especificamente de cidadania fiscal. Uma cidadania que implica, designadamente, que todos os membros da comunidade suportem o estado, ou seja, que todos os membros da comunidade tenham a qualidade de destinatários do dever fundamental de pagar impostos na medida da respectiva capacidade contributiva. O que significa que o estado fiscal implica uma cidadania de liberdade cujo preço reside em sermos todos destinatários do dever fundamental de pagar impostos. Deste modo, a estadualidade fiscal exprime mesmo uma ideia de alcance mais vasto, uma vez que tem subjacente a primazia da liberdade ou, o que vem dar no mesmo, a primazia dos direitos fundamentais face aos demais valores ou bens constitucionais em que naturalmente se integram os deveres fundamentais. ${ }^{1214}$

Essas conclusões não prescindem de uma consideração sobre a função do tributo - especialmente, do imposto - no Estado. Afinal, poder-se-ia argumentar que os Estados Patrimonial e Fiscal são equivalentes, observada a fungibilidade do bem de que se trata - o dinheiro. Um pelo outro, não importaria a origem da receita pública, desde que ela fosse efetivamente arrecadada.

Esta noção - como de fato já se sustentou nos capítulos anteriores - deve ser plenamente rechaçada.

O tributo, na visão de Reuven Avi-Yonah, tem 03 (três) funções: ${ }^{1215}$ “(i) gerar receitas ao Estado; (ii) redistribuir a riqueza ${ }^{1216}$ e (iii) regulamentação". 1217-1218

${ }^{1213}$ De forma semelhante, afirma Edmund Burke (apud Terry Lynn Karl): "The revenue of the state is the state". KARL, Terry Lynn. The paradox of plenty cit., p. 222.

1214 NABAIS, José Casalta. Por um estado fiscal suportável cit., p. 33-34. Para o autor, que, como visto, centra sua defesa do Estado Fiscal numa ideia de cidadania, esta "pode ser definida como a qualidade dos indivíduos que, enquanto membros activos e passivos de um estado-nação, são titulares ou destinatários de um determinado número de direitos e deveres universais e, por conseguinte, detentores de um específico nível de igualdade. Uma noção de cidadania, em que, como é fácil de ver, encontramos três elementos constitutivos, a saber: 1) a titularidade de um determinado número de direitos e deveres numa sociedade específica; 2) a pertença a uma determinada comunidade política (normalmente o estado), em geral vinculada à ideia de nacionalidade; 3) a possibilidade de contribuir para a vida pública dessa comunidade através da sua participação" - p. 34.

1215 AVI-YONAH, Reuven S. Os três objetivos da tributação. Trad. Luís Flávio Neto. Revista Direito Tributário Atual, n. 22, São Paulo: Dialética, 2008, p. 27.

1216 "Assim, a tributação pode ter uma função redistributiva, com vista a reduzir a desigualdade na distribuição da renda e da riqueza, que resulta do funcionamento normal de uma economia baseada no mercado. Tal função tem sido bastante debatida e as diferentes teorias de justiça distributiva podem ser utilizadas para afirmar ou negar a sua legitimidade. No entanto, é certo que muitas nações desenvolvidas têm realmente procurado atribuir à tributação efeitos redistributivos, embora seja discutível a eficácia obtida ou que é possível obter-se neste intento" (idem, ibidem, p. 10).

1217 "Outra função da tributação que se quer sublinhar é o seu componente regulamentar. A tributação pode ser utilizada para orientar a atividade no setor privado em direções desejadas pelo Estado. Esta função também é controvertida, como demonstrado pelo debate a respeito das deduções fiscais. Mas é difícil negar que a tributação tem sido amplamente utilizada para este fim regulamentar, tendo em vista 
Daí se vê, de imediato, que o sistema público financiado por receitas patrimoniais é carente de duas funções primordiais na atuação do Estado, uma delas - a de redistribuição da renda e da riqueza - que é fundamental na promoção dos valores de dignidade e liberdade humanas e de desenvolvimento econômico e social, além de ser, como já se referiu, indissociável do conceito de equidade intergeracional.

Só isto já seria razão suficiente para concluir pela necessidade de afastar-se da priorização desse tipo de receita no Erário público.

Alessandro Mendes Cardoso sustenta que o tributo deve ser compreendido como um dever fundamental de solidariedade, sendo "instrumento a serviço da política social e econômica do Estado redistribuidor", ${ }^{1219}$ ao lado de sua clássica concepção de "meio primordial de sustento do Estado". ${ }^{120}$

A ideia de solidariedade na tributação está referida também na doutrina de Álvaro Bereijo, para quem, numa análise jurídico-política, o dever fundamental de pagar impostos cumpre tripla função: (i) de legitimação do tributo, que tem fundamento no dever de solidariedade dos cidadãos de contribuir ao financiamento dos gastos públicos; (ii) de limite e garantia jurídica, constrangendo o poder estatal de tributar; e (iii) de orientação programática da atuação dos poderes públicos, em direção à criação de um sistema tributário justo. ${ }^{1221}$

No mesmo sentido, Oscar Sarlo indica que "a tributação expressa em termos jurídico-formais o dever de solidariedade com a vida em comum", ${ }^{122}$ daí que o direito tributário, e a administração tributária, são centrais na "compreensão dos deveres humanos, como partes inevitáveis da moralidade básica de uma sociedade". ${ }^{1223}$

inclusive a disseminação do método de deduções fiscais em todo o mundo, após a sua introdução nos EUA na década de 70" (idem, ibidem).

1218 Mencione-se a posição de Casalta Nabais, de conotação liberal, que resiste em incluir os fins sociais no conceito de "imposto". O autor português pleiteia que se faça distinção entre os objetivos fiscais e extrafioscais: "Em conclusão, seja numa visão mais radical ou mais moderada, há que fazer uma distinção dos impostos consoante os seus objectivos e/ou os seus efeitos, já que os impostos extrafiscais hão-de ter por parâmtero constitucional material essencialmente os direitos fundamentais, e os impostos fiscais essencialmente o princípio da capacidade contributiva" (NABAIS, José Casalta. $O$ dever fundamental de pagar impostos cit., p. 251).

1219 CARDOSO, Alessandro Mendes. O dever fundamental de recolher tributos no estado democrático de direito cit., p. 146.

1220 Idem, ibidem, p. 151.

1221 BEREIJO, Álvaro Rodríguez. El significado jurídico del deber constitucional de pagar impuestos. Revista de direito tributário, n. 113, São Paulo: Malheiros, 2011, p. 25.

1222 SARLO, Oscar. Republicanismo, derechos humanos y deberes tributarios. Revista Mestrado em Direito, ano 12, n. 1, Osasco, jan.-jul. 2012, p. 131. Tradução livre.

1223 Idem, ibidem. 
E ainda, Cristina Chulvi aponta que "com a chegada do Estado social $e$ democrático de Direito, adotou-se um conteúdo solidário ao dever de contribuir para o sustento dos gastos públicos ao empregá-lo como instrumento a serviço da política social e econômica do Estado redistribuidor". ${ }^{1224} \mathrm{E}$ ainda: "a conexão entre o dever de contribuir ao sustento dos gastos públicos e o princípio da solidariedade resulta inegável já que o cumprimento ou descumprimento do dever de tributar beneficia ou prejudica, respectivamente, a todos dado o caráter público do ente sustentado". ${ }^{1225}$

Fixe-se, portanto, que os tributos já não podem ser considerados apenas instrumentos de arrecadação.

Essa percepção foi registrada no livro influente de Stephen Holmes e Cass Sunstein, em que, desde o título, afirmam expressamente que a liberdade depende dos tributos $^{1226}$ - embora, deva-se registrar, seu objetivo não fosse contrapor as receitas tributárias com as patrimoniais.

O que se deve enfatizar, contudo, é que os tributos, diferente de outros tipos de receita patrimonial, são "o preço que pagamos por termos uma comunidade organizada baseada na ideia de liberdade, ou seja no respeito pelos direitos e liberdades fundamentais". ${ }^{1227}$ É o que já havia sido sintetizado por Oliver Wendell Holmes, da Suprema Corte Estadunidense, em 1927, com a frase que veio a se tornar de frequente repetição: "tributos são o que pagamos por uma sociedade civilizada". ${ }^{1228}$

Então, é viciosa a postura de abandono parcial da arrecadação tributária em prol da manutenção das atividades estatais com financiamento oriundo das receitas (próprias ou, o que é ainda pior, transferidas) de exploração do patrimônio natural não renovável.

Quer-se fixar, por todos, o entendimento de que as receitas públicas de impostos e as receitas públicas de royalties de recursos naturais não-renováveis não são intercambiáveis; não podem ser tomadas uma pela outra; embora o dinheiro seja fungível, deve-se, no mínimo, respeitar equivalência do valor de royalties ingressado no Erário, para

${ }^{1224}$ CHULVI, Cristina Pauner. El deber constitucional de contribuir al sostenimiento de los gastos públicos. Madrid: Centro de Estudios Políticos y Constitucionales, 2001. p. 70. Tradução livre.

${ }^{1225}$ CHULVI, Cristina Pauner. El deber constitucional de contribuir... cit., p. 71-72. Tradução livre.

${ }^{1226}$ HOLMES, Stephen; SUNSTEIN, Cass. The cost of rights: why liberty depends on taxes. Nova York: W. W. Norton \& Company, 1999.

${ }^{1227}$ NABAIS, José Casalta. Por um estado fiscal suportável... cit., p. 39.

${ }^{1228}$ No original: "Taxes are what we pay for civilized society". Compania General de Tabacos v. Collector 275, U.S. 87, 1927. Tradução livre. 
que seja gerido e gasto de forma específica. Esta especificidade característica, sobre a qual já se argumentou acima, decorre principalmente de a finitude ser intrínseca aos bens minerais e petrolíferos. Mas, na forma acima sustentada, que diz das propriedades dos tributos, não compartilhadas com as receitas patrimoniais, chega-se à mesma conclusão.

Outrossim, deve-se ficar expresso que a aceitação de uma estrutura assemelhada àquela descrita sobre o Estado Patrimonial - financiamento das atividades públicas por meio de royalties - teria a consequência imediata e necessária, no caso em estudo, de utilização das receitas de royalties para custeio das máquinas administrativas. Isto é: essa receita pública seria consumida.

E isto, pelos fundamentos delineados acima, não se aceita. O consumo dessa receita viola basicamente todas as recomendações que têm por desiderato evitar os efeitos deletérios da exploração, e que em geral apontam no sentido de diversificar a base econômica e adotar as medidas econômicas necessárias à proteção contra a volatilidade e contra intempéries cambiais. O consumo dessa receita é fundamentalmente oposto à mais comezinha ideia de equidade intergeracional, que admite esse gasto atual (isto é, se não desejada a formação de poupança para benefício das gerações futuras), desde que se dê em capital reprodutível, infraestrutura ou de formas quaisquer que impliquem um benefício protraído no tempo. Mesmo que se objetive a redistribuição de renda intrageracional, parte relevante da teoria intergeracional, a conduta narrada é incapaz de alcançá-la. O consumo, ainda, transgride as lições econômicas que comandam a própria razão de explorar, qual seja o processo de superação do subdesenvolvimento.

Logo, o financiamento das atividades estatais a partir da receita de royalties é, por todas as razões ora trazidas, inaceitável.

Contudo, o sistema de rateio espacial dos royalties minerais e petrolíferos, como visto, destina grande parte dessa receita aos entes subnacionais, o que pode incentivar esta sorte de comportamento. A questão que se faz, então, para análise da institucionalidade brasileira, é: quais formas seriam necessárias para evitá-lo?

Cabe dar um passo atrás. A literatura especificamente voltada aos recursos naturais não renováveis relata a redução da carga tributária dos Estados mais afetados por essa exploração - como faz Terry Lynn Karl, ${ }^{1229}$ que identifica nos gestores públicos o

1229 Em: KARL, Terry Lynn. Ensuring fairness: the case for a transparent fiscal social contract. In: HUMPHREYS, Macartan; SACHS, Jeffrey D.; STIGLITZ, Joseph E. (Org.). Escaping the resource curse cit., p. 262. 
"alívio do fardo de tributar seus próprios eleitores", ${ }^{1230}$ para concluir que "a dependência apenas dos petrodólares não é uma base sustentável para o desenvolvimento". ${ }^{1231}$ Da mesma forma, essa tributação em níveis abaixo dos regulares, pode até mesmo implicar prejuízos às práticas democráticas, como se referiu anteriormente. Vale lembrar, ainda, que menor tributação significa maior dependência; e que maior dependência de receitas oriundas da exploração de bens notadamente voláteis, significa maior suscetibilidade a essa volatilidade.

Mas é na teoria do federalismo fiscal que o tema se desenvolve, especialmente pela análise das transferências intergovernamentais, na medida em que busca o desenvolvimento de quadros federativos ótimos, em que as receitas são adequadas às despesas em todos os níveis de governo. Vale lembrar a nota já posta acima: para o caso brasileiro, em face do volume das receitas oriundas da exploração dos recursos naturais não renováveis, e do quadro de rateio federativo que se apresenta, o risco de financiamento da máquina estatal pelas receitas patrimoniais se dá nos entes subnacionais - e não na União. Portanto, revela-se adequada a análise a partir das lições do federalismo fiscal.

Marcos Mendes, Rogério Boueri Miranda e Fernando Blanco Cossio, em estudo elaborado para a Consultoria Legislativa do Senado Federal, afirmam que as transferências incondicionais "aumentam a autonomia do governo receptor, contudo tendem a ter baixa accountability, na medida em que as populações dos estados e municípios desvinculam a origem dos recursos do esforço tributário próprio". ${ }^{1232-1233}$

${ }^{1230}$ KARL, Terry Lynn. Ensuring fairness: the case for a transparent fiscal social contract. In: HUMPHREYS, Macartan; SACHS, Jeffrey D.; STIGLITZ, Joseph E. (Org.). Escaping the resource curse cit., Tradução livre.

1231 Idem, ibidem, p. 278. Tradução livre.

1232 MENDES, Marcos; MIRANDA, Rogério Boueri; COSSIO, Fernando Blanco. Transferências intergovernamentais no Brasil: diagnóstico e proposta de reforma. Textos para discussão. Brasília: Senado Federal, 2008. n. 40, p. 17-18. Prosseguem: "No que diz respeito aos incentivos à gestão eficiente e à responsabilidade fiscal, há robusta evidência na literatura de que as transferências incondicionais têm impacto negativo, pois estimulam a expansão mais que proporcional do gasto do ente público receptor (flypaper effect), a deterioração da qualidade desse gasto e desestimulam a arrecadação tributária local".

1233 No mesmo sentido: "The recent development literature suggests that countries receiving large revenues from natural resource endowments are likely to raise less revenue from domestic taxation, and that this creates governance problems because of the reduced incentive for the public scrutiny of government". BORNHORST, Fabian; GUPTA, Sanjeev; THORNTON, John. Natural resource endowments, governance, and the domestic revenue effort: evidence from a panel of countries cit., p. 9. Para Rodrigo Serra (SERRA, Rodrigo Valente. Rendas petrolíferas no Brasil: critérios de distribuição distorcidos induzem ineficiência do gasto. In: MENDES, Marcos (Org.). Gasto público eficiente cit., p. 205), "as transferências tendem a estimular o governo subnacional que as recebe a aumentar sua despesa total, a realizar gastos de menor qualidade e a reduzir o esforço de arrecadação própria. Esses impactos negativos tendem a se agravar nos casos em que os critérios de repartição das transferências são 
A ênfase, aí, deve ser no "esforço tributário próprio". Se restou fixado que o desinteresse pela tributação própria é deletério, então impõe-se exigir dos entes subnacionais, beneficiários das transferências de royalties, que exerçam suas competências tributárias, efetivamente instituindo e arrecadando os respectivos tributos, como aliás já ordena a Lei de Responsabilidade Fiscal, art. 11.

Assim é que se torna frequente, na doutrina do federalismo fiscal, que as transferências intergovernamentais sejam reguladas também (não apenas, é claro) pelo que chamam de critério do "esforço fiscal" ou da "capacidade fiscal"1234 - a significar um critério que identifique se os entes subnacionais destinatários das transferências estão efetivamente arrecadando o possível dentro das bases imponíveis que lhes foram outorgadas, ou, por outro lado, se estão escorando-se nas receitas transferidas para financiamento de suas atividades, negligenciando os tributos próprios. ${ }^{1235}$

Para Mauro Santos Silva, o desenho das transferências deve levar em conta mecanismos e critérios "compatíveis com os objetivos desejados e incentivos ao alcance de metas fiscais, por exemplo: esforço de arrecadação - a relação entre a arrecadação efetiva e a arrecadação potencial permite mensurar o grau de eficácia das administrações tributárias". ${ }^{1236}$ É o que defende José Roberto Afonso, a partir do FPE, afirmando que

inadequados, gerando grupos de estados e municípios sobrefinanciados. Esse parece ser o caso da partilha das PGs, que beneficiam um grupo restrito de estados e municípios".

1234 Vale mencionar posição dissonante de Boadway e Shah. Os autores, mencionando a possibilidade de transferências que tenham por condição a arrecadação tributária própria dos entes subnacionais, afirmam que este modelo pode ser aplicado (i) para internalizar externalidades tributárias positivas, ou (ii) para estimular os entes subnacionais a arrecadar mais de suas bases imponíveis (p. 339-340). Contudo, entendem que a medição da capacidade fiscal de um ente político é de difícil alcance (p. 358-360), bem como que há vários problemas em incorporar um critério de esforço fiscal nas transferências intergovernamentais (p. 371), daí que sugere evitar "transferências incondicionais que incluem incentivos para o esforço fiscal” (p. 387 - tradução livre). BOADWAY, Robin; SHAH, Anwar. Fiscal federalism cit., p. 460.

1235 "O fato, por exemplo, de existirem municípios com arrecadação própria per capita inferior a outros não lhes deve assegurar obrigatoriamente, por esse enfoque teórico, o direito de receber transferências redistributivas. Isso porque a arrecadação per capita do referido município depende, entre outros fatores, do seu esforço fiscal e não apenas das receitas efetivamente arrecadadas" (ORAIR, Rodrigo Octávio; ALENCAR, André Amorim. Esforço fiscal dos municípios: indicadores de condicionalidade para o sistema de transferências intergovernamentais. Brasília: ESAF, 2010. Monografia premiada com o primeiro lugar no XV Prêmio Tesouro Nacional - 2010: Homenagem a Joaquim Nabuco. Tópicos Especiais de Finanças Públicas. Brasília (DF). p. 9). Ensina ademais, Fernando Rezende: "Qualquer que seja o padrão de referência adotado, uma característica fundamental dos mecanismos de equalização fiscal é que a compensação financeira às unidades menos desenvolvidas deve levar em conta o uso que fazem dos tributos de sua competência - o esforço tributário próprio - e todas as demais fontes de recursos que compõem o seu orçamento. Assim, a compensação financeira fica limitada a recursos adicionais efetivamente necessários à equalização da capacidade de gasto ou da capacidade de prover um mesmo padrão de serviços" (REZENDE, Fernando. Os desafios do federalismo fiscal. In: REZENDE, Fernando (Coord.). Desafios do federalismo fiscal. Rio de Janeiro: FGV, 2006. p. 15).

1236 SILVA, Mauro Santos. Teoria do federalismo fiscal cit., p. 133. 
"novos critérios para o FPE devem ponderar o potencial e a efetiva arrecadação direta e as necessidades de cada ente federado". ${ }^{1237}$ E é como pondera Matheus Assunção, para quem a desconsideração do "esforço de arrecadação de tributos próprios" implica ampliar "ainda mais os desequilíbrios horizontais", arriscando criar, nas regiões menos desenvolvidas, “dependência de transferências". ${ }^{1238}$

Da mesma forma, Teresa Ter-Minassian, em análise específica dos modelos de federalismo latino-americanos, põe o esforço fiscal no centro das preocupações. Para a autora, fatores institucionais e de política econômica influenciam o esforço dos entes subnacionais em arrecadar os tributos próprios, o que pode ser endereçado pelas transferências intergovernamentais do ente central, ${ }^{1239-1240}$ como ocorre no Canadá. ${ }^{1241} \mathrm{~A}$ mesma ideia é sugerida ao caso do FPE brasileiro, embora Ter-Minassian considere difícil

${ }^{1237}$ AFONSO, José Roberto R. FPE: rateio sem critério, Observatório da jurisdição constitucional, Brasília: IDP, ano 3, 2009-2010.

${ }^{1238}$ ASSUNÇÃO, Matheus Carneiro. Repartição das receitas tributárias no federalismo fiscal brasileiro: os critérios de rateio dos fundos de participação. 2013. Dissertação (Mestrado) - Faculdade de Direito da Universidade de São Paulo. São Paulo: Universidade de São Paulo. p. 180.

1239 "The degree of sub-national tax effort is found to be influenced by both institutional factors (such as the administrative capacity of SNGs, and the levels of transparency and corruption) and political economy factors (such as the political alignment of the sub-national jurisdiction with the national ruling party). The design of inter-governmental transfers is also found to play an important role: discretionary transfers from the CG (as well as a history of repeated sub-national bailouts by the latter) tend to disincentivize sub-national own-revenue efforts, as they create moral hazard. In contrast, appropriately designed, formula-based equalization transfers are found to promote own-revenue mobilization in some countries (e.g., Colombia and Peru) [...] With the exception of Brazil and, to a lesser extent, Argentina, revenue decentralization has been limited, especially at the regional level. In most countries, regional governments have not been assigned significant sources of own revenue. Local governments, despite having appropriate tax handles (especially property taxes) do not exploit them adequately, reflecting lack of institutional capacity and political economy disincentives to own-revenue efforts [...] Against this background, and given growing challenges looming ahead for the region and its public finances, there is a clear need to reinvigorate the tax reform process in the years ahead. Special focus should be placed on reforms that would address simultaneously some of the shortcomings mentioned above. Among such reforms, the paper advocates in particular: [...] Revising revenue assignments to regional governments, with a view to reducing their dependence on central government transfers; promoting and assisting efforts by local governments to improve the collection of property taxes; and reforming especially distortive sub-national taxes" (TER-MINASSIAN, Teresa. More than revenue: main challenges for taxation in Latin America and the Caribbean. Inter-American Development Bank Working Paper, $\mathrm{n}$. IDB-PB-175, 2012, p. 31 e 44-46).

1240 Vale mencionar a lição de Ter-Minassian em outra oportunidade: "Arrengements that assign all or most taxing powers to the central government are undesirable as well. By separating spending authority from revenue-raising responsabilities, these arrengements obscure the link between the benefits of public expenditures and their price, namely, the taxes levied to finance them. Thus, they do not promote fiscal responsibility in subnational politicians and their electorate" (TER-MINASSIAN, Teresa. Intergovernmental fiscal relations in a macroeconomic perspective: an overview. In: TER-MINASSIAN, Teresa (Ed.). Fiscal federalism in theory and practice cit., p. 8).

1241 "O sistema mais complexo de equalização com base na capacidade de geração de receita é o usado pelo Canadá. Neste sistema, a capacidade tributaria relativa de cada província é calculada com referência a um sistema tributário representativo (RTS) que é essencialmente uma média dos sistemas fiscais provinciais. As transferências a cada províncias são baseadas na arrecadação potencial, para não desencorajar os esforços tributários acima da média e não premiar aqueles abaixo da média" (TERMINASSIAN, Teresa. Reforma do fundo de participação dos estados cit., p. 11). 
“calcular o potencial aumento das receitas". ${ }^{1242}$ É também o sugerido, em análise do sistema fiscal boliviano, por Giorgio Brosio. O autor recomenda uma série de medidas de descentralização fiscal, incluindo a alocação de tributação própria aos entes descentralizados, acompanhadas de transferêcias equalizadoras do ente central. Sobre estas, afirma: "As transferências devem derivar de todo o conjunto de tributos nacionais, não apenas do imposto sobre hidrocarbonetos, assim reduzindo sua volatilidade. Sua alocação deve ser estruturada de forma a incluir incentivos de estímulo ao esforço fiscal". ${ }^{1243}$ Idem para o estudo de Martinez-Vazquez e Jameson Boex, sobre a Federação Russa, em que afirmam: "É fundamental para um sistema de transferências intergovernamentais a compreensão dos conceitos de capacidade fiscal e esforço fiscal [...] uma medida de capacidade fiscal deve ser um fator importante na determinação da alocação de transferências intergovernamentais, de forma a equalizar a quantidade de recursos disponível a cada região". ${ }^{1244}$

Rodrigo Orair e André Alencar assim colocam a questão:

O objetivo explícito de um sistema de transferências deve ser equalizar as diferenças na capacidade fiscal, bem como as diferenças nas necessidades fiscais, que não só destoam dos gastos correntes como dependem de variáveis outras que não apenas o tamanho da população ou da área de uma jurisdição qualquer.

1242 TER-MINASSIAN, Teresa. Reforma do fundo de participação dos estados cit., p. 22.

1243 BROSIO, Giorgio. Reducing reliance on natural resource revenue and increasing subnational tax autonomy in Bolivia. Inter-American Development Bank Working Paper, n. IDB-WP-298, 2012, p. 25. Vale considerar, contudo, que o autor ressalva a dificuldade de trazer critérios de medida do esforço fiscal. Assim: "Linking transfers to tax capacity, or to the effective use of the tax potential, is not an easy task. It requires information about the potential rather than the assessed tax base which, in the case of property, is hard to estimate. Clearly, this task would be facilitated by the construction of regional, if not national, cadastres to ensure uniformity of evaluation criteria and practices. The use of statistical indicators is made difficult because: i) there are no good proxies of value of real property, and ii) if there were, and if they were accepted by all stakeholders, they would likely be unavailable at the municipal level. This is the case of GDP, for example, which is frequently, but not unanimously, considered a proxy of real property value. A simpler, secondbest alternative is to stimulate tax collection effort by linking transfers-or a portion of them-to the growth of collections or to other indicators of tax effort. To be more specific, a share of the total amount of grants could be allocated according to the difference, for each municipality, between the rate of growth of its collections and the national average growth rate. Growth rates should be calculated as moving averages over a three or four-year period to avoid sudden changes and strategic behaviors. Alternative and/or complementary indicators could be increases in the number of tax payers, and decreases in tax arrears" - p. 20-21. Na Venezuela há problemas similares: o sistema é deveras centralizado, e as poucas fonts de receita dos entes subnacionais não têm sido exploradas adequadamente ("there is room for improvement in the collection of existing taxes through the strengthening of institutional and administrative capacities of municipal governments"). Nesse sentido: RÍOS, Germán; ORTEGA, Federico; SCROFINA, J. Sebastián. Sub-national revenue mobilization in Latin America and Caribbean countries - The case of Venezuela. Inter-American Development Bank Working Paper, n. IDB-WP-300, 2012, p. 67.

1244 MARTINEZ-VAZQUEZ, Jorge; JAMESON BOEX, L.F. Fiscal capacity: an overview of concepts and measurement issues and their applicability in the russian federation. GSU Andrew Young School of Policy Studies Working Paper, n. 97-3, jun. 1997, p. 1-2. Tradução livre. 
A ideia de mensurar o esforço fiscal dos municípios permite estimarmos uma proxy do que seria a capacidade de gerar receitas próprias e, ao mesmo tempo, verificar empiricamente se existe relação entre esse esforço e o peso das transferências devolutivas e redistributivas no orçamento municipal". ${ }^{1245}$

\section{Os autores desenvolveram um Índice de Esforço Fiscal dos Municípios}

brasileiros. Suas análises "comprovaram que todas as categorias de transferências apresentam influência negativa sobre a arrecadação própria, o que corrobora a tese de que uma reforma no sistema de transferências se paute tanto pelo princípio da equidade quanto pelo da eficiência". 1246

Rodolfo Costa levou a efeito análise semelhante, ${ }^{1247}$ concluindo pela existência de "um movimento gestor baseado no financiamento via transferências em detrimento da sua base tributária individual", ${ }^{1248}$ mas não referendando a existência do efeito flypaper. ${ }^{1249}$ Arvate, Mattos, e Rocha entendem também - consoante suas análises, que as transferências incondicionais afetam negativamente a eficiência da arrecadação tributária no Brasil. ${ }^{1250}$

Vale considerar que são constantes as objeções fundadas na ausência de métodos seguros de valorar a capacidade arrecadatória dos entes subnacionais, daí por que impossibilitando a análise da presença ou ausência de esforço fiscal. Não é objeto destas linhas, mesmo por incapacidade técnica, afirmar quais são os critérios adequados ou se são suficientes ou não. Mas vale mencionar que, tal como nos artigos acima citados (de Rodrigo Orair e André Alencar, e de Rodolfo Costa), há diversos trabalhos destinados ao tema ${ }^{1251}$ pelo que cabe considerar, no mínimo, o esforço doutrinário nesse sentido.

1245 ORAIR, Rodrigo Octávio; ALENCAR, André Amorim. Esforço fiscal dos municípios... cit., p. 9.

1246 Idem, ibidem, p. 40.

1247 “Apesar de apresentar-se de forma imprescindível para as ações de um regime federativo, as transferências constitucionais podem incentivar um comportamento imprudente por parte dos gestores municipais. Em federações onde o principal componente das receitas correntes são os repasses intergovernamentais, pode-se observar um detrimento da utilização da base tributária individual e, ainda, uma realização de despesas sem compromisso com uma gestão de recursos equilibrada [...] Desta forma, buscando evidenciar o comportamento das ações fiscais dos municípios brasileiros perante o sistema de repasses intergovernamentais, o objetivo deste trabalho é investigar o efeito das transferências correntes sobre o esforço fiscal das jurisdições brasileiras, bem como verificar a ocorrência do efeito flypaper". COSTA, Rodolfo Ribeiro da. O impacto das transferências constitucionais sobre o comportamento fiscal dos municípios brasileiros. p. 4-5.

1248 Idem, ibidem, p. 71.

1249 Idem, p. 72.

1250 ARVATE, Paulo; MATTOS, Enlinson; ROCHA, Fabiana. Flypaper effect revisited: evidence for tax collection efficiency in Brazilian municipalities. Estudos econômicos, 2011, v. 41, n. 2, ISSN 01014161. Disponível em: 〈http://dx.doi.org/10.1590/S0101-41612011000200002〉. Acesso em: 9 dez. 2013.

1251 POSTALI, Fernando Antonio Slaibe. Rendas do petróleo e ineficiências administrativas nos municípios brasileiros cit.; HANDELWANG, Christian Von; IVANYNA, Maksym. Assessing the tax performance 
Em linha com tais considerações oriundas da teoria do federalismo fiscal, as análises políticas e econômicas dos impactos da exploração mineral e petrolífera, como dito, passaram a identificar o mesmo fenômeno - ausência de esforço fiscal nos entes receptores dessas receitas públicas não tributárias. Os fundamentos são os mesmos: o dinheiro que entra no Erário, não oriundo da tributação, é percebido de forma diversa, menos sujeito ao controle público, entendido como menos invasor da esfera patrimonial dos cidadãos, e, então menos impopular. ${ }^{1252}$

Assim, Bornhorst, Gupta e Thornton, após análise de 30 (trinta) países produtores de hidrocarbonetos, encontraram "uma relação negativa estatisticamente significante" entre (i) receitas fiscais e (ii) receitas relacionadas à exploração petrolífera: um padrão médio de redução de $0,2 \%$ das receitas tributárias a cada aumento de $1 \%$ da receitas de petróleo e gás. ${ }^{1253}$ Rolado Ossowski e Alberto Gonzáles igualmente afirmam que, na América Latina, o efeito das receitas de recursos naturais não renováveis nas receitas fiscais é negativo e estatisticamente significante, o que gera preocupações relacionadas à proteção contra a volatilidade e à sustentabilidade fiscal ${ }^{1254}$. Também Guillermo Perry e Sebastián Bustos encontram uma relação de "substituição" entre receitas de recursos naturais não renováveis e demais receitas, fazendo com que as últimas diminuam nos períodos de alta dos preços minerais e petrolíferos. ${ }^{1255}$

of developing countries. Deutsches Institut für Entwicklungspolitik Discussion Paper, n. 20/2010, 2010; PESSINO, Carola; FENOCHIETTO, Ricardo. Determining countries' tax effort. Hacienda Pública Española. Revista de Economía Pública, 195, 4, 2010; LE, Tuan Minh; MORENO-DODSON, Blanca; ROJCHAICHANINTHORN, Jeep. Expanding taxable capacity and reaching revenue potential: crosscountry analysis. World Bank Policy Research Working Paper 4559, 2008; PIANCASTELLI, Marcelo. Measuring the tax effort of developed and developing countries. Cross country panel data analysis 1985/95. IPEA Working Paper, n. 818, 2001; MARTINEZ-VAZQUEZ, Jorge; JAMESON BOEX, L.F. Fiscal capacity: an overview of concepts and measurement issues and their applicability in the russian federation cit.

1252 Vale recordar a "psicologia social da tributação" já mencionada acima, suscitada em: SANDBU, Martin E. Natural wealth accounts: a proposal for alleviating the natural resource curse cit., p. 1159 e ss.

1253 BORNHORST, Fabian; GUPTA, Sanjeev; THORNTON, John. Natural resource endowments, governance, and the domestic revenue effort: evidence from a panel of countries cit., p. 9.

1254 Interessante ainda, no referido estudo, a análise do comportamento das diversas bases tributárias dos países estudados, para identificar quais as que tiveram pior desempenho, isto é: quais as que sofreram com menos esforço fiscal. OSSOWSKI, Rolando; GONZÁLES, Alberto. Manna from heaven: the impact of nonrenewable resource revenues on other revenues of resource exporters in Latin America and the Caribbean. Inter-American Development Bank Working Paper Series, n. IDB-WP-337, 2012.

1255 Os autores, contudo, ressalvam a América Latina de enquadrar-se nesta regra geral: "We showed evidence that non-commodity revenues are more volatile in oil- and mineral-rich countries and that the quality of institutions is associated with lower volatility. In explaining this fact, we show that that the discretionary direct substitution effect of non-commodity revenues for oil and mineral revenues dominates over the positive indirect effect through higher public expenditures and GDP. That is, when oil and fiscal revenues increase, noncommodity revenues are reduced discretionally, and this effect is larger and faster than the indirect positive effect of the increase in GDP. This is not the case in oil- and mineral-rich Latin American countries. The substitution effect is lower in this region and does not 
Finalmente, vale mencionar a análise direcionada ao caso brasileiro, conduzida por Fernando Postali. O autor investigou o "impacto dos royalties e das participações especiais sobre o esforço fiscal municipal em duas dimensões: na maximização da produção de tributos locais e na adequação dos custos administrativos ao tamanho desejado de governo", ${ }^{1256}$ e concluiu em apenas parcial concordância com as análises acima. Segundo suas análises, "as rendas do petróleo não afetam o esforço fiscal, ${ }^{1257}$ tendo em vista que elas não se mostraram significativas para explicar as ineficiências técnicas na fronteira de produção", mas "são capazes de gerar ineficiências- $\mathrm{X}^{1258}$ na forma de excesso de gastos administrativos, dada a escolha do tamanho de governo pelos habitantes locais". ${ }^{1259}$

Portanto, mesmo se negada a hipótese de ausência de esforço fiscal, como faz Postali, a conclusão já acima alcançada (o financiamento das atividades estatais a partir da receita de royalties é inaceitável) deve ser reiterada: o autor, embora não subscreva a ideia de diminuição da tributação, igualmente afirma o consumo das receitas de royalties, através de "excesso de gastos administrativos".

Colocadas as premissas acima, cabem algumas notas sobre o tema no ordenamento jurídico brasileiro.

Como já amplamente sabido, as receitas de recursos naturais não renováveis, atualmente, são distribuídas fortemente em direção aos Municípios produtores - no caso da

dominate the indirect income effect through increased public expenditures and GDP. These findings are both good and bad news. They are good news insofar as the dominant direct substitution effect reduces the volatility of total fiscal revenues that would take place in its absence, and thus, mitigates to some extent the higher volatility of public expenditures observed in oil- and mineral rich countries. On the other hand, the substitution effect is also bad news, as the size of automatic stabilizers, which depends on the size of non-commodity-related fiscal revenues, is reduced precisely when they are most needed". PERRY, Guillermo; BUSTOS, Sebastián. The effects of oil and mineral taxation on non-commodity fiscal revenues. Inter-American Development Bank Working Paper Series, n. IDB-WP-348, 2012, p. 37 38.

1256 POSTALI, Fernando Antonio Slaibe. Rendas do petróleo e ineficiências administrativas nos municípios brasileiros cit., p. 114.

1257 O Índice Firjan de Gestão Fiscal (IFGF), ano-base 2011, não parece indicar o mesmo, tomando como exemplos os municípios de Macaé-RJ, Campos dos Goytacazes-RJ, Itabira-MG e Parauapenas-PA. Dos quatro referidos, apenas Macaé apresenta conceito "B" no indicador "receita própria", tendo os demais recebidos os conceitos “C” (Itabira) ou "D" (Campos dos Goytacazes e Parauapebas). Disponível em: <http://www.firjan.org.br/ifgf/>. Acesso em: 9 dez. 2013.

1258 Aumentar as ineficiências-X significa "induzir a um desvio do comportamento otimizador traduzido no excesso de gastos administrativos para gerir um dado tamanho de setor público municipal". POSTALI, Fernando Antonio Slaibe. Rendas do petróleo e ineficiências administrativas nos municípios brasileiros cit., p. 14.

1259 Idem, ibidem, p. 114. Isto é: os municípios "apresentam tendência a efetuar gastos administrativos além do necessário para sustentar o tamanho desejado do governo" - p. 103. 
CFEM; e substancialmente, embora em menor grau, aos Estados produtores e confrontantes, no caso dos royalties petrolíferos e participações especiais.

Contudo, tais transferências não observam nenhum critério de esforço fiscal, nem guardam qualquer incentivo para a exploração da capacidade tributária própria. Isto é verdadeiro também para a repartição federativa dos royalties petrolíferos por meio do sistema do FPE/FPM, já que "as transferências constitucionais, no caso brasileiro, são essencialmente redistributivas e não levam em conta a capacidade de arrecadação ou o esforço fiscal desempenhado pelas unidades federadas". ${ }^{1260}$

Este quesito, pelas razões já colocadas, merece críticas - cabendo elogiar, por outro lado, a disposição expressa da Lei de Responsabilidade Fiscal (art. 11) que, de forma muito diferente, obriga (embora nem sempre com efetividade) a instituição e arrecadação de todos os tributos da competência do ente político.

A ausência de qualquer relação entre a quantidade de transferências e a arrecadação dos tributos da competência do ente subnacional estimula a banalização das receitas de royalties, seu consumo na máquina administrativa, sua indistinção em relação à receita tributária. Tudo o que, já se teve a oportunidade de suscitar, é pernicioso, inclusive (ou especialmente) transgredindo os interesses das gerações futuras.

Ao estimular a substitutibilidade entre uma e outra receitas públicas, o Estado brasileiro vulgariza não apenas os royalties, ignorando seus preceitos subjacentes; como também os tributos: acatando a postura de não arrecadação destes em prol do financiamento da máquina pública por receitas patrimoniais, desprezam-se suas funções, tão caras ao ordenamento constitucional, incluindo a de redistribuição da renda e da riqueza nacionais, de forma a reduzir as desigualdades sociais e promover o desenvolvimento e as liberdades individuais.

1260 PIANCASTELLI, Marcelo; BOUERI, Rogério; LIMA, Edilberto Pontes. Descentralização fiscal, harmonização tributária e relações intergovernamentais: como distintas federações reagem aos desafios da globalização. In: REZENDE, Fernando (Coord.). Desafios do federalismo fiscal cit., p. 43. 
3.h. Constrangimentos na perspectiva do gasto e suas burlas. Nota sobre a qualidade do gasto. Necessidade de regras de vinculaçãolafetação do gasto público da receita de royalties.

Poder-se-ia objetar, não sem alguma razão, à conclusão do item que tratou da classificação financeiro-orçamentária das receitas de royalties. Se não há - e de fato não há - um vínculo rígido entre as receitas (de capital, como se argumentou) de royalties e as despesas de capital, então estaria o gestor público livre de quaisquer amarras para ordenar o gasto de maneira a consumir a receita pública, em nada beneficiando as gerações futuras. Afinal, a Constituição Federal vigente não vincula ou afeta as receitas de royalties. ${ }^{1261}$

De início, é de se argumentar que, embora a Lei n. 4.320/1964 não vincule as receitas de capital para que sejam apenas aplicadas em despesas de capital (salvo nos casos de receitas de capital oriundas de alienação de bens públicos - LRF, art. 44), a norma orienta o gasto público nesse sentido, e essa orientação - que decorre do "paralelismo classificatório" 1262 - representa um avanço na governança das receitas oriundas da exploração dos recursos naturais não renováveis.

Entretanto, e visando analisar a objeção acima referida, cabe observar quais são as demais restrições ao gasto público dessa receita, constantes do ordenamento jurídico, aplicáveis à situação.

Tais restrições estão presentes, especialmente, no art. 8. ${ }^{\circ}$ da Lei n. 7.990/1989. O caput está assim redigido desde 1990 (e a parte que ora interessa - vedações - mantém a redação original de 1989):

Art. 8..$^{\circ} \mathrm{O}$ pagamento das compensações financeiras previstas nesta Lei, inclusive o da indenização pela exploração do petróleo, do xisto betuminoso e do gás natural será efetuado, mensalmente, diretamente aos Estados, ao Distrito Federal, aos Municípios e aos órgãos da Administração Direta da União, até o último dia útil do segundo mês subsequente ao do fato gerador, devidamente corrigido pela variação do Bônus do Tesouro Nacional (BTN), ou outro parâmetro de correção monetária que venha a substituí-lo, vedada a aplicação dos recursos em pagamento de dívida e no quadro permanente de pessoal.

1261 TOLLINI, Hélio Martins; COSTA, Franselmo Araújo. Vinculações das receitas orçamentárias: teoria e prática. In: CONTI, José Maurício; SCAFF, Fernando Facury (Org.). Orçamentos públicos e direito financeiro cit., p. 940.

1262 GIACOMONI, James. Orçamento público cit., p. 140. 
Eis que a norma impede que as receitas de royalties sejam destinadas a (i) aplicação em pagamento de dívida; e (ii) pagamento de pessoal permanente.

Reputa-se que, pelas razões que vêm sendo apresentadas - a necessidade de considerar tais receitas de forma específica e evitar o seu consumo insustentável -, trata-se de norma de matriz benéfica, que, se não orienta o gasto, ao menos busca evitar que este se dê das formas compreendidas como mais equivocadas.

Nada obstante, caberia já uma crítica, com base no que foi acima mencionado: a vedação pura e simples de aplicação em despesas de pessoal pode vir a prejudicar os investimentos em alguns setores. Isto é: se fosse decidido, por exemplo, que as receitas de royalties deveriam ser dirigidas à pesquisa tecnológica de fontes de energia renováveis, tais verbas públicas poderiam construir laboratórios, mas não remunerar cientistas - e pode-se pensar em casos em que o investimento humano (despesa de pessoal) pode ser tão ou mais decisivo para atingir os fins colimados.

Mas prossiga-se.

Embora aquelas disposições possam ser vistas como fundamentalmente virtuosas, porque afastam a ideia de considerar a receita de royalties como mais uma no "caixa único", as análises concretas parecem indicar uma baixa efetividade em alcançar os objetivos pretendidos.

Em outras palavras: as vedações do art. 8. ${ }^{\circ}$ da Lei n. 7.990/1989, quanto às despesas com pessoal, são costumeiramente desrespeitadas ${ }^{1263}$ - e não através de elaborados artifícios, mas de simples manobras básicas, ${ }^{1264}$ facilmente perceptíveis: é o

1263 Estudo sobre o tema afirma: “em geral, e não apenas nos Legislativos, os gastos com pessoal são mais elevados no grupo dos cem principais beneficiários dos royalties, ultrapassando em $33 \%$ a média per capita dos demais municípios recebedores desse tipo de compensação financeira, apesar de a Lei $\mathrm{n}$. 7.990/1989 ter proibido a aplicação desse tipo de receita em pagamento de dívidas e no quadro permanente de pessoal. No período de 2002 a 2006, as despesas de pessoal nos vinte principais beneficiários de royalties cresceram 70,7\% em valores nominais, o dobro da inflação do período. Em Campos (RJ), a expansão chega a 306,9\% [...] os gastos com o ensino fundamental são praticamente uniformes em todos os grupos, as despesas com atenção básica em saúde são inferiores entre os recebedores de rendas do petróleo e os investimentos em gestão ambiental - um dos pilares da argumentação em favor da concentração dos royalties em um grupo restrito de localidades sob impacto das atividades petrolíferas - são irrisórios em todas as classes de municípios”. AFONSO, José Roberto Rodrigues; GOBETTI, Sérgio Wulff. Rendas do petróleo no Brasil: alguns aspectos fiscais e federativos cit., p. 231- 269, dez. 2008, p. 246-247.

1264 Rodrigo Valente Serra sustenta: "essas restrições têm sido contornadas ou removidas. No que diz respeito à contratação de pessoal, o uso de mão-de-obra terceirizada viabiliza o uso dos recursos de royalties para custeio da folha de pagamento. Além disso, o processo de repactuação dos débitos dos Estados com a União levou ao cancelamento da vedação de utilização das receitas de receitas dos royalties para pagamento de dívidas" (SERRA, Rodrigo Valente. Rendas petrolíferas no Brasil: critérios 
caso dos Municípios que promovem a contratação de empresas terceirizadas para exercer as mesmas funções do quadro permanente de pessoal.

A vedação de utilização da verba para pagamento de dívida já foi legalmente relativizada (talvez seja possível afirmar até mesmo sua extinção pura e simples) pela Medida Provisória n. 2.181-45, seguida pela Lei n. 10.195/2001 e mais atualmente pela Lei n. $12.858 / 2013$, todas que passaram a admitir o uso da receita de royalties para pagamento de dívida interna.

Vale lembrar que no início desta sequência legislativa, os Estados e Municípios que contam com receitas de royalties puderam (temporariamente), na prática, vender créditos futuros de royalties de recursos minerais não renováveis como forma de pagamento da dívida à União e/ou de capitalização interna ${ }^{1265}$ - o que, na prática, importa em transmutar a receita de royalties em mero ativo financeiro, o que vai contra tudo o que se vem postulando. ${ }^{1266}$ Embora esta operação (alienação de créditos futuros) já não seja válida, permanece a possibilidade (não mais temporária, mas definitiva) de utilização dos valores para quitar dívida com a União. ${ }^{1267}$

Mister notar que esta operação se torna tão mais perniciosa quando se percebe que a venda desses créditos de royalties pode representar, no Estado vendedor, a capitalização da previdência interna. Nesse caso, os beneficiários da previdência estadual (principalmente os servidores públicos), pode-se dizer, terão capturado, para proveito próprio, a expressão financeira da exploração do patrimônio mineral.

de distribuição distorcidos induzem ineficiência do gasto. In: MENDES, Marcos (Org.). Gasto público eficiente cit., p. 238).

1265 Como se vê do art. 16 da MP 2.181-45, ainda em vigor, a União pôde (em caráter temporário) adquirir créditos de royalties, pagando através da emissão de Certificados Financeiros do Tesouro - CFT, estes que serão, obrigatoriamente, utilizados no pagamento de dívidas para com a União e suas entidades ou na capitalização dos fundos de previdência.

${ }^{1266}$ Em forte crítica a essa "financeirização" dos royalties: SERRA, Rodrigo Valente; FERNANDES, Ana Cristina. A distribuição dos royalties petrolíferos no Brasil e os riscos de sua "financeirização". Revista de Desenvolvimento Econômico - RDE, ano VII, n. 11, jan. 2005. Para Bercovici, essa venda de créditos de royalties "contraria e impossibilita qualquer política de desenvolvimento voltada para a diversificação produtiva e a adaptação da economia estadual para o período seguinte ao esgotamento dos recursos petrolíferos". BERCOVICI, Gilberto. Direito econômico do petróleo e dos recursos minerais cit., p. 339.

1267 Sobre o tema, vale consultar a Ação Cível Originária (ACO) n. ${ }^{\circ}$ 2178, que tramita perante o Supremo Tribunal Federal. Na ação, o estado do Espírito Santo reclama que a venda de seus créditos de royalties à União (ocorrida em 2003) restou econômica e financeiramente desequilibrada pela alta dos preços do petróleo nos anos seguintes. O Ministro relator, Luís Roberto Barroso, concedeu a medida liminar pleiteada, para determinar que a União, a ANP e o Banco do Brasil deixem de descontar os valores referentes ao contrato nos regulares repasses de royalties petrolíferos que promovem em benefício daquele Estado-membro. 
Há claro déficit de fiscalização e controle sobre tais receitas e despesas. ${ }^{1268-1269}$ Como colocam Bruno Cruz e Márcio Ribeiro, "não há transparência na alocação dos recursos e o controle, em especial daqueles destinados aos municípios, é bastante precário". ${ }^{1270}$

Logo, os constrangimentos impostos pela Lei n. 7.990/1989 ao gasto público da receita de royalties têm sido deveras ineficientes, para dizer o mínimo.

Que dizer, de outra banda, da qualidade desse gasto? Pode-se afirmar que, apesar do descumprimento daquelas vedações, há razões para acreditar que os entes políticos brasileiros têm aplicado a receita de royalties de forma a diversificar a economia ou a prover seus jurisdicionados com investimentos que, por seu longo alcance, justificam a explotação dos bens minerais?

Embora ausente um estudo mais aprofundado e compreensivo sobre o tema, as informações existentes certamente não indicam nesse sentido.

A título de exemplo, a Revista Exame apresentou matéria indicando a diminuta porcentagem dos royalties de petróleo investida, em contraste com a consumida pela máquina administrativa ("ampla gama de gastos que vão desde o cafezinho até a compra de remédios e gasolina para ambulâncias"). ${ }^{1271}$

Da mesma forma, Rodrigo Valente Serra reuniu alguns exemplos de gastos públicos extravagantes de municípios beneficiados com grandes transferências de royalties: os relatos incluem financiamento de times de futebol (em um caso contratando até os torcedores), escolas de samba, e até instalação de materiais de construção de luxo nos espaços públicos (“calçadão de porcelanato”). ${ }^{1272}$

${ }^{1268}$ ENRÍQUEZ. Maria Amélia. Mineração... cit., p. 335.

1269 MORGANDI, Matteo. Extractive industrie revenue distribution at the sub-national level: the experience in seven resource-rich countries. Revenue Watch Institute, 2008. p. 38: "Management of EIR at the subnational level presents challenges to transparency similar to those faced by central governments, with additional practical constraints due to the lack of 'infrastructure' to monitor both payments and expenditures. It is not only a question of 'will' to be transparent, but also of simple circulation of information, local capacity to understand the agreement, and coordination between agencies. In almost every country analyzed, the disclosure of full information about shared revenues up to the local level is either absent or incomplete".

1270 CRUZ, Bruno de Oliveira; RIBEIRO, Márcio Bruno. Sobre maldições e bençãos cit., p. 37.

1271 Disponível em: <http://exame.abril.com.br/revista-exame/edicoes/0892/noticias/veja-como-as-cidadesbrasileiras-investem-os-royalties-do-petroleo-m0128066>. Acesso em: 19 jun. 2011.

1272 SERRA, Rodrigo Valente. Rendas petrolíferas no Brasil: critérios de distribuição distorcidos induzem ineficiência do gasto. In: MENDES, Marcos (Org.). Gasto público eficiente cit., p. 231-232. 
São exemplos nítidos de consumo irresponsável dessa receita pública, que infringem as ideias que desenvolvidas nos capítulos anteriores, sejam elas ligadas aos interesses das futuras gerações, sejam ligadas à necessidade de evitar os efeitos deletérios da exploração, sejam ainda relacionadas à razão mesmo de explorar os bens minerais. Em vez de cobertos pelo véu da ignorância, sugerido por Rawls, os Administradores Públicos que assim procedem parecem estar sob o efeito de um "véu de opulência", ${ }^{1273}$ alheios aos benefícios arbitrários que os entes políticos receberam, e acreditando que podem e devem gozar desses benefícios sem atentar para aqueles que, hoje e amanhã, deixarão de fazê-lo.

Assim, há de se criticar a ausência de comandos impositivos para o melhor gasto das receitas de royalties brasileiras. $\mathrm{O}$ aspecto necessita ser endereçado pela legislação de regência, de forma a direcionar a aplicação desses recursos a espécies de gastos que não amesquinhem, especialmente, o caráter de finitude dos recursos minerais. Afinal, como observa Bercovici, "essas rendas podem ser facilmente dispersadas, quando deveriam seu utilizadas de modo que criassem ativos duráveis, para assegurar a sua continuidade". 1274

O só reconhecimento - para todos os fins - de que a receita pública deve ser classificada como de capital (consoante se pleiteia acima), entende-se, já seria largo passo nesse sentido: esta mudança interpretativa implicaria, no mínimo, deixar transparente a todos os analistas das contas públicas que esta receita, que tem em sua origem o desfazimento do patrimônio nacional, está (ou pode estar) sendo consumida, violando regra financeira das mais básicas, como nos lembra Jèze. ${ }^{1275}$

1273 A expressão "véu da opulência", em contraponto ao "véu da ignorância" rawlsiano, é de Bejamin Hale, para quem "nowadays, the veil of ignorance is challenged by a powerful but ancient contender: the veil of opulence. While no serious political philosopher actually defends such a device - the term is my own - the veil of opulence runs thick in our political discourse. Where the veil of ignorance offers a test for fairness from an impersonal, universal point of view - 'What system would I want if I had no idea who I was going to be, or what talents and resources I was going to have?' - the veil of opulence offers a test for fairness from the first-person, partial point of view: 'What system would I want if I were so-and-so?' These two doctrines of fairness - the universal view and the first-person view - are both compelling in their own way, but only one of them offers moral clarity impartial enough to guide our policy decisions [...] But the veil of opulence operates only under the guise of fairness. It is rather a distortion of fairness, by virtue of the partiality that it smuggles in". HALE, Benjamin. The veil of opulence. The New York Times, The opinion pages - the stone, 12 ago. 2012.

1274 BERCOVICI, Gilberto. Direito econômico do petróleo e dos recursos minerais cit., p. 29.

1275 "En principe, lês dépenses publiques doivent être payées avec le revenu du pays et non avec le capital national". JËZE, Gaston. Cours élémentaire de science des finances et de législation financière française cit., p. 379. 
Ainda com Serra, ${ }^{1276}$ é conveniente recordar que a Lei n. 7.990/1989, que trouxe as regras de constrangimentos dos entes públicos quanto ao gasto de royalties; assim como a Lei n. 8.001/1990 e mesmo a Lei n. 9.478/1997, que estabelecem a divisão federativa antes do regime de partilha; todas são fruto de período em que o tamanho da receita de royalties era diminuto, quase desimportante. Daí pode-se melhor compreender a ausência de maiores debates como o que se quer suscitar, sobre a qualidade do gasto.

Face à possível insuficiência persuasiva da só classificação de royalties como receitas de capital, impõe-se o estabelecimento de regras que vinculem e/ou afetem ${ }^{1277}$ as receitas decorrentes da exploração dos recursos naturais não renováveis aos fins que honrem a natureza especial dos bens explorados. Como se tem argumentado, "o maior desafio que o país tem pela frente concernente à exploração do pré-sal é o de evitar que a riqueza seja dilapidada e, no final de algumas décadas, não tenha sido substituída por um acréscimo no estoque de capital". ${ }^{1278}$

Impõe-se direcionar com maior firmeza o gasto público dos royalties, já que, como postulam Rodrigo Serra e Ana Cristina Fernandes, "o comprometimento dos recursos naturais não renováveis para a geração futura em função da extração atual é o ponto de partida para a questão da justiça intergeracional, pois se espera que esta renda gerada seja aplicada de forma a oferecer à geração futura uma fonte de renda alternativa, quando ocorre a exaustão do recurso". ${ }^{1279}$

Assim é que, apesar das críticas já deitadas à Lei n. 12.858/2013, é necessário também recordar seus aspectos positivos: ao vincular a receita de royalties a uma área entendida como prioritária - e que pode ser considerada como eficaz na superação do subdesenvolvimento, no engrandecimento das instituições públicas para as gerações futuras, e mesmo na promoção de atividades outras que não as extrativas/primárias -, a Lei

${ }^{1276}$ SERRA, Rodrigo Valente. Rendas petrolíferas no Brasil: critérios de distribuição distorcidos induzem ineficiência do gasto. In: MENDES, Marcos (Org.). Gasto público eficiente cit., p. 241.

1277 Sobre as diferenças entre vinculação e afetação, ver: SCAFF, Fernando Facury. Royalties decorrentes da exploração de recursos naturais não renováveis cit., p. 394 e ss.

1278 PIRES, Adriano; GIAMBIAGI, Fabio; LUCAS, Luiz Paulo Vellozo; SCHECHTMAN, Rafael. Conclusões e propostas para o setor. In: GIAMBIAGI, Fabio; LUCAS, Luiz Paulo Vellozo (Org.). Petróleo cit., p. 323. Vale notar que a obra referida é engajada com ideias liberais e pró-Estados Produtores (v. especialmente o artigo de Humberto Ribeiro Soares), diversas vezes conflitando com posições defendidas nesta dissertação. Isto, contudo, não impede de concordar com o trecho transcrito, que ademais efetivamente está em consonância com outras colocações diversas feitas acima.

1279 SERRA, Rodrigo Valente; FERNANDES, Ana Cristina. A distribuição dos royalties petrolíferos no Brasil e os riscos de sua "financeirização" cit., p. 34. 
impede que gastos extravagantes (como financiar um time de futebol e sua torcida) sejam livremente realizados.

Esta sorte de norma deve ser replicada no âmbito da CFEM, e melhorada em suas disposições também aos royalties petrolíferos, aplicada em todos os níveis federativos, e em relação a quaisquer espécies de regimes de exploração.

Cabe discordar, portanto, do então Presidente da República, quando do veto do dispositivo de vinculação dos royalties à educação (na Lei n. $12.351 / 2010^{1280}$ ), que ao fim e ao cabo veio a ser introduzido pela Lei n. 12.858/2013. O mandatário afirmou que, embora o Fundo Social busque "assegurar os benefícios intergeracionais decorrentes da exploração do pré-sal", "não é adequado fixar, previamente, quais as áreas a serem priorizadas".

Entende-se que, embora o Conselho Deliberativo do Fundo Social deva manter certa discricionariedade, é sim adequado vincular a receita a determinados setores, especialmente no que impede a tentação de utilizar essas verbas de forma ineficiente, irresponsável ou até mesmo eleitoreira. ${ }^{1281}$ É claro que as vinculações ou afetações legais devem direcionar o gasto, evitando o desperdício dessas receitas, mas sempre que possível, respeitando a necessária manutenção de um espaço de discricionariedade do Administrador público, evitando seu engessamento, que também é prejudicial: o trade off entre o direcionamento vinculante dos gastos e a liberdade discricionária do gestor público deve ser pesado cuidadosamente. Daí que se deve concordar com a afirmação de que "o desafio central é desenhar um mecanismo legal que proteja as decisões sobre temas fundamentais do FS (e.g. os objetivos do FS) contra mudanças discricionárias promovidas por seu órgão diretor - ou de outro agente institucional que tente impor arbitrariamente sua vontade - e

${ }^{1280}$ Previa: Art. 47. [...] $\S 2 .^{\circ}$ Do total da receita a que se refere o art. 51 [Fundo Social] auferida pelo Fundo de que trata o caput $50 \%$ (cinquenta por cento) devem ser aplicados em programas direcionados ao desenvolvimento da educação pública, básica e superior, sendo o mínimo de $80 \%$ (oitenta por cento) destinado à educação básica e infantil.

1281 Rodrigo Serra e Carla Patrão, referindo o impacto dos royalties nos entes municipais brasileiros, afirmam: "Também foram detectadas a ausência de vinculações destas receitas a quaisquer programas de governo municipal e a lacuna de mecanismos de controle social sobre os dispêndios patrocinados com os recursos dos royalties. Tais fragilidades, asseverou-se, dificultam em muito uma efetiva utilização dos royalties como instrumento de promoção de políticas de justiça intergeracional ao nível local. Políticas estas que deveriam preparar os municípios para o momento inevitável de obsolescência e/ou saída dos capitais envolvidos com a atividade de produção e exploração de petróleo e gás natural". SERRA, Rodrigo; PATRÃO, Carla. Impropriedades dos critérios de distribuição dos royalties no Brasil. In: PIQUET, Rosélia (Org.). Petróleo, royalties e região cit., p. 211. 
permita, ao mesmo tempo, flexibilidade na tomada de decisões que necessitem respostas rápidas (e.g. política de investimentos)". ${ }^{1282}$

Tudo para garantir, mais uma vez, que esse dinheiro não seja tomado por substituível com o dinheiro arrecadado de outras fontes; que não seja apenas um montante a mais no Erário - e assim passível de ser aplicado em rubricas que vulgarizam a própria natureza dos bens explorados e, por conseguinte, da receita pública decorrente dessa exploração.

\section{3.i. Transparência fiscal.}

Já se mencionou que, em obra destinada especificamente a estudos sobre os impactos da exploração dos recursos naturais não renováveis, ${ }^{1283}$ resultou claramente definido que, contra os diversos efeitos adversos usualmente causados pela atividade, recomendou-se maior transparência no setor, tanto no aspecto regulatório quanto - o que ora interessa - na gestão dos recursos públicos oriundos.

Afirmaram os organizadores da obra, em capítulo final que apresenta e resume as contribuições apresentadas por diversos autores, que a transparência merece uma "nota especial", eis que "um número notável de capítulos nesse volume identificou a importância da transparência na resolução dos múltiplos problemas que emanam das atividades de petróleo e gás. Isso é ainda mais impressionante já que os autores são oriundos de uma gama de diferentes profissões, disciplinas e perspectivas [...] Embora a teoria seja variada, as análises empíricas sustentam muito claramente o argumento por maior transparência". ${ }^{1284}$ Organizações internacionais, como as já referidas RWI, EITI e PWYP advogam fortemente a necessidade de transparência e abertura de informações.

Transparência, no dizer de Regis Fernandes de Oliveira, "significa que nada pode ficar escondido e às escuras. Tudo deve ser público e subordinado aos procedimentos formais e sociais de controle. Transparência é fundamentar as decisões e atos que as seguem, é motivar os comportamentos, é não agir de forma tresloucada, é utilizar-se de raciocínio persuasivo, é demonstrar as razões de sua conduta, é subordinar suas decisões

${ }^{1282}$ Relatório II. Fundos financeiros baseados em receitas de petróleo e gás cit., p. 141.

${ }^{1283}$ HUMPHREYS, Macartan; SACHS, Jeffrey D.; STIGLITZ, Joseph E. (Org.). Escaping the resource curse cit.

${ }^{1284}$ HUMPHREYS, Macartan; SACHS, Jeffrey D.; STIGLITZ, Joseph E. Future Directions for the Management os Natural Resources. In: HUMPHREYS, Macartan; SACHS, Jeffrey D.; STIGLITZ, Joseph E. (Org.). Escaping the resource curse cit., p. 328 e 331-332. Tradução livre. 
aos controles instituídos na Constituição e nas leis, buscar demonstrar os fundamentos das razões invocadas, é respeitar o diálogo, é aceitar a dissensão, é buscar o consenco pelo dissenso". ${ }^{1285} \mathrm{Ou}$, como coloca Flávio Rubinstein, especificamente sobre a transparência fiscal, esta "exige que as atividades financeiras do Estado sejam visíveis e mensuráveis para a sociedade, a quem deve ser assegurada a possibilidade tempestiva de compreender as políticas dotadas - e também as pretendidas - por todos os níveis de governo". ${ }^{286}$ Gilmar Mendes e Celso Correia Neto observam que se trata, a transparência fiscal, de "condição iniludível para que o súdito passe a cidadão e possa erigir-se à categoria de partícipe do processo político-decisório e fiscalizar a atuação do Poder Público”, pelo que "orienta a relação entre Estado e sociedade, determina um modo de ser da atuação pública e um horizonte a alcançar". ${ }^{1287-1288}$

São várias as formas com que tais noções de transparência se aplicam ao caso em estudo - a exploração dos recursos naturais não renováveis em uma perspectiva especialmente financeira. Ora, já se referiu à necessidade de adaptar a contabilidade pública para que demonstre claramente o capital nacional exaurido na exploração de recursos naturais não renováveis, de forma a deixar transparente a quantidade de ativos que é inviabilizada em contraponto à quantidade de investimentos feitos, permitindo conhecer,

1285 OLIVEIRA, Regis Fernandes de. Curso de direito financeiro cit., p. 519. Prossegue o autor: "A transparência é reflexo e e consequência dos princípios republicano e democrático. É sujeição à legalidade, à legitimidade e à moralidade. A transparência aceita a crítica, buscado a eficiência".

1286 RUBINSTEIN, Flávio. Notas sobre a transparência fiscal no direito financeiro. In: CONTI, José Maurício; SCAFF, Fernando Facury (Org.). Orçamentos públicos e direito financeiro cit., p. 871. Diz mais, o autor: "Por mais variadas que as definições pareçam, contudo, elas deixam claro que a transparência está sempre intimamente relacionada à noção de 'responsabilização', o que leva a inferir que a busca pela transparência tem como propósito permitir que os cidadãos, as empresas ou os governos sejam responsabilizados pelas respectivas atuações e políticas que venham a adotar. Nesse passo, a transparência pode ser compreendida como a disponibilização de informações, por parte de instituições, para aqueles sujeitos que desempenhem papel relevante na avaliação dessas mesmas instituições, o que pressupõe tanto o direito quanto a capacidade - por parte desses sujeitos - de articular as demandas de responsabilização, bem como a disposição daquelas instituições para prover tais informações. A transparência fiscal, especificamente, pode ser definida como a abertura à sociedade sobre a estrutura e as funções do governo, os objetivos da política fiscal e as contas e metas do setor público. Essa transparência envolve o acesso a informações confiáveis, abrangentes, tempestivas, inteligíveis e internacionalmente comparáveis sobre as atividades financeiras do Estado (sejam elas realizadas dentro ou fora do próprio setor público), para que o eleitorado e os agentes do mercado possam avaliar com precisão as posições fiscais dos governos e os verdadeiros custos e benefícios daquelas atividades, incluindo as respectivas implicações econômicas e sociais presentes e futuras".

1287 MENDES, Gilmar Ferreira; CORREIA NETO, Celso de Barros. Transparência fiscal. In: MARTINS, Ives Gandra da Silva; MENDES, Gilmar Ferreira; NASCIMENTO, Carlos Valder do (Coord.). Tratado de direito financeiro cit., v. 1, p. 178.

1288 Para outras caracterizações de transparência, especialmente nos aspectos de "acesso à informação", "política fiscal", "direito tributário" e "transparência fiscal internacional”, v.: DE SANTI, Eurico Marcos Diniz; CHRISTOPOULOS, Basile Georges; ZUGMAN, Daniel Leib; BASTOS, Frederico Silva (Coord.). Transparência fiscal e desenvolvimento: homenagem ao professor Isaias Coelho. São Paulo: FISCOSoft, 2013. 
por todas as suas dimensões, o impacto patrimonial-financeiro que legamos ao futuro. Não à toa, mencionou-se a doutrina de Alan Auerbach, Jagadeesh Gokhale e Laurence Kotlikoff, que propuseram uma "contabilidade geracional", em que se aplica método de medição do fardo financeiro que a geração atual deixa às futuras; ${ }^{1289}$ as opiniões de Peer Ederer, Philipp Schuller e Stephan Willms, que propõem um "Indicador de Sustentabilidade Econômica”; ${ }^{1290}$ e ainda a defesa, feita pelo Banco Mundial, da utilização do mecanismo batizado de "Genuine Savings". ${ }^{1291}$ Tanto na perspectiva ambiental quanto no âmbito voltado especificamente à exploração dos recursos não renováveis, são relevantes os debates sobre a necessidade de conhecer exatamente os impactos causados, e por isso mesmo desenvolver métodos que os revelem. Também por isso é que há quem defenda uma aproximação cada vez maior entre o direito e a contabilidade, chegando mesmo a propor a existência de um ramo específico da ciência jurídica destinado ao tema. $^{1292}$

De outro lado, "em todas as suas dimensões, a transparência fiscal também facilita e promove a disciplina fiscal e boa governança, em uma correlação positiva claramente sugerida por diversos estudos empíricos". ${ }^{1293}$

Se, com Furtado, entende-se que "a utilização intensiva de recursos esgotáveis é economicamente condenável sempre que sirva principalmente para financiar gastos correntes", ${ }^{1294}$ então parece evidente a necessidade de identificar plenamente o quanto de recursos esgotáveis é explorado em cada período, em contraste com os gastos públicos realizados e $o$ quê eles estão financiando.

Estas considerações, vale recordar, estão intrinsecamente relacionadas com a necessidade de se tratar - em matéria contábil, escritural, e mesmo em efetiva gerência dos

1289 AUERBACH, Alan J.; GOKHALE, Jagadeesh; KOTLIKOFF, Laurence J. Generational accounting: a meaningful way to evaluate fiscal policy cit.

${ }^{1290}$ EDERER, Peer; SCHULLER, Phillip; WILLMS, Stephan. The Economic Sustainability Indicator. In: TREMMEL, Joerg (Ed.). Handbook of intergenerational justice cit.

1291 "Adjusted net or genuine saving measures the true level of saving in a country after accounting for depreciation of produced capital; investments in human capital (as measured by education expenditures); depletion of minerals, energy, and forests; and damages from local and global air pollutants. Economic theory suggests that current net saving should equal the change in future welfare, specifi cally the present value of future changes in consumption". WORLD BANK. Where is the wealth of nations? Measuring capital for the $21^{\text {st }}$ century cit., p. 9.

${ }^{1292}$ Seria o "direito contábil" ou "direito da contabilidade pública", como relata Émerson Gomes. GOMES, Emérson César da Silva. Arts. 83 a 100. In: CONTI, José Maurício (Coord.). Orçamentos públicos cit., p. 290 e ss.

${ }^{1293}$ RUBINSTEIN, Flávio. Notas sobre a transparência fiscal no direito financeiro. In: CONTI, José Maurício; SCAFF, Fernando Facury (Org.). Orçamentos públicos e direito financeiro cit., p. 880.

${ }^{1294}$ FURTADO, Celso. Desenvolvimento e subdesenvolvimento cit., p. 94-95, nota de rodapé n. 07. 
valores - os royalties de recursos naturais não renováveis de forma apartada das demais receitas, especialmente as de impostos. Deve-se evitar, para utilizar termo de Maria Amélia Enriquez, a "armadilha do caixa único", ${ }^{1295}$ tomando por idênticos, no mesmo "caixa", as receitas públicas oriundas de diversas fontes, e assim fazendo-as indistinguíveis, substituíveis. ${ }^{1296-1297}$ Não se impõe, nesta seara, que diferentes contas bancárias recebam ambas as receitas; mas faz-se necessário, isto sim, que haja equivalência no trato, de forma que a quantidade de dinheiro que ingressa no caixa, oriunda de royalties, seja representada em gasto de mesma monta, este a observar orientações aplicáveis especificamente a tal espécie de receita pública.

Trazendo a preocupação com a transparência ao caso brasileiro (e voltado à exploração dos recursos naturais não renováveis), impõe-se reconhecer que, de uma perspectiva comparada, o Brasil anda bem nesse aspecto.

A organização Revenue Watch Institute publicou em 2010 um Índice ${ }^{1298}$ de transparência dos governos de 41 (quarenta e um) países onde é relevante a exploração de petróleo, gás, e minérios. Analisou-se a disponibilidade de informações sobre (i) acesso aos recursos naturais; (ii) geração de receita; ${ }^{1299}$ (iii) definições institucionais; (iv)

1295 Maria Amélia Enríquez alerta ao que cunhou como “armadilha do caixa único”: o perigo do o Ente, deixando de contabilizar separadamente as receitas de royalties, passa a utilizar tais verbas em despesas correntes: "a CFEM é um instrumento econômico que tem grande potencial para ajudar a contornar os problemas que os municípios mineradores enfrentam e, se bem aplicada, pode contribuir para a melhoria da eqüidade intergeracional na distribuição dos benefícios da extração mineral. [...] No entanto, esse instrumento está sub-utilizado por causa da 'armadilha do caixa único', ou seja, de problemas associados à governança” (ENRÍQUEZ. Maria Amélia. Mineração... cit., p. 364).

1296 Seguindo a ideia da "armadilha do caixa único": MORGANDI, Matteo. Extractive industrie revenue distribution at the sub-national level: the experience in seven resource-rich countries cit., p. 39. "Once the funds are paid into the local budget, there is rarely a separate accounting system to monitor how the funds are used. In this respect, an accounting system to trace the expenditure of EIRs would serve two purposes. On the financial management side, it would facilitate assessing whether the statutory earmarks are being enforced. On the policy side, separate accounting would enhance the understanding of the spending behavior of local governments, and, in select cases, it would allow the evaluation of the development outcomes of the individual projects" (idem, p. 39).

1297 Afirmam Steven Barnett e Rolando Ossowski: "the non-oil balance should feature prominently in the formulation of fiscal policy. Decomposing the overall balance into an oil and non-oil balance is critical for understanding fiscal policy developments, evaluating sustainability, and determining the macroeconomic impact of fiscal policy. Indeed, highlighting the non-oil balance in the budget would itself be an important step toward improving fiscal policy [...] an excessive focus on the overall balance often leads to fiscal policy (as measured by the non-oil balance) moving in tandem with oil revenue, resulting in a volatile non-oil fiscal deficit with the concomitant adverse macroeconomic and fiscal consequences" (BARNETT, Steven; OSSOWSKI, Rolando. Operational aspects of fiscal policy in oilproducing countries. In: DAVIS, J.; OSSOWSKI, R.; FEDELINO, A. (Org.). Fiscal policy formulation and implementation in oil-producing countries cit., p. 71-72).

1298 REVENUE WATCH INDEX 2010. Transparency: Governments and the oil, gas and mining industries cit.

1299 O quesito está assim descrito: "the availability of detailed information published by various government agencies on production and payments, as well as an assessment of its accessibility and frequency". 
empresas públicas; (v) fundos de recursos naturais; (vi) transferências subnacionais; e (vii) participação e cumprimento dos padrões estabelecidos pela EITI. Explicitamente, o Índice não analisou medidas de corrupção ou de abertura orçamentária. A cada uma dessas variáveis é dada uma nota que varia de 0 (zero) a 100 (cem), com o resultado final representando uma média das notas de todas as variáveis.

No documento, o Brasil foi eleito como o mais transparente do mundo, alcançando a nota final 97 (noventa e sete), tendo logrado no quesito "geração de receita", que ora mais interessa, nota 100 (cem). É dizer: o Índice aponta que no Brasil há quase perfeita transparência nos diversos aspectos do trato dos recursos naturais não renováveis. Vale mencionar, contudo, a objeção de George Anderson, de que a metodologia deste estudo "não captura bem a falta de transparência nas empresas petrolíferas nacionais ou nos governos, pelo que sua avaliação deve ser tratada com cautela". ${ }^{1300-1301}$

A mesma organização ampliou o escopo desse estudo em 2013. Não tratando mais apenas de transparência, mas também de responsabilização (accountability), este novo Índice avaliou em 58 (cinquenta e oito) países a "qualidade de quatro componenteschave de governança": (i) definições legais e institucionais; ${ }^{1302}$ (ii) práticas de relato de dados e informações; ${ }^{1303}$ (iii) salvaguardas e controles de qualidade; e (iv) ambiente capacitador (que utiliza medidas de accountability, efetividade da governança, estado de direito, corrupção e democracia). ${ }^{1304}$ Avaliou também a transparência das empresas

REVENUE WATCH INDEX 2010. Transparency: Governments and the oil, gas and mining industries cit., p. 3. O estudo afirma que enquanto é comum a publicação de dados operacionais ("information on reserves, production volumes, prices, exports, investment, costs, companies operating in the country and disaggregated production volumes"), a publicação de dados financeiros é menos frequente: "disaggregated information about financial payments received by governments, such as profit shares in PSCs or royalties, special taxes, dividends, bonuses and extraction fees are less likely to be disclosed. The average score for all the countries is 46.7 , and six countries do not publish this type of information". p. 20.

1300 ANDERSON, George. Reflections on oil and gas in federal systems. In: ANDERSON, George (Ed.). Oil \& gas in federal systems cit., p. 399. Tradução livre.

1301 Para Flávio Rubinstein não referindo especificamente aos Índices do Revenue Watch Institute, "os estudos internacionais acerca da transparência fiscal no Brasil, via de regra, analisam apenas dados do governo federal" (RUBINSTEIN, Flávio. Notas sobre a transparência fiscal no direito financeiro. In: CONTI, José Maurício; SCAFF, Fernando Facury (Org.). Orçamentos públicos e direito financeiro cit., p. 878).

1302 "The degree to which the laws, regulations and institutional arrangements facilitate transparency, accountability and open/fair competition" (RESOURCE GOVERNANCE INDEX 2013. A measure of transparency and accountability in the oil, gas and mining sector. Revenue Waych Institute, 2013, p. 6).

1303 "The actual disclosure of information by government agencies. Because de facto disclosures are the best indicator of transparency, this component receives a greater weight" (RESOURCE GOVERNANCE INDEX 2013. A measure of transparency and accountability in the oil, gas and mining sector. Revenue Waych Institute, 2013, p. 6).

1304 RESOURCE GOVERNANCE INDEX 2013. A measure of transparency and accountability... cit., p. 6. 
exploradoras estatais, dos fundos de recursos naturais, e das transferências de receitas aos entes subnacionais.

A análise do caso brasileiro limitou-se ao setor petrolífero. O Brasil ficou em 5. lugar (atrás de Noruega, Estados Unidos, Reino Unido e Austrália), tendo recebido pontuação final de 80 (oitenta), do total de 100 (cem) - um dos itens apontados como problemáticos foi a falta de publicação dos contratos firmados com particulares para a exploração petrolífera. ${ }^{1305}$ Nos quesitos de "definição legal e institucional" e de "práticas de relato", teve as pontuações 81 (oitenta e um) e 78 (setenta e oito), respectivamente, alcançando sua menor pontuação (66) no critério de "ambiente capacitador". Tais práticas aplicadas especificamente à Petrobras receberam nota 92 (noventa e dois) (3. ${ }^{a}$ maior). $\mathrm{Na}$ avaliação da governança das transferências intergovernamentais, o Brasil recebeu pontuação máxima, ficando em $1 .^{\circ}$ lugar.

Embora a pontuação brasileira tenha sido significativamente reduzida entre um e outro Índices, vale notar que as notícias ainda são alvissareiras, quando postas em comparação com outros países. Basta notar que, no documento de 2013, o Brasil ficou à frente, dentre outros, de México $\left(6^{\circ}{ }^{\circ}\right)$, Canadá $\left(7 .^{\circ}\right)$, Chile $\left(8 .^{\circ}\right)$, Índia $\left(12 .^{\circ}\right)$, Venezuela $\left(20{ }^{\circ}\right)$, África do Sul $\left(21 .^{\circ}\right)$, Rússia $\left(22 .^{\circ}\right)$, Botsuana $\left(30 .^{\circ}\right)$ e China $\left(36 .^{\circ}\right)$.

As práticas nacionais, que podem (e devem) ser questionadas como frequentemente ofertando transparência apenas formal, estão muito à frente de vários países mundo afora. Para ficar em dois exemplos, veja-se que o Fundo de Investimento para Estabilização Macroeconômica, criado pela Venezuela em 1998, não publica quaisquer relatórios financeiros tampouco divulga qual a composição de sua carteira de ativos. ${ }^{1306}$ O Fundo “Autoridade de Investimento de Abu Dhabi”, dos Emirados Árabes Unidos, atualmente o $3 .^{\circ}$ maior do mundo, ${ }^{1307}$ não divulga (dados de 2008) o tamanho do fundo, a estrutura do portfólio ou quaisquer informações sobre seu desempenho. ${ }^{1308} \mathrm{~A}$ título de comparação: no Brasil o Fundo Soberano têm relatórios de administração e de desempenho publicados periodicamente pela Secretaria do Tesouro Nacional. ${ }^{1309}$

A tudo isso somem-se as medidas de transparência fiscal geral, presentes no Brasil e que vêm sendo melhoradas. Como ensinam Helio Tollini e José Roberto Afonso,

1305 RESOURCE GOVERNANCE INDEX 2013. A measure of transparency and accountability... cit., p. 7.

1306 MORGAN, J. P. Sovereign wealth funds cit., p. 90.

1307 Disponível em: <http://www.swfinstitute.org/fund-rankings/>. Acesso em: 15 dez. 2013.

1308 MORGAN, J. P. Sovereign wealth funds cit., p. 23.

1309 Disponível em: <https://www.tesouro.fazenda.gov.br/pt/fundo-soberano-brasil/relatoriosmonitoramento>. Acesso em: 15 dez. 2013. 
"em conformidade com o contexto de sua época, as exigências de disciplina fiscal e transparência constantes da Lei n. 4.320 eram mínimas". ${ }^{1310}$ Mas tais disposição foram muito incrementadas através da Lei Complementar n. 101/2000.

A Lei de Responsabilidade Fiscal pôs a transparência como pressuposto de uma gestão fiscal responsável (art. $1^{\circ},{ }^{\circ}$ § $^{\circ}$ ); exigiu ampla divulgação dos dados fiscais da gestão pública (art. 48); impôs uma série de relatórios, que devem ser publicados periodicamente (art. 52, que trata do Relatório Resumido de Execução Orçamentária e art. 54, que trata do Relatório de Gestão Fiscal).

Em 2009, sobreveio a Lei Complementar n. 131, que, alterando a LRF, aumentou o número e o alcance dos métodos de transparência lá previstos, exigindo, por exemplo, "liberação ao pleno conhecimento e acompanhamento da sociedade, em tempo real, de informações pormenorizadas sobre a execução orçamentária e financeira, em meios eletrônicos de acesso público" (art. 48, parágrafo único, II), e demandando que todos os entes públicos brasileiros disponibilizem informações aos cidadãos quanto às respectivas receitas e despesas (art. 48-A). ${ }^{1311}$

Vale ainda mencionar que em 2012 entrou em vigor a Lei n. 12.527/2011 - Lei de Acesso à Informação -, que permite aos cidadãos requerer informações (não sigilosas, é claro) ao Estado. A norma obriga o gestor a fornecê-las, prevendo sanções para o descumprimento (ou cumprimento enviesado) dessa obrigação.

Eis, então, que a institucionalidade brasileira revela-se avançada quanto à transparência, sendo digna de elogios.

O que não significa, contudo, que não possa ou deva ser objeto de outras análises e de críticas que pugnem pelo incremento desses níveis de transparência. Em se tratando especificamente da governança dos royalties oriundos da exploração de recursos naturais não renováveis, é nela que se deve focar.

1310 TOLLINI, Helio Martins; AFONSO, José Roberto R. A Lei n. 4.320 e a responsabilidade orçamentária. In: CONTI, José Maurício; SCAFF, Fernando Facury (Org.). Orçamentos públicos e direito financeiro cit., p. 495.

1311 "Quanto à divulgação por meia da internet, é interessante observar que a criação dos Portais de Transparência dos diversos entes estatais, nos diferentes níveis de governo, tem proporcionado a experimentação social da relação cidadão-Estado e o exercício do controle social dos gastos públicos em novas perspectivas". MENDES, Gilmar Ferreira; CORREIA NETO, Celso de Barros. Transparência fiscal. In: MARTINS, Ives Gandra da Silva; MENDES, Gilmar Ferreira; NASCIMENTO, Carlos Valder do (Coord.). Tratado de direito financeiro cit., p. 194. 
Primeiro, cabe reafirmar a crítica já sinalizada acima: embora seja positivo e louvável que o país estabeleça critérios de publicação de informações financeiras e contábeis, a divulgação dos competentes números é rotineiramente levada a efeito de maneira apenas formal, não permitindo seu conhecimento materialmente eficaz. ${ }^{1312}$

As informações constantes dos Relatórios e dos Balanços são, especialmente quanto ao gasto público, imperscrutáveis ao cidadão de conhecimento médio, não afeito aos conceitos da contabilidade pública. ${ }^{1313}$

Embora os conceitos utilizados sejam muitas vezes definidos pelos princípios técnico-contábeis como forma de uniformização procedimental ${ }^{1314}$ - o que mais uma vez revela-se acertado ${ }^{1315}$-, impõe-se permitir também o acesso à informação de modo compreensível à sociedade civil - demandando, portanto, não apenas uma maior quantidade das informações, mas também uma maior qualidade da informação prestada. ${ }^{1316}$

${ }^{1312}$ Relatório do ICMM (Conselho Internacional de Mineração e Metais) sobre a mineração no Brasil aponta que: "independentemente da Lei de Responsabilidade Fiscal citada acima, persiste a percepção comum de transparência limitada e busca de vantagens econômicas pela via da ação política na gestão financeira pública do governo municipal, estimulada em parte pelos baixos salários entre os servidores públicos. Embora exista uma grande variabilidade no desempenho de um município para outro, foi notável os participantes do workshop terem considerado esta como uma das questões mais importantes que vão contra a ampliação dos benefícios da mineração". ICMM. O setor de mineração no Brasil: fortalecimento institucional para o desenvolvimento sustentável. Mineração: parcerias para o desenvolvimento. 2013. p. 75.

1313 Afirma Rubinstein: "ainda que no Brasil possa ser constatada uma rápida evolução na disponibilização de informações fiscais ao público, essa disponibilização não é acompanhada de mecanismos que facilitem a compreensão dos cidadãos, dificultando sobremaneira a efetiva utilização de tais informações no controle da atividade financeira do Estado [...] Afinal, sem a adoção de medidas efetivas que possibilitem a compreensão das informações disponibilizadas, essas informações acabam tomando a forma de documentos empilhados em depósitos (virtuais ou reais), impondo à sociedade a árdua $\mathrm{e}$ custosa tarefa de procurar os dados relevantes no meio de bits infinitos [...] Como a experiência brasileira comprova, pilhas virtuais de documentos com informações fiscais serão de pouca valia para os cidadãos a menos que estes tenham a habilidade de compreender tais informações, algo bastante complexo quando se tem em vista a linguagem excessivamente técnica que costuma marcar as operações fiscais". RUBINSTEIN, Flávio. Notas sobre a transparência fiscal no direito financeiro. In: CONTI, José Maurício; SCAFF, Fernando Facury (Org.). Orçamentos públicos e direito financeiro cit., p. 900, 901 e 905 .

${ }^{1314}$ Cabendo lembrar, contudo, que mesmo estes critérios técnicos são passíveis de debate e de críticas materiais por serem ou não os "melhores" para representar as finanças públicas. Nesse sentido: AUERBACH, Alan J.; GOKHALE, Jagadeesh; KOTLIKOFF, Laurence J. Generational accounting: a meaningful way to evaluate fiscal policy cit., p. 73-75.

1315 "Do ponto de vista empírico, a mensuração da transparência fiscal traz algumas complicações intrínsecas. Primeiramente, como se viu, a definição de transparência apresenta variações consideráveis no corpo de estudos sobre o tema. Além disso, há um elevado grau de subjetivismo nas medições práticas, uma vez que elas costumam ser baseadas nas percepções de entrevistados. Esses problemas, contudo, podem ser mitigados pela adoção de uma definição objetiva e estreita de transparência fiscal". RUBINSTEIN, Flávio. Notas sobre a transparência fiscal no direito financeiro. In: CONTI, José Maurício; SCAFF, Fernando Facury (Org.). Orçamentos públicos e direito financeiro cit., p. 875-876.

${ }^{1316}$ MENDES, Gilmar Ferreira; CORREIA NETO, Celso de Barros. Transparência fiscal. In: MARTINS, Ives Gandra da Silva; MENDES, Gilmar Ferreira; NASCIMENTO, Carlos Valder do (Coord.). Tratado de direito financeiro cit., p. 179. 
Como alertam James Otto et alii, a apresentação das informações (incluindo as inumeráveis possíveis relações entre a informação apresentada e outras, relevantes) é também mui relevante à sua compreensão. ${ }^{1317}$ As normas e demonstrações devem ser acessíveis.

Assim, é de se notar que são de fácil compreensão e livre publicação as informações quanto às receitas de royalties - sua quantidade e sua distribuição aos entes subnacionais. Os sítios do DNPM e da ANP oferecem dados suficientes nesse sentido. ${ }^{1318}$

Contudo, quando se pretende saber $o$ quê tais receitas estão financiando, o mesmo já não é verdadeiro. Ainda que seja possível, especialmente após a Lei Complementar n. 131/2009, investigar um a um os gastos de determinado governo municipal, a ausência de distinção entre a gestão financeira ordinária e aquela ligada aos royalties conduz à impossibilidade de identificação do direcionamento que é dado à verba.

Vale considerar que a só mudança interpretativa defendida acima - que passa a considerar as receitas de royalties como receitas de capital - já seria um grande passo nesse sentido: obrigando os entes públicos a destacar esta do grande grupo de receitas tributárias permitiria ver com muito maior clareza o patrimônio público que é explotado, mas utilizado em custeio da máquina. Essa medida isolada, contudo, deixaria ainda a desejar, demandando maior controle e emparelhamento entre estas receitas - que por todas as razões já apresentadas acima, merece consideração específica - e os gastos que se fazem possível a partir dela.

1317 "The data or information disclosed must answer the questions being asked. For instance, government officials, political leaders, and other members of the public may not find the numerical value of taxes paid and received relevant. It is more relevant to report taxes paid as a percentage of total taxes or as a percentage of revenues paid or received. Similarly, information and data on production, payroll, social expenditure, and other indicators of the benefit streams produced by a mining operation are more relevant if they are put into context. For instance, the value of production has more relevance if reported as a percentage of total GDP; the relevance of employment is enhanced if reported in relation to local employment overall. This is often just a matter of presentation, and in most instances making such adjustments is simple. In other instances, however, compilation and analysis of additional data may be required. Disclosing information in a relevant way allows for those outside of the industry to better understand the importance of the revenues and benefit streams" (OTTO, James; ANDREWS, Craig; CAWOOD, Fred; DOGGETT, Michael; GUJ, Pietro; STERMOLE, Frank; STERMOLE, John; TILTON, John. Mining royalties cit., p. 242).

1318 Cabe, contudo, uma nota quanto à divulgação da receita: muitos entes políticos (com amparo legal - art. $11, \S 4 .^{\circ}$, da Lei n. 4.320/1964) utilizam da rubrica "cobrança da dívida ativa" sem especificações quanto à natureza da receita. Trata-se de evidente quebra da racionalidade do tema: tratar-se de cobrança de dívida ativa não diz nada a respeito do quê está sendo arrecadado; mas apenas de como isto ocorre. Basta referir que, no entendimento hoje vigente no Poder Executivo Federal (em que os royalties são considerados receitas correntes), pode-se incluir nessa rubrica grande parte da receita de royalties, sem que ela esteja discriminada ou identificada, o que se revela manifestamente equivocado. $\mathrm{O}$ mesmo se diga, também, em relação à arrecadação de taxas, em que é relevante contrapor a arrecadação do tributo com o gasto público na área que em teoria está sendo financiada por ele. 
De outra banda, merecem críticas, também, a série de movimentos contábeis levados a efeito nos últimos anos, visando atingir metas fiscais de superávit primário, prática que ficou conhecida por "contabilidade criativa". ${ }^{1319}$

Tais ações, muitos afirmam, prejudicam a credibilidade da política fiscal brasileira, causando clima de desconfiança internacional. ${ }^{1320}$

Nada obstante, o tema não seria mencionado nesta oportunidade não fosse a participação da Petrobras nessa intrincada teia contábil. Como referiu Delfim Netto, "a recente ‘quadrangulação’ para cumprir o superávit primário foi uma deplorável operação de alquimia. A repetição desses 'truques contábeis' está construindo uma relação incestuosa entre o Tesouro Nacional, a Petrobras, o BNDES, o Banco do Brasil e a Caixa Econômica Federal". ${ }^{1321}$

A atuação da companhia petrolífera brasileira no assunto se deu através da cessão onerosa, ocorrida em 2010 através da Lei n. 12.276, de grande quantidade (até cinco bilhões) dos barris de petróleo do pré-sal. Cedidos os barris, a Petrobras pagou à União com ações societárias próprias. A "quadrangulação" acima referida se deu através do BNDES e do Fundo Soberano, que adquiriram mais ações da companhia, abrindo espaço para pagamento da dívida desta com a União, e assim gerando mais receita à União.

Representantes do governo federal sustentaram que a utilização do Fundo Soberano nessas ações importou exatamente no cumprimento de seu objetivo anticíclico. O tema pode ser melhor explorado por economistas e contabilistas. Contudo, ao que ora

1319 "Um dos sinais no êxito na aplicação da LRF é a obtenção de uma sequência ininterrupta de resultados que atendem às metas fiscais fixadas para o país, em especial de geração de superavit primário. Apesar desse sucesso, a LRF não foi suficiente para impedir que alguns entes da federação recorressem à chamada 'contabilidade criativa' para ajudá-los a atingir suas metas. Em 2010, o próprio governo federal adotou prática não convencional, ao registrar como receita primária recursos obtidos de empresa estatal por intermédio de triangulação financeira feita com o BNDES. A existência dessas brechas, por vezes em valores significativos, é um indício de que os mecanismos de controle fiscal previstos na LRF precisam ser aprimorados" (TOLLINI, Helio Martins; AFONSO, José Roberto R. A Lei n. 4.320 e a responsabilidade orçamentária. In: CONTI, José Maurício; SCAFF, Fernando Facury (Org.). Orçamentos públicos e direito financeiro cit., p. 495).

1320 "Não obstante a sofisticação da legislação brasileira de direito financeiro nesse ponto [controle da dívida pública], recentes práticas fiscais do governo federal têm mitigado a transparência do gerenciamento da dívida pública federal. Entre as referidas práticas fiscais pouco transparentes, merecem destaque: (a) os chamados 'papagaios' (compromissos financeiros assumidos com credores que não são instituições bancárias, os quais deixam de ser contabilizados pelo Banco Central na mensuração da dívida pública; (b) a permissão de abatimento da parcela do investimento público do cálculo do superávit primário, introduzida em 2005 pelo Ministério da Fazenda; (c) a antecipação de dividendos das empresas estatais, que aumentam a receita e, por conseguinte, o resultado primário; (d) a capitalização da Petrobras efetuada no segundo semestre de 2010" (RUBINSTEIN, Flávio. Notas sobre a transparência fiscal no direito financeiro. In: CONTI, José Maurício; SCAFF, Fernando Facury (Org.). Orçamentos públicos e direito financeiro cit., p. 893-894).

1321 DELFIM NETTO, Antonio. Valor Econômico, 15 jan. 2013. 
interessa, resta notar que a utilização de (antecipações de) receitas oriundas de recursos naturais não renováveis nessa complexa engenharia, ${ }^{1322}$ fazendo-a joguete para alcance de melhores resultados conjunturais, não pode ser louvada, mais uma vez recordando-se a natureza diferenciada desses bens públicos, e da receita oriunda de sua exploração, o que vai contra sua utilização por instrumentos financeiro-bancários.

No mais, o tema está envolto em operações opacas, que por vezes não significam, materialmente, o que sua forma sugere. Está aí um típico exemplo de falta de transparência, que precisa ser endereçado e evitado.

O Fundo Monetário Internacional fez publicar um guia de transparência direcionado às receitas de recursos naturais. ${ }^{1323}$ Tomando-o por referência, vê-se que as práticas brasileiras deixam de observar várias das proposições lá contidas, o que demanda melhoras ainda no trato do tema no Brasil. Note-se:

O guia afirma a necessidade de apresentação clara e compreensível das bases de incidência dos tributos e royalties. ${ }^{1324}$ Mas no caso brasileiro, especificamente voltado à CFEM, vê-se que assim não ocorre. A incidência dos royalties da mineração se vê cercada de um sem-número de conceitos confusos, basicamente relacionados à sua base de cálculo, ${ }^{1325}$ estabelecida no art. $6 .^{\circ}$ da Lei n. 7.990/1989, como sendo o "faturamento líquido resultante da venda do produto mineral, obtido após a última etapa do processo de beneficiamento adotado e antes de sua transformação industrial", e acrescida pela Lei $n$. 8.001/1990 para que se entenda por faturamento líquido "o total das receitas de vendas, excluídos os tributos incidentes sobre a comercialização do produto mineral, as despesas de transporte e as de seguros". ${ }^{1326}$ Ainda, o Decreto Executivo n. 01/1991, que deveria

1322 "O efeito de tal operação financeira, portanto, foi o de antecipação de receitas públicas futuras, oriundas da exploração de petróleo, para fazer frente a despesas correntes presentes”. RUBINSTEIN, Flávio. Notas sobre a transparência fiscal no direito financeiro. In: CONTI, José Maurício; SCAFF, Fernando Facury (Org.). Orçamentos públicos e direito financeiro cit., p. 894, nota de rodapé n. 114.

1323 INTERNATIONAL MONETARY FUND. Guide on resource revenue transparency cit.

1324 Idem, ibidem, p. 19-24.

1325 Mas não apenas a base de cálculo traz controvérsias. Outros aspectos da incidência ainda são muito debatidos, como prescrição e decadência. Sobre o tema, v.: SCAFF, Fernando Facury; SILVEIRA, Alexandre Coutinho da. CFEM - normas aplicáveis à decadência e à prescrição. In: SOUZA, Marcelo Mendo Gomes de (Coord.). A compensação financeira pela exploração de recursos minerais cit.

1326 Exemplo claro dessa confusão conceitual diz respeito à dedução do ICMS da base de cálculo da CFEM A Lei refere que será deduzido o tributo incidente sobre a comercialização do produto mineral. A questão que muito se debate é: que quer dizer ICMS incidente? O DNPM entende (e assim aplica) que, face ao princípio da não-cumulatividade, ICMS incidente é representado pelo produto das operações escriturais de crédito e débito do tributo no final do mês-competência (Orientação Normativa n. 05/2012). Os concessionários, por outro lado, vêm há muito afirmando que o dispositivo legal (quando fala em incidência do ICMS) importa em deduzir o imposto diretamente objeto da operação comercial - 
regulamentar os conceitos, trouxe ainda mais insegurança na análise do tema tanto pelos interessados (particulares concessionários da exploração mineral) quanto por quaisquer interessados em conhecer a quantificação da CFEM, por exemplo, quando afirmou que por "processo de beneficiamento" deve-se entender aquele caracterizado por diversas formas de trato dos produtos minerais extraídos, "desde que não resulte na descaracterização mineralógica das substâncias minerais processadas ou que não impliquem na sua inclusão no campo de incidência do Imposto sobre Produtos Industrializados (IPI)". O critério da descaracterização mineralógica, para piorar ainda mais a compreensibilidade do tema, após anos sendo utilizado pelo DNPM, foi sumariamente descartado como inválido e ineficaz pelo mesmo órgão, através da Orientação Normativa n. 07/2012. ${ }^{1327}$

O guia do Fundo Monetário Internacional, ainda, recomenda que a política de extração de recursos naturais (aí incluída a taxa de exploração, os objetivos fiscais e econômicos desta, e os objetivos de sustentabilidade fiscal de longo prazo) deve ser plenamente incorporada pelas normas orçamentárias. ${ }^{1328-1329}$ Este tipo de relação não tem sido observada no ambiente orçamentário. Tomando de análise o Plano Plurianual 20122015 (Lei n. 12.593/2012) e a Lei de Diretrizes Orçamentárias 2013 (Lei n. 12.708/2012), vê-se que não há qualquer conexão com a política de exploração dos recursos naturais não renováveis. Não há menção às quantidades de exploração ou seus objetivos. Não há previsões que digam especificamente com a receita pública oriunda dessa exploração. Não há qualquer referência à sustentabilidade financeira nacional, a partir da exaustão destes ativos. O Plano Nacional de Mineração 2030 - que prevê, por exemplo, que "a política de royalties para a mineração no Brasil deve ter como meta contribuir para a conversão de

valor resultante da aplicação da alíquota sobre a base de cálculo -, sendo equivocado falar em apuração de créditos e débitos.

${ }^{1327}$ No mesmo sentido é a crítica de Jack Calder: "Resource tax legislation often confers considerable discretion on tax officials, in which case it needs to be reviewed to make it more objective and specific and remove discretions [...] So legislation needs to be backed up by publication of authoritative administrative guidance setting out how any remaining discretions will be exercised and how general principles in tax law will be interpreted and applied in practice [...] Companies may not agree with departmental interpretations set out in such publications, but will often put up with them so long as they are properly explained and do not come as a nasty surprise [...] Clear and explicit legislation achieves nothing if tax auditors are then free to misapply and misinterpret it". CALDER, Jack. Resource tax administration: the implications of alternative policy choices. In: DANIEL, Philip; KEEN, Michael; McPHERSON, Charles (Ed.). The taxation of petroleum and minerals cit., p. 367-368.

${ }^{1328}$ INTERNATIONAL MONETARY FUND. Guide on resource revenue transparency cit., p. 35-37.

${ }^{1329}$ Cabendo recordar, com Émerson Gomes, que "para as empresas, o relatório ou balanço anual é o documento financeiro mais importante. Para os governos, este documento costuma ser ignorado, tanto por insiders quanto por outsiders. É o orçamento anual que assume posição central, pois é a culminação do processo político. O orçamento é o documento que engloba as decisões políticas da organização". GOMES, Emérson César da Silva. Arts. 83 a 100. In: CONTI, José Maurício (Coord.). Orçamentos públicos cit., p. 287-288. 
uma riqueza não renovável, dada a exaustão de uma jazida mineral, em valor constante e sustentável para a sociedade", ${ }^{1330}$ e que prevê a "proposição de políticas para estimular formas de organização produtivas que ampliem os benefícios gerados pela mineração em prol do desenvolvimento regional, em articulação com os estados e municípios"1331 - não é sequer referido nas mencionadas normas orçamentárias.

Assim, o que se quer frisar é que, nada obstante o Brasil esteja bem colocado nas comparações internacionais quanto ao nível de transparência no trato dos recursos naturais não renováveis e as receitas públicas dele decorrentes, ainda há diversas e substanciais melhoras que necessitam ser instaladas, tendo em vista algumas práticas ainda marcadas pela opacidade, no sistema fiscal pátrio.

Especialmente, impõe-se que à sociedade seja dado conhecer com exatidão os dados relacionados à exploração dos recursos naturais não renováveis, para que possa efetivamente tomar parte no processo de tomada de decisões sobre a exploração desses bens e, principalmente, sobre a aplicação da receita pública decorrente dessa exploração.

Apenas com o conhecimento amplo dessas questões é que será possível, também, compreender quantitativa e qualitativamente o impacto levado a efeito no patrimônio nacional e, de outro lado, a magnitude da receita e demais benefícios fiscais e econômicos conseguidos pela exploração - assim viabilizando igualmente que as decisões presentes considerem de forma adequada o legado deixado às gerações futuras.

3.j. Uma crítica aos novos marcos regulatórios das explorações mineral e petrolífera. Oportunidades desperdiçadas. Ausência de regras que tragam as futuras gerações ao debate.

Por fim, cabe observar como as modificações legislativas brasileiras recentes têm endereçado o tema da governança dos royalties de recursos naturais não renováveis, especialmente em face das diversas questões que foram colocadas acima.

Vale recordar que: (i) em 2010, no rastro da descoberta de grandes quantidades de petróleo do pré-sal, foram promovidas vastas mudanças nas normas que regulam a exploração petrolífera, instituindo o regime de partilha, criando o Fundo Social da União,

${ }^{1330}$ MME - MINISTÉRIO DE MINAS E ENERGIA (BRASIL). Plano Nacional de Mineração 2030 Geologia, mineração e transformação mineral. Brasília, 2013. p. 65.

1331 Idem, ibidem, p. 131. 
modificando o rateio federativo para reduzir os valores destinados aos Estados e Municípios produtores e afetados e redistribuir estes valores na sistemática assemelhada aos Fundos de Participação, dentre outros; e (ii) em 2013, o Governo Federal finalmente submeteu ao Poder Legislativo a proposta de nova lei para reger a exploração dos recursos minerais, acabando com a regra de prioridade, criando uma agência de mineração, aumentando as alíquotas da CFEM, alterando sua base de cálculo (que passaria a ser a "receita bruta de venda"), e mantendo as regras de rateio federativo da receita de royalties, fortemente concentrada nos Municípios produtores.

Face às questões acima apreciadas, deve-se notar que a legislação do petróleo trouxe avanços. A criação de um Fundo, tanto no aspecto intergeracional quanto no anticíclico, representa uma melhora em relação ao regramento anterior, no que busca enfrentar alguns dos efeitos deletérios da exploração, referidos na literatura internacional, bem como no que demonstra preocupação com os interesses das gerações pósteras.

Contudo, esses avanços são tímidos. Como já se argumentou, a montagem do Fundo não traz reais melhorias a não ser que esteja acompanhado de regras de disciplina de longo prazo, evitando o saque dos valores poupados a cada pressão ocasional. Não é o que parece estar ocorrendo, tendo em vista a já estabelecida autorização legal para dispor do valor principal do Fundo, agravada pela ausência de um prazo objetivo para que isto cesse.

O projeto de novo marco legal da mineração, por sua vez, não traz quaisquer disposições, sequer marginalmente, capazes de enfrentar os temas em debate.

Em ambos os casos, não há disposições que destaquem o caráter diferenciado das receitas de royalties de recursos naturais não renováveis; não há vinculações, afetações ou direcionamentos quaisquer dos gastos públicos dessa receita; não há referêcias ao fato inafastável de que tal exploração importa, ao fim e ao cabo, em redução do patrimônio nacional; não há referências à interpretação atual - equivocada - de que tais receitas são correntes; não são feitas conexões entre a exploração desses bens e as razões mesmas pelas quais essa exploração deve ocorrer; a revisão do rateio federativo dessa receita, quando ocorrida, não observa a necessidade de priorização da União, como arguido acima; ${ }^{1332}$ tampouco esse rateio observa critérios de esforço fiscal, dessa forma possibilitando a

1332 Vale concluir com Rodrigo Serra e Sérgio Gobetti: "as regras vigentes para o rateio e a aplicação dos royalties estão, de fato, contribuindo para o empecilho de nosso desenvolvimento". SERRA, Rodrigo Valente; GOBETTI, Sérgio Wulff. Petróleo, royalties e desenvolvimento: Brasil e experiências internacionais. In: MONIE, Frédéric; BINSZTOK, Jacob (Org.). Geografia e geopolítica do petróleo cit., p. 173. 
vulgarização dessas receitas pelos entes beneficiados, que podem (e frequentemente o fazem) tratá-la como mera substituta da receita tributária; não há disposições que se destinem ao incremento da transparência da exploração, arrecadação e gasto.

Então, salvo pontualmente (como na criação do Fundo Social), as questões referidas nos itens anteriores não foram postas no centro dos debates. O Estado brasileiro centrou as discussões em itens especialmente regulatórios e arrecadatórios, deixando a segundo plano, quando não ignorando totalmente, a necessidade de dar-se tratamento financeiro diferenciado às receitas de royalties.

O debate do rateio dos royalties petrolíferos deixou isso muito claro. Muito se discutiu - e ainda discute, agora no plano judicial - sobre a partilha dessa receita pública. Contudo, a legislação deixou de fornecer parâmetros sobre a governança dessa receita e sobre o seu respectivo gasto.

Apenas em 2013 - ainda referindo especificamente os royalties petrolíferos - é que sobreveio a Lei n. 12.858, que teve o mérito de orientar a despesa privilegiando a educação (e assim o investimento em capital humano) e a saúde. Mas que ao mesmo tempo o fez de forma lata, deixando de oferecer parâmetros para que, dentro do sistema educacional, a verba seja utilizada efetivamente de forma a criar capacidades - cabendo recordar que já existem significativas vinculações constitucionais ao setor, e que nem por isso os índices educacionais nacionais têm melhorado na velocidade e qualidade desejadas, indicando que não apenas com destinações do Erário é que serão incrementados. Quer-se fixar, pois, que muito embora a preocupação com a destinação da verba de royalties seja louvável e mereça registro, ela necessita estar acompanhada de regras que direcionem, dentro do sistema educacional, aqueles recursos ao efetivo desenvolvimento das crianças e jovens brasileiros, tanto quanto possível evitando seu gasto em consumo imediato irresponsável; deve zelar não só pela quantidade do dinheiro remetido à educação, mas igualmente à qualidade do gasto público vinculado ao setor.

O projeto de Código Minerário, por sua vez, andou bem pior. Não só ignorou quase completamente quaisquer questões relacionadas à despesa pública como, no que tratou do tema, limitou-se a repetir as vedações já existentes (pagamento de dívidas e quadro permanente de pessoal) - que já se referiu serem notadamente insuficientes -, ratificando ainda a autorização para uso da receita em pagamento de dívida interna, assim permitindo que a natureza específica dos royalties seja tangenciada, confundindo-se com a receita oriunda de contração de dívida. Sequer há incentivos à verticalização da produção, 
o que incentivaria a agregação de valor no país, o desenvolvimento de tecnologia e capacitação de pessoal, e que poderia ser defendido como vantajoso à estratégia de superação do subdesenvolvimento.

Foi essa a conclusão, também, de estudo desenvolvido pela Consultoria Legislativa do Senado Federal voltado especificamente para o referido Projeto de Lei: “A sociedade é ignorada pelo PL, que é omisso quanto a questões de extrema relevância, como o licenciamento socioambiental, o pacto intergeracional e a transformação da CFEM em benefícios efetivos para a sociedade". ${ }^{1333}$

\section{O substitutivo apresentado em novembro/2013 pelo Deputado Federal} Leonardo Quintão (PMDB/MG) tampouco andou muito melhor nesse sentido. Manteve as vinculações a órgãos da União (já criticadas acima), fazendo a partilha federativa alcançar os Municípios não produtores, mas afetados - deixando, contudo, a prioridade da destinação aos entes políticos locais. Manteve as frouxas vedações à utilização da receita, incluindo a autorização para fazer frente a dívida interna. Andou bem, contudo, no que propôs a instalação de mais e melhores instrumentos de transparência e controle social, estabelecendo que os entes subnacionais deverão, anualmente, "prestar contas anuais da aplicação da parcela da CFEM a eles destinada" (art. 68, §5. ${ }^{\circ}$ ); e prevendo a criação de "conselhos de representação da sociedade e do setor produtivo, paritariamente compostos, para fins de acompanhamento da aplicação dos recursos da CFEM” (art. 68, §6. ${ }^{\circ}$ ).

Então, vistos os tímidos avanços mencionados, ao pouco ou nada disporem sobre as especificidades da exploração dos recursos naturais não renováveis e das receitas públicas oriundas dessa exploração, tais normas desperdiçam oportunidades de preencher lacunas relevantes da governança pública dos royalties. ${ }^{1334} \mathrm{Com}$ tudo o que se quis apresentar acima, vê-se que o ordenamento brasileiro ainda é deveras falho em reconhecer

1333 BUSTAMANTE, Luiz Alberto da Cunha; CAVALCANTE FILHO, João Trindade; BIATO, Márcia Fortuna; GOMES, Carlos Jacques Vieira. Análise do Projeto de Lei de Marco Regulatório da Mineração do Brasil. Brasília: Núcleo de Estudos e Pesquisas/CONLEG/Senado, 2013. Texto para discussão n. 137, p. 80.

1334 Referindo especialmente a partilha espacial dos royalties no Brasil, Rodrigo Serra e Carla Patrão afirmam no mesmo sentido acima proposto - de desperdício de oportunidades para melhor debater o tema: "Com a manutenção da forma atual de distribuição dos royalties entre os municípios, sustentada pelo próprio estado, a continuidade da atividade de exploração de petróleo em nossa plataforma continental - com duração estimada de pelo menos três décadas - pode forjar a configuração de novas metrópoles sujeitas às velhas mazelas de nosso histórico de urbanização. Seria uma grande perda de oportunidade, portanto, o Estado fechar-se ao debate sobre os efeitos da polarização e outras conseqüências danosas, subjacentes à distribuição dos royalties no Brasil, sob o risco de retornar ao tema como indutor de políticas compensatórias". SERRA, Rodrigo; PATRÃO, Carla. Impropriedades dos critérios de distribuição dos royalties no Brasil. In: PIQUET, Rosélia (Org.). Petróleo, royalties e região cit., p. 211. 
o tratamento diferenciado que é devido a tais receitas públicas; o amplo debate aberto por tais normas, no Poder Legislativo e ademais em toda a sociedade, poderia e deveria endereçar tais questões, mas deixou de fazê-lo.

Especialmente, o ordenamento brasileiro ressente-se de normas que tragam os interesses das futuras gerações ao debate, o que se impõe quando o tema é a exploração de bens finitos, e o que se nota na doutrina de John Rawls e seu princípio da poupança justa e Edith Brown Weiss com a noção de equidade intergeracional.

Afinal, como observa Paul Collier, "de longe a decisão mais importante a ser tomada diz respeito à proporção de receitas de recursos naturais que deve ser poupada". ${ }^{1335}$ E isto a atual legislação mineraria não traz, tampouco os Projetos de novos marcos; e a legislação da exploração petrolífera traz apenas timidamente e, como se vê a esta altura, de forma suficientemente frouxa a já ter sido alterada antes da construção do Fundo Social.

Ao deixar de trazer as gerações pósteras ao debate, então, os novos marcos legais do petróleo (este com a ressalva da criação do Fundo Social, já mencionada) e da mineração incentivam a utilização insustentável dessa receita, tomando-a como "mais uma" no Erário, substituível pela receita de impostos. Tudo o que, arguiu-se, é de ser combatido, porque ignora os caracteres intrínsecos da exploração de bens não renováveis, que envolve baixas no patrimônio da União.

O trato - necessariamente diferenciado - dessas receitas públicas necessita ser endereçado. Nesse sentido, convém recordar a sugestão de Fernando Facury Scaff pela criação de um "Código de Receitas Públicas", visando "harmonizar as relações federativas" ${ }^{1336}$ no plano da arrecadação, inclusive das receitas patrimoniais. A ideia é positiva no que permite referir o tema diretamente, afirmando no que essa arrecadação será conduzida de forma específica e no que será conduzida tal e qual a arrecadação das demais receitas públicas. Mas, em qualquer caso, ultrapassando a insegurança atual, onde diferentes normas (legais e infralegais) são chamadas a reger a cobrança de royalties, havendo debate até mesmo sobre quais as regras aplicáveis. Tome-se de exemplo o debate sobre prescrição e decadência de CFEM, onde são múltiplas a interpretações sobre os

${ }^{1335}$ COLLIER, Paul. Laws and codes for the "resource curse". Yale Journal of Law and Human Rights, v. 11. Disponível em: <http://50.57.111.125/archive_2011/files/PCollier_LawsandCodes_Yale_0.pdf>. Acesso em: 30 dez. 2013.

1336 SCAFF, Fernando Facury. Royalties decorrentes da exploração de recursos naturais não renováveis cit., p. 364-365. 
prazos incidentes: ${ }^{1337}$ seja optando por aplicar os mesmos prazos da receita tributária, seja optando por impor-lhes prazos diferentes, o "Código de Receitas Públicas" teria a virtude imediata de sanar dúvidas. E, ao fazê-lo, de considerar (especialmente nos debates legislativos) individualmente cada um dos tipos de receita, fixando-lhe as regras, mesmo que para afirmar uma unidade normativa

Contudo, não apenas no campo da arrecadação é que os royalties merecem maiores considerações. Toda a governança pública dessas receitas merece ser debatida em particular, desde a arrecadação, passando pelo gerenciamento e orçamentação, até o gasto público, que deve respeitar e honrar a natureza própria da exploração.

Vale considerar que há pelo menos 02 (dois) bons exemplos de trato específico da matéria, em (i) Gana e (ii) São Tomé e Príncipe.

O primeiro (Gana) estabeleceu em 2011 a Lei de Gerenciamento das Receitas de Petróleo (n. 815/2011), ${ }^{1338}$ trazendo disposições sobre contabilidade, arrecadação, transparência e gasto dessas receitas públicas, buscando o estabelecimento das melhores práticas internacionais (especialmente tendo como base a governança norueguesa) e expressamente tendente a evitar os efeitos da maldição dos recursos naturais. ${ }^{1339}$ A Lei criou Fundos de estabilização e poupança para o trato das receitas, prevendo ainda as normas básicas de seu funcionamento, inclusive privilegiando os investimentos dos Fundos dentro do país, e não remetendo a contas estrangeiras - o que pode ser objeto de crítica tendo em vista os riscos já mencionados, especialmente cambiais, associados à manutenção desse capital em solo nacional; e também regulou as interconexões entre o orçamento nacional geral e aquele voltado diretamente às receitas petrolíferas. ${ }^{1340}$

1337 Sobre o tema, ver: SCAFF, Fernando Facury; SILVEIRA, Alexandre Coutinho da. CFEM - normas aplicáveis à decadência e à prescrição. In: SOUZA, Marcelo Mendo Gomes de (Coord.). A compensação financeira pela exploração de recursos minerais - CFEM cit.

$1338 \mathrm{O}$ texto da lei, em língua inglesa, pode ser encontrado em: <http://www.revenuewatch.org/sites/default/files/Final\%20Petroleum\%20Revenue\%20Mgmt\%20Bill\%2 0July.pdf>. Acesso em: 22 dez. 2013.

1339 "Experts have described Ghana's Revenue Management Act - passed more than a year after the first oil was pumped from the country's Jubilee Field - as an "innovation." The law outlines clear mechanisms for collecting and distributing petroleum revenue. It specifies what percentage should help fund the annual budget, what should be set aside for future generations and what should be invested for a rainy day". DOVI, Efam. Ghana's 'new path' for handling oil revenue: Seeking to avoid the ill effects of Africa's resource "curse". Online African Renewal, janeiro/2013. Disponível em: <http://www.un.org/africarenewal/magazine/january-2013/ghana\%E2\%80\%99s-\%E2\%80\%98newpath\%E2\%80\%99-handling-oil-revenue>. Acesso em: 22 dez. 2013.

1340 "The Petroleum Revenue Management Bill provides a strong framework for managing Ghana's petroleum revenues. It provides (i) a clear system of controls for the collection of oil revenues and their allocation to the budget and the proposed stabilization and savings funds, (ii) a clear division of responsibilities among authorities, and (iii) strong transparency provisions. We would recommend 
Em São Tomé e Príncipe, uma lei direcionada à governança das receitas oriundas da exploração petrolífera existe desde o final do ano de $2004 .{ }^{1341}$ A Lei obriga a criação de uma conta específica para tais receitas, identifica quais são essas receitas, expõe como devem ser os depósitos (eletrônicos, direto na conta especificamente destinada ao trato do assunto), dispõe sobre as regras para saque da conta (inclusive visando a suavização dos repasses ao Governo), estipula o valor de todas as reservas petrolíferas do país (o que faz a partir das estimativas de quantidade e tomando uma média histórica de preços dos 10 anos anteriores), estabelece um Fundo, dando-lhe regras gerais de gerenciamento, funcionamento e atuação (inclusive dos investimentos feitos a partir dele, por exemplo vedando a possibilidade de que os investimentos se dêem dentro do território nacional), veda que sejam tomados empréstimos contra as receitas petrolíferas, cria órgãos internos de supervisão e controle da governança dessas receitas (como uma Comissão de Supervisão do Petróleo, composta por membros do governo e da sociedade civil, com poderes investigativos e administrativos, além de limitados poderes judicantes), prevê medidas de transparência e responsabilização (a conta nacional do petróleo é submetida a auditoria dupla, pelo Auditor Geral e por auditores internacionais externos), exigindo ampla (pela internet) e compreensiva divulgação dos dados financeiros (permitindo que assim não ocorra apenas nos casos legais de confindencialidade, sujeitando a pessoa que assim o classificar às responsabilidades legais), impõe penas para as más condutas relacionadas à governança das receitas do petróleo, dispõe sobre possíveis conflitos de interesses entre autoridades governamentais e empresas exploradoras, e exige que todos os

consideration of limited changes or additions: 1. Adoption of a withdrawal rule from the stabilization fund aligned with overall revenue shortfall but still limited to no more than 30-40 percent in any fiscal year of the then existing fund. 2. Limited further clarification of the minimum information about the funds to be made public and the buttressing of the funds strong disclosure provisions with a legislative mandate that all contracts be made public. 3. Clarifying the rules on withdrawals from the Heritage Fund, to provide a coherent, rule-based system for accessing any portion of this endowment for future generations. 4. In separate legislation provisions for the appropriate capitalization of the national oil company to avoid dependence upon annual budgetary appropriations. Finally, we reiterate the priority need to utilize petroleum revenue to increase domestic investment for long-run economic growth and development. In addition to the present legislation, this requires developing a detailed and costed development plan and medium term fiscal framework aligned with annual budgets to define the role of the extractive sector for Ghana's development strategy and guarantee the utilization of the resource windfall for productive investment in human capital and infrastructure". BELL, Joseph C.; HELLER, Patrick R. P.; HEUTY, Antoine. Comments on ghana's petroleum Revenue management Bill. Revenue Watch $\quad$ Institute, 2010.2 Disponível em: <http://www.revenuewatch.org/sites/default/files/Ghana_revenue_management_brief_final.pdf $>$. Acesso em: 22 dez. 2013.

${ }^{1341} \mathrm{O}$ texto da lei pode ser encontrado em: <http://www.parlamento.st/Lei/lrpetro.zip>. Acesso em: $22 \mathrm{dez}$. 2013. 
contratos sejam dotados de cláusula de não corrupção (incluindo o dever do particular concessionário de divulgar todos os pagamentos realizados). ${ }^{1342}$

É claro que a só existência de uma Lei não significa seu cumprimento estrito. Qualquer que seja a institucionalidade formalmente adotada, ela não será capaz de produzir efeitos benéficos se não estiver acompanhada de instrumentos que garantam a sua observância e, especialmente, de um panorama em que a sociedade civil exija e os governantes sintam-se compelidos a executar os mandamentos normativos.

Tampouco está-se a defender que normas como as de Gana ou São Tomé e Princípe (ou, para esses fins, da Noruega, Chile, Botsuana, ou qualquer outro país) sejam transpostas ao Brasil. Afinal, é imperativo reconhecer que "one size does not fit all". ${ }^{1343}$

Nada obstante, através dessas Leis, aqueles países levaram a debate - não apenas no Legislativo, mas no seio da sociedade - questões centrais da governança dessas receitas, e que têm como pressuposto básico a ideia, já aqui referida diversas vezes, de que não podem ou devem ser tratadas como outras quaisquer; que têm caracteres especiais, que por sua vez devem ser incorporados ao trato da questão. Gana e São Tomé e Príncipe debateram estas questões, chegando às conclusões expostas nas respectivas Leis.

O Brasil, contudo, salvo em itens específicos (como o Fundo Social), não o fez. Desperdiçou oportunidades de conduzir esse debate, e assim de honrar a natureza específica dos royalties decorrentes da exploração de recursos naturais não renováveis.

Os recentes marcos legais petrolífero e mineral (este ainda aguardando apreciação no Legislativo), nesse sentido, merecem crítica.

1342 BELL, Joseph C.; FARIA, Teresa Maurea. Critical issues for a revenue management law. In: HUMPHREYS, Macartan; SACHS, Jeffrey D.; STIGLITZ, Joseph E. (Org.). Escaping the resource curse cit., p. 288-309.

1343 BELL, Joseph C.; FARIA, Teresa Maurea. Critical issues for a revenue management law. In: HUMPHREYS, Macartan; SACHS, Jeffrey D.; STIGLITZ, Joseph E. (Org.). Escaping the resource curse cit., p. 287. 


\section{CONCLUSÃO}

Buscou-se ao longo da dissertação fixar dois eixos de análise para a governança brasileira das receitas públicas oriundas da exploração dos recursos naturais não renováveis. São eles: (i) os frequentes, embora não inevitáveis, efeitos deletérios dessa exploração; e (ii) a perspectiva intergeracional, que decorre do caráter intrínseco de finitude dos bens explorados e da consequente impossibilidade de as gerações posteriores utilizarem destes mesmos bens, é demandada por diferentes fontes - pela razão mesmo da exploração desses recursos (apresentada especialmente com a doutrina de Celso Furtado), pelas lições da economia dos recursos naturais (acima representada em Harold Hotelling, Robert Solow e John Hartwick), e pela filosofia política de John Rawls e sua paradigmática noção de justiça.

A atenção aos interesses das futuras gerações - tratada como equidade intergeracional por Edith Brown Weiss ou ainda como solidariedade ou isonomia entre gerações - exige que a sustentabilidade (não apenas ambiental, mas também econômicofinanceira) seja incluída nos debates relacionados à exploração dos recursos naturais não renováveis. E, como a referida exploração implica redução do patrimônio nacional, recebendo o Estado brasileiro valores em moeda - os royalties -, então o viés financeiro da sustentabilidade deve ser relevado. É através dele, pelo uso que é dado à receita pública, que se respeitam ou se desprezam as futuras gerações, que afinal não estão presentes a participar democraticamente da tomada de decisões atual.

Então, o Direito Financeiro é chamado a atuar. A necessidade de observar uma perspectiva intergeracional está prevista na Constituição Federal de 1988, dirigindo-se ao meio ambiente e também ao âmbito jurídico-financeiro.

Bem fixados os eixos de análise, foi possível partir à avaliação de alguns aspectos do ordenamento jurídico brasileiro quanto à governança dos royalties.

A conclusão a que se chega é que o Brasil não está - sob os pontos de vista da exploração dos recursos naturais não renováveis e da equidade intergeracional adequadamente aparelhado para a governança dessas receitas públicas. As instituições brasileiras, apesar de significativos avanços recentes, não estão desenhadas de forma a honrar com as especificidades dos royalties, que são transformação de ativos patrimoniais 
brasileiros em capital, e que por isso mesmo não podem ser tratados como "mais uma" receita, indistinta da oriunda da arrecadação de tributos e demais receitas públicas.

Para assim afirmar, convém isolar alguns aspectos dessa governança nacional.

A repartição federativa dos royalties - no que pesadamente direciona valores aos entes subnacionais produtores, no caso da CFEM; destacadamente prioriza os entes subnacionais produtores no caso dos royalties petrolíferos; e pulveriza o montante arrecadado entre todos os entes subnacionais, em regime assemelhado ao dos Fundos de Participação, também no caso dos royalties petrolíferos (embora movimento recente tenha incluído a União com maior participação do que na legislação anterior) - prejudica a promoção da diversificação produtiva, o que a um só tempo deixa o país mais vulnerável aos efeitos da chamada maldição dos recursos naturais e embaraça os interesses das futuras gerações, especialmente considerando que tal diversificação representa uma das principais formas de transformar a riqueza mineral em riqueza duradoura, reprodutível. Ainda, no que amarra parte da arrecadação de royalties a órgãos como o DNPM e o IBAMA, igualmente deixa de promover a diversificação produtiva (faz justamente o oposto, retroalimentando o sistema exploratório) e estimula a utilização dessa receita com custeio da máquina pública, tudo o que é equivocado, se visto sob os ângulos de análise propostos.

Ainda relacionado à partilha federativa dos royalties, mas de forma algo distinta, é de se observar que o ordenamento brasileiro não considera, para definição do quantum de transferências, critérios que considerem o esforço fiscal dos entes subnacionais. Assim, permite que os entes federativos receptores dessas verbas banalizem a receita de royalties, até mesmo substituindo, na prática, tais receitas pelas receitas tributárias próprias - conduta esta que é fartamente descrita como potencialmente nociva à economia e é prejudicial às gerações pósteras já que, ao fazê-lo, o ente político promove o consumo dos royalties, não os aplicando para geração de novas riquezas ou investindo-os para um proveito prolongado no tempo. Receitas públicas tributárias (bem como outras receitas patrimoniais) e receitas públicas de royalties de recursos naturais não-renováveis não são intercambiáveis: cada uma tem caracteres específicos, que devem ser observados na governança que lhes é dada.

A classificação financeiro-orçamentária da receita pública de royalties também é problemática: ao afirmar tratar-se de receita corrente, o Estado brasileiro direciona (embora não limite) o gasto desses valores em despesas igualmente correntes, estas que se 
destinam especialmente ao custeio da máquina pública e não têm impacto patrimonial, portanto não recompondo os bens minerais explorados. Ao deixar de reconhecer tais receitas como de capital - o que efetivamente são -, o Estado brasileiro nega a característica intrínseca da exploração, que diz com a certa finitude dos bens explorados. E deixa de observar os interesses das futuras gerações, no que dificulta o uso desse dinheiro público em investimentos capazes de perenizar a riqueza.

Como mencionado, a classificação que é dada à receita de royalties implica um direcionamento (paralelismo) do gasto. Mas não apenas através deste direcionamento é que o Estado brasileiro coage o gestor público. O faz também através de vedações. Especialmente, impede-se que tais receitas sejam utilizadas para pagamento de pessoal e para quitação de dívidas. Mas vê-se que tais vedações têm sido frouxas: são facilmente contornadas, inclusive por meio de Leis ou Medidas Provisórias, valendo mencionar a autorização legal que foi dada aos Estados da federação para transacionarem com a União créditos de royalties a serem recebidos no futuro. A ausência de regras (e de procedimentos de cumprimento das regras preexistentes) que comandem a utilização dessa receita de forma a beneficiar as futuras gerações é também passível de crítica.

Cabe mencionar também que o Brasil teve recentemente e ainda tem boas oportunidades de trazer tais questões ao centro do debate: as vastas mudanças, já efetivadas, da legislação relativa à exploração petrolífera; e o novo marco legal da mineração, ainda em debate perante o Poder Legislativo. Contudo, estas normas - salvo exceções referidas abaixo - focaram questões regulatórias e arrecadatórias, deixando de lado a governança da receita pública. Ao deixar de dispor sobre o assunto, o Estado brasileiro perde excelente oportunidade de promover o respeito à não renovabilidade dos bens explorados (e suas consequências), exigindo que o trato dado às respectivas receitas incorpore esta particularidade.

De maneira indiretamente relacionada à governança dos royalties de recursos naturais não renováveis, mas frontalmente ligada à noção constitucionalmente protegida de equidade intergeracional, deve-se recordar também que o Brasil não possui índices dirigidos à compreensão do valor do patrimônio não renovável explorado, então inviabilizando o desenho de políticas que atentem especificamente para os níveis de exploração, relacionando-os com os objetivos nacionais perseguidos, e com o impacto que a exploração exerce sobre as gerações futuras. Tampouco o Brasil mantém instituições 
quaisquer (como os casos referidos da Hungria e de Israel) destinadas a participar do processo de tomada de decisões atual defendendo os interesses das gerações vindouras.

Mas nem só críticas são merecidas à governança dos royalties no país. Como referido, alguns avanços significativos nesse tema foram feitos.

Merece referência a criação do Fundo Social da União, criado em consonância com boas práticas e promissora literatura internacional, e que busca gerir as receitas de royalties segundo princípios especificamente voltados à natureza específica dessa receita; mas deve ser criticada sua insegurança institucional, eis que já teve sua estrutura deveras alterada antes mesmo de sua efetiva entrada em operação, permitindo o saque de seu valor principal sem o estabelecimento de um prazo compreensivo para a cessação de tal prática.

A destinação do valor do Fundo à educação (maior parte) e à saúde também merece elogios, especialmente quanto à primeira: trata-se de investimento público em capital humano, a elevar as liberdades pessoais, qualificando os cidadãos para o exercício de outras atividades produtivas; mas seu estabelecimento se deu de modo abrangente, sem garantir o uso das verbas em gastos estruturais, permitindo pois que velhos problemas (como a drenagem dos valores ao custeio, sem repercussões geracionais) se façam presentes.

Ainda, é importante notar que a transparência fiscal, frequentemente referida como item dos mais relevantes da governança dos royalties, é fortemente observada no Brasil, alcançando boas notas nas análises de órgãos internacionais. E especialmente desde 2001, com a Lei de Responsabilidade Fiscal, o tema tem sido rotineiramente reforçado. Não é o caso, contudo, de afirmar que o país alcançou situação em que nada mais existe a corrigir; há melhorias substanciais a serem alcançadas, especialmente relacionados à compreensibilidade dos documentos fiscais publicados e viabilidade de cruzamento dessas informações com outras relacionadas à exploração dos recursos naturais não renováveis, que permitam a qualquer cidadão participar do processo decisório.

Por estas razões, reitera-se que no Brasil, apesar dos avanços recentes, vários aspectos da governança das receitas públicas de recursos naturais não renováveis ainda precisam ser melhor endereçados e debatidos, visando dar-lhes tratamento que impeça a ocorrência dos efeitos deletérios da exploração, e que observe os interesses das futuras gerações, que não participam do processo democrático atual. 


\section{REFERÊNCIAS BIBLIOGRÁFICAS}

ABRAHAM, Marcus. Curso de direito financeiro brasileiro. Rio de Janeiro: Elsevier, 2010.

ACOSTA, Andrés Mejía. The impact and effectiveness of accountability and transparency initiatives: the governance of natural resources. Disponível em: <http://eiti.org/files/the\%20impact\%20and\%20effectiveness $\% 20$ of\%20accountability $\% 20$ and\%20transparency\%20initiatives.pdf>. Acesso em: 2 set. 2013.

AFONSO, José Roberto Rodrigues. FPE: rateio sem critério, Observatório da jurisdição constitucional, Brasília: IDP, ano 3, 2009-2010.

; ARAÚJO, Erika Amorim; NÓBREGA, Marcos Antonio Rios da. O Imposto Predial e Territorial Urbano (IPTU) no Brasil: um diagnóstico sobre o grau de aproveitamento do imposto como fonte de financiamento local. Final paper. Lincoln Institute of Land Policy, fev. 2010.

; GOBETTI, Sérgio Wulff. Rendas do petróleo no Brasil: alguns aspectos fiscais e federativos. Revista do BNDES, Rio de Janeiro, v. 15, n. 30, p. 231 - 269, dez. 2008.

AGIUS, Emmanuel. Intergenerational justice. In: TREMMEL, Joerg (Ed.). Handbook of intergenerational justice. Cheltenham, UK: Edward Elgar, 2006.

AHMAD, Ehtisham; CRAIG, John. In: TER-MINASSIAN, Teresa (Ed.). Fiscal federalism in theory and practice. Washington: International Monetary Fund, 1997.

; MOTTU, Eric. Oil revenue assignments: country experiences and issues. In: DAVIS, J.; OSSOWSKI, R.; FEDELINO, A. (Org.). Fiscal policy formulation and implementation in oil-producing countries. Washington, D.C.: International Monetary Fund, 2003.

; SEARLE, Bob. On the implementation of transfers to subnational governments. In: AHMAD, Ehtisham; BROSIO, Giorgio. Handbook of fiscal federalism. Cheltenham: Edward Elgar Publishing, 2006.

AHMED, Abdelkader Sid. Celso Furtado e o desenvolvimento a partir da exportação de recursos naturais não renováveis. In: FURTADO, Celso. Ensaios sobre a Venezuela: subdesenvolvimento com abundância de divisas. Rio de Janeiro: Contraponto, 2008. 
ALMEIDA, Carlos Otávio Ferreira de. O planejamento financeiro responsável: boa governança e desenvolvimento no Estado contemporâneo. In: CONTI, José Maurício; SCAFF, Fernando Facury (Org.). Orçamentos públicos e direito financeiro. São Paulo: RT, 2011.

ALMEIDA, Mansueto. Despesa com educação no Brasil - 1. 2013. Disponível em: <http://mansueto.wordpress.com/2013/09/05/despesa-em-educacao-no-brasil-1/>. Acesso em: 7 dez. 2013.

AMARAL JÚNIOR, Alberto do. Comércio internacional e a proteção do meio ambiente. São Paulo: Atlas, 2011.

AMAZONAS, Mauricio de Carvalho. Valor e meio ambiente: elementos para uma abordagem evolucionista. 2001. Tese (Doutorado) - Faculdade de Economia da Universidade Estadual de Campinas.

ANDERSON, George. Reflections on oil and gas in federal systems. In: (Ed.).

Oil \& gas in federal systems. Ontario: Oxford University Press, 2012. . Una introducción al federalismo. Trad. Isabel Vericat y Celorio Morayta. Madrid: Marcial Pons, 2008.

ANDRADE, Cesar Augusto Seijas de. Orçamento deficitário. In: CONTI, José Maurício; SCAFF, Fernando Facury (Org.). Orçamentos públicos e direito financeiro. São Paulo: RT, 2011.

ANNAN, Kofi A. Foreword. Africa Progress Report 2013: Equity in extractives stewarding Africa's natural reosurces for all. Africa Progress Panel, 2013.

ARROW, Kenneth et al. Are we consuming too much?. Journal of Economic Perspectives, 118, n. 3, 2004.

ARVATE, Paulo; MATTOS, Enlinson; ROCHA, Fabiana. Flypaper effect revisited: evidence for tax collection efficiency in Brazilian municipalities. Estudos econômicos, 2011, v. 41, n. 2, ISSN 0101-4161. Disponível em: <http://dx.doi.org/10.1590/S010141612011000200002>. Acesso em: 9 dez. 2013.

ASFAHA, Samuel G. National revenue funds: their efficacy for fiscal stability and intergenerational equity. International Institute for Sustainable Development, 2007. Disponível em: <http://ssrn.com/abstract=1032877>. Acesso em: 7 set. 2013. 
ASHEIM, Geir B.; BUCHHOLZ, Wolfgang. The hartwick rule: myths and facts. CESifo Working Paper Series, n. 299, jun. 2000. Disponível em: $<$ http://ssrn.com/abstract=258960>.

ASSUNÇÃO, Matheus Carneiro. Repartição das receitas tributárias no federalismo fiscal brasileiro: os critérios de rateio dos fundos de participação. 2013. Dissertação (Mestrado) - Faculdade de Direito da Universidade de São Paulo. São Paulo: Universidade de São Paulo.

ATALIBA, Geraldo. Apontamentos de ciência das finanças, direito financeiro e tributário. São Paulo: RT, 1969. . Hipótese de incidência tributária. 6. ed. São Paulo: Malheiros, 2008.

ATTAS, Daniel. A transgenerational difference principle. In: GOSSERIES, Axel; MEYER, Lukas H. (Coord.). Intergenerational justice. New York: Oxford University Press, 2009.

AUERBACH, Alan J.; GOKHALE, Jagadeesh; KOTLIKOFF, Laurence J. Generational accounting: a meaningful way to evaluate fiscal policy. The Journal of Economic Perspectives, v. 8, n. 1, 1994.

AUERBACH, Bruce E. Unto the thousandth generation: conceptualizing intergenerational justice. New York: Peter Lang, 1995.

; REINHART, Michelle. Antonin scalia's constitutional textualism: the problem of justice to posterity. Intergenerational Justice Review, n. 01, p. 17-22, 2012.

AUTY, Richard M. Natural resources, capital accumulation and the resource curse. Ecological Economics, 2007, n. 61, p. 630.

- Natural resources, development models and sustainable development. Environmental Economics Programme Working Paper, n. 03-01, 2003.

AUTY, Richard M. Sustaining development in mineral economies: the resource curse thesis. New York: Routledge, 1993.

AVI-YONAH, Reuven S. Os três objetivos da tributação. Trad. Luís Flávio Neto. Revista Direito Tributário Atual, n. 22, São Paulo: Dialética, 2008.

AYALA, Patryck de Araújo. A proteção jurídica das futuras gerações na sociedade do risco global: o direito ao futuro na ordem constitucional brasileira. In: LEITE, José 
Rubes Morato; FERREIRA, Heline Sivini; BORATTI, Larissa Verri (Org.). Estado de direito ambiental: tendências. 2. ed. Rio de Janeiro: Forense Universitária, 2010.

Direito e incerteza: a proteção jurídica das futuras gerações no estado de direito ambiental. 2002. Dissertação (Mestrado) - Faculdade de Direito da Universidade Federal de Santa Catarina.

BALEEIRO, Aliomar. Uma introdução à ciência das finanças. 16. ed. rev. e atual. Dejalma de Campos. Rio de Janeiro: Forense, 2004.

BALTHAZAR, Ezequiel Antonio Ribeiro. Fundos constitucionais como instrumento de redução das desigualdades regionais na federação. In: CONTI, José Maurício (Org.). Federalismo fiscal. Barueri: Manole, 2004.

BARACHO, José Alfredo de Oliveira. Teoria geral do federalismo. Rio de Janeiro: Forense, 1986.

BARBOSA, Alfredo Ruy. A natureza jurídica da concessão para exploração de petróleo e gás natural. In: PIRES, Paulo Valois (Org.). Temas de direito do petróleo e do gás natural II. Rio de Janeiro: Lumen Juris, 2005.

BARNETT, Steven; OSSOWSKI, Rolando. Operational aspects of fiscal policy in oilproducing countries. In: DAVIS, J.; OSSOWSKI, R.; FEDELINO, A. (Org.). Fiscal policy formulation and implementation in oil-producing countries. Washington, D.C.: International Monetary Fund, 2003.

BARROSO, Luís Roberto. Federalismo, isonomia e segurança jurídica: inconstitucionalidade das alterações na distribuição de royalties do petróleo. Parecer. 2010. Disponível em: <http://s.conjur.com.br/d1/parecer-luis-roberto-barrosoroyalties.pdf>. Acesso em: 30 nov. 2013.

BAUNSGAARD, Thomas; VILLAFUERTE, Mauricio; POPLAWSKI-RIBEIRO, Marcos; RICHMOND, Christine. Fiscal frameworks for resource rich developing countries. IMF Staff Discussion Note SDN/12/04. 2012.

BECKER, Gary. S. 1968. Crime and punishment: an economic approach. Journal of Political Economy, 76 (2): 169-217.

BECKERMAN, Wilfred. The impossibility of a theory of intergenerational justice. In: TREMMEL, Joerg (Ed.). Handbook of intergenerational justice. Cheltenham, UK: Edward Elgar, 2006. 
BELISÁRIO, Ana Carolina Valladares. A natureza jurídica da compensação financeira pela exploração de recursos minerais - CFEM. In: SOUZA, Marcelo Mendo Gomes de (Coord.). A compensação financeira pela exploração de recursos minerais - CFEM. Belo Horizonte: Del Rey, 2011.

BELL, Joseph C.; FARIA, Teresa Maurea. Critical issues for a revenue management law. In: HUMPHREYS, Macartan; SACHS, Jeffrey D.; STIGLITZ, Joseph E. (Org.). Escaping the resource curse. New York: Columbia University Press, 2007.

; HELLER, Patrick R. P.; HEUTY, Antoine. Comments on ghana's petroleum Revenue management Bill. Revenue Watch Institute, 2010. Disponível em: <http://www.revenuewatch.org/sites/default/files/Ghana_revenue_management_brief_f inal.pdf>. Acesso em: 22 dez. 2013.

BERCOVICI, Gilberto. Dilemas do estado federal brasileiro. Porto Alegre: Livraria do Advogado, 2004.

. Direito econômico do petróleo e dos recursos minerais. São Paulo: Quartier Latin, 2011.

. Política econômica e direito econômico. Revista Fórum de Direito Financeiro e Econômico, v. 1, 2012.

BEREIJO, Álvaro Rodríguez. El significado jurídico del deber constitucional de pagar impuestos. Revista de direito tributário, São Paulo: Malheiros, n. 113, 2011.

BIRD, Richard M. Local and regional revenues: realities and prospects. In: VAILlANCOURT, François (Ed.). Perspectives on fiscal federalism. Washington: The World Bank, 2006.

Subnational taxation in developing countries: a review of the literature. World Bank Policy Research Working Paper Series, n. 5.450, 2010.

; VAILLANCOURT, François. Introduction and summary. In:

VAILlANCOURT, François (Ed.). Perspectives on fiscal federalism. Washington: The World Bank, 2006.

BIRDSALL, Nancy; SUBRAMANIAN, Arvind. Saving Iraq from its oil. Foreign Affairs, n. $83[4])$. 
BIRNBACHER, Dieter. Responsibility for future generations - scope and limits. In: TREMMEL, Joerg (Ed.). Handbook of intergenerational justice. Cheltenham, UK: Edward Elgar, 2006.

. What motivates us to care for the (Distant) Future? In: GOSSERIES, Axel; MEYER, Lukas H. (Coord.). Intergenerational justice. New York: Oxford University Press, 2009.

BLEISCHWITZ, Raimund. Forget "the resource curse". Resource hope is on the ascent. United Nations News \& Commentary Global News: Forum, 2013. Disponível em: $<$ http://www.undispatch.com/forget-the-resource-curse-resource-hope-is-on-theascent>. Acesso em: 23 dez. 2013.

BLIACHERIENE, Ana Carla; FUNARI, Marcos Hime; RIBEIRO, Renato Jorge Brown. Natureza jurídica do Fundo Soberano brasileiro e do Fundo Fiscal de investimentos e estabilização. Revista Fórum de Direito Financeiro e Econômico - RFDFE, Belo Horizonte, ano 1, n. 1, 2012.

BLOOM, Paul. The baby in the well. The New Yorker. 20 de maio de 2013.

BOADWAY, Robin. Intergovernmental redistributive transfers: efficiency and equity. In: AHMAD, Ehtisham; BROSIO, Giorgio. Handbook of fiscal federalism. Cheltenham: Edward Elgar Publishing, 2006.

; KEEN, Michael. Theoretical perspectives on resource tax design. In: DANIEL, Philip; KEEN, Michael; McPHERSON, Charles (Ed.). The taxation of petroleum and minerals: principles, problems and practice. New York: Routledge, 2010.

; SHAH, Anwar. Fiscal federalism: principles and practice of multiorder governance. Nova York: Cambridge University Press, 2009.

Boletim petróleo, royalties \& região, ns. 24 e 26, jun. e dez. 2009. Disponível em: <http://www.royaltiesdopetroleo.ucam-campos.br>.

BOLTON, Patrick; SAMAMA, Frederic; STIGLITZ, Joseph (Ed.). Introduction. Sovereign wealth funds and long-term investing. New York: Columbia University Press, 2012. ; ________ (Ed.). The state of Sovereign Wealth Funs: overview. Sovereign wealth funds and long-term investing. New York: Columbia University Press, 2012. 
BONAVIDES, Paulo. A Constituição aberta - temas políticos e constitucionais da atualidade, com ênfase no federalismo das regiões. 2. ed. São Paulo: Malheiros, 1996.

BONIN, Pierre-Yves. La justice internationale et le partage des ressources naturelles. Québec Les Presses de L’Université Laval, 2010.

BORGES, José Souto Maior. Introdução ao direito financeiro. São Paulo: Max Limonad, 1998.

BORNHORST, Fabian; GUPTA, Sanjeev; THORNTON, John. Natural resource endowments, governance, and the domestic revenue effort: evidence from a panel of countries. IMF Working Paper, n. 08/170, 2008.

BOUVIER, Michel. Crise des finances publiques, crise d'un modèle politique et naissance de "l'Etat intelligent". Colóquio internacional a moderna gestão financeira pública: uma resposta à crise económica? Lisboa: Tribunal de Contas, 2009.

BRANCO, Paulo Gustavo Gonet. Estado Federal. In: MENDES, Gilmar Ferreira; BRANCO, Paulo Gustavo Gonet. Curso de direito constitucional. 6. ed. rev. e atual. São Paulo: Saraiva, 2011.

BRASIL. Departamento Nacional de Produção Mineral. Sumário mineral. Brasília: DNPM, 2012. Disponível em: <http://www.mme.gov.br/mme/noticias/lista_destaque/destaque_879.html>. Acesso em: 3 jan. 2014.

. Ministério do Planejamento, Orçamento e Gestão. Secretaria de Orçamento Federal. Manual técnico de orçamento MTO. Versão 2013. Brasília, 2012. - Secretaria do Tesouro Nacional. Manual de contabilidade aplicada ao setor público. Parte IV: perguntas e respostas. 4. ed. Brasília: Ministério da Fazenda, 2011. Aprovado pela Portaria STN n. 406, de 20 jul. 2011.

BRÄTLAND, John. Rawlsian investment rules for "intergenerational equity": breaches of method and ethics. The journal of libertarian studies: an interdisciplinary review, v. 21, n. 04, 2007.

BRESSER-PEREIRA, Luiz Carlos (Org.). Doença holandesa e sua neutralização: uma abordagem ricardiana. Doença holandesa e indústria. Rio de Janeiro: FGV, 2010. 
BROSIO, Giorgio. Oil revenue and fiscal federalism. In: DAVIS, J.; OSSOWSKI, R.; FEDELINO, A. (Org.). Fiscal policy formulation and implementation in oil-producing countries. Washington, D.C.: International Monetary Fund, 2003.

BROSIO, Giorgio. Reducing reliance on natural resource revenue and increasing subnational tax autonomy in Bolivia. Inter-American Development Bank Working Paper, n. IDB-WP-298, 2012.

BROSIO, Giorgio. The assignment of revenue from natural resources. In: AHMAD, Ehtisham; BROSIO, Giorgio. Handbook of fiscal federalism. Cheltenham: Edward Elgar Publishing, 2006.

BRUHL, Aaron-Andrew P. Justice unconceived: how posterity has rights. Yale Journal of Law \& the Humanities, v. 14, Iss. 2, article 4.

BRUNNSCHWEILER, Christa N. Cursing the blessings? Natural resource abundance, institutions, and economic growth. World Development, v. 36, 3, Elsevier, 2008.

; BULTE, Erwin H. The resource curse revisited and revised: A tale of paradoxes and red herrings. Journal of Environmental Economics and Management, Elsevier, v. $55,3,2008$.

BUCHANAN, Neil H. Four out of four panelists agree: U.S. Fiscal policy does not cheat future generations. George Washington Law Review, v. 77, 2009.

What kind of environment do we owe future generations?. Lewis \& Clark Law Review, v. 15, n. 2, 2011.

BULTE, Erwin; DAMANIA, Richard; DEACON, Robert. Resource intensity, institutions, and development. World Development, v. 33(7), Elsevier, 2005.

BUSTAMANTE, Luiz Alberto da Cunha; CAVALCANTE FILHO, João Trindade; BIATO, Márcia Fortuna; GOMES, Carlos Jacques Vieira. Análise do Projeto de Lei de Marco Regulatório da Mineração do Brasil. Brasília: Núcleo de Estudos e Pesquisas/CONLEG/Senado, 2013. Texto para discussão n. 137.

CAGNIN, Rafael Fagundes et al. $O$ debate em torno dos fundos cambiais: experiências internacionais. Texto para discussão IE/UNICAMP, 2008. n. 150. 
CALABRESI, Guido; BOBBIT, Philip. Tragic choices: the conflicts society confronts in the allocation of tragically scarce resources. New York: W. W. Norton \& Company, 1978.

CALDER, Jack. Resource tax administration: the impl The taxation of petroleum and minerals ications of alternative policy choices. In: DANIEL, Philip; KEEN, Michael; McPHERSON, Charles (Ed.). The taxation of petroleum and minerals: principles, problems and practice. New York: Routledge, 2010.

CÂMARA DOS DEPUTADOS: Setor mineral rumo a um novo marco legal: rel. Jaime Martins; coord. Paulo César Ribeiro Lima; Alberto Pinheiro de Queiroz Filho; Leonardo Costa Schüler; Roberto Carlos Martins Pontes. Brasília: Câmara dos Deputados, Edições Câmara, 2011, Série Cadernos de Altos Estudos, n. 8.

CAMPILONGO, Celso Fernandes. Celso Furtado e o desenvolvimentismo: ele pode não oferecer a melhor saída para os nossos dilemas. Porém, tomá-lo como referência a respeito de como o Brasil deve ser estudado é imperioso [homenagem]. São Paulo: Fundação Getulio Vargas, v. 1, n. 1, jan. 2007, p. 33.

CAMPOS, J. Edgardo; PRADHAN, Sanjay (Ed.). The many faces of corruption. Washington D.C.: World Bank, 2007.

CANOTILHO, J. J. Gomes; MACHADO, Jónatas. A questão da constitucionalidade das patentes "pipeline” à luz da Constituição Federal brasileira de 1988. Coimbra: Almedina, 2008.

CARDOSO, Alessandro Mendes. O dever fundamental de recolher tributos no estado democrático de direito. Porto Alegre: Livraria do Advogado, 2014.

CARDOSO, Fernando Henrique; MBEKI, Thabo Mvuyelwa; PERSSON, Goran. Podemos trabalhar juntos. Folha de S. Paulo - opinião, 1. ${ }^{\circ}$ set. 2002.

CARNEIRO, Ricardo de Medeiros. Commodities, choques externos e crescimento: reflexões sobre a América Latina. Santiago: Nações Unidas, CEPAL, Div. de Desarrollo Económico, 2012.

CARRAZZA, Roque Antonio. Natureza jurídica da compensação financeira pela exploração de recursos minerais. Sua manifesta inconstitucionalidade. São Paulo: Max Limonad, 1995. 
CARREON-RODERIGUEZ, Victor G.; ROSSELLÓN, Juan. Mexico. In: ANDERSON, George (Ed.). Oil \& gas in federal systems. Ontario: Oxford University Press, 2012.

CARRIÓ, Genaro. Notas sobre derecho y lenguaje. 4. ed. Buenos Aires: Abeledo-Perrot, 1990.

CARVALHO, André Castro. Mecanismos para a otimização do federalismo fiscal brasileiro. In: CONTI, José Maurício; SCAFF, Fernando Facury; BRAGA, Carlos Eduardo Faraco (Org.). Federalismo fiscal: questões contemporâneas. Florianópolis: Conceito, 2010.

CARVAlHO, Paulo de Barros. Curso de direito tributário. 19. ed. rev. São Paulo: Saraiva, 2007.

CASELLI, Francesco; CUNNINGHAM, Tom. Leader behaviour and the natural resource curse. Oxford Economic Papers, n. 61, 2009.

; MICHAELS, Guy. Do oil windfalls improve living standards? Evidence from Brazil. NBER Working Paper, n. 15550, 2009.

CATARINO, João Ricardo. Problemas e perspetivas da governação financeira em ambiente aberto. Revista Fórum de Direito Financeiro e Econômico - RFDE, Belo Horizonte, ano 1, n. 1, mar.-ago. 2012.

CATARINO, João Ricardo. Processo orçamental e sustentabilidade das finanças públicas: o caso europeu. In: CONTI, José Maurício; SCAFF, Fernando Facury (Org.). Orçamentos públicos e direito financeiro. São Paulo: RT, 2011.

CHULVI, Cristina Pauner. El deber constitucional de contribuir al sostenimiento de los gastos públicos. Madrid: Centro de Estudios Políticos y Constitucionales, 2001.

CLÈVE, Clèmerson Merlin; MARTINS, Alessandra Ferreira. Princípios constitucionais da atividade econômica petrolífera e Lei n. 9.478 de 1997. A \& C-Revista de Direito Administrativo e Constitucional, n. 18, Belo Horizonte: Fórum, out.-dez. 2004.

CNI. A contribuição do setor brasileiro de petróleo, gás e biocombustíveis para o desenvolvimento sustentável no país. Confederação Nacional da Indústria, Instituto Brasileiro de Petróleo, Gás e Biocombustíveis. Cadernos Setoriais Rio + 20, Brasília, 2012. Disponível em: <arquivos.portaldaindustria.com.br/app/conteudo_18/2013/09/ 23/4970/20131003104228715851e.pdf>. Acesso em: 22 dez. 2013. 
COLLIER, Paul. Is aid oil? An analysis of whether Africa can absorb more aid. 2005. Disponível em: <http:// economics.ouls.ox.ac.uk/11503/1/uuidbe263d06-c5a9-4e2ea29c-16e80cdd7bc0-ATTACHMENT01.pdf>. Acesso em: 14 set. 2013.

Laws and codes for the "resource curse". Yale Journal of Law and Human Rights, v. 11. Disponível em: <http://50.57.111.125/archive_2011/files/ PCollier_LawsandCodes_Yale_0.pdf>. Acesso em: 30 dez. 2013.

. Small countries and big resources: harnessing natural resources for development in the g7+ countries. Paper prepared for the g7+ high level ministerial retreat. 2012. Disponível em: <http://www.g7plus.org/news-feed/2013/1/10/small-countries-and-bigresources.html>. Acesso em: 27 nov. 2013.

; GODERIS, Benedikt. Commodity prices, growth, and the natural resource curse: reconciling a conundrum. Centre for the studies of African economies Working Paper Series, 2007-15, University of Oxford, 2007.

; HOEFFLER, Anke. Democracy and resource rents. Global Poverty Research Group Working Paper Series, n. 016, 2005.

; __ Greed and grievance in civil war. Centre for the Studies of African Economies Working Paper Series, n. 2002-01, 2002.

; ___ Testing the neocon agenda: democracy in resource-rich societies. European Economic Review, n. 53, Elsevier, 2009.

; VAN DER PLOEG, Frederick; VENABLES, Anthony J. Managing resource revenues in developing economies. Disponível em: <http://users.ox.ac.uk/ econpco/research/pdfs/ ManagingResourceRevenuesinDevelopingEconomies.pdf>. Acesso em: 18 dez. 2013. COMPARATO, Fábio Konder. A afirmação histórica dos direitos humanos. 7. ed. rev. e atual. São Paulo: Saraiva, 2010.

. O indispensável direito econômico. Revista dos Tribunais, n. 353, São Paulo: RT, mar. 1965.

. Quem dá mais? Folha de S. Paulo - Opinião. 24 nov. 2004. Disponível em: <http://www1.folha.uol.com.br/fsp/opiniao/fz2409200409.htm>. Acesso em: 30 nov. 2013. 
CONFEDERAÇÃO NACIONAL DA INDÚSTRIA. A indústria e o Brasil: uma agenda para crescer mais e melhor. Brasília, 2010.

CONSELHO INTERNACIONAL DE MINERAÇÃO E METAIS. O setor de mineração no Brasil: fortalecimento institucional para o desenvolvimento sustentável. Mineração: parcerias para o desenvolvimento. 2013.

CONTI, José Maurício. A autonomia financeira do Poder Judiciário. São Paulo: Ed. MP, 2006.

- Considerações sobre o federalismo fiscal brasileiro em uma perspectiva comparada. In: CONTI, José Maurício; SCAFF, Fernando Facury; BRAGA, Carlos Eduardo Faraco (Org.). Federalismo fiscal: questões contemporâneas. Florianópolis: Conceito, 2010.

. Federalismo fiscal e fundos de participação. São Paulo: Juarez de Oliveira, 2001.

O Estado e o imposto: federalismo financeiro e fiscal. In: CATARINO, João Ricardo; GUIMARÃES, Vasco Branco (Coord.). Lições de fiscalidade. Coimbra: Almedina, 2012.

; SCAFF, Fernando Facury; BRAGA, Carlos Eduardo Faraco (Org.). Federalismo fiscal: questões contemporâneas. Florianópolis: Conceito, 2010.

(Coord.). Orçamentos públicos: a Lei n. 4.320/1964 comentada. 2. ed. São Paulo: RT, 2010.

COOTER, Robert D.; ULEN, Thomas. Law and economics. 5. ed. Boston: Addison Wesley, 2007.

CORREIA, Fernando Alves; MACHADO, Jónatas E. M.; LOUREIRO, João Carlos (Org.). Estudos em homenagem ao Prof. Doutor José Joaquim Gomes Canotilho. Coimbra: Ed. Coimbra, 2012.

COSTA, Hirdan Katarina de Medeiros. O princípio da justiça intra e intergeracional como elemento na destinação das rendas de hidrocarbonetos: temática energética crítica na análise institucional brasileira. 2012. Tese (Doutorado) - Universidade de São Paulo.

; SANTOS, Edmilson Moutinho dos. Justiça e sustentabilidade: a destinação dos royalties de petróleo. Estudos avançados, v. 27, n. 77, 2013. 
; SANTOS, Edmilson Moutinho dos. Sustentabilidade e a destinação dos royalties de petróleo: uma contribuição teórica. Documento apresentado ao evento Cleaner production initiatives and challenges for a sustainable world, 3rd International Workshop - Advances in cleaner production. 2011. Disponível em: <http://www.advancesincleanerproduction.net/third/files/sessoes/6A/8/Costa_HKM\%2 0-\%20Paper\%20-\%206A8.pdf>. Acesso em: 30 set. 2013.

COSTA, Rodolfo Ribeiro da. O impacto das transferências constitucionais sobre o comportamento fiscal dos municípios brasileiros.

CRUZ, Bruno de Oliveira; RIBEIRO, Márcio Bruno. Sobre maldições e bençãos: é possível gerir recursos naturais de forma sustentável? Uma análise sobre os royalties e as compensações financeiras no Brasil. Rio de Janeiro: IPEA, 2009. Texto para discussão n. 1412.

DAFFLON, Bernard. The assignment of functions to decentralized government: from theory to practice. In: AHMAD, Ehtisham; BROSIO, Giorgio. Handbook of fiscal federalism. Cheltenham: Edward Elgar Publishing, 2006.

DALEFFE, Adriano. Ilegalidade da compensação financeira pela exploração de recursos minerais. Revista Dialética de Direito Tributário, São Paulo: Dialética, n. 33, p. 7-15, 1998.

DALLARI, Dalmo de Abreu. Implicações do pacto federativo. In: RAMOS, Dircêo Torrecillas (Coord.). O federalista atual: teoria do federalismo. Belo Horizonte: Arraes Editores, 2013.

DAVIS, Jeffrey; OSSOWSKI, Rolando; DANIEL, James A.; BARNETT, Steven. Stabilization and savings funds for nonrenewable resources: experience and fiscal policy implications. In: DAVIS, J.; OSSOWSKI, R.; FEDELINO, A. (Org.). Fiscal policy formulation and implementation in oil-producing countries. Washington, D.C.: International Monetary Fund, 2003.

_______ FEDELINO, A. (Org.). Fiscal policy formulation and implementation in oil-producing countries. Washington, D.C.: International Monetary Fund, 2003.

DAVIS, Jeffrey; OSSOWSKI, Rolando; DANIEL, James A.; BARNETT, Steven. Oil funds: problems posing as solutions?. Finance and development, v. 38, n. 4. Disponível 
em: <http://www.imf.org/external/pubs/ft/fandd/2001/12/davis.htm>. Acesso em: 2 mar. 2013.

; ___ experience and fiscal policy implications. In: DAVIS, J.; OSSOWSKI, R.; FEDELINO, A. (Org.). Fiscal policy formulation and implementation in oil-producing countries. Washington, D.C.: International Monetary Fund, 2003.

DE SANTI, Eurico Marcos Diniz; CHRISTOPOULOS, Basile Georges; ZUGMAN, Daniel Leib; BASTOS, Frederico Silva (Coord.). Transparência fiscal $e$ desenvolvimento: homenagem ao professor Isaias Coelho. São Paulo: FISCOSoft, 2013.

DELFIM NETTO, Antonio. Valor Econômico, 15 jan. 2013.

DEODATO, Alberto. Manual de ciência das finanças. 20. ed. São Paulo: Saraiva, 1984.

DERZI, Misabel Abreu Machado. Arts. 40 a 47. In: MARTINS, Ives Gandra da Silva; NASCIMENTO, Carlos Valder do (Org.). Comentários à lei de responsabilidade fiscal. 2. ed. rev. e atual. São Paulo: Saraiva, 2007.

DIAMANDIS, Peter H.; KOTLER, Steven. Abundance: the future is better than you think. New York: Free Press, 2012.

DIERKSMEIER, Claus. John Rawls on the rights of future generations. In: TREMMEL, Joerg (Ed.). Handbook of intergenerational justice. Cheltenham, UK: Edward Elgar, 2006.

DOMINGUES, José Marcos. Tributação, orçamento e políticas públicas. Revista Tributária e de Finanças Públicas, v. 99, 2011.

DORAN, Michael. Intergenerational equity in fiscal policy reform. Tax Law Review, n. 61, 2008.

DOVI, Efam. Ghana's 'new path' for handling oil revenue: Seeking to avoid the ill effects of Africa's resource "curse”. Online African Renewal, janeiro/2013. Disponível em: <http://www.un.org/africarenewal/magazine/january-2013/ghana\%E2\%80\%99s\%E2\%80\%98new-path\%E2\%80\%99-handling-oil-revenue>. Acesso em: 22 dez. 2013.

DREZNER, Daniel W. Sovereign Wealth Funds and the (in)security of global finance. Journal of International Affairs, v. 62, n. 1, 2008, p. 115. 
DUARTE, Angelo José Mont’alverne; SILVA, Alexandre Manoel Angelo da; LUZ, Everaldo Manoel; GERARDO, José Carlos. Transferências fiscais Intergovernamentais no Brasil: uma avaliação das transferências federais, com ênfase no Sistema único de Saúde. Rio de Janeiro: IPEA, 2009. Texto para discussão n. 1457.

DUNNING, Thad. Crude democracy: natural resource wealth and political regimes. New York: Cambridge University Press, 2008.

Natural resources and democracy in latin america. Background paper prepared for latin america and caribbean regional flagship report on commodities (Office of the Regional Chief Economist, IBRD). 2009. Disponível em: $<$ http://siteresources.worldbank.org/ EXTLACOFFICEOFCE/Resources/8708921253047679843/6438618-1254513204494/Dunning2009. pdf>. Acesso em: 29 ago. 2013.

DWORKIN, Ronald. John Rawls. The Harvard Review of Philosophy, v. 11, 2003.

EDERER, Peer; SCHULLER, Phillip; WILLMS, Stephan. The Economic Sustainability Indicator. In: TREMMEL, Joerg (Ed.). Handbook of intergenerational justice. Cheltenham, UK: Edward Elgar, 2006.

EIFERT, Benn; GELB, Alan; TALLROTH, Nils Borje. The political economy of fiscal policy and economic management in oil-exporting countries. In: DAVIS, J.; OSSOWSKI, R.; FEDELINO, A. (Org.). Fiscal policy formulation and implementation in oil-producing countries. Washington, D.C.: International Monetary Fund, 2003.

EMENTÁRIO DE CLASSIFICAÇÃO DAS RECEITAS ORÇAMENTÁRIAS (2012) Brasília. Secretaria de Orçamento Federal - SOF.

ENGEL, Eduardo; VALDÉS, Rodrigo. Optimal fiscal strategy for oil exporting countries. IMF Working Paper, n. 00/118, 2000.

ENGLISH, Jane. Justice between generations. Philosophical studies. An International Journal for Philosophy in the Analytic Tradition, v. 31, n. 2, fev. 1977.

ENRÍQUEZ, Maria Amélia Rodrigues da Silva. Equidade intergeracional na partilha dos benefícios dos recursos minerais: a alternativa dos fundos de mineração. Revista Iberoamericana de Economía Ecológica, v. 5, 2006.

- Mineração: maldição ou dádiva. Os dilemas do desenvolvimento sustentável a partir de uma base mineira. São Paulo: Signus, 2008. 
EPSTEIN, Richard A.; ROSE, Amanda M. The regulation of sovereign wealth funds: the virtues of going slow. The University of Chicago Law Review, v. 76, n. 111, 2009.

ERNST \& YOUNG PARA O INSTITUTO BRASILEIRO DE MINERAÇÃO - IBRAM. Disponível em: <http://www.ibram.org.br/sites/1300/1382/00001165.ppt>

EVOLUÇÃO DOS PREÇOS DO BARRIL DE PETRÓlEO. Disponível em: <http://www.eia.gov/finance/markets/reports_presentations/eia_what_drives_crude_oil _prices.pdf>. Acesso em: 13 jul. 2012.

FARIAS, Lindbergh. Royalties do petróleo: as regras do jogo - para discutir sabendo. Rio de Janeiro: Agir, 2011.

FARREL, Martin Diego. Filosofia del derecho y económia. Buenos Aires: La Ley, 2006.

FEARON, James. Primary commodities exports and civil war. 2004. Disponível em: <http://isites.harvard.edu/fs/docs/icb.topic244653.files/Fearon_J_Prim_Commod_Expo rts_Civ_War_2004.pdf>. Acesso em: 7 set. 2013.

FENSTERSEIFER, Tiago. Direitos fundamentais e proteção do meio ambiente: a dimensão ecológica da dignidade humana no marco jurídico constitucional do estado socioambiental de direito. Porto Alegre: Livraria do Advogado, 2008.

FERGUSON, Niall. The least among us. New York Times, 1. jul. 2007. Disponível em: <http://www.nytimes.com/2007/07/01/books/review/Fergusont.html?pagewanted=all>. Acesso em: 7 set. 2013.

FERNANDES, Ana Cristina. A distribuição dos royalties petrolíferos no Brasil e os riscos de sua "financeirização". Revista de Desenvolvimento Econômico - RDE, ano VII, n. 11 , jan. 2005.

FERNANDES, Andressa Guimarães Torquato. Direito financeiro aplicado ao setor do petróleo. 2013. Tese (Doutorado) - Faculdade de Direito da Universidade de São Paulo.

FERREIRA FILHO, Manoel Gonçalves. Comentários à Constituição brasileira de 1988. São Paulo: Saraiva, 1992.

FERREIRA, Guilherme Simões; LIMA, Guilherme Corrêa da Fonseca. Competência da União Federal para cobrança, arrecadação e fiscalização da CFEM. In: SOUZA, 
Marcelo Mendo Gomes de (Coord.). A compensação financeira pela exploração de recursos minerais - CFEM. Belo Horizonte: Del Rey, 2011.

FERREIRA, Patrícia Galvão. Breaking the weak governance curse: global regulation and governance reform in resource-rich developing countries. 2012. Tese (Doutorado) Faculdade de Direito da Universidade de Toronto.

FIORILlO, Celso Antonio Pacheco; FERREIRA, Renata Marques. Curso de direito da energia - tutela jurídica da água, do petróleo, do biocombustível, dos combustíveis nucleares e do vento. 2. ed. São Paulo: Saraiva, 2010.

FRANCO, Antonio L. de Sousa. Finanças públicas e direito financeiro. Coimbra: Almedina, 2007. v. 1.

FRANKEL, Jeffrey. Escaping the oil curse. Project syndicate, 9 de dezembro de 2011. Disponível em: <http://www.project-syndicate.org/commentary/escaping-the-oilcurse>. Acesso em: 23 dez. 2013.

FRANKEL, Jeffrey. The natural resource curse: a survey. Discussion paper 2010-21. Cambridge, Mass.: Harvard Environmental Economics Program, 2010.

FREITAS, Paulo Springer de. Rendas do petróleo: questão federativa e instituição de Fundo Soberano. Artigo apresentado no IV Fórum Senado Debate Brasil. Nova fronteira do petróleo: os desafios do pré-sal. Brasília, 3 e 4 de dezembro de 2008.

FRIEDMAN, Thomas L. The first law of petropolitics. Foreign Policy, 1. ${ }^{\circ}$ maio 2006.

Disponível em: <http://www.foreignpolicy.com/articles/2006/04/25/the_first_law_of_petropolitics>. Acesso em: 4 set. 2013.

FUNDAÇÃO DO DESENVOLVIMENTO ADMINISTRATIVO DO ESTADO DE SÃO PAULO - FUNDAP. Fundos de riqueza soberana. São Paulo, 2008. Disponível em: <http://www.fundap.sp.gov.

br/debatesfundap/pdf/conjuntura/Fundos\%20de\%20Riqueza\%20Soberana.pdf $>$. Acesso em: 7 dez. 2013.

FURTADO, Celso. A invenção do subdesenvolvimento. Revista de Economia Política, v. 15, n. 2 (58), abr.-jun. 1995, p. 6.

. Desenvolvimento e subdesenvolvimento. Rio de Janeiro: Contraponto: Centro Internacional Celso Furtado, 2009. 
Ensaios sobre a Venezuela: subdesenvolvimento com abundância de divisas. Rio de Janeiro: Contraponto, 2008.

. Formação econômica do Brasil. 34. ed. São Paulo: Companhia das Letras, 2007.

. Globalisation et exclusion: Le Brésil dans l'ordre mondial émergent. Paris:

Publisud, 1995.

. Notas sobre a economia venezuelana e suas perspectivas atuais, 1974. In:

FURTADO, Celso. Ensaios sobre a Venezuela: subdesenvolvimento com abundância de divisas. Rio de Janeiro: Contraponto, 2008.

. O desenvolvimento recente da economia venezuelana, 1957. In: FURTADO,

Celso. Ensaios sobre a Venezuela: subdesenvolvimento com abundância de divisas.

Rio de Janeiro: Contraponto, 2008.

Os desafios da nova geração. Jornal dos economistas, n. 179, jun. 2004.

GARGARELLA, Roberto. As teorias da justiça depois de Rawls: um breve manual de filosofia política. Trad. Alonso Reis Freire. rev. trad. Elza Maria Gasparotto; rev. téc. Eduardo Appio. São Paulo: WMF Martins Fontes, 2008.

GAUTHIER, Bernard; ZEUFACK, Albert. Governance and oil revenues in Cameroon. OxCarre Research Paper 38, Oxford University, 2009.

GIACOMONI, James. Orçamento público. 14. ed. ampl. rev. e atual. 3. reimpr. São Paulo: Atlas, 2009.

GILSON, Ronald J. Sovereign Wealth Funds: perhaps we see what we want to see. In: BOLTON, Patrick; SAMAMA, Frederic; STIGLITZ, Joseph (Ed.). Sovereign wealth funds and long-term investing. New York: Columbia University Press, 2012.

GOBETTI, Sérgio Wulff. Federalismo fiscal e petróleo no Brasil e no mundo. IPEA, 2011. Texto para discussão n. 1669.

Política fiscal e pré-sal: como gerir as rendas do petróleo e sustentar o equilíbrio macrofiscal do Brasil. Brasília: ESAF, 2009. Monografia premiada com o segundo lugar no XIV Prêmio Tesouro Nacional - 2009: homenagem a Euclides da Cunha. Política fiscal e dívida pública. Brasília (DF).

; SERRA, Rodrigo Valente. Novo marco regulatório do petróleo: desafios na transição do regime de concessão para o regime de partilha. Brasília: ESAF, 2011. 
Monografia premiada com o segundo lugar no XVI Prêmio Tesouro Nacional, 2011. Tópicos Especiais de Finanças Públicas. Brasília (DF).

GODERIS, Benedikt; MALONE, Samuel W. Natural resource booms and inequality: theory and evidence. OxCarre Research Paper 08, Oxford University, 2010.

GOMES, Emérson César da Silva. Arts. 83 a 100. In: CONTI, José Maurício (Coord.). Orçamentos públicos: a Lei n. 4.320/1964 comentada. 2. ed. São Paulo: RT, 2010.

GOSSERIES, Axel. A justiça intergeracional e a metáfora do refúgio de montanha. Disponível em: <http://www.uclouvain.be/cps/ucl/doc/etes/documents/Refugio_de_Montanha.pdf>. Acesso em: 30 dez. 2013.

GOSSERIES, Axel; MEYER, Lukas H. (Coord.). Intergenerational justice. New York: Oxford University Press, 2009.

GRAU, Eros Roberto. Ensaio e discurso sobre a interpretação/aplicação do direito. São Paulo: Malheiros, 2002.

GRIFFITH-JONES, Stephany; OCAMPO, José Antonio. Sovereign wealth funds: a developing country perspective. Trabalho apresentado no workshop sobre Fundos Soberanos organizado pela Andean Development Corporation em Londres, 18 fev. 2008. Disponível em: <http://academiccommons.columbia.edu/download/fedora_content/download/ac:12703 7/CONTENT/Sovereign_Wealth_Funds_GJ-O_final.pdf>. Acesso em: 25 fev. 2013.

GYLFASON, Thorvaldur; ZOEGA, Gylfi. Inequality and economic growth: do natural resources matter? CESifo Working Paper Series, n. 712, 2002.

HABER, Stephen H.; MENALDO, Victor A. Do natural resources fuel authoritarianism? A reappraisal of the resource curse. American Political Science Review, v. 105, n. 1, 2010.

HÄBERLE, Peter. A constitutional law for future generations - the 'other' form of the social contract: the generation contract. In: TREMMEL, Joerg (Ed.). Handbook of intergenerational justice. Cheltenham, UK: Edward Elgar, 2006.

HALE, Benjamin. The veil of opulence. The New York Times, The opinion pages - the stone, 12 ago. 2012. 
HANDELWANG, Christian Von; IVANYNA, Maksym. Assessing the tax performance of developing countries. Deutsches Institut für Entwicklungspolitik Discussion Paper, n. 20/2010, 2010.

HAMILTON, Kirk; RUTA, Giovanni; TAJIBAEVA, Liaila. Capital accumulation and resource depletion: a hartwick rule counterfactual. World Bank Policy Research Working Paper, n. 3480, 2005.

HARTWICK, John M. Intergenerational equity and the investing of rents from exhaustible resources. The American Economic Review, v. 67, n. 5, dez. 1977.

Substitution among exhaustible resources and intergenerational equity. The Review of Economic Studies, v. 45, n. 2, jun. 1978, p. 347-354.

HAUSMANN, Ricardo; RIGOBON, Roberto. An alternative interpretation of the “resource curse". In: DAVIS, J.; OSSOWSKI, R.; FEDELINO, A. (Org.). Fiscal policy formulation and implementation in oil-producing countries. Washington, D.C.: International Monetary Fund, [s.d.].

HEAL, Geoffrey. Are oil producers rich?. In: HUMPHREYS, Macartan; SACHS, Jeffrey D.; STIGLITZ, Joseph E. (Org.). Escaping the resource curse. New York: Columbia University Press, 2007.

HERB, Michael. All in the family: absolutism, revolution and democracy in the middle eastern monarchies. Albany: State University of New York Press, 1999.

. No representation without taxation? Rents, development, and democracy. Comparative Politics, v. 37, n. 3, abr. 2005.

HERNANDEZ, Fernanda Guimarães. Compensação financeira pela exploração de recursos minerais: regra matriz de incidência. 2010. Tese (Doutorado) - Faculdade de Direito da Universidade de São Paulo.

HEYD, David. A value or an Obligation? Rawls on Justice to Future Generations. In: GOSSERIES, Axel; MEYER, Lukas H. (Coord.). Intergenerational justice. New York: Oxford University Press, 2009.

HOCHSTETLER, Richard Lee. Recursos naturais e o mercado: três ensaios. 2002. Tese (Doutorado) - Departamento de Economia da Faculdade de Economia e Administração da Universidade de São Paulo. São Paulo. 
HOLMES, Stephen; SUNSTEIN, Cass. The cost of rights: why liberty depends on taxes. Nova York: W. W. Norton \& Company, 1999.

HOTELLING, Harold. The economics of exhaustible resources. Journal of Political Economy, v. 39, n. 1, 1931.

HUMAN RIGHTS WATCH. Some transparency, no accountability: the use of oil revenue in Angola and its impact on human rights. New York, 2004. Disponível em: <http://www.hrw.org/sites/default/files/reports/angola0104.pdf>. Acesso em: 4 set. 2013.

HUMPHREYS, Macartan. Natural resources, conflict, and conflict resolution: uncovering the mechanisms. Journal of Conflict Resolution, v. 49, n. 4, 2005.

HUMPHREYS, Macartan; SACHS, Jeffrey D.; STIGLITZ, Joseph E. (Org.). Future Directions for the Management os Natural Resources. Escaping the resource curse. New York: Columbia University Press, 2007.

; ___ (Org.). Introduction: What is the problem with natural resource wealth? Escaping the resource curse. New York: Columbia University Press, 2007.

$;$ (Org.). The political economy of natural resource funds. Escaping the resource curse. New York: Columbia University Press, 2007.

ICMM. Minerals taxation regimes: a review of issues and challenges in their design and application. Report published with the Commonwealth Secretariat. Disponível em: <http://www.icmm. com/page/12880/minerals-taxation-regimes-report-published-withthe-commonwealth-secretariat>. 2009.

- O setor de mineração no Brasil: fortalecimento institucional para o desenvolvimento sustentável. Mineração: parcerias para o desenvolvimento. 2013.

IMPLEMENTING EITI FOR IMPACT - A handbook for policy makers and stakeholders.

Disponível

em: <http://eiti.org/files/Implementing\%20EITI\%20for\%20Impact_Handbook\%20for\%20P olicy\%20Makers\%20and\%20Stakeholders.pdf>.

INSTITUTO BRASILEIRO DE MINERAÇÃO - IBRAM. Informações e análises da economia mineral brasileira. 6. ed. Brasília: IBRAM, 2011. 
INSTITUTO DE PESQUISA ECONÔMICA APLICADA. Política fiscal e justiça social no Brasil: o caso do IPTU. Brasília: IPEA, 2009. Comunicado da Presidência n. 28.

INTERNATIONAL COUNCIL ON MINING \& METALS. Minerals taxation regimes: a review of issues and challenges in their design and application. London: ICMM, 2009.

INTERNATIONAL MONETARY FUND. Guide on resource revenue transparency. Washington D.C.: IMF Media Service Division, 2007. . Macroeconomic policy frameworks for resource-rich developing countries. Washington D.C., 2012.

. The role of fiscal institutions in managing the oil revenue boom. 2007. Disponível em: <http://www.imf.org/external/np/pp/2007/eng/030507.pdf>. Acesso em: 30 nov. 2013.

ISHAM, Jonatham; WOOLCOCK, Michael; PRITCHETT, Lant; BUSBY, Gwen. The varieties of resource experience: how natural resource export structures affect the political economy of economic growth. Middlebury College Economics Discussion Paper, n. 03-08, 2003.

JÁVOR, Benedek. Institutional Protection of succeeding generations - Ombudsman for Future Generations in Hungary. In: TREMMEL, Joerg (Ed.). Handbook of intergenerational justice. Cheltenham, UK: Edward Elgar, 2006.

JÈZE, Gaston. Cours élémentaire de science des finances et de législation financière française: manuel à l'usage des étudiants des facultés de droit et des candidats au ministère des Finances, à la Cour des comptes, à l'Inspection des finances, etc. Nouvelle Édition. Paris: V. Giard \& E. Brière, 1909.

JOHNSON, Simon. The rise of sovereign wealth funds. Finance and development, v. 44, n. 3, $2007 . \quad$ Disponível em: <http://www.imf.org/external/pubs/ft/fandd/2007/09/straight.htm>. Acesso em: 27 fev. 2013.

KARL, Terry Lynn. Ensuring fairness: the case for a transparent fiscal social contract. In: HUMPHREYS, Macartan; SACHS, Jeffrey D.; STIGLITZ, Joseph E. (Org.). Escaping the resource curse. New York: Columbia University Press, 2007. 
- Entendendo a maldição dos recursos naturais. In: TSALIK, Svetlana; SCHIFFRIN, Anya (Org.). Reportando o petróleo: um guia jornalístico sobre energia e desenvolvimento. Open Society Institute: Nova York, 2005.

KARL, Terry Lynn. The paradox of plenty: oil booms and petro-states. Berkeley: University of California Press, 1997.

KAUFMANN, Daniel; KRAAY, Aart; ZOIDO-LOBATÓN, Pablo. Governance matters: from measurement to action. Finance and development, v. 37, n. 2. 2000. Disponível em: <http://www.imf.org/external/pubs/ft/fandd/2000/06/pdf/kauf.pdf>. Acesso em: 15 fev. 2013.

KOLSTAD, Ivar; WIIG, Arne. Is transparency the key to reducing corruption in resourcerich countries? World Development, v. 37, n. 3, Elsevier, 2008.

; ___ It's the rents, stupid! The political economy of the resource curse. Energy Policy, n. 37, Elsevier, 2009.

KOPP, Raymond J.; PORTNEY, Paul R. Mock referenda for intergenerational decisionmaking. Resources For The Future Discussion Paper, 97-48, Washington, DC: Resources for the Future.

KURLYANDSKAYA, Galina; POKATOVICH, Gleb; SUBBOTIN, Mikhail. Russia. In: ANDERSON, George (Ed.). Oil \& gas in federal systems. Ontario: Oxford University Press, 2012.

LABAND, Paul. Derecho presupuestario. Madrid: Instituto de estudios fiscales, 1979.

LAPATZA, José Juan Ferreiro. Curso de derecho financiero español. 14. ed. rev. Madrid, Marcial Pons, 1992. Instituticiones de derecho financiero. Madrid: Marcial Pons, 2010.

LE, Tuan Minh; MORENO-DODSON, Blanca; ROJCHAICHANINTHORN, Jeep. Expanding taxable capacity and reaching revenue potential: cross-country analysis. World Bank Policy Research Working Paper 4559, 2008.

LEACH, Jeremy; HANTON, Angus. Intergenerational fairness index: measuring changes in intergenerational fairness in the united kingdom. Intergenerational foundation, 2012. Disponível em: <http://www.if.org.uk/wpcontent/uploads/2012/06/IFIndex_defin.pdf>. Acesso em: 30 dez. 2013. 
LEAL, José Agostinho; SERRA, Rodrigo. Uma investigação sobre os critérios de repartição dos royalties petrolíferos. In: PIQUET, Rosélia (Org.). Petróleo, royalties $e$ região. Rio de Janeiro: Garamond, 2003.

LEDERMAN, Daniel; MALONEY, William F. In search of the missing resource curse. Policy research working paper, n. 4766, World Bank, 2008.

LEDERMAN, Daniel; MALONEY, William F. (Ed.). Trade structure and growth. Natural resources, neither curse nor destiny. Washington: Stanford University Press e The World Bank, 2007.

LEITE, Camila de Morais; MARCUCI, Roberta Borella. A CFEM como indenização ambiental. In: SILVA, Paulo Roberto Coimbra (Coord.). Compensação financeira pela exploração de recursos minerais. São Paulo: Quartier Latin, 2010.

LEITE, Carlos; WEIDMANN, Jens. Does mother nature corrupt? Natural resources, corruption, and economic growth. IMF Working Paper, n. 99/85, 1999.

LIMA, Edilberto Carlos Pontes. Transferências da União para estados e municípios não originárias de repartição de receitas: para que se destinam e o que determina o montante. Disponível

em: <http://federativo.bndes.gov.br/bf_bancos/estudos/e001768pdf>. Acesso em: 30 nov. 2013.

LONG, Ngo Van. A mixed Bentham-Rawls criterion for intergenerational equity. CIRANO Working Papers, 2007s-08, Montreal: CIRANO, 2007.

LOUREIRO, Gustavo Kaercher. Participações governamentais na indústria do petróleo: evolução normativa. Porto Alegre: Sergio Antonio Fabris, 2012.

LUIS, Alessandro S. Octaviani. Recursos genéticos e desenvolvimento: os desafios furtadiano e gramsciano. 2008. Tese (Doutorado) - Faculdade de Direito da Universidade de São Paulo.

MACHADO, Paulo Affonso Leme. Direito ambiental brasileiro. 18. ed. rev. atual. e ampl. São Paulo: Malheiros, 2010.

MACHADO, Raquel Cavalcanti Ramos. A mudança do paradigma orçamentário: do controle do Estado para a implementação de políticas públicas. A função da receita pública no estado democrático e social de direito. In: CONTI, José Maurício; SCAFF, 
Fernando Facury (Org.). Orçamentos públicos e direito financeiro. São Paulo: RT, 2011.

MADUREIRA, Claudio. Royalties de petróleo e federação. Belo Horizonte: Fórum, 2012.

MARQUES NETO, Floriano Peixoto de Azevedo. Bens públicos: função social e exploração econômica. Belo Horizonte: Forum, 2009.

MARTINEZ, Gregorio Peces-Barba. Los deberes fundamentales. DOXA, n. 4, 1986, p. 336.

MARTINEZ-VAZQUEZ, Jorge. McLURE, Charles; VAILlANCOURT, François. Revenues and expenditures in an intergovernmental framework. In: BIRD, Richard M.; VAILLANCOURT, François (Ed.). Perspectives on fiscal federalism. Washington: The World Bank, 2006.

; JAMESON BOEX, L.F. Fiscal capacity: an overview of concepts and measurement issues and their applicability in the russian federation. GSU Andrew Young School of Policy Studies Working Paper, n. 97-3, jun. 1997.

MARTINS, Ives Gandra da Silva. Grandes questões atuais do direito tributário - Palestra proferida durante o simpósio. São Paulo: Dialética, set. 2013.

MAUGERI, Leonardo. Oil: the next revolution: the unprecedented upsurge of oil production capacity and what it means for the world. Belfer Center for Science and International Affairs Discussion Paper, n. 2012-10, Cambridge: Harvard University, 2012.

McGUIRK, Eoin F. The illusory leader: natural resources, taxation and accountability. Institute for International Integration Studies Discussion Paper, n. 327, 2010.

McKENZIE, Kenneth J. Fiscal federalism and the taxation of nonrenewable resources. In: BIRD, Richard M.; VAILLANCOURT, François (Ed.). Perspectives on fiscal federalism. Washington: The World Bank, 2006.

McPHERSON, Charles; MacSEARRAIGH, Stephen. Corruption in the petroleum sector. In: CAMPOS, J. Edgardo; PRADHAN, Sanjay (Ed.). The many faces of corruption: tracking vulnerabilities at the sector level. Washington: The World Bank, 2007. 
MEDEIROS, Carlos Aguiar de. Celso Furtado na Venezuela. In: FURTADO, Celso. Ensaios sobre a Venezuela: subdesenvolvimento com abundância de divisas. Rio de Janeiro: Contraponto, 2008.

MENDEL, Toby. Liberdade de informação: um estudo de direito comparado 2. ed. Brasilia: Unesco, 2009.

MENDES, Gilmar Ferreira. Tributação e finanças públicas na Constituição Federal de 1988. In: ; BRANCO, Paulo Gustavo Gonet. Curso de direito constitucional. 6. ed. rev. e atual. São Paulo: Saraiva, 2011.

; CORREIA NETO, Celso de Barros. Transparência fiscal. In: MARTINS, Ives Gandra da Silva; MENDES, Gilmar Ferreira; NASCIMENTO, Carlos Valder do (Coord.). Tratado de direito financeiro. São Paulo: Saraiva, 2013. v. 1.

MENDES, Marcos. Federalismo Fiscal. In: BIDERMAN, Ciro; ARVATE, Paulo Roberto (Org.). Economia do setor público no Brasil. Rio de Janeiro: Elsevier/Campus, 2005.

; MIRANDA, Rogério Boueri; COSSIO, Fernando Blanco. Transferências intergovernamentais no Brasil: diagnóstico e proposta de reforma. Textos para discussão. Brasília: Senado Federal, 2008. n. 40.

MEYER, Lukas. "Intergenerational justice". The Stanford Encyclopedia of Philosophyc. Spring 2010 Edition. Edward N. Zalta(Ed.). Disponível em: <http://plato.stanford.edu/archives/spr2010/entries/justice-intergenerational/>. Acesso em: 18 nov. 2013.

MIKESELL, Raymond F. Explaining the resource curse, with special reference to mineralexporting countries. Resources Policy, v. 23, n. 4, Elsevier, 1998.

MILARÉ, Édis. Direito do ambiente: a gestão ambiental em foco - doutrina, jurisprudência, glossário. 6. ed. rev. atual. e ampl. São Paulo: RT, 2009.

MINISTÉRIO DO DESENVOLVIMENTO, INDÚSTRIA E COMÉRCIO EXTERIOR. Disponível em: <http://www.desenvolvimento.gov.br/arquivos/dwnl_1331125742.pdf>. Acesso em: 23 jun. 2012.

MME - MINISTÉRIO DE MINAS E ENERGIA (BRASIL). Plano Nacional de Mineração 2030 - Geologia, mineração e transformação mineral. Brasília, 2013. 
MONK, Ashby H. B. Sovereignty in the era of global capitalism: the rise of sovereign wealth funds and the power of finance. Disponível em: <http://ssrn.com/abstract=1587327>. Acesso em: 16 fev. 2013.

MORAES, Alexandre de. Regime jurídico da concessão para exploração de petróleo e gás natural. Revista de Direito Constitucional e Internacional, n. 36, São Paulo: RT, jul.set. 2001.

MORGAN, J. P. Sovereign wealth funds: a bottom-up primer. J. P. Morgan, 2008.

MORGANDI, Matteo. Extractive industrie revenue distribution at the sub-national level: the experience in seven resource-rich countries. Revenue Watch Institute, 2008.

MUÑIZ-FRATICELLI, Víctor M. The problema of a perpetual constitution. In: GOSSERIES, Axel; MEYER, Lukas H. (Coord.). Intergenerational justice. New York: Oxford University Press, 2009.

NABAIS, José Casalta. O dever fundamental de pagar impostos. Coimbra: Livraria Almedina, 1998.

Por um estado fiscal suportável - estudos de direito fiscal. Coimbra: Almedina, 2005.

NASCIMENTO, Carlos Valder do. Arts. 1. ${ }^{\circ}$ a 17. In: MARTINS, Ives Gandra da Silva; NASCIMENTO, Carlos Valder do (Org.). Comentários à lei de responsabilidade fiscal. 2. ed. rev. e atual. São Paulo: Saraiva, 2007.

NASSIF, André. Há evidências de desindustrialização no Brasil? Textos para discussão, Revista do BNDES, n. 108, jul. 2006.

NÓBREGA, Marcos; FIGUEIREDO, Carlos Maurício. Renúncia de receita; guerra fiscal e tax expenditure: uma abordagem do art. 14 da LRF. In: FIGUEIREDO, Carlos Maurício; NÓBREGA, Marcos. Lei de Responsabilidade fiscal: aspectos polêmicos. Belo Horizonte: Fórum, 2006.

NOGUEIRA, Cláudia de Góes. A impossibilidade de as cláusulas pétreas vincularem as gerações futuras. Revista de Informação Legislativa, ano 42, n. 166, Brasília: Senado Federal, Subsecretaria de Edições Técnicas, abr.-jun. 2005.

NORREGAARD, John. Tax Assignment. In: TER-MINASSIAN, Teresa (Ed.). Fiscal federalism in theory and practice. Washington: International Monetary Fund, 1997. 
NORREGAARD, John. Taxing Immovable property: revenue potential and implementation challenges. IMF Working Paper, n. 13/129, maio 2013.

NORRIS, Pippa. Perhaps petroleum perpetuates patriarchy? A response and critique to Ross. Harvard Kennedy School. Disponível em: <http://www.hks.harvard.edu/fs/pnorris/Acrobat/Culture, $\% 20$ Islam\%20and\%20Oil.pdf $>$. Acesso em: 7 set. 2013. O texto foi publicado em: NORRIS, Pippa. Petroleum patriarchy? A response to ross. Politics and Gender 5.4, nov. 2009.

NORRIS, Pippa. Perhaps petroleum perpetuates patriarchy? A response and critique to Ross.

NORTH, Douglas C. The New Institutional Economics and Development. Disponível em: <http://www.deu.edu.tr/userweb/sedef.akgungor/Current\%20topics\%20in\%20Turkish \%20Economy/north.pdf>. Acesso em: 2 jul. 2013.

NOSSO FUTURO COMUM. Comissão mundial sobre meio ambiente e desenvolvimento. 2. ed. Rio de Janeiro: Fundação Getulio Vargas, 1991.

NUNES, Cleucio Santos. Arts. 71 a 74. In: CONTI, José Maurício (Coord.). Orçamentos públicos. 2. ed. São Paulo: RT, 2010.

NUSDEO, Ana Maria. Desenvolvimento sustentável do Brasil e o protocolo de Quioto. Revista de Direito Ambiental, v. 37, 2005.

O'SULLIVAN, Diarmid. What's the point of transparency? - the extractive industries transparency initiative and the governance of natural resources in liberia, timor leste and other countries. Disponível em: <http://publishwhatyoupay.org/sites/publishwhatyoupay.org/files/What\%27s\%20the\% 20point\% 20of\%20transparency\%20April\%202013.pdf>. Acesso em: 2 set. 2013.

OATES, Wallace E. Fiscal federalism. Cheltanham: Edward Elgar Publishing, 2012. . Toward a second-generation theory of fiscal federalism. International Tax and Public Finance, 12, ago. 2005, p. 349 e ss.

OCTAVIANI, Alessandro. A bênção de Hamilton na semiperiferia: ordem econômicosocial e os juros da dívida pública. In: CONTI, José Maurício; SCAFF, Fernando Facury (Org.). Orçamentos públicos e direito financeiro. São Paulo: RT, 2011. 
OECD/ECLAC/CLAT. Estadísticas tributarias em América Latina. OECD Publishing, 2011. Disponível em: 〈http://dx.doi.org/10.1787/9789264110540-en-fr〉.

OLIVEIRA, Regis Fernandes de. A Lei n. 4.320, de 17.03.1964 (Lei Geral de Orçamento). Revista Tributária e de Finanças Públicas, v. 59, 2004.

. Curso de direito financeiro. 3. ed. rev. e atual. São Paulo: RT, 2010.

. Dívida pública e operações de crédito. Revista Tributária e de Finanças Públicas, v. 64, 2005.

. Federalismo fiscal e pacto federativo. Revista Tributária e de Finanças Públicas, v. $61,2005$.

. Fundos públicos financeiros. Revista Tributária e de Finanças Públicas, v. 56, 2004.

Gastos públicos. São Paulo: RT, 2012.

OLIVEIRA, Ricardo Soares de. Oil and politics in the gulf of guinea. New York: Columbia University Press, 2007.

ORAIR, Rodrigo Octávio; ALENCAR, André Amorim. Esforço fiscal dos municípios: indicadores de condicionalidade para o sistema de transferências intergovernamentais. Brasília: ESAF, 2010. Monografia premiada com o primeiro lugar no XV Prêmio Tesouro Nacional - 2010: Homenagem a Joaquim Nabuco. Tópicos Especiais de Finanças Públicas. Brasília (DF).

OSKARSON, Annika. Intergenerational equity - Protecting future generations through domestic action. 2009. Dissertação (Mestrado) - Faculdade de Direito da Universidade de Lund.

OSSOWSKI, Rolando; FEDELINO, A. (Org.). Fiscal policy formulation and implementation in oil-producing countries. Washington, D.C.: International Monetary Fund, 2003.

; GONZÁLES, Alberto. Manna from heaven: the impact of nonrenewable resource revenues on other revenues of resource exporters in Latin America and the Caribbean. Inter-American Development Bank Working Paper Series, n. IDB-WP-337, 2012. 
OTTO, James; ANDREWS, Craig; CAWOOD, Fred; DOGGETT, Michael; GUJ, Pietro; STERMOLE, Frank; STERMOLE, John; TILTON, John. Mining royalties: a global study of their impact on investors, government, and civil society. Washington: The World Bank, 2006. Capítulo 6.

PACHECO, Carlos Augusto Góes. Avaliação de critérios de distribuição e de utilização de recursos das participações governamentais no Brasil. 2007. Dissertação (Mestrado) - Universidade Federal do Rio de Janeiro.

PEREIRA, Manuel H. de Freitas. Ética e fiscalidade. Revista de Finanças Públicas e Direito Fiscal, ano 4, n. 3, p. 22.

PEREIRA, Manuel Henrique de Freitas. Sustentabilidade das finanças públicas na União Europeia. In: CATARINO, João Ricardo; TAVARES, José F. F. (Coord.). Finanças públicas da União Europeia. Coimbra: Almedina, 2012.

PERIARD, Thiago; LOSEKANN, Luciano. Petróleo, doença holandesa e dependência da renda petrolífera. In: MONIÉ, Frédéric; BINSZTOK, Jacob (Org.). Geografia e geopolítica do petróleo. Rio de Janeiro: Mauad X, 2012.

PERRY, Guillermo; BUSTOS, Sebastián. The effects of oil and mineral taxation on noncommodity fiscal revenues. Inter-American Development Bank Working Paper Series, n. IDB-WP-348, 2012.

PESSINO, Carola; FENOCHIETTO, Ricardo. Determining countries' tax effort. Hacienda Pública Española. Revista de Economía Pública, 195, 4, 2010.

PIANCASTELLI, Marcelo. Measuring the tax effort of developed and developing countries. Cross country panel data analysis - 1985/95. IPEA Working Paper, n. 818, 2001.

; BOUERI, Rogério; LIMA, Edilberto Pontes. Descentralização fiscal, harmonização tributária e relações intergovernamentais: como distintas federações reagem aos desafios da globalização. In: REZENDE, Fernando (Coord.). Desafios do federalismo fiscal. Rio de Janeiro: FGV, 2006.

PIOVESAN, Flávia. Direitos humanos e o direito constitucional internacional. 12. ed. rev. e atual. São Paulo: Saraiva, 2011.

PIRES, Adilson Rodrigues. Breve ensaio sobre as participações governamentais nas atividades de exploração e extração do petróleo. In: CARNEIRO, Daniel Dix; 
PEIXOTO, Marcelo Magalhães (Org.). Aspectos tributários relacionados à indústria do petróleo e do gás. São Paulo: Ed. MP, 2011.

PIRES, Adriano; GIAMBIAGI, Fabio; LUCAS, Luiz Paulo Vellozo; SCHECHTMAN, Rafael. Conclusões e propostas para o setor. In: GIAMBIAGI, Fabio; LUCAS, Luiz Paulo Vellozo (Org.). Petróleo: reforma e contrarreforma do setor petrolífero brasileiro. Rio de Janeiro: Elsevier, 2013.

PIRES, Adriano; GIAMBIAGI, Fabio; LUCAS, Luiz Paulo Vellozo; SCHECHTMAN, Rafael. Conclusões e propostas para o setor. In: GIAMBIAGI, Fabio; LUCAS, Luiz Paulo Vellozo (Org.). Petróleo cit.

PLOURDE, André. Canada. In: ANDERSON, George (Ed.). Oil \& gas in federal systems. Ontario: Oxford University Press, 2012.

POSTALI, Fernando Antonio Slaibe. Renda mineral, divisão de riscos e benefícios governamentais na exploração de petróleo no Brasil. Rio de Janeiro: BNDES, 2002.

; NISHIJIMA, Marislei. Distribuição das rendas do petróleo e indicadores de desenvolvimento municipal no Brasil nos anos 2000. Estudos econômicos, 2011, v. 41, n. 2. Disponível em: <http://dx.doi.org/10.1590/S0101-41612011000200010>. Acesso em: 1. ${ }^{\circ}$ dez. 2013.

PRADO, Mariana Mota; TREBILCOCK, Michael J. Path dependence, development, and the dynamics of institutional reform. University of Toronto Law Journal - U Toronto, Legal Studies Research Paper, n. 9-4, 2009.

PROMOTING REVENUE TRANSPARENCY - 2008 Report on Revenue Transparency of Oil and Gas Companies) referente especialmente às economias dependentes de recursos naturais. Disponível em: <http://pwypdev.gn.apc.org/sites/pwypdev.gn.apc.org/files/prt_companies_ report_280408.pdf>. Acesso em: 2 set. 2013.

PRZEWORSKI, Adam. Institutions Matter? Disponível em: <http://as.nyu.edu/docs/IO/2800/go_2004.pdf>. Acesso em: 2 jul. 2013.

PUASCHUNDER, Julia M. On the social representations of intergenerational equity. 2012. Disponível em: <http://ssrn.com/abstract=2011359>. Acesso em: 19 nov. 2013.

RAMOS FILHO, Carlos Alberto de Moraes. Curso de direito financeiro. São Paulo: Saraiva, 2012. 
RAMOS, Dircêo Torrecillas. Composição da federação brasileira. In: RAMOS, Dircêo Torrecillas (Coord.). O federalista atual.

RAWLS, John. Justiça como equidade: uma reformulação. Trad. Claudia Berliner; rev. téc. e da trad. Álvaro De Vita. São Paulo: Martins Fontes, 2003. . Political liberalism. Nova York: Columbia University Press, 1993. . Uma teoria da justiça. Trad. Almiro Pisetta e Lenita M. R. Esteves. São Paulo: Martins Fontes, 1997.

RELATÓRIO II. Fundos financeiros baseados em receitas de petróleo e gás. São Paulo: Bain \& Company, Tozzini Freire Advogados, 2009.

RESOURCE GOVERNANCE INDEX 2013. A measure of transparency and accountability in the oil, gas and mining sector. Revenue Waych Institute, 2013. Disponível em: <http://www. revenuewatch.org/sites/default/files/rgi_2013_Eng.pdf>.

REVENUE WATCH INDEX 2010. Transparency: Governments and the oil, gas and mining industries. Revenue Waych Institute, 2010.

REZENDE, Fernando Antonio. Finanças públicas. 2. ed. São Paulo: Atlas, 2001. . Federal Republic of Brazil. In: SHAH, Anwar (Ed.). The practice of fiscal federalism cit.

. Os desafios do federalismo fiscal. In: REZENDE, Fernando (Coord.). Desafios do federalismo fiscal. Rio de Janeiro: FGV, 2006.

; OLIVEIRA, Fabrício Augusto de. Descentralização e federalismo fiscal no Brasil: desafios da reforma tributária; SCAFF, Fernando Facury. Aspectos financeiros do sistema de organização territorial do Brasil. Revista Dialética de Direito Tributário, n. 112, jan. 2005.

REZZOAGLI, Luciano Carlos; REZZOAGLI, Bruno Ariel. Teoría de la igualdad intergeneracional: una perspectiva financiera y tributaria en la República Argentina. Revista Brasileira de Direito Tributário e Finanças Públicas, n. 33, jul.-ago. 2012.

RIBEIRO, Nelson de F. As macroperspectivas do direito minerário a partir da nova Constituição. Revista de Informação Legislativa, n. 102, Brasília, Senado Federal, abr.jun. 1989 , p. 70. 
RÍOS, Germán; ORTEGA, Federico; SCROFINA, J. Sebastián. Sub-national revenue mobilization in Latin America and Caribbean countries - The case of Venezuela. InterAmerican Development Bank Working Paper, n. IDB-WP-300, 2012.

ROCHA, Carmen Lúcia Antunes. República e federação no Brasil - Traços constitucionais da organização política brasileira. Belo Horizonte: Del Rey, 1997.

ROCHA, Joaquim Freitas da. Breves reflexões sobre responsabilidade colectiva e finanças públicas. In: ROCHA, Joaquim Freitas da (Coord.). Anuário publicista da Escola de Direito da Universidade do Minho - Responsabilidade e cidadania. Braga: Universidade do Minho, 2012. t. I, ano 2012.

. Sustentabilidade e finanças públicas responsáveis - Urgência de um direito financeiro equigeracional. In: CORREIA, Fernando Alves; MACHADO, Jónatas E. M.; LOUREIRO, João Carlos (Org.). Estudos em homenagem ao Prof. Doutor José Joaquim Gomes Canotilho. Coimbra: Ed. Coimbra, 2012.

. Sustentabilidade e finanças públicas responsáveis - Urgência de um direito financeiro equigeracional. Mimeo.

ROJAS, Carlos. Valoración de recursos minerales bajo la teoria del desarrollo sostenible. Revista EIA, n. 13, p. 65-75, 2010.

ROSA JUNIOR, Luiz Emygdio. Manual de direito financeiro \& direito tributário. 14. ed.

Rio de Janeiro: Renovar, 2000.

ROSE-ACKERMAN, Susan. Corruption and government: causes, consequences and reform. New York: Cambridge University Press, 1999.

ROSS, Michael L. But seriously: does oil really hinder democracy?. 2008. Versão preliminar. Disponível em: <http://www.yale.edu/leitner/resources/papers/ButSeriously.pdf>. Acesso em: 2 set. 2013.

Does oil hinder democracy?. World Politics, 2001, n. 53, p. 357.

. How mineral-rich states can reduce inequality. In: HUMPHREYS, Macartan; SACHS, Jeffrey D.; STIGLITZ, Joseph E. (Org.). Escaping the resource curse. New York: Columbia University Press, 2007. 
Oil and democracy revisited. 2009. Versão preliminar. Disponível em: $<$ http://www.sscnet.ucla.edu/polisci/faculty/ross/Oil\%20and\%20Democracy\%20Revisi ted.pdf $>$. Acesso em: 5 set. 2013.

. Oil, Islam and women. American Political Science Review, v. 102, n. 1, 2008.

. The oil curse: how petroleum wealth shapes the development of nations.

Princeton: Princeton University Press, 2012.

ROTH, Gregory. Norway finds virtue (and value) in transparency. New York Times, 26 de setembro de 2008. Disponível em: <http://www.nytimes.com/2008/09/27/business/worldbusiness/27interview.html?_r=0> . Acesso em: 4 set. 2013.

RUBINSTEIN, Flávio. Arts. 9. a 11. In: CONTI, José Maurício (Coord.). Orçamentos públicos: a Lei n. 4.320/1964 comentada. 2. ed. São Paulo: RT, 2010.

- Notas sobre a transparência fiscal no direito financeiro. In: CONTI, José Maurício; SCAFF, Fernando Facury (Org.). Orçamentos públicos e direito financeiro. São Paulo: RT, 2011.

Receitas públicas de recursos naturais no direito financeiro brasileiro. 2012. Tese (Doutorado) - Faculdade de Direito da Universidade de São Paulo.

SACHS, Jeffrey D. How to handle the macroeconomics of oil wealth. In: HUMPHREYS, Macartan; SACHS, Jeffrey D.; STIGLITZ, Joseph E. (Org.). Escaping the resource curse. New York: Columbia University Press, 2007.

SACHS, Jeffrey D.; WARNER, Andrew M. NBER Working Paper 5398, natural resource abundance and economic growth, 1995.

; __ The curse of natural resources. European Economic Review, n. 45, Elsevier, 2001.

SALA-I-MARTIN, Xavier; SUBRAMANIAN, Arvind. Addressing the natural resource curse: an illustration from Nigeria. NBER Working Paper, n. 9804, 2003.

SALAMA, Bruno. O que é direito e economia?. In: TIMM, Luciano Benetti. Direito e economia. 2. ed. Porto Alegre: Livraria do Advogado, 2008. 
SALOMÃO FILHO, Calixto; FERRÃO, Brisa Lopes de Mello; RIBEIRO, Ivan César. Concentração, estruturas e desigualdade: as origens coloniais da pobreza e da má distribuição de renda. São Paulo: IDCID, 2006.

SAMPAIO DÓRIA, Antônio Roberto. Discriminação de rendas tributárias. São Paulo: José Bushatsky Editor, 1972.

SANDBU, Martin E. Natural wealth accounts: a proposal for alleviating the natural resource curse. World Development, v. 34, n. 7, Elsevier, 2006.

SANDEL, Michael J. Justiça: o que é fazer a coisa certa. 4. ed. Trad. Heloísa Matias e Maria Alice Máximo. Rio de Janeiro: Civilização Brasileira, 2011.

SANTA HELENA, Eber Zoehler. Justiça distributiva na teoria da justiça como equidade de John Rawls. Revista de Informação Legislativa, v. 45, n. 178, Brasília, abr.-jun. 2008.

SANTOS, Edmilson Moutinho dos; LOSS, Giovani R. Resource curse thesis e a regulação das participações governamentais do petróleo e gás no Brasil. Revista de Direito Público da Economia - RDPE, Belo Horizonte, ano 1, n. 4, Belo Horizonte: Fórum, out.-dez. 2003.

SARLET, Ingo Wolfgang; FENSTERSEIFER, Tiago. O papel do Poder Judiciário brasileiro na tutela e efetivação dos direitos e deveres socioambientais. Revista de Direito Ambiental, São Paulo: RT, v. 13, n. 52, out.-dez. 2008.

SARLO, Oscar. Republicanismo, derechos humanos y deberes tributarios. Revista Mestrado em Direito, ano 12, n. 1, Osasco, jan.-jul. 2012.

SARTOR, Vicente Volnei de Bona. Justiça intergeracional e meio ambiente. Florianópolis: Ed. do Autor, 2002.

SCAFF, Fernando Facury. Aspectos controvertidos sobre a CFEM - Compensação Financeira pela Exploração de Recursos Minerais (Royalties da mineração). In: SCAFF, Fernando Facury; ATHIAS, Jorge Alex Nunes (Coord.). Direito tributário e econômico aplicado ao meio ambiente e à mineração. São Paulo: Quartier Latin, 2009.

Direitos fundamentais e orçamento: despesas sigilosas e o direito à verdade. In: CONTI, José Maurício; SCAFF, Fernando Facury (Org.). Orçamentos públicos e direito financeiro. São Paulo: RT, 2011. 
O que são normas gerais de direito financeiro?. In: MARTINS, Ives Gandra da Silva; MENDES, Gilmar Ferreira; NASCIMENTO, Carlos Valder do (Coord.). Tratado de direito financeiro. São Paulo: Saraiva, 2013. v. 1.

Royalties decorrentes da exploração de recursos naturais não renováveis: incidência e rateio federativo. 2013. Tese (Livre-Docência) Faculdade de Direito da Universidade de São Paulo.

; ATHIAS, Jorge Alex Nunes (Coord.). Direito tributário e econômico aplicado ao meio ambiente e à mineração. São Paulo: Quartier Latin, 2009.

; ROCHA, Francisco Sérgio Silva. Equilíbrio orçamentário e sustentabilidade financeira: anotações sobre o Brasil. Revista dos Tribunais, v. 925, São Paulo: RT, nov. 2012.

; ROCHA, Francisco Sérgio Silva. Princípios, elementos e conceito de Estado Federal. In: RAMOS, Dircêo Torrecillas (Coord.). O federalista atual: teoria do federalismo. Belo Horizonte: Arraes Editores, 2013.

; SILVEIRA, Alexandre Coutinho da. CFEM - normas aplicáveis à decadência e à prescrição. In: SOUZA, Marcelo Mendo Gomes de (Coord.). A compensação financeira pela exploração de recursos minerais - CFEM. Belo Horizonte: Del Rey, 2011.

; SILVEIRA, Alexandre Coutinho da. Competência tributária, transferências obrigatórias e incentivos fiscais. In: CONTI, José Maurício; SCAFF, Fernando Facury; BRAGA, Carlos Eduardo Faraco (Org.). Federalismo fiscal: questões contemporâneas. Florianópolis: Conceito, 2010.

; SILVEIRA, Alexandre Coutinho da. Taxas de fiscalização sobre a exploração de recursos minerais. Revista Dialética de Direito Tributário, n. 210, mar. 2013.

SEIXAS FILHO, Aurélio Pitanga. Natureza jurídica da compensação financeira por exploração de recursos minerais. In: ROCHA, Valdir de Oliveira (Coord.). Grandes questões atuais do direito tributário. São Paulo: Dialética, 1998.

SEN, Amartya. Sobre ética e economia. Trad. Laura Teixeira Motta. rev. técnica Ricardo Doninelli Mendes. São Paulo: Companhia das Letras, 1999. 
SERRA, Rodrigo Valente. Contribuições para o debate acerca da repartição dos royalties petrolíferos no Brasil. 2005. Tese (Doutorado) - Instituto de Economia, Universidade Estadual de Campinas.

. Rendas petrolíferas no Brasil: critérios de distribuição distorcidos induzem ineficiência do gasto. In: MENDES, Marcos (Org.). Gasto público eficiente. Rio de Janeiro: Topbooks, 2006.

; FERNANDES, Ana Cristina. A distribuição dos royalties petrolíferos no Brasil e os riscos de sua "financeirização". Revista de Desenvolvimento Econômico - RDE, ano VII, n. 11, jan. 2005.

; GOBETTI, Sérgio Wulff. Petróleo, royalties e desenvolvimento: Brasil e experiências internacionais. In: MONIÉ, Frédéric; BINSZTOK, Jacob (Org.). Geografia e geopolítica do petróleo. Rio de Janeiro: Mauad X, 2012.

; PATRÃO, Carla. Impropriedades dos critérios de distribuição dos royalties no Brasil. In: PIQUET, Rosélia (Org.). Petróleo, royalties e região. Rio de Janeiro: Garamond, 2003.

SHAH, Anwar. Introduction: principles of fiscal federalism. In: SHAH, Anwar (Ed.). The practice of fiscal federalism: comparative perspectives. A global dialogue on federalism. Canadá: McGill-Queen’s University Press, 2007. v. 4.

SHAVIRO, Daniel. Editorial: how tax cuts feed the beast. The New York Times, 21 dez. 2004.

. The long-term U.S. Fiscal gap: is the main problem generational inequity? George Washington Law Review, v. 76, 2008.

SHOHAM, Shlomo; LAMAY, Nira. Comission for Future Generations in the Knesset: lessons learnt. In: TREMMEL, Joerg (Ed.). Handbook of intergenerational justice. Cheltenham, UK: Edward Elgar, 2006.

SIAS, Rodrigo. O Fundo Soberano brasileiro e suas implicações para a política econômica. Revista do BNDES, Rio de Janeiro, v. 15, n. 30, dez. 2008, p. 110.

SILVA, Herbert Pereira da. Inconstitucionalidade de leis estaduais e municipais que disciplinam a fiscalização, arrecadação e cobrança da CFEM. In: SOUZA, Marcelo Mendo Gomes de (Coord.). A compensação financeira pela exploração de recursos minerais - CFEM. Belo Horizonte: Del Rey, 2011. 
SILVA, Mauro Santos. Teoria do federalismo fiscal: notas sobre as contribuições de Oates, Musgrave, Shah e Ter-Minassian. Belo Horizonte: Nova Economia, 2005.

SILVA, Paulo Napoleão Nogueira da. Artigos 20 ao 24. In: BONAVIDES, Paulo; MIRANDA, Jorge; AGRA, Walber de Moura. Comentários à Constituição Federal de 1988. Rio de Janeiro: Forense, 2009.

SILVA, Paulo Roberto Coimbra. Compensação Financeira pela Exploração de Recursos Minerais - CFEM: natureza jurídica e questões correlatas. São Paulo: Quartier Latin, 2010.

SILVEIRA, Renata Marques da. Aspectos jurídicos da compensação financeira pela exploração de recursos minerais - CFEM. Dissertação de mestrado apresentada à Pontifícia Universidade Católica de São Paulo, 2010.

SILVEIRA, Reynaldo Andrade da. A compensação financeira: receita tributária ou patrimonial? Algumas questões. In: SCAFF, Fernando Facury (Org.). Ordem econômica e social. São Paulo: LTr, 1999.

SINGER, Peter. Ética prática. Trad. Jefferson Luiz Camargo. 3. ed. São Paulo: Martins Fontes, 2002.

SKANCKE, Martin. Fiscal policy and petroleum fund management in Norway. In: DAVIS, J.; OSSOWSKI, R.; FEDELINO, A. (Org.). Fiscal policy formulation and implementation in oil-producing countries. Washington, D.C.: International Monetary Fund, 2003.

SOLOW, Robert M. An almost practical step towards sustainability. Resources Policy, v. 19, 1993, p. 162-172. Intergenerational equity and exhaustible resources. The Review of Economic Studies, v. 41, Symposium on the economics of exhaustible resources, 1974. . On the intergenerational allocation of natural resources. The Scandinavian Journal of Economics, v. 88, n. 1, Growth and Distribution: Intergenerational Problems, mar. 1986.

STIGLITZ, Joseph E. What is the role of tha state?. In: HUMPHREYS, Macartan; SACHS, Jeffrey D.; STIGLITZ, Joseph E. (Org.). Escaping the resource curse. New York: Columbia University Press, 2007. 
SUNSTEIN, Cass R.; ROWELL, Arden. On discounting regulatory benefits: risk, money, and intergenerational equity. U Chicago Law \& Economics, Olin Working Paper, n. 252, maio 2005.

SUROWIECKI, James. The real price of oil. In: the new yorker. 03 de dezembro de 2001.

SÜSSMUTH, Bernd; VON WEIZSÄCKER, Robert K. Institutional determinants of public debt: a political economy perspective. In: TREMMEL, Joerg (Ed.). Handbook of intergenerational justice. Cheltenham, UK: Edward Elgar, 2006.

TALIERCIO, Robert R. Subnational own-source revenue: getting policy and administration right. In: WORLD BANK. East Asia decentralizes: makig local government work. Washington: The World Bank, 2005.

TER-MINASSIAN, Teresa. Intergovernmental fiscal relations in a macroeconomic perspective: an overview. In: TER-MINASSIAN, Teresa (Ed.). Fiscal federalism in theory and practice. Washington: International Monetary Fund, 1997.

More than revenue: main challenges for taxation in Latin America and the Caribbean. Inter-American Development Bank Working Paper, n. IDB-PB-175, 2012.

Reforma do fundo de participação dos estados. BID: Texto para debate. IDBDP-216, mar. 2012.

TILTON, John. Determining the optimal tax on mining. Natural Resources Forum, v. 28, 2004.

TOLLINI, Helio Martins; AFONSO, José Roberto R. A Lei n. 4.320 e a responsabilidade orçamentária. In: CONTI, José Maurício; SCAFF, Fernando Facury (Org.). Orçamentos públicos e direito financeiro. São Paulo: RT, 2011.

; COSTA, Franselmo Araújo. Vinculações das receitas orçamentárias: teoria e prática. In: CONTI, José Maurício; SCAFF, Fernando Facury (Org.). Orçamentos públicos e direito financeiro. São Paulo: RT, 2011.

TORNELL, Aaron; LANE, Philip. Voracity and growth. NBER Working Paper, n. 6498, 1998.

TORRES, Heleno Taveira. A compensação financeira devida pela utilização de recursos hídricos, exploração de recursos minerais ou produção de petróleo, xisto betuminoso e 
gás natural (art. 20, § 1. ${ }^{\circ}, \mathrm{CF}$ ) - sua natureza jurídica. In: ROCHA, Valdir de Oliveira (Coord.). Grandes questões atuais do direito tributário. São Paulo: Dialética, 1998.

TORRES, Heleno Taveira. Tributos e convenções internacionais em matéria tributária e o federalismo fiscal brasileiro. Revista Dialética de Direito Tributário, n. 86, nov. 2002. ; RODRIGUES, Felipe da Cunha. Fundo soberano do Brasil e finanças públicas: regime jurídico dos fundos públicos especiais, experiência internacional e a Lei n. 11.887/2008. Belo Horizonte: Fórum, 2012.

TORRES, Ricardo Lobo. A ideia de liberdade no estado patrimonial e no estado fiscal. Rio de Janeiro: Renovar, 1991. . Curso de direito financeiro e tributário. 12. ed. Rio de Janeiro: Renovar, 2005. 15. ed. atual. até 31.12.2007. Rio de Janeiro: Renovar, 2008. Responsabilidade fiscal, renúncia de receitas e guerra fiscal no ICMS. In: SCAFF, Fernando Facury; CONTI, José Maurício. Lei de Responsabilidade Fiscal 10 anos de vigência - Questões atuais. Florianópolis: Conceito, 2010. Tratado de direito constitucional financeiro e tributário, v. 5: o orçamento na Constituição. 2. ed. rev. e atual. Rio de Janeiro: Renovar, 2000.

TORRONTEGUY, Alessandra Folkze. A aplicação dos royalties do petróleo na efetividade dos direitos fundamentais sociais. São Paulo: LTr, 2011.

TRAN $\varnothing Y$, Bent Sofus. Norway - the accidental role model. In: YI-CHONG, Xu; BAHGAT, Gawdat. The political economy of sovereign wealth funds. Londres: Palgrave Macmillan, 2010.

TREMMEL, Joerg. A theory of intergenerational justice. London: Earthscan, 2009.

(Ed.). Establishing intergenerational justice in national constitutions. Handbook of intergenerational justice. Cheltenham, UK: Edward Elgar, 2006.

TRINDADE, Adriano Drummond Cançado. Royalties na mineração no direito comparado. In: SOUZA, Marcelo Mendo Gomes de (Coord.). A compensação financeira pela exploração dos recursos minerais - CFEM. Belo Horizonte: Del Rey, 2011.

TRUMAN, Edwin M. Sovereign Weakth funds: threat or salvation?. Washington D.C.: Peterson Institute for International Economics, 2010. 
UNDP. Governance for sustainable human development: a UNDP policy document. United Nations Development Programme, 1997. Disponível em: <http://mirror.undp.org/magnet/policy/ chapter1.htm\#b>. Acesso em: 15 fev. 2013.

VALENTIM NETO, Geraldo; COSTA, Solange Maria Santos. A compensação financeira pela exploração de recursos minerais (CFEM): os royalties da mineração. In: SOUZA, Marcelo Mendo Gomes de (Coord.). A compensação financeira pela exploração de recursos minerais.

VALOR ECONÔMICO. Em SP, cidades se preparam para disputar cadeia do pré-sal. 2 dez.2013. p. A3.

VAN DER PLOEG, Frederick. Challenges and opportunities for resource rich economies. OxCarre Research Paper, n. 2008-05, Oxford University, 2007.

; POELHEKKE, Steven. The pungent smell of "red herrings": subsoil assets, rents, volatility and the resource curse. Journal of Environmental Economics and Management, n Elsevier,. 60, 2010.

VAN OPSTAL, Rocus; TIMMERHUIS, Jacqueline. The role of CPB in Dutch economic policy. In: TREMMEL, Joerg (Ed.). Handbook of intergenerational justice. Cheltenham, UK: Edward Elgar, 2006.

VARSANO, Ricardo; FERREIRA, Sérgio Guimarães; AFONSO, José Roberto. Fiscal competition: a bird's eye view. Rio de Janeiro: IPEA, 2002. Texto para discussão n. 887.

VELASCO, Andrés. Sovereign Wealth Funds as stabilizers. In: BOLTON, Patrick; SAMAMA, Frederic; STIGLITZ, Joseph (Ed.). Sovereign wealth funds and long-term investing. New York: Columbia University Press, 2012.

VITA, Álvaro de. A justiça igualitária e seus críticos. 2. ed. São Paulo: WMF Martins Fontes, 2007.

WAKEMAN-LINN, John; Mathieu, Paul; VAN SELM, Bert. Oil funds in transition economies: Azerbaijan and Kazakhstan. In: DAVIS, J.; OSSOWSKI, R.; FEDELINO, A. (Org.). Fiscal policy formulation and implementation in oil-producing countries. Washington, D.C.: International Monetary Fund, 2003.

WALL, Steven. Just savings and the difference principle. Philosophical studies. An International Journal for Philosophy in the Analytic Tradition, v. 116, n. 1, out. 2003. 
WEINGAST, Barry R. Second generation fiscal federalism: the implications of fiscal incentives. Journal of Urban Economics, v. 65, Elsevier, 2009.

WEISS, Edith Brown. In fairness to future generations: international law, common patrimony, and intergenerational equity. Tokyo: The United Nations University, 1989.

WESTON, Burns H. The theoretical foundations of intergenerational ecological justice: an overview. Human Righs Quarterly, v. 34, 2012.

WOLF, Clark. Intergenerational justice and climate policy. In: GOSSERIES, Axel; MEYER, Lukas H. (Coord.). Intergenerational justice. New York: Oxford University Press, 2009.

Intergenerational justice and Saving. In: LAMONT, Julian; FAVOR, Christi; GAUS, Gerald (Coord.). Values, justice and economics. Palo Alto/CA: Stanford University Press, 2010.

Intergenerational justice. In: FREY, R. G.; WELLMAN, Cristopher Heath (Ed.). A companion to applied ethics. Oxford: Blackwell Publishers, 2003. . Justice and intergenerational debt. Intergenerational Justice Review, n. 1, 2008.

WORLD BANK. Better governance for development in the Middle East and North Africa: enhancing inclusiveness and accountability. MENA development report. Washington, DC: World Bank, 2003.

- What is governance? Disponível em: <http://go.worldbank.org/G2CHLXX0Q0>. Acesso em: 15 fev. 2013.

. Where is the wealth of nations? Measuring capital for the 21 century. Washington DC: World Bank, 2006.

WRIGHT, Gavin; CZELUSTA, Jesse. Resource-Based Growth: Past and Present. In: LEDERMAN, Daniel; MALONEY, William F. (Ed.). Natural resources, neither curse nor destiny.

XAVIER, Alberto. Natureza jurídica e âmbito de incidência da compensação financeira por exploração de recursos minerais. Revista Dialética de Direito Tributário, n. 29, São Paulo: Dialética, 1998. 
YI-CHONG, Xu. The political economy of sovereihn wealth funds. In: YI-CHONG, Xu; BAHGAT, Gawdat. The political economy of sovereign wealth funds. Londres: Palgrave Macmillan, 2010.

YOSHIDA, Consuelo Y. M. A efetividade e a eficiência ambiental dos instrumentos econômico-financeiros e tributários: ênfase na prevenção. A utilização econômica dos bens ambientais e suas implicações. In: TORRES, Heleno Taveira (Org.). Direito tributário ambiental. São Paulo: Malheiros, 2005.

Ato jurídico perfeito, direito adquirido, coisa julgada e meio ambiente. Revista de Direito Ambiental, v. 66, 2012.

TAC, TCA e composição prévia: a reparação do dano e medidas compensatórias no contexto da PNMA. Revista de Direito Ambiental, v. 64, 2011.

YUN-CASALILLA, Bartolomé; O'BRIEN, Patrick K. (Ed.). The rise of fiscal states: a global history, 1500-1914. Cambridge: Cambridge University Press, 2012.

ZANCHIM, Kleber Luiz. Arts. 12 a 21. In: CONTI, José Maurício (Coord.). Orçamentos públicos. 2. ed. São Paulo: RT, 2010. 